\title{
THE PRUNING-BOOK
}

\author{
L. H. BAIIEY
}

THE CARDEN-CRAFT SERIES 
Main Lis.

Experiment station

LIBRARY

UNIVERSITY OF CALIFORNIA.

Received June ${ }_{189} 8$ accessions No. 71768 . Class No. 
$5 x+3 x^{2}$ 



\section{PRUNING-BOOK}




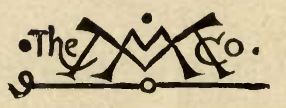




\section{THE PRUNING-BOOK}

A Monograph of the

Pruning and Training of Plants

as APPlied to AMERICAN

Conditions

BY

L. H. BAILEY

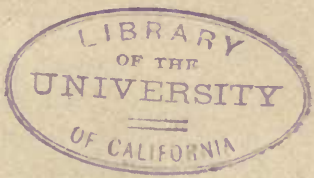

Notor 2900tk

THE MACMILLAN COMPANY

LONDON: MACMILLAN \& CO., LTD.

1898

All rights reserved 
$\beta \times$

Main Lis.

Agric. Dept.

$$
71768
$$

Copyright, 1898,

BY L. H. BAILEY

Flaunt Pleasant Pxintexp

J. Horace McFarland Company Harrisburg, $\mathrm{Pa}$. 


\section{IBRABY
OF UTM
ONIVERSITY
OCALIFOBNYY \\ OUTLINE \\ PART I \\ THE FUNDAMENTALS}

CHAPTER I

The Philosophy of Pruning ....... 1-20

Does pruning devitalize plants ?....... 4

\section{CHAPTER II}

The Fruit-Bud.............. 21-75

The bud and the branch......... 22

The leaf-bud and the fruit-bud ...... 27

The fruit-spur as illustrated by the apple . . 30

The fruit-spur as illustrated by the pear. . . 40

The fruit-spur as illustrated by the plum and cherry ............... 46

The peach and the apricot ...... 50

Gooseberries, currants and juneberries.... 56

Co-terminal fruit-bearing ....... 59

Grapes and brambles .......... 63

How to tell the fruit-buds . . . . . . 66

Summary synopsis of the positions of fruit-

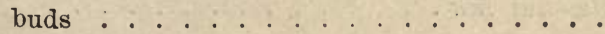




\section{CHAPTER III}

The Healing of Wounds . . . . . . . . 76-132

'The nature of the wound . . . . . . . . 82

Suggestions to the pruner . . . . . . . 95

When to eut the branches ....... 102

Dressings for wounds . . . . . . . . 109

How to make the cut.......... 114

The mending of trees . . . . . . . . . 116

\section{CHAPTER IV}

The Principles of Pruning . . . . . . . . 133-190

1. Heavy top-pruning produces wood . . . 136

2. Heavy root-pruning lessens wood . . . 138

3. Heavy top-pruning rejuvenates the plant . 139

4. Pruned plant resumes its normal habit . $\quad 150$

5. Habit varies from youth to age . . . . 153

6. One part lives at expense of another... . 154

7. Watersprouts are results of disturbed equi librium ............ 155

8. Plants grow from uppermost buds ... . 157

9. Heading-in develops lateral buds . . . . 157

10. Effect of obstructions ......... . 161

11. Checking growth induces fruitfulness . . . 162

12. Fruit-bearing is determined by habit . . . 163

13. Girdling and the like are special practices. $\quad 167$

14. Pruning thins the fruit . . . . . . . 174

15. Heading-in induces fruitfulness .. . . . 180

16. Season of pruning influences fruitfulness. 181

17. Pruning depends upon locality and climate. 185

18. What influences the healing of wounds ? 189

19. Dressings . . . . . . . . . . 190

20. General law........... . . 190 


\section{PART II}

\section{THE INCIDENTALS}

\section{CHAPTER V}

SOME SPECIFIC AdVICE ........... . . 193-340

The form of the top . . . . . . . . 193

How to trim young plants ......... 205

Root-pruning. . . . . . . . . . . 227

Root-pruning when transplanting.... . 232

Subsequent treatment of the plants . . . . . 250

Management of top-worked trees . . . . . . 263

Management of dwarf trees . . . . . . 269

Ringing and girdling ........... . 281

Pruning tools . . . . . . . . . . . . . 297

Remarks on specific plants........ . 309

Apple .............. . . 309

Apricot .............. . . . 310

Cherry ... . . . . . . . . . . . 313

Orange ............... . . . 314

Peach ............... . 315

Pear ... . . . . . . . . . . . 319

Plum .............. . . . 320

Quince ............. . . 322

Blackberries and raspberries . . . . . 323

Currants and gooseberries ... . . . . 327

Shade trees . . . . . . . . . . 333

Hedges ............... . . 333

Ornamental plants .......... 335

\section{CHAPTER VI}

Some Specific Modes of Training. . . . . . . 341-389

European practice . . . . . . . . . . . 342

Trees and bushes in pots ........... 374

Other special modes of training . . . . . . 384 


\section{CHAPTER VII}

PAGES

American Grape Training-General Sketch . . 390-430

Pruning the grape ........... . . . 402

Pruning young vines ........ 411

When to prune........... 413

Summer pruning .......... . . 414

Making the trellis ........... 416

Tying . . . . . . . . . . . 426

\section{CHAPTER VIII}

American Grape Training-The Various Modes . 431-493

The upright systems . . . . . . . . . 436

Horizontal arm spur system ....... 437

The high renewal .......... 441

Fan training .......... . . 455

The drooping systems . . . . . . . . . 458

The true or four-cane Kniffin . . . . . . 460

Modifications of the four-cane Kniffin . . . 466

The two-cane Kniffin, or umbrella system . 469

The low, or one-wire Kniffin ...... 472

The six-cane Kniffin . . . . . . . . 473

Eight-cane Kniffin ............ . 474

Caywood, overhead, or arbor Kniffin . . . 474

The cross-wire system . . . . . . . 477

Renewal Kniffin............ 478

The Munson system . . . . . . . . . 480

Modified Munson ........... 485

Miscellaneous systems ........... . 486

Horizontal training . . . . . . . . 486

Post training . . . . . . . . . . 488

Arbors . . . . . . . . . . . . . 490

Remodeling old vines........... 491 


\section{CHAPTER IX}

PAGES

Vinifera Grape Training......... 494-530

California practice . . . . . . . . . . 494

Proper method of making euts . . . . . 498

Short and long-pruning . . . . . . 500

Pruning of young vines ........ 503

Systems of pruning . . . . . . . 505

Summer pruning ........... . 521

Classification of the varieties ...... 525

Glass-house practice . . . . . . . . 528

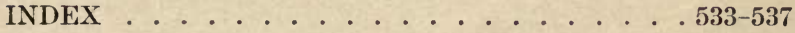





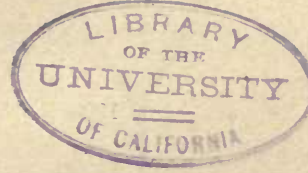

Part I

\section{THE FUNDAMENTALS}




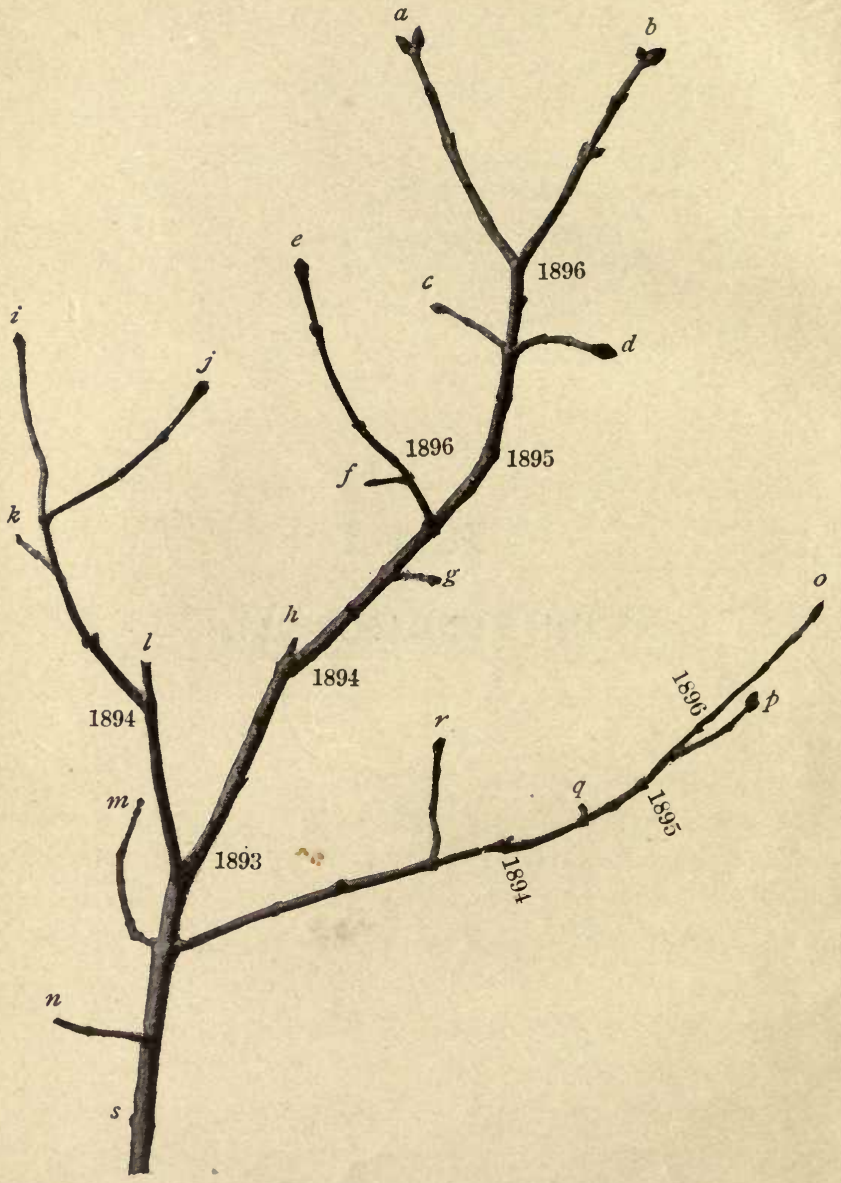

1. The history of a lilac shoot. 


\section{THE PRUNING-BOOK}

\section{Chapter I}

\section{THE PHILOSOPHY OF PRUNING}

A lilac branch is shown in the engraving on the opposite page (Fig. 1). Its most important characteristic, - as of any branch,-is the fact that its various parts are unlike. We must discover the reasons for these unlikenesses or differences.

The branch is five years old. The dates mark the termination of the growth of each year. The terminal growths all grew in 1897. Since the branches of any year spring from buds which were formed the previous year, we can determine the normal method of branching of the lilac by examining the buds upon the current year's growths. The branches $a$ and $b$ are each seen to have five pairs of buds. The buds are on opposite sides of the branch. The twig growth or branching of the lilac, therefore, should be a successive series of forks; but such is notably not the case. In other words, the normal method of branching has not taken place; and the reason is, 
that not all the branches could develop in the severe struggle for existence.

The effect of this struggle for existence is to be seen even in the buds upon the current year's growths, as on $a$ and $b$. The largest and strongest buds are on the tips, and, as a rule, the buds are smaller and weaker the nearer one approaches the base of the shoot: This unequal development of the buds is undoubtedly associated chiefly with the amount of sunlight to which the different parts of the shoot were exposed.

It is further to be observed that the twin terminal buds are not often alike. The difference is marked at $b$. It is evident that, if each of these buds develops a branch, the two branches will be very unlike.

Let us now trace the history of this interesting lilac branch. The first growth ended at the point marked 1893. In 1894, a shoot grew from each of the terminal buds, and three other shoots developed. It is noticeable, in the first place, that the strongest shoots are those arising from the terminal buds, while the lowest buds developed no shoots and still remain dormant $(s)$. In the second place, it is to be observed that no two of the five branches are alike. Three branches are strong, but two, $m, n$, have succumbed in the struggle for existence, and are now dead. That is, pruning has begun.

Tracing the strong branch at the right (running 
off to 0 ), it is seen that it grew to 1894 the first year. The second year it grew to 1895; and in that year, also, one branch, $r$, was developed. It is noticeable, too, that two branches started from the end of the 1894 growth, but one of them failed, and only a short stub now records the fact. The third year the branch grew to 1896 , and a very small branch, $q$, now dead, was produced on the growth of 1895. The fourth year (1897) the branch grew to $o$, and a single shoot, $p$, grew on the growth of 1896 . Altogether, this branch has made forty efforts to produce branches (that is, forty buds on the growths previous to 1897 , but not all traceable in the illustration), only five of which, $r$, at $1894, q, p$, and $o$ have been successful; and of these five branches, two are dead, and only one, o, seems likely to persist. That is, in the struggle for existence, only one effort in forty has been successful.

The large branch on the left, terminating at $i$, may now be examined. The first year it grew to 1894. The second year it grew in the direction $l$, but that branch died and the year's growth was lost. The stub or remains of this branch is seen at $l$. The third year the branch grew to 1896 . The fourth year (1897) the terminal branch grew to $i$, a side branch to $j$, and another side branch, now nearly dead, grew to $k$. The entire branch (1893 to $i$ ) has made over twenty efforts at branches, four of which efforts were successful, 
but two of which, $k, l$, are now dead. That is, two efforts, $i, j$, out of more than twenty, give promise of being useful. It is noticeable that whereas these two branches-terminating at $o$ and at $i$-are of the same age, they have developed in very different size and form.

Without waiting for the details, we may say that the entire branch in Fig. 1 has made about one hundred and forty attempts at branches. Of these attempts, or buds, twenty-four have produced branches, and of these branches, nine are already dead. The lessons to be derived from this study of the lilac branch may be applied to all plants. They are: (1) there are more efforts at branches than there are branches; (2) there is, therefore, severe struggle for existence; (3) the results are that differences arise and that some branches die. In other words, plants must and do prune themselves.

\section{DOES PRUNING DEVITALIZE PLANTS?*}

A year ago I read a paper before this Society upon some of the relations between grafting and the vitality of the plant [reprinted in The NurseryBook, third edition, pp. 82-94], and it seemed to me that the sum of the argument showed that grafting, while often improperly and injudiciously done, is not of itself a devitalizing or injurious

*Address before the Peninsula Horticultural Society, January, 1893, and published in the Proceedings of the Society for that year, pp. 43-49. 
practice. I now ask you to follow a similar argument with reference to pruning. This subject is, perhaps, even more important than the other, for every owner of a fruit tree expects to prune, or at least he considers the advisability of the operation. There is the greatest difference of opinion as to the merits of particular styles and methods of pruning, and perhaps equal difference as to the effect of the operation on the life and health of the tree. Perhaps every fruit-grower has observed evil effects to result from pruning, and many of these observers have reasoned therefrom that pruning is itself injurious, or at least hazardous. I cannot, of course, uphold nor explain away the examples of injury which follow pruning. They are patent even to the casual observer; but we must not exalt individual instances, however numerous, into proofs of the perniciousness of pruning. There should have been at this day sufficient study and experience to enable us to pass upon the merits of the practice, as a whole. It is urgent, also, that the subject be discussed, for however much of correct teaching may be promulgated, there is a constantly recurring wave of error and prejudice. For myself, I am convinced that pruning, even when somewhat heroic, is not a devitalizing practice; and in support of this conviction I shall present arguments from three sources,-philosophy, plant physiology, and common experience. I must say at the beginning, 
however, that I do not propose to discuss mechanical injuries to the trees, as a result of wounds, for we all know that such injuries are a result of careless or injudicious pruning. My proposition is this: Does it injure a plant to remove a part of it? Is the entire growth of a plant necessary to its health and longevity?

1. The argument from philosophy. There is an intense struggle for existence among all organisms. The world is now full, and there can probably be no permanent increase in the sum total of animals and plants. If one species increases, another must decrease. Changes in the numbers of individuals are, therefore, largely matters of readjustment between different types. Each kind is held down to a certain equilibrium in relation to other kinds. It is easy to see that any species of animal or plant could completely occupy the surface of the globe, if it could multiply to the full extent of its powers. Not only do some species compete with others, but the individuals of the same species compete with each other for standing room. The greater the number of thistles in a given field, the less is the opportunity for another thistle plant to gain a foothold. Now, a tree is essentially a collection or colony of individual plants. Every branch, even every joint of the branch, is endeavoring to do what every other branch does-to bear leaves, flowers and seeds. Every branch competes with 
every other branch; and there are more germs of branches-that is, more buds-than there can be branches upon any tree. So it comes that no two branches of a tree are exactly alike, but are what their position or condition makes them to be. Some are strong and some are weak. That is, there is no definite or proper size or shape for any branch, as there is for the different members of an animal or flower. The limbs and organs of an animal are not competitors but copartners, each performing some function or office which another does not, and they all obtain a definite maturity of size and shape. But a branch never attains its full size until it ceases to grow and thereby begins to die. Branches are not organs, but competing individuals. If all these statements are true, then three conclusions follow: there is struggle for existence amongst the branches of a tree, and some of the contestants perish; the destruction of these branchess must conduce to the betterment of the remaining ones; all the branches of a tree are not necessary to it, but some of them may be a detriment to it. In other words, pruning is a necessity.

Two years ago a wild black cherry tree came up near my door. The first year, it sent up a single straight shoot nineteen inches high, which produced twenty-seven buds and one branchlet eight inches long. This branchlet bore twelve buds. At the end of the first season, therefore, 
the little tree had produced a total of thirty-nine buds, one branchlet, and twenty-seven inches of growth. The second year, 1892, nineteen of these thirty-nine buds produced branches and twenty did not start. These nineteen branches made a total growth of 231 inches, and produced 370 buds. The terminal branch or shoot grew thirtysix inches long. Here, then, is a little tree two years old and four and one-half feet high which has made an effort to bear 409 branches. It is plain that more than ninety per cent of these efforts must be futile. Many of the buds will not start, but the tree now has a total of twentyseven branches and subdivisions as a result of its first year's growth; if it makes a proportional number this year from the growth of 1892 , it will bear 216 branches at the close of 1893 and will have made a total effort of about 3,500 branchgerms or buds. This little tree will undergo a severe pruning in the coming years, although a knife does not touch it.*

But the natural thinning of the top will continue in geometrical ratio as long as the tree grows; and after a time this pruning will become more severe, for larger branches will be sacrificed. Probably less than a fifth of the buds upon any tree ever make branches, and less than a fifth of the branches persist. The greater part of these

\footnotetext{
*The subsequent history of this cherry tree, and record of its tragic death, may be found in "The Survival of the Unlike," pp. 88, 89.
} 
branches die before they come to bearing age, no doubt, but some of them perish after they have attained to a considerable size. A forest tree grows a tall, straight bole because the side branches are lopped 'off; and the more vigorous this pruning, the taller and stronger the tree becomes.

Another black cherry tree, two years old, found in the woods, is shown in Fig. 2. The first year it grew from the ground to $a$, and it bore buds at regular intervals,-about two dozen of them. The second year, the terminal bud sent out a shoot to $b$, and thirteen lateral buds gave rise to branches. Of these thirteen lateral branches, obviously only three stand any chance of living in the dense shade of the forest. In fact, four or five of the lowest twigs were dead when the picture was made; showing that the struggle for existence does not always result from competition among fellows, but may arise from the crowding of other plants.

These three strong branches in Fig. 2 are less than four feet from the ground, but other old cherry trees standing near it had no branches within fifteen and twenty feet of the ground. They no doubt branched low down, as this one, but the branches eventually died in the struggle; and we therefore have reason to conclude that of all the branches on this little tree, only the terminal one, $b$, can long survive. One has only to look on the forest floor to see how freely trees 


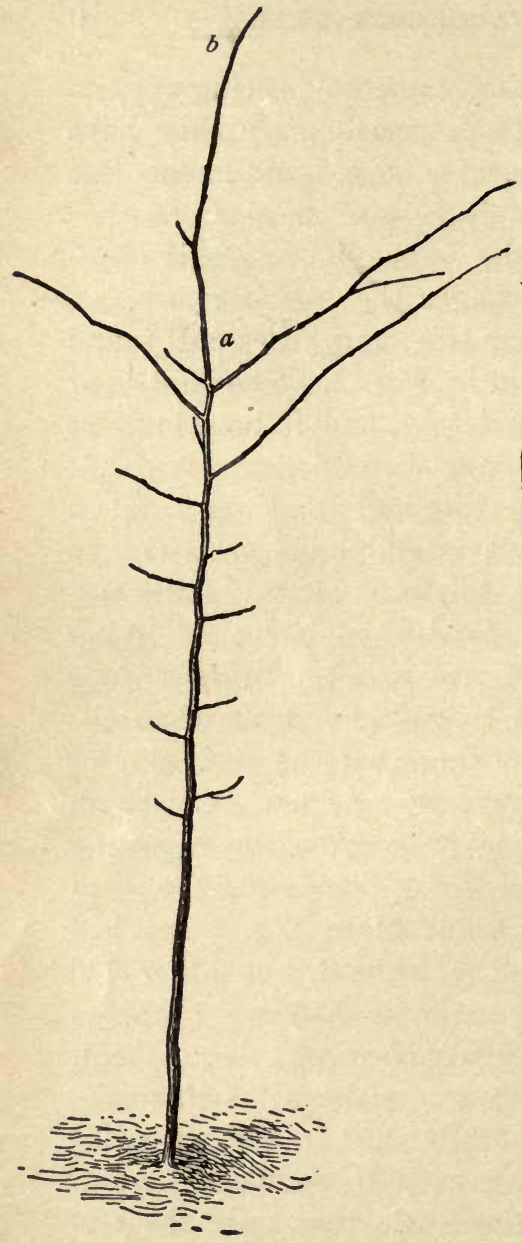

2. The curious history of a wild cherry tree.

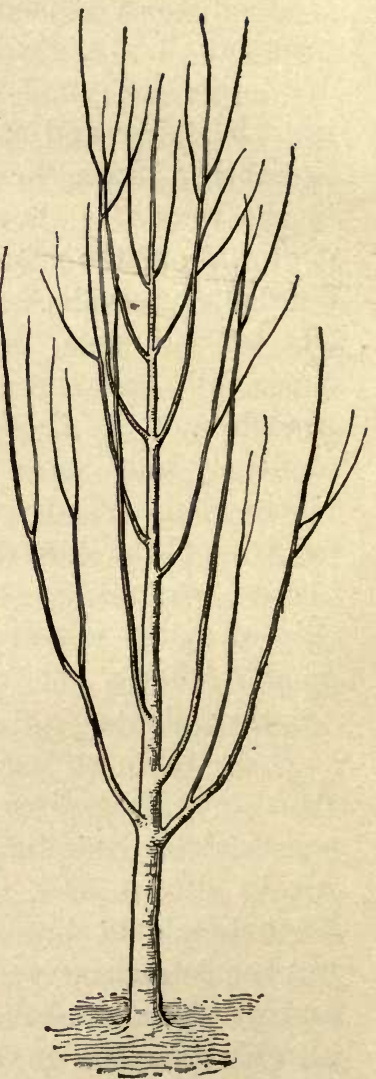

3. Upright habit of the sweet cherry. 
have shed their twigs. The trunk of a tree, then, is the remainder in a long problem of subtraction. A young tree of the sweet garden cherry is

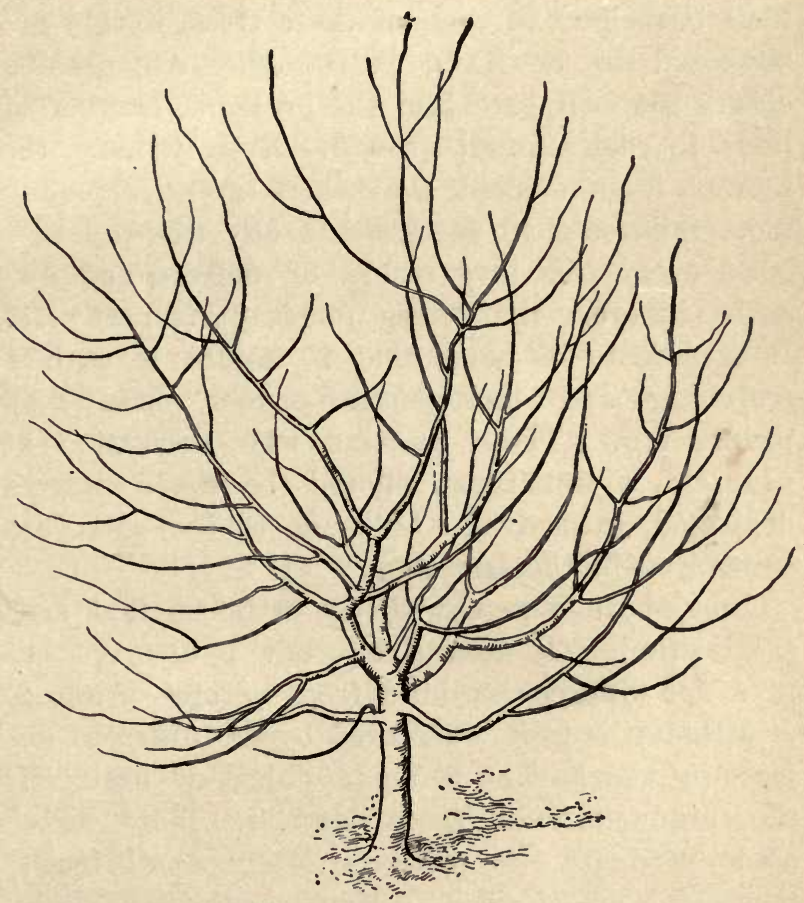

4. Diffuse habit of the sour cherry.

shown in Fig. 3, and one of the Morello or pie cherry in Fig. 4. In the former, the terminal growths are strong, and the leader, or central trunk, has persisted. The latter has long since 
lost its leader, and the side growths are strong. Let the reader now figure out how many buds have perished (or at least failed to make permanent branches) in each of these trees, if they are supposed to be seven years old. Any garden cherry tree will give him the probable number of buds to each annual growth. Even without the figures, it is evident that there are very many more failures than successes in any tree top.

So every tree is a record of defeats and disasters in order that the stronger parts may live. It is safe to conclude that if nature is such a searching and undogmatic pruner, man may prune, too. Those persons who declaim that pruning is unnatural, should be taken into a neglected orchard and be made to see what has transpired in the tree tops.

I may be met here with the criticism that artificial pruning is excessive; but I answer that it is not different in kind from natural pruning, and that it is fully warranted by the different objects in view. The ultimate object of nature is the production of seeds, and the more viable seeds produced, the better. Many small fruits, therefore, are desired. Man covets the fleshy portion of the fruit, or some other character which is of minor importance to the plant. He must, therefore, thin the plant rigorously,-reduce the struggle for existence-in order that size and quality may come before number. He 
simply deflects the energy into another channel.

2. The argument from plant physiology is equally important. It is a common assertion that cutting off a limb is an injury because it removes a given amount of tissue in the production of which the plant expended effort; that is, that pruning exhausts the plant. This statement assumes that a plant has a certain fixed vitality, from which a given amount is withdrawn whenever a portion of the plant is cut away. I might illustrate this by supposing that a plant has an initial vitality represented by the figure 10 ; then, if one-tenth of the top is removed, there is left a vitality of 9 . But this assumption is wholly gratuitous. The vitality of a plant is very largely determined by the conditions under which it grows-the character of the soil and treatment; and, I may add, that as plants have no nerves, they cannot die of shock, as we sometimes hear it said. Every fruit-grower knows that two trees of the same initial vigor may differ widely from each other in thrift and healthfulness at the expiration of five years, if given different soil and care. If the plant is very largely what its food supply and other environments make it to be, if it is constantly renewed and augmented, then the removal of a portion of it cannot destroy its vitality unless the removal is so great as to interfere with the nutrition of the remaining 
parts. It may be replied that the tissue, the wood, which is removed in large limbs, might have been saved to the tree by directing it into other parts of the top by means of earlier pruning. This may be true; but I must contend that this saving would have resulted only in an economy of time by building up the other parts earlier in the lifetime of the tree, and not in an economy of vitality, for vitality is constantly renewed.

It may be a question if we really save a proportionate amount of time by early pruning; that is, whether we can direct the same amount of growth into the remaining portions of the plant by pruning very early in its lifetime as we can by pruning when the superfluous branches have attained some size and have, perhaps, begun to bear. There is an exact balance between the feeding capacity of the plant-that is, its root-system and food supply-and the superficial growth of the plant. The more active and efficient the root, the larger the top. If we remove a large portion of this top, there is an endeavor to supply the deficiency by an exceedingly rapid growth. So pruned plants are nearly always more vigorous than unpruned ones, because of the concentration of a somewhat constant food supply into a smaller number of branches. Therefore, pruning must have much the same effect as manuring. The stimulating 
effect of this new growth, or new disposition of energy, must be felt upon the root-system also ; and I can conceive that it is a point for discussion as to whether this stimulus and response to new conditions may not be greater when the pruning is somewhat heroic than when it is so evenly distributed over the lifetime of the tree as to be imperceptible. Growth is certainly more emphatic following a heroic pruning, but it may not be greater in sum than that which follows several prunings of equal aggregate severity. My own observation and experience lead me to believe that annual pruning of all fruit trees is desirable, but I am equally convinced that it does not pay, either in cost of pruning or in good to the tree, to cut out all the superfluous twigs at each pruning. These superfluous twigs can often be left until they are two or three or even four years old with advantage. Although stimulating effects may result from the considerable unbalance of the plant when many branches are removed, these superfluous and unpruned twigs often afford a very useful shelter or sun-screen to the inner parts of the top, and they lessen the danger of over-pruning, by which the nutrition of the tree may be injured.

I have said that pruning increases vigor. Two trees of Siberian Crab were set near my house in the spring of 1890. These trees are as near 
alike as any two apple trees which I have ever seen, and they stand only twenty-five feet apart. I measured the growth of 1891 on one of these trees and found it to have been 745 inches. The tree was then thoroughly pruned (February 17), and this pruning removed 460 inches of wood, of which 432 inches was new wood. The total weight of this wood was seven and three-eighths ounces. The other tree was not pruned. During 1892, the unpruned tree produced 118 new twigs, with a total length of 1,758 inches, while the pruned tree produced 120 new twigs and made a total growth of 1,926 inches. The pruned tree, therefore, made 14 feet more growth than the other, which is a large proportion for a tree only three years set; and the growth was stouter upon this tree, also. In other words, a tree from which about forty feet of branches had been eut bore at the end of a single season fourteen feet more wood than a similar tree which had not been pruned. Aside from the greater growth which this pruning induced, the experiment shows-in common with all similar ones-that it is impossible, as I have already said, to injure trees by what is called a shock. It is often said that the time of the year when pruning is performed influences the amount of growth. It is said that pruning in winter makes wood and pruning in summer makes fruit. It is certainly true that winter 
pruning makes more wood in the current year than summer pruning, because the season's growth is nearly or quite completed when the summer pruning is performed; but beyond this statement it is not the purpose to venture at this point (see Section 16, Chapter IV.).

I have said that pruning, of itself, cannot be injurious so long as it does not interfere with the nutrition of the plant. It is important, therefore, that I explain how this interference occurs. A plant derives a certain portion of its food from the soil in the shape of soluble inorganic materials. These materials ascend to the leaves through the young wood, and become associated with organized compounds like starch and sugar. These organized compounds are used in the repair and growth of all parts of the plant, and they are, therefore, distributed to the leaves, twigs, trunk and roots. The growth of the roots is, therefore, largely determined by the amount and vigor of the top or leaf-bearing portion. The removal of the greater part of the top may interfere, therefore, with the vigor of the plant by preventing the supply of a sufficient amount of elaborated food. This difficulty is sometimes experienced in the girdling or ringing of grape-vines, which prevents the distribution of the elaborated plant-foods to the roots. It should be said, however, that the grape is pruned the most severely of all fruits, and it is, 
therefore, easy to overstep the danger line; and yet it is strange that while certain writers disparage the pruning of trees they do not object to the common pruning of the vine. In fruit trees the instances of injurious interference with nutrition by pruning are rare, and they need not be further considered here. This is proved by the good results which so often follow the heroic treatment of top-grafted trees.

But, you want to say, if pruning is not devitalizing, if the removal of strong branches induces more vigorous growth in the remaining ones, and if there is little danger of disturbing the nutrition of the tree, it must follow that there can be no objection to the removal of large branches. I cannot agree to this inference, although I am willing to say that the removal of such branches may not be objectionable so far as direct injury or shock to the vitality of the tree is concerned. But there are important reasons why large branches should not be removed. Such pruning exposes dangerous wounds, it is apt to open the tree so much that some of the remaining parts scald and borers obtain a foothold, it may despoil the symmetry or convenience of the tree, and such branches may represent a certain amount of energy which should have been earlier directed elsewhere; and aside from all this, the cutting away of very large branches often indicates a lack of enterprise and forethought on the part of the 
grower, and suggests the feeling that he may be remiss in all his operations. But while I discourage the removal of branches three and four inches in diameter, I must repeat that it is not because I consider such practice a devitalizing one. And I should much prefer the removal of such large branches to total neglect. I have myself removed many such branches ten and fifteen years ago from apple trees which are to-day in most perfect health and vigor.

3. If philosophy and physiology show that pruning is not a devitalizing process, common experience affords still stronger proof. One of the commonest absurdities in our horticultural literature is the admonition to prune only with a knife, thereby avoiding the cutting of large limbs, while there is not an orchardist in the country who practices this advice if he prunes thoroughly. If scientific teaching and permanently successful practice are opposed, then the teaching is wrong. I am afraid that some of our accepted teaching on the subject of pruning will not stand the test of time. I have frequently observed that well pruned trees live as long as those unpruned, and I am inclined to believe that they may live longer; and they produce more during their lifetime.

But suppose that pruning is a devitalizing process-what then? Even then we could not afford to discontinue it. The gains in size and 
quality of fruit, in ease of cultivation and spraying of the plants, are advantages which progressive horticulture ean never forego. Advise a grapegrower to discontinue pruning !

It appears to be safe to conclude, from the foregoing considerations, that pruning is a legitimate practice, finding warrant in wild plants, in physiology and in the experience of centuries. It is not of itself, as ordinarily performed, a devitalizing practice, while its advantages are several and important. There is abundant opportunity for improvement in methods, and every plant needs a particular treatment, and perhaps some species or varieties demand little, if any, thinning; but as a whole, pruning is indispensable to successful horticulture. 


\section{Chapter II}

\section{THE FRUIT-BUD}

Since one of the objects of pruning is to secure more and better fruit, it is very important that the reader know what the fruit-buds are and upon what part of the plant they are produced. The best way of gaining this knowledge is to examine the plants in company with a competent instructor; but since the author can produce neither of these requisites, the reader must be content, for the time, to look at pictures and to read about them. The book will explain a few type examples, and will suggest methods of inquiry. It is hoped, however, that as soon as the page becomes dull, the reader will betake himself to the tree, and there obtain his knowledge first hand; but if he should complain that the book and the tree do not always tell the same story, the author will declare that the observer did not see what he looked at.

Without further parley, let us look at the plants.*

*Parts of these observations are adapted from the author's "Lessons with Plants." 


\section{THE BUD AND THE BRANCH}

A twig cut from an apple tree in early spring is shown in Fig. 5. The most hasty observation shows that it has various parts or members. It seems to be divided at the point $f$ into two parts. It is evident that the portion from $f$ to $h$ grew last year, and that the portion below $f$ grew two years ago. The buds upon the two parts are very unlike, and these differences challenge investigation.

In order to understand this seemingly lifeless twig, it will be necessary to see it as it looked late last summer (and this condition is shown in Fig. 6). The portion from $f$ to $h$,-which has just completed its growth,-is seen to have only one leaf in a place. In every axil (or angle which the leaf makes when it joins the shoot) is a bud. The leaf starts first, and as the season advances the bud forms in its axil. When the leaves have fallen, at the approach of winter, the buds remain, as seen in Fig. 5. Every bud on the last year's growth of a winter twig, therefore, marks the position occupied by a leaf when the shoot was growing.

The portion below $f$, in Fig. 6 , shows a wholly different arrangement. The leaves are two or more together ( $a a a a$ ), and there are buds without leaves $(b b b b)$. A year ago this portion looked like the present shoot from $f$ to $h$,-that is, the 


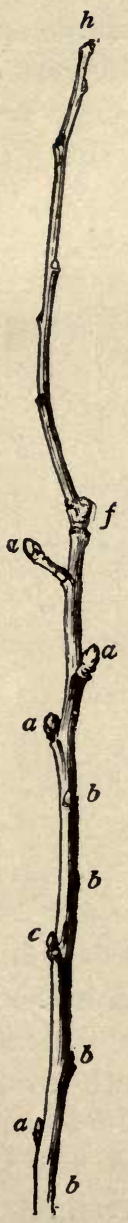

5. An apple twig.

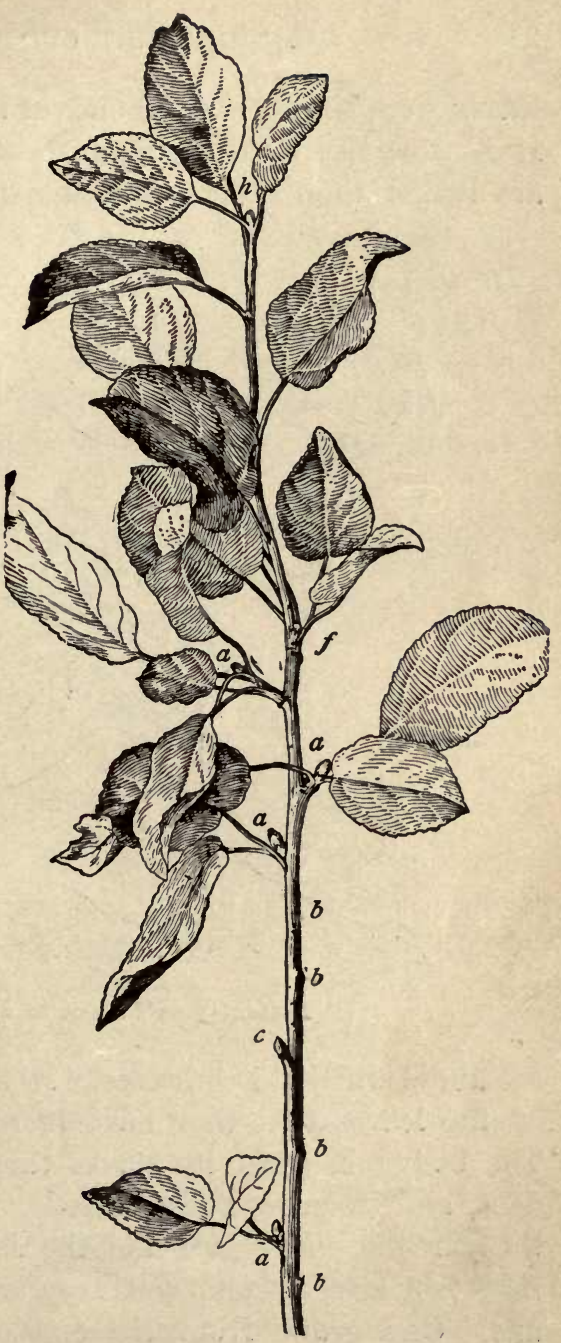

6. Same twig before leaves fell. 
leaves were single, with a bud in the axil of each. It is now seen that some of these bud-like parts are longer than others, and that the longest ones

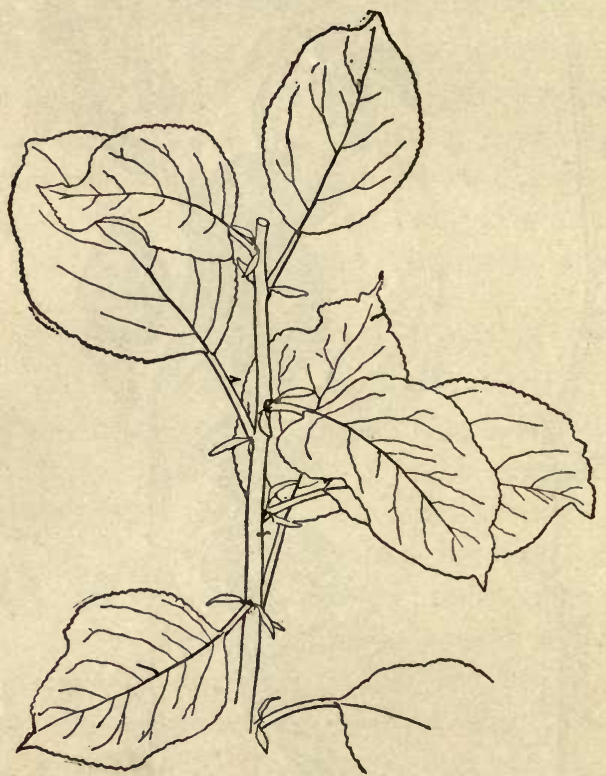

7. Present year's shoot of apple.

are those which have leaves. It must be because of the leaves that they have increased in length. The body $c$ has lost its leaves through some accident, and its growth has ceased. In other words, the parts at $a a a a$ are like the shoot $f h$, except that they are shorter, and they are of the same age. One grows from the end or terminal bud 
of the main branch, and the others from the side or lateral buds. Parts or bodies which bear leaves are, therefore, branches.

The buds at $b \quad b \quad b \quad b$ have no leaves, and they remain the same size that they were a year ago. They are dormant. The only way for a mature bud to grow is by making leaves for itself, for a leaf will never stand below it again. The twig, therefore, has buds of two ages,-those at $b \quad b \quad b \quad b$

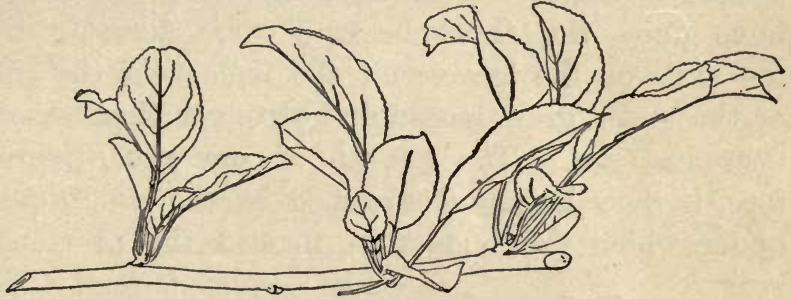

8. Last year's shoot of apple.

are two seasons old, and those on the tips of all the branches ( $a a a a, h)$, and in the axil of every leaf, are one season old. It is only the terminal buds which are not axillary. Buds are buds only so long as they remain dormant. When the bud begins to grow and to put forth leaves, it gives rise to a branch, which, in its turn, bears buds.

It will now be interesting to determine why certain buds gave rise to branches and why others remained dormant. The strongest shoot or branch of the year is the terminal one $(f h)$. The next 
in strength is the uppermost lateral one, and the weakest shoot is at the base of the twig. The dormant buds are on the under side (for the twig grew in a horizontal position). All this suggests that those buds grew which had the best chance,the most sunlight and room. There were too many buds for the space, and in the struggle for existence those which had the best opportunities made the largest growths. This struggle for existence began a year ago, however, when the buds upon the shoot below $f$ were forming in the axils of the leaves, for the buds near the tip of the shoot grew larger and stronger than those near its base. The growth of one year, therefore, is very largely determined by the conditions under which the buds were formed the previous year.

All these remarks are still further illustrated by Figs. 7 and 8 . Fig. 7 is the current year's growth of apple. The leaves are placed singly, and there is a single bud in the axil of each. (The two awl-like bodies at the base of each leaf are stipules, or appendages of the leaves.) Fig. 8 is a shoot a year older than the other. Four buds were formed in the axils of as many leaves in the previous year; one of these buds is dormant, but the other three have produced short, leafy branches. Any tree or shrub will show the same differences between the two last annual growths. 


\section{THE LEAF-BUD AND THE FRUIT-BUD}

Another apple branch is shown in Fig. 9. It seems to have no slender last year's growth, as Figs. 5 and 6 have at $f h$. It, therefore, needs special attention. It is first seen that the "ring" marking the termination of a year's growth is at $a$. There are dormant buds at $b b$. The twig above $a$ must be more than one year old, however, because it bears short lateral branches at $e e$. If these branchlets are themselves a year old (as they appear to be), then the portion $f g$ must be a similar branch, and the twig itself $(a f)$ must be two years old. The ring marking the termination of the growth of year before last is, therefore, at $f$. In other words, a twig is generally a year older than its oldest branches.

The buds $c c$ (Fig. 9) are larger than the dormant buds $(b \quad b)$. That is, they have grown; and if they have grown, they are really branches, and leaves were borne upon their little axes in the season just past. The branchlets $d d d$ are larger (possibly because the accompanying leaves were more exposed to light), and $e e$ and $g$ are still larger. For some reason the growth of this twig was checked last year, and all the branches remained short. We find, in other words, that there is no necessary length to which a branch shall grow, but that its length is dependent upon local or seasonal conditions. 


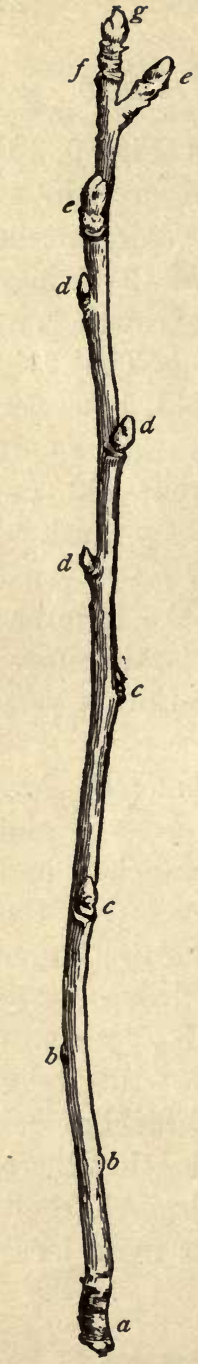

9. Formation of fruit-buds.

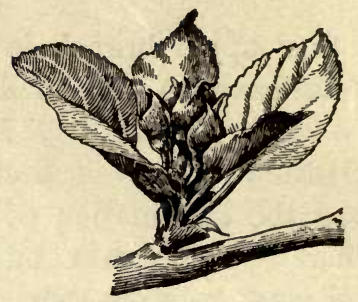

10. Opening of flower-bud of apple.

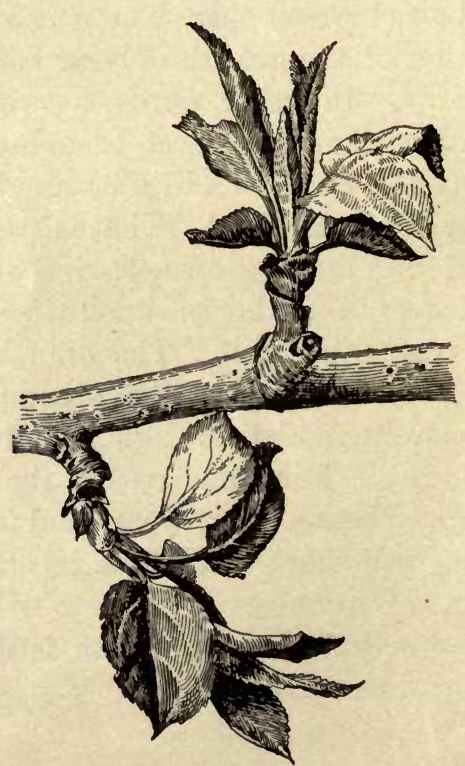

11. Opening leaf-buds of a crab-apple. 
There are other and more important differences in this shoot. The buds terminating the branches ( $e$ e $g$ ) are larger and less pointed than the others are. If they were to be watched as growth begins in the spring, it would be seen that they give rise to both flowers and leaves (Fig. 10), while the other buds give leaves only (Fig. 11). In other words, there are two general kinds or types of buds, fruit-buds (that is, flowerbuds) and leaf-buds; and checking the growth induces fruitfulness.

If the buds on the ends of the branchlets $e e g$ produce flowers, the twig cannot increase in length; for an apple is invariably borne on the end of a branch (which is often so short as to be called a spur), and therefore no terminal bud can form there. If growth takes place on the twig next year, therefore, it must arise from one of the lower or leaf-buds. The buds terminating the branchlets $d d d$ will stand the best chance of continuing the growth of the twig, for they are the largest and strongest, and are most exposed to sunlight. These failing, the opportunity will fall to one or both of $c c$; and these failing, the longwaiting dormant buds may find their chance to grow. The reader should see these dormant buds for himself. In other words, there are more buds upon any twig than are needed, but there is, thereby, a provision against emergencies. 
THE FRUIT-SPUR AS ILLUSTRATED BY THE APPLE

We have now found (Figs. 9, 10, 11) that there are two kinds of buds, the leaf-buds, and the fruit-buds (or flower-buds). Some of these fruit-

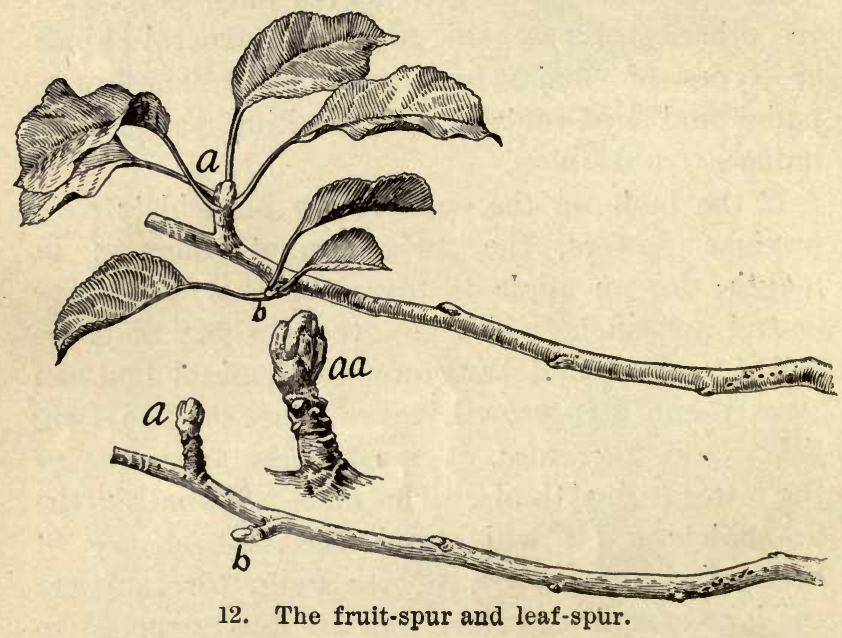

buds on the apple tree terminate short branches (e e g, Fig. 9), but now and then one is borne on the end of the axial shoot of the season. Fig. 12 is an apple twig as it looks in late summer and in winter. Several dormant buds are seen on the lower part. $\Delta$ t $a$ and $b$ are short branches. The branch $b$ has made a small and pointed bud, which is evidently to bear only leaves next year, while 
the stronger branch (a) has made a thick and rounded bud, which is to bear flowers. This fruit-bud is shown natural size at $a a$. The short lateral branches are called spurs, in distinction from the longer axial growths. We have already found (page 29) that checking growth induces

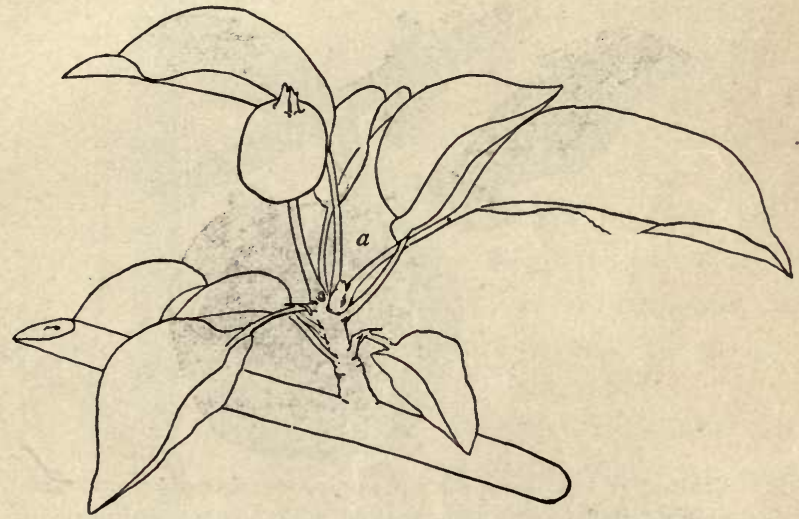

13. Formation of the lateral bud on the fruit-spur.

fruitfulness, but on the other hand, starving or greatly weakening the growth generally gives only a weak leaf-bud.

When fruits or flowers are borne on the end of a spur, the direction of the subsequent growth is necessarily changed. Fig. 13 is a bearing spur of apple. While the apple is growing from the terminal bud, a lateral bud $(a)$ is forming to continue the spur the next year. The same thing is illustrated in Fig. 14. This side bud ( $a$, Fig. 13) 
is, therefore, a leaf-bud, for it must be the means of continuing the growth of the spur, and it is not likely to get nourishment enough,- - seeing that the apple is the chief concern,- to enable it to develop into a blossom-bud. There is, therefore, an alternation of fruit-bearing buds and

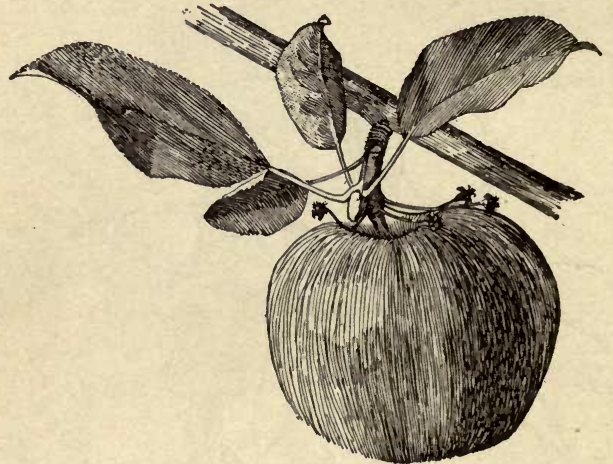

14. Fruit-spur bearing a mature apple, remains of the flowers which failed to set, and the bud which is to continue the growth of the spur.

non-fruit-bearing buds in the spur of an apple tree; and this is true of most fruit trees.

A twig of Siberian crab apple, taken in spring, is shown in Fig. 15. Year before last, each of the spurs developed a fruit-bud at its summit, and last year each of these spurs bore flowers. The proof of this is seen in the scars left by the flower stems at $a a$. None of these flowers developed into ripe fruits, otherwise some of the 
scars would have been much larger than they are. It was probably for that very reason,- the failure

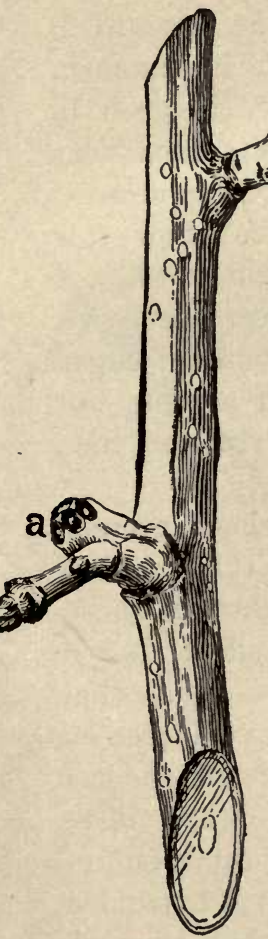

15. Spurs of a crab-apple.

of the fruit, that the spurs were able to throw out leafy shoots nearly or quite an inch long, to continue the growth. Yet, even then, no fruit-bud developed on the ends of these spurs, for the small pointed ends clearly indicate leafbuds. It is seen, therefore, that there may be an alternation in the fruit-spur, even when the spur does not bear fruit.

To still further elucidate the formation of fruit-buds on the apple, and to recapitulate some of the foregoing observations, let us trace the history of given branches in detail.*

One of these twigs (Fig. 16) was taken from a strong young tree, which bore its first good erop of apples last year. This

\footnotetext{
*This account of these three apple twigs is adapted from the author's leaflet entitled "Four Apple Twigs," issued as a nature-study suggestion by the College of Agriculture of the Cornell University, 1896-7. This leaflet (and also "Lessons with Plants") contains the detailed history of an older and more complicated branch.
} 
simple twig is plainly of two years' growth, for the "ring" between the old and new wood is seen at B. The main stem from the base to B grew in 1895 (the picture was made in January, 1897), and the part from B to the tip grew in 1896. The buds on these two parts look very unlike. Let us see what these differences mean.

We must now picture to ourselves how this shoot from B to 10 looked last summer while it was growing. The shoot bore leaves, one below each bud; or, to be more exact, one bud developed just above each leaf. These buds did not put out leaves. They grew to their present size and then stopped (see $f h$, Fig. 6).

What are these buds of the tip shoot proposing to do in 1897? We can answer this question by going back one year and seeing what the buds on the lower (or older) part of the shoot did in 1896, as we did in Figs. 5 and 6 . Upon that part (below B) the buds seem to have increased in size. Therefore, they must have grown last year. There were no leaves borne below these buds in 1896, but a cluster of leaves came out of each bud in the spring. As these leaves expanded and grew, the little bud grew on; that is, each bud grew into a tiny branch, and when fall came each of these branches had a bud on its end to continue the growth in the year to come. What we took to be simple buds at $2,3,4,5,6$, are therefore little branches (compare Fig. 9). 


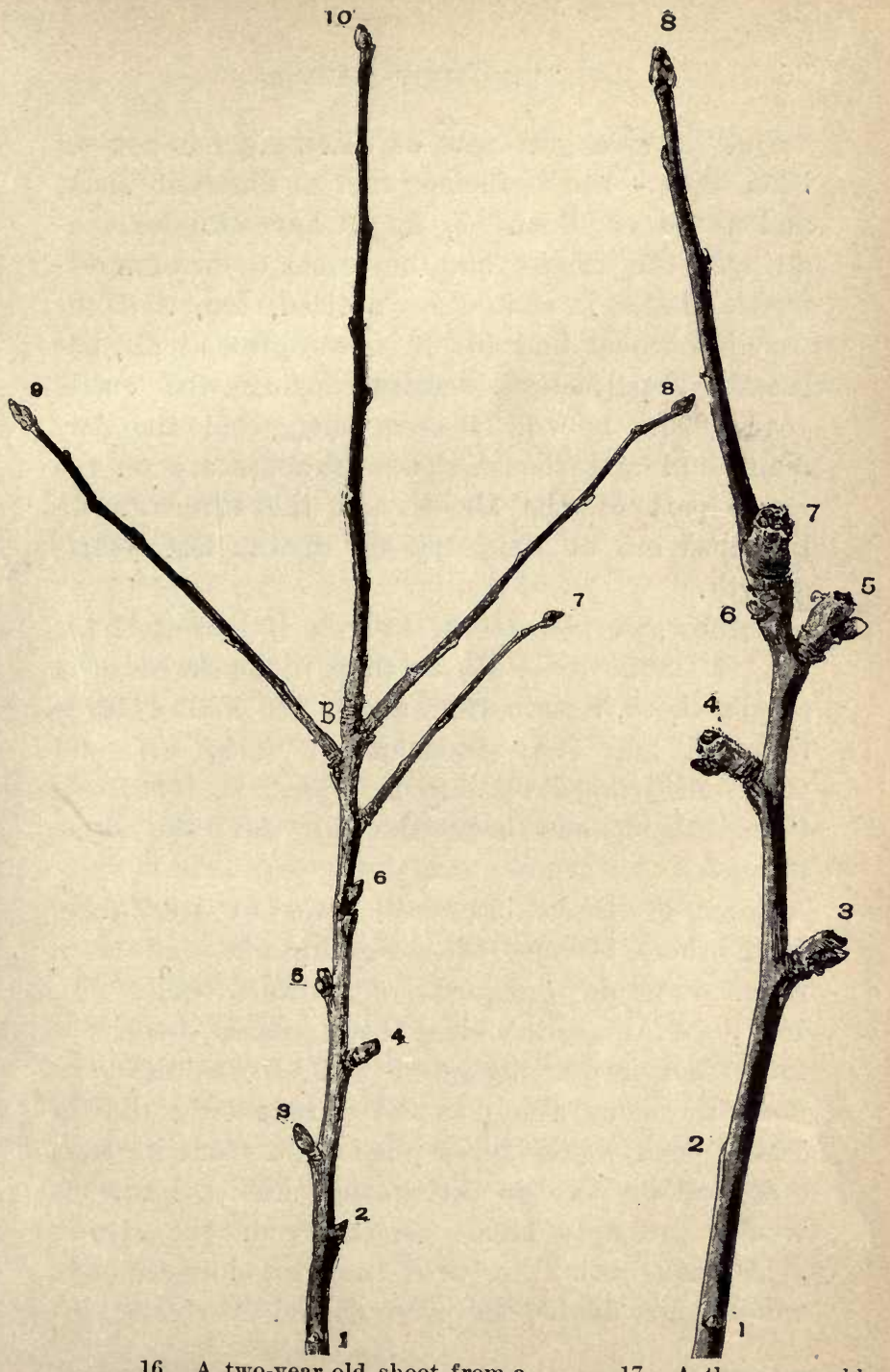

16. A two-year-old shoot from a

17. A three-year-old young apple tree.

Half size. shoot and fruit-spurs. Half size. 
But the strangest part of this twig has not yet been seen,-the branches are of different sizes, and three of them $(7,8,9)$ have so far outstripped the others that they seem to be of a different kind. It should be noticed, too, that the very lowermost bud (at 1) never grew at all, but remained perfectly dormant during the entire year 1896. It will be seen, then, that the dormant bud and the smallest branches are on the lower part of the shoot, and the three strong branches are at the very tip of the last year's growth.

If, now, we picture the twig as it looked in the fall of 1895, we will see that it consisted of a single shoot, terminating at B. It had a large terminal bud (like those at $7,8,9,10$ ), and this bud pushed on into a branch in 1896, and three other buds near the tip did the same thing.

Some of these branches grew to be larger than others because of more sunlight and more room on this outward or upward end. In 1897, - if this shoot had been spared,-each of these four largest twigs $(7,8,9,10)$ would have done the same thing as the parent twig did in 1896: each would have pushed on from its end, and one or two or three other strong branches would probably have started from the strong side buds near the tips, the very lowest buds would, no doubt, have remained perfectly in- 
active or dormant for lack of opportunity, and the intermediate buds would have made short branches like $2,3,4,5,6$. In other words, the tree always tries to grow onward from its tips, and these tip shoots eventually become strong branches, unless some of them die in the struggle for existence. What, now, becomes of the little branches lower down?

From another apple tree the twig shown in Fig. 17 was taken. We see at once that it is very unlike the other. It seems to be two years old, one year's growth extending from the base up to 7 , and the last year's growth extending from 7 to 8 ; but we shall see upon looking closer that this is not so. The short branchlets at $3,4,5,7$ are very different from those in Fig. 16. They seem to be broken off. The fact is that the broken ends show where apples were borne in 1896. The branchlets that bore them, therefore, must have grown in 1895, and the main branch, from 1 to 7 , grew in 1894. It is plain, from the looks of the buds, that the shoot from 7 to 8 grew during the year 1896 .

Starting from the base, then, we have the main twig growing in 1894; the small side branches growing in 1895; these little branches bearing apples in 1896, and the terminal shoot also growing in 1896. Why was there no terminal shoot growing in 1895? Simply because its tip developed a fruit-bud (at 7), and therefore could not 
send out a branch; for there are two kinds of buds, - the small, pointed leaf-bud and the thick, blunt fruit-bud. If the branchlets, $3,4,5,7$, are two years old, the dormant buds-1,2-must be the same age. That is, for two long years these little buds have been waiting for some bug to eat off the buds and leaves above, or some accident to break the shoot beyond, so that they might have a chance to grow; but they have waited in vain.

We have now found, therefore, that the little side shoots upon apple twigs may become fruitbranches or fruit-spurs, while the more ambitious branches above them are making a display of stem and leaves.

But will these fruit-spurs bear fruit again in 1897? No. The bearing of an apple is hard work, and these spurs did not have enough vitality left to make fruit-buds for the next year; but they must perpetuate themselves, so that they have sent out small side buds, which will bear a cluster of leaves and grow into another little spur in 1897, and in that year these new spurs will make fruit-buds for bearing in 1898. The side bud is plainly seen on spur 5, also on spur 4, while spur 7 has sown a seed, so to speak, in the bud at 6 . It is, therefore, plain why the tree bears every other year (see page 32 , Figs. 13, 14).

There was one tree in the orchard from which the farmer had not picked his apples. Perhaps 
the apples were not worth picking. At any rate, the dried apples, shriveled and brown, hang on the twigs in midwinter, and even the birds do not seem to care for them. One of these twigs is drawn in Fig. 18. Let us see how many apples this twig has borne. We can tell by the squarecut scars. An apple was once borne at 1 , another

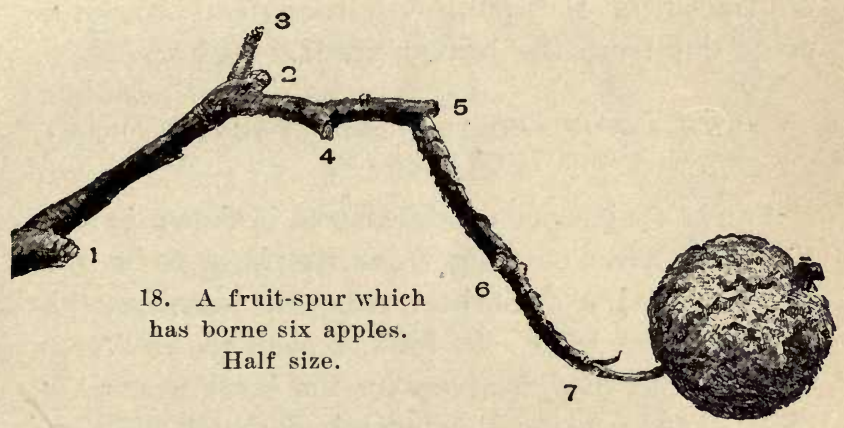

at 2 , another at 4 , another at 5 , another at 6 , and another at $7,-$ and at 7 there will be a scar when the apple falls. Six apples this modest shoot has borne! We may speculate how many of them got ripe, or how many were taken by the worms, or urchins.

A curious thing happened when the fruit was growing at 2. Two side buds started out, instead of one, and both of them grew the next year. But one of the little branchlets fell sick and died, or a bug nipped off its end, or it starved to death; and the grave is still marked by the little stick. 
standing at 3 . The other branchlet thrived, and eventually bore apples at 4, 5, 6 and 7 .

We have found that these fruit-spurs bear only every other year; then, if this branch has borne six apples, it must be twelve years old. The truth is that it is about twenty years old, for some years it failed to bear; but the age cannot be traced in the picture, although it could be made out from the branch itself.

\section{THE F'RUIT-SPUR AS ILLUSTRATED BY THE PEAR}

An old fruit-spur of a pear tree is shown in Fig. 19. One year it grew from the base to $a$, and there formed a fruit-bud. Let us suppose that this year was 1880 . In 1881, a pear matured from this bud, as may be seen by the large scar at $a$. In this year, also, a lateral bud developed. In 1882 , this bud gave rise to a shoot. The "rings" whence it started are plainly seen at $a a$. It is noticeable, also, that the spur ceased to grow in the direction $a$. In this year, 1882, the shoot grew to the rings $b b$, and there developed a fruitbud. In 1883, this fruit-bud opened and produced flowers, one of which bore fruit, as shown by the large scar (b). The short growth from $b b$ to $b$ is that which took place in the elongation from the bud in this spring of 1883 . While this fruit was developing, a leaf-spur pushed out from just below the fruit $(b)$, and grew to the next 
series of rings $(c c)$. A weaker bud also developed, which in 1884 pushed toward $c$. The six years' growths can be traced on this side shoot, and it once made a flower-bud, and a fruit set at $c$; but the small size of the scar shows that the fruit never attained maturity. It probably fell in very early summer. It is apparent that there is an alternation in the fruit-bearing of the pear, as in that of the apple; from this we may infer that there is something like an alternation of effort, or division of labor, in the successive growths of many plants.

The further history of this interesting pear spur (Fig. 19) may be summarized as follows: 1884, the barren shoot grew to $e e$, and made a fruitbud; 1885, pear borne and carried to maturity at $e$, two side buds developing, and also

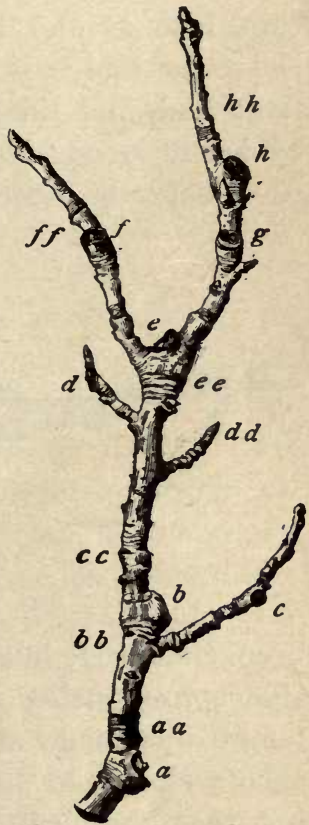

19. Old spur of pear. two weaker spurs at $d$ and $d d$,-giving four chances of continuing the growth of the main spur; 1886, the spurs $d$ and $d d$ remained small and slender, but one of the upper branches grew 
on to $g$ and there made a fruit-bud, while its twin bud (upon the left) did not elongate; 1887, fruit borne at $g$, but it did not mature (as shown by the small size of the scar), and the spur continued to $h$, and there made another fruit-bud; the twin bud now pushed on to $f$ and made a fruit-bud, and the spurs $d$ and $d d$ are alive, but evidently doomed soon to perish; 1888, fruits were borne at $f$ and $h$ (the bearing year having

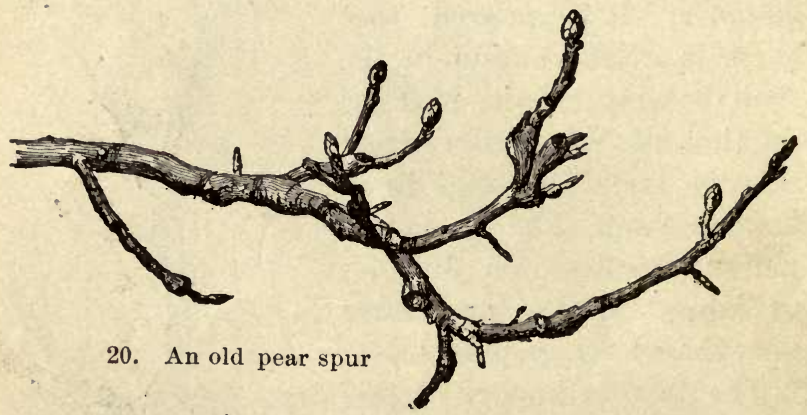

been changed), but neither of them matured, the side spurs pushed on to $f f$ and $h h$, and an attempt was made at fruit-bearing at $d ; 1889$, all shoots elongated and all end in leaf-buds, showing that the change in the bearing year had interfered with the normal development, for this should have been the year of fruit. Our spur, therefore, is ten years old; it has borne good fruits three times, and has made five unsuccessful attempts at fruit-bearing; some of the branches are too weak for further usefulness; 
and dormant buds still remain on the old wood near its base.

The struggle for existence in an old pear spur is still further illustrated in Fig. 20. On five of the strongest and upturned branchlets there are fruit-buds. Some of the branchlets terminate in the small and pointed leaf-buds, and some are dead. If the reader has become expert in reading the histories of twigs, he may find in this picture the records of ten efforts at the bearing of pears.

Another pear twig is drawn in Fig. 21. In 1895 , a pear was borne at $a$, and in that year two side buds were developed (as they have formed in Figs. 13 and 14). In 1896, these two buds gave rise to branches or spurs, each of which developed a fruit-bud at its end, $b c$. It was on the 17th of April, 1897, that the picture was made. Three weeks later all the buds had burst (Fig. 22). Buds $b, c, d, e$, produced flowers, and $f$ made only a feeble effort at leaves. That is, all but one of the buds are fruit-buds. In July, however, the branch looked like Fig. 23. Although severa? flowers had been produced by each of the four fruit-buds, only one flower in the bud $b$ and another in $c$ persisted and set fruit.

Another twig upon this same pear tree was drawn (Fig. 24) upon the 17th of April, 1897. There are three thick, rounded buds which are evidently fruit-buds. They terminate spurs which 

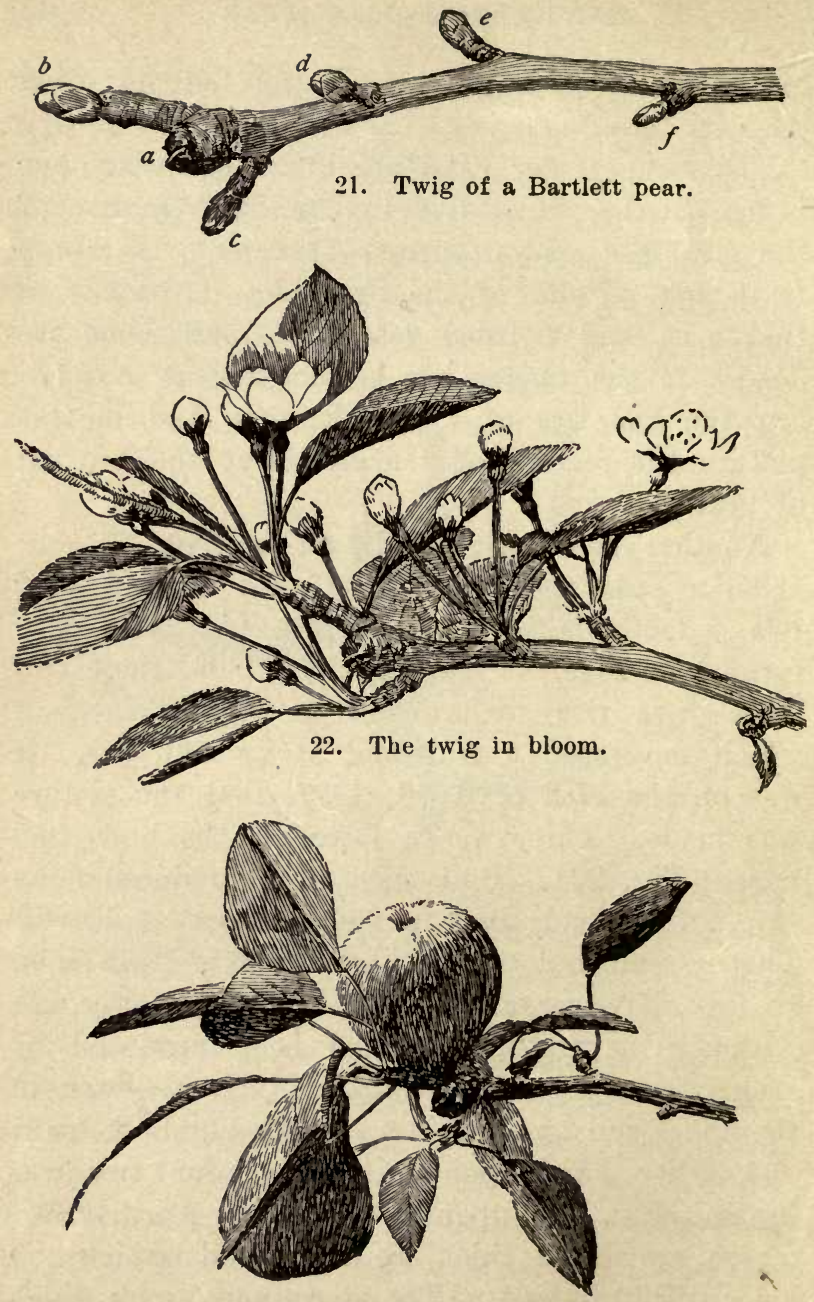

23. The tinal result. 
spring from the top of the growth of 1895 . That is, the spurs grew and developed fruit-buds in the season of 1896. On the 4th of May, the twig

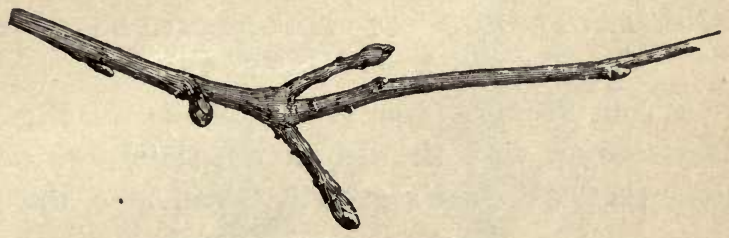

24. Three fruit-spurs of pears.

looked as in Fig. 25. The three buds had produced flowers, only one of which still persists, and even that soon fell. No fruits were pro-

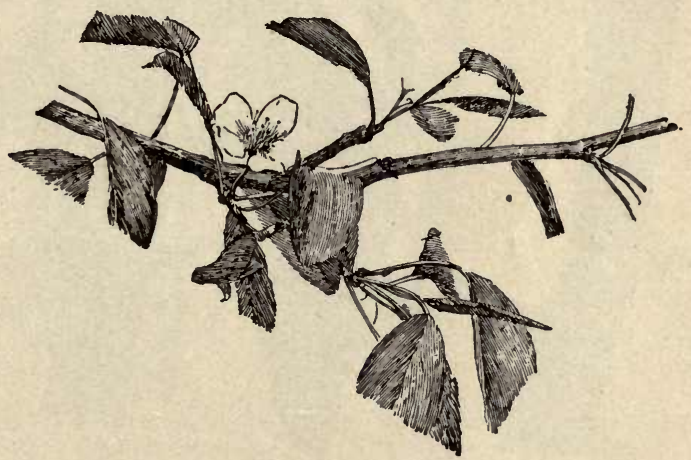

25. The sequel.

duced. The buds were too weak to set fruit, although they produced blossoms.

Still another pear twig is seen in Fig. 26. It is evident that only the lowest bud is a fruit-bud. 
The others are too small to be fruit-buds. In May the twig was drawn again (Fig. 27).

THE FRUIT-SPUR AS ILLUSTRATED IN THE PLUM AND CHERRY

A spur from a plum tree is shown in Fig. 28. If we begin with the tip of the shoot, we determine that last year's growth began at $c$, the pre-

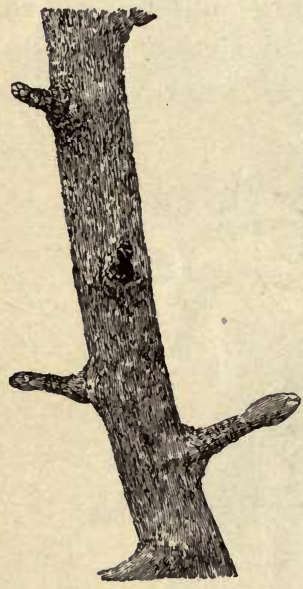

26. Leaf-spurs and a fruit-spur of pear.

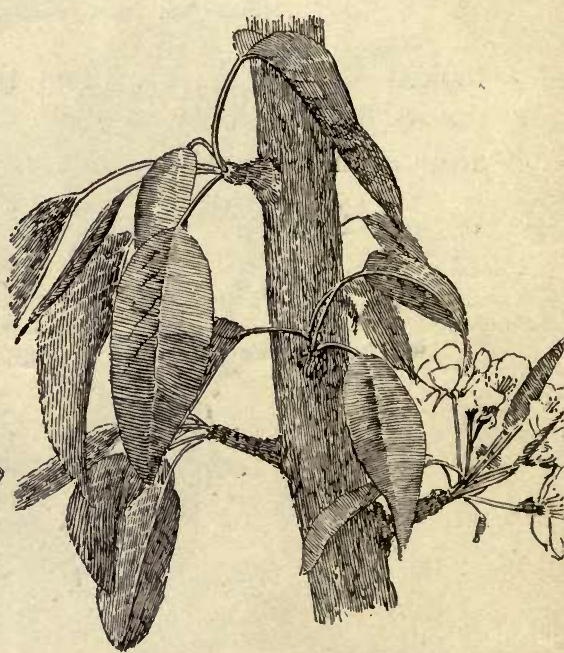

27. The sequel.

vious year's at $b$, and the preceeding year's at $a$. The lower side spur has grown to $a$, then to $b b$, then to the end. It will be seen that the 


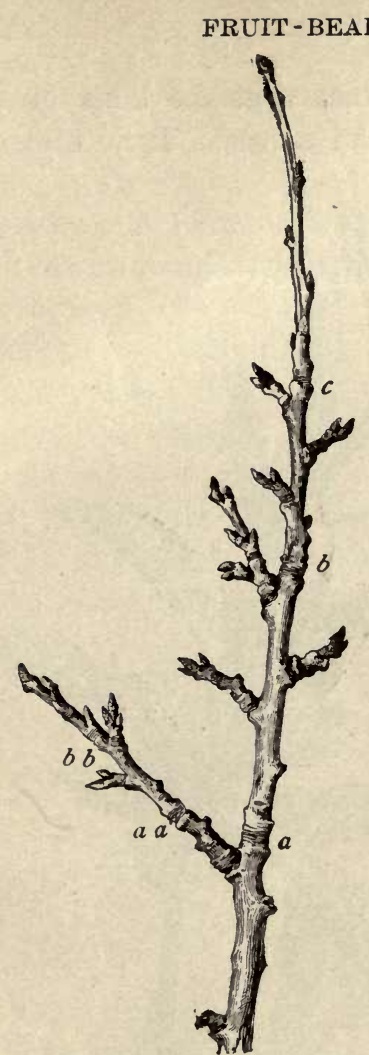

28. Fruit-spur of plum.

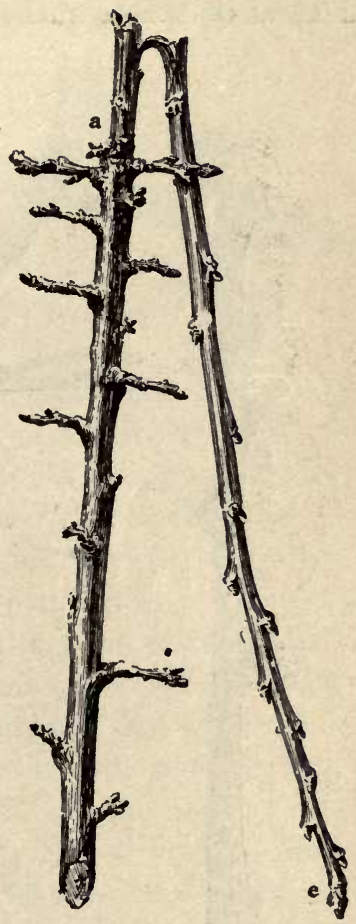

29. Spur of Lombard plum.

buds and side spurs are borne usually near the ends of the growths, but the many scars show that buds were once present on the lower or older parts, but have perished in the struggle for existence. The spur differs greatly from 
those of the pear, in the fact that the buds are in twos or threes rather than single. It is diffi-

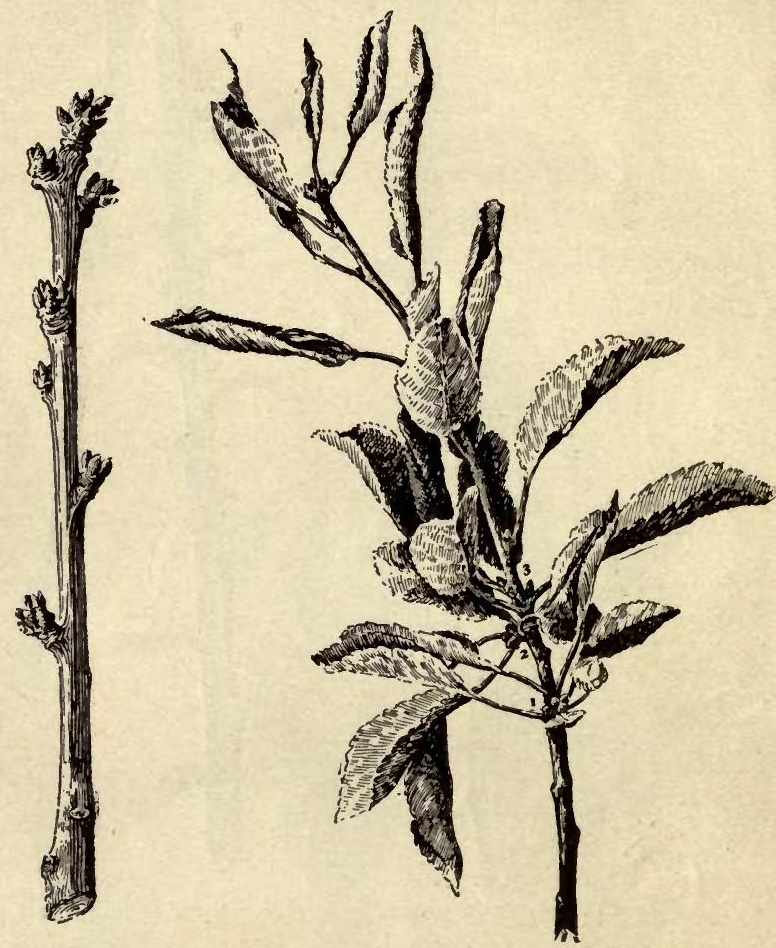

30. Spur of Satsuma plum.

31. Buds and spurs of cherry.

cult to distinguish which are leaf-buds and which fruit-buds. The character of the buds is to be determined from their positions rather than from their shapes. The first point to 
notice in determining which are leaf-buds and which fruit-buds is the direction of growth of the entire spur. The pear spur (Fig. 19) is crooked and forked because the fruitbuds are terminal; if, therefore, the plum spur is straight or

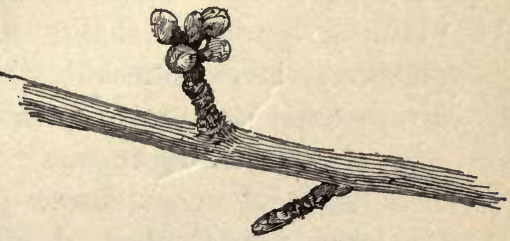

32. Cherry spurs. continuous in growth, it is because the terminal buds are leaf-buds. The side buds may therefore be inferred to be fruit-buds. The reader should examine a plum

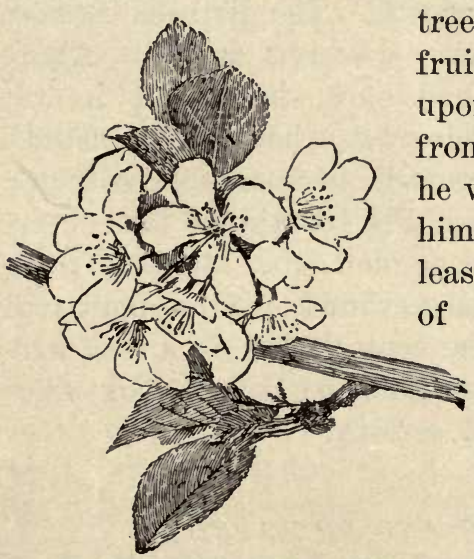

33. The same spurs in May. tree in either flower or fruit for further light upon this point; and from all his observations he will be able to satisfy himself that there are at least two general types of spurs upon fruit trees, - with terminal fruit-buds and terminal leaf-buds.

The fruit-bearing of the common plum is further illustrated in Fig. 29, which shows the growths of the two last years. The last season's growth is from $a$ to $e$, and upon 
this part there are no fruit-buds. The second year's growth, below $a$, bears many fruit-spurs, each of which has several fruit-buds, thus explaining how it is that plums are borme in dense clusters. It is noticeable that the strongest spurs are nearest the top of the two years' growth, where more sunlight was received.

A spur of a Japanese plum, Fig. 30, shows clustered fruit-buds. A single smaller leaf-bud is in the center of each cluster. Japanese plums also bear from twin fruit-buds on the last year's growth, in the way of the peach and apricot.

A twig of Morello cherry is shown in Fig. 31. It is of two years' growth. The division between the two years is seen between 2 and 3 . Above this division, the buds are single and in the axils of leaves; below it, they are clustered on spurs. The rounded buds on these spurs, 1, 2, are fruit-buds. Fig. 32 shows two cherry spurs, one a leaf-spur and the other a fruitspur. The four large buds on the fruit-spur are flower-buds; the central one is a leaf-bud. Fig. 33 shows how the same spurs look when they have burst into growth.

\section{THE PEACH AND THE APRICOT}

The next picture (Fig. 34) shows a twig cut from a peach tree in spring (or winter). It is two seasons old, as shown by the ring at $a$, and 
by the different buds upon the two parts. Upon the older portions there are dormant buds; there are also curious angular bodies at $e e e$. We understand what the dormant buds mean, but the other bodies demand explanation. They are not growing branches, because they have no buds. The truncate or squared ends are scars. These cannot be leaf-scars, because no buds are left above them (and we have found that buds grow in the axils of leaves). They must, then, be fruit-scars (or flower-scars).

If we could have seen this twig (below $a$ ) in the spring of last year, a piece of it would have looked like Fig. 35. Three buds are borne together, the two lateral ones (which are evidently fruit-buds) being large and thick. If it were the habit of the peach to bear three leaf-buds together, the method of branching of the peach tree would tend to be by threes, but we know that this is not the fact. We know that these objects $a$ a are not spurs (or branches), because the leafsear is visible below each one. That is, they are normal buds, formed the previous year in the axils of leaves. If we could go back to this previous year, we should find the condition shown in Fig. 36 , in which a triplet of leaves is making this group of buds; but there are other leaves borne singly, and in the axils of these only leaf-buds are borne (as a rule). From this it is seen that the method of fruit-bearing of the peach is very 

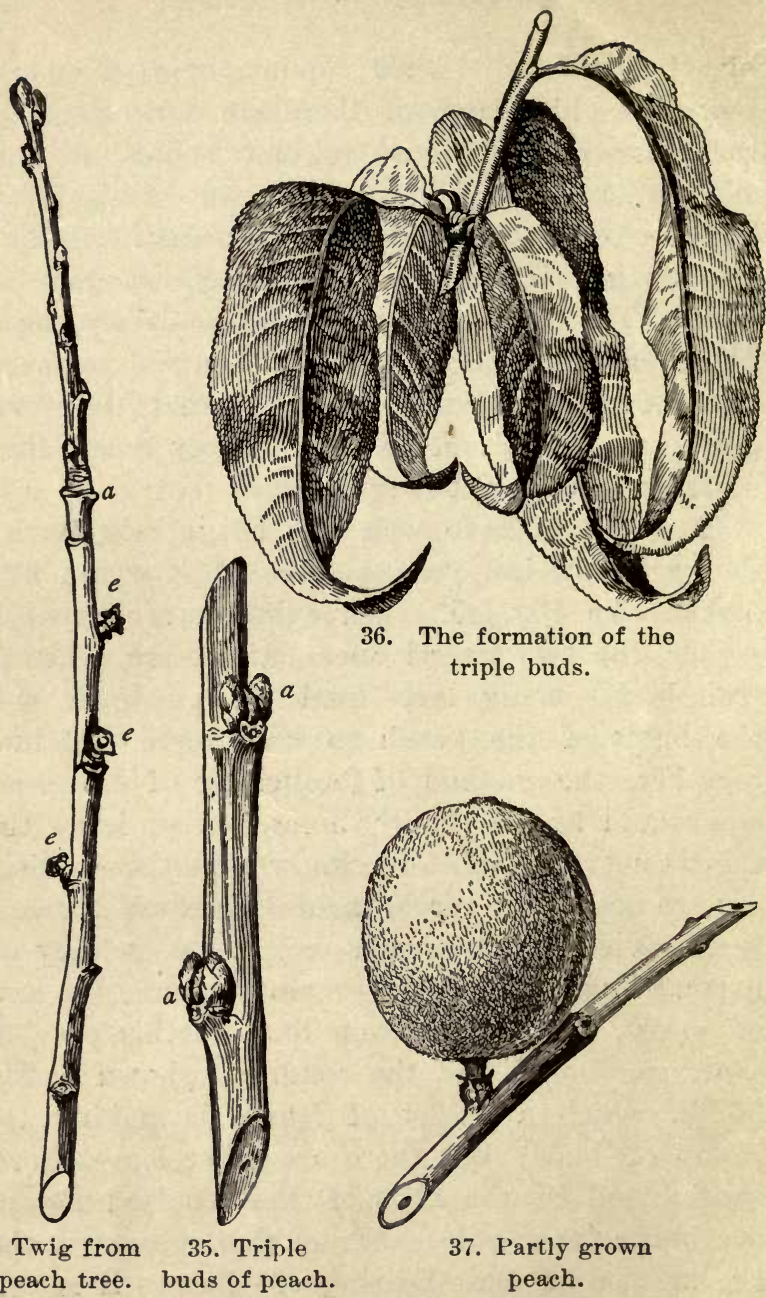

34. Twig from

a peach tree. buds of peach. peach. 
different from that of the apple, pear, plum, and cherry.

It must now be determined why the fruit-scars are single on the twig in Fig. 34 , while the fruit-buds are in pairs (with a leaf-bud between them) in the first place (Figs. $36,35)$. Fig. 37 shows a halfgrown peach which has arisen from one of the buds. A flower was produced from each bud, but in the struggle for existence one of them (and also the leafbud) perished. The twig in Fig. 34 has no buds upon the bodies which bore the peaches; therefore, these bodies are not leaf-bearing branches (or spurs), and they do not bear again. We have seen (Figs. 36, 35) that these fruit-buds are formed on the axial growth of the current year, and bear the next year, and not upon spurs. Very short fruit-bearing growths often arise from two or three-year-old wood of the peach, but these are really not spurs-although they look like spurs-because they bear but once. It is plain,

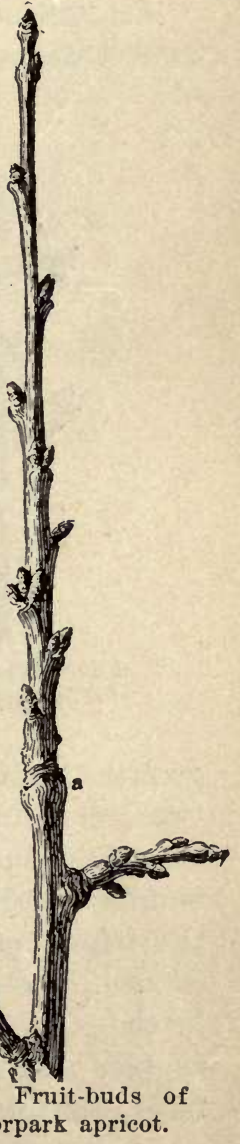


therefore, that the peach-grower should always aim to so manage his trees as to have a liberal supply of new growths.

An apricot shoot is seen in Fig. 38. It is of two seasons' growth. Upon the last year's

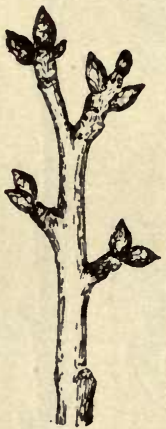

39. Short branching spur of apricot.

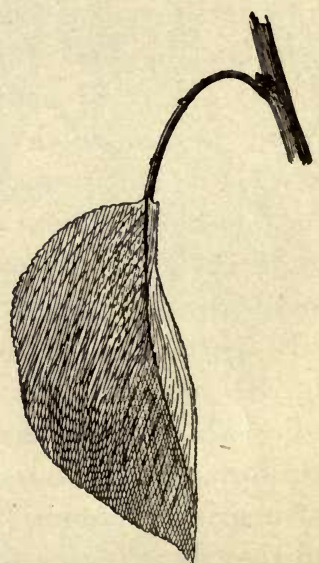

40. The three buds with but a single leaf.

growth, above $a$, the buds are borne singly, in twos, or in threes. Normally, a bearing young twig has buds in threes, as the peach has, the middle one being a leaf-bud, but one or two of the triplet often perishes in the struggle for existence. Below $a$ there are fruit-spurs, much as in the plum. These spurs in Fig. 38 are long and simple, and bear several buds; but one often finds branching spurs, like Fig. 39, remiuding him 
of the pear, although the apricot spur never attains such great age as the pear spur does. The apricot, therefore, makes fruit-buds both upon the current year's growth and upon spurs.

We have found (Fig. 36) that the triplet buds of the peach are subtended by three leaves. The

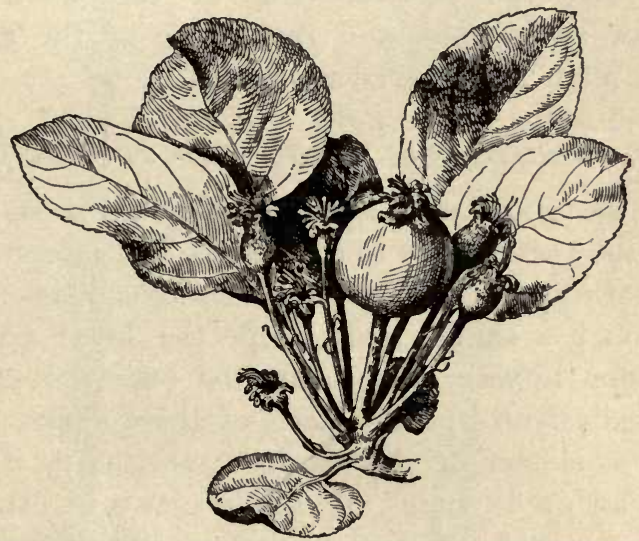

41. Struggle for existence among the apple flowers.

apricot is not so, for the three buds are borne in the axil of a single leaf (Fig. 40). We have seen in Figs. 10, 22 and 33 that the blossom-bud of the apple and pear and cherry contains leaves as well as flowers. These leaves persist through the season and aid in nourishing the fruit. Notice them in Figs. 14 and 23. They are also shown in Fig. 41; and this picture (as, also, Fig. 14) shows how it is that apples are usually borne 
singly although the flowers are in clusters of six or more.

In the peach, however, the fruit-buds do not contain leaves (Fig. 37), and, moreover, the flowers are borne singly. Fig. 42 shows that the same is true of the apricot. We may say, therefore, that the blossom-buds of the peach and apricot are simple, and that those of the apple, pear, plum and cherry are mixed.

GOOSEBERRIES, CURRANTS AND JUNEBERRIES

In the gooseberry shoot in Fig. 43 , it is plain that the part from $a$ to $b$ grew the last season, and the portion below $a$ two seasons ago. The upper portion has simple buds, while the lower portion has what appear to be elongated buds, but which are really fruit-spurs. Each of these spurs, then, bore a cluster of leaves last year, as if it had been an apple spur. If the reader will examine currant and gooseberry bushes at any time of the year, he will readily conclude that they usually bear fruits on spurs, but that these spurs generally bear only two or three times.

The two-year-old twig of a black currant is drawn in Fig. 44. It was taken in spring, and yet the remains of the old fruit-stems persist on each of the spurs. The point of attachment of these stems shows the lengths of the spurs of the year before, and the crook in the spur at that point shows that the fruit-bud was terminal 


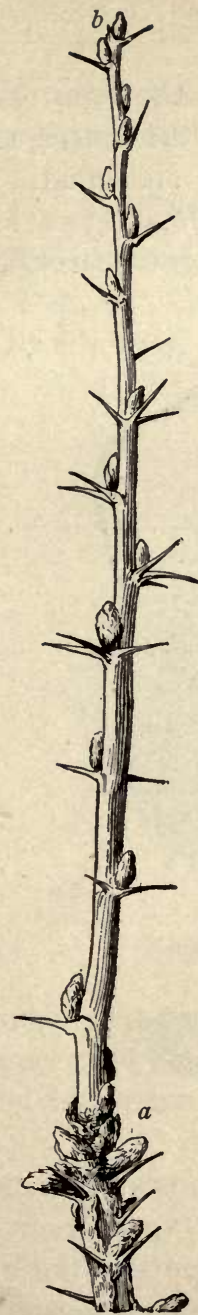

43. Gooseberry shoot.

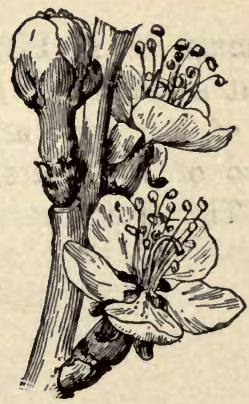

42. The single and leafless flowers of apricot.

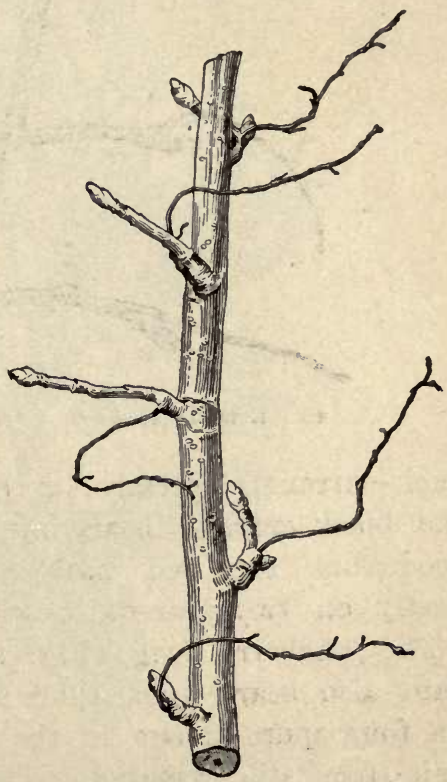

44. Fruit-bearing of the black currant. 
(as it must be in Fig. 43, since the spur contains but a single bud), also that the subsequent growth of the spur arose from a side bud. In fact, two of the spurs, $a, b$, developed two side buds. The fruit-bearing of the gooseberry and

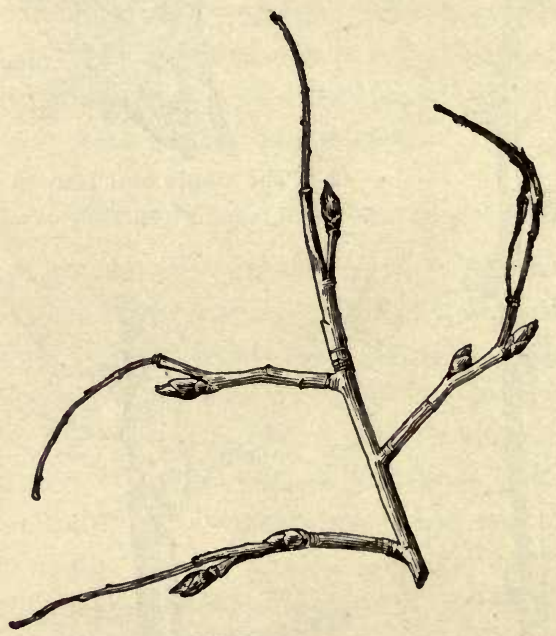

45. Bearing shoot of dwarf juneberry.

black-currant, therefore, is by means of spurs. The black-currant bears mostly on last year's wood, but the red and white currants bear mostly on two-year-old wood.

The juneberry twig (Fig. 45) shows that this plant also bears upon spurs; and upon each of the four spurs shown in the illustration the old fruit-stem still remains. The best clusters the 
following year may be expected to come from the strong terminal buds.

CO-T'RMINAL FRUIT-BEARING

The expanding shoot of a maple is illustrated in Fig. 46. It came from a winter bud terminating a twig. The enlarging seales of this bud are at $1,2,3,4$. This shoot bears not only

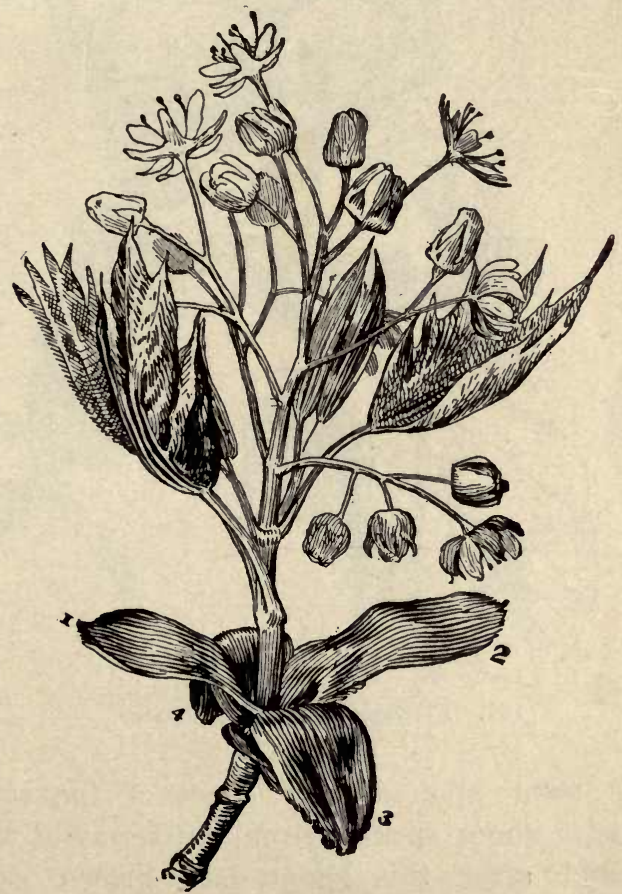

46. Expanding shoot of Norway maple. 
flowers but leaves, and the shoot is growing. That is, the axis has elongated considerably since the opening of the bud.

A quince flower is drawn in Fig. 47. This,

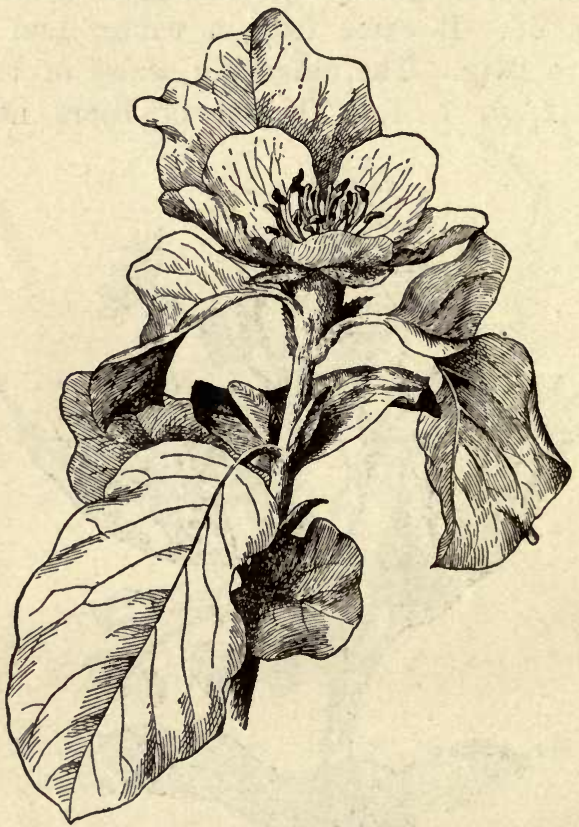

47. Flowering shoot of quince.

too, is borne upon a leafy shoot of the season. That is, a shoot sprung from the terminal winter bud, and after this shoot had grown several inches a flower was produced. Such methods of 


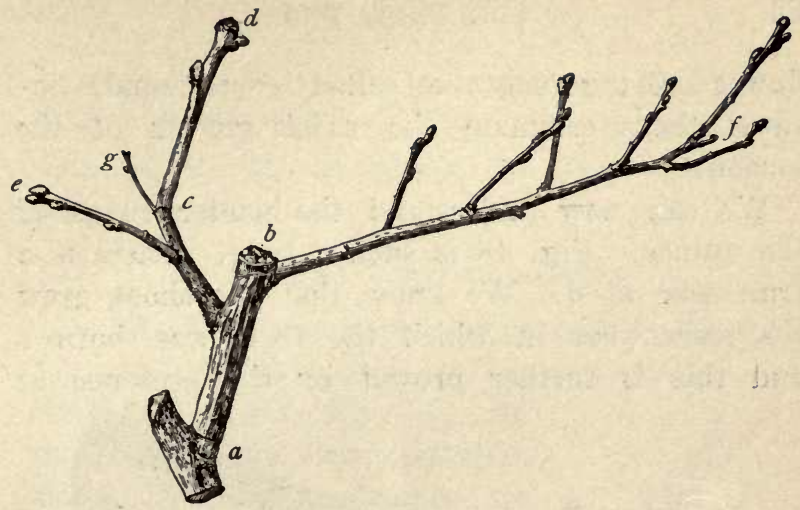

48. Twig of quince.

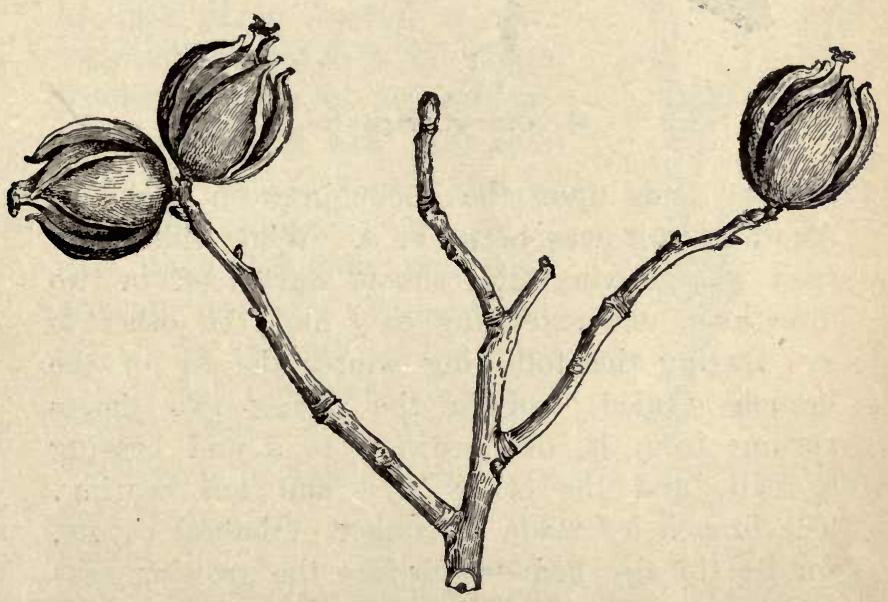

49. Branch of small-fruited hickory. 
flower-bearing may be called co-terminal, because they terminate the axial growth of the season.

We can now understand the winter twigs of the quince. Fig. 48 is such a twig. There is a fruit-scar at $d$. We know that the shoot grew the same year in which the fruit was borne; and this is further proved by the presence of

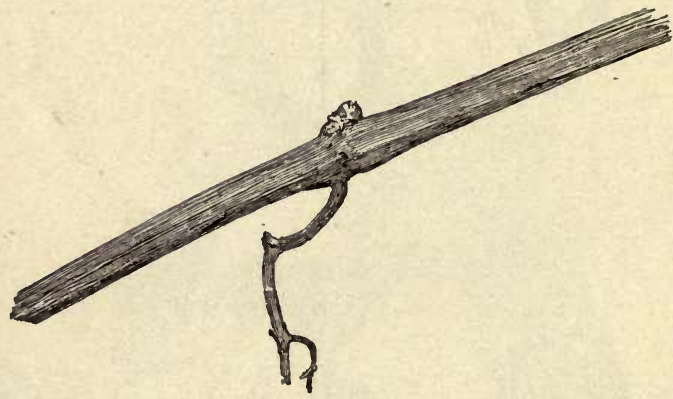

50. Cane of grape vine.

axillary buds upon the shoot between $c$ and $d$. Another fruit was borne at $b$. While this latter fruit was growing, side shoots started off in two directions, one extending to $f$ and the other to g. During the following winter the tip of the branch $g$ died, and in the spring two shoots sprung from it, one growing to $d$ and bearing a fruit, and the other to $e$ and not bearing. The branch $b f$ made a number of lateral shoots, for its tip also had died before the growing season began. The twig 48, then, is four years old. 
In like way, the reader may trace the history of any of the hickories (Fig. 49), butternut and walnuts, in all of which the fruit-bearing is also co-terminal.

\section{GRAPES AND BRAMBLES}

A bit of a grape cane, with a bud, is shown in Fig. 50. In May, this bud has given rise to a shoot like that in Fig. 51. As the shoot grows, flower-clusters arise. Two such clusters are now well developed, and a third is forming near the tip; and the shoot will continue to grow from the tip, $a$. This shoot, in fact, is to become a cane, growing several feet in length before the close of the season; but the flowers will not continue to form, for only two to four clusters are borne, as a rule, upon each cane, and these are all near the base of the cane. In the fall, the grapes hang from the lower, or older, joints (Fig. 52), the cane continuing in the direction $a$; and from some or all of the

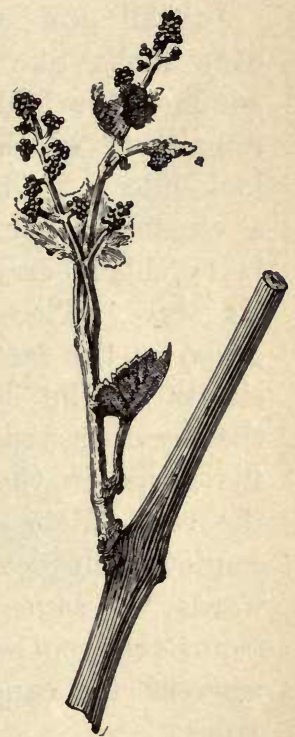

51. The young grape shoot. axillary buds on this cane, other flower-bearing shoots may arise the following year. Therefore, 
we may say that the fruit of the grape is borne upon growing shoots of the season which arise from wood of the last year's growth. If, therefore, two to four clusters of grapes may be expected from each bud upon the recently matured canes, the pruner can determine how many buds he shall leave,- that is, how long he shall cut his canes, - to produce a given crop.

In fall and winter, a recent black raspberry cane looks like A, Fig. 53. In the following summer, the bud above A sends forth a shoot, the remains of which may persist the next winter and look like B. This shoot bore several leaves, and a cluster of berries at its top. The red raspberry, blackberry and dewberry behave in a similar way. These plants are, therefore, like the grape in the fact that they bear fruit upon leafy shoots of the season which arise from wood of the previous year's growth; but they differ from the grape in the fact that the fruit is borne on the end of the shoot, and the shoot, therefore, cannot itself develop into a long cane. In other words, the canes of the brambles arise each year from the root-and bear the following yearwhereas the canes of the grape arise from other canes.

Very many plants bear their flowers or fruits at the ends of leafy shoots of the season, and their fruit-bearing might, therefore, be said to be coterminal (page 59); but this term should be 


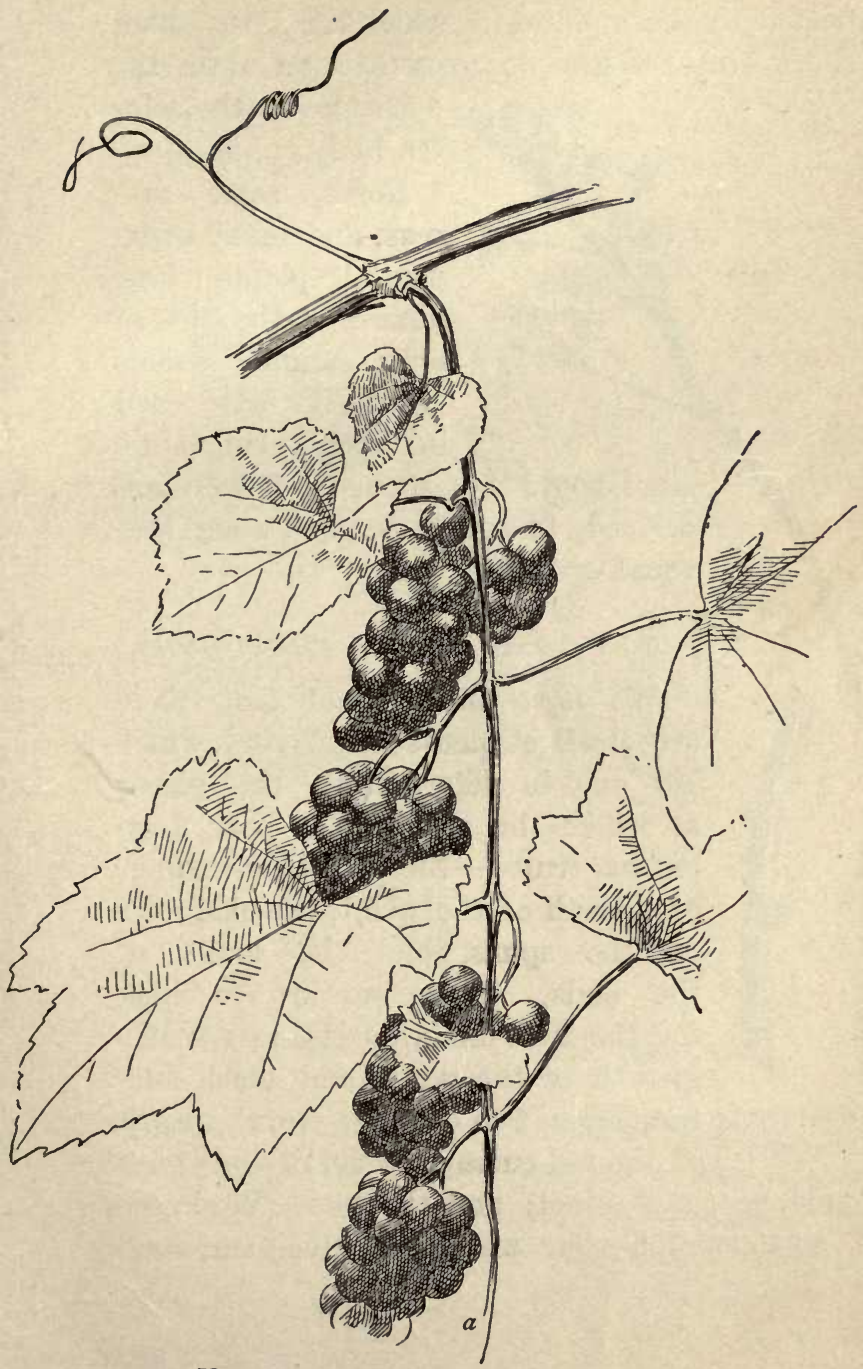

52. The fruit-bearing of the grape. 
restricted to those plants in which the leafy shoot is short and reaches its growth soon after the
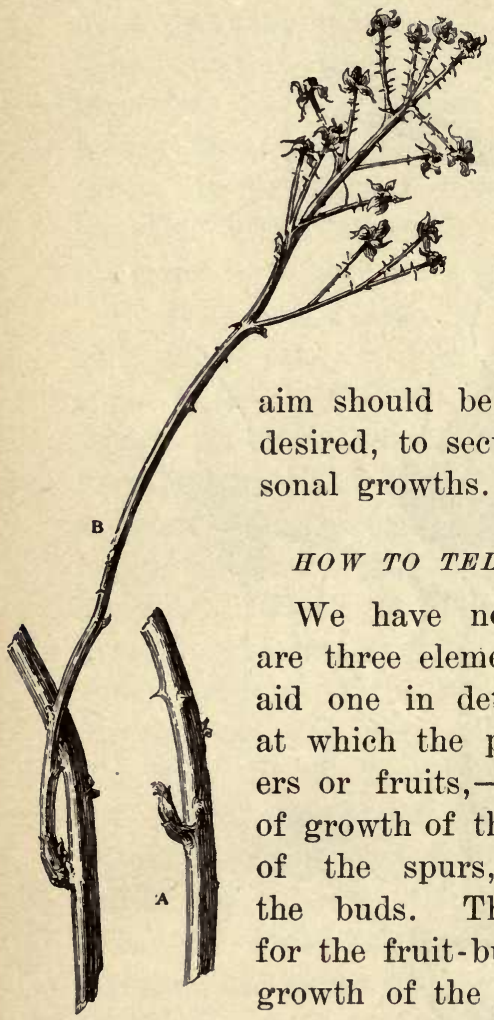
opening of the winter bud.

Roses, some spireas, and many ornamental plants, bear flowers at the ends of long summer shoots (see Fig. 54); and in such plants the aim should be, if many flowers are desired, to secure many strong seasonal growths.

\section{HOW TO TELL THE FRUIT-BUDS}

We have now found that there are three elements or factors which aid one in determining the places at which the plant is to bear flowers or fruits, - the habit or manner of growth of the plant, the character of the spurs, and the looks of the buds. Thus, we are to look for the fruit-buds on the last year's growth of the peach and black cur53. Fruit-bearing rant, upon two or three years' growth of raspberry. of the red currant, generally on spurs of apple, pear and plum; and the like. We know that, as a rule, a spur which matures fruit one 
year produces only leaf-buds that year, and makes blossom buds the following year. We know that these fruit-buds are often formed a season ahead, in which case they can be distinguished in the

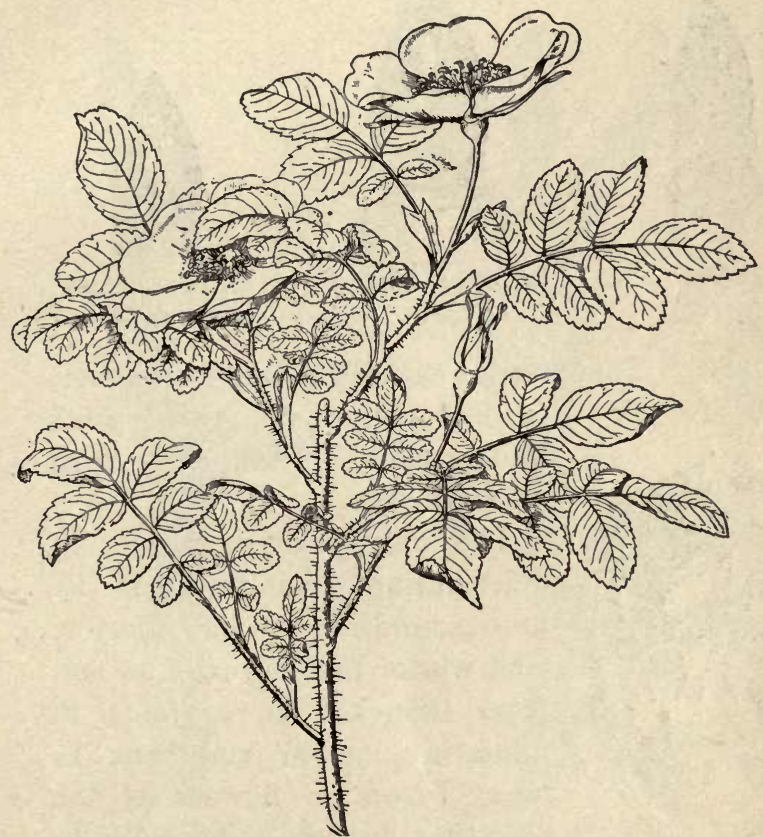

54. Flower-bearing of wild rose (Rosa Sayi).

winter, as in most of the fruits; but we also know that in roses, and some other plants, there is no way of telling in advance,-except by experience,-how many flower-buds there will be. 
We have found that the winter fruit-bud is generally larger, thicker and rounder than the winter leaf-bud, and it is usually more pubescent

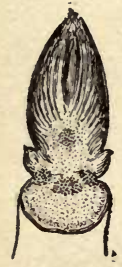

55. Leaf-bud of pear.

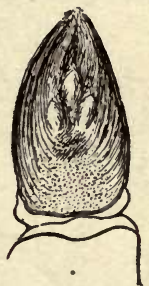

56. Flower-bud of pear.

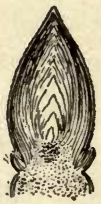

57. Leaf-bua of apricot.

or fuzzy. There are weak fruit-buds, however, which are very like leaf-buds; and these weak

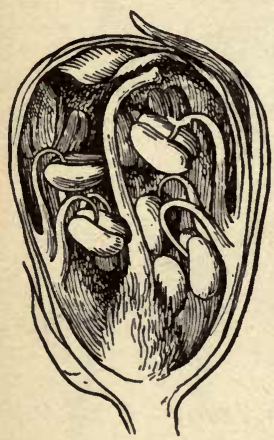

58. Flower-bud of apricot in section. buds usually do not carry fruit to maturity.

The only positive means of determining fruit-buds is by an examination of the interior. The winter bud is really an embryo branch. It contains in miniature or in rudiment as many leaves or flowers as the resulting branch is normally to bear. With a razor or very sharp knife, cut a bud in two lengthwise. Sharp eyes can determine between leaf-buds and fruit-buds in apples, pears, and most other fruits; but it is best to have a small lens. A common pocket 
lens is usually sufficient. If the section of a pear or apple bud looks like Fig. 55, it is a leaf-bud; if like Fig. 56, it is a flower-bud.

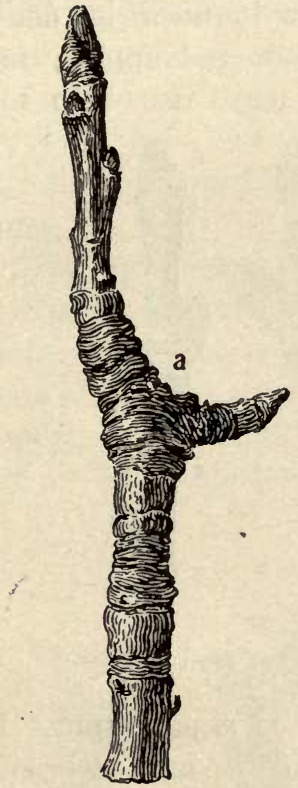

59. Pear spur with leaf-buds.
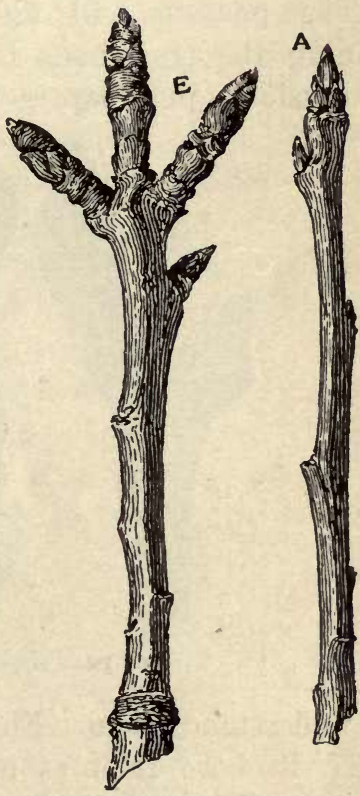

60. Pear spurs, E with three fruit-buds.

The globular bodies in the latter are the miniature unopened flowers; one sees them further expanded in Fig. 10. The imbricated plates in Fig. 55 are bud-scales and leaves; one sees them expanded in Fig. 11. A leaf-bud of apri- 
cot is seen in section in Fig. 57. A flower-bud (taken after it had begun to swell) is shown enlarged in Fig. 58.

The pictures will aid the inquirer in deter"mining the fruit-buds in pears and apples; and discussions in Chapter IV. may also help him

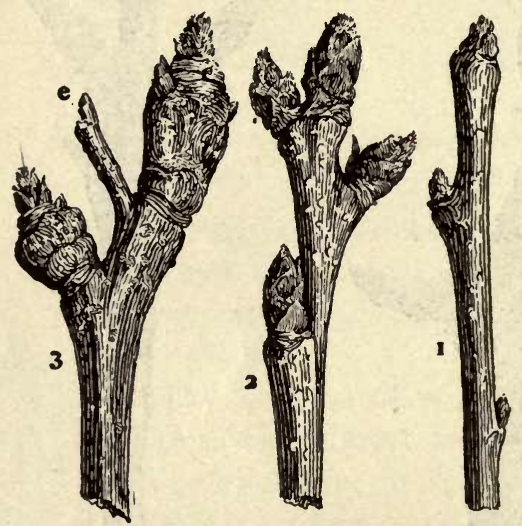

61. Tips of pear shoots; 2 has fruit-buds.

to understand them. Fig. 59 is a pear spur. In 1897, it bore fruit at its end, $a$, and two side spurs, each terminated by a leaf-bud, arose from below the fruit. In 1898, these two branches may be expected to produce fruit-buds and to bear in 1899. Fig. 60 shows a terminal leafbud at $\mathrm{A}$, and three terminal fruit-buds at $\mathrm{E}$. Below these three is a leaf-bud. These two twigs in Fig. 60 are short spurs.

In Fig. 61 are shown the tips of three strong 
top shoots from a dwarf pear tree. Shoot 1 is terminated by a leaf-bud, and shoot 2 by four fruit-buds. During the season, the end of shoot 3 was injured. The dead tip is still seen at $e$. Two side buds developed, and there was a great deposition of tissue below each one; but both of these buds are still leaf-buds. (See Chapter IV. for further discussion of this common occurrence.)

Two apple spurs are reported in Fig. 62. One, $s$, ends in a leaf-bud, and the other, $o$, in a fruitbud. Both set fruit the year before, but the fruits did not persist. Fig. 63 shows tips of strong apple shoots. At $d$ is

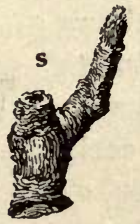

62. Apple spurs; $o$ has a fruit-bud.

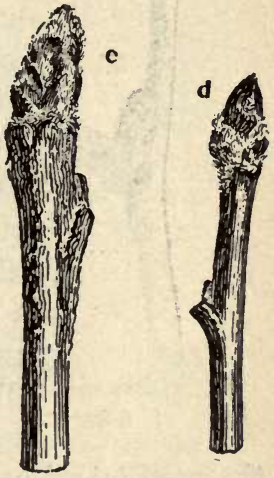

63. Tips of apple shoots; $e$ is a fruit-bud.

a leaf-bud and at $e$ a fruit-bud. Observe that the stoutest twigs bear the fruit-buds.

In some cases, the two sexes-the stamens and pistils-are in different flowers on the same plant, and in a few trees (as willows and poplars) they 
are on different plants. Plants are said to be monœcious when the stamens and pistils are separate on the same plant, and diøeious when they are on different plants. In both cases, it is necessary that the inquirer should find two kinds of blossom-buds, if he desires to locate the parts. Fig. 64 is a twig from a filbert taken in winter. The catkins, or flower-clus-

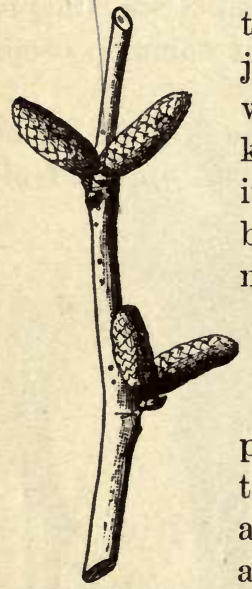
ters, are two at each joint. With the first warmth of spring, the eatkins elongate and dangle in the wind. But they bear only staminate or male flowers. The pistillate or fruit-bearing flowers are hidden in short, rounded buds, and the pistils do not protrude until spring. Fig. 65 shows a twig of hazel (filberts and hazels are very closely 64. Winter catkins of filbert. allied) taken in early spring, and the styles of the pistillate flowers are protruding from the two lower buds. Other monœeious fruit plants ! are the walnuts, butter-

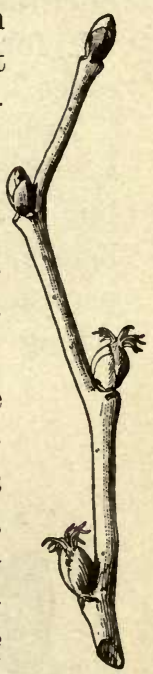
nut, hickories, and chestnuts, but chestnuts produce their flowers in summer, and the buds from which fruits are to come cannot be so well dis- 
tinguished in winter except by their position upon the tree. In the walnuts and hickories, the pistillate flowers are co-terminal, but the staminate flowers arise from lateral winter flower-buds on the last year's growth.

If the reader has followed the discussions in this chapter he will have derived a general knowledge of the external features of fruit-spurs and fruit-buds. It now remains for him to verify and expand his knowedge by examining the plants themselves. It will not be profitable to detain him longer here. It will be necessary only to answer the question which he will be sure to ask,- - how to tell when fruit-buds are winter-killed. It is generally the embryo flowers which are 66. Apricot buds live, killed by cold, although, in severe winters, the entire bud
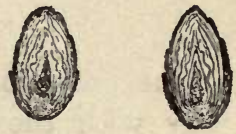
and dead. Longitudinal section. of the mixed fruit-bud type may be killed, so that the bud makes no attempt to swell on the approach of spring. The normal color of the interior of fruit-buds is green or greenish. When the interior is black or
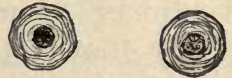

67. Peach buds, live and dead. Cross section. very dark brown, it is generally safe to infer that the bud is dead. Figs. 66 and 67 illustrate differences between live and dead buds, the dead buds being on the right in each case. It should 
be added, however, that much of the reporting upon condition of fruit-buds is little more than guessing. The surest way to determine the condition of the buds is to examine them carefully under a lens or dissecting microscope. Having determined just how a dead bud looks, in the particular plant under consideration, the inquirer may then extend his observations to a more general examination in the field.

SUMMARY SYNOPSIS OF THE POSITIONS OF FRUIT-BUDS

The positions of the fruit-buds in any species vary with the age and vigor of the plant, with the variety, and other conditions; but the habitual modes of fruit-bearing may be conveniently presented in synoptical form :

I. Flowers produced immediately from distinguishable winter buds.

(a) Buds lateral, and no spurs: Peach, almond (mostly), Japanese plum (in part), apricot (in part), filbert, hazel.

(b) Buds terminal for the most part, on spurs: Apple, pear, cherry, plum (mostly), apricot (mostly), almond (in part), currant (in part), gooseberry.

II. Flowers on shoots of the season.

(c) Co-terminal,-borne in early spring on the end of a very short shoot which 
arises from a winter bud: Quince, medlar, hickories, walnut.

(d) Terminal, or approximately so, on lateral summer shoots: Raspberry, blackberry, dewberry, orange.

(e) Lateral on strong shoots (or on canes): Grape, chestnut, persimmon, mulberry, olive.

(f) Terminal on terminal shoots: Loquat. 


\section{Chapter III}

\section{THE HEALING OF WOUNDS}

Let us consider for a moment the general

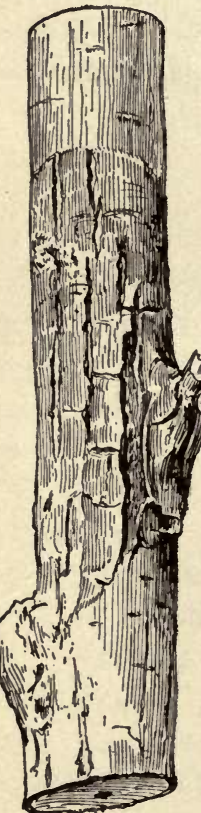

68. Cracking of the bark on an elm branch. make-up of the plant cylinder. The young shoot is tightly enveloped with bark. We observe that in many plants the increase in diameter of the stem comes about by the formation of rings of new tissue (or new wood) under the bark, and we know that in all plants the growth in the thick-

ness takes place upon the inside of the cylinder, and not upon the very outside. It is evident, then, that the covering of bark must expand in order to allow of the expansion of the woody cylinder within it. The tissues must, therefore, be under constant pressure or tension. It has been determined that the pressure within a growing trunk is often as much as fifty pounds to the square inch.

A piece of an elm branch ten years old is drawn in Fig. 68. It is an 
inch in diameter, yet the bark at the top is smooth and intact. At one time, the shoot was not more than one-eighth of an inch in diameter at this point. The reader may figure out how

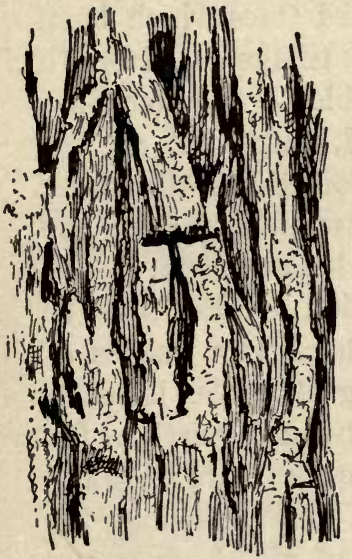

69. Piece of bark from an old elm trunk.

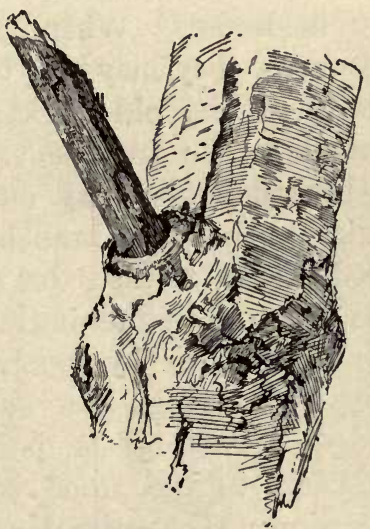

70. A dead branch and the mass of healing tissue at its base.

much this bark has expanded by the combined action of intercalary growth and stretching.

The lower part of the limb shows that the outer layers of bark (which are long since dead, and act only as protective tissue) have reached the limit of their expanding capacity and have begun to split. The reader will now be interested in the bark upon the body of an old elm tree (Fig. 69); and he should be able to suggest one reason why stems remain terete or cylin- 
drical, and why the old bark becomes marked with furrows, scales and plates.

If, for any reason, the bark should become so dense and strong that the trunk eannot expand, the tree is said to be "bark-bound." Such a condition is not rare in orchard trees which have been neglected. When good tillage is given to such trees, they may not be able to overcome the rigidity of the old bark, and, therefore, do not respond to the treatment. Sometimes the thinner-barked limbs may outgrow in diameter the trunk or the old branches below them. The remedy is to release the tension. This may be done either by softening the bark (by washes of soap or lye), or by separating it. The latter is done by slitting the bark-bound portion (in spring), thrusting the point of a knife through the bark to the wood and then drawing the blade down the entire length of the bark-bound portion. The slit is scarcely discernible at first, but it opens with the growth of the tree, filling up with new tissue beneath. Let the reader consider the ridges which he now and then finds upon trees, and determine if they have any significance. In other words, are the trunks of trees ever perfectly cylindrical? If not, what may eause the irregularities? Do trunks often grow more on one side than the other? Slit a rapidly-growing limb, in spring, with a knife blade, and watch the result during the 
season. Consult the woodpile, and observe the variations in thickness of the annual rings, and especially of the same ring at different places in the circumference.

We have seen that some of the side branches on the little cherry tree (Fig. 2) died, and that all the others will probably perish. Fig. 70 shows a dead limb on an oak tree. The limb became weak because the shade was too dense, and because branches above it took more than their share of food. Finally, borers

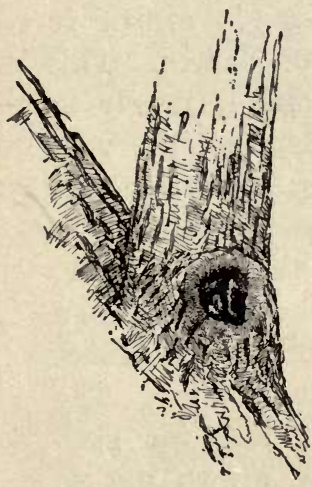

71. A knot hole.

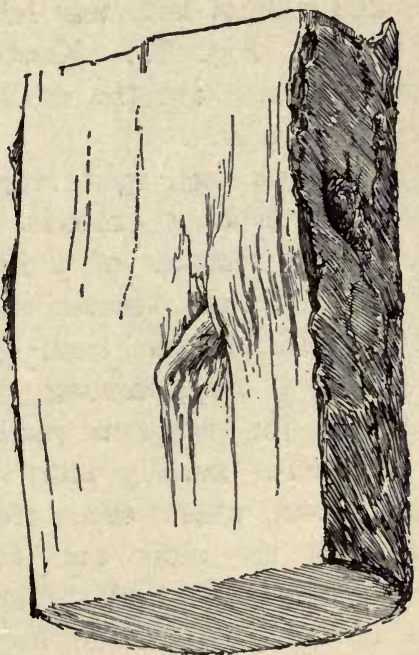

72. Knot in a hemlock log.

and fungi attacked it, and it died. It rotted slowly away, year by year its twigs fell, and finally a heavy fall of snow broke it off as we 
now see it. As soon as it died, it became a menace to the tree, for the rot in its tissues might extend into the trunk. The tree made an effort to cover it up. The tissue piled higher and higher about its base, reaching for the end of the wound. The limb was eaten away by decay, and became smaller and smaller in diameter, leaving a cup-like ring about its base. Finally it broke off, and a knot-hole was left. Such a knot-hole is seen in Fig. 71. Knot-holes on the bodies of trees, then, are the cavities left by dead and decaying limbs.

A hemlock log, split lengthwise, is drawn in Fig. 72. A knot extends to the center. This knot is the remains of a limb, and is nearly as old as the trunk, because it starts from the very center; that is, the limb sprung off when the tree was a mere sapling. The probability is that it is just one year younger than the trunk, for branches usually start only on the second year's wood, unless some stress of circumstances starts out the older and dormant buds. The limb finally died and broke off, and the stub was buried. The tissue has now grown out to the end of the stub, and nothing remains but to close over the hole. If the limb had rotted away, a squirrel or a woodpecker might have taken up his quarters in the cavity. The woodchopper, however, found only a knot; and a board sawed from the log would have had a 
knot whenever the saw cut across the old stub. If the knot were loose, it would fall out, and the board would have a knot-hole. Knots and knot-holes in boards, therefore, represent cross-

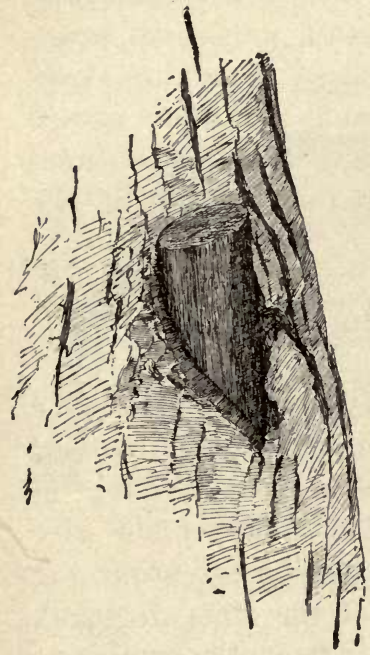

73. Improper cutting of a limb.

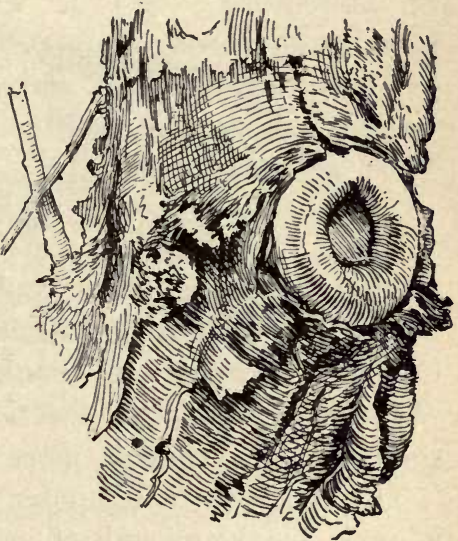

74. Proper cutting of a limb.

sections of branches; and each one is the record of an event in the history of the tree.

A limb was sawn from a tree. Several years afterwards a drawing was made of the stub (Fig. 73). The limb had not yet healed-in. The reason is apparent: the stub had been left so long that the tissue had not yet been able to pile up over it, and, having no life in itself, 
the branch could not make healing tissue of its own. The stub is now a monument to the man who pruned the tree. Fig. 74 shows how another limb was cut, and although the wound is not nearly so old as the other, it is being rapidly closed in. There are most important practical lessons, then, to be learned from this study of knot-holes, - two of which are that nature is a most heroic pruner, and that limbs must be sawn off close to the parent branch if the wounds are to heal well.

\section{THE NATURE OF THE WOUND}

The foregoing paragraphs give the reader a general view of the practical problems involved in the expansion of trunks and the healing of wounds. It will be profitable, however, to give some of the problems more specific attention.

The increase in diameter of the stem or trunk is made by the growth of cells from the cambium, which is a tissue lying upon the outside of the woody cylinder and beneath the bark. From its inside, the cambium produces wood, and from its outside, it produces the soft or inner bark. As the outer bark is ruptured by the expansion of the stem, portions of the inner bark give rise to the corky external and protective layers. A mere abrasion or surface wound, which does not expose the wood, is healed by the formation of new cork 
cells from the inner bark; but a wound which exposes the wood is healed by growth from the cambium.

The cambium, then, is the active, living tissue of the plant cylinder. The wood cells soon become lifeless, and have no power to grow or to multiply. It is apparent, therefore, that when a

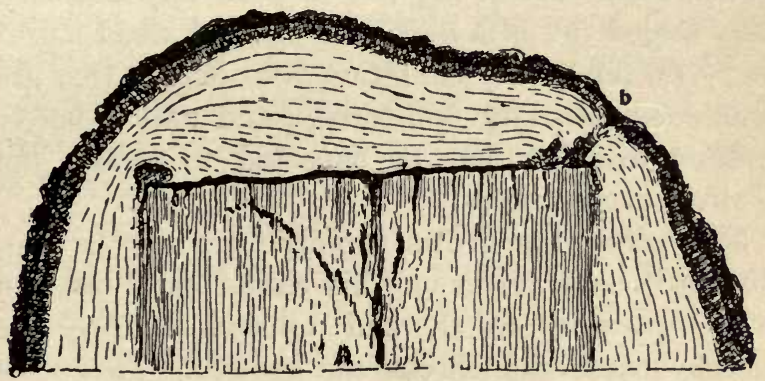

75. Cross-section of callus on an apple tree.

limb an inch or more in diameter is cut off, the exposed hard wood can never heal, as a wound heals in flesh. The pressure on the cambium being relieved, however, excessive growth arises from it and from the inner bark, and a mass of tissue, known as a callus, rolls out over the wound and covers it. Fig. 74 is an excellent picture- of this callus ring. The ring will eventually cover the wound; and if a longitudinal section of the healed wound were then made, we should find the condition shown in Fig. 75, - the end of the old stub remaining as sharp-cut as it was when left 
by the saw, and eapped over with wood, much as a fruit-jar is capped with a metal cover.

This Fig. 75 is one of the most important pictures in the book, and it is drawn most accurately from a normal and average specimen. It is important because it shows that the end of the old stub has no organic or vital connection with the callus which covers it, but it is merely hermetically sealed in, as a nail or a plug of wood might be. * So far as the vital functions of the tree are concerned, this stub is a foreign and useless body; and no dressing can be expected to hasten the healing-over process.

The callus ring grows rapidly for a year or two. But hard bark forms on this callus, as it does on other growing wood, and tension or pressure thereby arises and checks the growth. This bark even forms on the under side or lip of the callus. Over the end of the stub in Fig, 75 there is a thin layer of bark. We have already found that slitting the bark upon a trunk relieves the pressure and allows of extra-rapid growth at that point. Suppose, then, that if the callus ceases to grow, the operator make a circular eut with a knife-point on the inner edge of the callus-roll!

In surface wounds which expose the wood, the callus also forms from the cambium and covers the denuded area. If the injury does not extend

*If the reader desires to know how a graft-stub is buried, he may consult Fig. 133 in the last edition of "The Nursery-Book." 
below the sapwood, or if the wood has not dried out and died, the callus may make a vital connection with the exposed surface of the wound.

The reader now wants to ask what purpose the healing of the wound may serve the plant. The healing serves as a protection. It prevents or checks evaporation from the exposed parts, and prevents decay by protecting the wood from the weather and by excluding bacteria and fungi. A rotten heart, or rotten wood of any kind, is a diseased condition; and this disease is the work of living organisms.

The exposed wood dies. It cracks and checks. The surface collects dust, which, with the dead cells, makes a thin soil in which germs find congenial conditions for growth. Even after the wound is covered by the callus, the mycelium of the fungi may continue to extend itself in the wood, often reaching the heart and causing the trunk to become hollow. Normally, the heart of a tree should never decay; but sooner or later, most trees are exposed to injuries, either in top or root, through which the organisms of destruction may enter.

The pictures will help us to understand. Fig. 76 shows a cross-section of a maple trunk in which a nail is imbedded. The wood elosed tight about it and no harm resulted. Now, this was the nail upon which a sugar-maker hung his bucket. Just below it was the tap-hole; and this 
hole, now completely covered by the wood, is seen in Fig. 77. But mischief has come to pass. The tap-hole was an open wound, and fungi entered;

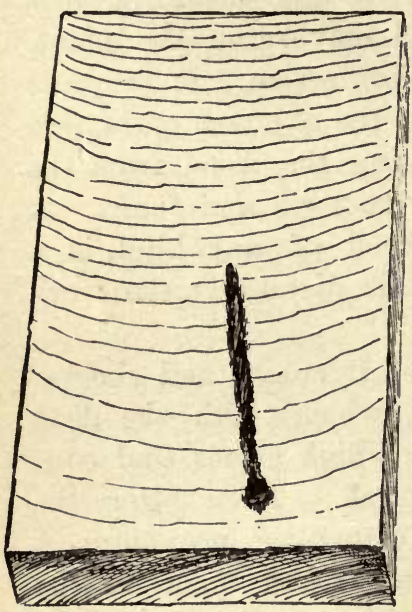

76. Nail buried in the wood.

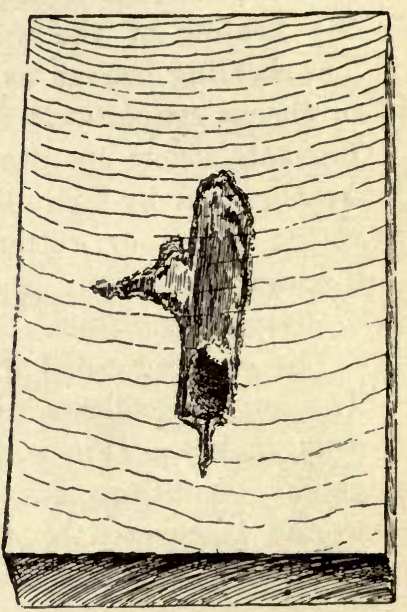

77. Tap-hole buried in the wood.

and the discolored tissue shows the progress of the decay.

Pictures of ash logs are shown in Fig. 78. The one on the right had a perfect-looking trunk, although a scar was discernible at one point. A section of the trunk shows that a large limb was once broken off and its stump completely buried under the new tissue; but the $\log$ is rottenhearted (a), and the decay of the old stump (b) 
shows where the mischief began. The stump on the other log is not yet closed in, and its end is decayed; and a colored streak (c) running down the heart of the old limb shows the trouble that is coming.

A hickory stub has been covered (Fig. 79), and, from outside appearances, the tree is now safe;
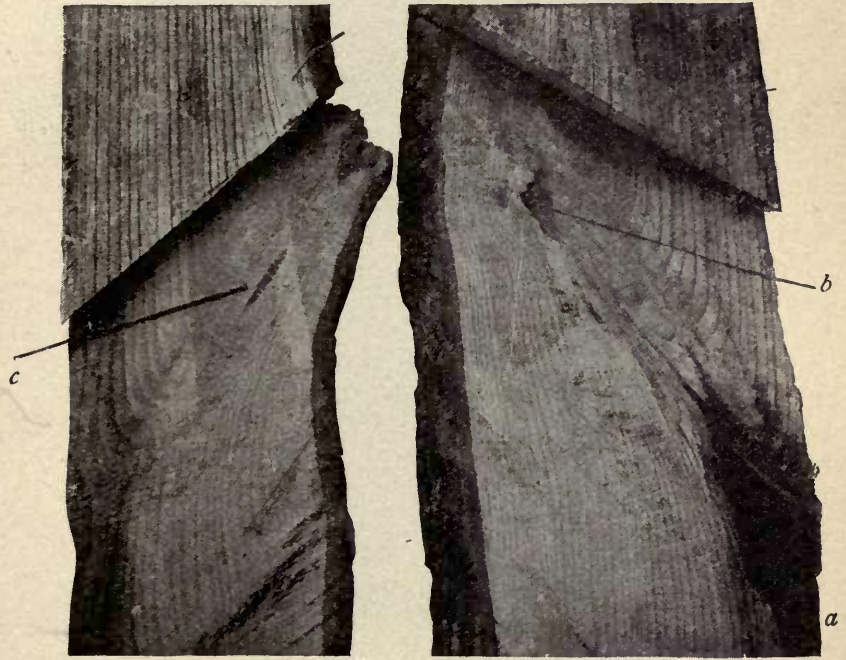

78. Disease in ash trunks.

but a section (Fig. 80) shows that decay began before the healing was complete, and the injury is already serious. Even in the apple stub in Fig. 75, wound-rot is serious. The rougher the surface of the wound, the greater is the likeli- 
- hood that disease will gain an entrance. On perfectly smooth and solid wounds, the greatest

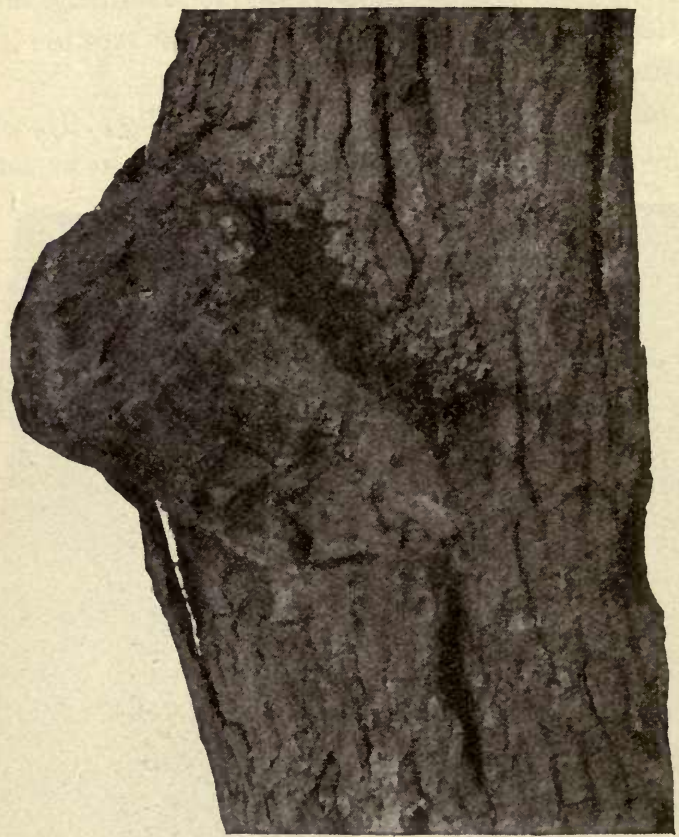

79. A healed-in stump.

danger is on the lower edge, where the up-rolling callus-ring forms a cup which holds water.

It would be untrue to conclude that decay follows from all serious and exposed wounds. Fig. 81 shows a section of a maple $\log$, in which the 
buried stump is hard and sound; but such instances are the exception, particularly in humid climates.

We are now able to understand that while

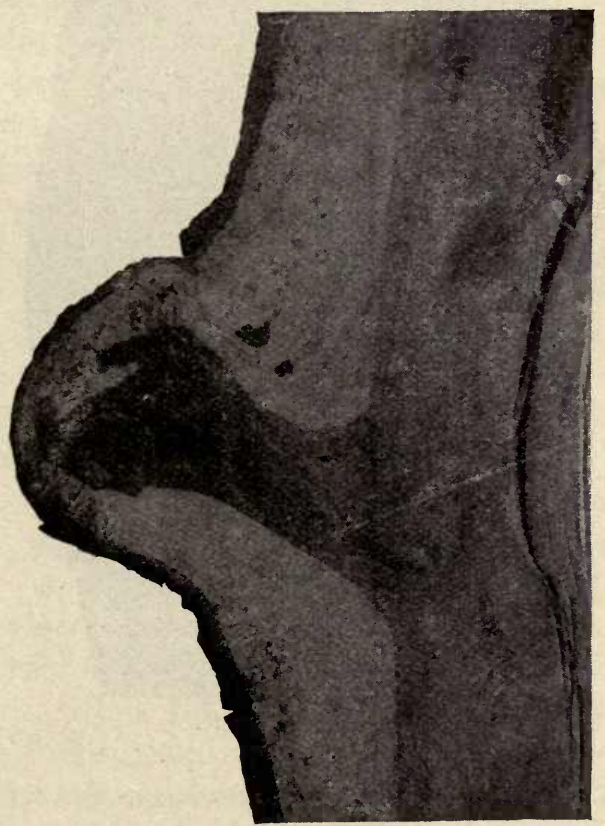

80. The stump is diseased.

dressings or applications to the wound cannot directly hasten the healing process (page 84), they may aid it by preventing the decay of the parts, and they may be the means, thereby, of 
saving the tree. That is, dressings are preventive, not curative; and in this they are akin to the antiseptic dressings of the surgeon, which

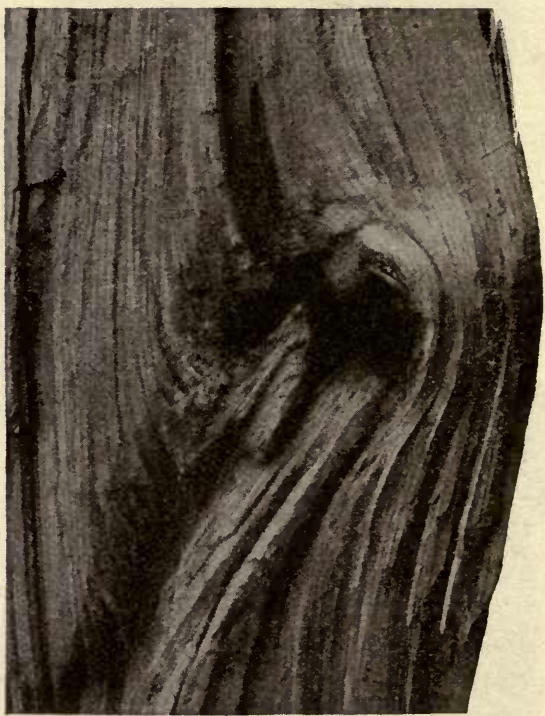

81. A sound knot.

prevent contamination of the wound and thereby allow nature to heal it.

In order to present another view of wood decay as a result of pruning, I have asked my colleague, B. M. Duggar, to prepare a few paragraphs on the subject, and these now follow:

"The exposed surface left by the pruning saw 
is a mechanical injury as truly as the mark of the whiffle-tree or of the wind. If this exposed surface is not cared for, it may prove an inlet for disease and decay. Unfortunately, this matter has not received adequate attention from mycologists studying wound-rot fungi; and all that we can do at this place is to suggest in a general way what may take place, especially in the larger wounds. It is not to be understood that all neglected wounds lead to wound-rot diseases; but the point is that they may induce such diseases, since a certain amount of death and decay are inevitable; and the larger the wound, the greater the danger.

"First, then, we are concerned with the conditions which bring about and encourage this rotting. It is well known that when only the corky outer layer of bark is removed, another corky layer is readily formed for needed protection; but when a branch is sawn across, as in pruning, the wood elements are directly exposed to the air. It is then impossible for a corky layer to be formed, and it may be several years before a ca'lus will inclose the exposed part. The sapwood of this exposed area soon loses connection with the active functions of the plant, and dies. All heart wood is inactive, but in sound trees it is thoroughly protected from the air, while the exposed scar left by the pruning saw is open to weather. The open tubes which make up the 
younger wood may be blocked to a large extent by ingrowths and often by gummy substances, but this does not give complete protection. Moisture is absorbed, oxidation proceeds, and the dissolved organic matter is the beginning of a fertile ground to which wind and rain must bring the germs of bacteria and of our common dead-wood molds. These germs find lodgment, and sufficient moisture for their germination and growth. It is a small beginning, but it is sufficient gradually to form a soil more retentive of moisture and full of the products of decay,-conditions more favorable for the development of wound-rot fungi.

"From what is known of this matter, it seems fair to assume that bacteria are prominent in this first slow process of weathering; but they are doubtless only secondarily concerned in the deeper. seated injuries where the decay has penetrated to a considerable portion of the trunk. In most cases, they seem to prepare the way for fungi belonging to the toadstool family. One is everywhere familiar with these fungi growing upon dead logs or stumps, or even upon the decaying parts of living trees. The fleshy parts which we see are produced at the surface for the production of the spores or reproductive bodies; but the truly vegetative parts are usually beneath the bark or within the tissues, and it is well to note how these develop from the spores. 
Germination consists in sending out a few delicate threads from the spores. These threads enter the moist, decaying parts, branch considerably, and at first confine themselves to that portion which is already dead. As they grow farther and farther inward, they may become so well established and so vigorous as to induce decay of themselves. They may encourage the further entrance of air and moisture, and thus continually they may be preceded by the atmospheric conditions necessary for their further action. At any rate, entrance to the trunk may thus be effected; and with this entrance local rotting is induced, and eventually the decay may extend to a considerable portion of the trunk. There are many instances of rot in which the conditions do not favor the formation of the fleshy fructification of the fungus, and the cause of the decay may not be very evident.

"In the case of some trees used for timber, and many other deciduous trees, there are wellknown rots and decays caused by members of this toadstool family, some of them being peculiar to a single species of tree, and others very general in their attacks. Some of these fungi are truly parasitic, being able to enter through very small branch wounds, passing rapidly to the sound tissues, where decomposition and decay readily follow. 
"In Germany the large, fleshy, sulphur-yellow punk-fungus, Polyporus sulphureus, is known to have attacked and caused decay of pear trunks, gaining an entrance through a wound. This fungus occurs in America, and while it is not reported on orchard trees, I have found it growing luxuriantly upon the wild cherry, Prunus serotina, killing the trunk, apparently, for a considerable distance below a dead branch.

"The common little agaric, Schizophyllum commune, I have observed growing in clusters between the new bark and the dead wood on an apple tree to which the knife had been severely applied after sun-scorching, but this fungus doubtless only aids decay.

"Among pyrenomycetous fungi, there are some which may take advantage of the injuries from pruning. In Europe, Nectria ditissima is known on the apple and bird cherry, producing on the smaller branches the characteristic canker spots. This fungus must enter through abrasions or pruning wounds, and the decay which follows is often considerable. Nectria cinnabarina is another one of these fungi, common in this country on many hosts, and this I observed last year on a large branch of pear, extending to a considerable distance either way from a broken branch of small size.

"Rots and decays as a result of pruning deserve more attention, in order that we may 
fully understand the necessity for proper aseptic treatment."

\section{SUGGESTIONS TO THE PRUNER}

If the reader has grasped the principles involved in this discussion of the healing process, he will be able to arrive at many sound conclusions respecting the rational making and treatment of wounds. He will also see how futile it is to attempt to construct any theory of the management of wounds from a few isolated experiments; for the interpreted results of such- experiments often contradict fundamental principles, and therefore cannot be true, however clear and unequivocal they may appear to be.

First of all, the pruner wants to know how and when he shall cut the limbs so that they will heal as quickly as possible. Let us think about the matter, and see.

A twig of a peach tree was cut back in the fall. By spring it had died back an inch, as shown in Fig. 82. This stump cannot heal over of itself. If it is ever inclosed, it must be buried by the growth of a branch which shall spring from a side bud. There is such a bud on the twig, and if a branch arises from it, the stump may be overtopped in the course of a few years; but the probability is that this bud will not grow, because the drying out of the twig has injured it. The responsibility must fall, therefore, on a lower bud. 
Two dwarf pear shoots are reported in Fig. 83. The one on the left was cut at some distance above a bud, and the dead and dangerous stub persists. The twig on the right was cut just above a bud, and the wound is already securely covered.

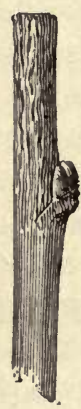

82. The dying-back of a winter-cut shoot.

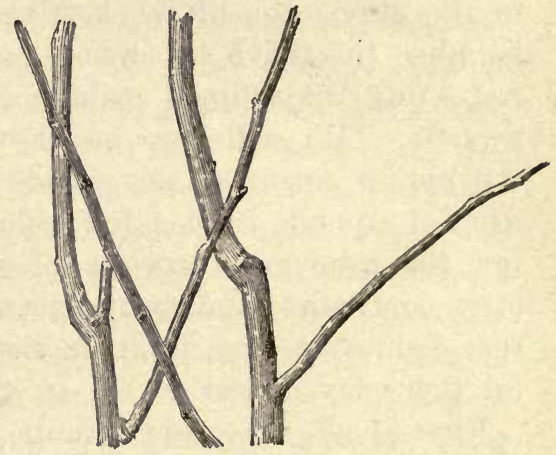

83. Poor and good heading-in of dwarf pear.

There are two important lessons to be drawn from these simple examples,-the nature of the healing process, and the relation of the length of the stub to the welfare of the uppermost buds. In respect to the healing process, it may be said that stubs which project far beyond a branch or far from a trunk, rarely heal over. The end of the branch being removed, the stub cannot heal itself, but the healing must depend upon the activities of other parts or branches. This statement is an exceedingly important one, and we shall see its applications as we proceed. 
In respect to the welfare of the buds which are near an open wound, the pictures seem to tell contradictory stories. In Fig. 82, the bud is in danger; but in Fig. 83, one wound healed over because the bud was near it. These apparent contradictions are explained by two circumstances. The twig in Fig. 82 was on a newly-set, fall-planted tree. The roots had not yet taken hold of the soil, and could not supply the moisture which was lost from the wound. The cell contents were therefore injured. The twigs in Fig. 83 were on well-established trees. Again, the cut in Fig. 82 was made in the fall, and those in Fig. 83 in late winter. Conditions, therefore, greatly modify the problem; but, as a rule, it may be said that in severe and dry winter climates, and particularly with tender fruits, heading-in of the annual growths had better be done late in winter rather than early in winter; and this is especially true of recently fall-set trees. The healing of the stub takes place most quickly, other things being equal, when a strong bud or branch stands close to the wound, provided, always, that this bud is not injured by the drying out of the stub. How long this stub may be and not cause injury to come to the bud, depends, as we have seen, upon circumstances. If the cut is made in spring, the bud may usually stand close to the edge of the wound; if it is made in winter, the stub should usually be about a quarter of an inch long. In 
the pruning of trained trees, European gardeners often take off the shoots in winter when there is time to spare, leaving the stubs two or three inches longer than desired; in spring an assistant, who may have had insufficient experience to en-

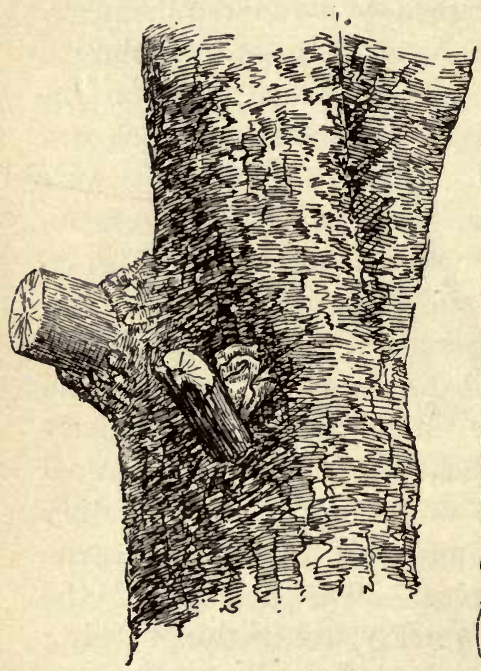

84. In memory of the pruner.

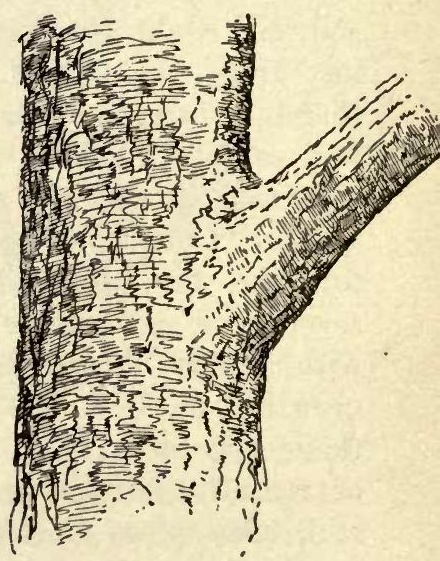

85. The bulge at the base of the branch.

able him to block out the pruning, goes over the trees and cuts back the stubs to a fresh bud.

The reader has already seen in Fig. 73 the monument which a man erected to his memory. It is a stump which is so long that it cannot be healed over; for, as we have seen, a leafless and 
branchless stump has no life in itself. The only chance for this stub to be healed-in is from the activities of the trunk; but the end of it is too far removed from the base of supplies to receive much benefit therefrom. Having no vital part in the life of the tree, it is side-tracked, and must starve. Fig. 84 is another case. Above the stub at the right a cluster of toadstool fungi has found a happy foothold.

Where should these limbs have been cut? There is an enlargement-or brace-at the base of a limb, and this bulge is usually larger the longer and more horizontal the limb. This bulge is well shown in Fig. 85. It is a common notion, - which the writer, much to his humiliation, once aided to promulgate,-that the eut should be made just beyond the bulge, and at right angles to the direction of the limb. This leaves a stub like that in Fig. 86. The proper way, however, is to cut as shown in Fig. 87, for all parts of the wound are then in most intimate relations with the trunk, which supplies the materials to be used in covering the exposed surface. The area of the wound is larger, to be sure, but this is of minor consequence; and to such large wounds it is expected that the operator will apply a dressing.

The writer has no doubts as to the soundness of the advice given in the last paragraph, but he is glad to fortify it by two excellent authorities. Professor Sargent, in his introduction to the 
American edition of Des Cars' pruning book,* says that "it is necessary to prune in such a manner that no portion of an amputated or dead branch shall be left on the trunk. The
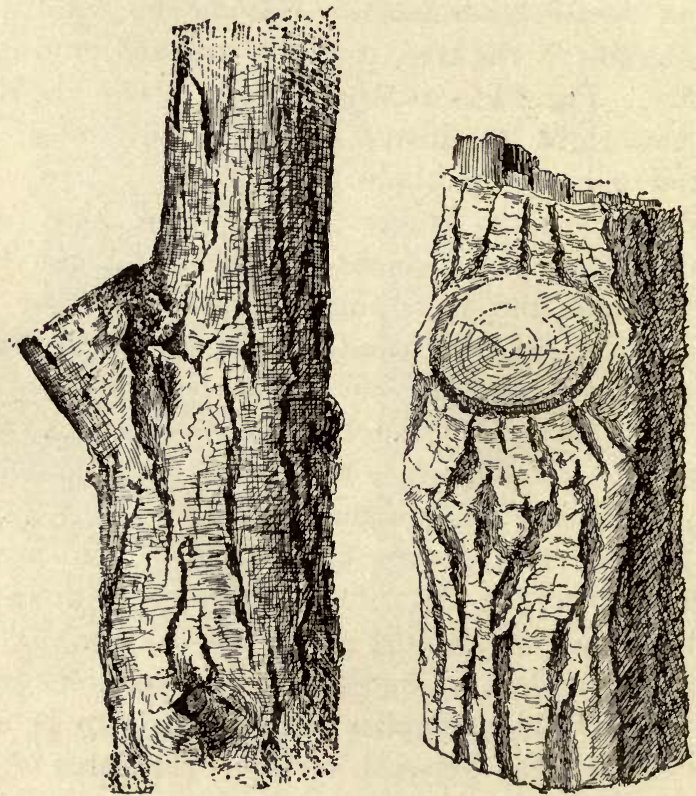

86. The wrong way to make the wound. Side and front views.

cut should always be made close to and perfectly even with the outline of the trunk, without regard to the size of the wound thus made. This

*A. Des Cars, A Treatise on Pruning Forest and Ornamental Trees. By Charles S. Sargent, Boston, 1881. 
is the essential rule in all pruning, and on its observance the success of the operation depends." Des Cars himself speaks as follows: "It follows that a wound caused by the amputation of a branch
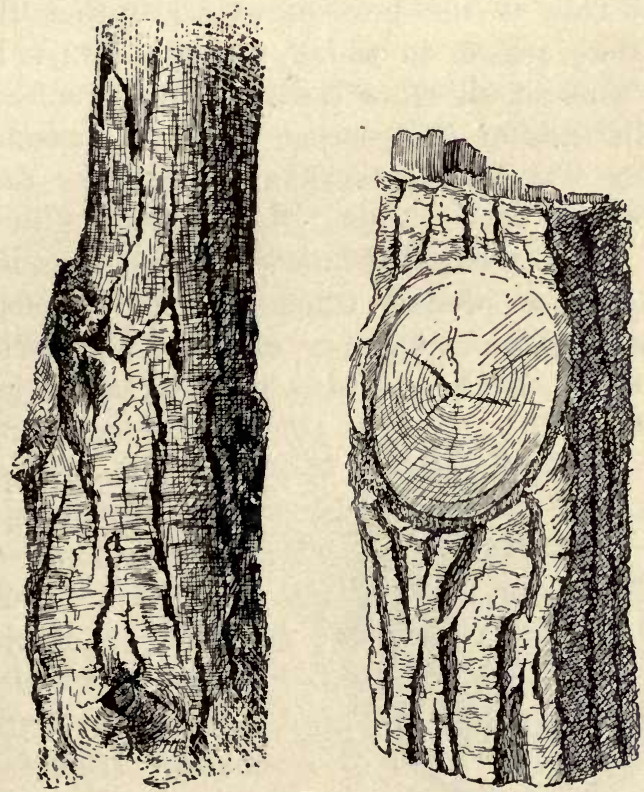

87. The right way to make the wound. Side and front views.

must, in order to heal properly, be made perfectly even with the trunk, that every part of its outer edge may be brought into direct communication with the leaves through the net-work of cells destined to convey the descending sap." 
WHEN TO CUT THE BRANCHES. - At what season of the year shall wounds be made, so far as the healing process is concerned? There are as many opinions as there are months in the year. This is the best of evidence that there is no one season in which wounds always heal better than in all other seasons. It is indication that the time of the year at which the wound is made is less important than some other factor or factors.

We have seen that the healing of serious wounds is a process which depends primarily on the cambium. Healing cannot begin, therefore, when the cambium is inactive, as it is in

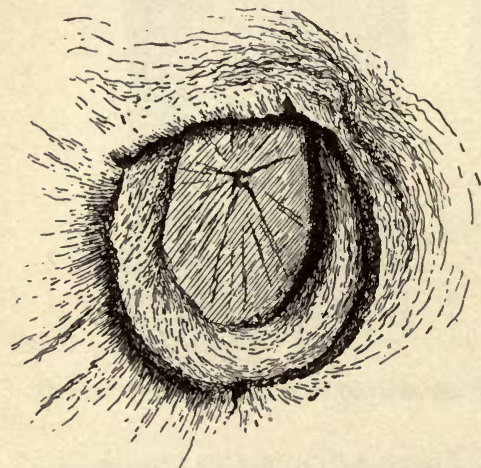

88. Healing of a wound. late fall and winter. We have also seen (Fig. 82) that exposed tissue may die back during winter; and this is particularly true in severe and dry climates. There is always a tendency for the cambium and bark to die about the edges of a wound made in late fall or winter, and this sometirnes progresses so far that the edge of the bark becomes loose. All this is clearly a disad- 
vantage to the healing process; and the checking of the stub from its longer exposure is also to be considered.

On the other hand, pruning in the growing season of spring exposes the plant to bleeding. It is not germane to the present discussion to consider the effect of this bleeding on the plant, although it may be said that injury rarely follows. It is said, however, that the sap sours upon exposure to the air and injures the bark and cambium about the edges of the wound. Although this is a very common notion, I have looked in vain for a number of years for a single confirmation of it. Fruit trees rarely bleed to any extent, and on trees which do bleed, it is doubtful if this injury follows. The Japanese walnut bleeds profusely. On the 10th of April, 1896, I cut a limb two inches in diameter from one of these trees. The sap ran freely, and kept the bark wet for two weeks for a distance of nearly two feet below the cut. At this writing (Jan. 15, 1898) the wound looks as shown in Fig. 88. It is healing well on all sides, and there has never been the least injury from the bleeding. Moist wounds, however, do not allow of the efficient application of dressings.

Let us now go to the trees. In the fall of 1891, experiments were begun at Cornell to determine the best season for the making of wounds and the best dressings for covering 
them. The tests were made on vigorous mature apple trees (Greenings, Baldwins and Kings). Branches were cut every month in the year, and at various lengths. Dressings were made of tar, linseed oil, grafting wax, white lead paint and tallow. The results were studied in the winter of $1895-6$. It is unnecessary to recount the full experiment at this place, but wounds representing typical average conditions are shown in Figs. 89-92, and these we may profitably examine. Unless otherwise stated, these wounds are selected from two very similar Greening trees standing side by side. One tree is designated (1) and the other (2).

Fig. 89.-

(1) cut Oct. $31,1891$.

Fig. 90.-b

(1) cut Nov. 18, 1891.

bb (1) cut Dec. 19, 1891, wood frozen.

bbb (2) cut Feb. 23, 1892.

c (1) cut Oct. $12,1891$.

ce (1) eut May, 1892.

ece (1) cut Nov. 18, 1891.

d (2) cut Oct., 1892.

dd (2) eut Mar. 25, 1892.

ddd (2) eut Feb. 1892.

Fig. 91.-e

(2) cut June 20, 1892.

f (1) cut Oct. 12, 1891.

g (2) cut July 27, 1892.

h (2) cut Sept. 15, 1892.

i (2) cut Feb. 23, 1892.

j. (2) cut July $27,1892$. 
Fig. 91.-k (2) eut July 27, 1892.

1 Baldwin, eut May 26, 1892.

m (1) cut Oct. $31,1891$.

n (1) cut Jan. 2l, 1892.

o (1) cut Jan. 21, 1892, wood frozen.

p (1) eut Oet. 12, 1891.

Fig. 92. $-q$ (1) eut Oct. 12, 1891.

r (1) cut Oct. 12, 1891.

s (2) cut Aug. 26, 1892.

t (2) cut June 20, 1892.

u (2) cut May 26, 1892.

v (2) cut Mar. 25, 1892.

w (2) cut June 23, 1892.

x (2) cut Mar. 23, 1892.

y (2) eut Feb. 23, 1892.

z (2) eut Feb. 11, 1892.

zz (2) cut May 26, 1892.

zzz (1) eut Dec. 19, 1891, wood frozen.

Every month, except April, is represented in these incisions. Let us pick out the wounds which are healing well. They are Fig. 89, all of Fig. 90, and e, f, i, j, k, l, m, w, y, z. These were made in the months of February, March, May, June, July, October, November, December, -nine months. The wounds which are not healing well are $\mathrm{g}, \mathrm{h}, \mathrm{n}, \mathrm{o}, \mathrm{p}, \mathrm{q}, \mathrm{r}, \mathrm{s}, \mathrm{t}, \mathrm{u}, \mathrm{v}, \mathrm{zz}, \mathrm{zzz}$. These were made in January, March, May, June, July, August, September, October, December,nine months. Comparisons giving similar results could have been made on a more extended scale and for every month in the year, from 


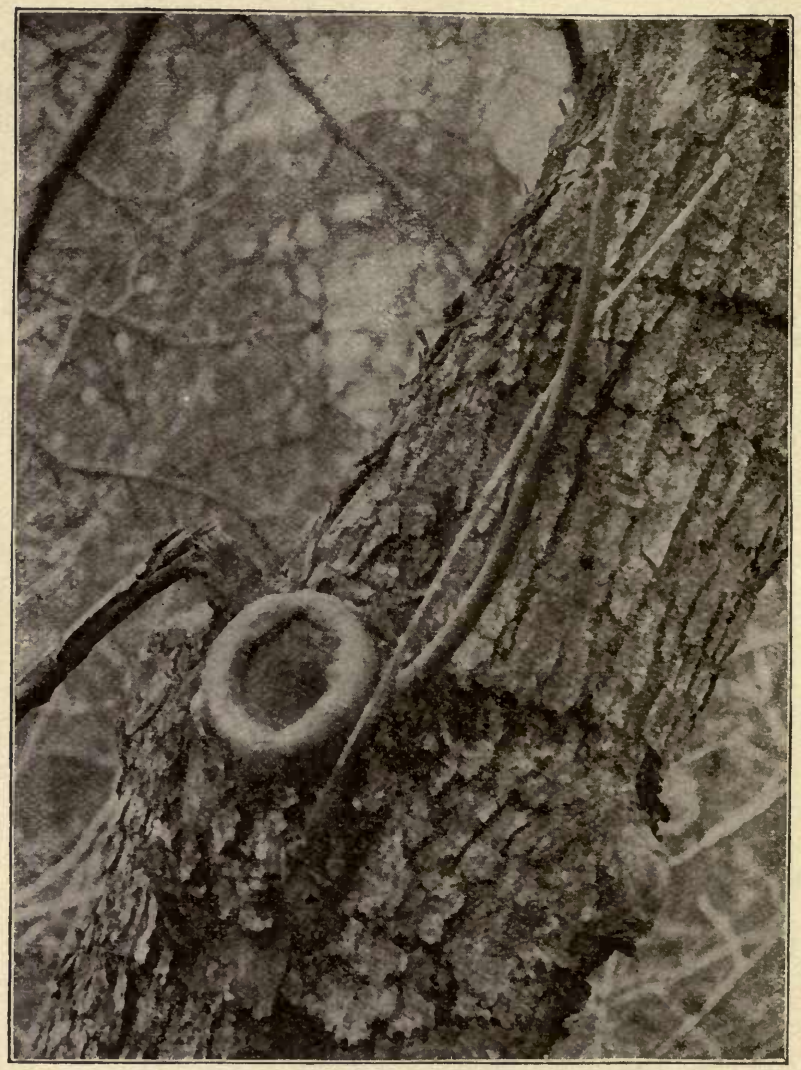

89. Ideal results in the healing of a large wound. Four years' growth of callus. A smaller wound on the lower side entirely closed. 
the wounds which are not reported in these pictures.

We are forced to conclude that some factor other than season is the most important in determining the healing of these wounds. It requires but a superficial examination of the pictures to show that these important factors are two,-the position of the wound in the tree, and the length of the stub; and of these the former is the more important. Wounds on strong limbs, especially those which are vertical or ascending, heal best (compare Fig. 89, Fig. 90 , and e, i, j, k, l, m, w, y). Very long stubs die back, instead of healing (see $n, o, p)$. Wounds lying close to the parent branch heal best, and those eut beyond the bulge or shoulder are intermediate between these and the very long stubs. (Compare, in the first eategory, Fig. 89, b, bb, bbb, c, ce, cec, ddd, e, i, j, k, l, m, w, y, z; and in the second category, $d, d d, f, h, q, r, s, t, v, x$, zzz.)

Three of the wounds were made when the wood was solidly frozen. Of these, bb is healing well, showing that pruning when the wood is frozen does not of itself delay the healing process. (See Section 3, Chapter IV., for a further discussion of this question.) Wounds o and zzz are not healing well, but the reason is to be sought in the position and nature of the wound, not in the fact that the wood was frozen at time of cutting. 


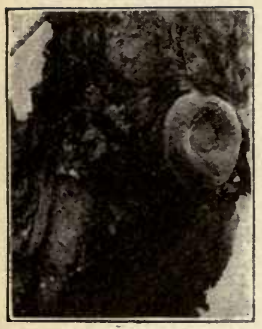

b

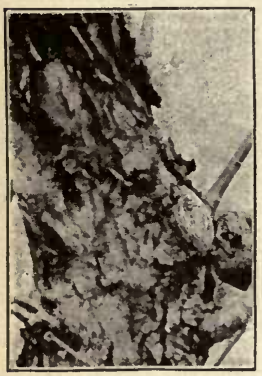

c

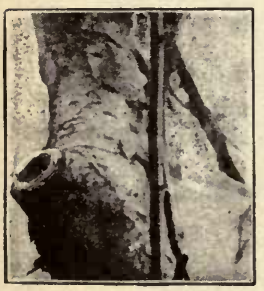

d

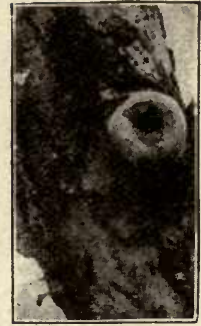

$\mathrm{bb}$

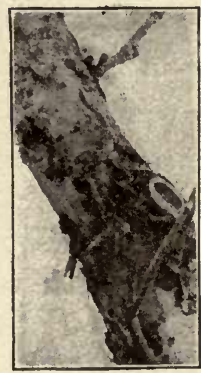

cc

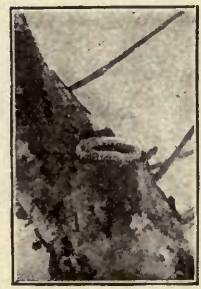

dd

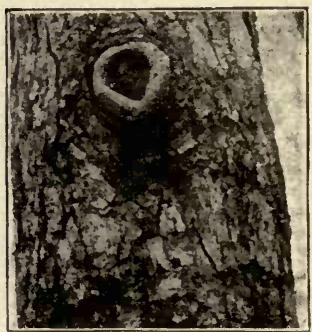

bbb

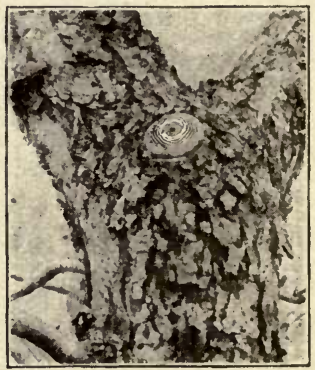

cec

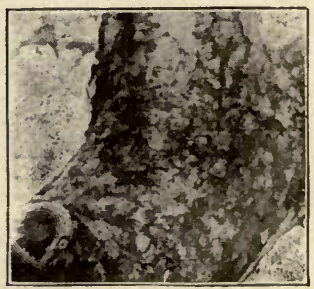

ddd

90. The healing of wounds. 
The conclusion,-and my general opinion,in respect to season of pruning, so far as the healing of wounds is concerned, is this: The ideal time is in spring, before growth begins (late February, March and early April in New York), but more depends on the position of the wound in the tree and the length of stub than on the time of year.

DREssings FOR wounds.-Having now obtained a general conception of the nature of the healing process, we are prepared to understand that a dressing for a wood wound must possess two properties, -it must check the weathering of the wound, and it must prevent the growth of bacteria and fungi; and it must also be of such a nature as not to injure the cambium and bark. In other words, the ideal dressing is a protective compound and an antiseptic. It does not hasten the healing process, except as it prevents decay. It is preservative and preventive.

It follows from the above considerations that the first thing to be sought in a wound dressing is durability. Paint and tar answer this requirement. It should also have intimate contact with the wood. Wax and shellac do not satisfy this requirement, for they tend to peel off and to crack. Lead paint and tar are antiseptics, whereas wax, shellac, tallow and the like, are not. Bordeaux mixture is also an almost perfect anti- 


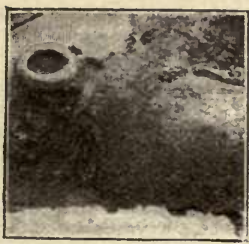

e

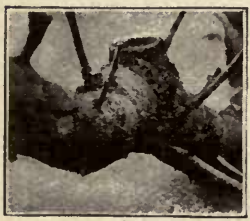

h

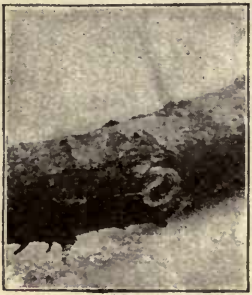

k

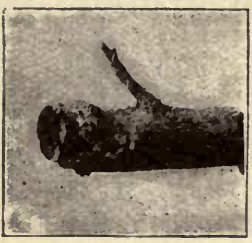

n

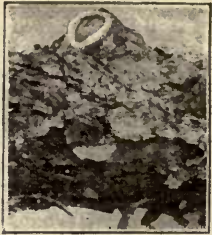

f
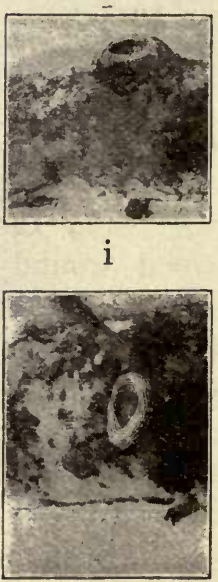

1

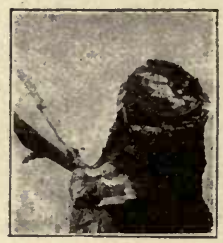

o

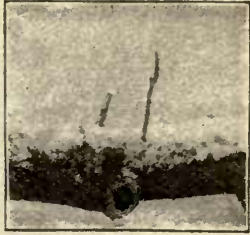

g

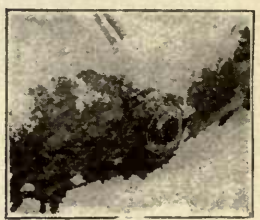

j

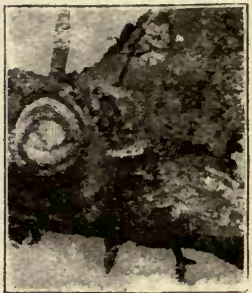

m

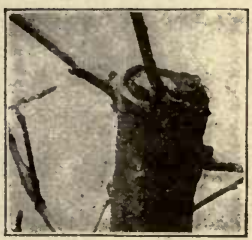

p

91. The healing of wounds. 
septic, and if it had the power of persisting and of preventing checking or weathering, it would be an ideal wound dressing. On quick-healing wounds it can be used with great satisfaction, as we shall discover later; and it is a question if it would not pay to thoroughly spray trees, from which many small limbs have been eut, with the mixture. This advice has other recommendations than its suggestion for the preserving of wounds, for Bordeaux mixture is an excellent general fungicide; it cleans the trunks and branches of lichen or "moss;" and it probably exerts the same influence as the washing of trees in softening the bark and preventing the parts from becoming bark-bound (see page 78 ).

Paint and tar are the dressings most universally recommended. Tar and coal-tar are popular with foresters, but it is certain that they often injure the cambium and bark of fruit trees. Dressings of tar, and even bandages of tarred paper, made to protect plants from borers, often destroy the bark, particularly on young trees. Des Cars strongly advises coal-tar for forest trees, but makes this remark respecting its use on fruittrees: "The application of coal-tar should not be made except with considerable caution in the treatment of wounds on drupaceous fruits (cherries, peaches, plums, etc.), and especially on the plum tree. It has often been observed that the bark of fruit-trees of this class has suffered from 


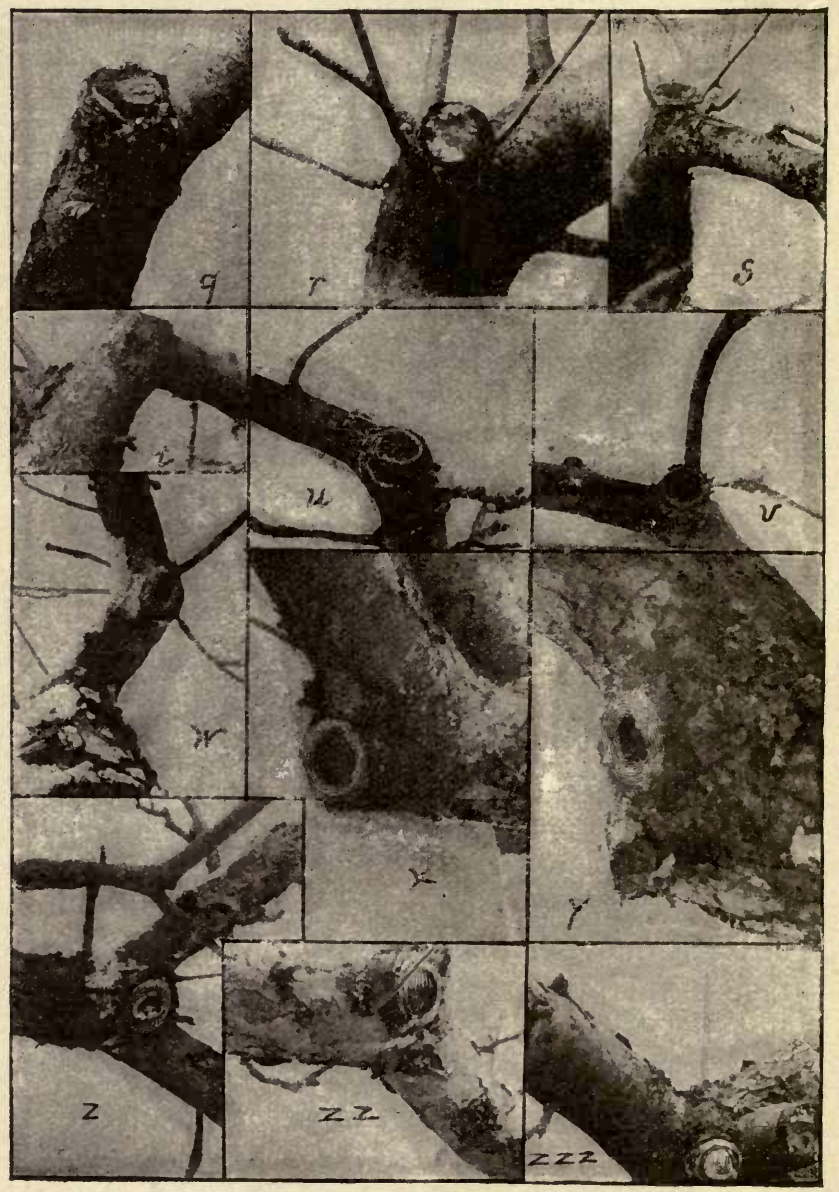

92. The healing of wounds. 
the application of coal-tar. This is not the case, however, with pome-bearing trees (apples, pears, etc.); to these coal-tar may be applied with perfect safety." Card reports* that in experiments in Nebraska "coal-tar seems to have been a positive hindrance to the healing process, not one wound having been reported as healing extremely well." It is not said, however, whether the tar injured the tissues, or whether the apparent results may not have been due to the position and character of the wound quite as much as to the dressing. In my own experiments, which I have already reported (pages 104 to 109), tar did no damage. In fact, the rapid-healing wound bbb, Fig. 90, was dressed with tar. In those experiments, paint, grafting-wax, linseed oil and tallow were also used, but all the differences in the healing of the wounds were evidently the result of other conditions than the dressings. I will expand my affirmation on page 109 to read: The position of the wound on the tree and the nature of the cut exert more influence in determining the healing than either the season in which the wound is made, or the kind of dressing which it receives.

My conclusion is, after having had the question in mind for a decade, that a heavy application of lead paint is the best all-round dressing for com-

*Notes on Pruning, Bull. 50, Nebraska Experiment Station. 
mon pruning wounds; and this, I believe, is the commonest opinion with careful orchardists.

How TO MAKE THE CUT.-I have just spoken of the "nature of the cut." I refer to both the length of the stub and the smoothness of the wound. The length of stub has been discussed (Figs. 84-87).

If the danger to wood wounds arises mostly from the absorption of moisture and the entrance of germs from the atmosphere, then it must follow that a wound which is smooth and solid is better than one which is haggled or splintered. We can conceive, too, that the progress of the cal-

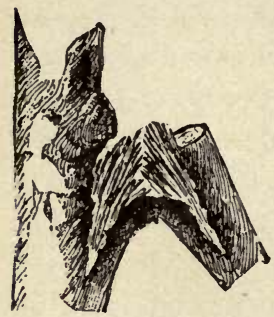

93. Careless pruning.

lus would be greatly obstructed by notches and splinters.

Most of my readers-assuming that I shall have such-need no explanation of Fig. 93. The disaster would have been prevented if the operator had cut the limb as suggested in Fig. 94. A cut is first made as at $a$, sawing the limb half in two, and then the cut is made at $b$. The stub is then sawn off close, as shown in Fig. 87. Every pains should be taken to prevent the splitting of the wound or the tearing away of the bark, for ragged wounds seldom heal without becoming seriously diseased. Although this is not the proper place for the 
discussion of pruning tools (see Chap. V.), it may nevertheless be said that for the severing of large limbs no tool leaves a better wound than a sharp saw. If the wound is not torn or split by the

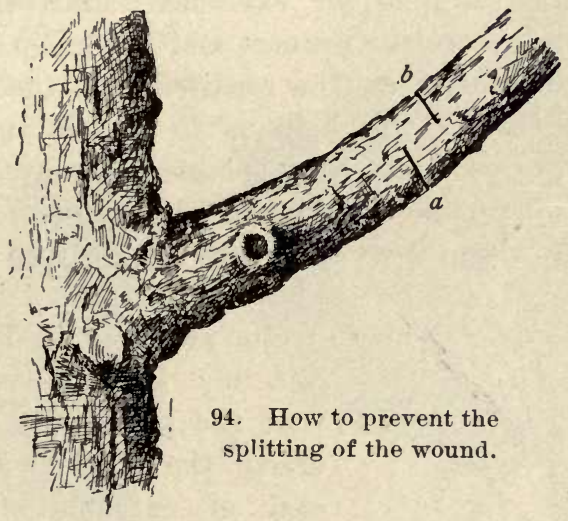

weight of the limb, it will not be necessary to smooth the cut with a knife,-as some persons recommend. Chisels leave good wounds, although they are likely to split the wound near its upper side when they are operated from the ground with a mallet. It is surprising how careless many people are in the making of wounds on trees. Axes and hatchets are often brought into requisition, and the operator goes at his work as he would at a stick of timber. Leonard Coates' remark will apply to more states than one: "Many pruners in California have mistaken their vocation: they are carpenters." 


\section{THE MENDING OF TREES}

Plants are exposed to injuries of storm, weathering, and animals, and to the disasters which result from the struggle for existence; and they are maimed by careless pruners and workmen. Many of these injuries can be repaired, and the preceding discussions will help us to understand how. A few cases may be explained, however, as a means of further elucidating the subject.

Label wires were carelessly left on the trunks

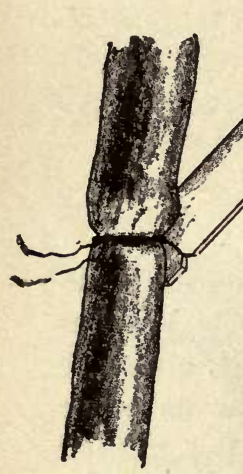

of young trees. The results are seen in Figs. 95 and 96 . It will be noticed that the larger diameter is above the girdle. This is easy of explanation. We have already found (page 17) that the materials taken in by the roots are not directly available or useful in the making of plant tissue. They ascend to the leaves, and are there 95. The mischiev- elaborated, in connection with maous label wire. terial taken from the air, into organized compounds, or become incorporated with such compounds. These organic compounds-of which starch is the chief-are transferred to every part of the plant to build up its tissues. The transfer takes place in the inner layers of bark; therefore, whatever food 
passes down the stem is intercepted at the girdle and is there deposited as abnormal tissue. Fig. 97 shows how a girdled pine tree lived, and piled up tissue above the barrier, until the roots were starved and the tree

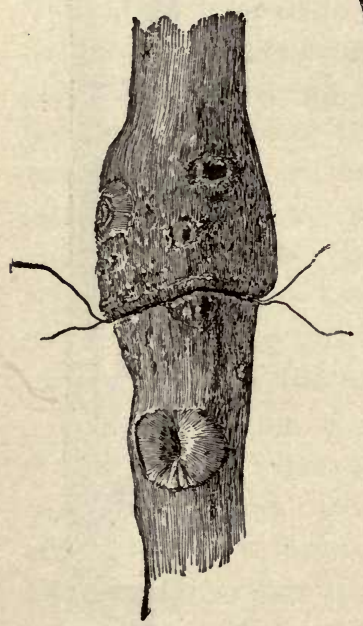

96. Ruined by a label wire.

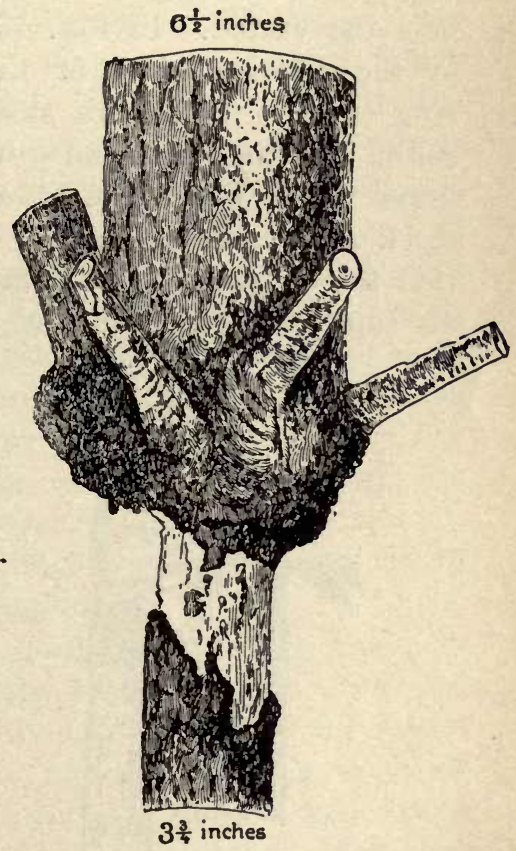

97. A girdled pine. The lower part had four annual circles of wood and the upper part eight circles.

died. All these remarks have a direct bearing on the question of ringing, which we shall discuss in Chapters IV. and V. 
The careful observer will often see the callus of wood wounds growing most rapidly from the upper side. In Fig. 88 the bark has grown down over the wound. In Fig. 75, the point of union of the opposite sides of the callus ring is at $b$. This stub stood horizontal on the tree, and $b$ was the lower side. The union of eion and stock sometimes acts as an obstruction to the free downward movement of sap, causing a bulge on old

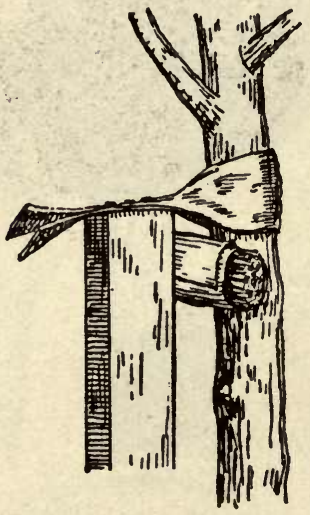

98. Suggestion to prevent galling of a staked tree.

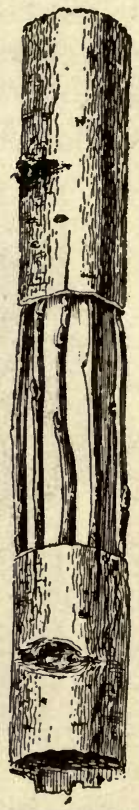

99. Bridge-grafting of a girdled trunk.

top-grafted trees; but this phenomenon should not be confounded with the normally more rapid growth of some cions, due to the variety, as compared with that of the stock (see Fig. 133, Nur- 
sery-Book). The reader will also notice the deposition of tissue above the braces in Fig. 107.

We now see the importance of preventing the girdling of trees by label wires and by careless tying to stakes; but we are also informed that a girdle is not necessarily fatal to a tree. If the young wood remains live and moist, the crude food materials may pass up from the roots, and the plant continues to live for some time, and in the case of coniferous trees, often for several years. If the girdle is made early in the season, the tree may cover the girdle with bark the same year, and thus live on; but if the girdle is made late in the season, the sap wood is likely to dry out and die, and the tree to perish before the return of another season. If it is desired to kill trees quickly by girdling them, the girdle should extend through the sapwood.

In the treating of girdled trees, it is first necessary to see that the exposed wood does not become dry and diseased. Trim away the rough edges of bark, apply an antiseptic (a wash of Bordeaux mixture is to be recommended), then cover the entire surface with melted wax* and bind it up with cloth bandages. Fruit trees may

*Many recipes for tree-waxes may be found in "The Nursery-Book." The following is excellent: Into a kettle place one part by weight of tallow, two parts of beeswax, four parts of rosin. When completely melted, pour into a tub or pail of cold water, then work it with the hands (which should be greased) until it develops a grain and becomes the color of taffy candy. 
be saved in this way, even if the girdles completely encircle the tree and if they are as much as a foot long, providing the trees are vigorous, and the treatment is applied before the wood becomes hard and dry.

If the tree is particularly choice, or if the girdle is unusually serious or of long standing, and especially if the wounds extend into the wood, it may be advisable to supply a connection between the separated parts of the truik. Fig. 99 explains how this may be done. The edges of the girdle are trimmed, and cions are inserted under the bark so as to bridge the wound. These cions are cut to a wedge shape on either end as for ordinary cleft-grafting, ${ }^{*}$ and they are inserted between the bark and wood. A cloth bandage is tied about each edge of the wound, to hold the bark in place over the cions, and melted wax is then poured over the entire work, covering the exposed wood and also the edges of the bark for a couple of inches or more back from the wound. It will do no harm if the cions are buried in the wax. Care should be taken that the cions do not send out shoots from their buds. Some persons prefer to cut the buds from the cions to avoid this difficulty, but it is probably better to leave the buds on, inasmuch as their effort to grow may hasten a union. Fig. 100 is a cross-section of

\footnotetext{
*The whole subject of grafting is explained in "The Nursery-Book."
} 
such a bridge-grafted tree, as it looked seventeen years after the work was done. This specimen was reported in The Rural New-Yorker in 1892 by Leroy Whitford; the picture is reproduced from that paper.

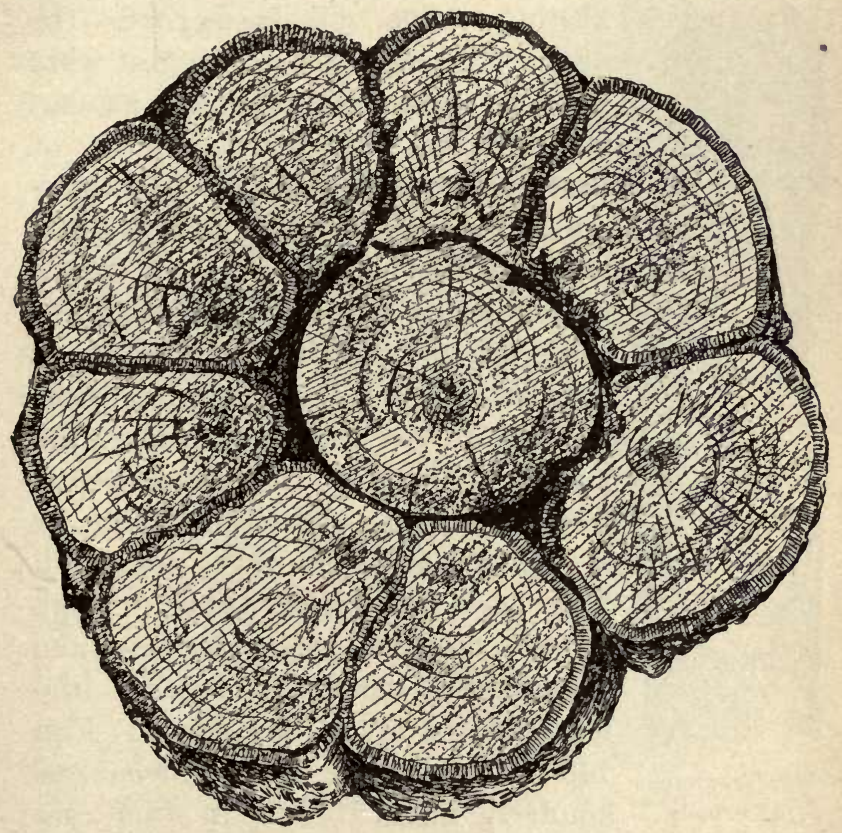

100. Cross-section of bridge-grafted tree.

Body wounds on trees may be treated in the same way as girdles,-dress the edges back to live bark, scrape out all splintered and decayed wood, apply Bordeaux mixture or paint (or other antiseptic), then cover with wax. Fig. 101 shows 
such a wound properly trimmed and cleaned. It was a case of disease starting at a knot. The knot has been wholly cut away, and all diseased tissue is removed. If decay is now checked, the 412 healing callus will soon cover the

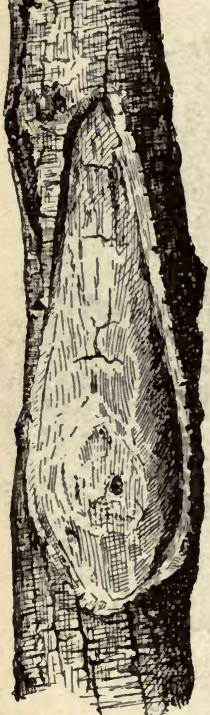
area. This will at once suggest what is to be done with the dead patches of bark left by body attacks of pear-blight, borers, injury from sunscald, gnawing by horses, loose bark, and the like.

It is but a step from these cases to those of the splitting of the trunk by cold, concerning the treatment of which so many questions are asked. Fig. 102 is a sweet cherry tree which was split to the heart by a cold winter and then neglected. The bark has rolled back through the action of alternate wetness and dryness, the wood has become lifeless and the crack has gaped. Fig. 103 is a peach tree which was similarly injured; but in this ease the bark was trimmed back to the quick as soon as spring opened and the injury discovered, and the area was painted with Bordeaux mixture. At the end of the same year, the wound was nearly healed, and the tree is probably the better for the accident, since the pressure 
of a hide-bound trunk has been released. In these cases of splitting it is very important that the bark be trimmed back at once, before it begins to roll and loosen itself; for as often as the bark rolls the healing is interfered with and forced

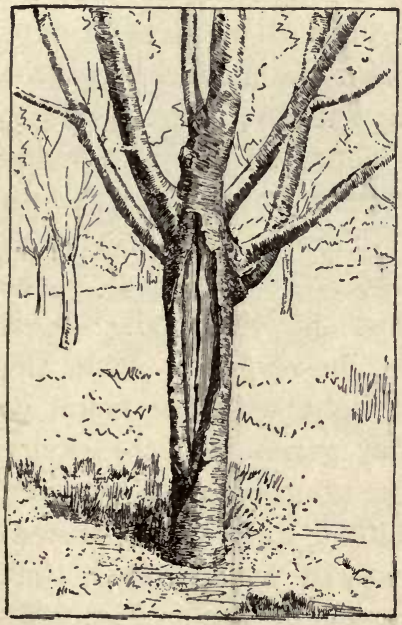

102. A neglected weather split.
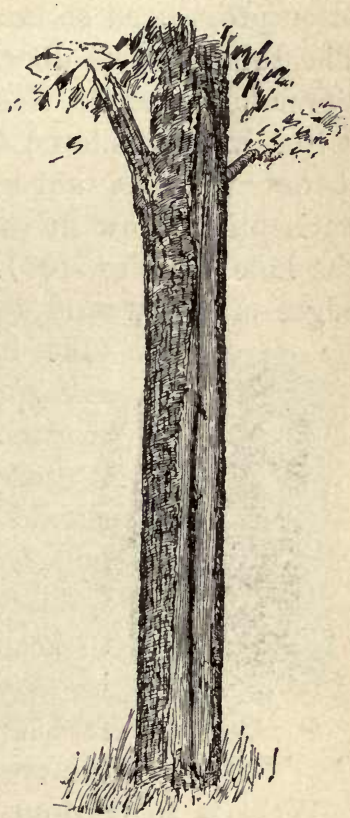

103. A treated split.

further back from the original wound. In the cherry and some other trees, there is a strong tendency for the bark to roll, and in such cases it is advisable to bind the wound with cloths, having first applied melted wax to keep the parts fresh and soft. 
Among the most difficult wounds to treat are the rotten cavities following careless pruning. Such a cavity is seen in Fig. 71. The decay has often progressed so far that it cannot be checked. The things to be done are to remove all diseased tissue and then to close the cavity. Cut out the rotten and discolored tissue with a knife or bore it out with an auger. Then soak it with an antiseptic. Now drive a plug of wood tight into the hole (A, Fig. 104), paint the surface, trim the edges of the wound to live tissue, and let nature

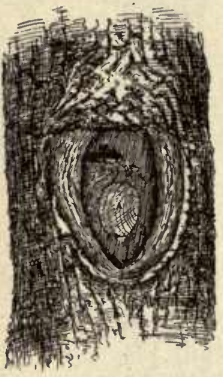

104. Plugging a cavity. take her course. Large wounds are sometimes covered with tin or zinc. This is good as far as it goes, but the diseased tissue should first be removed. It is impossible, however, to cover the wound so tight with the metal as to keep out germs. If the cavity is securely plugged, and the surface smoothed and kept painted, the results will usually be better.

What is to be done in such a case as Fig. 105? It would probably be best to cut off the limbs at $\mathrm{A}$ and $\mathrm{B}$, and allow the remaining branch to form the top. In that case, the wound at $\mathrm{A}$ must be trimmed back smooth and clean, and painted or otherwise protected. It may be desirable, however, to save the broken part. In that case, head it back, raise it into position, and bolt it fast. 
An iron bolt may be run through the base, holding it securely in place, and a brace may be supplied higher up, as shown in Fig. 106. These bolts are run through the trunk or branches and drawn up with a nut. Both the nut and the head

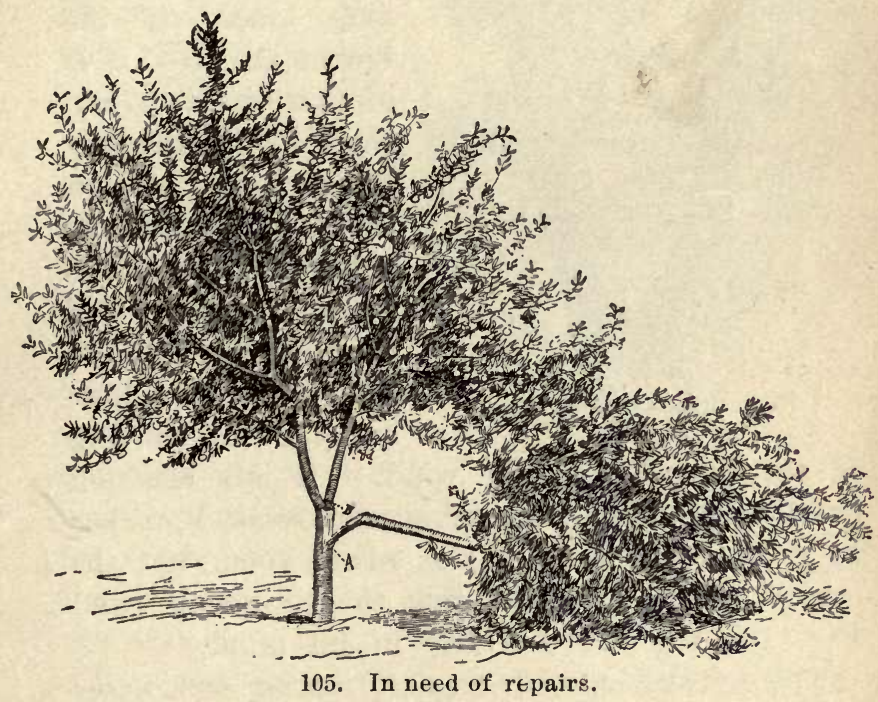

of the bolt should be large, so that they will not draw into the wood. The bolt should fit tight in the auger hole. When the work is done, apply paint or other covering at the place where the bolt emerges. The bolt will soon be buried, as the nail is buried in Fig. 76, and the tree does not suffer. 
Very large branches may be raised and secured in this way. Be careful to keep the old split well

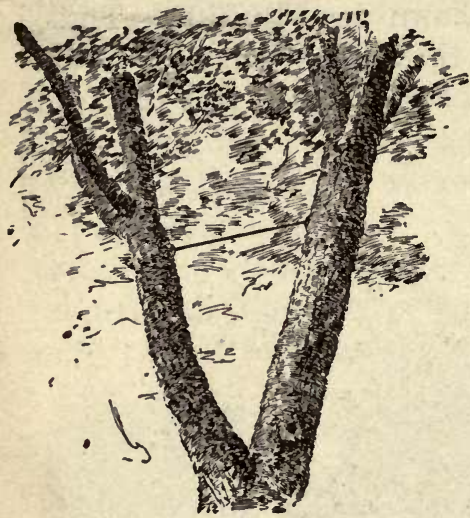

106. Crotch held by a bolt. covered with wax or thick paint. If it is necessary to apply long braces in the top of the tree, it is often advisable to run short bolts through the branches, and on the inner ends to have hooks or eyes into which another rod or a chain may be secured, thus allowing for the moving of the branches in the wind. It is a common practice to support crotches and weak branches by putting bands or chains about them, but the reader will at once see that this is wrong; and Fig. 107 will fix the error in his mind.

There is still another way of treating such cases as Fig. 105. If a stub is left by the breaking of the limb, the stump may be smoothed and cions set in it freely, the remaining top being shortenedin at the same time. One or two good branches may be obtained from the cions, and the symmetry of the tree be thereby restored. In Fig. 108, the large branch on the right was grown from a cion set between the bark and wood in a splintered 
stub (which terminated at $a$ ) six inches in diameter.

The ideal treatment is to prevent the crotch from splitting. This ean be done by not having the crotch, or by bracing it before it shows signs of weakness. The bolt (Fig. 107) may be used for this purpose. A living brace may be grown over the crotch, as shown in Figs. 109 and 110. Two small limbs, preferably not larger than the little finger, arising from opposite branches, are twisted tightly together, the

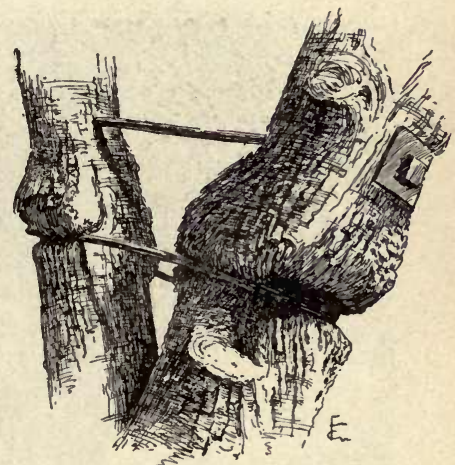

Fig. 107. Right and wrong methods of bracing a crotch. free ends being allowed to project as they may beyond the opposite branch.

In a year or so the bark of the two will begin to knit together, at which time the free tips-and many shoots which have arisen from lateral budsare headed-back or removed. As the branches continue to unite, the leafy parts are curtailed, and in a few years a perfectly solid and continuous living brace will be formed from limb to limb. Fig. 109 is from an actual example, which the writer has had under observation for more years 
than he cares to admit. Fig. 110 was made in a different way. The brace is a single branch arising at the right. When as large as one's finger, it was thrust through a slit made through the branch at the left, allowing it to project two

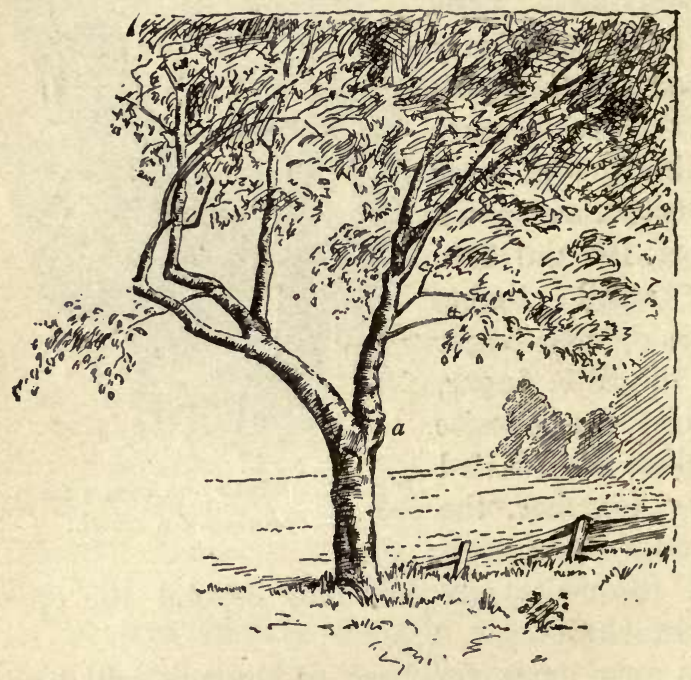

108. A repaired apple tree.

or three feet beyond the wound. It soon grew fast, and the free part was then removed; the result is a perfect union and a strong living brace.

In closing this sketch of tree surgery, I must enter my protest against reckless treatment of street trees. The most wanton and inconsiderate 
despoiler of shade trees at present is the lineman who runs telephone and telegraph wires. He generally has no appreciation of the value of a tree, and still less of any need of giving thought to the proper eutting of the limbs. Everything

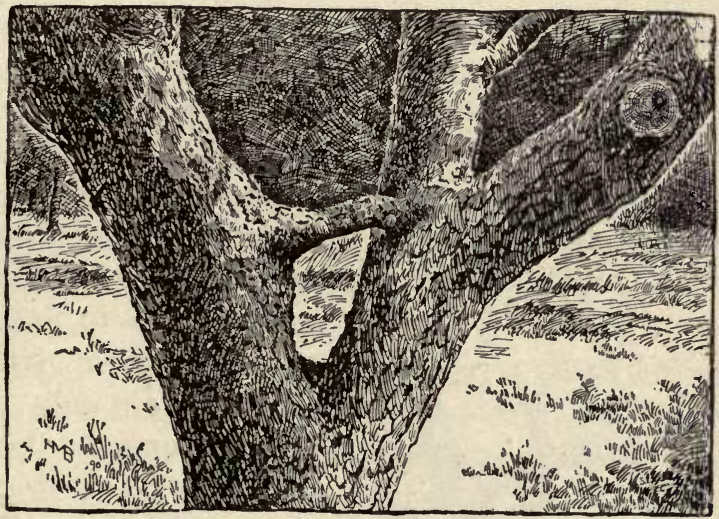

109. Living brace in a Talman Sweet apple tree.

is secondary and subsidiary to the lining of the wires, and the result is that many fine trees are wickedly sacrificed. Our duty towards street trees is vigorously set forth in the following sketch by Professor Farlow:*

"I must not, however, close my remarks on this subject without uttering an emphatic protest against the way in which the shade trees of our

*W. F. Farlow, "Diseases of Trees likely to Follow Mechanical Injuries". Lecture before Mass. Hort. Soc., Mar. 7, 1891. 
cities and towns are treated. The responsibility rests not only with those who, perhaps unintentionally and ignorantly, are directly guilty of what an enlightened public opinion should regard as vandalism; but it rests in part on ourselves, if we do not in all possible ways seek to give information to the public, and attempt by all legal means to secure the enforcement of such regulations as shall assure proper protection for our trees. As it is, the care of the trees in our public grounds, parks, and streets is too often placed in the hands of those who are ignorant of the principles of vegetable physiology, and

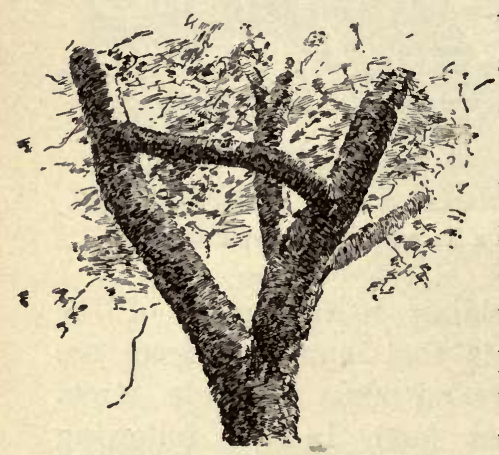
their efforts to prune and eut down trees are guided only by what seems to them temporary convenience, or by what commends itself to their not infrequently perverted sense of the beautiful. When the whim seizes them

110. Living brace in a Newtown Pippin apple tree. and they wish to get rid of a stately tree, it is only necessary for them to say that it is rotten, and dangerous because likely to fall. Many times I have seen trees whose shade could ill be spared, cut down because their trunks were 
rotten, when examination after they were felled showed that they were sound and would have lasted many years. It ought to be considered a crime to cut down a handsome tree-certainly in public grounds-unless compelled by absolute necessity. When it is thought necessary for the public safety to destroy animals supposed to be suffering from contagious diseases, there is, at least, a consultation, and the opinion of experts is asked. I hope that the time will come when it will not be allowed to cut down trees which are public property, except on the advice of those whose training entitles them to be called experts.

"If one is amazed sometimes at the abuses of trees on the part of those who are their authorized guardians, it must be admitted that the poor condition of our trees is principally due to the recklessness of the public. * * * In most of our streets the trees are very near the edge of the sidewalk, if they do not project into the street itself. Those on the corners of the streets are almost sure to be grazed by passing vehicles, and as wagon after wagon passes along, the grinding process is kept up until the wood is exposed. It is perhaps fortunate that such trees are short-lived, for they become very unsightly, and when they die, the curbstone can be replaced as often as is necessary.

"Walk along any of our streets where the 
trees are placed on the edge of the sidewalk, and notice the effects due to our general negligence. In some instances you will find that the house-owners have placed guards around the trunks, and the trees are symmetrical and have attained a good size. But in most cases, they have been left to take care of themselves. Bright and early the milkman comes along and jumps off with his can, leaving his horse to make a scanty breakfast by gnawing the bark of the nearest tree. Later on come the butcher and the grocer, whose horses lunch upon what was left by their predecessor, inflicting an amount of damage to the tree limited only by the length of time which their owners are pleased to spend in conversation with the girls in the kitchen. Last of all comes, perhaps, the doctor, whose visits, if they are not frequent, are proportionally long. He, at least, ought to know that trees cannot be wounded with impunity. No wonder that the bark is not only soon removed and the wood exposed, but since the horse is an animal which prefers the softer bark to the harder wood, the fresh borders of the wound are repeatedly attacked, until deformities of enormous size are produced, and, apart from the danger of fungous growths, the nutrition of the tree is seriously deranged." 


\section{Chapter IV}

\section{THE PRINCIPLES OF PRUNING}

We are now prepared to enter on a discussion of some of the more fundamental considerations governing the rational pruning of plants. It is difficult to write on pruning, from the fact that no two plants are alike, and many and various objects are to be attained. It is impossible to instruct any person in pruning by merely showing him how to do the work on a given plant; for the very next plant may present a new set of problems. If there are no generalizations or principles to be enunciated, then writing on the subject is well nigh useless.

It is astonishing how few lucid eonceptions there are of the problems at issue in pruning, and of the factors which modify the results. There is no literature which seems to clearly analyze the whole subject, at least from the fruit-grower's standpoint, and to present any consecutive body of laws upon which the intending operator can act. It is unavoidable, therefore, that the present sketch should be far from complete and satisfactory.

There are two great classes of ideas concerned 
in the pruning of plants, - those which are associated directly with the welfare and behavior of the plant, and those which are associated with the mere form or size to which the plant shall attain. The former includes questions of pruning proper; the latter comprises questions of training, which depend primarily on the taste and abilities of the pruner. Shall I grow my trees to round heads or conical heads, high heads or low heads, one trunk or two trunks? Whichever you like. It is largely a question of personal preference and opportunity, as it is whether you shall plow with horses or oxen, build a rail fence or board fence, or plant Ben Davis or Baldwin apples.

Of all the operations connected with the growing of trees and shrubs, pruning and training bring the person into closest contact and sympathy with the plant. One shapes and cares for the plant tenderly and thoughtfully, working out his ideals as he would in the training and guiding of a child. There are some persons, to be sure, who cannot feel this sympathetic contact with a plant: they are the ones who, if they prune at all, use an axe or a corn-knife. If a person cannot love a plant after he has pruned it, then he has either done a poor job or is devoid of emotion. It is a pleasure to till the soil and to smell the fresh crumbly earth, but the earth does not grow; it is still a clod. The plant responds to every affectionate touch. Spraying, that modern 
evolution of horticulture, is not to be compared with pruning in producing a sense of fellowship with plants. In fact, spraying has the opposite effect with me. When I have sprayed a plant, I am conscious that I have besmeared it, and have taken a mean advantage of a lot of innocent and defenseless bugs; and I want to quit the premises forthwith.

We shall now try to find a few general statements, upon which we can all agree, respecting the principles which underlie the practice of pruning and training. Some of these principles follow from a general consideration of the way in which a plant lives and grows, some of them are restatements or summaries of discussions in the preceding chapters, and others are suggested by direct experiment. All of them are intended to be general truths, not statements of specific facts. Writings on pruning are usually confusing, because they are a mass of details, facts and opinions, with little effort to arrive at laws or principles. I advise beginners not to read them. Principles must come first if practice is to be satisfactory. The details are to be worked out on the plant itself, after the operator has learned why. Before entering upon this disputed ground, we may pause to say that the reasons for pruning may be ranged under eight general heads:

1. To modify the vigor of the plant.

2. To produce larger and better fruits or flowers. 
3. To keep the plant within manageable shape and limits.

4. To change the habit of the plant from more or less wood-bearing or fruit-bearing (or flowerbearing).

5. To remove superfluous or injured parts.

6. To facilitate spraying and harvesting.

7. To facilitate tillage and to improve the convenience of the plantation.

8. To train the plant to some desired form.

1. Heavy pruning of the top of a plant tends to increase the production of wood (or strong vegetative growth).

A plant growing under normal conditions has a perfect balance of top and root. The top and root mutually supply, support and nourish each other. The one must respond to the other. The more root, the greater the amount of crude materials taken in; and the greater the amount of these materials, the greater must be the elaborating leaf surface, and the greater, therefore, the growth of all parts of the plant. If a large part of the top is removed and the root is untouched, the balance is broken. An equal amount of root supplies a smaller amount of top. There is more food for all the remaining branches. The result is greater growth of these parts than they normally would have made; or new parts-suckers -may arise. Let the reader recall the crab-apple 
trees described on pages 15,16 , or let him consider the behavior of the dwarf pear tree in Fig. 111. All these considerations explain the gardener's rule that in roses and other ornamental plants, the weak kinds should be heavily pruned and the strong kinds lightly pruned.*

If it is necessary to resort to severe pruning for the purpose of correcting the shape or training of a plant, and it is desired at the same time to avoid excessive growth, the operator should remove the superfluous parts gradually. This caution is important, even in the training of herbaceous plants.

A grower of winter tomatoes writes me as follows on this point: "I find

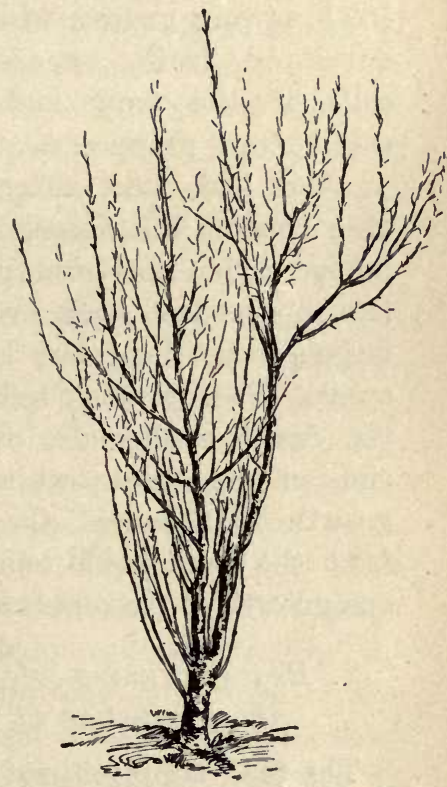

111. Heary pruning produces wood (in this case, a profusion of watersprouts). that when planted thickly in the beds the foliage needs heavy trimming to keep it within bounds; and would say further of this trimming that it

*See, for example, Ernest Walker, in "Garden-Making," page 298. 
must be done frequently, and only a moderate proportion of the leafage removed at one time, for if heavy trimming is indulged, it will cause a fresh, strong growth which splits open the partly developed fruits, exposing the interior or seed cells of the fruit and rendering it unfit for sale. Our practice is to remove the outer end of the leaf and afterwards take off a joint at a time as the leaves on the inner part increase in size under the trimming, as the first two leaflets on the leaf stalk eventually attain almost as large size as the entire leaf under ordinary treatment. The gardener tells me that the splitting of the fruits would also result from stopping the ends of the shoots while the plants are still in growth. Of course, the fresh shoots coming up from the roots would tend to overcome this vigorous growth of the plants and consequent splitting."

2. Heavy pruning of the root tends to lessen the production of wood.

The food supply is cut off. Root-pruning is to be compared to poor feeding. The reader knows that he prunes the tops of transplanted plants because the roots have been cut, and he must thereby reduce the area to be supported. Rootpruning is practicable chiefly in the growing of specimen plants, or in small amateur plantations, particularly when trees are trained on walls, cordons, and the like. (Consult Chapter V.) 
3. Heavy pruning of the top tends to rejuvenate weak or declining plants.

This is because the remaining parts receive more food. The proposition is really a corollary of Section 1, but it has such distinct and important applications that it is well to give it an independent statement. When plants begin to fail from general debility (not from the attacks of insects or fungi), manure or prune them heavily, or do both. It is generally best to remove the weakest parts, particularly if the decline has progressed far; but if it is desired to save the particular branches which are involved, a heavy pruning of the healthy parts may be expected to throw new activity into the weak ones In many cases, however, it is impossible to rejuvenate weak branches; but suckers or watersprouts may be developed, and these may form a new head. Old and decrepit peach trees are often headed-back severely for the express purpose of securing this new wood. The tops of birches, maples and other ornamental trees sometimes show signs of failing. If there are no borers or other specific troubles, the tree should be heavily pruned, and if the trunk and roots are sound, renewed activity may be expected.

Under Section 1 (page 136) we found that weak kinds or varieties of plants should be pruned severely and strong kinds moderately. These reinarks were meant to apply to plants of different habits, not to weakness due to disease or debility; 
yet the rule holds good in either case,-heavy pruning for wood, light pruning to maintain the habitual condition. One must be careful, however, not to apply these contrasts to differing branches on the same plant, for it is a fact that one branch may appropriate the food of another (see Section 6); if, therefore, it is desired to even up the branches on any plant, prune the strong shoots severely and the others only moderately, and thereby throw the energy into the weaker shoots. This type of pruning is often done in the summer. "Meehan's Monthly" gives the following advice on this point: "This summer pruning is especially effective with coniferous trees. In the case of pines, we know that in the springtime three or four branches push out at the end of last year's sprouts, looking like gas burners. The central one is very vigorous and those on the sides are weaker. If we pinch out the point of the stronger ones the sap at once flows into the weaker ones, and they become strong, and new buds form at the place where the strong one was pinched off. Next year this bud continues the growth of the branch almost as straight as if it had never been pinched-back. We can pinch off the terminal bud of the main stem, a new bud forming a leader without any bend. One who understands this business of summer pruning of evergreens can so manage that trees form an absolutely perfect specimen from the ground to the top, no one branch 
being any stronger than another. The chief thing to remember is that in summer pruning the weak branches of the shoot should not be touched; it is only the stronger ones that require checking."

These remarks have a most important bearing on the treatment to be given to severely winterinjured trees. My own thought about the matter is expressed in the following quotation from "Principles of Fruit-Growing": "The proper treatment for frozen-back trees must be determined for each particular case; but it should be borne in mind that the injured portion is no longer of use to the plant, whereas it may be a positive detriment by accelerating the evaporation of moisture. The best treatment for plants seriously injured upon the extremities is to eut them back very heavily. This severe heading-in-sometimes to the extent of three or four feet-removes the driest and weakest portions, and concentrates the energy of the tree into a comparatively small area of top. Heavy pruning always tends toward the production of wood, and this wood production is probably never more needed than in winterinjured trees, for it tends to renew the vitality of the tree. The philosophy of this becomes apparent upon a moment's reflection. The browned and injured wood can never regain its former usefulness. New tissue must be developed as quickly as possible, in order to carry forward and to maintain the vegetative energies. This new 
tissue is laid on over the old, and the old, there-
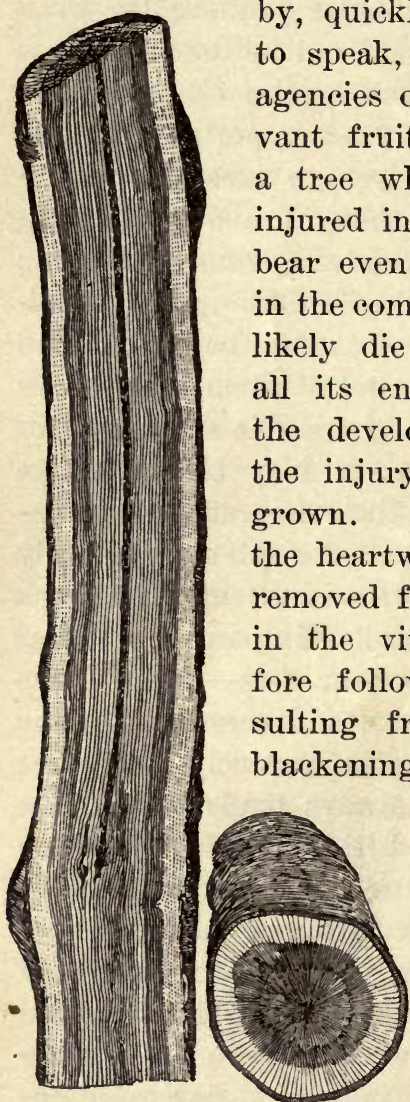

112. Showing the new tissue formed around winter-injured wood. by, quickly becomes sealed in, so to speak, and removed from the agencies of decay. Every observant fruit-grower knows that if a tree which is severely winterinjured in limb and trunk were to bear even a partial crop of fruit in the coming season, it would very likely die outright. If, however, all its energies were directed to the development of new tissue, the injury might soon be overgrown. The injured wood, like the heartwood of the tree, is soon removed from active participation in the vital processes. It therefore follows that the danger resulting from the browning or blackening of the wood by winterinjury depends very much upon the subsequent treatment of the plant. Fig. 112 shows the body of a young plum tree (in longitudinal and crosswise sections) which was frozen black in the severe winter of 
1895-6. It was heavily pruned in the spring of 1896, and in the fall had made a ring of bright new wood, which was amply sufficient to maintain the tree in perfect health for a long life. This appearance is common in nursery stock the year following a very hard winter, but such trees may not be permanently injured.

"There are instances in which this heavy heading-back seems to do more harm than good. These are eases in which the entire tree is almost uniformly injured, and the plant seems to need the stimulus of all its buds to bring out the feeble life which is still left to it; but these eases are comparatively rare. It is probable that the greater number of reported instances of death due to heavy pruning of winter-injured trees are of such trees as would have died under any treatment. Winter-killed plants often retain sufficient vitality to enable them to leaf out or to bloom, and sometimes even to begin growth, but when the stored vitality of the tissues is exhausted the plant perishes. This explains the phenomenon which, after a bad winter, nearly always puzzles the unobservant fruit-grower, of trees starting into feeble growth, and then suddenly dying when warm and dry weather approaches."

There are many unsolved problems associated with the pruning of winter-injured trees in very severe climates. There are evidently two factors concerned in the question,-the general effect of 
heavy pruning on the tree, and the injury resulting from the wounds. In the dry and cold climates of the North, Northwest and the Plains, there is excessive evaporation from winter-made wounds, and this injury may be so great as to make severe winter pruning inadvisable in many localities. (See Section 17.) It is therefore difficult to judge of the merits of controversies concerning the advisability of the heavy pruning of winter-injured trees, particularly in severe climates, because two or more unanalyzed problems may be involved.

Since opinions differ as to the advisability of severely heading-back trees which are much injured by cold, I here insert extracts from letters of various fruit-growers in the Northwest, to whom I was referred by E. S. Goff, of the University of Wisconsin. Professor Goff himself writes as follows:

"I have discussed the question as to the advisability of pruning winter-injured trees with Wisconsin friends. Some of them are very positive that pruning such trees in spring has caused their death in several cases; also that similar trees not pruned until they had recovered vigor, have outgrown the effects of the winter and made good trees. The hypothesis that I have used to explain the opinions that such trees should not be pruned in spring is this: The buds, being enfeebled by cold, are not able to use a large quantity of water from the roots, and hence thinning out the buds, which naturally tends to increase the pressure of sap in the remaining ones, proves injurious. That this is true, I am by no means sure, but the fact that winter- 
injured trees often throw up many sprouts from the base of the trunk, seems to me evidence in the affirmative."

Professor Budd, Iowa: "In cutting back injured parts of raspberry, blackberry, shrubs, or the orchard fruits injured by winter, I prefer to wait for the starting of the buds, and then cut to the point where the buds start in a healthful way. But in severe injury, such as that of the Florida orange trees, I gave the advice to cut before there was any show of buds."

Professor Green, Minnesota: "I prefer to prune after the trees have leafed out quite a little, rather than early in the spring. Early spring pruning, and pruning just as the sap starts strongly, is liable to cause bad wounds, that heal slowly, and the wood is apt to die back in apple trees in this section when so pruned. But this latter trouble we sometimes avoid by covering all the wounds with grafting-wax. Then, in the case of winter-injured wood, we can tell more certainly as to the extent of the injury, if the pruning is not done until the growth has started."

O. M. Lord, Minnesota City, Minn.: "My experience with apple trees, though covering a period of more than forty years at this place, has been limited to few varieties and to my own grounds. I have found that it is almost sure death to eut or trim apple trees at any time except when the trees have begun to leaf out. I do not know of any trees in the fruit line that will bear such severe cutting as the native plums, but I prefer to trim them when the foliage is nearly full."

J. S. Harris, La Crescent, Minn.: "My opinion, based upon a long experience in this Northwest, is that if the injury is so great that any considerable portion of the top will need to be removed, the pruning had best be done as soon as the winter is broken, and long enough before spring opens that there shall be no starting of sap. The pruning shall extend down to uninjured wood and the wounds properly covered. Where the injury is not so great as to re- 
quire the removal of much wood, I prefer the last half of June for such pruning. Our experience here is, the worst time of all for pruning is when the trees or buds are about ready to swell and start, until they are nearly fully open."

A. J. Philips, Sec. Wisconsin Horticultural Society, West Salem, Wis.: "My plan with a tree that has been injured would be to prune it after the severe weather of winter is over, and before the tree exerts any of its weakened forces, to start growth on all the top, thereby concentrating its strength on a smaller surface. But in this trying climate I spend but little time trying to bring back trees that are badly injured. I much prefer to top work those varieties that are subject to injury on a known vigorous and hardy stock. My rule now is to top-work one hundred each year on three to five-year-old stocks, and my orchard is gradually increasing in value and productiveness."

B. Wade Hewett, Pardeeville, Wis.: "My experience has taught me that the earlier trees can be pruned in the spring after severe freezing is past, the better. To be sure, sometimes trees are so badly tipped-back that it becomes necessary to wait for the selection of a leader until the buds are well swollen, but all possible trimming should be done before this. For best results, I would say, do all fruit-tree trimming before leaves break."

Charles Hirschinger, Baraboo, Wis.: "Severely injured trees should not be pruned till the year following, not in the year of injury. If pruned, wait till after the leaves are half grown, or, better, till June first. Severely injured trees are sometimes killed by early pruning, or by pruning the same year that they were injured; but if left till the next year, they frequently recover, and wounds heal over nicely, which is often not the case if pruned same year they are injured."

George J. Kellogg, Janesville, Wis.: "Prune injured shade (except maples) trees in March after zero weather is past. Prune fruit trees after the weather will not get 
colder than $10^{\circ}$ above zero. Farther south, where zero weather is not likely to prevail, prune shade and fruit trees any time in winter, at least thirty days before the buds are likely to open."

The great Florida freezes of 1894-5 brought much discussion as to the proper methods of treating frozen orange trees. Many persons cut the trees back to fresh wood, others practiced rootpruning at the same time to equalize root and top, and others did nothing. The last-named persons practically lost badly frozen trees. The writer studied the effects of the various treatments in the winter of 1896-7, and it seemed clear that vigorous cutting-back is to be recommended in such cases. Some of the best results were seen on the estate of H. S. Williams, at Rockledge, Fla.; and Mr. Williams' own advice* is here reprinted:

"As a rule, all my trees were budded low, and on sour stocks. In April they began to show signs of life, varying from two to fifteen feet from the ground. All the branches, with but few exceptions, were killed back to the main trunk. Some trees were killed to the ground on south side, while on the north they threw out vigorous sprouts up some two or three feet. *** Some of the sprouts, high up on the trunk, where the wood did not have vigor enough to sustain life-a mere shell under the barkhave died the past summer, but not as many as I was led to expect. The crop of the season of 1894-95 was ten oranges. The present erop, $1895-96$, may be 30 boxes. Owing to the excess of roots over the top, hence the excess of sap and food taken up by the roots, the fruit is somewhat coarse,

*As given in Indian River Advocate, Dec. 4, 1896. 
while some trees have the red-rust, causing the fruit to split and drop. This disease, however, will rapidly disappear as the roots and tops become more evenly balanced. As some trees were flowing more sap than others when the last freeze struck them, so some were hurt much worse than others, even though standing side by side in the grove. The present condition of the trees, however, is, in the main, very satisfactory, and the fruit-bearing wood should give us a fair crop another season-say 20 or more boxes where we now count one. The rapid growth of this new fruit-producing wood will tax our ingenuity to the utmost to keep it from being crushed by its own weight, as these sprouts have, in many instances, but a thin shell of live wood to give them strength as against the wood fiber from the wood of the tree, as is the case with the tree in its normal condition. These sprouts, growing at an angle of some forty-five degrees, when weighed down with fruit will have to be artificially supported with the greatest care. * *

"Profiting by the experience of the past, I would change but little in the work done to bring out my orange grove to the best advantage, and in the least possible time. If all the trunks of the trees had been well wrapped the morning after the second freeze, or better yet, the day before, if the Signal Service would give us the notice in time, it would, no doubt, prove of invaluable benefit.

"Then I should advise the following treatment: Cut off the lower branches and cut top immediately above. The trees treated in this way, as before noted, are alive all around the trunk, and the branches and sprouts thrown out seem to be more firmly united with the trunk than any others. Cut all trees less than six years set close to the ground, and draw the dirt away from the collar, so as to expose the surface roots slightly to the sun. As soon as practicable, plow the grove, breaking as many roots as may come in contact with plow, and have a man follow with keen grub-hoe, and eut off all such roots smoothly. 
"If one has a small grove, I would advise digging a trench fully ten inches deep, grading the distance from trunk according to size of tree, and eutting off all roots. Some trees treated in this way, a year after the freeze, show a marked improvement in the way of growth the second summer just passed. As soon as the sprouts from the ground get large enough, insert your buds and get them started as soon as possible. If you wait until the next spring the buds will make too rank a growth. * * *

"Regarding the number of buds that is best to let grow, there is a great diversity of opinion, and it will take years to decide positively what is really best. In all my younger trees, where the stump will probably heal over, I have adopted the rule to let only one grow, as we much prefer to have a single trunk only. In the case of old trees killed to the ground, I cannot but think that it will be a temporary make-shift at the best, to get a few oranges while the newly-set tree is growing, so that it really makes small difference whether two or half-a-dozen are grown. Never have we had such an opportunity to change our varieties."

How to treat grape vines which are frozen after growth has begun is also a perennial question. Much will depend on the severity of the freeze, and on the amount of growth which had taken place. The following extract* is believed to explain the best method of procedure: "In proceeding to treat frozen vines, it must be borne in mind that the injured parts are of no further use to the plants, and they are very apt to weaken the plant by causing it to lose much of its moisture. The rational procedure, there-

*e Principles of Fruit-Growing," p. 329. 
fore, is to strip off all the frozen shoots soon after the disaster, so as to allow the energies of the plant to divert themselves to the production of new shoots. When the injured parts are soft and small, it is customary to remove them by pulling them off, rather than by cutting them off. In well pruned vineyards the cost of stripping ought not to exceed one dollar an acre."

4. A pruned plant tends to resume its natural habit.

Every plant has individuality. One plant is unlike every other plant. It may be round-headed, conical-headed, very straight or strict, prostrate, and the like. In whatever way or however much the plant may be pruned, it immediately makes an effort to regain its former or habitual shape and behavior; and the more vigorous the plant, the more rapidly and completely does it resume its former state. Vigorous firs and spruces make a new leader without difficulty; the Northern Spy tends to grow erect, however much it is pruned, whereas the Longfield tends as persistently to droop. It is evident, therefore, that the most rational pruning-when fruit and the - welfare of the plant are chief concerns-is that which allows the plant to take its natural form, merely correcting its minor faults here and there. In a pear orchard, for example, there should be as many types or methods of pruning as there 
are varieties of pears. Arbitrary ideals are useful only when it is desired to sacrifice other considerations to mere form and looks. (See Chapter VI:) They are chiefly useful in the growing of plants for certain ornamental effects and when it is necessary,-because of lack of space, or uncongenial climate, or growing under glass-to train to some definite form. It is well to remember that mere handsomeness or comeliness of the plant is unimportant in fruit-growing. On this point, A. J. Downing writes as follows: "Every fruit tree, grown in the open orchard or garden as a common standard, should be allowed to take its natural form, the whole efforts of the pruner going no further than to take out all weak and crowded branches."

One cannot visit a forest without seeing that pruned and injured trees tend to regain their formal stature. Observe how the leader was renewed in Fig. 113, - a tree which was once broken over. The new leader, which sprung from the declined trunk, now continues the bole of the tree. In Fig. 114 several leaders have started from the prostrate trunks, each one simulating the upward growth of the original tree. These remarks will also apply to the roots. It is the commonest notion that a tap-root should not be cut, else the plant will be shallow-rooted; but a new tap-or, what may be better, two or three taproots-arises from the old (from $a$, Fig. 115). The 


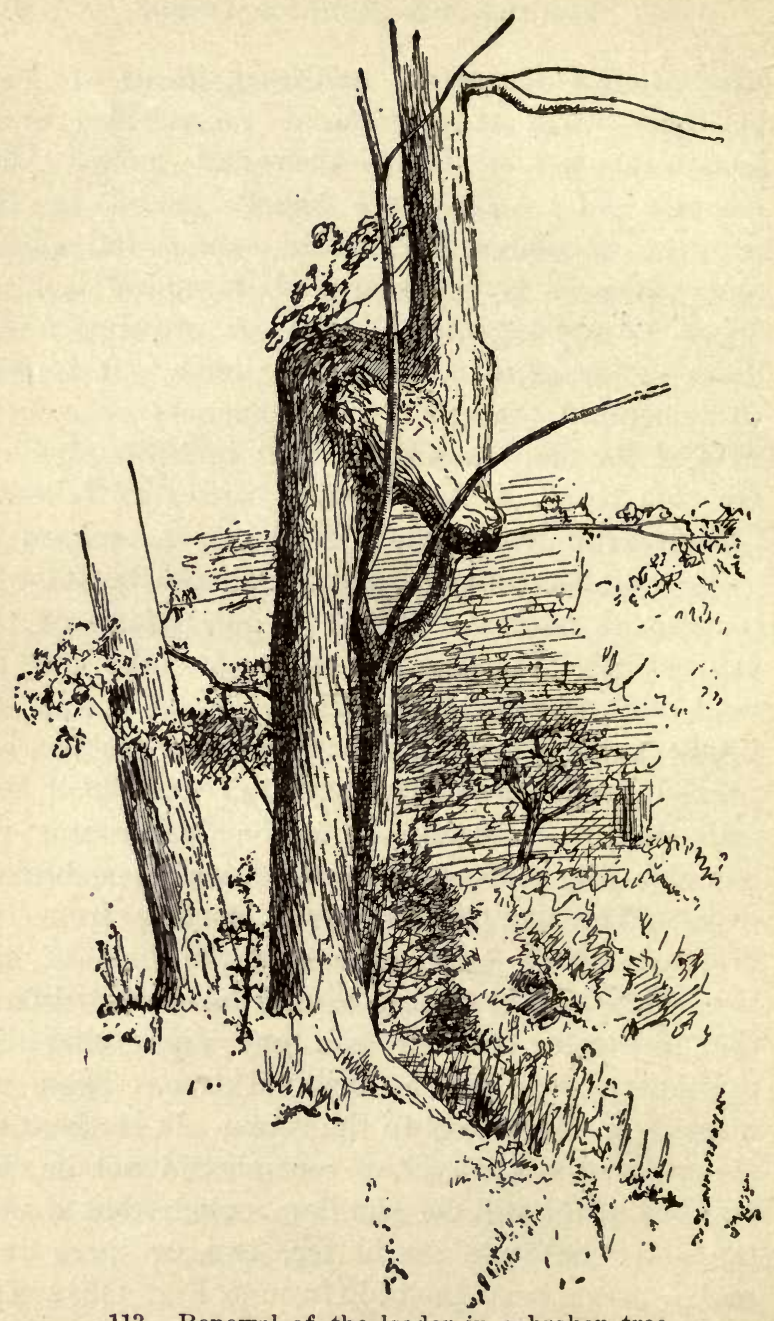

113. Renewal of the leader in a broken tree. 
tap-root is one of the ancestral bogies of horticulturists; and, like the sap, being out of sight, alinost any assertion may be made of it without danger of disproof. The direction of the roots is much influenced by the particular piece of earth in which they grow, but beyond this, roots be-

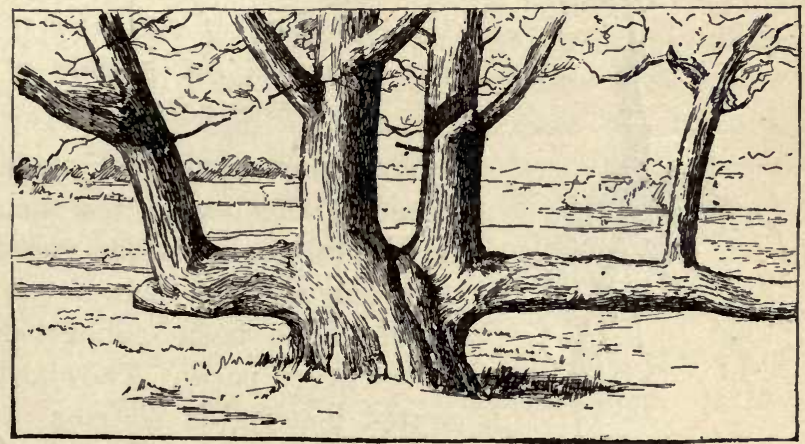

114. Renewal of leaders on trunks which were crushed to the horizontal.

have essentially as branches do, in respect to pruning.

5. The habit of the plant varies from youth to age.

Young plants are vigorous and rapid-growing. They tend to make strong, upright growths. Eventually they reach a limit of stature, and the nearer they approach that epoch the less rapid is the growth. Fruit-bearing tends to reduce growth and to broaden the top. Young pear trees, par- 
ticularly of the Kieffer type, make very long and erect growths, but when bearing-time arrives the growth is less marked and the limbs spread. The treatment of a young tree, therefore, may be very different from that demanded by the same tree when it arrives at maturity.

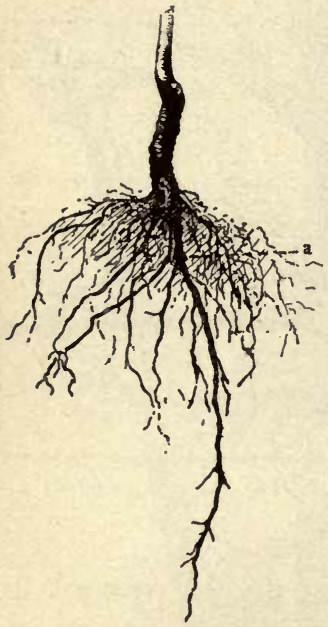

115. Renewal of the leader on the root.

\section{One part of a plant may live at the expense of another part.}

We know that the plant cannot make use of the materials taken in by the roots and leaves until these materials have been elaborated in the green parts. The elaborated material is distributed to every living and growing point. Some of this material is stored, particularly in the fall, and from this stored material the early bloom and growth of spring is partly and sometimes largely made. Strong spring shoots are supplied from other parts of the plant as well as from newly appropriated materials. On this point Sorauer writes* that "it must not be forgotten that at the commencement every

*e Physiology of Plants for the Use of Gardeners," translated by Weiss, 146. 
young shoot draws like a parasite upon the food matter of the older branch; this applies as much to the consumption of water as to the stored-up material."

More than this, one shoot may rob another, and thereby grow the faster. Shoots may be both parasites and robbers. Very vigorous shoots rarely have leaf surface enough to supply their own needs. Being profusely supplied with water, they appropriate building materials which have been elaborated by other branches. Such shoots are watersprouts or suckers. Robbers should be arrested.

7. Watersprouts are results of a disturbed equilibrium of the plant; and the formation of watersprouts is influenced more by the vigor of the plant and the amount of pruning than by the season of the year in which the pruning is done.

This is really a corollary to Section 1 . We know that heavy pruning produces wood, and this extra production may arise either as an elongation of existing shoots or in the origination of wholly new shoots. When these new shoots are particularly lusty, they are watersprouts. Fig. 111 explains the outeome of heavy pruning.

If the reader agrees to the above propositions, then he must admit that the season of pruning 
has a very secondary influence on the production of watersprouts, however confidently he may have asserted to the contrary; for if the plant is not vigorous, and if the root force is not in excess of the top, watersprouts cannot arise. 'To be sure, watersprouts may follow the bending or twisting of the top, but even in this case the equilibrium of root and top is disturbed, as we shall find in Sections 10 and 13.

It is probable that the season of pruning exerts some influence on the appearing of watersprouts. After midsummer, watersprouts cannot arise, as a rule, for growth has then ceased; and if the plant is pruned at that epoch it may have opportunity to re-adjust its energies before another year, and thereby exert its redundant forces rather more in the prolongation of existing growths than in the establishing of new ones. I must admit that this philosophy is difficult of proof (see Section 16), but it is as good an hypothesis as I can formulate to sustain what is a sound maxim of practice, viz., that the operator should not allow the fear of watersprouts to dictate the season of pruning. In fact, watersprouts are a result of pruning as weeds are of plowing, and the likelihood of the appearing of either is in proportion to the preceding neglect. Subsequent pruning is the remedy for watersprouts, as tillage is for weeds. 
8. The tendency of plants is to grow from the uppermost buds; and this tendency is most pronounced in young plants.

We have had ample proof of this in Chapters I. and II. We know that it must be so, too, from the fact that it is the natural outcome of struggle for light and air, and from the fact that were it not so, strict-stemmed plants would grow broad rather than high. If these considerations do not satisfy the reader, let him go out and look.

We may prune in such way as to maintain or augment this natural tendency, or to thwart it. The means of checking it are of two types,hindering the upward flow of sap (as by girdling, notching, bending, twisting, and the like, discussed in Sections 10, 13, and in Chapter V.), and by heading-in. To consideration of the latter category we shall now proceed.

9. The heading-in of young growths tends to develop the lateral and the dormant buds.

That is, headed-in plants thicken and broaden their tops. The objects of heading-in are two,to correct an objectionable habit, and to induce fruit-bearing. The latter consideration is discussed specifically in Section 15.

Inasmuch as the shape which a plant shall assume is largely a question of personal preference, it is impossible always to give good advice respecting the heading-in of trees and shrubs. 
The rational heading-in of trees for the purpose of correcting the habit devolves upon four conditions or factors,-the rapidity or amount of growth, the distance apart of the trees, whether the trees are dwarfs or standards, and the personal choice of the owner of the trees.

In fruit trees, annual growths of three feet or more may be headed-in, particularly if the trees are close together and it is necessary to reduce the size of head. This operation is necessary only with young and unfruitful trees, as a rule, for we have found (Section 5) that mature and fruit-bearing trees rarely grow wantonly. If mature trees are making too much growth, the fundamental remedy is to check the growth rather than to cut it off, for heavy heading-in tends to augment the difficulty (Section 1). The growth may be checked by modifying the tillage or fertilizing of the plantation, unless the excessive growth is due to excessive pruning.

In dwarf trees, it is essential that heading-in be practiced, in order that the top shall not overbalance the root. This question is discussed in its specific aspects in Chapter V.

In general, the matter of heading-in resolves itself into a question of personal ideals. If the owner wants a thick-topped and round-headed tree, heading-in is necessary. If he wants a free-growing, open-centered tree, heading-in should be avoided, except, perhaps, while the 
tree is very young. Although the writer's personal opinions upon this subject may be of no value to the public, they may nevertheless be expounded by a concrete example.

A Kieffer pear tree is shown in diagram in Fig. 116. It is two years set. When planted, it was a mere whip. The first season it sent out four very strong lateral branches, as shown in the picture. At the end of that season the growths were cut back half their length. The second season, two to four shoots started from near the top of each shortened branch. If a similar treatment be given at the end of the second year, still other lateral growths will arise the following year, and the tree will have far too many branches. Three things ean

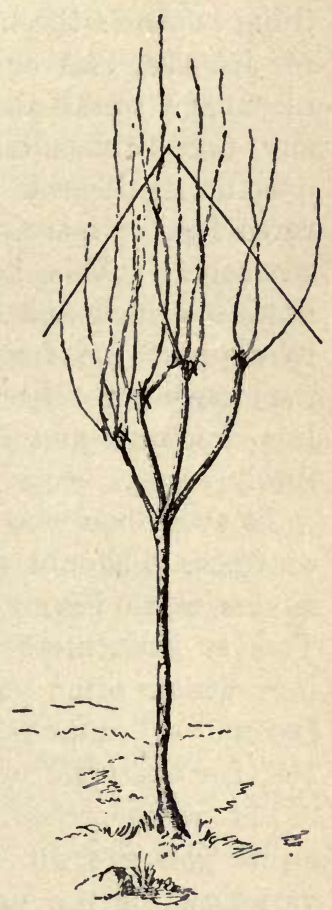

116. Diagram to represent cutting-back of young tree. now be done. The existing branches may be headed-in as represented by the two long lines; some of the branches may be cut away bodily, 
as shown by the several short bars; the treatment may be a combination of these two. One thing is clear: the tree now has too many branches for its size, and some of them (say half of the secondary ones) should be eut away. Whether any further. heading-in shall be done, is a local question. If the tree is making a growth of three feet or more, heading-in would probably be advisable. This heading-in tends to make the branches thick and stocky, thereby enabling them to support the forthcoming crops of fruit. As the tree approaches maturity, heading-in may be less frequent and less severe, and it may eventually cease.

To every one who contemplates the cutting-back of trees, it should be said that heading-in neces. sitates more pruning in the interior of the top This is particularly true of early summer prun ing, which often causes new lateral growths to become so numerous as to be very troublesome (as, for example, in summer pruning of grapes).

The writer, then, believes - in heading-in vigorous young fruit trees of very strong-growing varieties, for the purpose of inducing a stockier growth of the branches and of promoting the early branching of the main or scaffold limbs. As the tree increases in age, the heading-in should be less and less, and should generally cease when full bearing arrives. If the mature tree grows too rapidly, the fundamental correc- 
tive is to withhold tillage or manure. Another motive for heading-in is merely to keep the tree in shape, or to trim into some desired form. This is a matter of a personal ideal, and, although the writer's ideal is counter to this, there is no arbitrary standard by which the one ideal or the other is to be judged. The writer believes that an opencentered and free-growing fruit-tree is generally preferable to a compact-headed and sheared-in tree, but most excellent commercial results, particularly in stone-fruits, are often secured under the latter method of tree-growing. The orchardist should determine his own purpose when he begins to prune his trees, and then carry out his plan systematically and logically to the end. Aside from these purposes, there remain the necessary heading-in of dwarfs (Chap. V.) and the heading-in for production of fruit-buds (Section 15).

10. An obstruction just above a bud or limb tends to produce strong longitudinal growth in that part; an obstruction below it tends to produce a thickening of the part and a quiescent state.

The obstruction below the bud tends to cut off the supply of water, upon which rapid growth largely depends; but the deposition of elaborated materials from the leaves builds up tissue. Since rapid wood growth is hindered because of the obstruction to the upward-moving sap, the 
parts tend to thicken rather than to elongate. We are already prepared for these assertions from the study of girdling (Figs. 95, 96, 97, 107).

A complete obstruction amounts to a severing of the shoot or heading-in; and we have already found (Section 9) that heading-in tends to develop strong growths from the lateral buds. The common methods of obstructing the movements of sap are by girdling or ringing, notching, and bending or twisting the shoot. Girdling by the removal of bark, however, is such a complete obstruction as to starve the part below the girdle, and the statements which may be made concerning its effects do not always apply to notching and bending the shoot. (See discussion in Chap. V.)

It should be remembered that the upward movement of sap takes place in the young or sapwood, and a notch only through the bark does not directly affect this movement. The downward movement takes place in the inner bark, or bast, and a notch only through the bark is, therefore, able to check it. A notch through both the bark and sapwood cuts off both movements and is equivalent, in this respect, to eutting off the shoot.

11. Checking growth, so long as the plant remains strong and healthy, induces fruitfulness.

Very strong growth is usually at the expense of fruit-bearing. Tilling and manuring may be 
carried so far as to make the plant over-vigorous and under-fruitful. Heavy pruning may do the same. Other conditions aside, deep notching of the twig above a bud, tends to make the bud produce a long, woody shoot; notching below the bud tends to make it develop a fruit-spur (see Section 13). Heading-in tends to start woody shoots from the buds near the cut. Girdling just through the bark (or ringing) tends to develop fruit-buds above the wound. If, however, the girdle is below the foliage (that is, on the stem or trunk), new shoots which may arise below the wound must grow at the expense of material stored in the part below the wound; and if such stored nutriment is small, shoots may not be able to start. Girdling by cutting through the young wood tends to develop strong growth below the girdle and to starve and kill all the parts above it.

In a word, a strong supply of root-sap tends to stimulate wood growth; a pronounced deposition of elaborated food tends to develop fruit-buds.

12. Fruit-bearing is determined more by the habitual performance and condition of the plant than by the kind or extent of pruning; it is associated with a quiescent rather than with a stimulated or fitful state; and the habit is more amenable to treatment when the plant is young than when it is old.

Plants vary greatly in fruit-bearing. Some of 
this variation is a matter of individuality. No two trees are alike in this respect any more than they are in form of top or length of life. Some of the variation, however, is due to soil or other environment. It is natural, however, for plants to bear, and when they once come into bearing they should be maintained in that habit by continuous good care. With such plants, any treatment which greatly disturbs their equilibrium tends to break or upset the bearing habit. If, however, through neglect or poor management, plants have never acquired a bearing habit, the grower may experiment, hoping to find something which will bring them into fruit. One type of experiment is to change the management of the land; another is to modify the plant-food; another is to change the method of pruning; another is to give treatment for insects and diseases.

The principle under discussion is the most important one enunciated in this book, from the fact that it advises the fruit-grower to depend more on good, thoughtful and consecutive management of his plants year by year than upon any disconnected, spasmodic or unusual treatments now and then. A good plan moderately worked out is better than a hundred experiments.

Let us apply these reflections to the treatment of a neglected and unfruitful apple orchard. The general advice is to till, fertilize, prune and spray; and this advice is good. The pruning, 
however, has more effect in bringing the trees into shape and in correcting the neglect of preceding years than in directly inducing fruit-bearing. A heavy pruning adds vigor and produces new wood (Sections 1, 3). The orchard is renovated and rejuvenated, and the grower may then begin and carry forward a consecutive treatment, which he should have begun when the trees were planted. After two or three years, the trees begin to steady down, and fruit-bearing should then begin; but fruit-bearing cannot be maintained if the orchard is allowed to lapse into its former condition.

We are now able to see that the common habit of pruning the orchard heroically every two or three years is one of the very best means of keeping the trees unbalanced and upset, and of inducing wood growth, and thereby preventing fruitbearing. All efforts to make plants bear annually must fail unless consecutive good care is given year by year. Light pruning every year is more useful than the same aggregate amount of pruning given only in occasional or even in alternate years.

Over-bearing is itself a disturbance of equilibrium, and is almost necessarily followed by a reaction of under-bearing. This corollary has such important bearing on practice that it should receive careful attention. One extreme follows another, and the oftener these extremes occur the greater is the likelihood that they will become an unremedi- 
able or fixed habit of the plant. It is interesting to note that the habit of alternate bearing is most pronounced in plants of long life, suggesting that the habit is largely, if not wholly, the result of the frequent occurrence of over-bearing while the plant was young. Apples and pears are particularly given to alternate bearing, plums and peaches less so, bush-fruits still less, and strawberries not at all. It is a question, therefore, if any treatment ean set some old orchards into annual bearing. The habit of alternate cropping may have become too fixed to be changed; and, at all events, pruning is only one of the means of overcoming and correcting the habit (see Section 14).

Although it is a cardinal principle in horticulture that checking growth induces fruitfulness, it is only a means of inducing a bearing habit; and when this habit has once been secured, every effort should be exerted to maintain it. It does not follow, however, that trees of slow growth are necessarily most fruitful. The most fruitful apple tree I know is one which has made a very heavy growth from the beginning; but the bearing habit was early induced by good tillage and good feeding, and the extra growth enables it to bear the more fruit. This bearing habit, as I have said (page 163), is sometimes a matter of individuality in the plant, sometimes a question of variety, and oftener a question of good and rational care begun when the plant is young. 
13. All means of obstructing the movement of sap-as notching, shredding, bending, twisting, girdling - are matters of special and local application, and are to be associated more with modes of training than with pruning proper.

This principle is the complement of Section 12 . If the habitual performance of the plant-induced by consecutive rational treatment-determines its usefulness, then the treatment of individual buds and spurs must be merely incidental and special matters. The fact is, that all the advice in respect to notching, bending, and the like, is born of the amateur and garden-culture fruit-growing of the Old World. Whether the authors were conscious of the fact or not, our older American pomological writings are direct offshoots of European small-area practices. The emphasis is placed first on varieties, and always on facts rather than on principles. In vegetable gardening literature the same has been emphatically true, and it was not until Henderson wrote his "Gardening for Profit" that the large-area and commercial American gardening found its tongue; but even Henderson followed the detached and cyclopedic method of arrangement, which is born of a desire for facts and ready-reference rather than for great truths and principles. But the transcendent merit of Henderson's book-which marks an epoch in American horticultural litera- 
ture-is the fact that it caught the rising commercial spirit of the time and threw off the bonds of the amateur.

These remarks will, I hope, put the reader in the right attitude towards all these petty matters of pruning, as it will towards the common fault of putting emphasis first on varieties and other isolated, local and personal facts. If a person must train his pear tree or peach tree to a wall or a trellis, then he must perforce count his buds, force spurs to arise at stated intervals, and be familiar with the refinements of pinching, ringing and notching Grape training is much confused because people do not distinguish that it involves two sets of ideas,-the pruning to remove superfluous wood, and the training into some set form. The number of buds to leave on the cane depends more on the system of training than on the principles of pruning.

We have already enunciated a principle which underlies the results of the notching and bending of shoots (Section 10). Full directions for performing these operations may be found in European writings. It may only be said here that these practices are not generally productive of predictable results in fruit-bearing; but the obstruction to the movement of elaborated sap tends to develop fruit, whereas the obstruction to the movement of crude or root-sap tends to develop wood. 
Notching into the wood above a bud tends to produce strong growth from that bud. Notching just through the bark above a bud, tends to weaken the bud, because the root-sap is not stopped and the elaborated sap is stopped. Notching into the wood below a bud tends to pile up reserve materials at the bud and thereby to induce fruit-bearing. Notching just through the bark below a bud tends to pile up tissue at the bud, but since the root-sap is not cut off, the bud may use this tissue in rapid growth, and fruit-bearing, therefore, may not be induced. (See remarks on page 162.)

Girdling or ringing (practice discussed in Chapter V.) tends to develop fruit-buds above the girdle. Bending the shoot to a horizontal or deflexed position tends to lessen growth, perhaps because of its position, but chiefly because of the kinking or modification of the tissues at the bend.

The following extracts from recent studies by Koopmann* give a clear conception of the effects of notching:

"Notches are made on twigs of one year's growth or more, to influence a particular bud in various ways, or they are

*Karl Koopmann, "Elementarlehren aus dem Gebiete des Baumschnitts" in Landwirtschaftliche Jahrbücher, xxv. (1896), heft 4 u. 5. Koopmann's studies in pruning have been commended by state and society medals. This memoir gives copious references to the German literature of pruning. A most significant conclusion of this extensive study of special methods of pruning-treatments is the following sentence (which the 
made below or above a twig in order to influence the a $\theta-$ velopment of this twig, or of a larger part of a tree.

"Notches in the bark under a bud are equivalent to onethird or one-fourth girdle, and can be made as girdles are. The effect of the operation in eausing the production of fruit is confined, in this case, to a single bud; at least a more extended influence on the parts above it is hard to observe, and probably does not exist, as the hindrance to sap movement is very small, and the root is not essentially drawn into participation. If, however, many such notches or partial girdles are made on a twig and following each other closely, as perhaps in the case of following the spiral of the bud positions, the effect must be more and more nearly that of a complete girdle.

"A notch above a bud into the sap-carrying wood has a contrary effect, as of a one-third or one-fourth cutting-back, which really is done. If the twig were cut off at the same point, a large number of rapidly-growing woody shoots would be expected, particularly if the cutting-back were done in older wood. The deeper into the sap-carrying tissues the knife advances, the more pronounced must be the result. The crude sap taken up by the root and not directly of use in building tissue, gan only do the work of fitting for use the stored reserve materials. For these reserve materials, thus set into solution, there is no other outlet than that they be worked up and used in a leafbud that had remained dormant or in a newly forming adventitious bud below the notch. However, as soon as

student should consider in connection with our Section 12): "Je weniger wir zu schneiden haben am Baum, desto gesunder bleibt er und desto schöner entwickeln sich die Früchte" (The less we are obliged to cut a tree, the sounder it remains and the finer its fruits develop). This sentence must not be taken to mean that Koopmann would discourage pruning, but that it is the part of wisdom to resort to pruning as little as possible, and yet obtain the desired results.

The student will find an excellent account of special treatments of pear shoots and spurs in Opoix's "La Culture du Poirier," Paris, 1896. 
growth has taken place, the organ, whether originally weak or strong of constitution, is stimulated to the greatest activity through the energetic upward-pushing root-sap, and the result of this is, by fall, a wood branch of luxurious development.

"A pronounced notch in very old wood ealls forth either a very rank twig or is without effect. In these cases, it is evidently caused by the absence of a bud or a location for one. If untoward conditions of nutrition are present, it may possibly be due to a defective storage of the necessary reserve materials. This latter supposition it might be diffcult to prove.

"The freezing of buds ean eall forth similar results on the youngest wood, as those just described for old wood on which there are, in general, no buds able to grow. On many plants the buds suffer sooner than the cambium layer of the wood. This is less noticeable on orchard wood than on many natural woods; on the latter, in spite of the strongest flow of sap, the sprouts will be missed under such circumstances.

"The notchings spoken of in the foregoing paragraphs have great importance to the fruit-grower, partly in the shaping of the tree and partly in the production of a balance in the branching (or clothing) of the scaffold limbs of dwarf orchard trees. But the notehes above a bud into the bark, and under a bud into the wood, cannot attain any importance in practice.

"From what is known about the circulation and effect of the sap, it may follow with some degree of clearness that a notch above a bud, which removes but the bark and bast layers, must tend to enfeeble and prevent sprouting, because the upward-moving sap is not stopped at the bud, and the products of assimilation, which are a surplus from the leaves, are withheld from the bud as long as the wound is open. Many practical experiments with this notch gave; however, chiefly two results. In most cases no marked 
change could be determined on the bud. It remained dormant, and thereby passed naturally to its destruction, whether more rapidly than other buds not artificially influenced, we have so far not been able to determine. In many other cases, a sprout did develop which sometimes grew into a long shoot. This appearance made the matter very unclear, until it was noticed that in such eases the euts had not been made with the eare which they require. The bark and bast layers had been removed, but at the same time the younger layers of wood had been injured, as appeared very prominently in longitudinal sections.

"There yet remains the notehing into the wood below a bud, and this, again, must be looked upon as a partial cutting-back. Through such a notch the bud is cut off from the root, and the cambium fluids are piled up at the bud, which is, therefore, too abundantly supplied with reserve materials without being itself caused to grow. The result is similar to the notehing into the bark, only the wound is larger, and therefore takes a longer tíme to heal. The deeper the sap-carrying wood-layers are cut, the less is the tendency of the bud to develop a shoot, and it usually remains as a well-developed fruit-bud without any clearly observable lengthening of the axis, as though sleeping; or it develops a leaf rosette, in order to bear fruit the next year. A notch in younger wood, so executed between two buds that both are equally influenced, results always in a woody shoot from the lower one and a fruit-bud, or a very small fruit-spur terminated by a fruit-bud, from the upper one; the woody shoot is self-active, the fruit-bud seemingly a parasitic creation. As the notch into the bark under the buds, with reference to the production of fruit-spurs, has generally the same effect as a notch into the wood, the latter is superfluous. A slight damage to the outer wood (splintschicht), however, does not in any way lessen the expected result.

"While in the foregoing we have kept in view the effect of 
notches on single buds, an exhaustive treatment of the subject requires a short notice of the influence which similar notches exert on already existing branches. Bark-notches above or below a branch bearing spurs act in a very slight degree on the branch in question; a complete girdle around the base of the branch acts, of course, as an ordinary girdle. A quarter girdle on the under side causes the same effect, but in a small degree, for the stopping of the cambium fluids is almost completely obviated by the possibility of their moving off to one side. An upper cut out of the bark can also have but the same small influence on the spurs of the branch under experiment, as the eut attains the importance of a quarter girdle to the spurs while the branch itself ean in no way be influenced by this bark-notching, because the downward-flowing eambium fluid from the spurs can, of course, be held back, but cannot exert an influence on the branching below the girdle. In practice, therefore, such bark injuries have no importance whatever.

"It is otherwise with vigorous notches in the wood below or above a branch. By means of these notches the root-sap is either cut off or led to these branches. The more vigorous the notching on a spur above one of its branches, the more the latter receive of the crude sap, and the leaves are the more stimulated to activity; the leaves become larger, the internodes of greater length, the number of shoots and leaves is increased, and an increased production of wood is the result. Directly opposite is the effect of a noteh under a branch or twig. A large portion of the supply destined for the assimilating organs is eut off from the branch, and the diminished production of wood is a natural consequence. The sap hindered in its course is carried to other branches in increased quantities, and particularly to one which may be notehed above and therefore already favored, if such should happen to be in the immediate neighborhood of the first.

"With reference to the technical execution of the notches, 
it may be said that they are made in the bark with a knife in simple notch form, or like a half-moon. As to the notch in the wood, the simple notch is used, also a gable-like eut. The latter seems to have a slightly increased effect. In place of the notches, in wood of a greater age than six years, carefully made simple saw cuts, perpendicular to the axis of the spur, or roof-like in form above or below the organs to be influenced-aggregations of buds, twigs or branches-are more desirable, as notches generally cause too large wounds if they are to enter the wood to a sufficient depth. A saw cut made at the proper time in the early spring heals outwardly in from six to eight weeks, although it causes in the wood a not insignificant wound, and can cause necrotic appearances on sickly trees. As, however, the never-healing wood wounds are protected from injurious influences from without by walling over, permanent ill results need not be feared. Weak or sickly trees and stone fruits should be spared from such treatment as much as possible, as every disease-producing organism is given a new ground to occupy by such saw cuts."

14. Pruning may be made a means of thinning the fruit; and thereby it may indirectly contribute to the control of the bearing year of the plants.

Fruit is thinned both by picking it off and by removing the buds which are to bear it. The removing of the buds may be accomplished expeditiously by pruning. This pruning may be the heading-back of shoots upon which fruit-buds are borne or the removal of fruit-spurs. The operator must first know the mode in which the plant bears its flower-buds. Heading-back of the 
annual growth thins peaches, quinces, raspberries, blackberries, black currants, and, to a less extent, red and white currants, and grapes,-all those plants which develop blossom-buds on the wood of the last season, or which have a coterminal habit (page 59) of fruit-bearing. The great disadvantage of thinning fruit by means of pruning is the impossibility of knowing how many buds or young fruits may subsequently be destroyed by cold, insects or diseases. Yet the practice should be more generally in vogue, for in most cases of too heavy prospective fruitbearing the danger can be partially averted by a cheaper means than hand-picking the young fruits. With tender fruits and in cold climates, this thinning by pruning should be delayed until danger of winter-injury is thought to be past.

The second part of the proposition is very important,- the fact that the energies of the tree can be conserved by thinning the fruit. This is really a corollary of Section 12. It is necessary to discover just how this conservation comes about. We have observed (see Figs. 13, 14, 15) that there is an alternation in fruit-bearing on the individual spur because the demands made by the fruit are so great that a fruit-bud cannot develop the same year. In the year of fruitbearing, therefore, a small leaf-bud develops to continue the spur the following year; and in this following and barren year, a fruit-bud is devel- 
oped for bearing the succeeding year. Alternateyears' fruit-bearing, therefore, is largely a question of food supply. If, then, we are to make the tree bear every year, we must supply more food materials to the tree (a subject which is not germane to this treatise) or remove part of the fruit. Removing the fruit affects chiefly the spur on which it is borne; in large fruits, as a rule, one spur, or one branch of a spur, matures one fruit: therefore, it must follow that if thinning the fruit induces annual bearing in some spur-fruits, it must be because one spur is made to bear one year and another spur to bear another year. That is, there is an alternation in fruit-bearing on the spur, the same as before, but the bearing year of part of the spurs is changed by means of the thinning. It would seem, therefore, that the thinning will have most effect in inducing annual bearing when it removes all the fruits from certain spurs, thereby allowing these spurs to bear in the alternate years. But it is probable that no amount of thinning can produce an annual-bearing habit unless the plants receive other necessary consecutive good care. It is a question if it would not be advisable to change the bearing year of entire plants, thereby allowing part of the trees in an orchard to bear one year and the others to bear the following year.

It is a fact that the bearing year of fruit trees 
can often be changed by removing the crop very early in the season; but it is also true that the trees tend to revert to their accustomed habit, and it is probable that this reversion is the more rapid and the more complete the older the tree (page 166) and the more indifferent the general treatment of it. In fruits which are most systematically thinned (either by picking the fruit or by means of the accustomed methods of pruning), annual bearing is the most pronounced. The grape and peach are examples. Of trees which are not habitually thinned, it seems as if annual bearing is a quality of short-lived species more than of long-lived species, as suggested on page 166. In the short-lived species, as the bushfruits, there is not sufficient time, perhaps, to allow such habits to become thoroughly fixed.

Bearing in mind the alternation in fruit-bearing in the spurs in Figs. 13 and 14, let us consider what might happen if the fruit were removed when very small. Fig. 117 tells the story. In this case, the very young fruit was removed, and two blossom-buds have developed the same season. In this spur the bearing year is changed. We also found that the bearing year was once changed in the pear spur shown in Fig. 19. I must hasten to say, however, that this change in the bearing year does not always follow the removal of the flowers or young fruits, for very much depends on the habit of the tree, as well as 
on its general thrift and vigor; but it is safe to say that removing the flowers or very young fruits from a spur or branch tends to cause that part to bear the following year.

The fact that work is expended in the bearing of fruit may be understood if one examines the swellings on the spurs or fruit-bearing twigs of

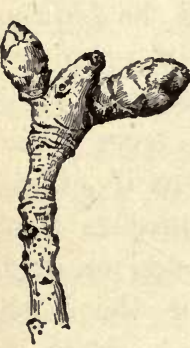
pears. In Fig. 118, these swellings are seen at $a a$. The scars at the ends show that fruit was borne there. In the transfer of food to this point and the arrest of longitudinal growth, a building up of mechanical tissue has taken place; and it is probable that the long 117. Pear fruit- growth of the lateral branches buds resulting (which, in this case, bear only leaffrom the re-buds) has been made possible by the moval of fruit. Natural size. excess of nutriment. The reader must not confound these swellings with the thickening due to mere arrest of longitudinal growth, as shown in 3, Fig. 61 (which is also mentioned in Section 15).

Chemical tests show that these swellings (like Fig. 118) are not storage reservoirs of plant-food. My colleague, Mr. A. L. Knisely, has made examinations of these swellings for me, and found that the starch-like contents of the swellings were less than that of vigorous and normal shoots of the same age. In normal twigs, the moisture was 
found to be 50.94 per cent; in swellings, it was 59.20 per cent. In both samples, the contents (as starch, dextrine, pentosans, and the like) were ealculated as reducing sugar. In normal winter twigs, the reducing sugar was 28 per cent; in the swellings, at the same date, it was 27.1 per cent. Calculated to fresh substance, the percentages were

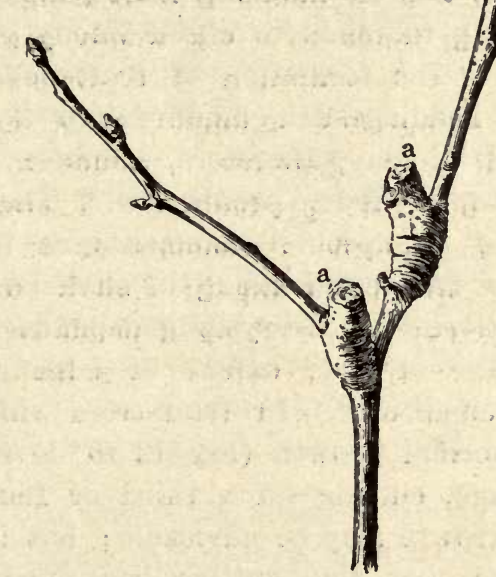

118. Swellings on pear, resulting from fruit-bearing. Half size.

13.74 for the twigs and $\mathbf{1 1 . 0 6}$ for the swellings. These tests still further show that these swellings are mechanical tissue, resulting from the strain of fruit-bearing, and that they are not to be 
looked upon as conducing in any way to subsequent fruitfulness of the plant.

15. Heading-in induces fruitfulness by checking exuberant growth and by encouraging the formation of short lateral growths.

In Section 9 we have discussed effects of heading-in on the growth of wood and the form of the top of the plant. We are now enquiring what effect it has in inducing fruit-bearing. So far as heading-in tends to check woody growth, it conduces to the formation of fruit-buds; but very heavy heading-back amounts to a heavy pruning and it may, therefore, conduce to the very opposite of fruit production. Therefore, there can be no specific statements as to how much or how frequent heading-in shall be to induce productiveness. Everything depends on the vigor and age of tree, extent of cutting, and other local conditions. In fruit-trees which are making a normal growth (say 12 to 20 inches) at bearing age, cutting off a third or fourth of the annual growth may be advisable; but it must be considered that this cutting-back may have other objects than the inducing of fruit-bearing, such as thinning the fruit, keeping the tree in shape, preventing dwarf trees from outgrowing their stocks, and keeping the stature small in crowded plantings. Heading-in to induce fruitfulness must not be confounded with the head- 
ing-in of young trees to check too long and slender branches. It is doubtful if an occasional heading-in has much effect in developing fruitbearing. It should no doubt be an accustomed practice, if employed at all for this purpose.

There is no question that heading-in the terminal growths tends to develop short spurlike branches in the interior of the top; and the tendency of such branches is to develop fruitbuds. However, it is a question if this result is not an advantage to training rather than to the ultimate productiveness of the tree. That is, it concentrates the fruit in a smaller space; but if the top is allowed to take its natural course, it will probably develop as great prolificacy as if it is headed-in. It is often a distinct advantage of heading-in that it tends to develop fruit-bearing early in the lifetime of the plant. As a matter of practice, the writer believes that the value of heading-in as a means of inducing fruit-bearing has been overestimated.

16. The season in which pruning is done has some influence on fruit-bearing, for winter pruning tends to produce wood, whereas summer pruning does not.

Plants which are cut in midsummer, or later in the growing season, seem to have the power to adjust themselves to the new conditions during the same season (page 156). That is, the 
effect of the pruning is very largely taken up before the return of spring, which is the season of growth. Plants which are pruned in winter, or any time during the dormant period, expend their redundant energy at once in growth, upon the return of the growing season. Aside from all this, the removal of leaves during the summer reduces the working or elaborating surface, and thereby tends more in the direction of starving or weakening the plant than in feeding or strengthening it. It is well known, for example, that watersprouts are less frequent following summer pruning than following winter pruning. These remarks are necessarily very general, and the condition of the plant and amount of cutting may be expected to obscure results which might: be expected to transpire in typical or selected cases. If the pruning is such as to check wood growth without perceptibly weakening the plant, fruit-bearing is generally promoted; and herein lies the value of summer pinching of strong or leading shoots. In respect to the proper time for pinching, Sorauer remarks :* "The greatest success will attend the process if the pinching takes place just at the period when the buds have still sufficient time to swell up and become stored with food material, but when the supply of water begins to diminish, so that the upper

*e Physiology of Plants," 138. 
buds do not grow out into long laterals. * * * To prevent disappointments, we state emphatically, - as the practice is very common, - that no fixed rule can be laid down for the commencement of summer pruning. Trees may even be pinched to death. The favorable time for this operation depends on the climate, the soil, the variety and even upon the individual characteristics of the plant."

The reader should know that the effect of this pinching depends very much on the general habit and vigor of the plant, and that it is very difficult to predict results unless the particular plant has been under training for some time (and preferably from the time it was planted). The best results in pinching the tips of shoots are obtained when plants are trained to definite forms, as on walls, cordons, in glass houses, or in arbitrary pyramids or other geometrical figures. The practice is, therefore, of little use in the commercial fruit-growing of this country.

The operator must not expect fruit-buds to form in the same year in which pinching or heading-back is done, although such immediate results are sometimes obtained. If heading-in is done before active growth has ceased, mischievous lateral growths may be expected (Section 9); if done after the leaves have ceased to be active, little if any results may be antici- 
pated. Theoretically, the proper time is just as growth begins to cease, which, in the North, is in early summer The shoot in Fig. 12 (Stark apple) was cut back in winter, and the following season the fruit-bud $a$ was formed. This was a comparatively weak shoot on the lower part of the tree. Had it been a strong terminal twig, the bud $a$ would probably have produced a long shoot. The injury to the shoot 3 in Fig. 61 (at $e$ ) occurred about midsummer. The two lateral buds received an extra food supply and gave rise to late-season branchlets. The parts became greatly thickened, but only leaf-buds formed. It is probably correct to say that heading-in and pinching exert more marked effects, in inducing fruit-bearing, in subsequent years and in proportion to the persistency with which they are practiced, than in the very year of the operation.

Before we can suggest perfectly rational treatment to produce fruit-buds, we must know at what period in the formation of the winter bud the differentiation between the leaf-bud and the blossom-bud takes place. This question cannot be answered with our present knowledge. In its very earliest stages, it is probable that the winter bud is undifferentiated; but its character is probably determined before it becomes conspicuous on the branch. At all events, it seems to be settled, as a matter of practice, 
that any treatment designed to produce blossombuds must be made before midsummer if it is to have effect in that year. In general, however, as has been said, the effect of treatment is to be expected in the year or years following the treatment, rather than in the very year. in which it is applied.

17. The effect of pruning, as well as the necessity of it, depends greatly upon locality and climate.

Not only does the vigor of plants differ widely in different places, but there are local dangers to be avoided. In the coldest parts of the country, winter-made wounds are the means of depriving the tree of much of its moisture (page 143); in such regions, plants need the protection of a continuous cover of bark. In the hot and dry interior regions, sun-scalding often follows very heavy pruning, and there has thus arisen a feeling that trees should not be pruned on the Plains. It is undoubtedly true that in those regions outdoor plants need less pruning than in humid climates, but trees which need to be so heavily pruned that they are injured by sun-scald are usually those which have been neglected in the beginning. On this subject Card writes* as follows:

"Shall we prune fruit trees in the West? To the east-

*Fred W. Card, "Notes on Pruning", Bull. 50, Nebr. Exp. Sta. 1897. 
ern man this will appear like a foolish question, and he will at once say, Why, yes, of course; prune fruit trees everywhere. To the western man it will not appear so foolish; indeed, many men upon the Plains would say No! in answer to this question. Where is the trouble? Plainly a difference in conditions. The eastern fruit-grower has learned by experience that pruning is an essential part of his method of treatment. The western grower, on the other hand, has not only found that he can produce good fruit without pruning, but has sometimes found injurious results from it. He may, therefore, if his experience is somewhat limited, jump at the conclusion that all pruning is to be avoided. Some of the reasons for pruning which apply in the moister climate of the eastern states lose their force wholly, or in part, upon the Plains. The eastern grower finds it necessary to thin his trees and admit light and air to produce fruit of high eolor and good flavor. The western man, on the other hand, finds that, under his conditions of intense sunlight and low humidity, fruit will develop color well regardless of such precautions. The eastern grower, if he neglects this, may find his fruit suffering from attacks of fungous diseases; but in general, fungi are less troublesome in the dryer elimate of the Plains, so this reason likewise loses its force.

"Yet there are reasons for pruning which are worthy of consideration, even in Nebraska. It is frequently essential to correct bad habits of growth in young trees, and this occurs as often in one climate as in another. Then, too, a tree which has come to maturity may attempt to do more than it can perform, so that it becomes necessary to thin the fruit. This, in part, can be done by pruning. In the case of small fruits and grapes it is wholly so done, though with trees additional measures are often needed. Still another reason would make itself evident to any one who would pick fruit for a short time in 
some of the trees which may be seen in Nebraska. Picking fruit is not an easy task under the best of conditions, and when the tree is so full of limbs and suckers that it becomes almost inaccessible, the work is doubly aggrayating. Pruning is needed in Nebraska as well as in New York, but the methods employed, or at least the measure of wood which is cut away, will need to be varied. In general, it should be much less severe in the western states than in the Atlantie states. The main thing needed is to watch the habit of growth of the young trees, to prevent the formation of undesirable and crowding limbs, and to remove occasional suckers and water-shoots which may spring out from the trunk and base. of the branches as the tree gets older.

"The top of the tree needs to be kept more dense than in moister elimates. The fruit itself is much less likely to suffer from shade than from exposure to wind and sun. In the eastern states it is necessary to keep the lower limbs well up from the ground, or the fruit produced upon them will be lacking in color and flavor. In the West this is an unnecessary precaution, and low-headed trees are much in favor because they are believed to suffer less from the wind and to protect the bodies of the trees from sun-scald."

The different ideas to be followed in two parts of one state are set forth by Balmer:*

"Climatic conditions will largely determine what practice we shall adopt in pruning our fruit trees. In a state like Washington, where such dissimilar climatic conditions exist as between the regions west of the Cascades and the regions east of the Cascades, no practice can be laid down that will be applicable to both sides of the range. What would be a perfectly proper practice west of the

*J. A. Balmer, "Pruning Orchard Trees," Bull. 25, Wash. Exp. Sta., 1896. 
Cascades, where the sun is obscured a large part of the year, and where the moisture conditions are conducive to a large wood growth, would be almost suicidal on the east side of the range, and vice versa. Therefore it will be necessary to adopt a different practice for each side.

"Let us first observe the conditions prevailing in Eastern Washington. Here we have a long, dry summer, with a fierce, scorching sun and strong, drying winds, with a maximum rainfall of probably less than eighteen inches per annum, followed by a severe winter with fluctuating temperature and sudden changes. In portions of the fruit belt there is barely enough natural moisture in the ground to sustain a tree. Under these conditions who can wonder that trees on the east side come to maturity at an early age, and produce fruit at a time in their lives when they ought to be making wood growth and establishing a strong, healthy frame for future usefulness. And yet conditions which at first sight would seem totally unfitted for the production of healthy trees and fine fruit are, with the aid of intelligent cultivation and judicious use of water, made to produce abundantly of the choicest fruits of the earth.

"There is no question in my mind as to what is the proper method to adopt in pruning our fruit trees on the east side of the mountains. We must prune in winter, and prune hard. The tendency of all our young trees is to run to premature fruiting, cherries carrying a erop of fruit at two years old, and pears and apples bearing full crops at five and six years old. To overcome this tendency in our trees we must practice a system of pruning that is conducive to wood and leaf growth, and to discourage all forms of summer pruning and pinching. The practice of allowing nature to have her sway in our orchards has been tried and found wanting. A tree left to nature's way will soon become a brushpile in the air.

"The above practice is recommended for all regions east 
of the Cascades. Trees on the west of the mountains should be treated a little differently. In most sections on the west side, and especially in the warmer valleys, trees make an extraordinary wood growth. It is no uncommon thing to find young prunes and cherries making a growth of six to ten feet in a single season. The excessive moisture in soil and atmosphere, and the mild climate, are conducive to this rapid growth. Trees grow late in the season, and there is some difficulty in securing thoroughly ripened wood. To eut back severely in winter aggravates the evil, and more and longer wood is the result. The way to check this excessive growth is to resort to summer pruning and pinching and even to root-pruning.

18. The healing of large wounds is influenced chiefly by the kind of plant, the general vigor of the plant, their position on the plant, the length of the stump, and the character-as to smoothness or roughness -of the surface; other factors are the healthfulness of the wood, and the season in which the cut is made.

These questions have been considered in detail in Chapter III. Theoretically, the best time to make the cut, so far as healing is concerned, is in the early part of the growing season, for the healing process then begins without delay; but other factors exert much greater influence than the mere season of eutting. Wounds on pomefruits (apples and pears) heal more readily than those on stone-fruits. Those on the common shade and timber trees (except pines and spruces) usually heal very quickly. 
19. Dressings do not hasten the healing of wounds, but they allow the healing to progress unchecked because they may prevent disease; a good dressing, therefore, is one which is antiseptic and durable, which affords mechanical protection, and which does not itself injure the tissues.

The various questions involved in this statement have been somewhat fully discussed in Chapter III., in which it was concluded that lead paint is perhaps the best single dressing or preservative for wood wounds.

20. The best pruning is that which results from a definite purpose or ideal, and which is founded on a consideration of fundamental principles and a careful study of all the local conditions; and special pruning-treatments designed to promote fruitbearing are of secondary importance to the consecutive good care of the plant. 


\section{PART II}

\section{THE INCIDENTALS}





\section{Chapter V}

\section{SOME SPECIFIC ADVICE}

Having now traversed the fundamental problems involved in the pruning of plants, we may give attention to various details of practice. These details are largely personal opinions, and are, therefore, of restricted application; for practice must vary with every personal ideal and every environmental factor. The advice in this chapter is not given with the expectation that the reader shall follow it literally, but it may suggest some of the methods which may be employed to secure given results. The reader is again urged to bear in mind the distinction between training or trimming the plant into some desired form, and pruning for definite results in the welfare of the plant and in fruit-bearing.

\section{THE FORM OF THE TOP}

Much of the discussion respecting the best way in which to prune young plants is confused beeause the disputants are not agreed upon the form of top which it is desired to produce. It goes without saying that different treatments must be given two trees if one is to have a high head and 
one a low head; and yet persons give the most dogmatic advice upon the pruning of newly-set trees, without once stopping to consider what form or height of tree is to be ultimately obtained. It will be well, therefore, to have a brief discussion of the form of the top before considering the details of practice.

The form of the top is largely a matter of personal preference, as we have already said; but there are distinct arguments in favor of various ideals. It is not the province of this book to consider these arguments, for they are not primarily matters of pruning. The book desires only to aid the operator in working out his ideal, not in deciding what ideal is best for his conditions. Yet a few general hints may be given.

The mental ideal has freest scope in ornamental plants, for questions of profit and loss enter very little into the problem. As a question of art, it should be said that the natural habit of the plant is, in nearly all instances, far better than an artificial or geometrical habit. This is both because of the greater intrinsic beauty of a freegrowing tree or shrub, and because the plant is less important for its own sake than for the part it contributes to the general foliage-mass of the place. These questions are somewhat fully discussed in "Garden-Making." The satisfaction derived from a formal bush resides in the perfectness of its formality. As soon as it becomes 
ragged, it is unkempt, and is neither formal nor free. The suggestion is, that trees and shrubs which are trimmed into formal shape should be sheared several times during the growing season, not in winter alone. Fig. 119 illustrates the point. The bush was sheared in winter. The operator wanted a flat-topped and thick-topped specimen ; but he had such a specimen only in winter, for the bush began to cover its shame with the first opportunity of spring, by making long and free growths.

In this case (Fig. 119), therefore, the strong new

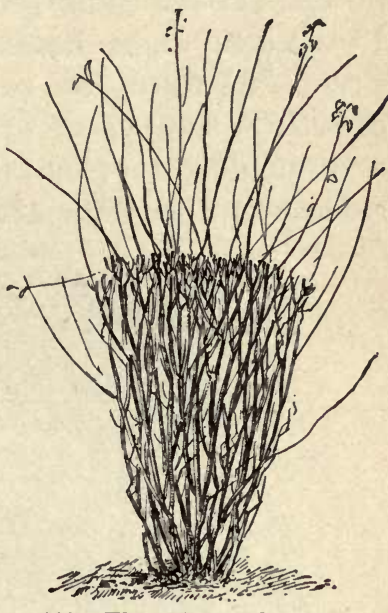

119. The winter-sheared bush. growth is a blemish, because the operator did not want it (although it should be said that he took the very best means to secure it by pruning heavily in winter). In a fruit-tree, however, a similar growth might not be a blemish, because the object of heading-back in this case is not to produce a definite form of tree, but to keep the plant within bounds, and to modify the fruitbearing habit. Fig. 120 shows headed-in plum trees as they look when first leaved out. Fig. 121 
shows the appearance in fall, after the season's growth has taken place. These pictures are made from selected and typical trees, as grown by a man in the famous plum-growing region at Geneva, New York, where heading-in is much practiced. From one-third to two-thirds of the annual growth is sheared off every winter.

In distinction from these plum trees, let the reader consider Fig. 122. This picture is made

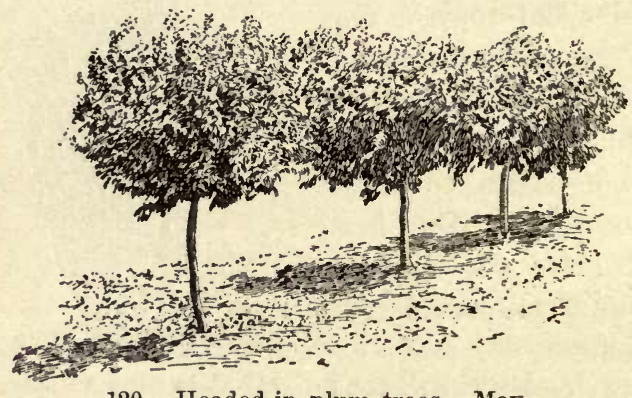

120. Headed-in plum trees. May.

from a typical plum tree as grown by a New York man who does not head-in his trees. Both these men are successful plum-growers. The trees bear as well in the one case as in the other. Shall I head-in my plum trees? That depends upon whether you want trees like Fig. 120 or Fig. 122, - that is, upon whether you want to head them in or whether you do not!

The relative merits of high heads or low heads for fruit trees are always in dispute. This con- 
troversy is partly the result of confusion of ideas, and partly of differing mental ideals and of varying cliınates. Two factors are chiefly concerned in these disputes, - the question of ease of cultivation, and the question of injury to the trunk by sun-scald. It is the commonest notion that short trunks necessarily make low heads, and yet anyone who can see a tree should know better. The number of trunks which a tree has, does not determine the direction of the leaf-bearing limbs. The tree in Fig. 123 can be worked around as easily as it could be if it had only one long trunk. In fact, branches which start high from a trunk are very apt to become horizontal and to droop. There must be a certain number of main or scaffold limbs to form the head. If these limbs are taken out comparatively low, they may

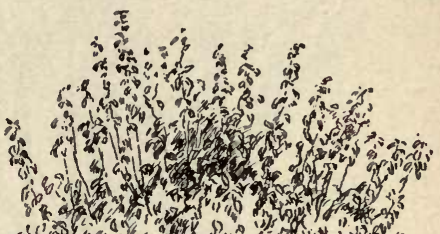

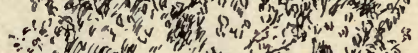

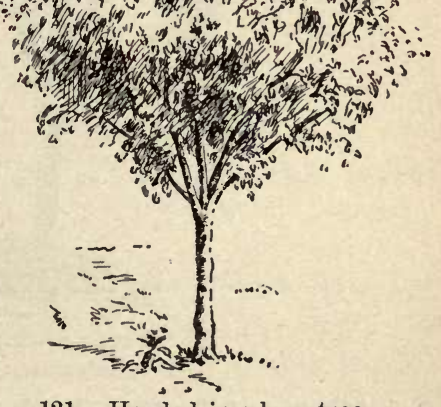

121. Headed-in plum tree. September. be trained in an upright direction and hold their weight and position. If they are started out very high, they will not take such an upright direction, 
because the tree will not grow beyond its normal stature. High-trained trees are often practically lowest-headed. Tillage is as easy about such a tree as Fig. 124 as about one like Fig. 125; and

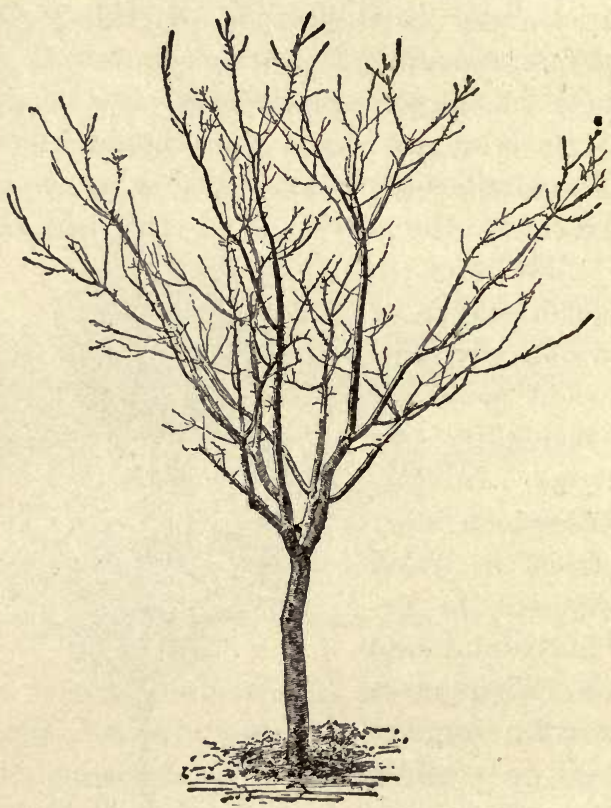

122. Free-growing plum tree.

the former will often hold its shape the longer if properly pruned. The question of the relation of modern tillage of orchards to low heads is discussed in "Principles of Fruit-Growing."

In regions where tree trunks are apt to sun- 
scald, the bodies should be short. In nearly all regions outside of the Atlantic States this danger threatens, and it is often serious on the Plains and westward. Nearly all writers urge short. bodies and low heads for the Pacific Coast. In the Plains regions it is a common practice to shade the trunk by some artificial means, but it is a question if low-heading would not be a better practice.

What length of trunk constitutes a high head or a low one, depends upon the species of tree under consideration. In apple trees it may be

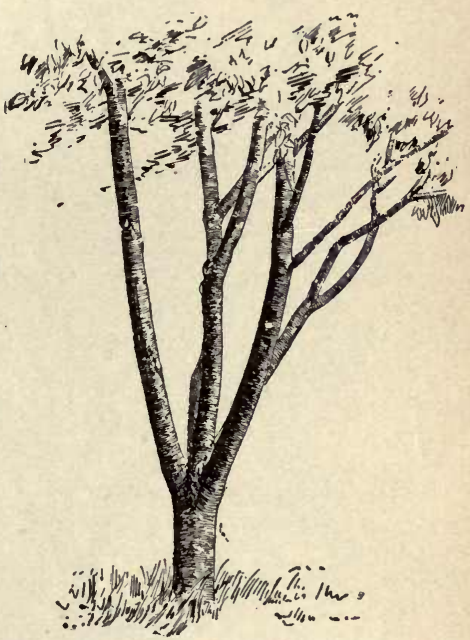

12:. A high-headed short-trunked tree. said that a top is high when the branches start not less than five reet above the ground, and low when they start not over three feet. Pears, peaches and plums are seldom started as high as five feet. The question of high or low heads is largely one of climate, methods of tillage to be employed, and kind of tree; but the writer believes that in the East the commoner error is to train too high rather than too low. 
Wickson*, of California, protests strongly against the prevailing fashion of high-topped trees: "Low heading has for us all the advantages for which this practice is approved in other

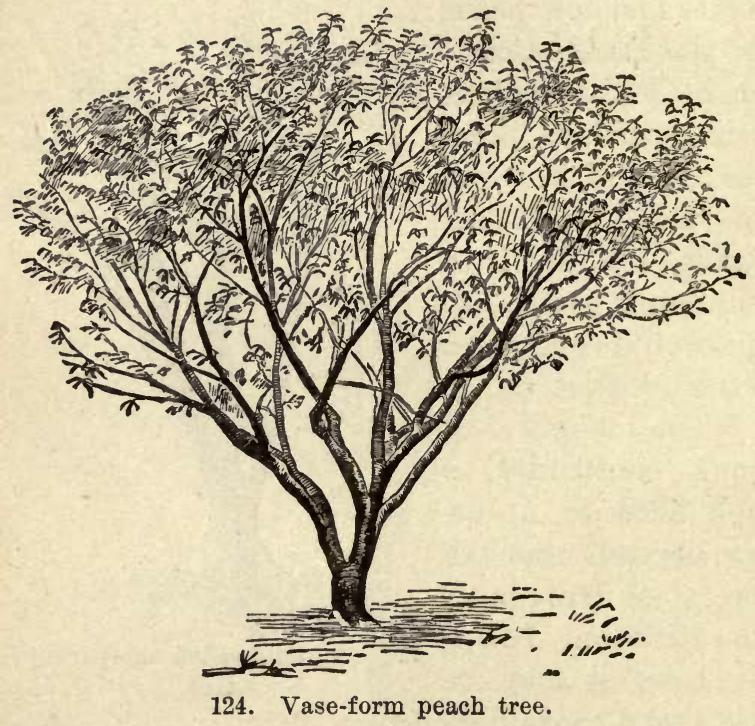

parts of the world; viz., accessibility of fruit and ease of pruning, symmetry and solidity, and consequent decrease of danger from high winds, and greater facility of approach to the trunk with the horse in cultivation. This last point has been contested on our own soil, for experi- 


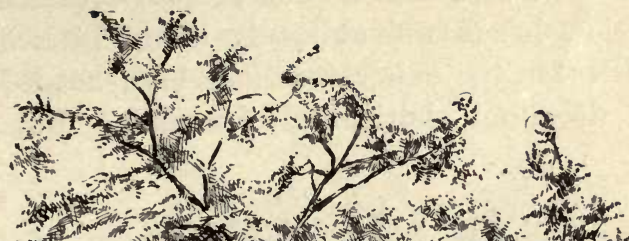

H. an-

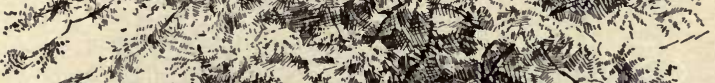

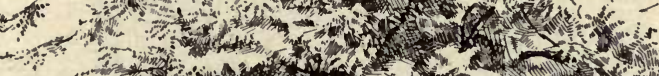

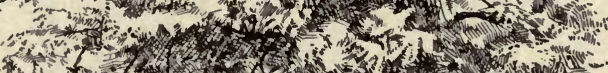

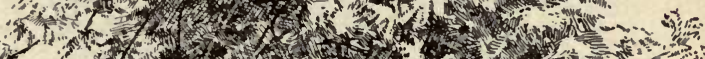

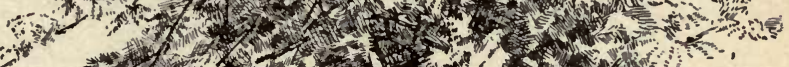

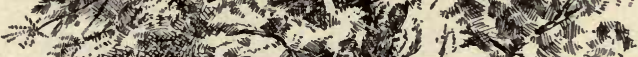

$\Rightarrow$ 3.

in

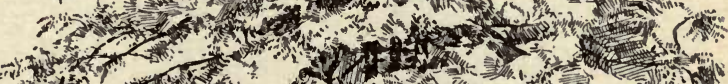

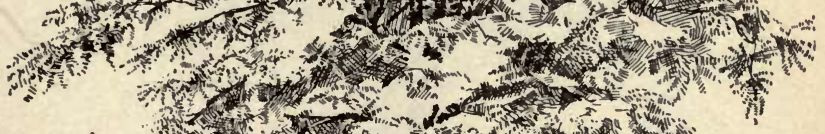

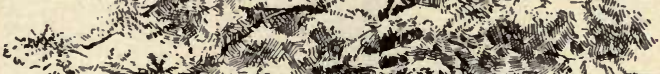

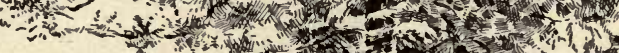

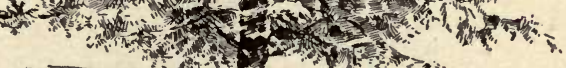

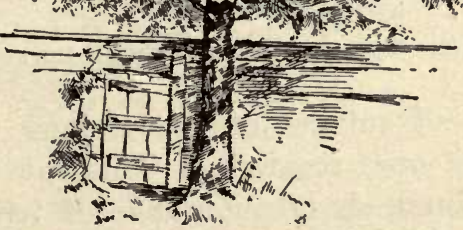

125. A long trunk does not necessarily give a high top. 
ence has demonstrated that properly trained trees with low heads and obliquely-rising branches are handier for the cultivator than high-headed trees with drooping, horizontal branches. But these

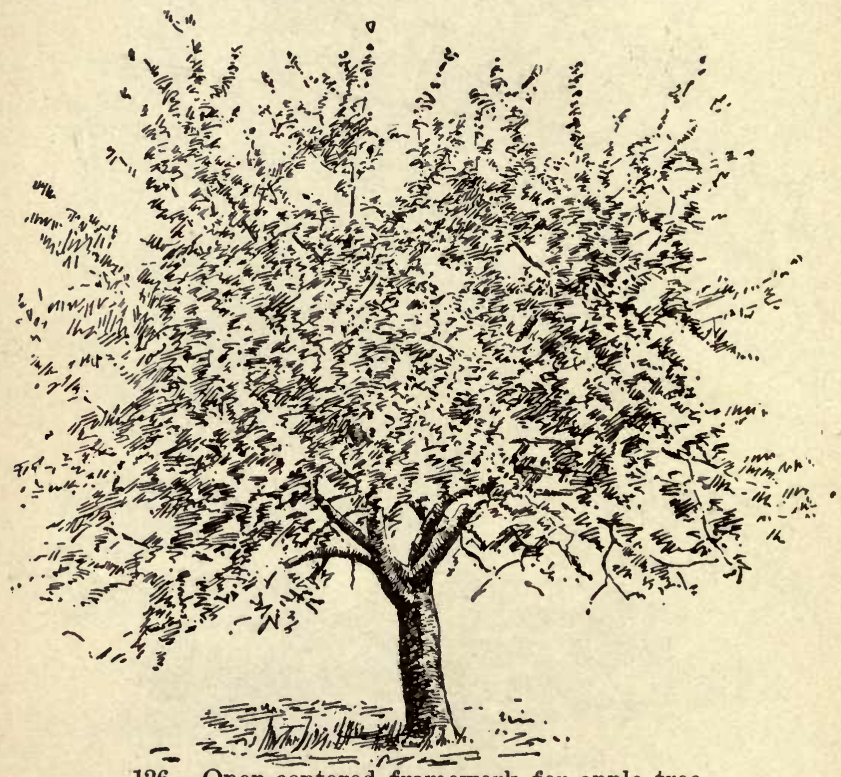

126. Open-centered framework for apple tree.

general advantages of low-trained trees are not the chief ones secured in California in low-heading. Hundreds of thousands of trees have been destroyed by the exposure of a long, bare trunk to the rays of the afternoon sun. The sunburned sides have given the conditions desired 
by borers, and destruction has quickly followed. Sometimes young trees have not survived their first season in the orchard, because of burned

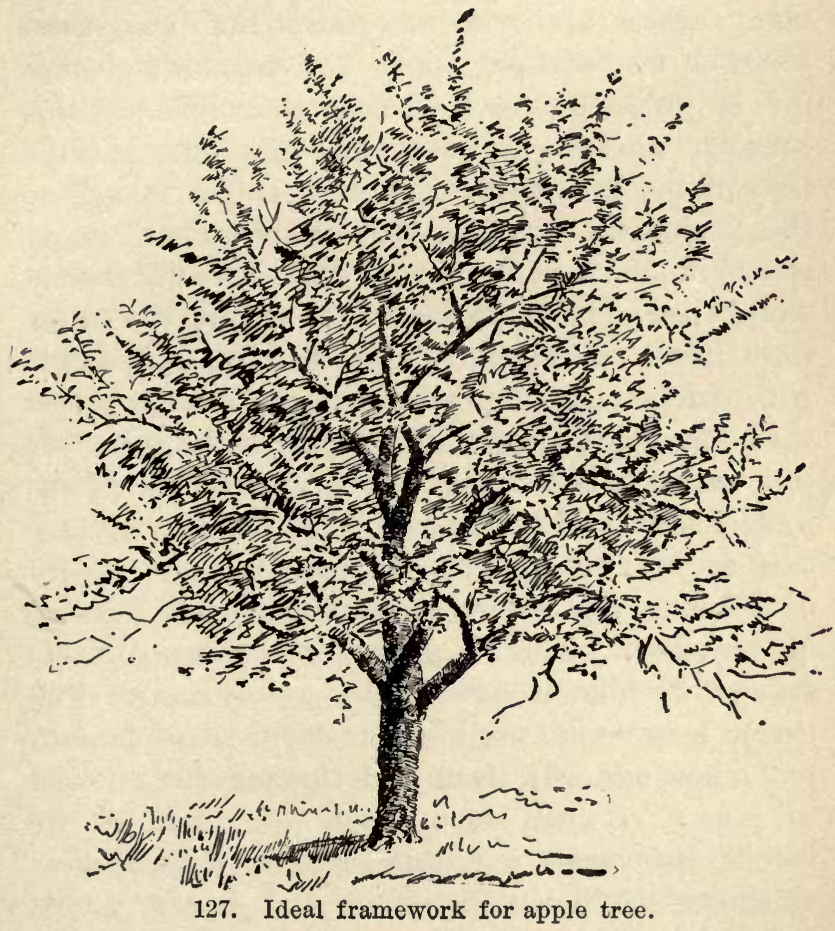

bark; or this, with the added injury of borers. It is found by California experience that the growth is more vigorous in the branches when they emerge near the ground." 
The number of main or scaffold limbs should be decided upon, in a general way, before pruning of the young tree is seriously begun. Too many limbs are more frequent than too few. Four or five scaffold limbs are usually sufficient for an orchard tree. The operator should also consider whether he wants the trunk to continue beyond the branches. Figs. 126 and 127 suggest the problem. In Fig. 126 is shown a "single story" apple tree, and in Fig. 127 a "double story" tree. It is impossible to secure the latter form in all varieties of apples, and rarely possible with peaches, but it is nearly always easily secured with pears. Wherever such form can be obtained, the writer believes that it (Fig. 127) is to be preferred. It is then possible to secure a greater surface for fruit-bearing, the load is more evenly distributed, and there is less danger of splitting of crotches. This high-centered framework is secured by allowing the leader to continue. The leader may be cut back when the tree is planted, but a new one will start, and this may be allowed to grow. It will soon reach the limit of its height and make a normal system of branches, as shown in Fig. 127.

Two most important points in the general pruning of fruit trees are, (1) to determine upon the proper framework for the top, and (2) to thereafter keep the tree open and shapely, allowing it to continue its natural habit of growth. 


\section{HOW TO TRIM YOUNG PLAN'TS}

The general questions involved in the pruning of woody plants when they are transplanted are discussed in "Principles of Fruit-Growing"; and that account is here reproduced, after the study of which we may proceed to a consideration of various specific applications.

"So far as the root is concerned, it is advisable to cut away all roots which are broken or badly torn. These should be cut off just back of the injury. It is the custom to eut off the ends of all roots of the size of a lead pencil or larger, for a clean, smooth wound is supposed to heal quicker than a ragged one. These cuts are made from within outwards, so that the wound is more or less slanting across the roots, and so that it rests firmly upon the ground when the tree is set. When the tree is planted, all the roots should be straightened out to nearly or quite their normal position. If it is found that one or two roots run off to an inordinate length, they may be cut back to correspond somewhat with the main root system.

"Perhaps half the entire root system of the young tree is left in the ground when it is dug. It is, therefore, evident that the top should be cut back to a corresponding amount. In fact, the top should be more severely shortened-in than the root, because the root, in addition to being reduced, is also dislodged from the soil, with 
which it must establish a new union before it can resume the normal activities. Trees which are allowed to carry too much top when planted may fail outright to grow; or if they start, they are very likely to be overtaken by the droughts of summer. Even if they live, the growth is generally small and uncertain, and the tree may fall a prey to borers or a victim to high winds. On the other hand, trees may be trimmed too severely when set. Except possibly in the case of peaches, it is probably unwise to trim the trees to a mere pole; and with peaches, it may be better to leave spurs with at least one bud than to trim to a whip. There should be a number of strong, bright buds left upon the top, for these are the points where early and active growth begins. These buds are upon strong branches. If they are removed, the weaker or half dormant buds upon the main trunk or low down in the erotches must take up the work, and these start slowly and often feebly.

"There are two general methods of trimming the tops of young trees at planting time. One method cuts back all the branches to spurs of from one to three buds; or sometimes, particularly with dwarf pears set when two years old, the side branches may be cut entirely away, leaving only the buds on the main stem or trunk. The tree, therefore, 'feathers out' the first season; that is, it makes many small shoots along the main trunk. The following fall or spring, the top is started at 
the desired height. Fig. 128 shows a peach tree as received from the nursery, and Fig. 129 the same tree trimmed in this manner, ready for

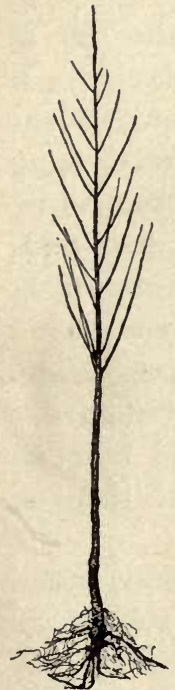

128. Peach tree as received from the nursery.

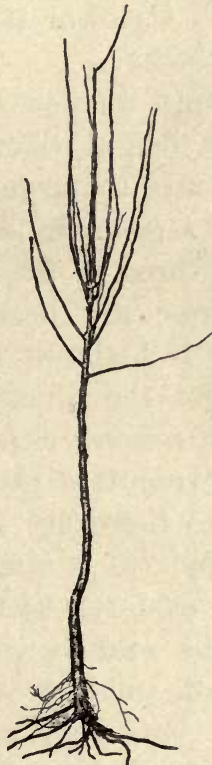

130. Pear tree.
129. The tree

pruned.

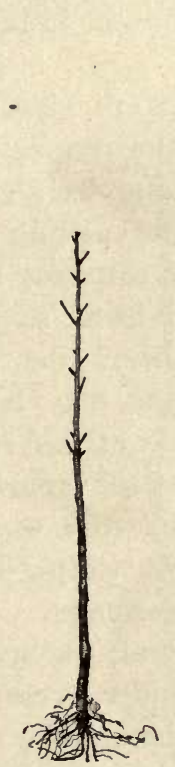

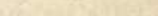

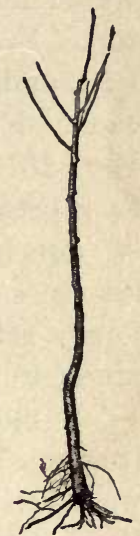

131. The

same pruned.

planting. This method is the one generally best adapted to the peach, which is always set when a year old; but for other fruits, unless the trees are slender and without good, branchy tops, it is doubtful if it is the best practice. If the bodies 
are thought not to be stiff enough, this manner of trimming may be used to good advantage. The main shoot should usually be headed-back in this as in all styles of trimming, in order to make the trunk stocky.

"The second method aims to start the top at the required height when the tree is planted. It is adapted only to strong and well grown stocks which have a more or less branching and forking top. From three to five of the best branches are left, and these are headed-back to a few buds each. Fig. 130 shows a pear tree, trimmed in Fig. 131, and the illustration may be considered to represent a good example of its class. Many of our best planters prefer the spur system for all trees, and there are some who would trim all newly set trees to a straight whip; but there is much to be said for both methods.

"It may be said in general, then, that peach trees and all small or slender trees, should be well headed-back and spurred (Fig. 129); but that strong, well-branched trees may have the head started at the desired height at the time of setting, all the branches being well headed-back (Figs. 130 and 131). Fig. 132 shows a small plum tree cut to spurs, and the roots have also been properly dressed. Figs. 133 and 134 show second-class apple trees. In these the tops are not well formed, and it might be best to trim to a whip, allowing the branches $\mathrm{A}$ to become the 

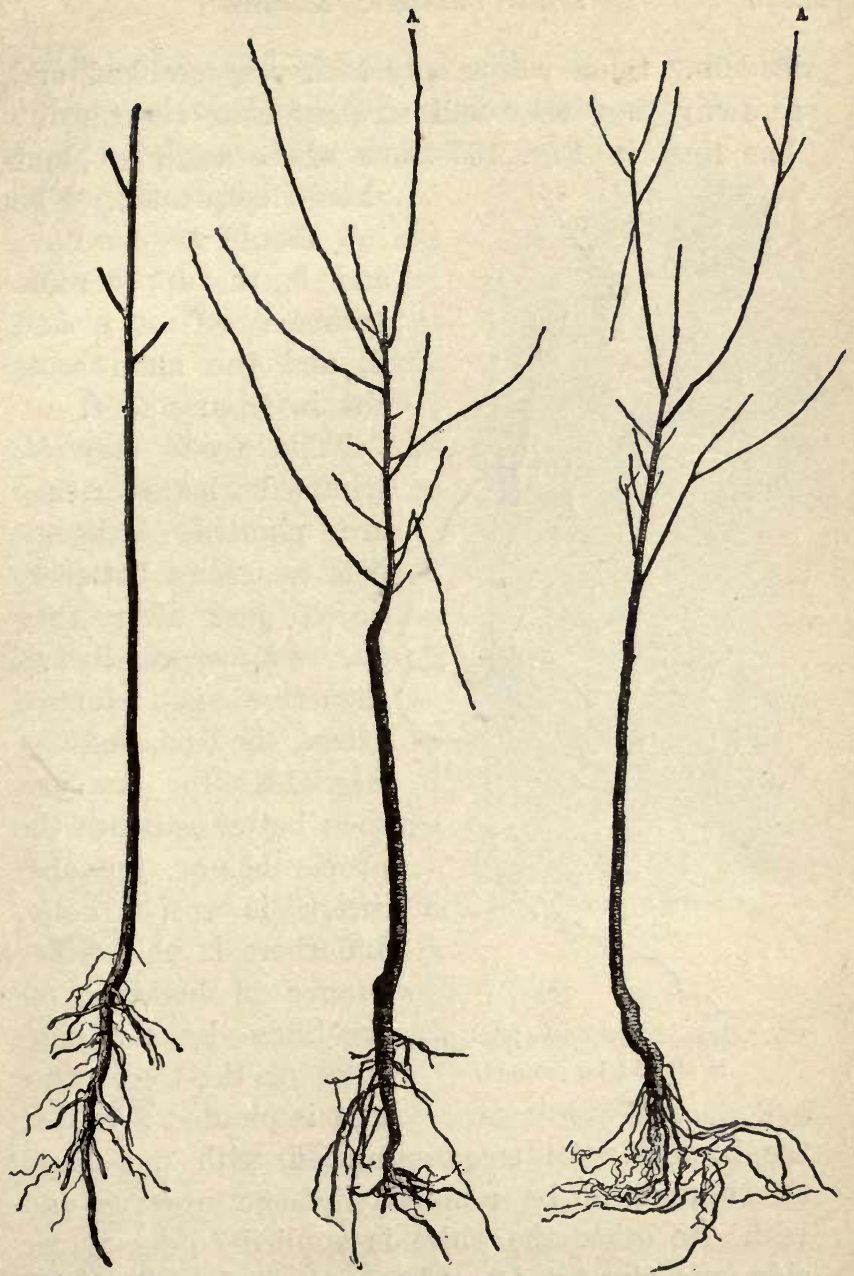

132. Young plum stock well trimmed.

133. Second-class apple tree, showing leader at $\mathrm{A}$.
134. Second-class tree, showing leader at $\mathrm{A}$. 
leaders. Such whips may look very crooked and scrawny, but they will straighten as they grow. The lines in Fig. 135 show where a grape plant

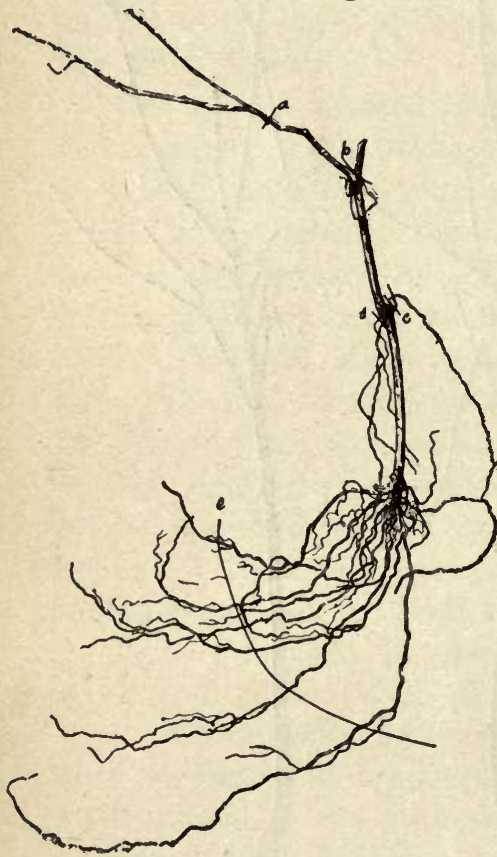

135. Grape plant, showing where the limbs by the hanit should be pruned.

should be pruned. The top should be cut at $a$ and $b$, the upper roots trimmed off at $c$ and $d$, and the main roots cut in from $e$ to $f$.

"The trees may be trimmed before they are planted, although it is generally better to do it just after they are set, especially if the tree is trimmed after the method of Fig. 131, for one can then better estimate the proper height, the operation is easier done, and there is no further danger of breaking off dling of the tree. One foot is planted firmly at the base of the tree, and then with one hand the branch to be removed is bent upwards and with the other the knife is applied to the under side, and the cut is made neatly and easily (Fig. 
136). Never eut downwards on a limb, for a ragged wound nearly always follows.

"In fall-set trees it is generally inadvisable to prune them before spring (unless the tops are so heavy and the bodies so weak that they are likely to be injured by wind), because the cut surfaces are likely to dry out. The roots of the tree are not yet sufficiently established in the soil to supply the added evaporation which takes place from the wounds. If it seems to be desirable to

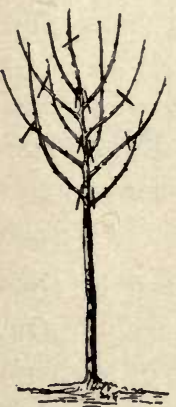
trim the trees when they are set, they should be eut back

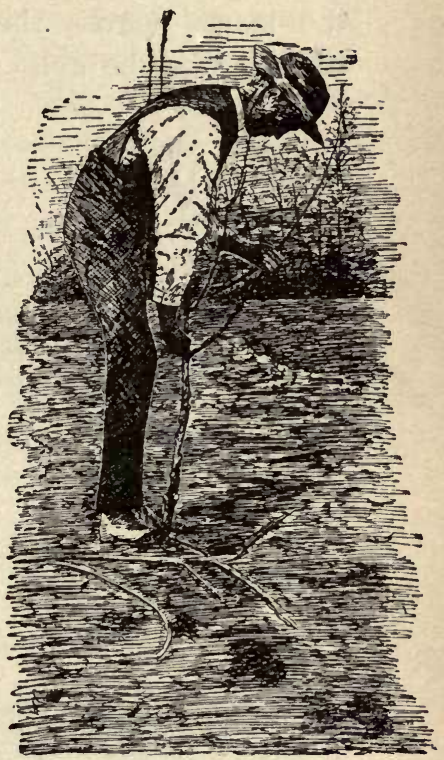

136. Trimming a newlyset tree.

only part way. They may be cut again, to fresh wood, in the spring." (Page 96.)

Having the general subject now well in mind, we may consider various particular questions of practice. The ex-

137. Showing where to cut the limbs. desirable in young trees is shown in 
the various preceding pictures. It is also illustrated in Figs. 137 and 138, in each of which the marks across the branches show where the cutting may be done. Fig. 139 is designed to
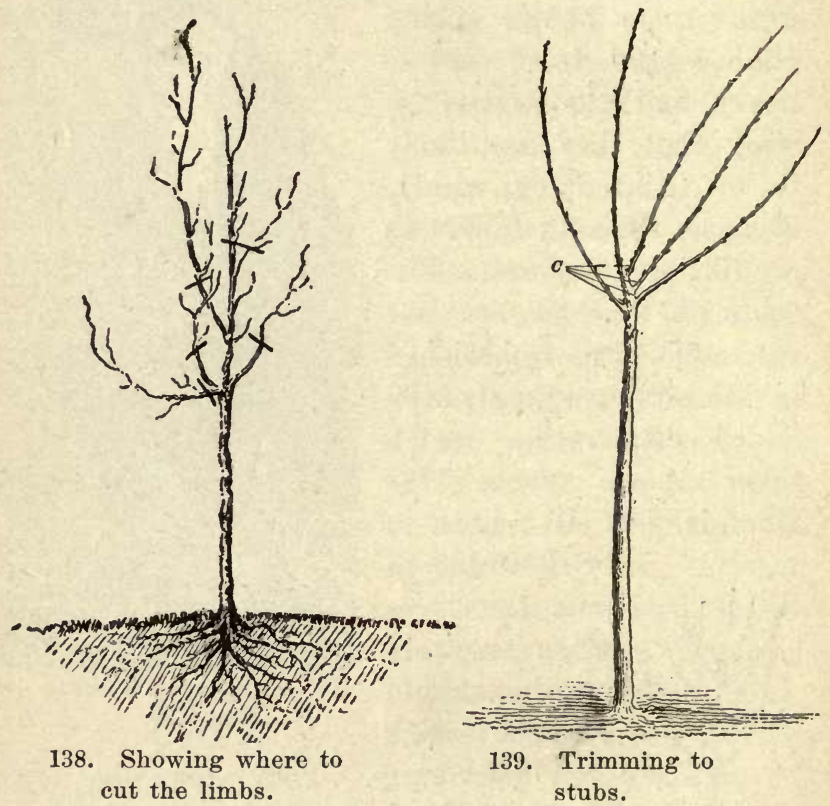

show where the branches may be severed in trees which it is desired to head-in very closely. One or two of the lower branches are to be entirely cut off, and others cut back to one or two buds, as shown at $c$.

In all the cases which we have so far considered, 
it is assumed that the operator desires to have a distinct trunk to his tree, and to start the top at a height of three feet or more from the ground. It is upon this assumption that nurserymen prune their trees, making a single shaft. Persons who wish a very low-topped tree, therefore, may find difficulty in obtaining it from the strong-bodied trees which the nurserymen supply. When it is desired that the limbs shall start low, it is generally best to buy yearling trees. These carry strong, live buds on the main shaft, with very few or weak side branches. What side branches may exist are cut off, and the tree is headed-back to a single whip, so that side branches are thrown out freely near the base of the plant. Fig. 140 illustrates such treatment. At the expiration of the first year, the tree should look something like that in Fig. 141, at which time some of the branches may be removed, leaving only as many as it is desired shall form the main or scaffold limbs. Some fruit-growers prefer to allow the leader to continue in trees of this kind; but it is usually desirable to take out the leader and to allow the tree to form all its top upon four to six main branches, which arise at intervals along the short trunk. Two-year-old trees may also be trimmed to a whip,

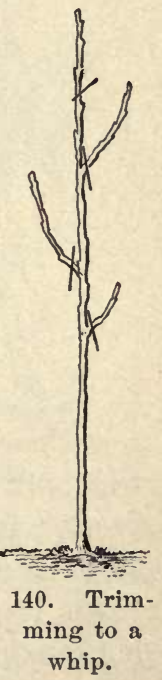


and if they are headed-in, or the young growths near the top are taken off as they start, one may expect to secure branches near the base.

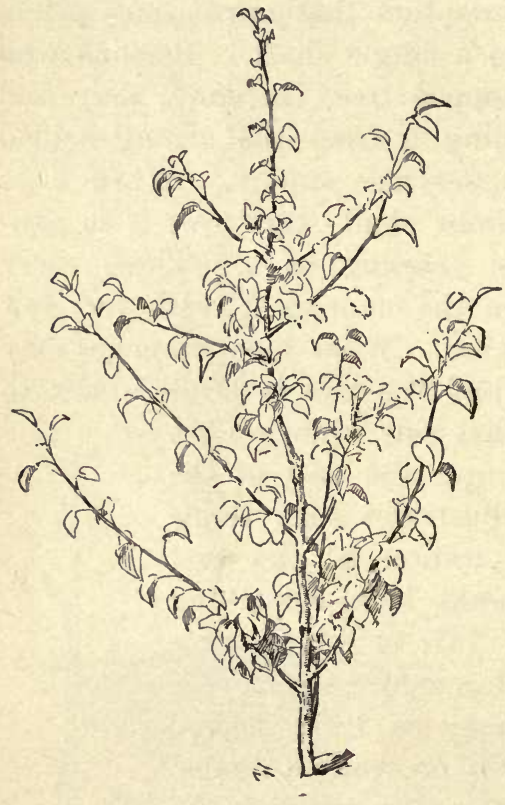

141. The second year's growth.

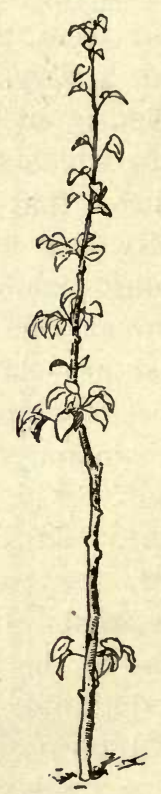

142. Two years old, trimmed to a whip.

Fig. 142 shows a two-year-old tree which has been trimmed to a single cane; a branch is starting near the ground. By heading-in this tree when it is set, or soon after growth begins, the bottom branches may be still further encouraged. 
Although peach trees are planted when they are one year old, they have generally been trimmed up in the nursery, so that the lower branches are destroyed. The tendency for such trees is to throw out branches near the top, and it is often impossible to make them branch within two feet of the ground, where many people desire that the top shall arise. Fig. 143 is a tree which has thrown out two sets of branches, one near the top of the long trunk, and the other near the base. After this tree has grown one season, it may be cut off at the point indicated by the bar; and the tree should then make a low and vase-formed top, like that shown in Fig. 124.

Balmer gives the following advice* for the pruning 143. Opportunity for a of young trees in Wash-
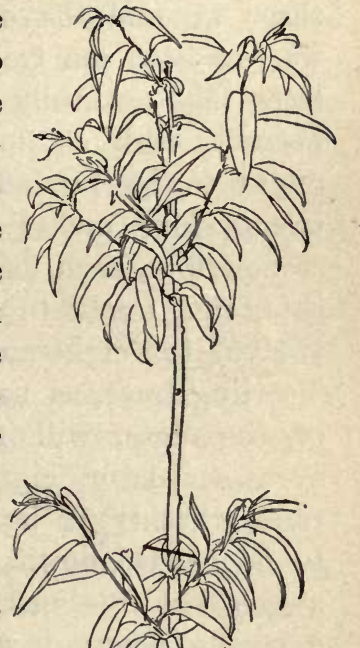
ington (and the same advice will apply to California, or to any place in which low heads are desired):

*Pruning Orchard Trees, Bull. 25, Wash. Exp. Sta. See also page 187. 
"Low heading is the watchword for planters in eastern Washington. Commence with a yearling tree, switches preferred [as in Fig. 140], for in these we find the entire bud system intact, and we can head our trees at any desired height. All trees that naturally have a tall, upright habit of growth, such as apple, pear and sweet cherry, ought to be headed not higher than twenty to twenty-four inches from the ground. And all stone fruits, such as peaches, plums, prunes, apricots, etc., ought to be headed a little lower, say twelve to eighteen inches from the ground. Yearling trees, as usually found in the nurseries of the state, will range from two to four, or even seven or eight feet high. At planting time, whether it be spring or fall, these ought to be headed-down to the proper height. I am aware that it seems like a great sacrifice to take a strong young tree and cut away three-fourths of its top, but it must be done, and done at once; for if you allow one year to pass without attention to this topping, your chances to secure a well-formed, low-headed tree are lost. For while you may at any time cut a tree back to the desired height, yet, to cut back into wood that is two or three years old never gives the same results as does attention to this matter at the proper time.

"It will be seen that the treatment of the tree the first season is of a very simple nature. Your 
young orchard contains a lot of stubs sticking out of the ground to a height not exceeding two feet. During the first season's growth these stubs will develop numerous branches, almost every bud will start, and what was lately a stub will become a little forest of shoots. [See Fig. 141]. * * * Allow every limb and every leaf to develop to its fullest extent. Remember that the leaves are to a tree what our lungs and blood are to us,-its very life. And every leaf you deprive the tree of in summer is robbing it of its tissue-forming organs. Without leaf action there can be no root action; and the fullest development in root and branch ean only be secured by religiously preserving the foliage.

"We will proceed to prune our tree for the second time. The switch that you planted and headed back last year has developed a number of shoots, may be five or six, but more often fifteen or twenty. From these select from three to five of the strongest, best ripened limbs (cutting out all the rest), at the same time exercising care to have them evenly fill the space around and above the tree. Observe carefully that no two limbs emerge from the trunk opposite each other, forming what is known as a crotch. A crotch in an old tree is always an evil, causing a weak spot, where the tree will be likely to break down or split during a heavy fruit crop. The remedy is in your own hands; when you 
prune your two-year-old tree, cut out every limb that forms a erotch with its neighbor.

"The tree in Fig. 144 will convey the idea of what a two-year-old tree ought to be like after having received its second pruning. Notice the arrangement of the limbs. All erotches have been avoided; from the ground to the lowest branches is twelve inches, and the entire height of the tree thirty inches. Contrast this little stocky tree with the weaklings of the same age one commonly meets in orchards to-day, with thin, misshapen trunk three or four feet high, surmounted by two or three long spindling branches, the whole innocent of knife and shears. No wonder our trees break down; they have not strength to carry a heavy crop of fruit!

"After having selected the desired number of limbs intended to form the frame of the tree, shorten these back to within a foot of the trunk, always cutting to a plump prominent bud. The tree may be spread, or it may be contracted, by cutting to a bud which points outward, for

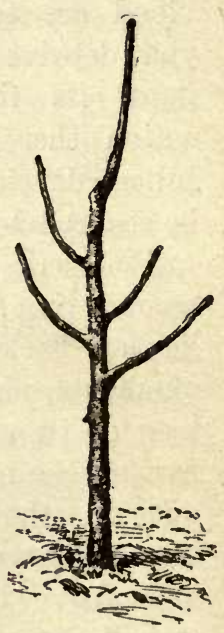

141. Pruned the second time. the former, and to a bud that inclines inward for the latter. You need not hope to alter the character of the tree by this cutting to a bud, 
yet a little may be done to improve its shape. As a rule the weaker the growth the harder it ought to be cut back; this will encourage an increased wood growth the following summer. Trees treated in this way make a growth that is often very perplexing to the amateur; the result of this shortening-in of all the limbs will be an increased number of shoots to treat the following season. * * *

"The third pruning is conducted on the same lines as the second, with this difference: Select the limbs you wish to continue the upward growth of the tree; these will usually be not more than two on each of those left last year, observing the same care not to leave crotches, and shortening-in the growth made in that season; but instead of taking off all of the inside shoots clean to the branch, they are left an inch or two long, and in the course of a season or two all these stubs that you leave will be converted into fruit-spurs. I would practice pruning if for no other reason than to develop every bud on all the limbs, and would treat these buds in such a manner that all would eventually become fruit-spurs. * * * The third season's pruning, then, differs from the first and second in leaving a part of all the growth, instead of taking it off clean, as in the case of very young trees. I object to leaving spurs before the third season, for the reason that by so doing we encourage a fruit- 
ing condition in our trees at too early an age, and this is the very end we are trying to defeat.

"The necessary pruning during the following two or three years does not materially differ from that described for the third year. Let the aim be a symmetrical low, somewhat round-headed tree-the top ought not to be too full of woodand not too thin! Do not expect that every tree can be pruned so as to assume an ideal form, for in this you will be disappointed. No two trees have exactly the same habit of growth. Some are tall and close, others spreading and willowy. All may be vastly improved by an intelligent use of the knife during the early years of the tree's growth. At the age of four or five years we find cherry, plum, and even apple and pear, rapidly developing fruit buds. And as this condition becomes evident, the use of the knife had better be gradually discontinued. All the pruning necessary on bearing trees is to encourage a proper development of the leading shoots, and if these are making a growth of over twenty-four inches annually, they ought to be shortened-in to encourage a stocky habit of tree. All weak shoots appearing lower down on the tree should be cut back to within an inch or two of the limbs, thereby forming a full and correct system of fruit-spurs on every part of the tree." In contrast to this instruction for the low heading of trees, I insert directions given by $\mathrm{T}$. 
G. Yeomans \& Sons, of New York, most successful fruit-growers, but who start the limbs of apple trees not less than six feet from the ground: "The trees should be carefully examined, and all broken or bruised roots carefully pruned; and with apple, standard pear and peach trees not over seven feet high, every side branch should be cut away, leaving the tree a straight stem. The reasons for this are: (1) this pruning will reduce the top to correspond with the diminished capacity of the roots, so that they will furnish a full supply of sap, and cause it to stand and grow vigorously; (2) it will stand more upright, and not be so liable to be swayed about by the winds, and allows one to dispense with a stake, which many recommend for holding the tree in an upright position, but which commonly injures, if it does not destroy, the tree; (3) the buds on the last year's growth of the upright stem will form all needed branches, of better form and more vigorous growth than the old ones would if left on, and will be at the necessary height from the ground, as cannot be the case where they are spurred."

We have already discussed the importance of pruning near a bud (Figs. 82 and 83 ), because the part which projects beyond the bud dies and remains a dangerous part. We have also found that trees which are planted in the fall should not be cut back severely, because the roots, not hav- 
ing a hold upon the soil, cannot supply the moisture which is lost from the wound. The stubs are, therefore, cut back to a fresh bud in the spring, just before growth begins, leaving a stub above the bud not more than a quarter of an inch in length. Figs. 145 and 146 illustrate the

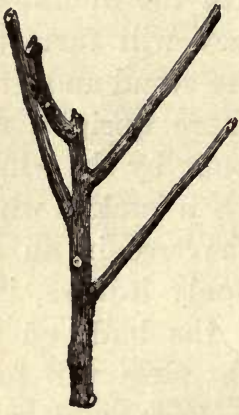

145. Shaping the top.

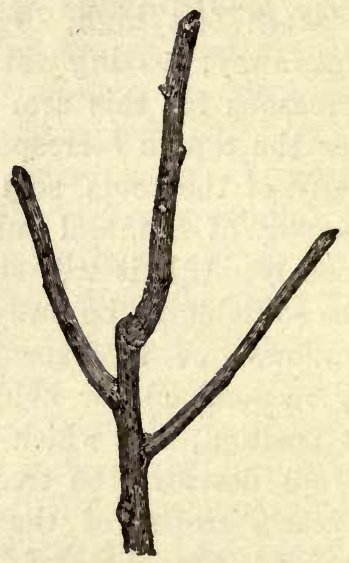

146. Shaping the top.

proper pruning of trees with reference to the buds. It is considered by some pruners to be important to eut to a bud which stands upon the outside of the twig, thereby causing the top to spread. It is usually the top bud which grows, providing the stub is not dried back and the bud is strong and healthy. If this top bud is on the inside of the limb, it does not tend to spread so far from the perpendicular as one which is on the 
outside. Figs. 146 and 147 are made from the same plant, the latter illustration being taken in May. It will be seen that the top buds are the ones which have grown, and that the tendency of the upper growth at 3 is more nearly perpendicular than that at 1 . As growth progresses, however, the shoot 1 will turn upwards and will very nearly approach the perpendicular. It is not often worth the while to pay much attention to the location of the upper bud, with respect to the axis of the shoot, but it is certainly important to trim back to a strong, healthy bud.

The illustrations 145 and 146 show the proper method of leaving the main scaffold branches. They arise alternately from the main stem, and therefore do not form crotches, and there is little danger that such injuries will occur as that shown in Fig. 105. If it is desired that the leader shall continue so as to form a two-storied tree, like that in Fig, 127, the shoot from the 147. How the uppermost bud may be allowed to growth starts. 
grow for this purpose. That is, even though the leader is eut off, the plant throws out a new one, as we have already seen (Section 4, Chapter IV.).

It is often impossible to start the top in the form in which we desire, and our ideals may

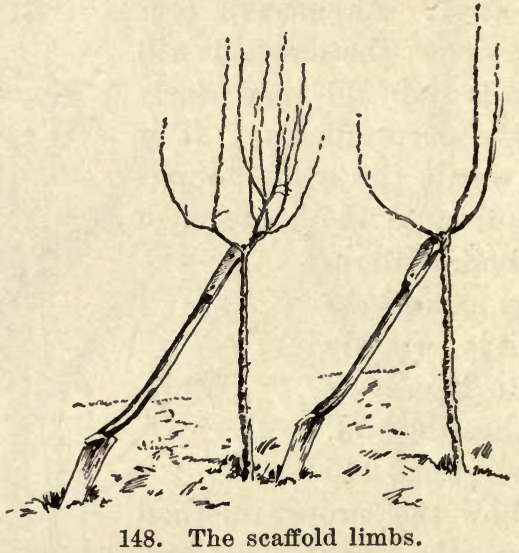

change from year to year, so that we may be called upon to modify the form which we at first projected. It will also be necessary to thin the top considerably, else too many scaffold limbs will arise. Fig. 148 shows a Bartlett pear tree at the end of its second year in the orchard. At the left, the unpruned tree is shown; and at the right, all the limbs have been removed except three, which it is desired shall form the framework of the tree. When set, this tree was cut 
back to three limbs, as may be determined by the method of branching of the specimen upon the left; and from the end of each of these stubs two or three branches arose during the next season. Now that the tree has established itself, and it is no longer necessary to head-in the young growths, this forking branching will not occur, and the

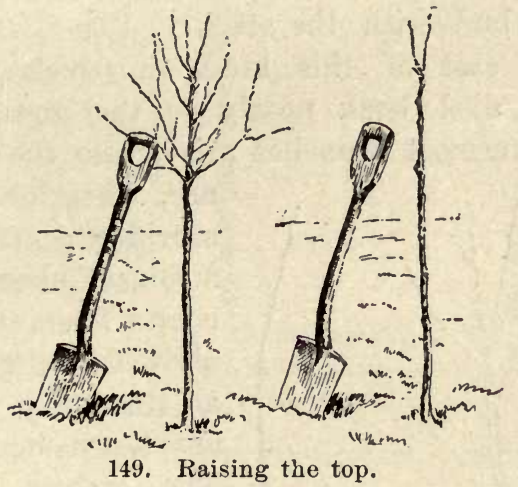

tree will now need comparatively little attention in pruning, except, of course, that all the superfluous growth shall be removed each year. Fig. 149 shows the treatment of a Bartlett pear which the owner had started too low. He has now taken off the lower circles of limbs and has elevated the top by about a foot, leaving two or three stubs for the foundation of his growih for the year to come.

There is more difficulty in starting the tops of o 
peach trees than of most other fruits, from the fact, as has been said, that the trees are usually pruned too high in the nursery. The trees are also likely to die back from the top, especially if they have been set in the fall; and since they have few buds on their bodies, they may throw out adventitious shoots near the point of union of the bud with the stock. Fig. 150 shows a typical case of this kind, in which the trunk -A has died back nearly to the ground. The two lowermost branches arise from the stock and

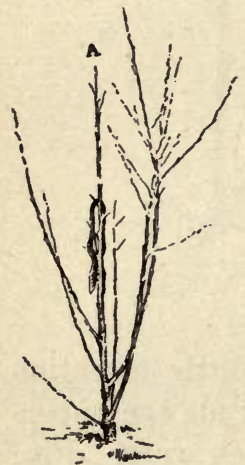

150. A common fault with peach trees.

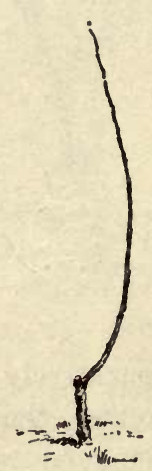

151. How to manage

it. are, therefore, to be sacrificed; but the first strong shoot which comes from the bud is allowed to grow, and all the rest is cut away, as shown in Fig. 151. The grower now has the plant under his control, and can start the top where he may choose. Peach trees also have a tendency to throw out strong growths from one side and to be blind or dormant on the other side. Such one-sided growth from the top of a peach trunk is shown in Fig. 152. In this figure, the long trunk has been cut back to the 
branches, and these branches should now be headed-in to five or six buds. Strong shoots, with an upward tendency, will now start from the base of these branches, and at the end of the second year, a tree something like that in Fig. 153 may be secured. If it is desired to start the limbs of a peach tree very low, to make a 152. Another trouble low head, the tree with young peach should be cut to a trees.

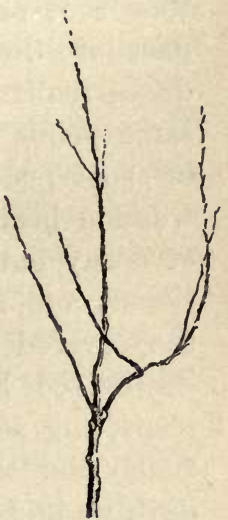

153. How to correct it. stub a foot or two long when it is planted.

\section{ROOT-PRUNING}

In order to understand the vexed question of root-pruning, it is necessary that the subject be analyzed. We prune the roots

I. Of established plants-

1. To keep the growth within bounds, particularly when it is desired that the plant shall be dwarf;

2. To concentrate or contract the foraging of the roots;

3. To make plants fruitful. 
II. Of plants which are being transplanted.

We have already found (Section 2, Chap. IV.) that root-pruning checks growth: it cuts off a part of the food supply. Checking growth induces fruitfulness (Section 11, Chap. IV.). The same principles of physiology govern the practice of root-pruning as that of top-pruning. The wounds heal by the formation of a callus, germs of decay enter exposed wounds, new or adventitious roots start as the result of heavy pruning, the severed leader (or tap-root) tends to renew itself (see Fig. 115), and the general remarks respecting seasons for pruning apply to roots with nearly the same force as to tops. Since roots have no buds, the new branches do not arise in as definite order as they do on tops, but this is a matter of no consequence, for the shape of the root system is of no practical importance. The direction of the roots is important, however,-whether they run horizontally and near the surface, or perpendicularly. The direction of the roots, however, is not determined primarily by methods of pruning; but by the nature of the plant, by the soil, and the position of moisture and food.

The root-pruning of established plants is practicable only on a small scale. It is practiced in amateur plantations, or in those cases in which it is desired to keep plants within definite bounds or shapes. It is essentially a garden idea. It is practiced in European enclosures, in the growing 
of trees to pyramids, cordons, on espaliers, and the like (see Chapter VI.). By cutting the roots, they are kept within a prescribed area, and do not interfere with other plants. The tops of the plants are thereby checked of exuberant growth, and are more manageable on walls and trellises. In Europe, these small bearing trees are often taken up and replanted, in order to keep them within bounds. In the well tilled gardens, and in cool and moist climates, it is often thought to be desirable to keep the roots near the surface; but in American orchard conditions it is desirable that the roots strike deep.

In the large-area or field conditions under which American fruits are grown, root-pruning is rarely necessary or even useful. Under such conditions, the plant takes its natural habit and reaches its normal stature, and fruit-bearing comes naturally with the maturity of the plant; or, if fruit-bearing does not come, the fundamental treatment lies in correcting faults of tillage, soil, varieties, or other cardinal matters. In our country, root-pruning may be associated with ringing or girdling, and such other special operations which may be used experimentally now and then, when other means have failed. It is of special rather than of general importance.

The European books and periodicals contain many detailed instructions for root-pruning, and to these the reader should go if he desires ex- 
plicit information on practices. A single typical quotation is here inserted to show the general nature of the advice.

"Root-pruning of pyramidal pear trees on quince stocks.* -Before entering on the subject of root-pruning of pear trees on quince stockss, I must premise that handsome and fertile pyramids, more particularly of some free-bearing varieties, may be reared without this annual or biennial operation. If the annual shoots of the tree are not more than eight or ten inches long, no root-pruning need be done. I have a large plantation of pear trees on the quince stock, which have been made very handsome and fertile pyramids, yet they have not been root-pruned, neither do I intend to root-prune them. But I wish to impress upon my readers that my principal object is to make trees fit for small gardens, and to instruct those who are not blessed with a large garden how to keep the trees perfectly under control : and this ean best be done by annual, or at least biennial attention to their roots; for if a tree be suffered to grow three or more years, and then be root-pruned, it will receive a check if the spring be dry, and the crop of fruit for one season will be jeopardized. Therefore, those who are disinclined to the annual operation, and yet wish to confine the growth of their trees within limited bounds by root-pruning, say once in two years, should only operate upon half of their trees one season; they will thus have the remaining half in an unchecked bearing state; and those who have ample room and space may pinch their pyramids in summer, and suffer them to grow to a height of fifteen or twenty feet without pruning their roots. I have seen avenues of such trees in Belgium, really quite imposing. In rich soils, where the trees grow so freely as to make shoots eighteen

*Ihomas Rivers, "The Miniature Fruit Garden." 
inches in length in one season, they may be root-pruned annually with great advantage.

"The following summary will perhaps convey my ideas respecting the management of pyramids and bushes when cultivated as garden trees. In small gardens with rich soils, either root-prune or remove all the trees annually early in November. In larger gardens, perform the same operation biennially at the same season. For very large gardens with a dry, good subsoil, in which all kinds of fruit trees grow without any tendency to canker, and when large trees are desired, neither remove nor root-prune, but pinch the shoots in summer, thin them in winter when they become crowded, and thus make your trees symmetrical and fruitful.

"Pyramidal pear trees on the quince stock, where the fruit garden is small, the soil rich, and when the real gardening artist feels pleasure in keeping them in a healthy and fruitful state by perfect control over the roots, should be annually operated upon as follows: A trench should be dug around the tree, about eighteen inches from its stem, every autumn, just after the fruit is gathered if the soil be sufficiently moist,-if not, it will be better to wait till the usual autumnal rains have fallen; the roots should then be carefully examined, and those inclined to be of perpendicular growth eut with the spade, which must be introduced quite under the tree to meet on all sides, so that no root can possibly escape amputation. All the horizontal roots should be shortened with a knife to within a circle of eighteen inches from the stem, and all brought as near to the surface as possible, filling in the trench with compost for the roots to rest on. The trench may then be filled with the compost (well-rotted dung and the mold from an old hotbed, equal parts, will answer exceedingly well); the surface should then be covered with some half-rotted dung and the roots left till the following autumn brings its annual 
care. It may be found that, after a few years of rootpruning, the circumferential mass of fibers will have become too much crowded with small roots; in such eases, thin out some of the roots, shortening them at nine inches or one foot from the stem. This will cause them to give out fibers, so that the entire circle of three feet or more around the tree will be full of fibrous roots near the surface, waiting with open mouths for the nourishment annually given to them by surface dressings and liquid manure.

"Thus far for the gardener who does not mind extra trouble,-who, in short, feels real pleasure in every operation that tends to make his trees perfect in fruitfulness and symmetry. But it is not every amateur gardener that can do this, nor is it always required in the south of England, except for small gardens and in rich, moist soils, in which pear trees are inclined to grow too vigorously. But with our too often cool, moist summers in the northern counties, annual root-pruning is quite necessary to make the trees produce well-ripened wood. In other cases, as I have before observed, shortening the shoots in summer, taking care to produce a handsome pyramidal form, and if they are inclined to grow vigorously, biennial root-pruning, will be quite sufficient."

ROOT-PRUNING WHEN TRANSPLANTING.-Rootpruning results from the removal of plants. That is, it is practically impossible to dig up plants of any size-as shrubs or trees-without cutting some of the roots. The severed roots, when as large as a lead pencil, should be cut back to live, uninjured wood, and the wound should be clean-cut. This is to ensure rapid healing. How short the roots shall be cut is a problem to be settled for each case, in the same way as the similar problem 
DO ROOTS STRIKE FROM THE CALLUS? 233

respecting the proper length to leave the branches. In general, it may be said that the main roots of

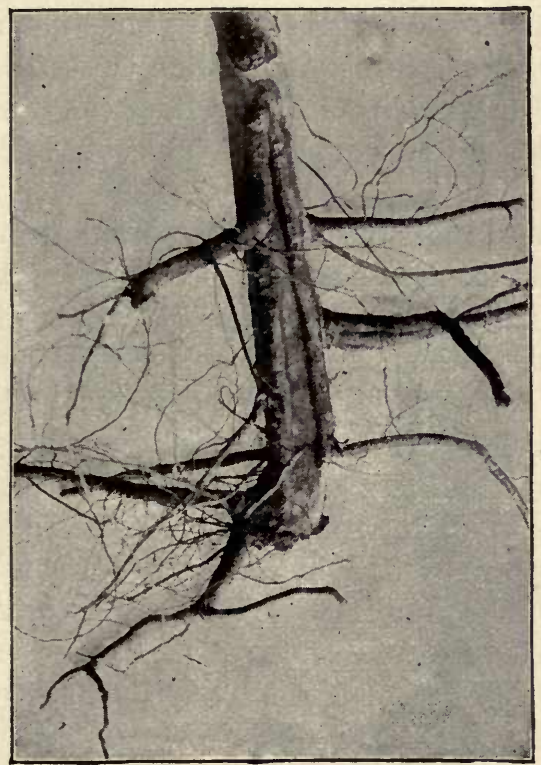

154. Roots do not start from the callus.

trees two to four years old may be left six to eight inches long.

There is much discussion as to where the new roots arise in transplanted trees. It should first be said that the roots do not necessarily arise from the callus, ${ }^{*}$ although this is the almost uni-

*See also, L. C. Corbett, 9th Ann. Rep. W. Va. Exp. Sta., 196. 
versal notion. In fact, they very rarely, if ever, arise as an outgrowth of the callus tissue. From an apple tree two years old, one side of the root was shaved. The tree was planted, and after growing two years, was taken up and photographed (Fig. 154). The callus had formed on both sides of the wound, but no roots had started from it.

The new roots usually arise from firm, strong roots the size of a lead pencil or larger; but they may also arise from the hair-like roots which are on the tree when it is transplanted, although the common opinion is to the contrary. The place from which the new roots arise is largely determined by the habit of the individual plant. In some cases, all the roots will spring from the main shaft or trunk, and in others they seem to arise almost indiscriminately from the trunk, large roots and very fine roots. The figures, carefully drawn, from actual examples of apple trees, illustrate the point. The root shown in Fig. 155 was trimmed of all its fine roots when transplanted. It is seen that the new roots start from various parts of the root system. The root in Fig. 156 had some small, but not very fine, roots left. The new roots are starting from near the ends of these roots, large and small alike. (See also Fig. 161.) In none of these cases do the roots start from the calluses. The common notion that roots will start directly downward if the old roots are cut diago- 
DO ROOTS FORM FROM THE CALLUS? 235

nally on the under side, so that the callus looks downwards, is a fallacy. The direction of the roots, as already said (page 228), is determined

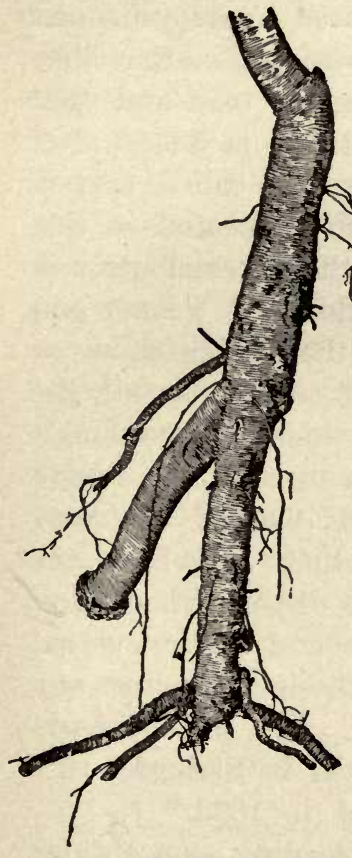

155. Where the new roots start.

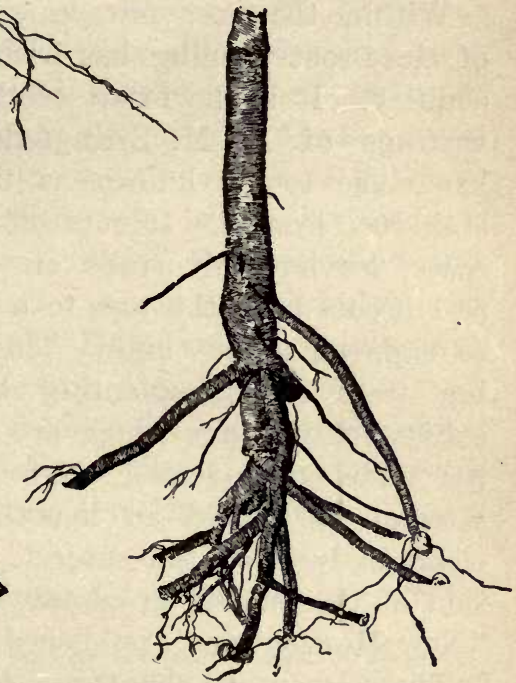

156. Where the new roots start.

by the nature of the plant, the texture of the soil, and by the water and food supply. The position of the callus does not influence it.

As a matter of practice, it is generally inad- 
visable to exercise much care to save the very fine roots when transplanting shrubs and trees, for such roots are apt to be killed by short exposure to the weather, and to be injured in shipping and transplanting; but the common notion that they are of no use in a transplanted tree, and that new roots do not arise from them, is false.

Within the past few years a so-called system of close root-pruning has been advocated in this country. It is the result of the experiments and writings of H. M. Stringfellow, of Texas, and has come to be known as the Stringfellow or stub-root system. It cuts off practically all the roots, leaving only stubs an inch or two long; and it cuts back the tops to a mere stump twelve to eighteen inches high. This method of treating trees at transplanting time has been the subject of writings which are distinguished more for their controversial spirit and their evident attempt to uphold an hypothesis than for any clear analysis of the subject. The best exposition of the subject is contained in Stringfellow's "New Horticulture", published in 1896.*

There seem to be three leading conceptions

*Some of the current writings may be found in Texas Farm and Ranch, 1895, reprinted in Galveston Tribune, Dec. 20, 1895; Fruit Growers' Journal, Feb. 15, 1894, Feb. 1 and May 1, 1896 ; California Fruit Grower, May 30, 1896. Excellent contributions in support of the method, by T. L. Brunk, may be found in American Farmer, July 15, 1892, and Fruit-Growers' Journal, Jan. 15, 1896. Report of experiments is made in Bull. 39, Texas Exp. Sta, by R. H. Price. 
upon which the superiority of this stub-root system is assumed to rest: Seedling non-transplanted trees are longer-lived, hardier and healthier than the trees of orchards; this superiority is largely due to the presence of a taproot system; the nearer the transplanted tree is reduced to the form of a young seedling or cutting, the greater is its tendency to develop a tap-root system. All these categories are mere assumptions. The old seedling trees at which we wonder are a few out of many. For every one that has reached a hale old age, hundreds have probably perished; and since the dead are not in evidence, we enlarge the exception into the rule. As a matter of fact, the orchards of to-day, at least in the East, are more uniformly healthy and productive than the seedling orchards of other days. In our time, every break in the orchard is missed and commented upon; in those times, the breaks were of small consequence.*

In the second place, a tap-root is not an in-

\footnotetext{
*A fuller discussion of this question may be read in Essay XX., "Survival of the Unlike". Mr. Stringfellow cites such seedlings as the original tree of Sudduth pear and Mammoth Black Twig apple. It would be interesting to know what has become of all the other seedling pears and apples which presumably started at about the same time. Such trees are isolated facts, not averages; they do not necessarily slow laws or tendencies. It is easy to find such patriarchs among grafted and transplanted trees. For example, the so-called original Tompkins County King apple is a grafted and transplanted tree, and it still bears well, although about seventy years old, and outliving most of its progeny.
} 
variable attribute of seedlings, any more than a distinct leader is always an attribute of their tops. Some plants have tap-roots and some do not. They vary in this regard, as they do in stature, form, kind of fruit, or habit of growth. When seedlings first start, they usually have a tap-root, but this tap-root tends to vanish as the root system enlarges and becomes diffuse, in the same way that the leader in the top may be lost. There is no evidence that a tree necessarily thrives better if it has a tap-root (see page 151).

In the third place, a tap-root does not form merely because the roots are cut long or short, or in one way or another. If it is the habit of a plant to develop a tap-root, it will generally do so, even after its original tap is cut (Fig. 115), unless prevented by some peculiarity of soil. It will generally throw down two or even several tap-roots instead of one. It must follow, however, that in short-pruned roots, these new leaders will be very close together and approximately under the main shaft of the tree, and therefore appear to constitute a truer tap-root system than when they arise at some distance to the side of the main shaft; and it is probable that the centermost ones will tend to be the stronger.

The gist of the whole matter, so far as the theory is concerned, is that individual instances and the results of certain experiments have been 
enlarged into an hypothesis which has been applied to all plants. The stub-root system is really not a system at all. It is not founded on a body of principles. It is a matter of practice, which will sometimes be useful and

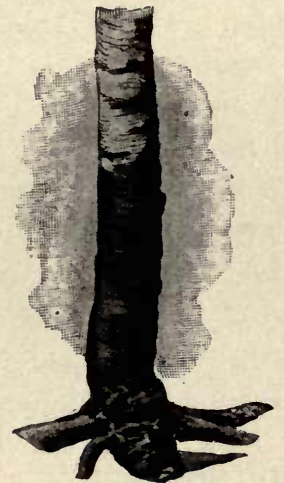

157. Stringfellow's model.

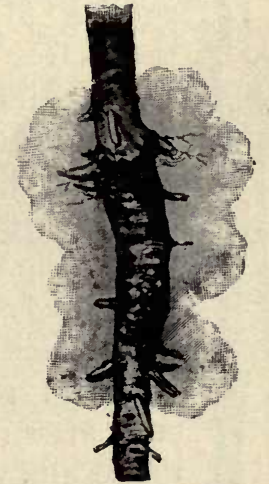

158. The wrong ideal.

sometimes not. Its success depends on local and incidental conditions. It would be as true to say that because many people find the pyramidal training of dwarf pears to be useful, therefore it is necessarily best everywhere and for all species and varieties.

The accompanying pictures, from Stringfellow s "New Horticulture," show the method of this stub-root pruning. Fig. 157 is the correct form, - "cut back just below the collar, and just under the first good side roots." We should "not leave any length of the main or tap-root, with side 
roots eut back,"* as in Fig. 158. It is impossible to cut Fig. 158 to the form of Fig. 157, because

the root did not grow in the same way.
This is true of most trees, especially if budded stock; they cannot be cut according to directions. Peach trees lend themselves most readily to this form; also cutting-grown pear trees (such as are grown in the South). The theory is that the new roots arise from the under surfaces of roots which are cut as in Fig. 157, and then grow directly downwards. Fig. 159 is Brunk's model of a peach tree properly trimmed, showing both root and top, the whole being only fifteen inches long. Fig. 160 shows the results which Mr. Stringfellow secures from stub-roots and long roots.

In 1896, experiments on the stub-root pruning were begun at Cornell, and these are now reported. This account of the tests is inserted more for the purpose of affording concrete instances with which to diseuss

159. Brunk's model. the statements advanced in support of stub-root prun-

*ee Hold the tree top down, and eut all roots back to about an inch, sloping the cuts so that when the tree is set the ent surface is down- 
ing than to make a record of an experiment. Not all the trees were trimmed in the Stringfellow fashion, for other problems than mere stub-root pruning were in mind. Besides the four hundred trees here reported, the roots of two hundred apple trees were cut in different

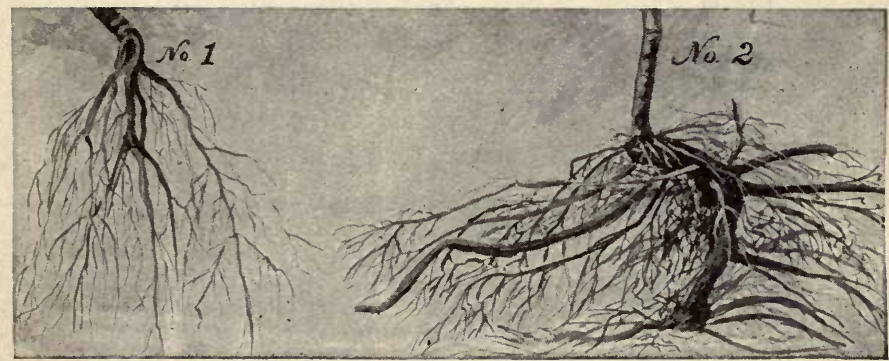

160. Results of stub-root and long-root pruning (after Stringfellow). No. 1, trimmed to stubs ; No. 2, ordinary long roots.

ways, in order that the formation of the new root system might be studied. The trees were commercial northern-grown, and were set in a moist and well-tilled sandy loam. They were set on the 4th of May, which was as early as

wards. Experience has shown that the roots are generally emitted perpendicularly to the plane or surface of the cut. This final pruning should be done shortly before planting, so as to present a fresh surface for the callus to form on. If trees are to be kept some time, or shipped by a nurseryman, about two inches of root should be left, the planter to cut back as directed when the tree is set. About a foot of top should be left. More or less makes no difference. If the tree is well staked, three feet may be left without diminishing the growth much."-Stringfellow in "The Nevo Horticulture," 85. 
the ground could be fitted. Every care was taken to have all the conditions ideal and uniform. One hundred trees were set each of peach, plum, pear

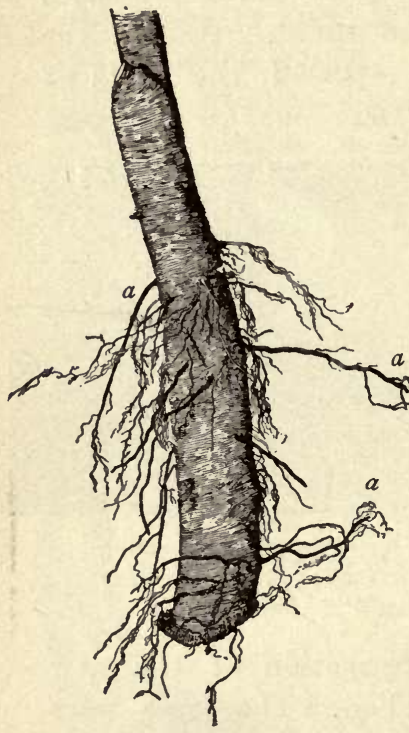

161. New roots start from both the trunk and the fine roots. and apple. Each kind was divided into four or five lots, one lot being cut very short, and the others successively longer, until the last lot, in which the roots were not trimmed. The weather for the first month after planting was hot and dry, but the land was frequently tilled to conserve the moisture.

The trees were photographed before being planted, and some of them were removed at intervals and again photographed. In this way, the process of root formation was carefully studied.

It was found, as I have already indicated (pages 228,235 ), that neither the place of origin of the new roots nor the direction of them was determined by the mode of pruning. Fig. 161 is an apple root trimmed to a simple stub, with some of the fine side roots, $a$, left on. The new roots arose both from the main trunk and from 
the small rootlets, and none of them arose from the callus; and there was no tendency for them to arise from the lower end of the stub (compare Figs. 154, 155, 156). Two similar apple trees were trimmed in different ways, and a month after planting they were taken up and engravings made. The close-pruned specimen (Fig. 162) was barely alive, but the other (Fig. 163) was making a good growth. The roots shown in Figs. 161 and 162 are not of the form prescribed by Mr. Stringfellow, nor is it possible to prune most strong New-York-grown trees in that fashion. However, many of the trees had strong lateral roots, and with these care was taken to copy the orthodox form; and some of these are illustrated.

162. Reduced to a cutting.
For example, Fig. 164 shows the roots of four

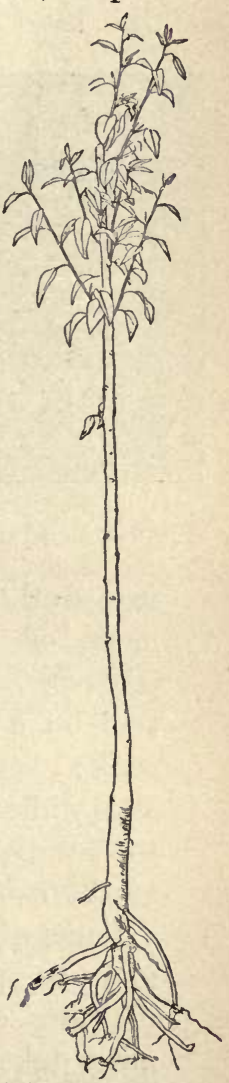

163. Better results 
average peach trees after they had grown two seasons. The one at the left was trimmed to the form advised in Fig. 157, and yet it was the most shallow-rooted of all the trees; and

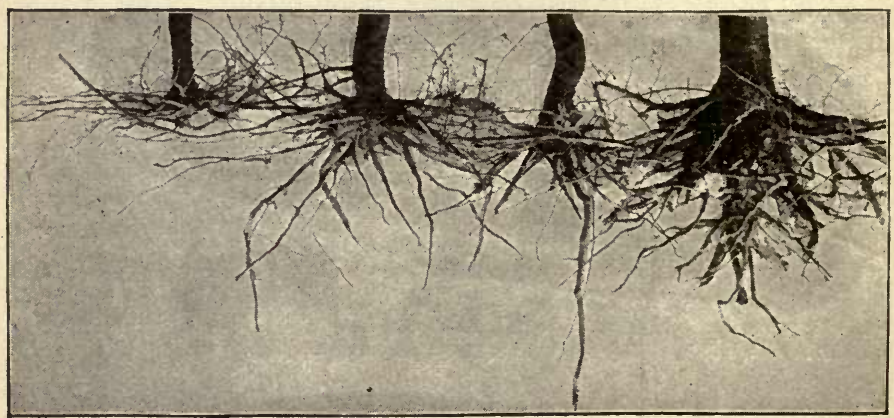

164. Typical results in peach trees.

many other trees told the same story. Yet this mode of pruning has for its object "to concentrate all the vital energy of the newly set tree on a limited root-surface, and compel it to strike several strong, perpendicular tap-roots, and while doing this, not to allow its attention to be diverted to forming side or lateral roots at the same time."*

Some of the facts of this experiment at Cornell may be presented in the following form (the planting dates being in May, 1896, and the final notes taken December, 1897):

\footnotetext{
*Stringfellow, "New Horticulture," 100.
} 


\section{Peach (Horton Rivers)}

(Twenty trees in each lot)

A. Roots normal, six inches long. Sixteen lived. All roots had a strong downward tendency. See right-hand root in Fig. 164. Average weight of trees, December, 1897 , seventeen pounds.

B. Roots cut to four and one-half inches long. Eighteen lived. The strongest, thriftiest, most shapely trees in any of the lots. Roots all striking downwards.

C. Roots eut to three inches long. Fifteen lived. Ten had downward-growing roots, and five had very flat or horizontal root systems.

D. Roots cut to two inches long. Nine lived. Five had downward-growing roots and four had horizontal roots.

E. Roots eut to one inch long. Twelve lived. Six had roots with downward tendency, and six had all roots almost perfectly horizontal. The three left-hand specimens in Fig. 164 are from this lot E. The tree on the extreme left weighed one pound fourteen ounces, and represents an average specimen. The second from the left weighed five pounds eight ounces, and is the best tree in the lot. The third from the left is the only one in the lot that had a distinct tap-root. It weighed four pounds five ounces.

From first to last, the moderately pruned trees were clearly the best, and the stub-root trees were poor and weak, even after two years' growth.

\section{Pear (Bartlett) \\ (Twenty-five trees in each lot)}

A. Normal. Roots six to eight inches long. Twenty-one lived; sixteen first-class trees. 
B. Tap-root not trimmed; side roots two to three inches long. Twenty-two lived; sixteen first-class trees. The best lot. $b$ and $b b$, Fig. 165, are average roots; $b$ weighed three pounds eight ounces, and $b b$ three pounds twelve ounces.

C. Tap-root not trimmed; side roots one inch long. Fifteen lived; seven first-class trees. A poor lot.

D. Tap-root cut to six inches; side roots one inch long. Fifteen lived; 1 first-class tree. $d$, Fig. 165, was the

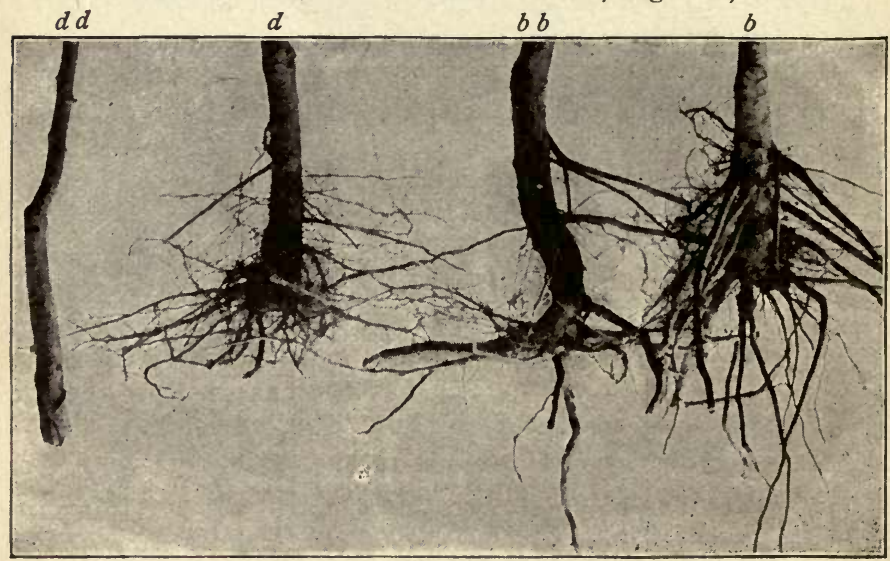

165. Typical results in pear trees.

only tree in the lot worth saving. $d d$ shows a tree still living after having been in the ground two years, but it had made no roots whatever. It was trimmed to a bare stump when set. Six trees behaved in this way, and only two of them made a callus on the wound. The tops did not grow, but they supported a few leaves. The stub-root probably absorbed a little moisture, and there was some food stored in the wood, so that the plant was able to live. 
Plum (Lombard, budded on Myrobalan roots)

(Twenty-five trees in each lot)

A. Normal. Tap-root, eight inches; side roots, three to six inches. Twenty-three lived. Right-hand specimen in Fig. 166 is an average root. Weight of tree and root, five pounds ten ounces.

B. Tap, six inches; side, two to four inches. Twenty-three lived.

C. Tap, four inches; side, two inches. Twenty-four lived. D. Tap, four inches; sides, one inch. Twenty-two lived. Left-hand specimen, Fig. 166, is an average root. Weight six pounds ten ounces.

All the lots were remarkably uniform in size and thriftiness. From the tops it would have

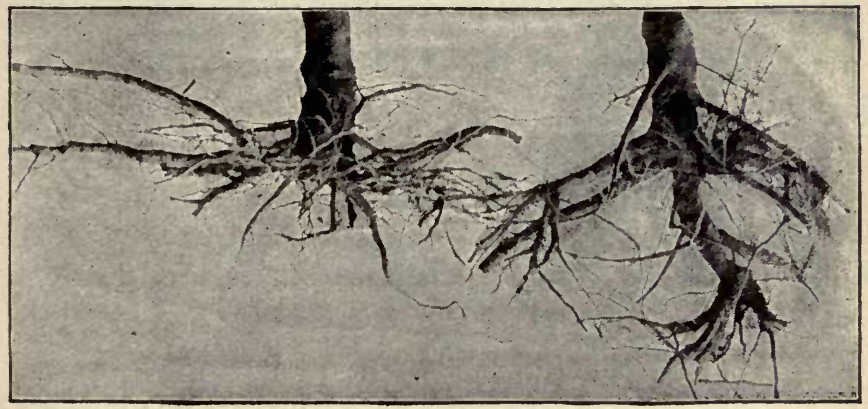

166. Stub-root and long-root on plum.

been difficult to distinguish them. The shortpruned roots gave the shallowest root systems, however. It is easy to account for the large size of the short-pruned trees, for the Myrobalan plum grows readily from euttings. 


\section{Apple (HubBardston, BUdDed sTock)}

(Twenty-five trees in each lot)

A. Normal. Roots six to eight inches. Twenty lived; seventeen first-class; $a$, Fig. 167, average specimen, one pound fourteen ounces.

B. Roots two to three inches long, and tap not cut. Eighteen lived; thirteen first-class. $b$, Fig. 167, average

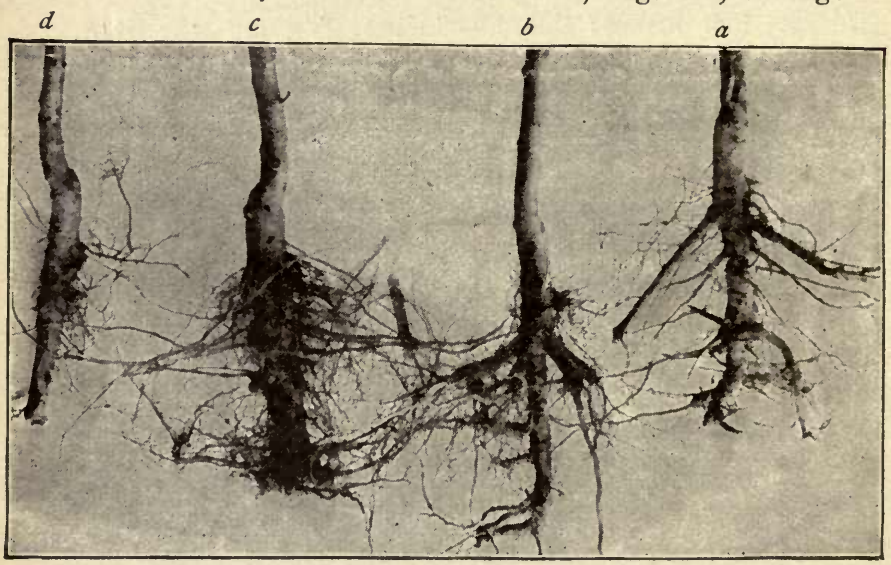

167. Average results on apple trees.

specimen (a good root system!), one pound fourteen ounces.

C. Roots one inch long, and tap not eut. Twenty lived; twelve first-class. $c$, Fig. 167 , best specimen in the lot, two pounds eleven ounces.

D. Roots one inch long, and tap eut back, thirteen lived; four good trees, but not first-class, and four more with fairly good roots but poor tops. $d$, Fig. 167, average and typical specimen. 
In all these trees, except the Myrobalan plum roots, the short-root pruning was a decided disadvantage. Yet there is no contradicting the fact that others have obtained good results from it, and it has been put to a successful commercial test. All this shows, as has been said (page 238), that stub-root pruning is to be considered a matter of local practice, not a matter of general principle. The practice may be good and it may not: the explanation or assumed theory is wrong. It will probably be found to be best adapted to the South, where plants grow from cuttings more readily than in the North; and the nature of the land as respects texture, and the nearness of the water-table, will probably influence the result. The kind of tree may also be important. The stubbing-back of the top is a disadvantage to those who desire to grow long-bodied trees.

It is always well to challenge established practices and accepted theories, for thereby we make progress. In this respect, Mr. Stringfellow and his followers have no doubt done a distinct service.* Perhaps we have placed too great value on a large root-system when transplanting trees, and

\footnotetext{
*Aside from its merits as a matter of pruning, Mr. Stringfellow sees the following advantages of stub-roots: (1) Saving the nurseryman in digging his stock; (2) Saving in packing the stock; (3) Saving in transportation; (4) Saring in planting; (5) Reducing danger of carrying insects and diseases; (6) Enables the planter to set extra large trees, which the nurseryman now has to throw away, and thus obtain fruit much sooner.
} 
our opinions may need to be revised; but it does not follow that the opposite extreme is the better. The writer prefers trees with roots on; but he has no quarrel with those who prefer them with roots off.

\section{SUBSEQUENT TREATMENT OF THE PLANTS}

Having now obtained a general conception of the type of tree which we wish to grow, and having started off the main or scaffold branches, the subsequent treatment consists in eutting out all interfering and superfluous limbs and keeping the top within the shape which we have in mind. It is impossible to give specific advice as to what branches should be cut, for every branch is a problem in itself, and must be solved for itself. In fruit trees, the head should be kept fairly open, so that all parts are exposed to sun and air, and the tree is made accessible to pickers, and easy to spray. All limbs which tend to make an over-vigorous growth should be cut out or checked, in order that the tree may keep its balance, and limbs which run directly crosswise the top, and those which rub each other, should be removed.

Some of the problems connected with the form of the top may be suggested in a series of pictures taken from an individual tree of Rhode Island Greening. This tree was set in the spring of 1889. Having grown two years without prun- 
ing, in the fall of 1890 it looked like Fig. 168. In the winter of $1890-1$ it was pruned, as shown in Fig. 169. The tree stands in rich soil and has made a heavy growth. As the top begins

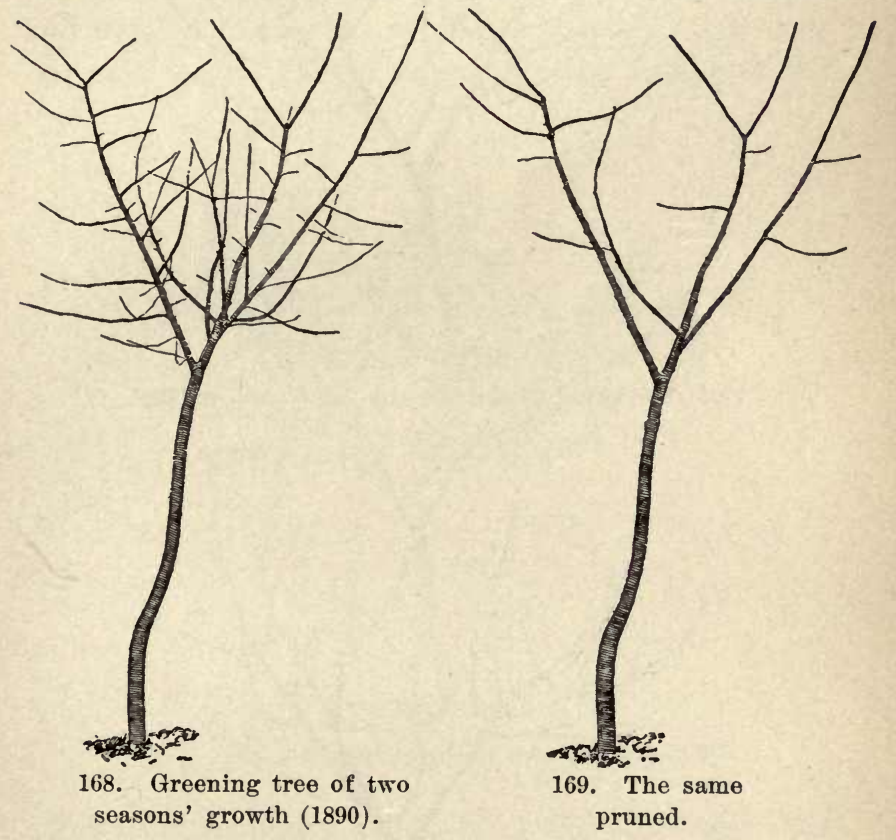

to expand, the apparent length of the trunk decreases, and in the fall of 1892 the tree looked as shown in Fig. 170 ; that is, tops which may appear to be very high when trees are young may appear to be low when the trees have 


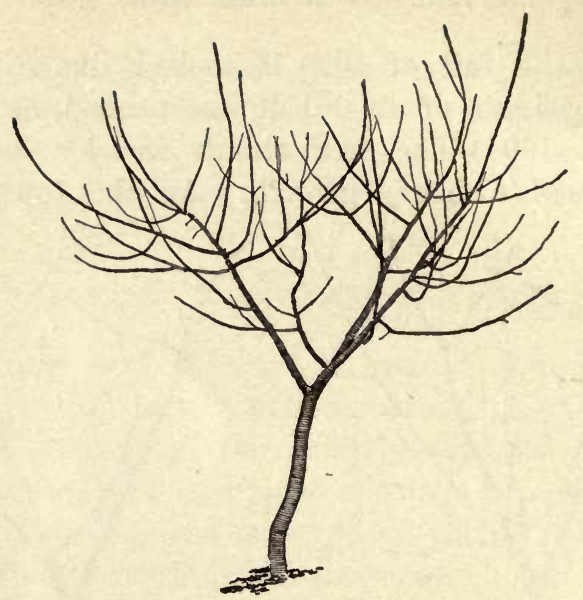

170. The same tree, two years later (fall of 1892).

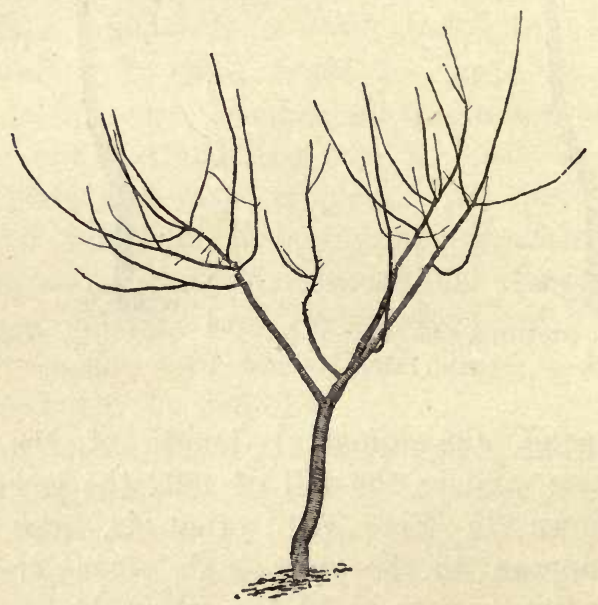

171. The tree again pruned. 
attained some age. All these pictures (168-174) are drawn with great care to a scale, and the length of trunk bears a true proportion to the width of the top in every case. In the winter of 1892-3 the tree, as shown in Fig. 170, was pruned to the extent shown in Fig. 171, and the

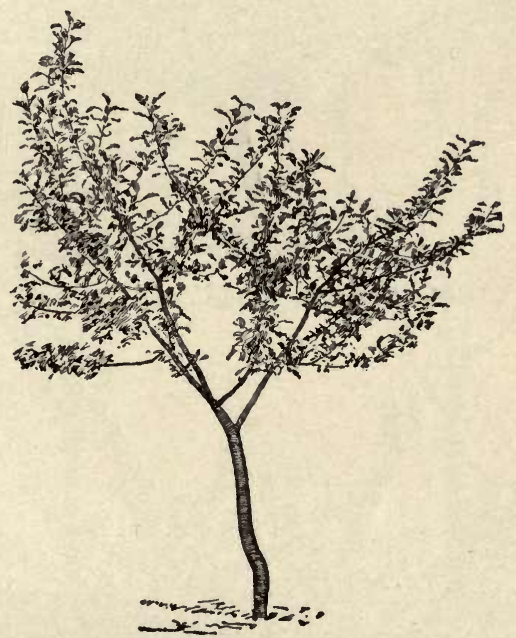

172. The same tree starting into growth (1893).

following summer (that is, 1893) the tree had the form shown in Fig. 172. Late in the season of 1894 the tree was drawn again, as shown in Fig. 173. The following winter it was again pruned, and in the spring of 1895 it had the appearance of Fig. 174. It will be seen that the long and stilt-like character of the tree has wholly 


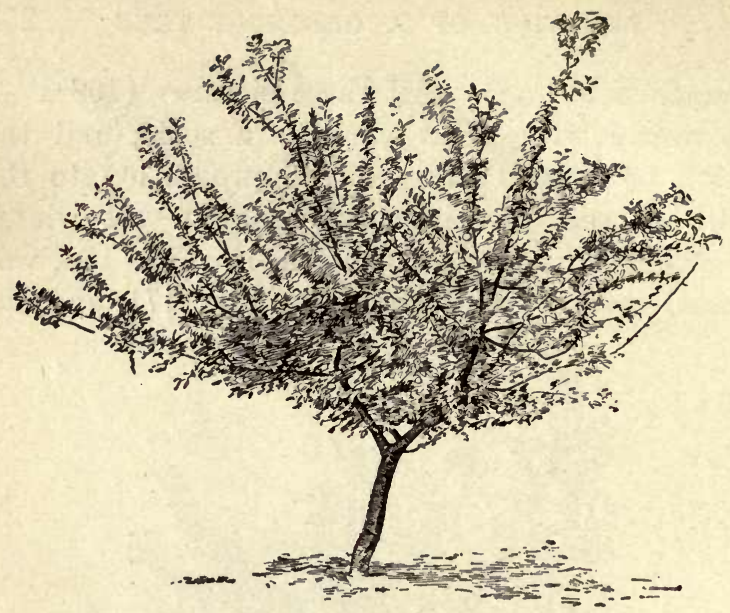

I73. The tree in the fall of 1894 .

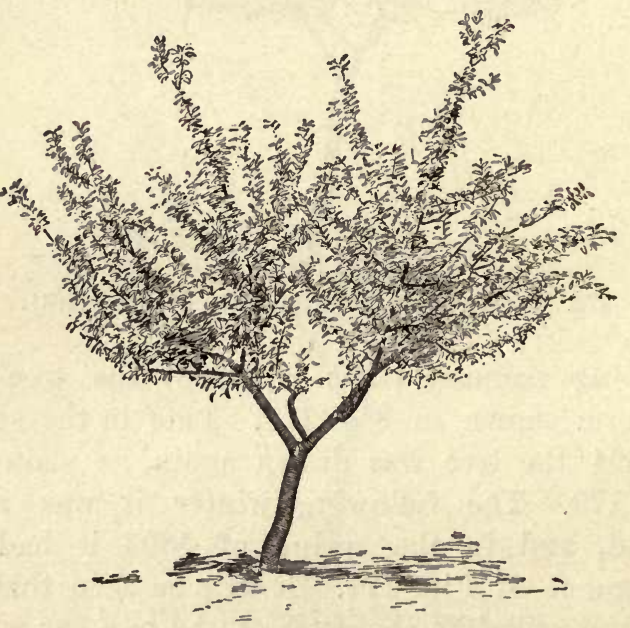

174. In the spring of 1895 , having been pruned in the winter. 
disappeared, and the very perceptible crook in the trunk has tended to straighten. The tree now begins to have character, and its four scaffold limbs are well established. The tree is not ideal in form, however, since it has too much

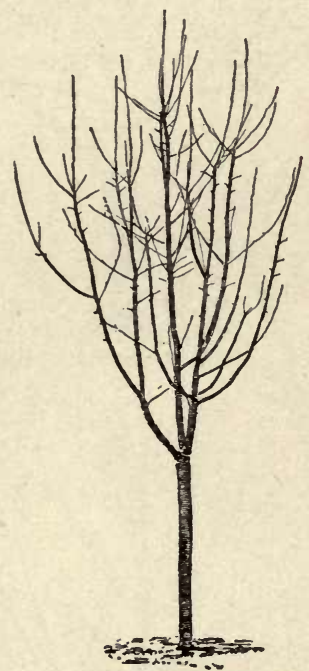

175. Tetofsky apple tree.

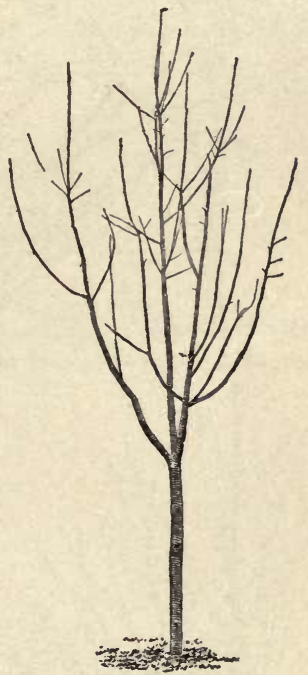

176. The Tetofsky pruned.

of a crotch; and at the present time a living brace has been interwoven between the two crotches, as shown in Fig. 109.

A Tetofsky apple tree, two years planted, is shown in Fig. 175. It is a variety which makes very few strong interior growths, and therefore needs comparatively little thinning. It is already 


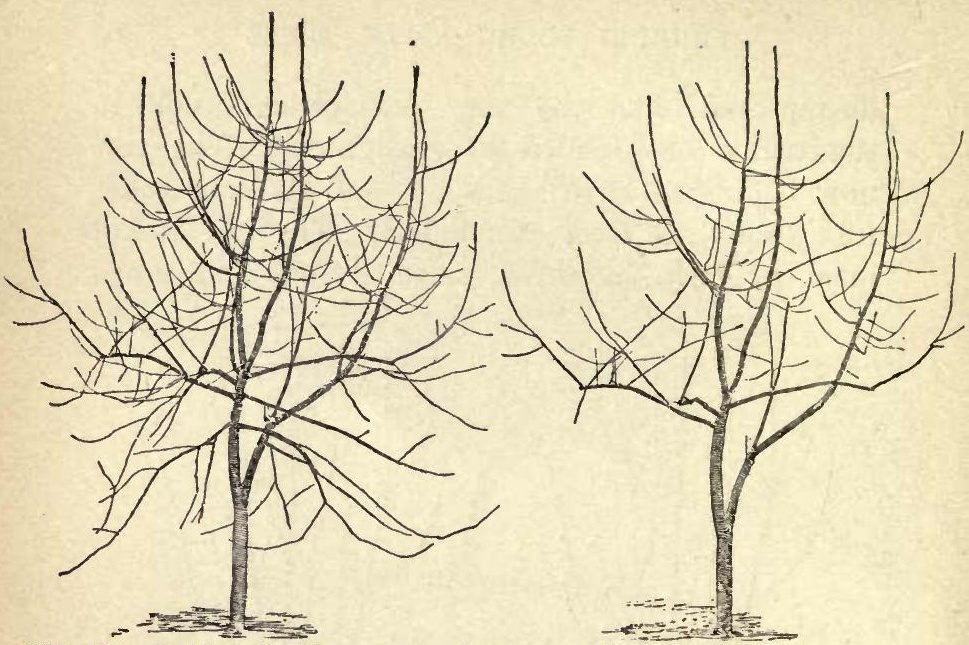

177. Longfield apple, four years set.
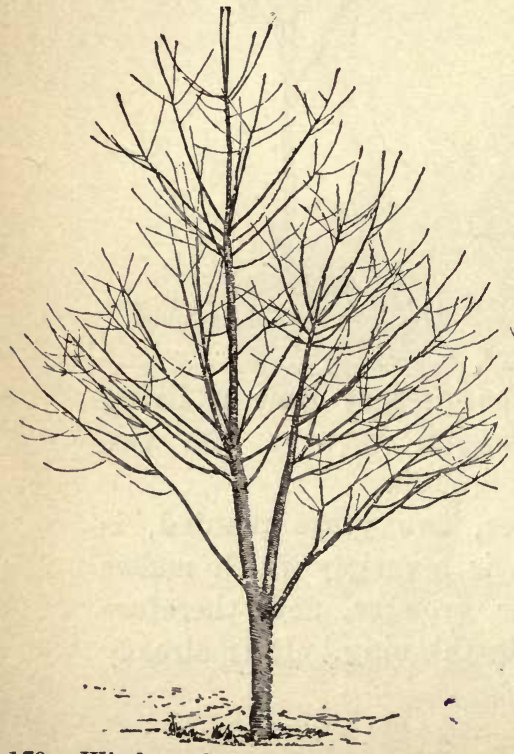

179. Windsor cherry, four years set.

178. Longfield pruned.

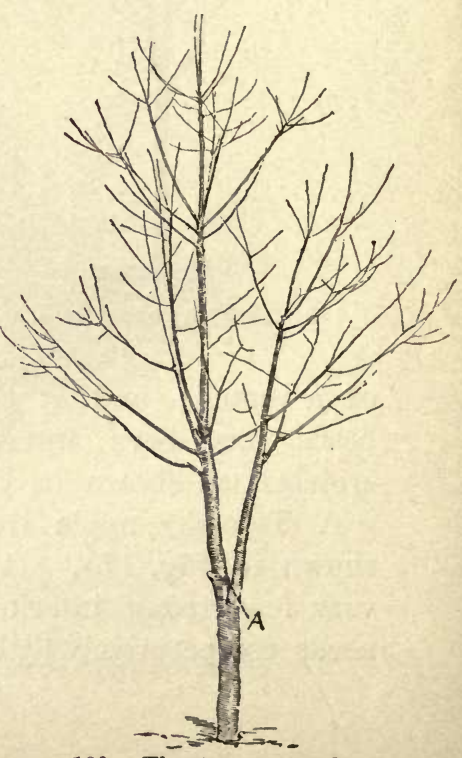

180. The tree pruned. 
making conspicuous fruit-spurs alongside the upright branches. The pruning of the tree is shown in Fig. 176. There are three main or scaffold limbs. Some of the other branches, which are left, it may be necessary to remove as time goes on; but it is always difficult to determine in the beginning just which ones are

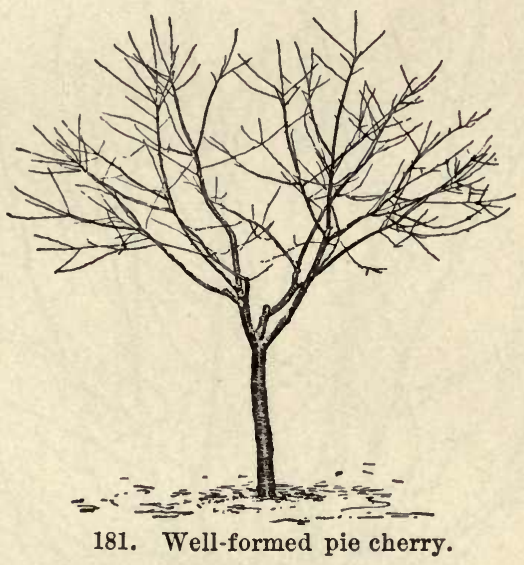

wanted, and it is well not to trim the tree too heavily, so as to reduce its leaf-bearing capacity, and to set it into too strong growth of watersprouts.

A Longfield apple tree is shown in Fig. 177. The variety has a weeping habit, and the effort must be to encourage the upper limbs and to remove the lower or drooping ones. How this 
is done is shown in Fig. 178. The tree was started too low in the first place, and it has a bad crotch; and later on, the large fork on the right was entirely removed. It then had

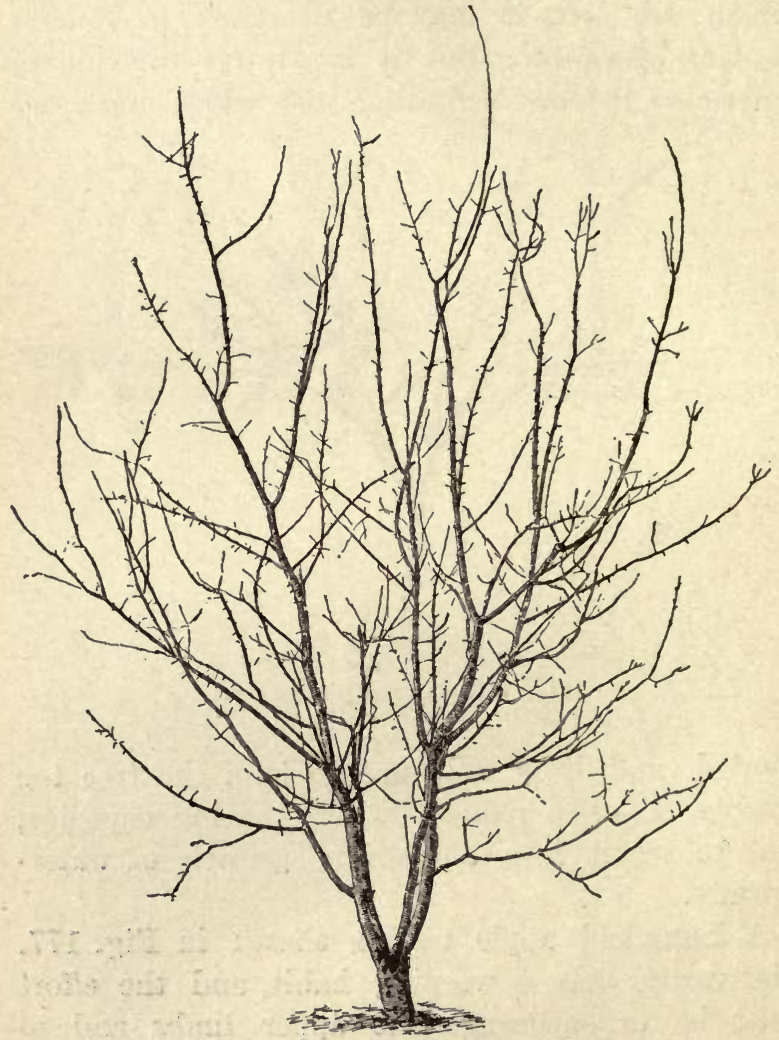

182. Apricot in need of pruning. 


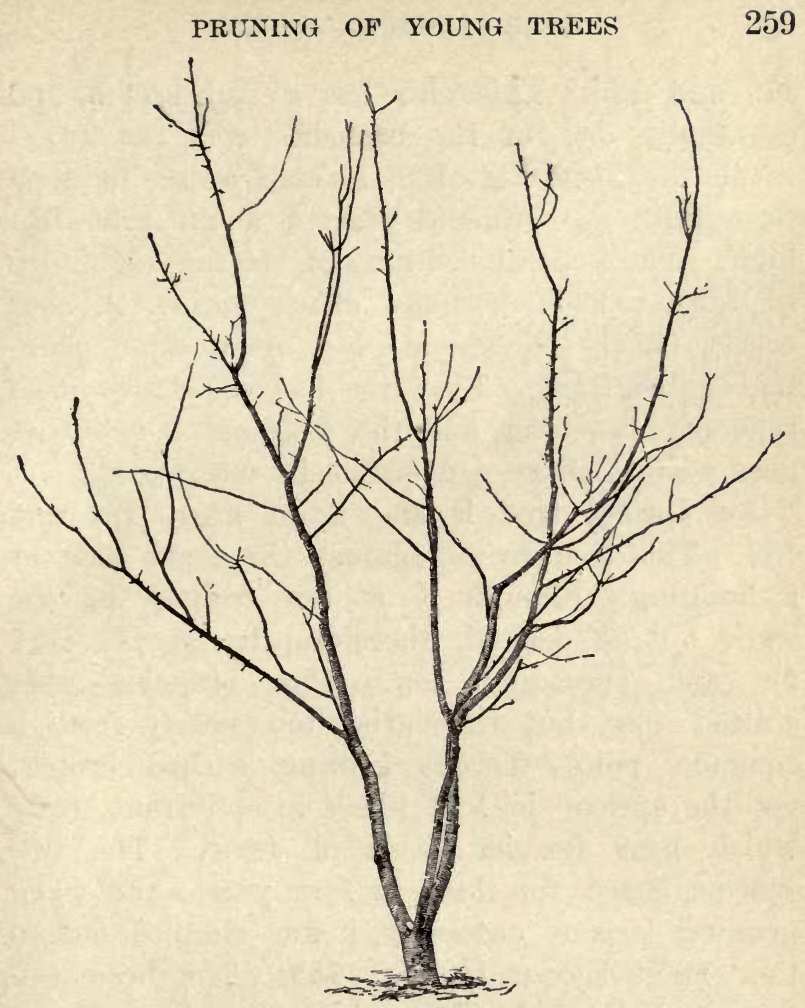

183. One way of treating Fig. 182.

a good form, but the tree is now weeping as much as ever; that is, it is impossible to overcome the natural habit of the tree, and however high the Longfield may be trained, it will eventually reach nearly or quite to the ground.

A sweet cherry (the Windsor) is shown in Figs. 
179 and 180. This also has a bad crotch, and eventually one of the branches was cut away, as shown in A, Fig. 180, leaving a tree of good form, with the branches started about four feet high. The general thinning of the top, as shown in Fig. 180, is perhaps about right. A sour cherry (Early Richmond) is shown, after pruning, in Fig. 181. This tree has an almost ideal type of branching, and the pruning is about as near perfect as we can ordinarily make it.

An apricot tree is shown in Figs. 182 and 183. This tree grows against the south side of a building, although it is not trained on the wall. It is desired, therefore, to have a very flat and spreading top. The branches were started low, but they arise too nearly from a common point, thereby making a bad crotch, yet the apricot is less likely to split than trees which bear heavier loads of fruit. The tree was neglected for three or four years, and when pruning became necessary, it was thinned out to the extent shown in Fig. 183. The head can thereafter be kept free and open with only a slight amount of annual cutting.

A neglected peach tree, four years planted, is shown in Fig. 184. It is very thick, and some of the lower branches are weak and almost dead because they have been overshaded by the dense top. This tree was pruned to the form shown in Fig. 185, and is now a handsome and prolific 
W $1(1)$ kis

(n)

(1)

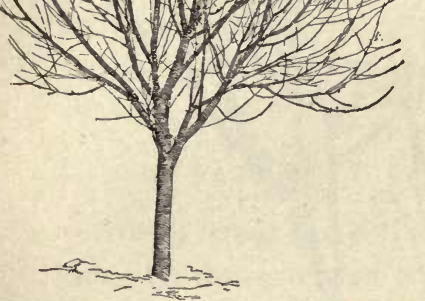

184. Neglected peach tree, four years set.

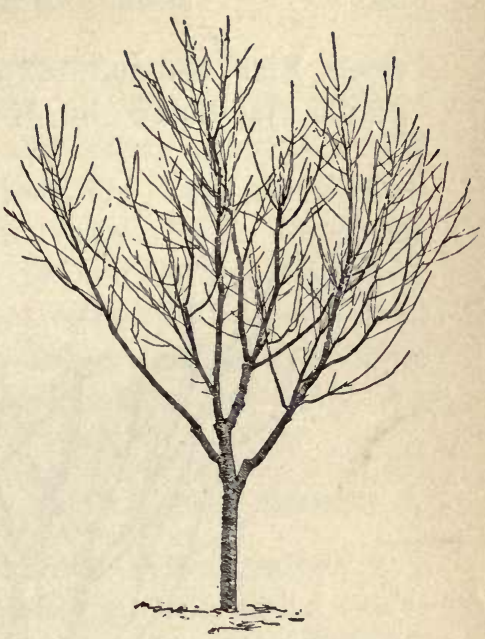

185. The tree pruned.

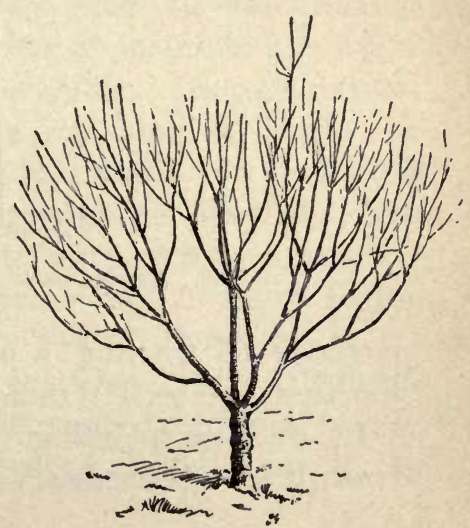

187. The peach tree pruned and headed-back. 
tree. Figs. 186 and 187 are adapted from photographs published by J. H. Hale, to show the

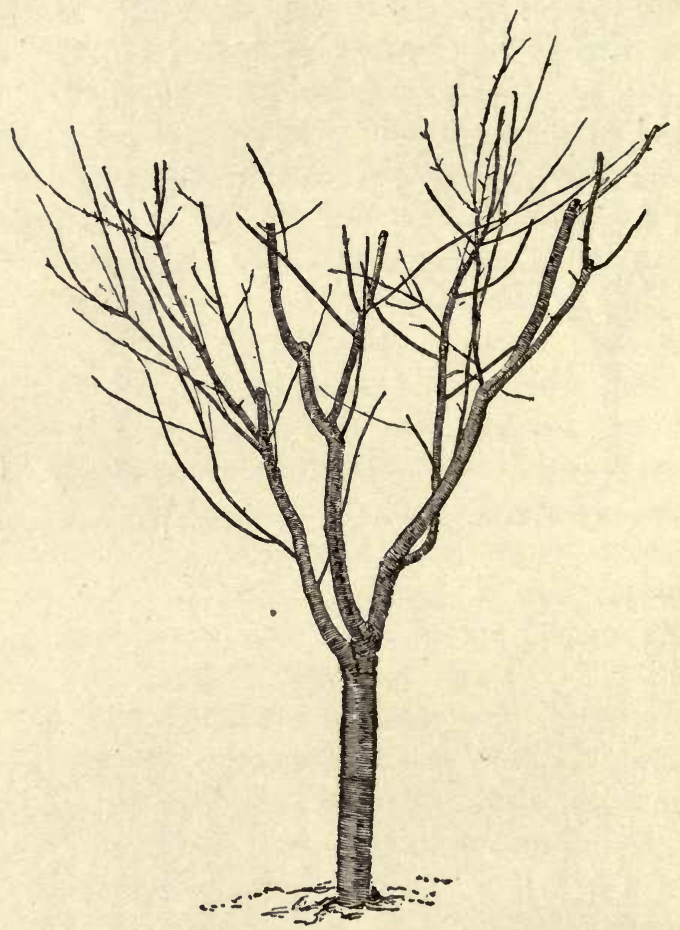

188. Headed-back upon transplanting.

methods of treating a peach tree. In Fig. 187, the tree has been thinned and headed-back.

In the transplanting of large or established trees, it is very necessarv that the tops be headed- 
back, and the more serious the cutting of the roots, the more extensive should be the cuttingin of the top. Fig. 188 shows a six-year-old cherry tree which has been cut back after transplanting. In all such cases, it is important that old and dry stubs are not left on the trees. The stubs should be cut back from time to time as new branches start, always giving preference to the strong growth, and cutting out the feeble wood.

\section{MANAGEMENT OF TOP-WORKED TREES}

When trees are top-budded or top-grafted, it is usually the purpose to change their entire top to the new variety. The methods of performing the work, and the general position of the buds or grafts, are somewhat fully discussed in the last edition of "The Nursery-Book." In old trees it is generally desirable to graft all the leading limbs, thereby endeavoring to maintain the original shape as nearly as possible. In young trees, only two or three of the limbs can be grafted or budded, and sometimes the whole top is eut off and the main stock or trunk is grafted. The grafting of the main trunk has some disadvantages, because a bad fork is apt to occur at the graft, and it is usually better, therefore, to set the cions or buds in the branches. Fig. 189 shows the treatment of a small apple tree which is topbudded. Three buds are inserted, one in the 
main trunk or leader, and one in each of the two side branches. The buds are inserted in summer,

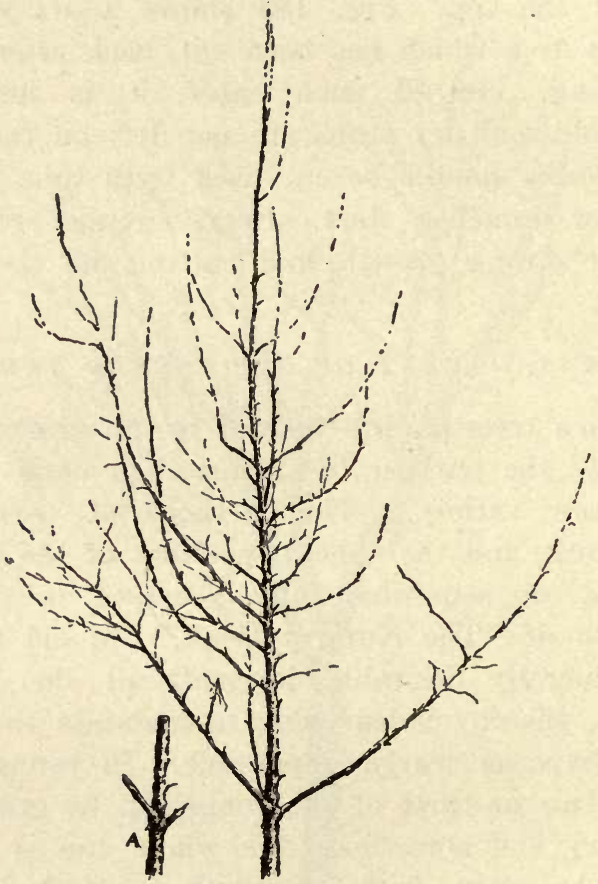

189. Top-budded apple tree.

and early the next spring the limbs are cut a quarter of an inch above each bud, as in A. Fig. 190 shows another tree in which many buds have been set, all of which are growing. It shows that the stubs project beyond the buds. As soon as the 


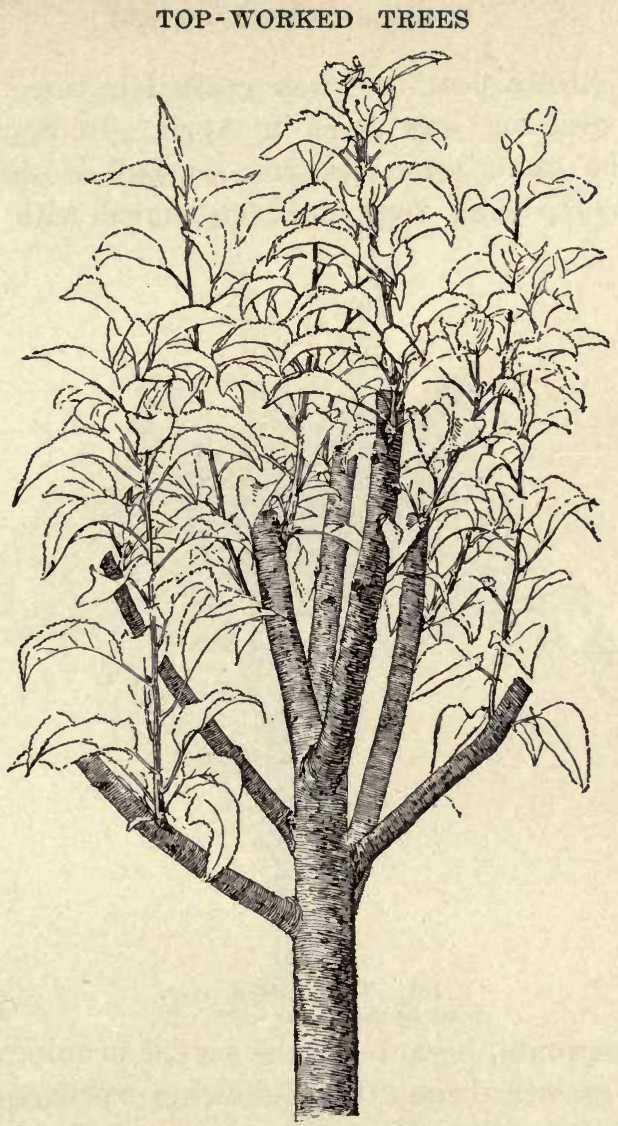

265

190. Top-budded apple tree.

buds have begun to grow vigorously, these stubs should be cut back close to the base of the new branch, to facilitate their healing over. 
A strong pear tree was grafted in three limbs. The grafting was done in April. In September of the same year, the tree looked as shown in Fig. 191, being very much entangled with strong

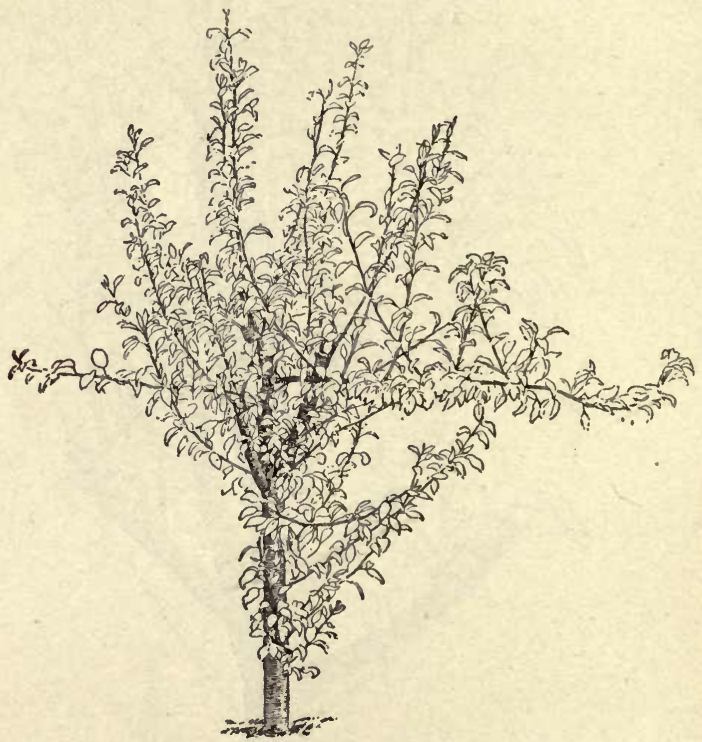

191. Top-grafted pear.

watersprouts, because of the severe pruning. Before growth began the following spring, all of this adventitious growth was removed, the tree then looking like Fig. 192. Some of the branches of the stock were left, since the grafts were not yet large enough to form the whole top. If too much of the stock is eut off the cions tend to 
grow too long, and are likely to be broken by snow and wind.

In trees which have been set only two to four years, the top can be changed in two years;

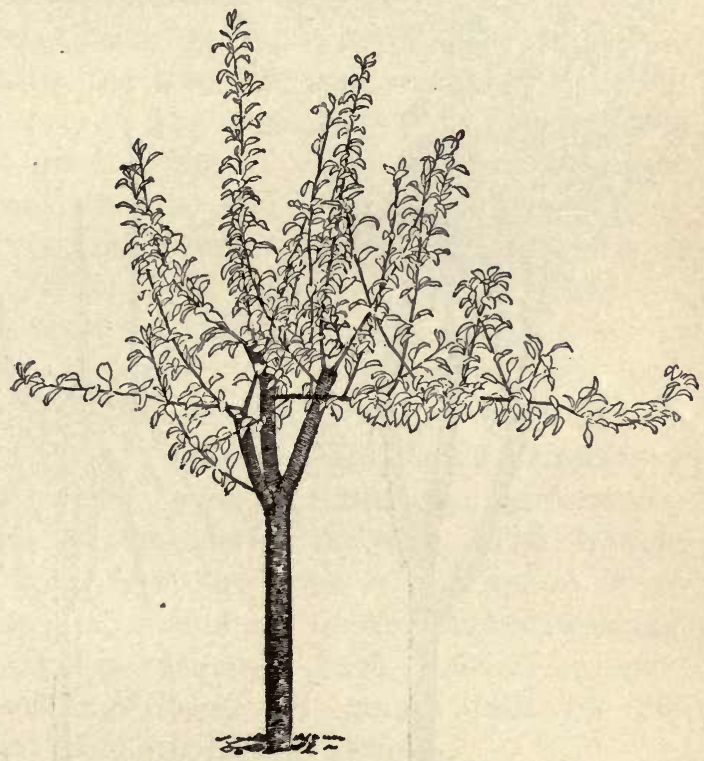

192. The pear tree pruned.

but apple trees which are fifteen or twenty years old can ordinarily not be changed so rapidly. Four or five years may be required in some cases. Fig. 193 is a Lombard plum tree which was grafted to a Japanese variety. The tree was four years old when grafted, and the second year there- 


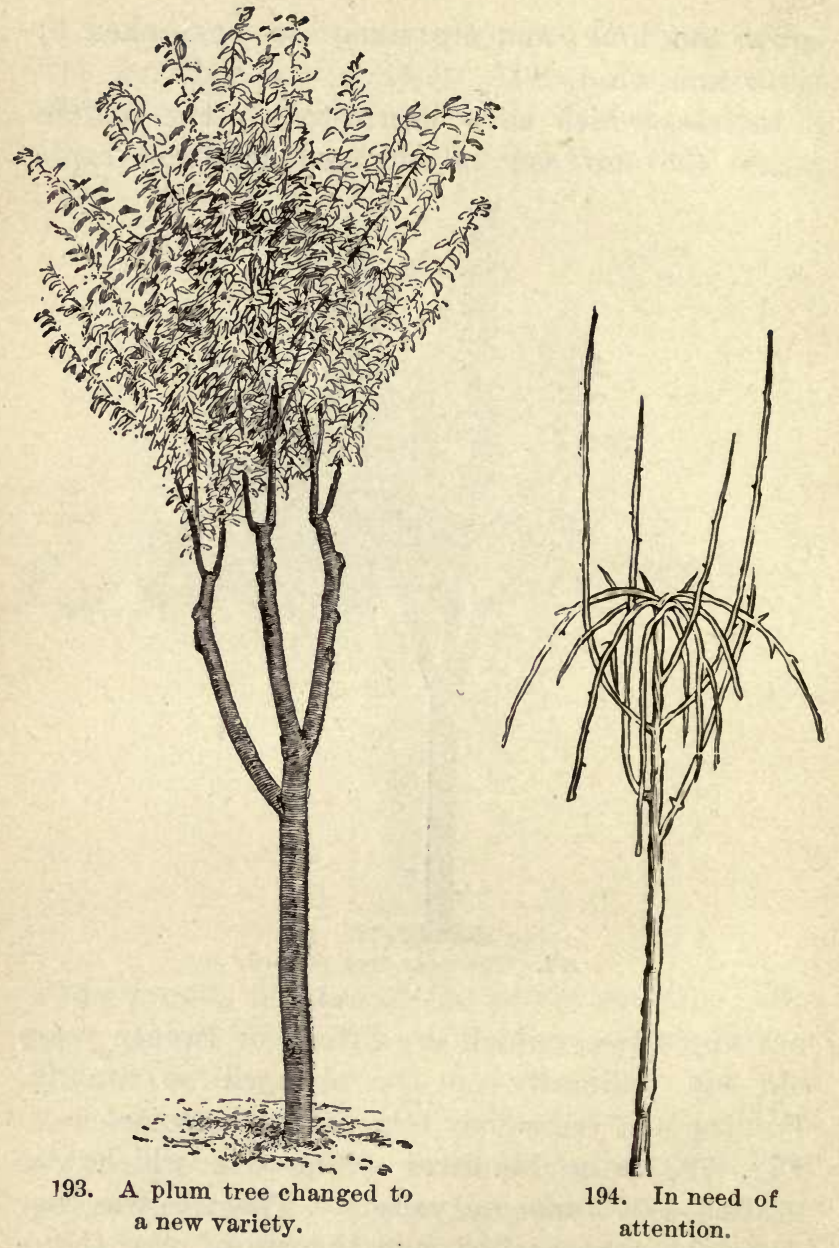


after all the old top was removed, as shown in the illustration. It will now be necessary to cut off some of the cions and to thin out the top, much as if the tree were recently planted.

It is always essential that the operator look out for adventitious growths or suckers from the stock, after the tree has been changed to the desired variety. The equilibrium of the tree has been so much upset by the heavy pruning that these watersprouts and auxiliary growths may arise for several years. Fig. 194 is a Kilmarnock willow. This is a weeping variety, which is grafted upon a strong, upright-growing stock. In this case, the stock has thrown out long suckers, and the drooping head is beginning to famish and die. These suckers should be removed as soon as they begin to form, else good results cannot be obtained with the cion. This trouble of suckering from the stock is very apt to occur in ornamental plants, as in top-worked weeping and variegated varieties. Such varieties are generally weak growers, and cannot take up the exuberant strength of the root.

\section{MANAGEMENT OF DWARF TREES}

Dwarf plants are those which do not attain to the normal or habitual stature of the species or variety to which they belong. There are two general categories of dwarf plants,-dwarf varieties, and dwarf individuals. The former class 
retains its dwarfness of itself, without artificial aid. It is the nature of such plants to be dwarf. The manner of their origin is usually obscure, and it appeals to the plant-breeder.* The second class is forced to be dwarf by some treatment which is applied to each individual plant. Plants are dwarfed by three means, -

By grafting or budding on a slower-growing root;

By confining the tops by means of pruning or training ;

By confining the roots by means of pruning or by growing in pots, boxes, or other restricted place.

The first category is not a subject for discussion in a pruning-book, but it may be said that it is not enough that the plant be worked on slowgrowing root: it must also be systematically headed-in if its stature is to be kept within bounds. This is true of dwarf pears, dwarf apples, dwarf cherries, and all the rest.

Root-pruning, as a means of limiting growth, has already been discussed (page 227). In practice, it is nearly unknown in this country. In small areas it can be employed, but it is inapplicable to our commercial plantations.

*A discussion of dwarfs from the breeder's standpoint may be found in "Plant-Breeding;" from the propagator's standpoint, in "The Nursery-Book;" and from the fruit-grower's standpoint, in "Principles of Fruit-Growing." 
Top-pruning of a dwarf has two objects,-to limit the growth, and to train the plant to some desired form. Pruning to limit growth is merely heading-back. This should be done every winter. How much the growth shall be headed-back depends on its length and the age of the tree. Dwarf pears and apples which make an average growth of eighteen to thirty inches on their uppermost twigs are usually headed-back a half to five-sixths of that growth. This cuttingback will induce a lateral or interior growth (Section 9, Chap. IV.), and this must be thinned out. It is generally best to prune very late in winter or early in spring, and to cut to within threeeighths inch of a bud (see Figs. 82, 83).

Pruning to secure some desired shape of the top must, of course, be governed by the ideal of the operator. There are two general forms to which dwarf fruit trees are pruned,-the pyramid and the inverted cone. The pyramid is popular in Europe, and the Old World writings contain minute descriptions of the details of pruning for this ideal. Fig. 195 shows dwarf pear pyramids in the grounds of the Royal Horticultural Society, at Chiswick, England. The essential feature of this type of training is a central shaft from which successive tiers of branches are taken.

The flat-topped or inverted-cone-shaped style of training is the commonest ideal in commercial 
American orchards, although there are few plantations in which it has been systematically worked out. Probably the best example of it in America is the orehard of T. G. Yeomans \& Sons, Walworth, New York, an orchard which is still vig-

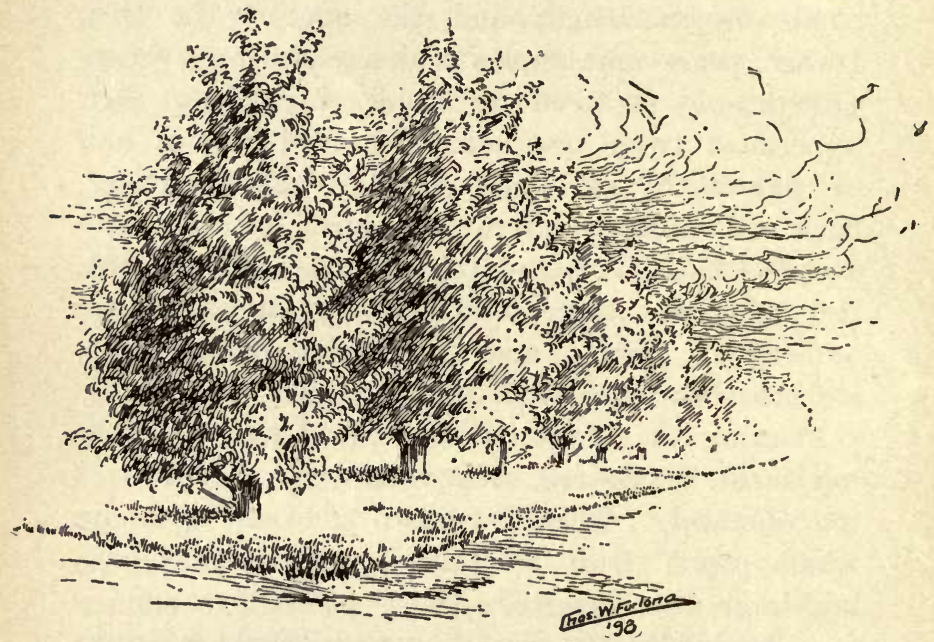

195. Pyramidal training of dwarf pears. England.

orous and productive, although it has been commercially successful for nearly half a century (planted in 1852). Good trees from this plantation are shown in Fig. 196. The essential feature of this type of training-which the writer believes to be the best for American conditions-is a framework of several approximately coördinate branches arising near the ground. 
Since the Yeomanses have been so successful with dwarf pears, it will be profitable to study their description of the method of pruning, and

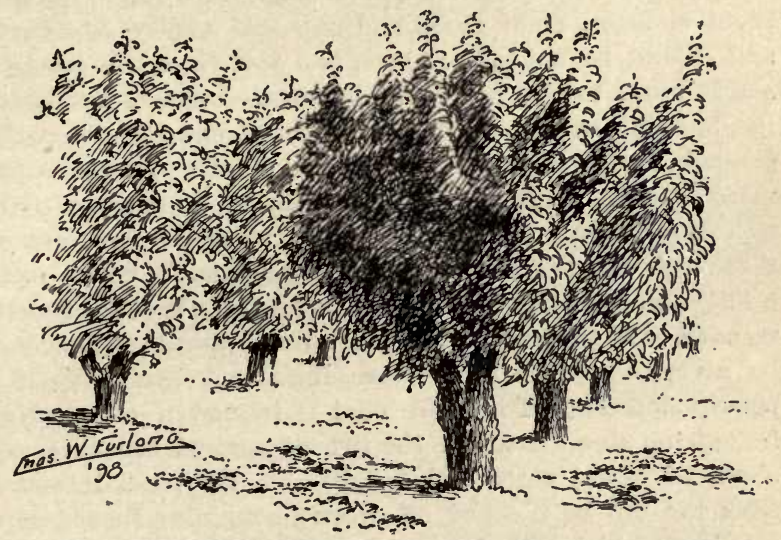

196. Flat-topped training of dwarf pears. New York. These trees were forty-five years old when the picture was taken.

especially so, also, since this account seems to be the clearest exposition of dwarf pear pruning for commercial orchards which is accessible to the American student:*

"Experience has convinced me that, with good trees of well chosen varieties, on any good land, which is never too wet, and with the culture a good farmer gives his other crops, and the important-nay, more, the indispensablerequisite to success,--thorough pruning, - no one need fail

\footnotetext{
*'This sketch is a copyrighted article published in the nursery circulars of T. G. Yeomans \& Sons, at the time when the firm was in the nursery business. Reprinted by permission.
} 
of attaining a degree of success highly satisfactory and profitable.

"A dwarf pear tree should never be planted at one year old. A good one-year-old tree consists of a single upright shoot or stem, from three and one-half to five feet high, and should be cut off at about two feet from the ground; and in order to give a smooth, handsome stem or trunk, let the buds be rubbed off to the height of one foot from the ground, leaving on the upper portion six to nine buds, more or less. With, the tree standing in its original position in full vigor, and cut back as above stated, each one of these buds will throw out a good, strong branch, which gives a full, round, distaff form to the tree. This is the time and manner, and the only time, when that desirable shape can be given on which the future form and symmetry and beauty depends. To aroid what is termed a crotched or forked-top tree, in which the two uppermost branches are about of equal vigor and height, let the second branch from the top be pinched off when about nine inches or a foot long, which will check and weaken it, while the uppermost one becomes a strong, central leader. Whereas, if the tree be transplanted at one year eld, and cut back as above stated, the vital forces of the tree will be weakened half or three-fourths by transplanting, and as the result, only two or three (more or less) of the buds on the trunk will grow so as to form branches, and they, perhaps, only at the top or all on one side, while the remaining buds remain dormant, never afterwards to be developed, as the other branches form new channels, which will more readily carry the sap to the other and upper portions of the trees.

"For transplanting, therefore, let a tree be two or more years old from the bud, well eut back at one year old, and with six to nine main branches, which form the framework or foundation, which is to give form and character to the future tree, with proper care and management.

"The annexed eut (Fig. 197) will illustrate a two-year-old 
tree, as above described, its lower branches about one foot from the ground, its upper branches being the strongest and most upright, and those below less vigorous and more horizontal. I speak of this more particularly for the reason that all the cuts which I have noticed in works on pomology, and in agricultural papers, represent a two-year-old tree, with branches much the longest and strongest at the bottom and diminishing in vigor towards the top, except, perhaps, the center top branch; while all experience illustrates the principle that the sap flows most freely and readily to the upper branches, giving them vigor, strength and uprightness, to the diminution of the same characteristics in those

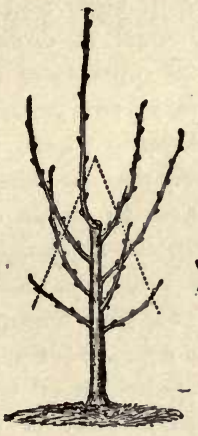

197.

Treatment of two-year-old dwarf pear tree:

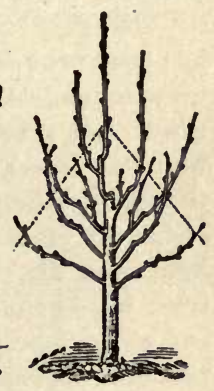

198.

Treatment for a threeyear-old tree.

below. The dotted lines indicate where the branches should be cut back at the time of planting.

"In cutting a tree, with the branches formed as above described, let the leader be eut down within four or six inches of the place where the one-year-old tree was cut off, and just above a good bud on the side of the tree over the previous year's eut, thus keeping the leader in a perpendicular position over the original trunk or bottom of the tree.

"If the side branches aro too horizontal, upper buds are left for their extension; if too upright, lower buds are left. Side direction may be given, if desirable, to fill wide spaces, in the same way. Cut the other branches at such a distance from the trunk that the ends of them will form a pyramid, the base of which should not be over twelve to sixteen inches in diameter, and in smallish trees much less; thus 
the lowest branches will be left the longest, the object of which is to check the natural flow of sap to the upper branches, and induce it to flow more forcibly to the lower ones, increasing in vigor and force of the latter as much as possible, which must be done at that time or never.

"The Fig. 198 represents a three-year-old tree, after it has been pruned at two years old and made the third years' growth, and showing where it should be cut back at that time. All subsequent pruning will become easy to any one who has attended to these directions thus far-observing the same principles-thinning out or eutting back any secondary or other branches, as shall seem necessary to admit light and air, or give vigor or symmetry of form to the tree; but as the greater force of sap will flow to the central and upright branches, they will need to be cut-back most, retaining as near as may be the pyramidal form. Pruning may be done at any time from November to April."

These trees, shown in Figs. 197 and 198, start out with a pyramidal treatment, but as they mature, they approach the form shown in Fig. 196 ; and the Yeomans trees are now not over twelve feet high, although nearly fifty years old.

Other illustrations may elucidate some of the ways of treating dwarf pears. Fig. 199 is a tree at the end of its first season's growth in the orchard. The forks near the ends of the branches show where it was cut at planting time. Fig. 200 shows the way in which it was again pruned.

A dwarf pear three years set is shown in Fig. 201. The top was started wrong,-with only two branches and these in the form of a crotch. 
When pruned (Fig. 202) two sprouts were left. The tree will now have four scaffold branches; but it will never be a model tree.

A low-branching Duchess dwarf pear is shown in Fig. 203. This variety is a narrow and tall

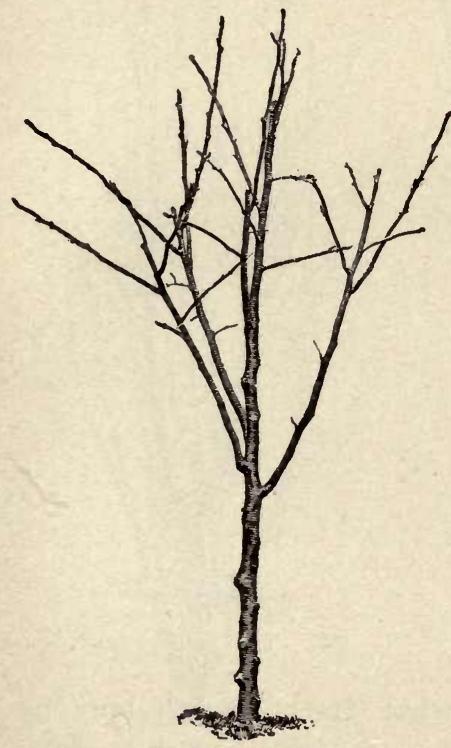

199. Dwarf pear at end of first year in the orchard.

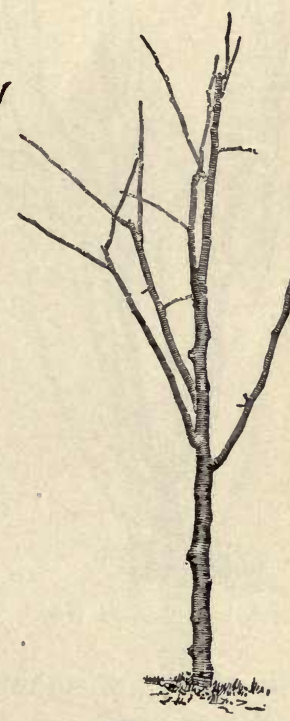

200. The tree pruned.

grower when young. It has a well-marked leader and several scaffold limbs. It is pruned in Fig. 204. This will make a good tree.

The pruning of dwarf apples is essentially like that advised for pears. If the tree is on 
Paradise stock, very close attention must be given to pruning, else the top will become too large for the root. If it is on the larger-growing

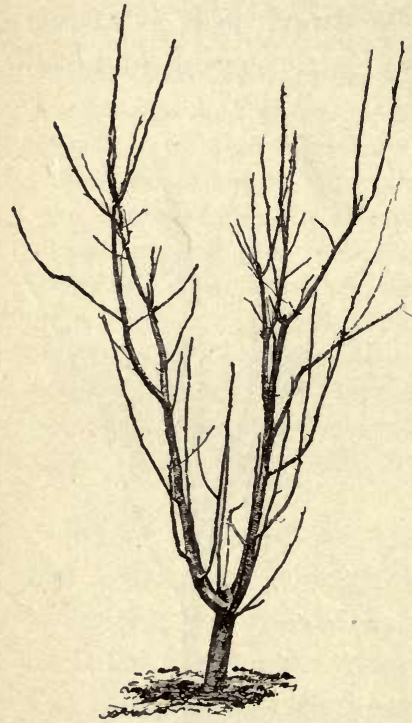

201. A bad-formed tree.

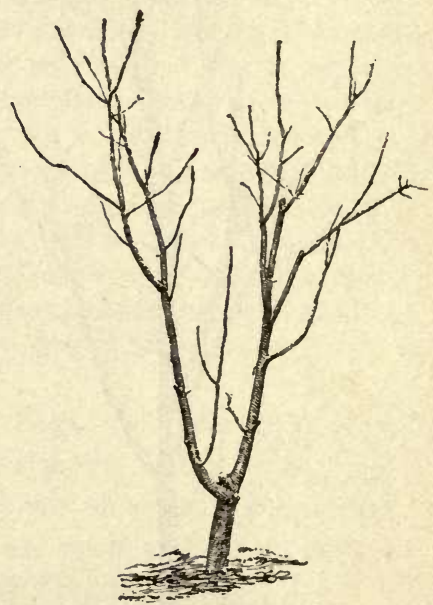

202. The tree pruned.

Doucin stock, a somewhat freer growth may be allowed.

The following remarks on pruning dwarf apples are by Lodeman:*

"Dwarf apple trees should be very thoroughly pruned from the time they are set. The object of this pruning is three-fold: the wood which is eapable of bearing fruit will

*Dwarf Apples, Bull. 116, Cornell Exp. Station. 
be more freely produced, the fruit-spurs will be distributed evenly over all the lower parts of the tree as well as the top, and the tree will be kept in a dwarf habit. These results may not be obtained if too little wood is removed. Each year's growth, if vigorous, should be eut back at

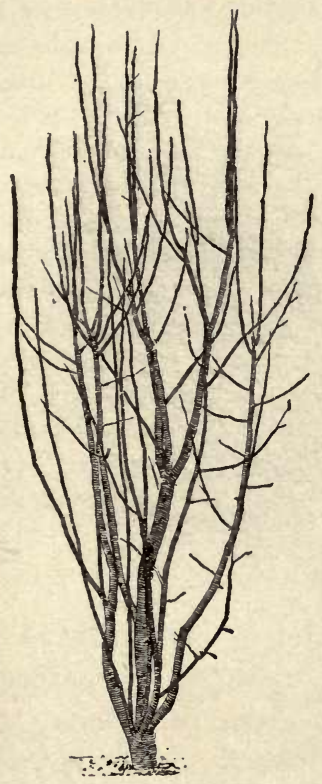

203. A Duchess dwarf

pear, four years set.

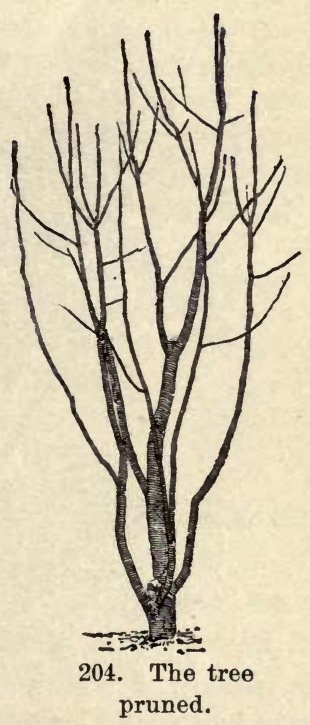

pruned.

least one-half or two-thirds, and generally more may be removed with perfect safety. Occasionally, dwarf trees will be found in which the natural vigor of the cion seems to have stimulated an undue growth of roots, so that the tree, instead of remaining small, increases rapidly in size, and soon it bears little resemblance to the plants fre- 
quently illustrated in books to show how a dwarf apple tree ought to appear. The annual growths may be from one to two feet in length, and at this rate good-sized trees are formed in a short time.

"The tree shown in Fig. 205 represents a good type. The original from which the drawing was made was five

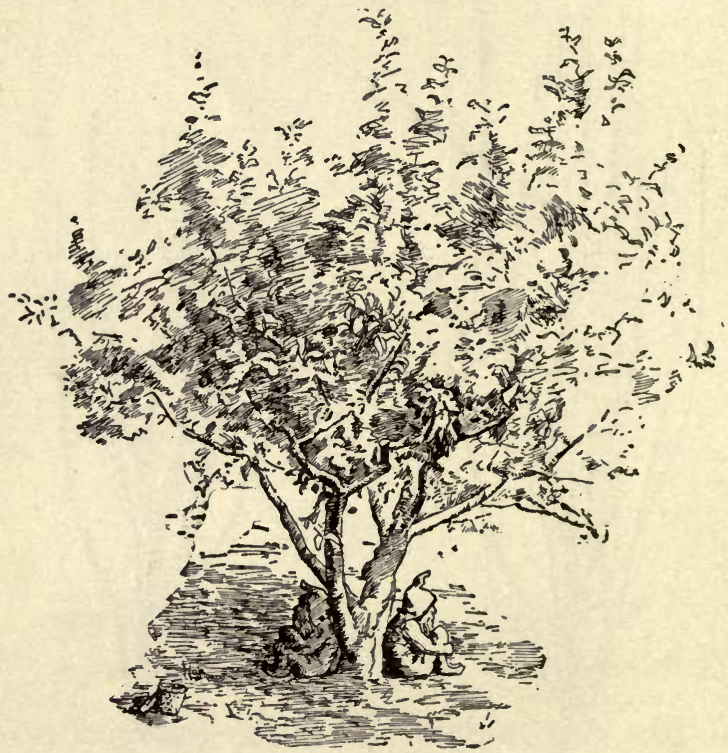

205. A good dwarf apple tree.

feet in height, the lowest leaves being but eighteen inches from the ground. The top has been allowed to assume its natural spreading form, but a firm control has continually been exercised over any too ambitious efforts of the branches. The tree has practically the same form and size which it will retain during its entire existence. The main branches will increase in circumference, the outer 
limbs will gradually lengthen, and the fruit-spurs will become more crooked, yet the tree will always be low and spreading. The one eriticism which might be made is that the lowest fruiting branches are still too high. The foliage of the ideal dwarf apple tree almost touches the ground; it has all its main branches well studded with smaller ones, or with fruit-spurs, so that when in full leaf, it shall appear 'feathered' from bottom to top. * *

"Much wood is allowed to remain near the ground and in the center of the tree, for it is always easier to remove superfluous branches than it is to insert them when they are wanted. The form of the pruned tree is that of a rather broad vase, this being the shape which the tree naturally assumes. During the eoming season, it should be well provided with foliage, so that none of the main branches shall be exposed to the full glare of the summer sun. The fruit produced will also receive proper shade. The specimen as a whole may be considered as a good type of dwarf apple tree which has not been forced to assume a form which is unnatural to it."

\section{RINGING AND GIRDLING}

Girdling is a generic term used to designate the making of a wound completely around a stem. A girdle may extend only through the bark, or deep into the wood. Ringing is a specific horticultural term used to designate a girdle which extends only through the bark. The wound may be a simple incision with the point of a knife, or it may be made by the complete removal of a section of bark. In horticultural practice, girdling into the wood is rarely desirable, and we shall, therefore, use the word ringing. 
We have already seen the philosophy of ringing (pages 161, 166). It promotes fruitfulness of the part above the rings, because the elaborated food is held there, not being able to pass the girdle in its downward course. The fattening of the top, so to speak, is at the expense of the part below the ring. If the bark is not allowed to cover the ring, the root must eventually starve, unless there is foliage below the ring to support it. As a matter of practice, however, the ring is made in spring and is allowed to heal, and the direct effect is, therefore, confined mostly to the year in which the ringing is performed.

Ringing is useful in two ways, - it may set unproductive trees into bearing, and it may modify the fruit which is borne above the ring. The former effect usually does not come until the year following the ringing-sometimes not till the second year. The latter effect is immediate. The philosophy of the one is that the extra food tends to develop fruit-buds ; the philosophy of the other is that the extra food hastens the maturity and increases the size of the fruit already growing.

Ringing to induce fruit-bearing is to be regarded as a special practice. It is generally a last resort,-not because ringing injures the tree (for it usually does not), but because there are more fundamental and general means of promoting fruitfulness (read pages 163-166). If a tree here and there persists in being barren, ring it as an 
experiment. If the whole plantation is fruitless, and has yet received all the eare which legitimately makes for fruitfulness, then ring all the trees; then if they do not bear, graft them or eut them down. Ringing is sometimes done on young trees in test plantations to bring them early into bearing, but young trees are often seriously injured thereby.

Ringing is usually done about the time growth begins to start. It is well to experiment on one or two branches first. Run the point of a knifeblade around the stem, sinking it to the wood. This will usually be sufficient; but removing an inch of bark at this season of the year usually does no harm if the tree is vigorous (see page 116). I have known rings six inches wide, on apple trees, to heal perfectly in a single season, with no dressings applied; but such wounds are unnecessary and dangerous.

Ringing to increase the size and hasten the maturity of fruits is such a well-known practice that reputable societies have long refused to award premiums to fruits which have been modified in this way.* The quality usually suffers. It is customary to make the ring just after the fruit has set, so that individual specimens may be selected. A strip of bark a quarter of an inch wide is often taken out. The part above the ring should bear

\footnotetext{
*See, for example, page 203, 4th Ed. "Horticulturist's Rule-Book."
} 
an abundance of foliage, else there will be insufficient food to support the fruit.

Gaucher remarks* that "the width of the bark to be removed from the whole circumference of the shoot or branch varies between three and five millimeters [a millimeter is $.039 \mathrm{inch}$, hence one-tenth to two-tenths inch]. Wider than this, the cut should not be made, as otherwise it is to be feared the wound would remain open all summer and bring about the death of the part above the cut." "If performed extensively upon a tree," writes Lindley, $\dagger$ ringing "is very apt, if not to kill it, at least to render it incurably unhealthy; for if the rings are not sufficiently wide to cut off all communication between the upper and lower lips of the wound they produce little effect, and if they are, they are difficult to heal."

In 1893 the writer made a symposium $\ddagger$ on ringing grapes, most of which is here reprinted:

"Grapes can be made to ripen earlier and to grow larger if the vine is girdled in early summer. Many fruit-plants have been girdled or ringed for centuries, but the utility of the practice is still in dispute. A mere narrow girdle or incision around the trunk may cause an apple or pear tree to eome into bearing, and as the wound heals over in a few weeks, probably no harm ean result. But the section of bark removed from the grape vine is so large that the wound never heals, and the whole eane is cut away at the annual winter pruning. The renewal wood of the vine is not

*Die Veredelungeu, 364.

† Theory of Horticulture, Amer. ed. 255.

†American Gardening, xiv. 74-80. 
ringed, however, and this maintains the growth of the plant. But it is a question if this renewal wood is sufficient to keep the plant strong and healthy. Grape-ringing is practiced by many growers in the Hudson River Valley, and mostly with good success so far as the precocity and enlargement of grapes is concerned. It is yet a question if it is profitable throughout a series of years and with all varieties of grapes.

"Girdling or ringing various fruit-trees was certainly practiced by the Romans, and the Agricultural Society of France awarded a premium to Buchatt about a century and a half ago for a method of ringing the grape-vine. The practice, both with grapes and other fruits, has had an intermittent history, and it appears never to have become an accepted practice for any number of years. This fact is presumption against the operation. But its application to the American vine is comparatively recent. The first valuable experiments made with the ringing of the grape vine in America were begun in 1877, at the Massachusetts Agricultural College, and the practice has been employed there more or less continuously since that time. A valuable report was made upon the composition of ringed grapes in the report of the Massachusetts Board of Agriculture for 1879.

"The status of grape-ringing in this country may be expressed as follows: Ringing usually hastens maturity and increases size of fruit; it is supposed to lessen the quality of the fruit; its effect upon the vine is not elearly determined.

"The quality of the fruit of girdled vines has been made the subject of much chemical inquiry at the Massachusetts Experiment Station, and as this point is an exceedingly important one, and is under much discussion at present, we have reproduced Dr. Goessmann's analyses very freely. The following table is from Dr. Goessmann's report for 1889: 
Effects of Ringing Grapes, 1889.

\begin{tabular}{|c|c|c|c|c|c|}
\hline NAME aNd CoNdition. & Date. & 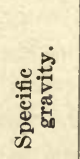 & 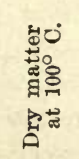 & 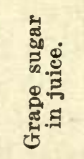 & 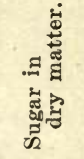 \\
\hline 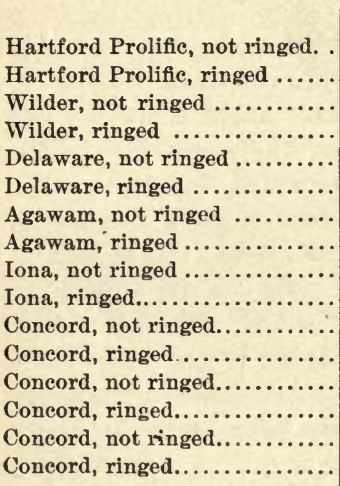 & $\begin{array}{l}\text { 1877. } \\
\text { Sept. 3, } \\
\text { Sept. 3, } \\
\text { Sept. 3, } \\
\text { Sept. 3, } \\
\text { Sept. 4, } \\
\text { Sept. 4, } \\
\text { Sept. 4, } \\
\text { Sept. 4, } \\
\text { Sept. 6, } \\
\text { Sept. 6, } \\
\text { Sept. 6, } \\
\text { Sept. 6, } \\
\text { Sept.26, } \\
\text { Sept.26, } \\
\text { Oct. 5, } \\
\text { Oct. 5, }\end{array}$ & $\begin{array}{l}1.045 \\
1.065 \\
1.055 \\
1.075 \\
1.065 \\
1.075 \\
1.060 \\
1.075 \\
1.0625 \\
1.085 \\
1.045 \\
1.070 \\
1.065 \\
1.080 \\
1.075 \\
1.085\end{array}$ & $\begin{array}{c}\text { Per ct. } \\
12.85 \\
17.18 \\
15.41 \\
17.24 \\
15.75 \\
19.14 \\
16.60 \\
18.45 \\
16.60 \\
21.48 \\
13.46 \\
17.53 \\
17.63 \\
24.47 \\
20.92 \\
\ldots . .\end{array}$ & $\begin{array}{r}\text { Per ct. } \\
8.77 \\
12.50 \\
10.42 \\
14.70 \\
11.76 \\
15.15 \\
11.37 \\
16.31 \\
13.51 \\
15.63 \\
7.46 \\
13.88 \\
13.70 \\
19.61 \\
17.50 \\
17.86\end{array}$ & $\begin{array}{c}\text { Per ct. } \\
68.25 \\
72.76 \\
67.62 \\
85.26 \\
74.66 \\
79.16 \\
68.48 \\
87.42 \\
68.31 \\
72.76 \\
55.42 \\
79.18 \\
78.27 \\
80.13 \\
85.37 \\
\ldots \ldots\end{array}$ \\
\hline & Date. & $\overbrace{}^{\frac{\pi}{4}}$ & $\begin{array}{l}\text { PARTS } \\
\text { CONT }\end{array}$ & $\begin{array}{l}\text { OF GRA } \\
\text { INED- }\end{array}$ & ES \\
\hline $\begin{array}{l}\text { Concord, not ringed........... } \\
\text { Concord, ringed............... } \\
\text { Concord, not ringed.......... } \\
\text { Concord, ringed.............. }\end{array}$ & $\begin{array}{l}1889 . \\
\text { Sept.23, } \\
\text { Sept.23, } \\
\text { Oct. } 8, \\
\text { Oct. } 8,\end{array}$ & $\begin{array}{r}. . . \\
.42 \\
.53 \\
.37\end{array}$ & & $\begin{array}{l}.69 \\
.00 \\
.51 \\
.69\end{array}$ & $\begin{array}{l}6.24 \\
8.13 \\
6.09 \\
8.50\end{array}$ \\
\hline
\end{tabular}

"In 1888, Dr. Jabez Fisher, of Fitchburg, Mass., 'the father of grape-growing in northern Massachusetts,' began experiments in connection with the Massachusetts College 
which have extended to the present time, and have given invaluable results. The following analyses of grapes, which grew from vines girdled by him July 5 , were reported by Dr. Goessmann in Bulletin 7 of the Massachusetts Hateh Experiment Station in 1890:

September 20.

Moisture at $100^{\circ}$

Ash

Sugar

Soda solution required to neutralize acid.

\section{Ringed.} .83 .00 per et. .42 per ct. 8.13 per $c$ t. .84 .4 C.C.
Not ringed. 84.69 per et. . per ct. 6.24 per et. 75 C.C.

\section{October 1.}

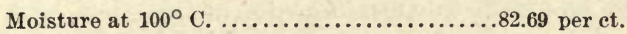
Ash $. . \ldots \ldots \ldots \ldots \ldots \ldots \ldots \ldots \ldots \ldots . .37$ per ct.

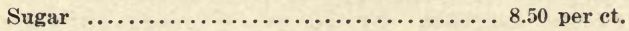
Soda solution required to neutralize acid .... 50 C C.

85.51 per ct. .53 per ct. 6.09 per et. 48 C.C.

"In every case the amount of sugar was greater in the ringed grapes.

"The experiments at the Massachusetts College were, on the whole, satisfactory, and seemed to show that ringing is advisable, and that it does not injure the vine; but Dr. Fisher's experiments upon a larger scale, which are detailed below, show opposite results."

\section{Dr. Jabez Fisher on Ringing}

"Knowing that a number of cultivators had girdled their grape vines for two or three years with satisfactory results, and noting the commendation which began to come from the Massachusetts Agricultural College, I determined to ascertain how much value there might be in the method. I could find no account of any careful experiments directed to this end, and having three acres of bearing Concord vines, well situated for comparative experimentation, I decided to try girdling a few of them. The girdling was done in July, 
1888 , when the berries were about one-fourth of an inch in diameter. The girdled fruit showed color August 24, and the ungirdled September 2, a difference of nine days. A temperature of $29^{\circ}$ on the morning of October 1 killed all the foliage and froze the ungirdled berries, leaving the others untouched, but though the girdled ones were nearly ripe, the season was such that the appreciable amount of sugar they contained was insufficient to give them value for any purpose, and the entire erop was left unharvested.

"In 1889, I girdled, July 2 to 5, one each of two bearing arms on sixty vines. This was done by taking out a ring of bark from one-half to three-fourths of an inch wide around the arm near the trunk. The result of this operation was to increase by 30 or 40 per cent the size of the berries at maturity, and they showed color August 12, while those on the opposite half of the same vines began to color August 18, six days later. September 20, grapes on girdled vines were fit for market, while the others became fully ripe October 1, a difference of ten days.

"In order to get a good understanding of these results and their value, I made a comparison as the matter then stood. I was an earnest inquirer, with little faith, but entirely open to conviction. I had gained ten days in time, which, in an unfavorable season, might mean the difference between success and failure. In addition to this gain, the berries would weigh from one-fourth to one-third more from their increased size, and this, again, would add to their attractiveness and thus help their sale. On the other hand, the normal amount of rain, 3.35 inches during September, resulted in splitting open from 20 to 40 per cent of the berries, the larger proportion on the heaviest and best elusters. This entailed not only the loss of these split berries but also the time required in cleaning the clusters for market, leaving them deformed and unsightly. The 
berries were also soft and did not bear carriage well, and as a result nothing was gained in price from their earliness. There was no opportunity to institute a comparison of quality September 20, as at that time those not girdled were sour and unpalatable. The girdled ones seemed to the anxious waiter to be nearly perfect, but in five, or six days the not-quite-ripe ungirdled ones were preferred, and October 1, when the latter had arrived at perfection, the former were left uneaten. These girdled grapes were comparatively flat, insipid and unsatisfying. They were quite as sweet to the taste as the others but lacked their refreshing sparkle, partly from seeming to be less acid and partly from suggestive, incipient decay. This was the case whether they had been housed September 20 or left on the vines until October 1.

"These results were unsatisfactory. I repeated the experiment, using for the purpose the same vines and adding to their number. In this I was largely influenced by the consideration that if we should have a dryer September, the objectionable features mentioned would be reduced to a minimum.

"In $1890 \mathrm{I}$ girdled, in all, vines covering nearly an acre. They were all Concords, trained on the renewal system, each vine having two bearing arms six feet long. These arms are fruited but once, and replaced every year by new canes grown for the purpose, upon which no fruit is allowed while growing. Half the vines, those in alternate rows, had only one arm girdled. The others were girdled on both arms, which comprised all of the bearing wood except two, three or four central eanes that sprung from the trunk bolow the arms. The operation was performed July 18 and 19. The girdled grapes showed color August 17, the ungirdled August 25. Those girdled were first sent to market September 22, and the others October 3. September 22 specimens of each were sent to Dr. C. A. Goessmann, of the Agricultural College at Amherst, Massachu- 
setts, for analysis, and I give here the percentage amounts of grape-sugar and tartaric acid respectively :

Ringed. Not ringed.

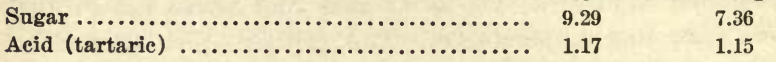

"At this time the girdled grapes were fairly well ripened, very nearly as good as they became a week later, and bet ter than those gathered October 8. They were sweet, with about the right porportion of acid, while those not girdled were quite sour and entirely uneatable. October 8, samples were gathered of each and again analyzed, with the results here given:

Ringed. Not ringed.

Sugar . . . 9.12

6.65

Acid (tartaric)

"At this date the girdled grapes had lost their refreshing sparkle, while the others were quite satisfactory, being sweet and having sufficient acid; yet the analysis tells us that while the former had lost nearly two per cent of sugar, together with more than 36 per cent of acid, the latter had lost nearly ten per cent of the sugar that they contained September 22 when uneatable, but had also lost more than 55 per cent of their acid. It would appear from these analyses that it is not so much the absolute amount of sugar present which renders fruit palatable by its sweetness, as the corresponding absence of an excess of accompanying acid; and that the sense of taste is quite unreliable in judging of the amount of sugar present.

"The proportionate enlargement of the berries was about the same as in 1889, and notwithstanding that more than five inches of rain fell between September 6 and 18, yet, because of the looseness of the berries on the clusters and the fine weather which followed, the girdled crop ripened with only a trifling loss by splitting of berries, so that it was all marketed by the time that the other grapes were 
ready to follow. The average price which the girdled grapes sold for during this time was but very little bigher than that the main crop commanded. Concord here is not early enough to compete with grapes raised farther south, and it brings quite as good prices later.

"An important circumstance forced itself upon my attention about this time. Upon these vines, half of which had been girdled, it was found that the fruit upon the ungirdled arm colored and ripened very slowly. It was so far behind that (of vines not treated, and so general, that the conviction could not be avoided that the girdling of one-half of the vine had correspondingly retarded the ripening on the other half. So prevalent was this tardiness that the crop of the average vine as a whole was less valuable than where girdling was not practiced. A little later it was found that upon those vines that had both arms girdled, where a few clusters remained upon the central shoots not treated, these clusters did not ripen so as to be of any value. They remained red and very sour to the end. This was the point where light began to show through. I had by the operation of girdling been simply transferring the nutritive pabulum that would naturally have gone equally to all parts of the vine to a portion only. The vine possesses in its sap sufficient material, if naturally elaborated, to ripen its entire crop, but if one part of it is caused to receive an excess, there must be a corresponding deficiency elsewhere. Another idea was suggested: whether it were possible for girdled vines to mature and ripen their roots so as to be in condition to furnish a crop the following year. It might be that as the bearing vine was all cut away at the fall pruning, there would be no use for the corresponding roots [if there are such!], as they would die under any circumstances. The new or renewal cane was not girdled, and its particular roots might not be affected by the girdling of the other parts of the vine.

"Having determined that the gain in value of the erop 
by girdling in my case was not enhanced, as a whole, in any material degree, and being in possession of all the conditions for ascertaining the after-effects upon the vine and its roots, I decided to continue the operation no further, but to watch the results in the season of 1891. As the spring opened there was no noticeable difference in the size or appearance of the canes, whatever their previous treatment. It was observed that the buds on the vines that had been girdled broke quite unevenly, that the clusters of fruit-buds were smaller and the early growth of the new eanes less vigorous than with others. This state of affairs was intensified as growth progressed, becoming more and more apparent as the season advanced. While all were entirely healthy, the vines which had been girdled in 1890 showed a decided lack of fruit and smaller and weaker eanes for fruiting in 1892. A favorable autumn made up a part of this difference, and at the close of the season all the vines looked well and the grapes were thoroughly ripened.

"In harvesting the crop I kept the fruit grown upon three different plots separate. No. 1 had never been girdled, No. 2 had had one-half of each vine girdled, and No. 3 both halves. From each plot 120 vines were selected, each lot covering about 11,500 feet. All were contiguous and fairly comparable with each other. After the leaves had fallen, I measured with ealipers the diameter of each new cane of these 360 vines, 720 canes in all, at half their length, three feet, from the trunk.

"In the first column of the following table, 100 is assumed as the product of average ungirdled vines. In the second and third columns, the percentages of the half-girdled and full-girdled vines, respectively, are given. The difference between the whole amount of fruit and that denominated first-class consisted of small and fragmentary clusters, which could be disposed of only at inferior prices. The quality of all the fruit was satisfactory. 
Not ringed.

Total fruit................. 100

Half ringed.

Full ringed.

First-class ................. 100

Diameter of new canes...... 100

83

62

77

97

"I cannot avoid the conclusion that wherever a grape vine will fairly ripen fruit by natural processes, girdling is an operation that cannot be commended, certainly not for its commercial results. Its disadvantages are greater than its advantages. The fruit possesses no attractions for the connoisseur, and one year or more must be given the vine to recover from its effects. It is possible that in some situations or circumstances where the seasons are not long enough to ripen the fruit naturally, a crop might be saved by girdling if the grower were willing to devote the succeeding season to generous feeding, without production of fruit, in order to fit the vine for a crop in alternate years. I doubt somewhat if even this is feasible, as my vines girdled in 1890 have not yet full recovered."

\section{Ringing in the Hudson River Valley}

"For many years, I know not how long, it has been known that by obstructing the return flow of sap in the part of a grape vine bearing fruit, the size of the fruit would be increased, and it would color abnormally early. This could be attained by removing a ring of bark, or binding the branch tightly with a wire. It is only within the last decade that this knowledge has been turned to practical account in America. Some twelve or fifteen years ago, grape-growers in the Hudson River Valley would occasionally exhibitat the fairs enormous specimens of grapes. That the vines producing them had been girdled was frequently charged, sometimes denied ; and if admitted, it was with shamefacedness, and the specimens were generally ruled out of the competition. A little later a few vines were girdled, and their product 
put on the market. The practice grew annually, until now a large proportion of the vineyardists of the region girdle more or less vines. A prejudice against the practice existed in the minds of many who had never experimented in this line, and it was charged that the fruit of vines thus treated was only fit to sell, that the method was destructive to the permanent value of the vines, and was fraudulent and ruinous.

"That some varieties of grapes, when girdled, produce much larger fruit more than a week earlier, without materially impairing its quality, is a fairly well-established fact. About two or three years ago one of the state experiment stations is said to have reported [see previous pages] that girdling increased the amount of sugar in the fruit, improved its quality, increased its size, and hastened its ripening. This statement encouraged the practice.

"That girdling destroys the flavor of some varieties has been well shown; that others when girdled never seem to ripen, or in other words remain sour, is also true. 'A girdled Catawba rivals a cucumber-pickle for acidity, and a Delaware so treated never gets sweet.' Empire State loses all character when girdled, while Martha and Wyoming Red suffer no loss in quality. Concord and Champion are girdled freely without bad effects. Worden and Lady sometimes crack badly when girdled; both are very thinskinned varieties. As a general rule, the more delicateflavored grapes, especially if they contain foreign blood, deteriorate most by girdling.

"The operation is a severe tax on the vine, particularly in a dry season. Therefore, over-bearing must not be allowed. When a vine too heavily loaded is girdled, it will stop growing at about the time for the fruit to begin to color, and the fruit will not ripen. It is the opinion of a careful observer, who has practiced girdling the last five seasons, that 25 per cent less fruit should be left on a girdled arm than on the same arm if left ungirdled. Some vineyardists 
girdle the same vine only every other year; others girdle two of the four arms grown in the Kniffin system of training. All agree that heavy fertilizing is necessary to keep up the vigor of girdled vines. All weak-looking vines are left ungirdled.

"The time for girdling is shortly after the fruit is formed, and when the young grape is about the size of a pea. It is done by removing a ring of bark nearly an inch broad from the arm or branch of last year's wood. One or two shoots of the present season's growth should be left back of

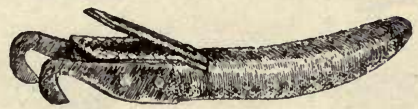

206. Grape ringing-knife.

the girdle for renewal, or for the nex season's bearing wood. A knife is made specially for this purpose; its form is shown in the illustration (Fig. 206). It consists of two hooked blades, attached to a wooden handle, parallel to each other and about seven-eighths of an inch apart. The inner part of each blade is filed to a cutting edge. A chisel-shaped knife is fastened on the back of the handle. In operation the blades are hooked over the vine and the handle passed around it, at the same time holding the blades firmly on the vine; this will eut two lines seven-eighths of an inch apart through the bark. The knife is then lifted from the vine, turned over, and with the chisel-shaped part the ring of bark is severed and lifted from its place. The whole operation is performed in a few seconds.

"The grapes should be removed from the shoots left growing back of the girdle, as it is desirable that these shoots should make a vigorous growth of wood for bearing fruit the next season. The vine beyond the girdle makes a great growth of wood and fruit, and the edge of the girdled spot calluses and partly overgrows the naked wood. Shortly

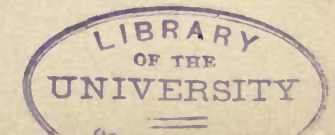


after the fruit has been harvested the girdled part is severed from the vine for the benefit of next year's bearing wood.

"Whether girdling grape vines is a profitable operation or not can be determined only by a succession of carefully conducted experiments. Its real effect on the quality of

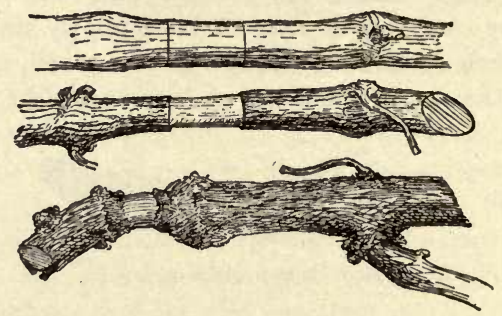

207. The incisions. The bark removed The cane in the fall.

the fruit of those varieties which are best adapted to it is, as yet, not fully determined. Whether two vines, with precisely the same treatment, except that one is girdled annually, will for a series of years show a difference of profit in favor of the girdled one, is only a matter of conjecture. The effect of girdling on grape-juice for winemaking is also yet to be tested. All these are subjects for investigation at our experiment stations.

"The accompanying picture (Fig. 207) shows the effect of girdling in augmenting the size of the eane above the girdle, and also the general shape of the wound."-W. D. B., Middle Hope, Orange County, N. $\boldsymbol{Y}$.

From John Burroughs, Hudson River Valley.

"My opinion of the practice of girdling grape vines is, that on the whole, it is poor business. Grape-growers, I 
fear, are killing the goose that lays the golden egg. If all take to girdling, where is the advantage? It is like the erowd all getting up on chairs at the show; what better off are they? Girdling hastens the coloring up of most varieties of grapes, but hastens the ripening very little, while it distinetly injures the quality of certain kinds. Girdled Delawares are uneatable. People who buy them probably lose their appetite for Delawares for some time. They are as sour as vinegar. Red grapes seem to be injured by girdling more than black ones. Girdled Niagaras are large and pleasing to look upon, but their quality is not equal to the ripe ungirdled fruit. Moore Diamond is ruined by girdling. Wordens are not increased in size by girdling, but they color four or five days earlier. They are, however, much more liable to crack, as are all other girdled kinds. Fruit on a girdled Moore Early is larger and earlier, and the quality is not much injured, but it may erack badly. A vine heavily loaded will not ripen its fruit any earlier by being girdled. Girdle other kinds if you will, but when you come to the Delaware, hands off!"

\section{PRUNING TOOLS}

It is often said that all pruning should be done with a pocket knife, meaning thereby that the pruning should receive such constant attention that the removal of large branches is unnecessary. It is even said that the only safe pruning tool is the thumb and finger, which should be used to pinch out the objectionable growths as soon as they start. Theoretically, these statements may be true, but practically they are of little value, because it is impossible for any person who has 
more than a few plants to give such close attention to each one, and it is often impossible to

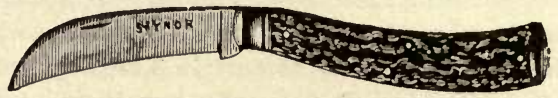

208. Pruning-knife.

tell which branches should be removed until they have assumed their permanent characteristics.

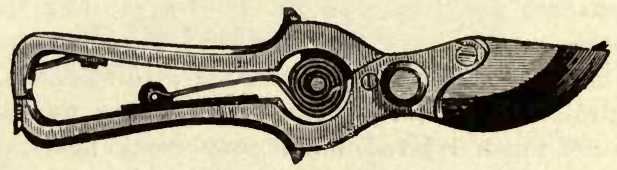

209. Pruning-shears.

The most essential pruning tools are three, a heavy knife (Fig. 208), hand shears (Figs. 209, 210), and a narrow saw (as e, Fig. 211).

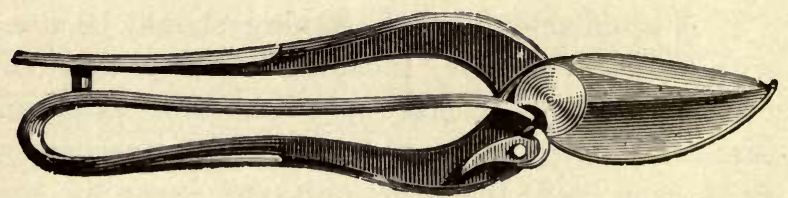

210. Pruning-shears.

Aside from these types, there are various patterns of chisels and hooks.

Various characteristic pruning tools are shown 


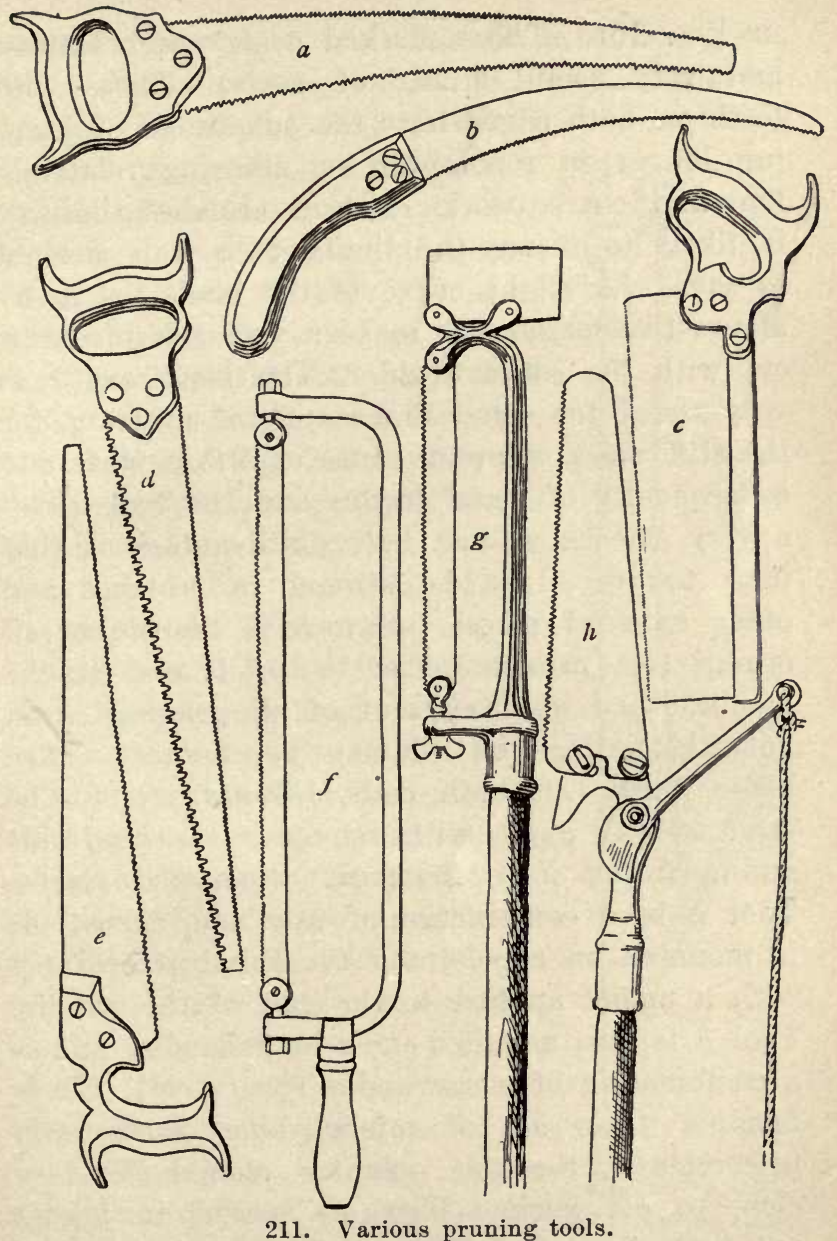


in Fig. 211. Those marked $a, d, e$ are common and very useful kinds of saws. Those with teeth on both edges have the advantage of keeping longer in repair and of allowing relatively fine and coarse work; but in crotches the saw is likely to injure the limb which it is desired to save. A slight curve to the blade (as in a) allows the operator to make a very forcible draw cut with the concave side. The back-saw, $c$, is very useful for small limbs and for grafting, for the stiff back allows the use of a thin plate and consequently of small teeth; and the tool leaves a very smooth wound. Its disadvantage is that it is too broad to be worked in crotches and other crowded places. Saw $b$ is known as an orange-tree pruner. The tool $f$ is one of the handiest and most efficient of all pruning saws, notwithstanding its clumsy appearance. The blade turns at both ends, allowing it to be used at any angle with reference to the frame and adapting it to the most constricted places. Tool $g$ is a combination of saw and chisel. It is mounted on a pole, and the chisel is operated with a mallet applied to the end of the handle. Tool $h$ is also mounted on a long handle, and is a combination of a saw and a shear tool. Longhandled tools are of minor value, particularly in orchards, for the operator should be very close to his work. They are useful in taking out limbs here and there and for use on orna- 
mental trees which are difficult to climb. The Waters' tree-pruner,-which is very useful for heading-in outlying limbs,-works upon the prineiple of the knife in $h$, Fig. 211. A tool of the same principle, but looking upward instead of downward, is shown in Fig. 212.

Other shear tools are shown in Figs. 209, 210, 213, 214, 215, 216. An exchange describes the tool shown in Fig. 216 as follows: "Anyone can make pruning shears like those here illustrated for his own use. The movable shear, to which the pitman rod is attached, does most of the cutting. Both shears are made of thin, hardened steel. From the bolthole in the movable shear, a rod (the pitman) longer or shorter, to correspond with the length of the pole used, runs to the lever shown at the bottom of the cut. In pruning trees and vines, the handle of the lever is raised, which forces up the bar and opens the jaws of the shears. * *

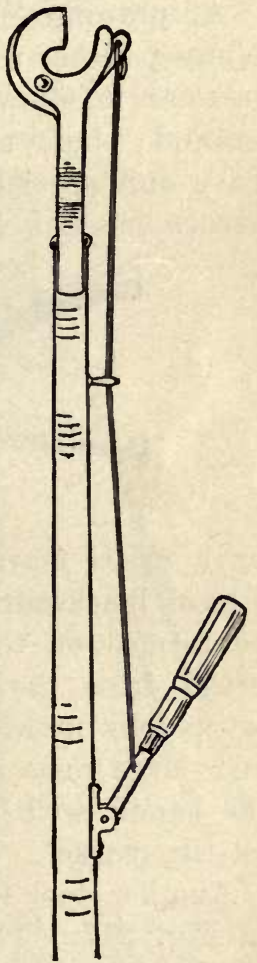

212. A good tool for heading-in outstretching limbs and removing small must be ground at an angle somewhat more acute than that com-branches. 
monly employed for tailors' shears. The highest part of each bevel must come against the bevel upon which it acts."

A pruning chisel is shown at $g$, Fig. 211. Many persons prefer a chisel to all other tools, because it allows the operator to stand on the ground; but, as said above, such implements have only special uses. A two-inch or three-inch carpenter's chisel may be mounted on a stiff pole;

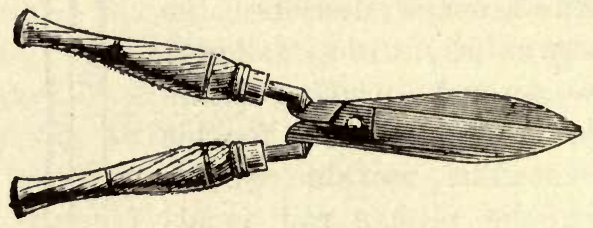

213. Hedge-shears.

or a chisel may be made from a large file by a local blacksmith, and, in this case, a hook may be formed on the side with which to draw the brush from the tree. Small branches may be severed by means of a simple thrust of the tool, and large ones are cut by striking the end of the handle with a mallet. Tools of this type are on the market.

Another tool with a chisel-like edge is shown in Fig. 217. This is an European tool, and is used in pruning forests. Des Cars describes it as follows:* "The best tool for the purpose is

* A Treatise on Pruning Forest and Ornamental Trees," Amer. Ed., 22. 
one which has been used for many years in Holland, and which has lately been improved by Courval (Fig. 217). It weighs 2 lbs. 12 oz., to $3 \mathrm{lbs}$. $6 \mathrm{oz}$, or more, according to the strength of the workman [and is sixteen inches long]. The blade is reinforced in the middle to increase its strength and concentrate the weight. In the north of France this tool is generally hung to an iron hook attached to a leather strap buckled round the workman's waist, who is thus left perfectly free in his movements."

Another European device is the dendroscope (Fig. 218). This is used when it is desired to reduce the top of a large tree to a given form. A figure of the desired form is cut in a piece of cardboard, and a thread or wire is stretched across the opening from top to bottom. The operator holds the card before his eye, bringing the wire against the center of

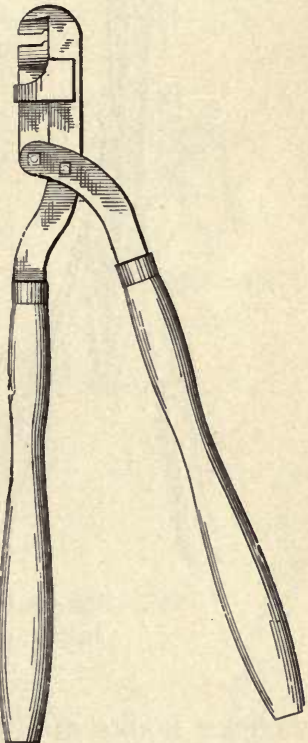

214. Two-hand pruning shears. the trunk, and walks towards the tree until the bottom of the opening strikes the ground line. He can then make a mental note of 
the places to eut the branches in order to produce the desired outline.

For removing the canes from bush-fruits (as raspberries, gooseberries), roses and other shrubs,
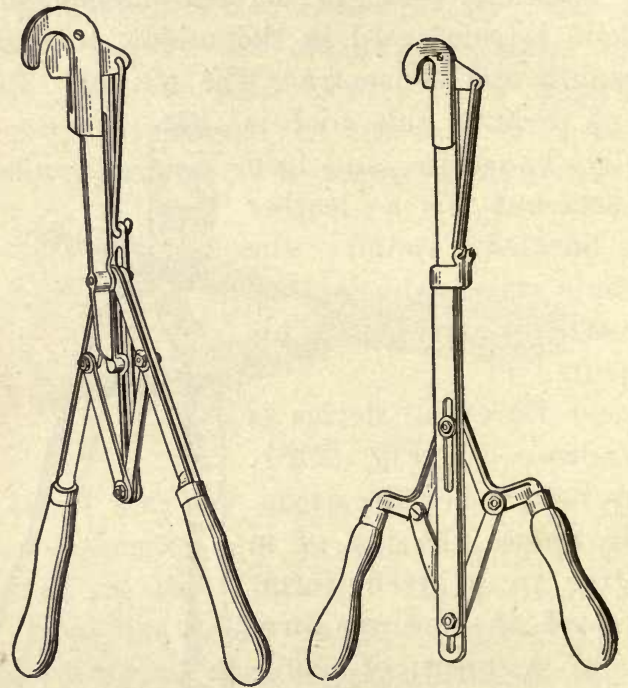

215. Powerful pruning shears. (The Myticuttah, an English implement.)

various hooks and spuds are useful. Three styles of these are shown in Figs. 219, 220, 221.

There are also many devices for cutting the runners from strawberry plants, one thrust of the implement leaving the hill in proper size and shape. One of these is represented in Fig. 222, 


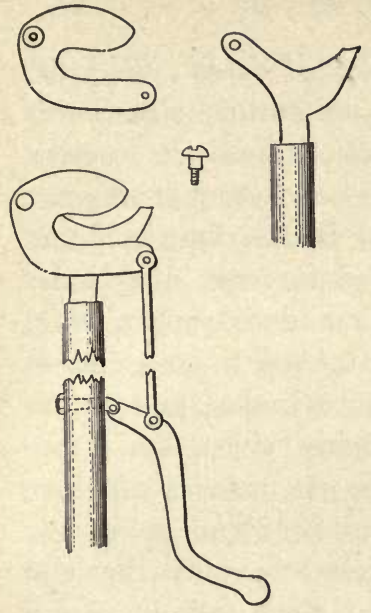

216. Home-made shears.

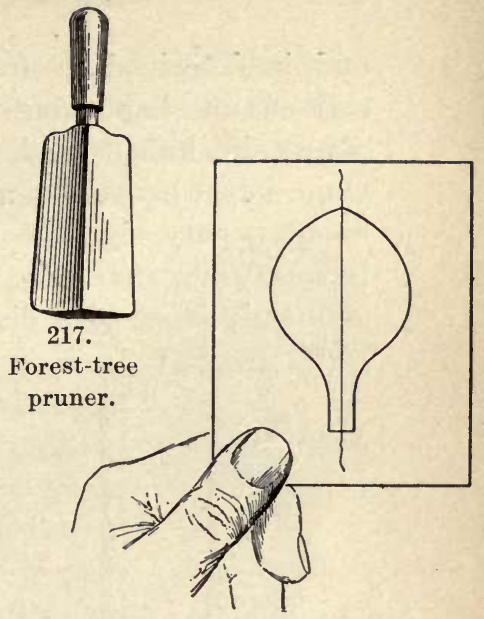

218. Dendroscope.

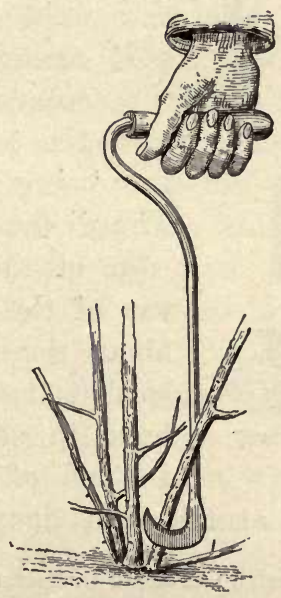

220. Bramble hook.

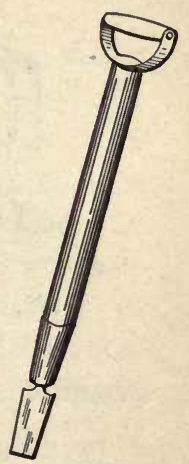

221. Bush spud. 
and is described as follows:* "E. W. Reid described an implement for trimming strawberry plants in hills, which is much used in eastern Ohio. It consists of a piece of heavy sheet-iron about twenty-eight to thirty inches long and six inches wide, the ends riveted to form a cylinder about nine inches in diameter and six inches long.

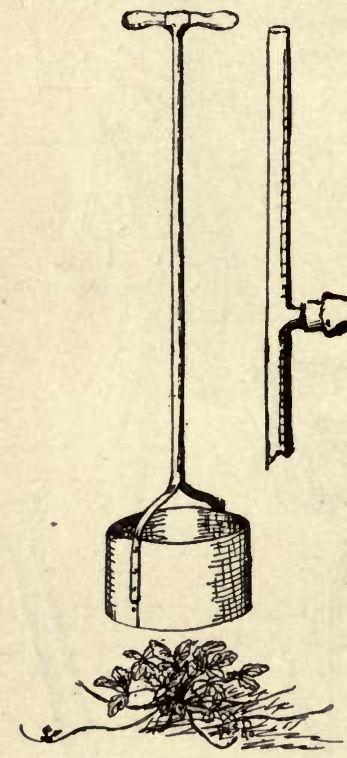

222. Strawberry pruner.

Attached to one end of the cylinder, and on opposite sides, are two pieces of strap-iron which extend about six inches beyond the end of the cylinder and join on the line of the axis to a handle of wrought-iron with a wooden cross-piece at the top, to be grasped in using the implement. The distance from the lower edge of the cylinder to the top of the handle should be about three feet four inches, so that the workman will not have to stoop in using it. Instead of a cross-bar the handle shown at the right may be used. With

*W. S. Devol, reporting meeting of O. Hort. Soc. in American Garden, xii., 175. 
this it is easier to direct the blows, and the use of the implement is less tiresome, because the position of the hands can be changed. The projecting handle should be about the same distance above the cutting cylinder as the crossbars, and the perpendicular projection should reach twelve or fifteen inches higher. The edge of the implement should be kept very sharp, to prevent pulling and disturbing the plants when using it. By walking between two rows and setting the implement down over two hills on

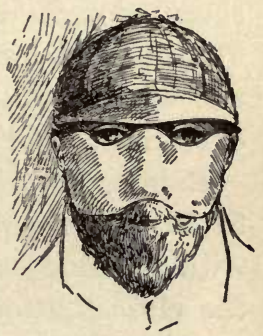

223. Pruning mask. one side, and then two on the other, the runners can be trimmed off very rapidly, and the plants be kept in neat, round hills. The implement appears to be a valuable thing for facilitating the work of the strawberry grower."

A recent writer describes the following mask (Fig. 223) to protect the face while pruning: * "I am pruning, and for the past few years have found great comfort in a mask over the face to keep off the sun and wind. It often makes the difference between being able to stay at work or not during some days at this time of year. I wear spectacles, and to prevent the breath freezing on them, use a stiffish wire hooked behind

*C. T., in The Rural New-Yorker, March 20, 1897. 
each ear and bent around close to the face, just clearing the eyes, and over the nose like a spectacle frame ; on this is run a thick piece of cotton, covering the nose and face to the beard, and short enough not to eatch the breath. A rather loose tape from the corners under the chin keeps the wind from getting under, and turning it up over the eyes."

Balmer describes* the following device in which to burn the prunings: "A matter in connection with pruning, and one which should always have the closest attention, is that of gathering up the prunings. These are oftentimes the harbor of aphis eggs, and the eggs of other injurious insects, and if left lying on the ground too long these eggs may hatch and do a great amount of damage. Our practice is to rake up the prunings into bunches and load them into a wagon, to be hauled away and burned. In parts of California where they have very large orchards, a kind of portable furnace is used; this is a large sheetiron receptacle mounted on four wheels, with an iron frame. In the center of the iron trough is a grate. On this a fire is lighted, and the prunings, having been previously raked with a horse-rake into rows, are loaded on to this fire. A horse is hitched to this portable furnace, and the whole orchard gone over, the fire being kept up all the

*Bull. 25, Wash. Exp. Sta. 
while. This is said to work well in vineyards, but may be too cumbersome for our Washington orchards. At all events, see to it that the prunings are burned and the ashes returned to the orchard."

REMARKS ON SPECIFIC PLANTS

\section{Apple}

The apple tree is a vigorous plant, and should be pruned every year. In very cold climates,as in northern New England, Wisconsin, Minnesota,-it is generally considered to be advisable to delay the pruning until the cold weather is past (pages 143, 184), but in other regions pruning in late winter is the rule. Yet the apple tree, like other fruits, may be pruned in early spring or summer. The average height at which the limbs of apple trees are started is about four feet from the ground; but the height must be governed by climate, variety, and the personal ideals of the grower. From three to five limbs should form the scaffold of the top. When the general form of the top has been well established,-by three or four years of thoughtful attention,-the subsequent pruning consists mostly in removing all superfluous limbs in the center of the top,-that is, those which run crosswise the top, which rub other limbs, or which tend to make certain parts of the top too thick. Avoid pruning all the side 
branches off the main limbs, else these limbs will become too long and pole-like. There are no particular precautions to be observed in the pruning of an apple tree. For spurs and buds, see Figs. 5, 6, 7, 8, 9, 10, 11, 12, 13, 14, 15, 16, 17, 18, 41, 62, 63. For trees, see Figs. 123, 126, 127, $133,134,145,146,147,154,155,156,161,162$, $163,167,168,169,170,171,172,173,174,175$, 176, 177, 178, 189, 190, 205 (dwarf).

\section{Apricot}

The apricot is treated in essentially the same way as the plum (which see); but since some of its fruit is borne on the last year's shoots, heading-in may thin the fruit. For spurs and buds, see Figs. 38, 39, 40, 42, 57, 58. For trees, see Figs, 182, 183.

The following directious for the pruning of apricots in California are by J. B. Neff, ${ }^{*}$ and they may be applied-with minor modificationsto other stone fruits and to other regions:

"Trees of four to five feet in height are preferable for planting, and when planted should be trimmed to a single stem and eut off at eighteen inches from the ground. These will throw out shoots vigorously and frequently two or three shoots from one bud. These shoots should be thinned out, leaving not more than four or five, no two of which should come from one bud, nor be directly opposite. The first shoot should start twelve inches from the

*Before Farmers' Institute, Anaheim, Cal., Apr. 9, 1897. 
ground, the others in such a manner as to divide the space and make the branches balance, leaving the top shoot to form the central part of the tree. It will be necessary to go over the trees several times the first year to remove shoots that may start where not wanted, but no general heading-back should be done, as it tends to dwarf the tree; though if some of the limbs are making an overgrowth they should be pinched-back to keep the head balanced.

"The pruning for the second year should be done in January, as the tree will not be dormant until then, if it has been kept in a thrifty condition. The first year's growth should be cut back to within five to ten inches of the body of the tree, and all forks should be cut out, even if it necessitates forming a new head, as it is much better to lose some growth on a young tree than to take the risk of splitting down when the tree begins to bear fruit.

"When the shoots start for the second year's growth, take off all that come on the under side of the limbs and thin to one, two or three, as may be needed to balance the tree, bearing in mind that an apricot tree always inclines toward the coast breezes in this locality. The second year will require much more attention than the first year, in order to keep off suckers and all lateral growth that may start on the under side of the new limbs, the object being to make the limbs grow as near upright as possible. The remark on heading-back holds good for the second year also.

"The trees will become dormant earlier the second year than they did the first, but should not be trimmed earlier than December and a month later is preferable, as the ends of the limbs are not exposed to the drying winds so long before the sap begins to flow and consequently will heal over better. The second year's growth should now be eut back to within fifteen to twenty inches of the old wood, except the central stem, which may be left twenty- 
four to thirty inches long, depending on the number of laterals it may have thrown out.

"When the new shoots start they should again be thinned down to two or three on each limb and all taken off that tend to turn down or out at right angles. The trees will need to be gone over about three times before July, to remove suckers and lateral growth that may start on the lower side of the limbs, as the tendency in the third year is to make an immense growth of downward laterals, and these must be taken off so as to develop wood that is to be left for fruit. If the orchard is on good land and has been properly irrigated and cultivated, the trees should now be large enough to begin to yield fruit.

"The object in trimming during the first two years and the first half of the third year has been to grow a vigorous, upright tree with strong limbs, eapable of carrying a heavy load of large fruit, and to get the fruit as close to the body of the tree as possible.

"There will be a few specimens of fruit the third year, and as soon as these are gathered the trees should be summer pruned for the first time, care being taken that the land shall have been allowed to become moderately dry, so that the trees may be partially dormant. If the downward growth of the laterals has been kept cut off, all that remains to be done is to cut off about onehalf of all this season's growth all over the tree, using the same judgment as before with reference to prevailing winds and symmetry of tree. If this is properly done and water at once turned on the orchard, a new growth will be made and the fruit buds for next year fully developed.

"The only pruning necessary in the following winter will be to take out any cross limbs and sprouts that may have been overlooked in the summer.

"After the trees begin to produce regular crops they 
will not grow so vigorously, and the numerous prunings of the first three years will not be necessary, as almost all can be done by summer pruning until the trees get so old that they need the old wood taken out. This can be more readily done without damage to the trees where from twenty-four to thirty limbs are grown, than in the old method of leaving only eight or ten large limbs. When it becomes necessary to take out old wood-as the best fruit grows on new wood-a few limbs can be taken out each year until a full top of new wood is again made."

\section{Cherry}

Remarks on plum and apricot will apply to cherry. For spurs and buds, see Figs. 31, 32, 33. For trees, see Figs. 3, 4, 179, 180, 181, 188.

Of the pruning of the sweet cherry, Powell writes as follows:*

"The eherry orchard will require little pruning after the first two or three years, and before that time the tree can be made to assume any desired form. I believe, however, that in general the pruning should be such as to give the tree a low, spreading head, with a trunk about four feet high, and with the top built out on three to five main arms. We have pursued this method on the Windsor and other varieties, and the trees, instead of growing in the usual spire-shape, assume an apple-tree form. After the first two or three years no pruning is needed, except to remove dead branches, and to keep superfluous branches from intercrossing. The advantages gained from this form of tree are of great importance. First, the body of the cherry tree is less likely to be injured from the hot sun, which causes it, especially on the side of the prevailing wind, to erack and split, exude

*G. H. Powell, Bull. 98, Cornell Exp. Sta. 
sap, and finally to die. The low, spreading head shades the trunk and large branches, and obviates this difficulty to a great extent. In western New York this trouble is not so serious as it is on the black lands farther west. A second advantage, of equal or greater importance, lies in the fact that, if allowed to grow upright, the limbs reach the height of thirty to forty feet in twenty-five years, making it very difficult to gather the fruit and to spray the trees. The bearing branches are always found towards the extremities of the limbs, and the time which men lose in going up and down long ladders is of no small account to the fruitgrower."

\section{Orange}

"The best form of tree is a low-headed, compact growth. It is secured by trimming the young tree, at transplanting, to a straight shoot of four to six feet in height, and tying it to a stake to give it support and straightness. All shoots from above the bud are permitted to grow to shade the trunk and to stiffen it, though a too strong lateral may be pinched. The trunk must be protected from the sun by wrapping with paper or something of the kind, until the leaves do that service. The lower branches will bear the first fruit, and as the tree attains age, they will stop growing and can be removed. Thus the head of the tree is raised gradually, and space is given for the drooping of the higher branches. In the top of the tree, too, the rule for pruning should be to remove the weaker branches which seem to have outlived their usefulness, and thus give more 
room for the vigorous ones. High heading is practiced by some growers. It is open to the general objection to high heading (see discussions on pages 193-203, and page 216). The natural form of the orange tree is undoubtedly superior so long as the tree is not persecuted by pests, and is in a situation where natural conditions favor it. When it is beset by evils its treatment may have to be changed to aid in conquering them." *

For discussion of the treatments to be given frozen orange trees, see pages 146-149.

\section{Peach}

The peach usually bears on the shoots of the previous year; therefore, heading-in thins the fruit. Heading-in also induces a growth of new shoots, and thereby increases the fruit-bearing wood. Heading-in is also advantageous in removing winter-injured twigs. Notwithstanding these advantages. heading-in of the peach is a question of local application and of training the top to some given form. It is more generally practiced on heavy lands-on which the trees grow exuberantly-than on sandy lands. The writer believes that heading-in is less essential to peachgrowing in North America than the literature of

*Wickson, "California Fruits," 449. 
the subject would lead us to believe. In the commercial peach regions, trees are rarely headedin, at least not after they begin to bear. If heading-in is not practiced, the chief attention to be given the tree-after the general framework of the top is formed-is to trim out the weak and dead interior wood by means of handshears. This fine wood dies or becomes weak after bearing, and should be removed. For buds and twigs, see Figs. 34, 35, 36, 37. For trees, see Figs. 124, 128, 129, 143, 150, 151, 152, 163, 164, 184, 185, 186, 187.

The general form of the top for a peach tree has already been discussed (Fig. 124, pages 261, 262). The following remarks by J. H. Hale will still further elucidate the subject:

"Young peach trees allowed to grow at will all the first season after setting should have their three or four leading branches make a growth of from two and a half to four feet each. Fall and early winter pruning has not been satisfactory with us, and therefore all pruning is delayed until late winter or early spring. In the earlier days it was my custom, in trimming trees one year planted, to eut branches back to within twelve or fifteen inches of the main stem; but as this tends to form rather a too close head for the foundation year, I now prefer to leave the first season's growth two and a half to three feet long, and to reserve the severe shortening-in for the second, third and fourth years, particularly the second and third years. Besides the main branches to be eut away the first year, it will be necessary to eut off some lateral branches entirely and to shorten others somewhat. With liberal 
culture and manuring, each of the three or four main branches will, in the second year, throw out from their tips two or three leaders, each of which should make a growth of three to four feet. Early in the spring following pruning should begin, with the object of building a broad, low, open-headed tree. This is best accomplished by first thinning out all erowding inside branches and leaders, and shortening-in all others from one-half to three-fourths of the new year's growth, the closest cutting being in the central top. The third year's work should be on the same general plan; and it will often be found, unless the second year's work was exceedingly well done, that some of the third year's work ought to have been done then. The object of the first three years' pruning is to establish a well-formed tree best suited to forcing the greatest amount of fruit to the highest perfection at the least possible cost.

"After the right sort of tree has been established and trees have reached a bearing age, pruning for a year or two may be continued, partially on the line of a correct tree form, but more particularly as relating to fruit production. And so right here we abandon late winter and early spring pruning, and do most of the work after the fruit-buds begin to swell, so that we can judge on inspection which are alive and which are dead. In years when very few buds have survived the frosts of winter, pruning should be done with the object of retaining a great majority of the living buds, regardless of tree form, which can be somewhat righted the next year. Of course, in years when a good number of buds are found alive, pruning can be continued for form, but as the tree grows older, less and less pruning will be required. The methods here described have in their early years given handsome, even-headed, well-rounded trees, which have been exceedingly profitable, although in later years they have become less shapely. As it is resultsfruit results and dollar results-that count in commercial peach culture, we judge the method to be a decided success, 
at least for sections where winter-killing of fruit-buds is the greatest drawback to success, and we shall follow it closely till some better plan presents itself. There should be no offyear with peaches, except when fruit or blossom buds are entirely killed by frosts. Right culture, proper feeding and pruning should each year stimulate enough new growth to furnish far more buds than are required for abundant erops."

Another view of peach-tree pruning may be presented:*

"The methods of pruning peach trees are the occasion of much discussion among pomologists. The differences of opinion turn chiefiy about three practices,-short trunks with rapidly ascending branches, high trunks with more horizontal branches, and shortening-in or heading-back the annual growth. Each of these three methods of handling or training peach trees has ardent advocates and pronounced opponents. It is probable that each system has distinet merits for particular eases. I believe that the nature and fertility of the soil are the dominating factors in these opposing methods. A system of pruning which fits the slow growth and hard wood of sandy soils may not be adapted to the rapid growth and heavier tops of trees on strong soils. Fig. 124 shows what I believe to be, in general, the best method of pruning peach trees upon sandy or what may be ealled peach soils. It is the natural method. The tree is allowed to spread its top at will with no heading-in. The foliage is comparatively light, and does not place great weight upon the branches, and the trees, upon such lands, do not grow quickly to such great size as upon heavy lands. This method of allowing a tree to make its natural top is the common one in the Chesapeake peninsula and in the

*L. H. Bailey, Bull. 74, Cornell Exp. Sta. 
Michigan peach belt. It will be observed, also, that the picture to which I have referred shows a tree with short trunk and forking branches. It is a prevalent opinion in many places that such trees are more likely to split down with loads of fruit than those which have more horizontal branches, but I think this to be an error. Of course, some care should be exercised to see that the branches do not start off from the trunk at exactly the same height, thus making a true fork or $\mathrm{Y}$. With this precaution, the crotehy trees are no more likely to split than the others, while they allow of a much better form of top, unless the tree is to be headed-in. * * *

"Yet there is much to be said, fairly, for the high-topped trees. They are more easy to till, and it is quite as easy to pick their fruit; and there is less tendency to make long and sprawling branches as a result of careless pruning. On rich lands, it is perhaps the better method. And here is the chief reason for heading-back in this climate,-the necessity of checking the growth and keeping the tree within bounds when it is growing in a strong soil. Whether one shall head-in his trees or not, therefore, must depend entirely on circumstances."

\section{Pear}

Pear trees are generally started lower than apple trees. This is because the top tends to grow more upright, and therefore to be out of the way, and because the trunk is very liable to be injured by sun-scald. Three to four feet is the usual height of pear trunks in the East. The top should be thinned out every spring (preferably before the leaves start); but heavy pruning should always be avoided, because it 
causes a quick growth, and thereby exposes the tree to danger from fire-blight. Removing the fruit-spurs,- which are very prominent in the pear, persisting for several or many years,-is a direct and economical means of thinning the fruit. It is well to keep all spurs and sprouts off the trunk and the lower parts of the main limbs, for if blight attacks these shoots the disease is apt to run down into the trunk and cause irreparable damage. For spurs and buds, see Figs. 19, 20, 21, 22, 23, 24, 25, 26, 27, 55, 56, $59,60,61,117,118$. For pictures of trees, see Figs. 116, 130, 131, 141, 142, 148, 149, 165, 191, 192 ; for dwarfs, 111, 195, 196, 197, 198, 199, $200,201,202,203,204$. For treatment of bodyblight, consult Fig. 101.

\section{Plum}

In the East, most plum-growers prefer to start the top about three or three and a-half feet from the ground. If the top is to be sheared-in, it may be started somewhat higher. Figs. 120 and 121 should be contrasted with Fig. 122, as showing typical examples of headed-in and free-growing trees. The fruit is borne mostly on spurs, and simple heading-in is not a means of thinning. The Japanese and native varieties, however, often bear on the last year's shoots (Fig. 224). Trees bear as well if not headed-in as 
they do when they are headed-in. The practice of heading-in is therefore not fundamental, but is to be determined by the grower's ideals, the

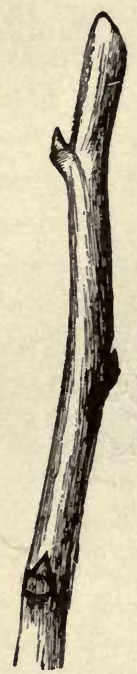

1

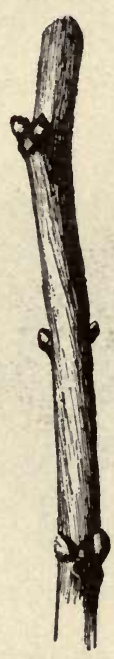

2

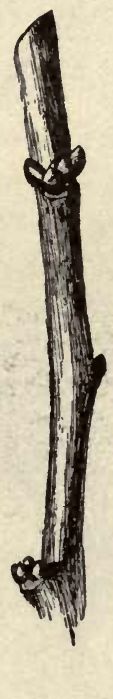

3

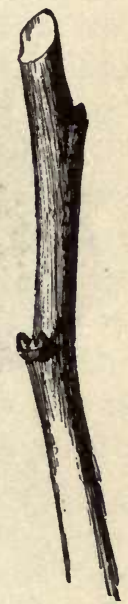

4

Fig. 224. Buds on the new growth of plums. 1, domestica (Coe Golden Drop), leaf-buds only. The others have lateral fruitwuds : 2, Japanese (Burbank); 3, Japanese (Kerr); 4, Native (Wild Goose).

rapidity of growth, distance apart of the trees, and the like. For buds and spurs, see Figs. 28, 29, 30, and compare Fig. 224. For trees, see Figs. 120, 121, 122, 132, 166, 193 . See Apricot (page 310 ). 


\section{Quince}

Quince trees should be headed very low. Fig. 225 shows what may be considered to be model commercial trees. Some people grow them to bush form, but a distinct short trunk is generally

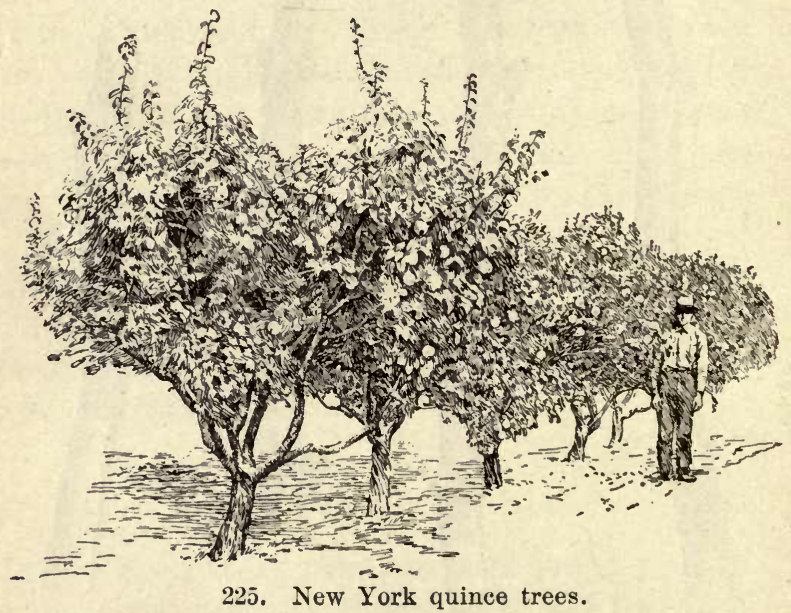

to be preferred. The interior growth is thinned out each winter or spring, and if the growth is very heavy - say eighteen to thirty inches on bearing trees-it may be headed-back. Headingin thins the fruit, since the flowers are co-terminal; but cutting off all the tips generally removes too much of the fruit. For twigs and buds, see Figs. 47, 48. 


\section{Blackberries and Raspberries}

Blackberries, raspberries and dewberries bear on canes which grew the preceding year, and, having borne once, these canes become worthless (read page 64). Pruning of these fruits consists (1) in removing superfluous shoots from the base of the plant, so that too many canes shall not form (five or six to a plant usually being suffcient); (2) in heading-back the shoots when they reach the desired height, eausing them to throw out laterals and to become stocky; (3) heading-back these laterals (usually done the next spring, before growth starts); (4) cutting out the canes after they have borne (usually done the following winter or spring, but should be done, in general, soon after the fruit is off).

Of blackberries, the growing canes should be headed-in, -two to four inches of the tips cut off,-when they are from two and a-half to three feet high. It will be necessary to go over the plantation three or four times for this purpose, as the different canes reach the desired height at different times. Laterals will now push out vigorously, but these are allowed to grow their full length. Early the following spring, these laterals are shortened. There is no rule respecting the proper length to leave these laterals. Sometimes they are injured by the winter, and must be cut-in short. And there is great difference in varieties in the way in which they bear their fruit; some kinds, like Wilson Early, bear the fruit elose to the eane, while others, like Snyder and Early Harvest, should be eut longer. Some varieties are variable in their habit of 
bearing fruit, and on such kinds some growers prefer to delay the pruning of laterals until the blossoms appear. From twelve to twenty inches is the length at which the laterals are generally left. It must be remembered that these laterals are to bear most of the fruit; hence it is important that they make a good growth, become well matured, and that the grower familiarize himself with the habits of different varieties. It is generally important

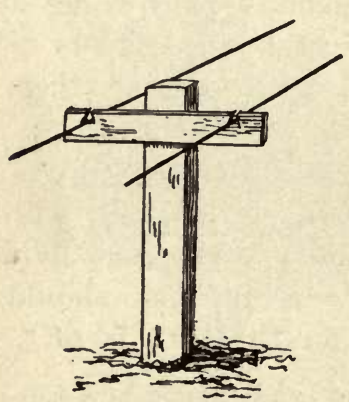

226. Trellis for berries.

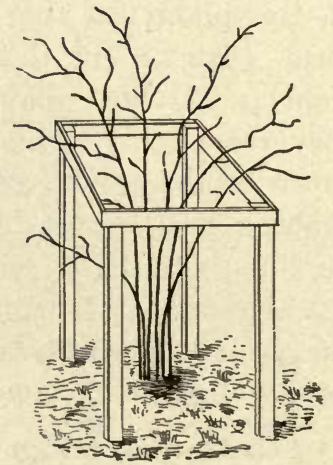

227. Rack for blackberries.

that the heading-in of the main cane be done early, so that the laterals may make an early and hard growth, and that they may start rather low down on the cane, and thereby prevent the cane from tipping over with its load of fruit. Blackberry bushes which are managed as here outlined will stand alone, without stakes or trellises. The bushes are sometimes kept from lopping by stretching a single wire along either side of the row, securing it to stakes which stand two or three feet high (Fig. 226). Individual bushes may be supported by a rack, as suggested in Fig. 227. In some places, particularly along the Hudson, blackberries are trained on wires, after 
the manner of grapes. A blackberry trellis is shown in Fig. 228. The two-wire trellis is generally preferred. The young canes are headed-in just above the upper wire, and they are gathered in bunches in the hand and tied to the upper wire, where they will least interfere with the ripening fruit. These canes may remain on the wires

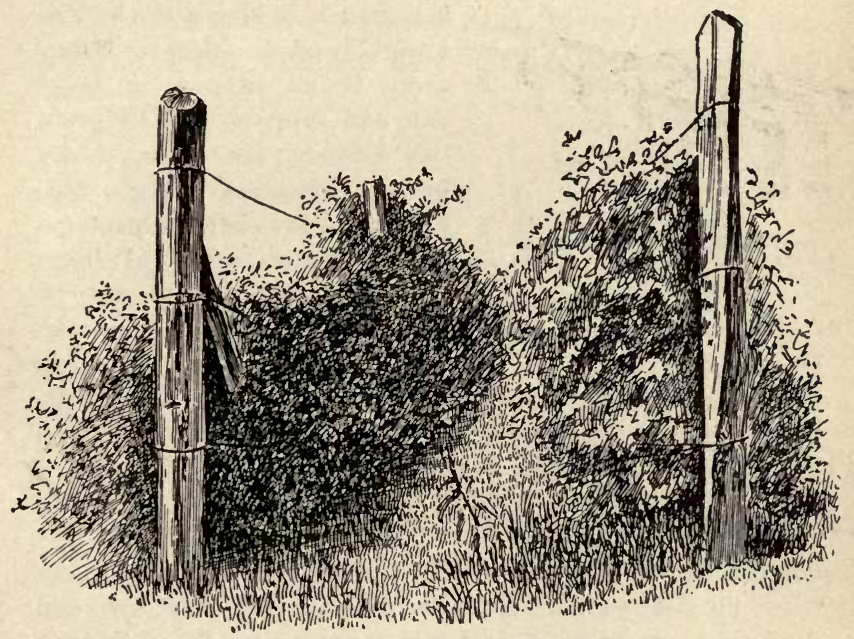

228. Blackberries on a trellis.

all winter, or they may be laid down for protection. Early the followiug spring, they are tied securely to both wires. This makes, therefore, one summer tying for the young canes, and one spring tying for the bearing canes. Blackberries may also be tied to single stakes, although the practice is scarcely advisable, because the fruit is apt to become too much massed in the foliage.

An exchange writes as follows on supports for berry bushes: "Wire is very commonly used as a support for raspberry and blackberry bushes, this being stretched 
tightly along stout stakes, the end stakes being of necessity very stout and very firmly braced. But this does not suffice to keep the wire stiffly in place. Where wires are stretched along each side of a row already, they can be made much more efficient by tying them together with cross wires every ten feet or so. This pulls them

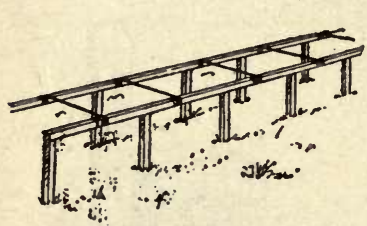

Fig. 229. A handy wire support. together and keeps the bushes upright and in place. Where there is no support at present, and support is to be given the bushes, the plan shown in the diagram (Fig. 229) can be followed to advantage. light wooden strips of inchsquare stuff are held up by stakes of the same material and rigidly attached to each other by cross wires. These cross wires are the most important part of the whole, for they are constantly pulling the bushes up into close quarters, - the one thing for which supports are desired."

Black-raspberries, or black-caps, are usually headed-in when from one and one-half to two feet high. It is important that this heading-back be done as soon as the canes reach the desired height, for the laterals then start low, and the bush becomes stout and self-supporting. The following spring the laterals are cut back to twelve to eighteen inches, as blackberries are. Black raspberries are sometimes supported by wires (Fig. 226), but best results are usually obtained when the plants are made to stand alone.

Red raspberries are seldom headed-in during the growing season, but otherwise they are treated like black-caps. Fig. 230 shows a cane (of Cuthbert) well pruned, but the canes in Fig. 231 are pruned too high and are top-heavy. Wellpruned black-caps and blackberries have essentially the form of Fig. 230 .

The canes of dewberries are tied to stakes, disposed on 
trellises (as on Fig. 229), or tied to wire screen (Fig. 232). The best method, probably, is to tie to stakes, allowing three to six canes to each stake (Fig. 233).

\section{Currants and Gooseberries}

The canes of currants and gooseberries bear several times, but the first two or three crops are

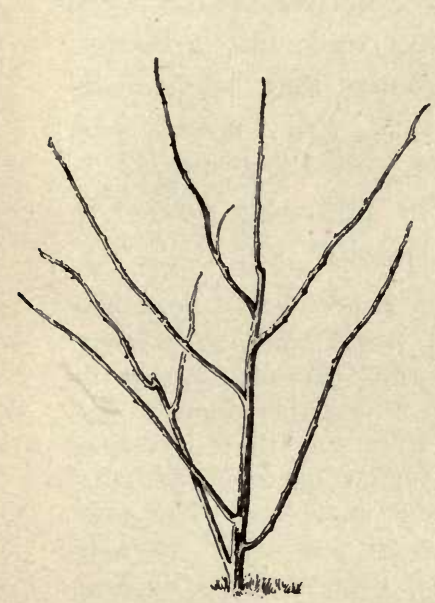

230. Well pruned.

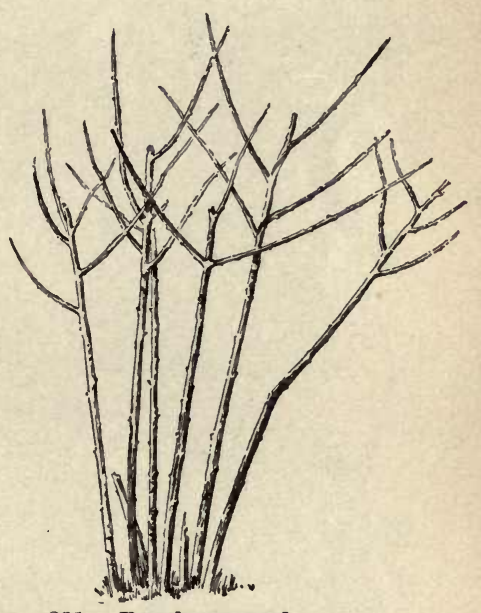

231. Poorly pruned.

the best. It is therefore desirable, after the plants have come into bearing, to cut out one or more of the oldest canes each year, and to encourage as many new ones. The bush is, therefore, constantly renewed. If the old canes are allowed to remain, the fruit becomes small, the 
bushes get too tall, and the currant borer is encouraged. In Fig. 234, the old branching cane

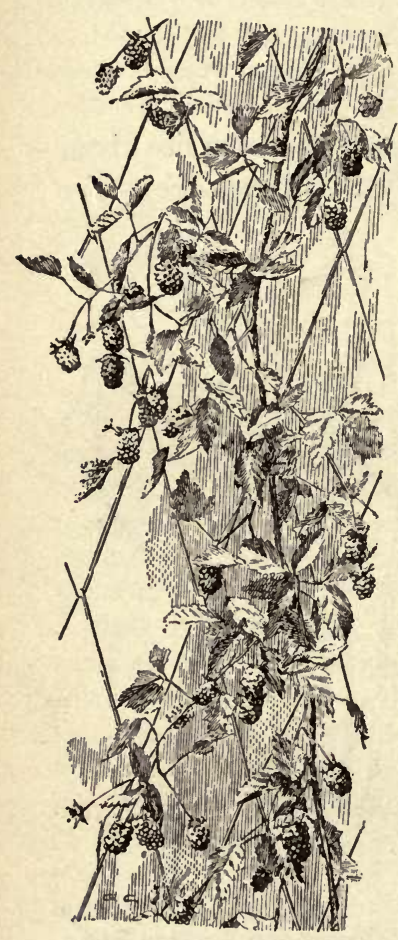

232. Dewberries on wire screen. $a$ should be removed. At its left, two vigorous canes -one two seasons old and the other one season oldare ready to take its place. When bushes make very strong and tall growths, the canes may be headedback. For spurs and buds, see Figs. 43, 44

The following advice is by Beach:*

"In large plantations it has been found most satisfactory to permit currants to grow in bush form rather than in the tree form, as the old canes may then be removed when they become unproductive, as they do after a few years, and their places may be taken by new canes that have been permitted to grow for this purpose. Then too, if the trunk of a currant in tree form is broken off or injured in any way, a new plant must be set in its place, but when several canes are permitted to grow, as is the case when the plants are grown in bush form, the acci-

*Bull. 95, N. Y. State Exp. Sta. 
dental breaking of a trunk does not cause the death of the whole plant, but its place is readily filled by permitting other canes to grow from the root. The tree form is well adapted to well-cultivated gardens, as the plants may be

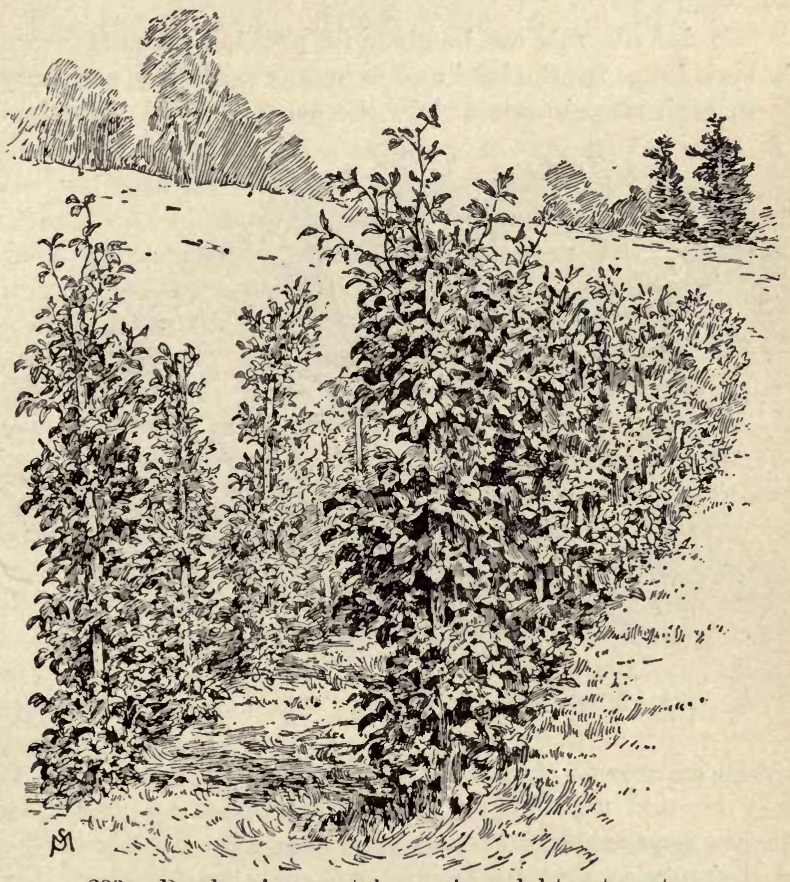

233. Dewberries on stakes. A model treatment.

pruned into more symmetrical, attractive shape as trees than as bushes. To grow currants in tree form it is simply necessary to remove all buds from the part of the cutting or layer that is put in the ground. This prevents the growth of shoots from below the surface of the soil, and conse- 
quently no suckers are formed. The tree currants may be kept in symmetrical shape by annually cutting-back the shoots of new wood, leaving but two or three buds to the shoot. This may be done at any convenient time while the leaves are off.

"No definite rule can be given for pruning currants grown in bush form, for the kind and amount of pruning necessary is in each case determined by the condition and individual

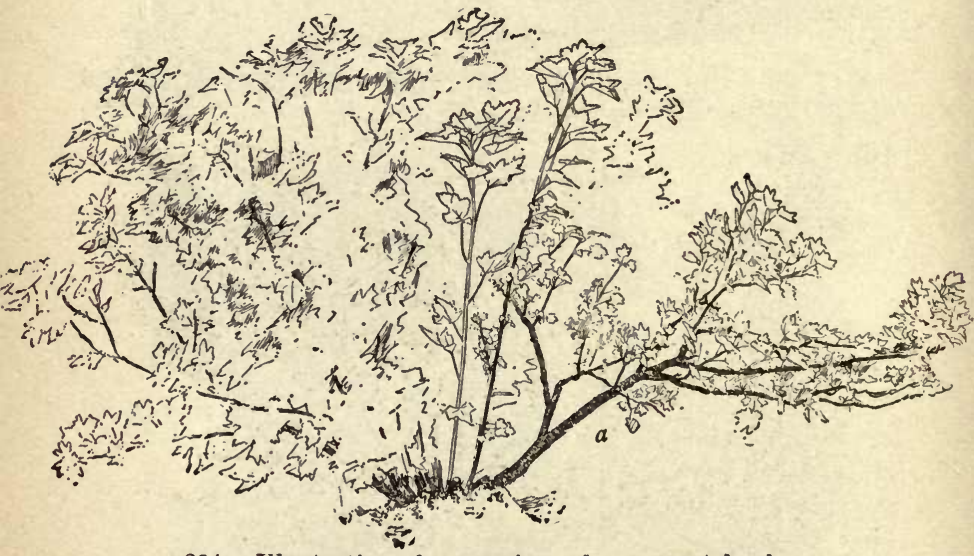

234. Illustrating the pruning of a currant bush.

habits of growth of the bush to be pruned. In general, it may be said that during the first two or three years the bushes require but little pruning except to head-back the new shoots so that fruit-spurs will develop all along the cane. Otherwise the fruit-bearing branches and fruit-spurs will be found mostly near the top of a long cane. When this is permitted, especially with some varieties, such as Fay, for example, the weight of the fruit is quite apt to bend the canes nearly or quite to the ground. Besides this headingin to keep the bushes in shape, the pruning consists of re- 
moving the broken branches, or those that droop too closely to the ground, and removing the old wood after it has passed the age of greatest productiveness."

For gooseberries, Beach writes as follows:*

"English writers usually recommend that gooseberries be trained in tree form; that is, with a single main stem for each plant, and that method is largely followed in the old country. On account of their neat, symmetrical appearance, such plants are well adapted to well-cultivated gardens. * * * A bush grown in this form does not produce suckers, and if it is broken off accidentally it cannot be renewed by letting new sprouts grow, but must be removed and a new plant set in its place. After they have borne five or six good crops it is generally best to replace them with new bushes, for they gradually become less productive than plants which are grown in the bush form, because the latter may be renewed from suckers whenever it is thought desirable to do so. To grow bushes in tree form, it is simply necessary to remove all buds or eyes from the portion of the eutting or layer which is covered with earth in planting. No underground shoots, or suckers, will then be formed, and the plant will have but one main stem or trunk. By annually cutting back new shoots to about three eyes, and removing all weak or crowded branches, the tree form may easily be kept in symmetrical shape.

"For general purposes it is best to set plants that will send up suckers. The older canes, which have passed their period of highest productiveness, may then be removed annually, and their places taken by young, vigorous ones which have been allowed to grow for this purpose. By this method of renewal, the skillful grower may keep

*Bull. 114, N. Y. State Exp. Sta. 
his plantation in a high state of productiveness for an indefinite period. Including the young eanes which are to be used for renewal, as above suggested, there will usually be five or six canes to a bush, or even a greater number than this with varieties of the American class, which have more slender canes.

"Gooseberries generally require little pruning during the first two or three years after they are planted except to elip a few inches off from the strong new shoots and a less amount from the less vigorous ones. This may be done at any time after the leaves fall. The object is to favor the development of the fruit-spurs all along the eane. If it is not done the strong buds at or near the end of the cane will start into such vigorous growth in spring that the lower buds will not start or will make but little growth, so that eventually most of the fruiting branches and spurs will be developed near the upper end of a long cane which, when loaded with fruit, is apt to bend nearly or quite to the ground.

"Besides heading-in the bushes in the way just described, the pruning consists in removing weak or broken branches and those which have made an excessively vigorous growth. Old canes that have passed the age of greatest productiveness, and branches that are close to the ground, should also be taken away. No definite rule ean be given for pruning gooseberries, because the kind and amount required varies with the individual habits and condition of growth of the bush. A little attention each year is necessary to keep the bushes in best shape for cultivating, spraying, fruit picking, and for the free circulation of air through and especially underneath the branches. It is a mistake to think that the center of the bush must be kept open to let the sunlight in, as is sometimes advocated. In this climate the fruit may be ruined by such unnatural exposure to direct sunlight, and it is better to have it shaded by the foliage. 
"Summer pruning is sometimes practiced with good results. It consists in pinching off the ends of the vigorous shoots at the period of active growth in early summer. The object is to favor the development of fruitspurs."

Further remarks on the pruning of small-fruit plants may be found in Card's "Bush-Fruits."

\section{Shade Trees}

When shade trees are once well established, they usually need no attention in pruning except to remove broken or dying parts, to cut off limbs which hang too low, and to correct any tendency towards unshapely growth. When planted, the shade tree, if well branched, should be pruned in essentially the same way as apples and pears. Figs. 144, 145, 146 may be taken as models. Young trees which are well supplied with buds on the main axis may be cut to a whip, but the common practice of chopping large trees into the form of bean-poles is to be discouraged.

\section{Hedges}

The beauty and value of hedges lie in the thickness of the hedge, and in its uniformity from end to end. The plants should be set very close together, and the hedge should be systematically and thoroughly pruned every year from the first. It is best, in fact, to prune the hedge 
two or three times during the season, in order to prevent too great and straggly growth of any one plant or any one branch of a plant. The practice of cutting down the hedge severely in winter, and then not touching it again until the following winter, results in a heavy growth which makes the hedge look ragged and unkempt during the summer, and which also makes it diffcult to bring the hedge under subjection. The hedge should be pruned in the winter time, and also should be sheared two or three times during the summer. The season of the year is immaterial, so long as strong growths are kept down and the hedge is kept in uniform shape and condition. The operator must first decide upon the shape of hedge which he desires, whether conicaltopped, round-topped or flat-topped, and then work to that model. The form should be blocked out very early in the life of the hedge,-in fact, just as soon as the plants begin to grow thick enough to form a wall. This same form can be kept year by year; but the hedge will necessarily rise a little in height every year, at least until the plants have grown several years, and the vigor has begun to be checked by the continuous pruning and the crowding of the roots.

In order to make hedges impenetrable to pigs and other animals, the plants are often plashed when young. This consists in bending the main shoots over to an oblique or diagonal position, 
and securing them there by wiring them down, one plant bending over the following one. Plants which are to be plashed are generally set at an angle when transplanted to their permanent positions. Deciduous-leaved and thorny plants, as osage orange, are generally used for the making of pig-tight hedges.

\section{Ornamental Plants}

Three objects are involved in the pruning of ornamental trees and shrubs,-to produce some desired form, to cause the plants to develop strong and uniform foliage, to produce flower-buds. The desired form is secured by shearing, the luxurious and continuous foliage by cutting back rampant growths and thereby encouraging a uniform development of the different parts of the plant, and the flower-buds by giving attention to the flowerbearing habit of the particular plant in question.

The pruner should know whether the flowers are borne on the ends of terminal or lateral shoots of the season, or on the ends or sides of last year's shoots.

Most early-flowering shrubs bear terminal flowers. Every effort should be made, therefore, to secure many shoots. The flower-buds in the early-flowering shrubs are formed the year before. Heading-in in winter, then, destroys the bloom. Heading-in just as soon as the flowers fall encourages the growth of new shoots, which 
will bloom the following year. Of such plants are lilac, mock orange, many spireas, and the like. These shoots will form, of course, wholly without the aid of pruning, but when the bush begins to get crowded or weak, vigorous heading-back and thinning-out may be advisable. The important point is, that if the person desires to prune to keep his plant within a given form or stature, he should know when the cutting will not sacrifice the bloom.

Summer-blooming trees and shrubs bear flowers on shoots of the same season. That is, the flowerbuds are not formed the fall before. In these plants, we want a profusion of strong spring or early summer growths, and fall, winter or very early spring pruning is, therefore, desirable. Of this class are most of the roses. Rose bushes are pruned mostly in fall or winter. The hybrid perpetuals are often cut to the ground and strong flowering shoots arise in the spring. The hardier and more perennial kinds-as the moss and cabbage and rugosa types-are cut back when dormant, much as one would head-in and thin out a small fruit-tree.

Walker gives the following hints on pruning outdoor roses:*

"Pruning is an important matter in rose-growing. Climbing and pillar roses need only the weak branches and the

*Ernest Walker, in "Garden-Making," 297. 
tips shortened-in; other hardy kinds will usually need cutting-back about one-fourth or one-third, according to the vigor of the branches, either in the spring or fall. A slight cutting-back, also, after their June-flowering in the case of remontants, will encourage more flowers. Severe pruning, however, will only induce the growth of vigorous, leafy shoots without flowers. The everblooming roses will need to have all dead wood removed at the time of uncovering them in spring. Some pruning during the summer is also useful in encouraging growth and flowers. The stronger branches which have flowered may be cut back one-half or more. The rule in trimming roses is, cut back weak-growing kinds severely ; strong growers moderately."

The following extracts give another view of the essential principles in the pruning of flowering shrubs:*

"There are two or three elementary rules which are to be observed when the production of flowers is primarily desired. Shrubs which blossom early in the spring form their flower-buds the year before, and ingeniously protect them during the winter with a warm covering, so that they are ready to open with the early days of spring sunshine. Any one who will eut off the twig of a peach tree in the winter or of an early-flowering spirea and put it in water will understand this, for the flowers will expand in a few days after it has been brought into a warm room. Obviously, if the branches of such shrubs are cut-back hard in autumn, all the flower-buds are cut away and there is no bloom in the spring. If, however, the branches are eut-back immediately after the flowering season is over, this will encourage the growth of new shoots from buds near the base of the branch, and these will grow rapidly to take the

*Editorial in "Garden and Forest," December 2, 1896. 
place of the part that has been lost, and cover themselves with flower-buds for another year.

"Another class of shrubs, like the hydrangeas, althæas and certain tamarisks, which flower in late summer or autumn from buds which have developed on the wood grown during the current summer, should be pruned in late autumn after flowering, or, at least, before the wood starts in the spring, so as to encourage abundant summer growth and flower-buds for the next autumn.

"But these are the simplest elementary rules, and relate solely to the production of flowers. Shrubs are useful for many other purposes than merely to display their blossoms. They are beautiful all the year round. Even in the winter the variously colored barks of many of them add a singular charm to the landscape. We, therefore, prune them not only to promote the production of flowers, but of wood and foliage and fruit as well, to insure grace or symmetry of outline, and to make them vigorous and healthy.

"The simple cutting-in of flowering wood in spring or fall is thus a small part of the art of pruning, and where there is a large variety of shrubs there is no time of year when something in this direction cannot be done, and it is especially useful when it is continued throughout the entire growing season.

"If surplus wood is to be removed, a clean cut in midsummer will heal over much more readily than it will in cold weather, and there is no better time for removing superfluous branches or for shortening-in over-vigorous shoots which interfere with the symmetry of a specimen. Some trees and shrubs, whose branches bleed when cut in spring, will heal over quickly if pruned while in full leaf.

"If the strong branches are pinched back in summer the wood will ripen into such a sound condition for withstanding cold that trees naturally tender have been known to endure our winters fairly well when their branches have been 
properly stopped. This summer pinching is especially useful in wet seasons, when otherwise the wood keeps growing late in autumn and is eaught by freezing weather in a soft and sappy condition. It also discourages upward growth where this is undesirable, and tends to develop fruit-buds, so that shrubs and trees will bear fruit at an earlier age when they are properly pinched-back. For the same reason shrubs will ripen their fruit more perfectly when the stronger shoots above it have been stopped. * * *

"A young plant earefully pruned when it is set out in good ground, with room enough to grow in, will sometimes need, as it grows, to have interior branches cut away for the admission of light and air, and the over-strong shoots pinched-back in midsummer and dead wood carefully removed. Little more will be required, as a rule, except to shorten-in judiciously the flowering wood after bloom, and under this treatment shrubs will develop into their best form, and flower abundantly year after year."

The important point to remember, then, in the pruning of flowering shrubs is that there are two great categories of shrubs as respects the time and mode of flower-bearing,-those flowering in early spring more or less directly from winter buds, and those flowering in summer or autumn from buds formed that season. The methods of pruning to produce a given form of bush are the same in either case; but if it is desired to headin and yet not to sacrifice the bloom, the earlyflowering shrubs should be cut-back just after blooming rather than in winter, and the summerflowering kinds in winter (or when the plants are dormant). Some of the common shrubs 
may be ranged in these two categories, as examples :

\section{SPRING-FLOWERING}

(Head-back immediately after blooming)

Kalmia.

Rhododendron.

Azalea.

Snowball.

Lilac.

Mock-orange.

Most woody spireas.

Exochorda.
Weigela.

Forsythia.

Flowering Currants.

Kerria.

Barberry.

Viburnums.

Flowering Crabs.

Magnolias.

\section{SUMMER-FLOWERING}

(Head-back when dormant)

Many roses.

Spiræa sorbifolia.

Clematis.

Hydrangea.
Althæa and hibiscus.

Tamarisk.

Elder. 


\section{Chapter VI}

\section{SOME SPECIFIC MODES OF TRAINING}

There are many modes of training which are so special and of such local and personal application, that they should be considered in a class by themselves. They are essentially old World methods, born of garden-culture and of climates less hot and sunny than ours. (See remarks under Section 13, Chapter IV.). They are not adapted to commercial fruit-growing or plantgrowing in this country, nor to any country in which land is cheap and hand labor dear. Yet, so common are these special methods of training fruit-trees in Europe that the Old World literature of pruning is largely descriptive of methods and modes of growing plants on walls and trellises and in geometrical figures. It is not necessary to make any extended discussion of these matters in this book, although a few summary hints may be given for the benefit of those who want the fun of training a few plants or who desire to copy European methods. For details the reader should consult foreign books, $\in$ specially those in French.

We may analyze the subject as follows: 
342 SOME SPECIFIC MODES OF TRAINING

I. Training of plants growing in the open soil.

1. Without permanent support.

Pyramids,

Globe-form,

Vase-form, etc.

2. On permanent support.

a. On Espaliers-

cordon,

horizontal,

oblique,

fan-shape,

horizontal arm, etc.

$b$. On walls-

cordon,

horizontal,

oblique,

fan-shape,

horizontal arm, etc.

II. Training of plants in receptacles (as pots or tubs).

Trained in various fashions, but chiefly as self-supporting bushes of many shapes.

\section{EUROPEAN PRACTICE}

Before proceeding with our subject of special forms of training, it will be necessary to consider some of the words used in the above synopsis. In Europe (and properly) the word stand- 
ard means growing to a single trunk and not trained to a wall, trellis, or other permanent support. In this country, it is used in contradistinction to the word dwarf. An espalier is a trellis, or a plant which is grown on a trellis. The word does not refer to the mode of training. A cordon is properly a plant grown to a single shoot, or to two shoots trained in diametrically opposite directions. It is sometimes used, however, to designate plants trained to two or more straight shoots which are nearly or quite parallel.

Although the mode of training is largely a question of personal preference, it must nevertheless conform to the principles of pruning, if it is to be successful. One of the best accounts which I know of the general principles underlying the training of plants, is by $\mathrm{Du}$ Breuil.* Before proceeding to these principles, we may enumerate Du Breuil's reasons for training:

1. It enables us to impart to trees a form suitable to the place they are intended to occupy.

2. Each of the principal branches of the tree is furnished with fruit branches throughout its full extent.

3. It renders the fructification more equal; for in removing every year the superabundant buds and branches, we contribute to the formation of new fruit-buds for the next year.

\footnotetext{
*Alphonse Du Breuil, "The Scientific and Profitable Culture of Fruit. trees", English edition. An excellent book for the student.
} 
4. It conduces to the production of large fruit and of finer quality.

$\mathrm{Du}$ Breuil's "general principles of training," with corollaries, which apply with particular force to training on walls and espaliers, now follow:

The permanency of form of trained trees is dependent upon the equal diffusion of sap being maintained throughout the whole extent of their branches.

Prune the strong branches short; but allow the weaker ones to grow long.

Depress the strong parts of the tree, and elevate the weak branches.

Suppress the useless buds upon the strong parts as early as possible, and practice this suppression as late as possible upon the weak parts.

Suppress very early the herbaceous extremities of the strong part, but practice the suppression as late as possible upon the weak part, taking off only the most vigorous shoots, and those that must in any case be removed on account of the position they occupy.

Nail up the strong part very early and very close to the wall or trellis, but delay doing so to the weak part.

Suppress a number of the leaves upon the strong side.

Allow as large a quantity of the fruit as possible to remain upon the strong side, and suppress all upon the weak side.

Soften all the green parts on the weak side with a solution of sulfate of iron. ("This solution, in the proportion of twenty-four grains to a pint of water, applied after sunset, is absorbed by the leaves, and powerfully stimulates their action in drawing the sap from the roots.") 
Bring forward the weak side from the wall, and keep the strong side close to it.

Place a covering upon the strong part, so as to deprive it of the light.

The sap develops the branches much more vigorously upon a branch cut short, than upon one left long.

The sap has always a tendency to flow towards the extremity of the branches, and to make the terminal bud develop with more vigor than the lateral ones.

The more the sap is retarled in its circulation, the less wood and the more fruit-buds will it develop.

Apply to the branches which grow from the successive extensions of the wood, and also to those which spring from them, the operations calculated to diminish their vigor.

Apply to the larger branches a certain number of Girardin's side grafts. (These are cions of fruit-spurs or fruit-buds set into the twigs as common buds are set. "These grafts, when fruiting, will absorb a considerable part of the superabundant sap.")

Arch all the branches, so that a part of their extent be directed towards the sun.

In the month of February, make an annular incision with the hand-saw, near the base of the stem, rather less than one-fourth of an inch in width, and sufficiently deep to penetrate the exterior layer of the wood. ("The incision has the effect of retarding the ascension of the sap; the branches acquire less vigor, and the tree forms fruit.")

At the spring of the year, uncover the foot of the tree in such a manner as to expose the principal roots throughout nearly their entire extent, and allow them to remain in this state during the summer. 
Uncover the foot of the tree at spring, and eut away parts of the roots, and then replace the earth.

Transplant the trees at the end of autumn, but with great eare so as to preserve all the roots. (This is equivalent to root-pruning.)

Every method which conduces to diminish the vigor of the wood and to make the sap flow to the fruit, tends to augment the size of the fruit.

Graft upon stocks of a less vigorous species than the cions.

Apply to the trees a suitable winter pruning; that is, do not leave upon them more branches, or parts of branches, than is requisite for the symmetrical development of the tree and the formation of fruit-bearing branches.

Make fruit-spurs to grow close upon the branches by pruning them as short as possible.

Cut the branches very close when the flower-buds are formed.

Mutilate the summer shoots by repeatedly pinching off those shoots that are not required for the development of the size of the tree.

When the fruits have attained a fifth degree of their development, suppress a further number of them.

Make an annular incision upon the fruit-bearing branches at the time they expand their blossoms; the incision must not be wider than three-sixteenths of an inch. ("Experience continually demonstrates that, following such incision, the fruit becomes much larger and ripens better." See p. 281.)

Graft some of the fruit branches of vigorous trees with the Girardin side graft. (See last page.)

Place under the fruits, during their growth, a support, to prevent their stretching or twisting their foot-stalks or pedicels. ("If left without support, it will often happen 
that the fruit grows unequally, and a twisting movement of the stalk follows, which injures the sap vessels. Besides, the weight of the fruit alone, hanging on its stem, stretches the sap vessels, and diminished their diameter. When the fruits are supported, the sap penetrates more freely, and their size is augmented accordingly.")

Keep the fruits in their normal position during the entire period of their development; that is, with the fruitstem lowermost. ("The sap acts with greater force when it flows upwards; a vertical position of the stalk, therefore, eauses the sap to ascend more easily and in greater quantity, and the fruit will become larger.")

Place the fruits under the shade of the leaves during the entire period of their growth. ("If a young fruit be exposed to the power of the sun, it will be smaller than one shaded by the leaves, because its skin will be hardened, and not give way to the tendency of the sap to expand it.")

Apply to the young fruits a solution of sulfate of iron. ("We have already seen (page 334) that a solution of sulfate of iron applied to the leaves, stimulates their powers of absorbing sap. The thought occurred to apply the solution to the fruits, and the effect in increasing their size was extraordinary. The solution should be in the proportion of twenty-four grains to a pint of water. Apply it only when the fruit is cool. Repeat the operation three times: when the fruits have obtained a fourth part of their development; when they are a little larger; and again when they are three parts grown.")

Graft by approach a small shoot upon the peduncle or fruit-spur, to which the fruit is attached when it has attained a third part of its development. ("It has been found that consequent on this operation the fruit becomes larger, doubtless because the graft draws to the peduncle a larger quantity of sap." See p. 132 of "The NurseryBook," Third Ed.)

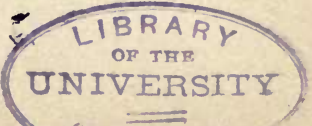


The leaves serve the important purpose of elaborating the sap of the roots and preparing it for the proper nourishment of the tree, and the formation of buds upon the boughs. A tree, therefore, that is deprived of its leaves is in danger of perishing.

The yearly extensions of wood should be shortened more or less, as the branches approach a vertical line, or the contrary.

Plants are trained on walls for purposes of decoration or for fruit-bearing. Fruit trees so trained are protected from winter cold, and the fruits receive greater warmth and sunlight than they do when grown free. In sunny countries, with hot weather at the period of fruit-ripening, fruits develop their full color and flavor without the aid of walls. In fact, in America the south face of a wall may be too hot for the best results with some fruits. On a south wall, too, the blossoms open very early in spring and are in danger of being caught by frosts. This is especially true of apricots and peaches, and for them a westerly or even northerly exposure may be preferable.

In Europe, gardens are very often surrounded with brick walls several feet high; and in many cases, such walls are built across an area for the particular purpose of fruit-growing. The walls of buildings, whether of brick, stone or wood, may be used. An apricot, peach, pear or other fruit tree trained against a barn, shop, shed or 
outhouse is not only a decoration but is an object of much interest and, if the location, variety and training are right, it should yield fruit of extra quality. It should be said that these trained trees eannot compete with orchard trees in quantity of fruit, but they should surpass them in the quality of the product.

Following is specific advice, from the English standpoint, on the arrangement and construction of walls and fences, ${ }^{*}$ by Cheal:

"WALLS. - The arrangement and position of walls will, of course, depend upon the size and the nature of the surroundings, ete., but they should always be arranged, if possible, in a square, with the principal wall facing south, or as nearly so as practicable. Where it is possible, place the walls in such a position that the outside as well as the inside borders may be used for fruit, thus making use of the whole of the wall space; and bear in mind that upon the north side many useful fruits may be grown. The position, size and requirements are so varied that it is impossible in the compass of this work to give more than a general idea as to arrangements.

"The height of the walls should be from eight feet to fifteen feet, according to eircumstances. In most eases the south wall may be lower, to admit more sunshine into the garden; and in the case of large gardens, one or more cross walls may also be introduced. As to their construction, they should be built without any piers. Architects have generally a great fancy for piers, and in many instances, insist upon having them; butwalls ean be built without piers, and they are always a great difficulty and nuisance to

*J. Cheal, "Practical Fruit-Culture," London, 1892, 112. 
the gardener. They frequently interfere with the arrangement of the trees when planting, and in training they are a great trouble, and often cause much damage to the trees. Another matter of importance in construction is to provide a good permanent coping of tiles or stone, projecting at least six inches from the face of the wall. These should in all cases be provided independently of any further coping for the protection of the trees at the time of flowering.

"Removable glass copings are very useful for peaches, nectarines and apricots. These are only required for a few weeks in the spring, at the time of blossoming and setting the fruit, and should be removed when no longer required. Fixed glass copings are very objectionable, as they keep off all rain, encourage red spider and other vermin, and necessitate constant syringing. There are several manufacturing firms who make light iron framework to carry the sashes, these being so constructed as to allow of their easy removal.

"In all cases it is a great saving of labor to wire the walls or fences. These should be placed in lines not exceeding nine inches apart. Galvanized hold-fasts, tighteners, and all needful appliances are easily obtainable for the purpose. The wires should be fixed at about two inches from the wall.

"Tring to the wire is much more quickly done than nailing to the wall, and does not afford the same shelter to insect pests, whilst it preserves the wall from injury due to constant nailing, and allows the wood to ripen more thoroughly and evenly. The branches are also enabled to form fruitspurs and buds all round, and it frequently happens that the inside or back blossoms escape injury from frost which damages the outer ones, and a crop is thereby saved. In the case of all fruits, however, and especially that of peaches and nectarines, it is needful to be very careful in tying the trees in order to prevent the branch coming immediately into contact with the galvanized wire. Many instances have occurred of disease and decay resulting from 
this. There is, however, no danger if the precaution is always taken in tying to cross the tie between the branch and the wire, so that the branch is held firmly in position without coming into actual contact with the wire. And the danger may be still further lessened by painting the wires and hold-fasts after fixing.

"Espalier fences. - These can generally be placed to advantage in a kitchen garden, as they occupy but little space, and produce an abundance of fine fruit. They may be used as a bordering near to the paths, or at the back of the flower border, which is usually arranged on either side of the central walk, but there are also other positions outside the kitchen garden where they can be placed to advantage. If the fruit is well grown, such fences present an artistic appearance, and are admissible even in the ornamental garden, or may be used as a division between the ornamental and kitchen garden. The fences themselves are usually formed of galvanized iron posts, with wires stretched between. They require at each end a strong post made of angle iron, with anchor feet and stays, to bear the strain of tightening the wire. The intermediate posts need only be flat iron with anchor feet. For the ordinary horizental form of training, five to six feet in height will be sufficient, but if made high enough-say from seven to nine feetthese fences are very gool for training cordons upon. Gooseberries may also be trained upon low espalier fences of three to four feet in height, and when trained as double cordons, or as palmettes with three to five branches, they produce the finest possible fruit; and this mode is strongly recommended for growing the choice dessert varieties.

"Wire arches. - These may sometimes be suitably introduced into the kitchen garden, spanning some of the paths. They occupy but little ground space, and afford excellent means for the training of cordons. They give a pleasant shade to the path, the trees are well supported, and the fruit spread out to the full effect of the sun, and in some respects 
they are better for training the cordon trees upon than ordinary espaliers. The turn at the top gives the gentle check to the upright flow of sap so desirable and advantageous for securing fine fruit at the base of the tree. A garden in this neighborhood has one of these arches 350 feet in length, spanning the central road through the large kitchen garden, and being fifteen feet wide and of the same height, it forms a magnificent avenue.

"WoOden FENCES. - It sometimes happens that wooden fences are placed in such a position as to be available for fruit. A wooden fence is in no case so good as a wall, as in the best of them there is always some draught, so that there is not the same uniform temperature maintained as in the case of walls, which, from their greater substance, retain a certain amount of warmith during the night. Nevertheless, wooden fences are very useful for fruit. They should always be wired before planting the trees, as it is difficult to nail to the wooden fences, whilst wire also possesses other advantages. I have seen wooden fences employed to great advantage in Guernsey for fruit-growing. In one case in particular I noticed a number of light wooden fences, about six feet high and nine feet apart, running north and south, and parallel to each other. These were covered on both sides with cordon-trained pears, and at the time of my visit they were laden with heavy crops of remarkably fine fruit, and the cultivator was by these means enabled to grow a very large quantity in a small space.

"Many wooden fences surrounding the gardens of suburban villas might be turned to very useful account for growing fruit, and would afford healthful and interesting employment to the over-wrought brain-worker in cultivating it, as well as enable him to supply his own table with the freshest of fruit. There are also numberless wooden fences, as well as walls, in many of our farms and homesteads, which could be turned to profitable account by covering them with fruit, trained as above described. 
"BUSH-FRUITS.-Plantations of these are usually made outside the walled-in garden, either below orchard trees or in the open ground. The latter is much preferable, as they can receive better treatment and safer protection from birds. The last mentioned consideration is an important one. Where choice dessert fruit is required it must of necessity remain on the trees until fully ripe, and some of it has to remain as long as possible after ripening, to prolong the season of use. With these the birds are extremely troublesome. The best way of protecting them, and also the cheapest in the long run, is to eover the plantation with galvanized wire netting.* Erect sufficient posts, and stretch from these galvanized wire at a height of six feet from the ground. Then across the wires fix the netting. Wire it together, and fasten it to the ground all round. If erected as above, it allows any one to work inside-to prune, clean and gather, etc.-whilst effectually preventing birds from approaching the fruit.

"The position of the bush-fruit outside the walled-in garden would, of course, depend upon circumstances, but it can generally be arranged very close at hand, and in conjunction with it, the sea-kale and rhubarb beds, etc., which are somewhat untidy in the spring, owing to the copious application of manure, ete., required. The soil for the bush-fruits should be prepared by trenching and manuring as described for the inside kitehen garden."

In the Old World, trees are trimmed in the nursery to adapt them to particular modes of training. In fact, the training is often begun there. Fig. 235 is a young peach tree trained for a palm shape. The main shaft is supported by a stake, and two long stakes are attached to it, like a

*A bird-netting is made in this country. See "Principles of FruitGrowing," 296.-L. H. B. 
gable. Other stakes are tied across this frame, and to them the arms of the tree are secured.

Persons in this country who desire to train trees

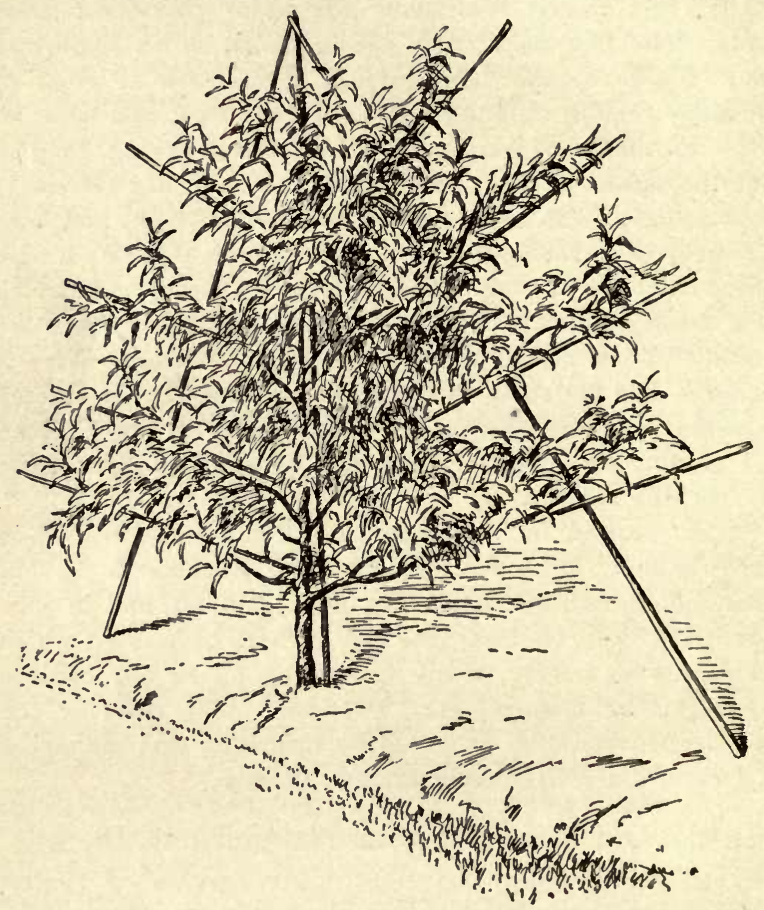

235. Trained peach tree, ready for setting in permanent quarters.

to special shapes, should buy yearling trees of the nurseries. These are provided with buds on the main trunk or shaft, and when they are 
headed-back, the required number of shoots may be secured in the proper positions. It may even be important not to select the largest yearlings, for on them the lower buds may be very weak. This is particularly true with peach trees, for in these the lower side buds break the first year, and the nurseryman trims them off into order to get a straight and long-bodied tree.

How high to leave the trunk and how many branches to take out, depend entirely upon the mode of training which the operator has in mind. I have inserted various extracts which will serve as specimen examples to suggest the general methods of procedure.

Before undertaking any method of special training, the operator should apprehend the idea that there is no necessary or essential mode for any fruit. The mode of training is diametrically opposed to the natural habit of the plant, and it is, therefore, a mental and arbitrary ideal. This fact will be apparent if the reader considers that most of the illustrations in the Old World literature of the subject are diagrams, not pictures. The operator works to geometrical figures. He sets a pattern ; and the more nearly the plant approaches this pattern the more satisfactory is the training.

Some of the common forms in which fruit trees are trained are suggested in the following translation from Bois :*

*D. Bois, "Le Petit Jardin," Paris, 264. 
"The PYramid. - An old and a good form, suitable especially for pear trees. Its advantages are, that it can be eultivated in borders, where it relatively takes up little room; that it freely allows cireulation of air and light; that it easts very little shade; and that it bears abundantly. The pyramid or cone consists of a principal or vertical stem, covered with lateral branches from a point thirty centimeters [a centimeter is about two-fifths of an inch] above the ground to the top of the tree. The branches, which grow somewhat obliquely, are separated from each other by a distance of about thirty centimeters, diminishing gradually in length from the bottom to the top, thus forming a cone, the largest diameter of which is about one-third of the total height.

"THE COLUMN OR SPINDLE. - This form is adapted to pears and apple trees. It has the advantage of taking up less room than the pyramid, and of bearing more quickly. On the other hand, it is not so long-lived, and is suitable for less vigorous varieties only. The column differs from the pyramid only in the fact that its lateral branches are shorter.

"THE VASE.-Around a central stem, and at a distance of about fifteen centimeters above the ground, arise branches which grow first horizontally and then vertically, in such a way as to give to the entire tree the form of a vase. The branches must be separated from each other by a distance of about thirty centimeters, and they are maintained in this position by bying them to hoops fastened to stakes inserted in the ground. This form is justly much esteemed. It freely allows a circulation of light and air through all its parts.

"THE BUSH OR TUFT. - The bush is suitable for currants, raspberries, etc. From the eroteh of the plant, or at a short distance above the ground, arise branches which grow in every direction. It is simply necessary to train them so that they do not interfere with each other. 
"THE HoRizontal cordon (Fig. 236) is suitable especially for apple trees grafted on Paradise stock, and to the less vigorous varieties of pear trees grafted on quince stock. This form is especially to be recommended for the borders of walks. It consists of a stem which first grows vertically, then bent at a certain height, and is maintained in this horizontal position by attaching it to wire. The trees are planted at a distance of two or three meters [a meter

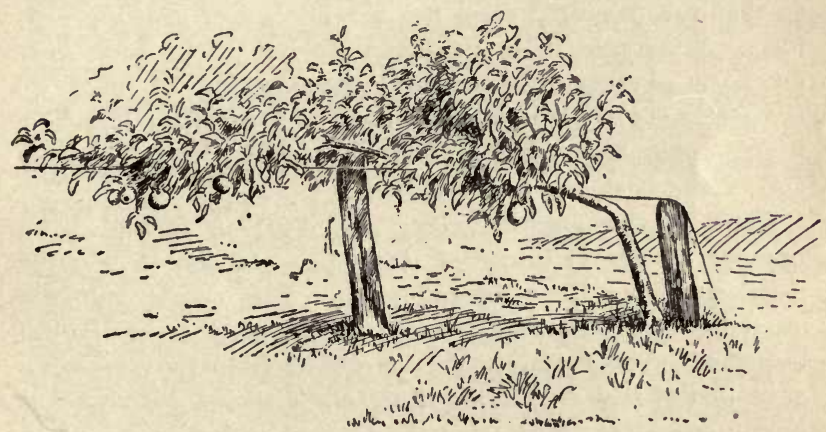

236. Apple trained to a simple cordon.

is nearly forty inches] from each other, and their stems, when meeting, form a long, uribroken garland or wreath, which makes a very pretty effect.

"Espalier training is to be especially recommended. It is suitable for all kinds of fruit trees, and allows the cultivation, in our latitude, of varieties the fruits of which would not ripen at all, or would ripen incompletely in a more exposed situation. When trained against walls, they receive an amount of heat sufficient to produce fruit of a superior quality. These include peaches, grapes, certain kinds of apricots, apples, pears, etc. The utilization of these walls is much neglected, and there would often be much profit in covering with espaliers the fronts of houses and all kinds of walls, especially when placed in a good 
situation, training the trees according to the form of the wall. The simplest form of espalier is the vertical cordon, which allows the trees to be planted very near together, which soon brings in a moderate return, and in a few years covers the wall. Like the column, this form is suitable only for the less vigorous varieties. It must be trained against a moderately high wall, for its growth is considerably stimulated by the suppression of its lateral branches, so that the principal stem has a tendency of growing rapidly. Whenever it is necessary to cut them back very much, it produces an excessive development of wood, to the detriment of its productiveness. A form like a U, which is self-explanatory, is frequently employed. It is certainly one of the best.

"The Candelabrum (Figs. 237, 240) is formed by a number of lateral branches, from three to six, distributed regularly along the principal stem. The simple palmette or palm leaf (Fig. 235) has a larger number of lateral branches. The Palmette Verrier differs from the preceding only in the fact that after a certain distance its branches grow vertically. Palmettes are formed with $6,7,8,10,12$ branches, and even with more."

How to train a pyramid standard pear tree is explained as follows by Rivers :*

"If a young gardener intends to plant, and wishes to train up his trees so that they will become quite perfect in shape, he should select plants one year old from the bud or graft, with single upright stems; these will, of course, have good buds down to the junction of the graft with the stock. The first spring a tree of this description should be headeddown, so as to leave the stem about eighteen inches long. If the soil be rich, from five to six and seven shoots will be

*Thomas Rivers, "The Miniature Fruit-Garden." 
produced; one of these must be made the leader, and if not inclined to be quite perpendicular, it must be fastened to a stake. As soon, in summer, as the leading shoot is ten inches long, its end must be pinched off; and if it pushes forth two or more shoots, pinch off all but one to three leaves, leaving the topmost for a leader. The side shoots will, in most cases, assume a regular shape; if not, they may be this first season tied to slight stakes to make them grow in the proper direction. This is best done by bringing down and fastening the end of each shoot to a slight stake, so that an open pyramid may be formed-for if it is too close and cypress-like, enough air is not admitted to the fruit. They may remain unpruned till the end of August, when each shoot must be shortened to within eight buds of the stem.

"The second season the tree will make vigorous growth; the side shoots which were topped last August will each put forth three, four, or more shoots. In June, as soon as these have made five or six leaves, they must be pinched off to three leaves, and if these spurs put forth shoots, which they often do, every shoot must be pinched down to one or two leaves, all but the leading shoot of each side branch; this must be left on to exhaust the tree of its superabundant sap, till the end of August, unless the tree is being trained as a compact pyramid. The perpendicular leader must be topped once or twice; in short, as soon as it has grown ten inches, pinch off its top, and if it break into two or three shoots, pinch them all but the leader, as directed for the first season: in a few years most symmetrical trees may be formed.

"When they have attained the height of six or eight feet, and are still in a vigorous state, it will be necessary to commence root-pruning, to bring them into a fruitful state.

"If some of the buds on the stem of a young tree prove dormant, so that part of it is bare and without a shoot 
where there should be one, a notch, half an inch wide, and nearly the same in depth, should be cut in the stem just above the dormant bud. If this be done in February, a young shoot will break out in the summer. ${ }^{*} \quad * \quad *$

"As the summer pinching of pyramidal pears is the most interesting feature in their culture, and perhaps the most agreeable of all horticultural occupations, I must endeavor to give plain instructions to earry it out.

"The first season after the planting, about the middle or end of June, the side buds and branches will put forth young shoots; each will give from one to three or four. Select that which is most horizontal in its growth (it should be on the lower part of the branch, as the tree will then be more inclined to spread) for a leader to that branch, and pinch off all the others to three leaves. If these pinched shoots again push, suffer them to make three leaves, and then pinch them to two leaves; but if the horizontal branch has a good leader, it will take off all the superfluous sap, and prevent the pinched spurs from breaking; the buds will only swell, and the following season they will be fruit-spurs. The upper shoots of the tree, say to about two feet from its top, should be pinched a week before the lower shoots: this gives strength to those on the lower part of the tree.

"In spring the perpendicular leader of the preceding year's growth will put forth numerous shoots, which must be pinched in June in the following manner: those nearest the base, leave six inches in length, gradually decreasing upwards, leaving those next the young leading shoot only two inches long. The leader of these ready-formed pyramids need not be shortened in summer, as directed for younger trees; it may be suffered to grow till the hori-

*Bare places in the stems of pyramids, and in the branches of espaliers or wall trees, may be budded towards the end of August with blossom-buds taken from shoots two years old. This is a very interesting mode of furnishing a tree with fruit-bearing buds. Page 345. 
zontal leaders are shortened in August, and then left six or eight inches in length; but if the trees are to be kept to six or seven feet in height under root-pruning, this leading shoot may be shortened to two inches, or even eut elose down to its base. For tall pyramids of ten, twelve, or fifteen feet, it may be left from eight to ten inches in length till the required height be attained; it may then be cut to within two inches of its base every season."

The methods to be pursued in the training of trees on espaliers may be explained by a concrete example. I choose an extract from Hardy* respecting the training of a palmette on an espalier. A simple palmette is a plant with a single erect stem and a number of side branches, as in Fig. 235; a vertical-branched palmette or candelabrum is shown in Fig. 237.

"We endeavor to obtain three branches,-one to continue the growth of the trunk, the two others to furnish two lowest lateral branches. To secure this result, we will choose a bud [head-in the shoot] about thirty centimeters [a centimeter is nearly two-fifths of an inch] from the ground. The middle bud will push a shoot upwards and the two others obliquely, but not too near the horizontal, so that they can make a vigorous growth. There is nothing else to do during the growing season, if the equilibrium between them maintains itself.

"The vertical-branched palmette does best in soils of medium quality, as well as for high walls. In the first case, the verticality of the main branches assures to the last a

*J. A. Hardy, "Traité de la Taille des Arbres Fruitiers," Paris, 1865, 129, 137. One of the best books on the subject. 
more sustained vegetation than when they are horizontal. In the second case, they more promptly cover the wall, for with this form we can plant the trees very close to each other, a meter [about forty inches] or a meter and a quarter apart, according to the distance which we leave between

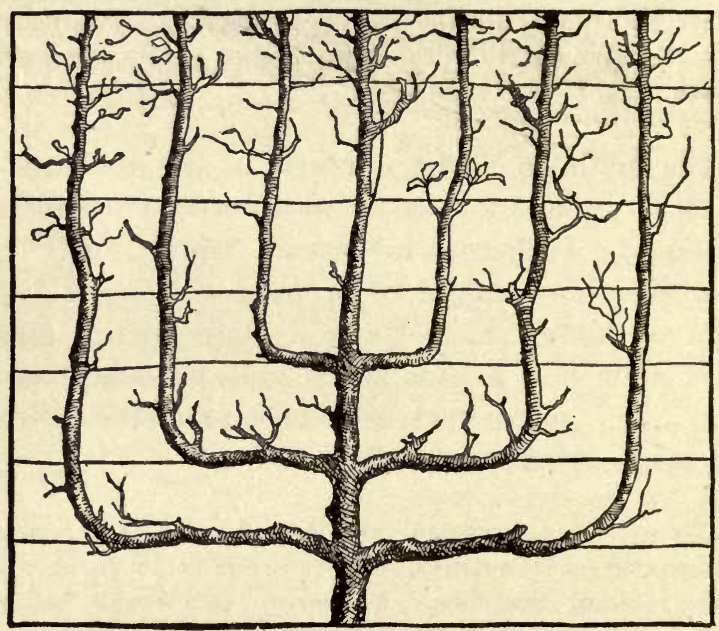

237. Candelabrum espalier pear tree.

the branches; the more we stretch out the framework the more the sap is reserved for a less number of branches.

"The manner of establishing this form scarcely differs from that of the simple palmette. The first year we trim as described in the first paragraph, only that instead of obtaining two oblique lateral shoots, as there described, it is necessary to eut the stem back to only about forty centimeters, and we train the two branches (A) up vertically. * * * The second year we pinch the shoot to obtain the second pair of branches about twenty centimeters above the 
first, and we direct these into the center of the space between the first two branches, training these framework branches twenty centimeters from each other. Then we trim the first branches (A) to a length double that of the trunk. The space of twenty centimeters is not absolute; we ean make it twenty-five centimeters. Then, instead of planting the trees one meter apart, we ean place them a meter and a quarter, in such manner that the extremes of the framework of neighboring trees shall be as far apart as are the main branches of the tree itself. This second distance is preferable, as the branches receive more light and air, a condition which is essential for good fruit-bearing.

"The following years the treatment follows the method indicated, with all the main branches [two pairs and the trunk], but, however, taking care that we leave the outside branches (A) a little longer than the others, so that they ean maintain their predominance. The tree thus treated arrives at the height of the wall in the sixth year, if its vigor is maintained and it meets with no accident."

The treatment of a simple horizontal cordon (Fig. 236) is thus described by Bellair :*

"When grown in this way, the pear tree consists of a stem bent at a distance of forty centimeters above the ground, then trained horizontally and covered with fruitbearing branches. The cordons are trained as much as possible toward the strongest light. If the plantation is established on a slope, it is necessary to train the cordons toward the summit of the slope. Only pears grafted on quince stock, and apple trees grafted on Paradise or Doucin stock, ean be grown in this way. Pear trees and apple trees grafted on their own stock are too vigorous, as they require (for otherwise they would remain sterile) more

*G. Ad. Bellair, "Les Arbres Fruitiers," Paris, 1891, 164. 
room than the horizontal cordon allows. One-year-old apple cions grafted on Paradise stock must be planted at a distance of three meters from each other. One-year-old apple cions grafted on Doucin stock, and pears on quince stock, must be planted at a distance of four meters from each other. The first year they are cut at a distance of about sixty centimeters above the ground, and near a bud, which is located on the side toward which the stem is to be inclined. In the autumn or in the following spring, these cions are gradually bent. But if the part beyond the bend must be strictly horizontal, it is necessary that the extremity of the cordon be slightly raised, in order to facilitate the flow of the sap, and consequently the elongation of the cordon. From this time, the yearly growth of the cordon must be cut in such a way as to preserve two-thirds or three-fourths of its length. It is soon covered with branches, some of which are entirely fertile (that is, bearing fruit-producing buds), while the others, or sterile ones, must be cut away. This kind of treatment prevents them from obtaining too large a growth and thus still more destroying its fertility."

Excepting the grape, the training of the peach has probably been the subject of more literature* than that of any other plant; yet so different are the American conditions and ideals from the European that this technical literature has almost no application in this country. The United States is a land of peaches, notwithstanding the fact that this fruit is adapted to only special localities. It is not necessary that we

*Consult, as an example, Bréhaut's "Modern Peach Pruner"; also Hartwig "Die Kultur des Pfirsichbaumes am Spaliere," Weimar, 1886. 
train them to walls, or that we give them any other special or peculiar treatment in the way of training. Those who are interested in Old World practices, however, or who desire to train peaches on walls or in houses, will appreciate the following extract from Thomson :*

"Many ways of training and pruning the peach and nectarine have been practiced and recommended. French horticulturists especially have been very suceessful in training them in several ways characterized by regularity and neatness. The single-cordon as well as the multiciplecordon systems are favorite modes of training in France. Modifications, partaking more or less of the French systems, have been practiced and recommended, especially by Seymour, in England. But the ordinary fan system of training is by far the most generally practiced and liked. It is, especially under glass, the mode of training which the most successful forcers of the peach have adopted, and it is that which I recommend. Many grand old examples of peach trees under glass are to be found in this country, which have all along been trained.on the fan principle, and that are yet in fine bearing condition, being well furnished from top to bottom with young bearing wood. Taking a young tree, which I have recommended for planting as the foundation of a fan-trained tree, different cultivators who are most in favor of this system of training would deal differently with the ten young growths [five branches on each side, and no leader, all arising from near the top of a short trunk] with which it is furnished. Some would eut them all back again to within five or six buds of their base; others would not shorten them at all, but would let them

*David Thomson, "Handy Book of Fruit Culture Under Glass," 152, with figures. 
start into growth with as many young shoots as could be tied to the trellis without crowding them. What I have practiced and would recommend is a mean between these two. The two center shoots I would shorten back to half their length, the other eight shoots to be merely topped back to solid, well-ripened wood. The cutting somewhat closely back of the two center ones makes it certain that two or three good, strong growths will start from near their base to properly fill up the center of the tree with leaders. Each of the other eight shoots should have all their buds removed by degrees, except one near the base, and one or two at equal distances between it and the leading bud, according to the length of the shoots; two buds to be left on the under side-if the shoots are long enough to have room for three on the upper side, - the buds on the one side to alternate in position with those on the other. These lateral growths, with the leader, are enough to lay a foundation to serve for the future full-grown tree. The lateral growths should be allowed to grow without being stopped. Should the leaders show signs of growing very vigorously at the expense of the side growths, stop them whenever they show such a tendency. This will cause them to make lateral growths freely, and equally balance the growth of all the young shoots. This encouragement of lateral growths, especially on the young wood in the center of the tree, gives sufficient to furnish the tree without having recourse to the undesirable practice of first allowing a few very strong leaders to monopolize the sap, and then to cut them down at the winter pruning. In this way much time is gained in covering a wall or trellis with bearing wood.

"A young tree thus managed on what may be termed a mean between the extension and the cutting-hard-back systems produces a comparatively large, well-furnished tree the autumn after it is planted, and one which requires very little or no winter pruning before starting it into another year's growth. If the summer disbudding and 
pinching of the first season's growth have been properly attended to, the tree will be so thoroughly furnished with young wood that all the pruning that should be done is simply to remove any shoots that would erowd the tree. The distance between the shoots should not be less than three or four inches. In February, 1878, I planted a number of young peaches and nectarines in an orchard-house. In the autumn not a single shoot was shortened-back, and at the close of their second year's growth the trees thoroughly furnished, in many instances, spaces of eighteen feet by thirteen feet, and a great many of them sixteen feet by twelve feet, besides bearing a good crop the season after being planted. There are some magnificent trees at Brayton Hall, which Mr. Hammond, the able gardener there, managed on the extension system, and consequently filled their allotted spaces and bore grand crops in half the time in which this could have been done by the old euttingback system.

"After the trees have grown and covered the space allotted to each, the system of pruning must be directed so as to continually keep the whole tree regularly supplied with young fruit-bearing wood. With a view to this, of course, the yearly removal of old wood in winter, and the laying in of a corresponding amount of young wood in summer, must be carefully attended to. ****

"Some make a practice of cutting back the young bearing wood to two-thirds its length. I do not advocate this indiseriminately. Where the shoots are long and not wellripened, and the buds consequently weak, they should be shortened-back to where the wood is firm, and always to a strong wood-bud. Peach trees in a healthy condition have their buds in elusters of three-a wood-bud in the center, and a fruit-bud on each side of it; and to such a cluster of buds they should always be cut when cut at all.

"Well-established trees that have borne heavy crops regularly, and especially those that have been forced early, 
generally make shorter and stronger growths, well studded with strong elusters of buds. In this case it is inadvisable to shorten them back at all. A watehful eye must always be kept on the lower portion of the tree, so that it is not allowed to get bare of young fruit-bearing growths. It need scarcely be said that, from the fact that it is the young wood that bears, the tendency is for it to be in greatest abundance at the top.

"The best guarantee against trees becoming bare of young bearing-wood at their lowest parts, is to annually eut back a few healthy young growths to two or three eyes, and allow as many of these to bud and grow as may be required to keep up the supply of young wood. This is an indispensable necessity, from the fact that portions of old wood have annually to be removed at the top of the tree. In practice, all other things being equal, there is little difficulty experienced in thus furnishing the lower portions of the tree with bearing-wood. All cutting should be effected with a sharp, thin knife; and whenever it becomes necessary to remove an old limb, the wound should be painted solidly over with white paint."

In order to show the nicety to which training may be carried, the following extract from $\mathrm{Du}$ Breuil will be interesting :*

"Training OF the PEAR IN VASE OR GOBLET FORM.Trees in the pyramidal form are, in some situations, liable to injury from high winds. When that is the ease, the vase or goblet form may be substituted. But it is not otherwise to be preferred, for it requires as much room as the pyramid form, and does not present so great a fruitbearing surface.

"Trees in vase form should leave a diameter of about six

* "The Scientific and Profitable Culture of Fruit Trees." 
feet six inches (and an equal height), so that the solar rays may act upon the whole interior surface of the vase. An interval of twelve inches should be left between each of the branches. Supposing the tree to be twenty feet in circumference, there should be about twenty branches at the base, from which to form the tree.

"The branches may either be trained vertically, or made to eross each other alternately right to left, following an angle of thirty degrees, as shown in Fig. 238. We consider the latter form preferable. The sap acts more equally throughout the entire extent of the branches, which also fruit more regularly, and the tree ean better support itself when eompletely formed.

"The method of proceeding to develop the wood is as follows: Choose plants that have been grafted a year, and apply the first pruning; when they have been planted out another year, eut them down to sixteen inches from the ground. During the summer select five shoots, and maintain an equal degree of vigor by pinching. At the second pruning, eut off each of the branches to sixteen inches from their base, above two buds growing laterally, so as to make each of the branches fork; lower the branches a little and dispose them regularly round the circumference of the stem by means of a hoop. During the summer equalize the vigor between the ten shoots that have now been obtained. At the third pruning, eut back each of the ten shoots to twelve inches from their base, to make them fork a second time. Incline the branches again, and equalize the spaces between them by means of two hoops, the uppermost being the larger. Treat the twenty shoots that have grown during the summer in the same manner as the previous ones. At the fourth pruning, suppress only the third of the length of the new branches, and again incline them downwards to an angle of about twenty degrees, then raise the ends of the branches in a vertical position at about three feet from the stem, and keep them in that position by means of addi- 
tional hoops. During the summer allow only one terminal bud to develop. When the time arrives for the fifth operation, cross the branches at the place of their second forking, directing them alternately right and left, inclined to an

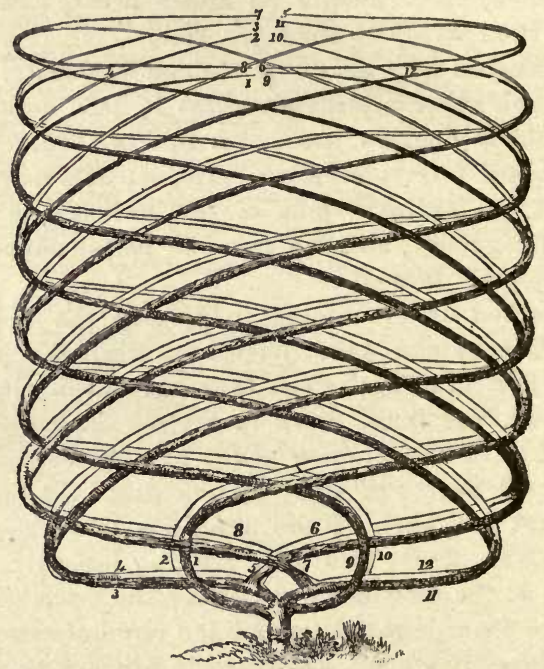

238. Outline of pear trained in vase form.

angle of thirty degrees. Fig. 239 shows the plan of a pear tree trained in this form, and how the branches should be crossed. The new extensions, obtained during the previous summer, must be left entire, and so on from year to year, until the tree has attained its proper size. The inclined position of the branches will cause them to put forth numerous shoots, each of which must be trained in a spiral direction, to be arrested only when the tree attains a height of about six or seven feet, when it will be fully formed, and resemble Fig. 238. 
"As the tree increases in height, each of the branches must be grafted together by approach [inarching] at each of the points where they cross. This will give great strength

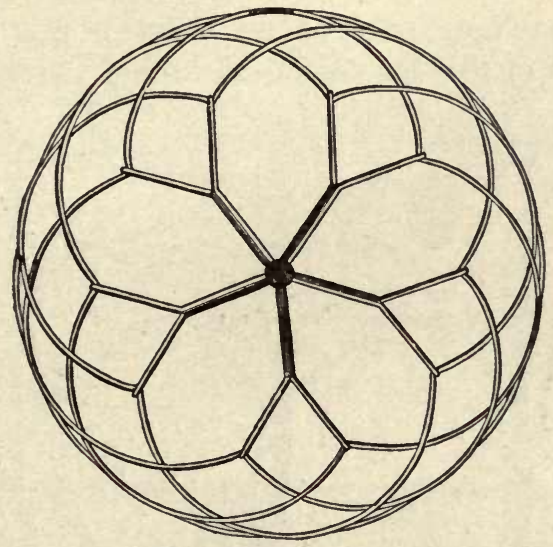

239. Plan of the tree.

and solidity to the tree, and enable it to dispense with any other support when the wood is completely established.

"The fruit branches, which are not shown on the figures, are formed and kept in bearing in the same manner as in pyramid trees."

Before leaving this part of our discussion, we may look at the pictures. With the exception of Figs. 238, 239, 242, these are made from photographs taken at various times by the writer. Fig. 235 is a palm-leaf (or palmette) peach tree, ready for planting against a wall. This tree was on exhibition at the Gartenbau Austellung, at Hamburg, in 1897. Fig 236 is a cordon dwarf apple 
from Saxony. The wire is about twenty inches above the ground, and the single arm or trunk of the tree extends about eight feet. Fig. 237 is a sketch of part of an espalier pear in the grounds of the Gartenbau Hochschule, near Berlin.

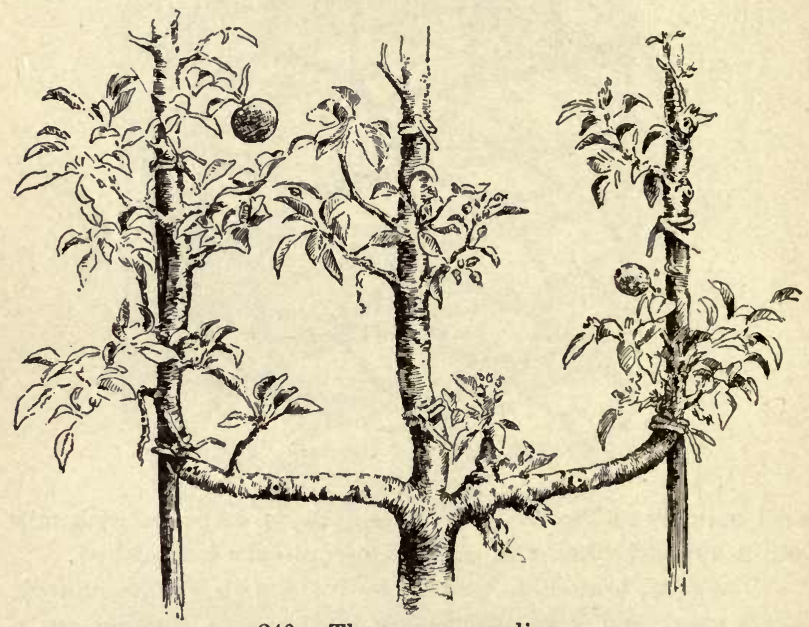

240. Three-arm espalier.

Fig. 240, from Germany, is part of a three-arm candelabra espalier apple tree. Fig. 241 is an old espalier Greening apple tree growing in western New York. The trellis has long since been removed and the tree now supports itself, although extending over a space about thirty feet long. This is not a good specimen of training, but it shows how readily a dwarf apple can be made 
to assume a horizontal direction. Fig. 242 is a diagram of a wall-trained apricot. Fig. 243 is

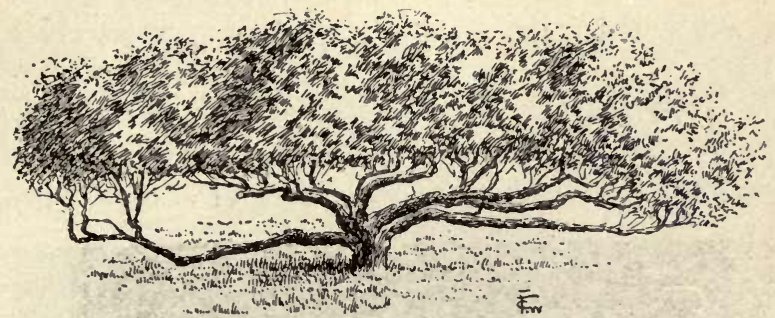

241. Old apple espalier in New York.

a dwarf pear trained in fan-shape on a wall, in England. Fig. 244 is a pear tree covering the

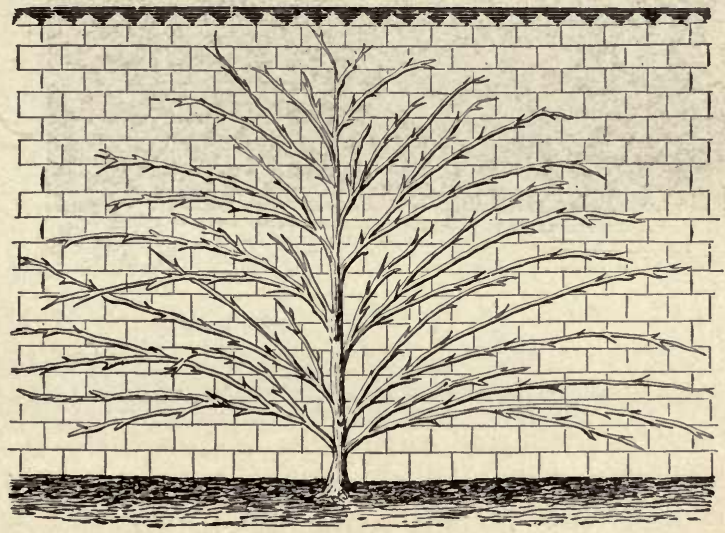

242. Wall-trained apricot of palmette form.

south front of a cottage in southern Bavaria. The photograph was taken in August, and the 
374 SOME SPECIFIC MODES OF TRAINING

season's growths are seen projecting beyond the roof-line.

\section{TREES AND BUSHES IN POTS}

Many fruit trees are successfully grown in pots or boxes, being used either for forcing purposes or for fruit-bearing at their normal season. Such

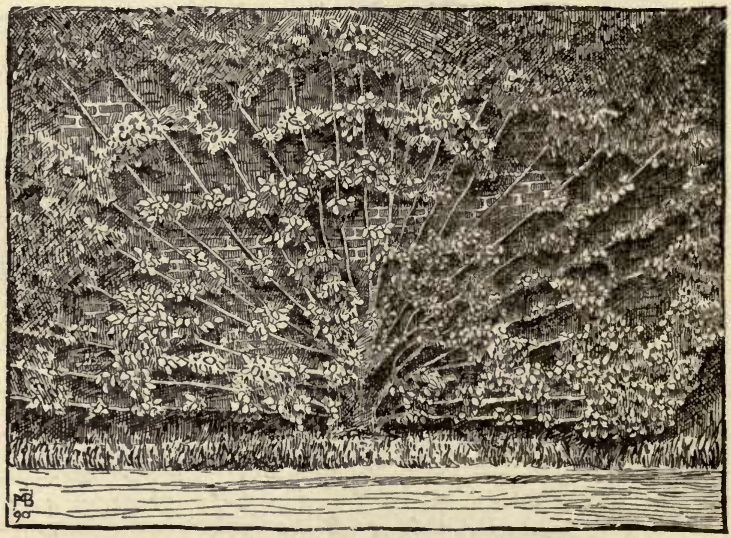

243. Fan-trained dwarf pear.

trees, unless used for forcing, are chiefly valuable as ornamentals and curiosities, although the fruits should be of the very finest quality. Fig. 245 is an apple tree several years old, in full bearing. It is in a sixteen-inch pot. Trees of this size should ripen from ten to twenty-five apples. Potgrown apples and pears should be dwarfs. 
Peaches and apricots on their own roots do well in pots. Cherries are usually worked on Mahaleb

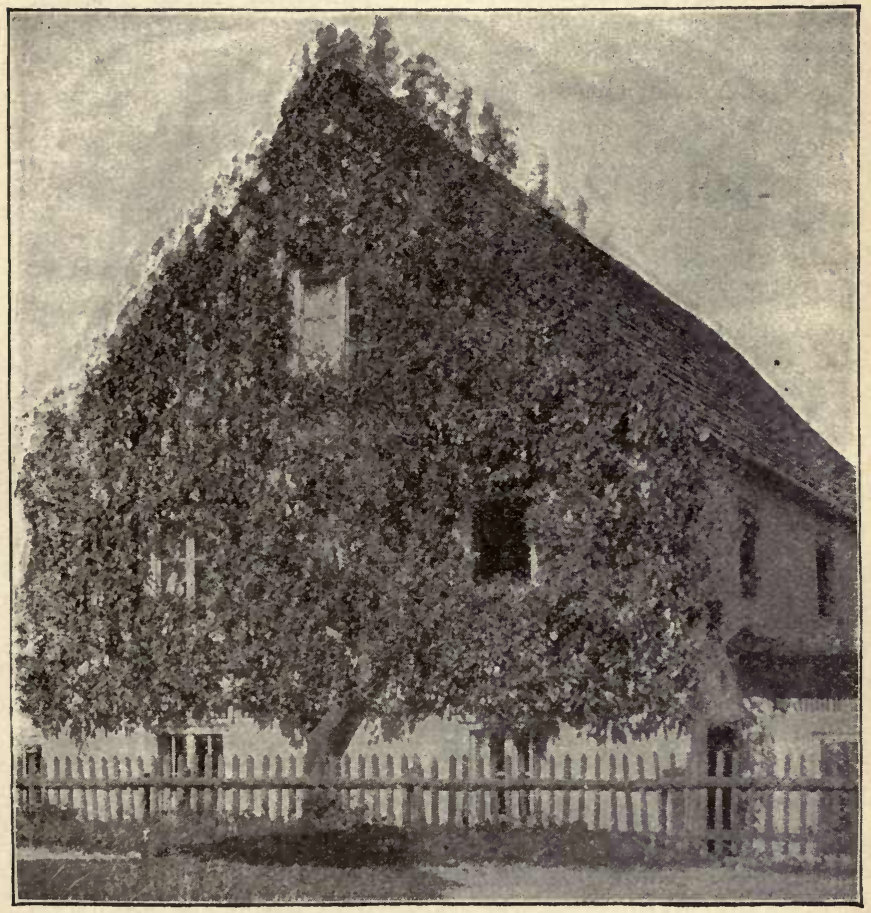

244. Good specimen of wall-trained pear tree.

for this purpose, and plums are often grown on Myrobalan roots. Trees should bear in the third or fourth year. 


\section{SOME SPECIFIC MODES OF TRAINING}

The following sketch from Warneken* conveys a general idea of the method of trimming and training pot-fruits in the pyramid form (which is the most popular shape):

"The form of trees is given but little attention by many pot-fruit tree growers, they looking only to large yields of fruit. Others, again, desire to give pot-fruit trees every conceivable artificial form, even espalier forms having been recommended. Although it must be constantly our aim to produce a large fruit yield, it is not necessary, thereby, to neglect the form of the trees; and a pleasing form with a large yield can be readily combined.

"Form OF THE TREES. - Our pot trees must at times be set closely together, and it is, therefore, not desirable to produce such large forms as demand much space; as, e. g., erown trees or trees of eup shape. If, however, it is desirable to train these forms in pots, their pruning may be studied in a pruning book. We shall not describe this pruning, as we do not eare to puzzle the beginner with so many artificial forms, but we shall suggest such simple and easily made forms as appeal to a rational culture, and which are the result of many years of experience. For such varieties of fruits as in their nature are suitable to the pyramidal form, this remains the best. We, therefore, give our trees, with advantage, only the following form.

"Apples and pears we train to a narrow shape,-in the full grown condition a pyramid about fifty to sixty centimeters wide [a centimeter is about two-fifths of an inch]. Peaches, plums, cherries, apricots and figs we train to a pyramidal bush, which, however, should not be over sixty centimeters wide at the bottom. With peaches and plums, the more practical narrow pyramids recommended for

*H. B. Warneken, "Die Kultur des Obstbaumes im Topfe", Frank. furt a. d. Oder, 1889, 33. 
apples and pears, also columnar pyramids, may be used. Grapes cultivated in pots are trained to so-called spiral cordons, which have a corkscrew-like, twisted stem earried on three stakes.

"PREliminary training, IN ITS FIRST YeAR, OF A TREe DESTINED FOR POT-CULTURE.-Peaches and other fruits ean

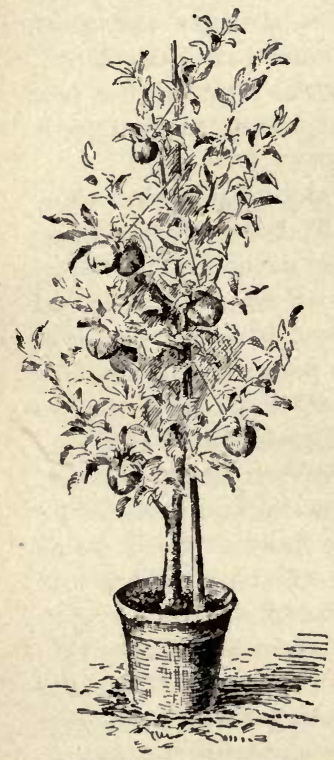

245. Pot-grown apple in full bearing.

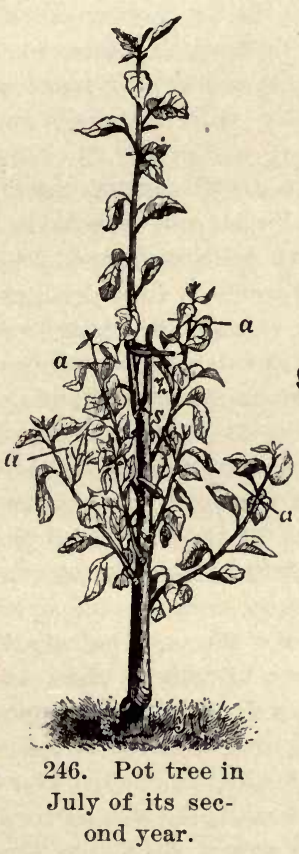

247. Showing

how the tree is to be pruned.

be prepared for pot eulture in their first year. If we have personally budded our trees, we pinch off the tip of the young shoot which appears in early summer, according to its strong or weak development, when it has grown to a 
length of thirty to fifty centimeters. As a result, the buds at the side will develop in the first year into small shoots. As soon as these have formed four or five buds, they are pinched back to two or three buds. If the highest of these lengthening buds develops a strong shoot, and if the side shoots are backward and irregularly placed, the main shoot can be pinched again. The trees thus treated during the first year have a stronger and more compact form, and all the lower buds are better developed. We gain time, therefore, by making the best of the first year, particularly with peaches, and secure more rapidly bearing trees.

"THE ONE-YEAR-OLD TREE, generally smooth and unbranched, will be at our disposal. If, however, too early side shoots have been developed, they must be removed at their base on the stem, in order nct to secure a confused tree. We now ent all such unbranched one-year-old trees of all fruits to the length noted for peaches, that is, fifty centimeters, and to a strong bud. With stone fruits we now choose three to four buds pointing in different directions, beginning above fifteen centimeters from the ground, and crescent-like cuts are made with a sharp knife into the bark above each of these. If all the buds on these stems develop, we retain but six or seven of those on top and pinch off the lower ones, as our pyramids shall not branch immediately above the soil, but shall first make a stem fifteen to twenty centimeters high, in order that the fruits shall not be too near the soil and get dirty and be of lesser value. The uppermost shoot is fastened perpendicularly to the projecting stub (Fig. 246) The remaining side shoots we try to have equally strong, and we secure this by pinching back the stronger. All shoots have their points pinched off as soon as they are thirty centimeters long. From July to August we remove the stub which projects beyond the uppermost branch (Fig. 246). On apples, pears, peaches, apricots, plums, and cherries we have nothing to do other 
than what has been mentioned, and to keep them in health and free from pests. If the plant lice are not promptly removed, they greatly injure the young trees while they are yet developing their structure, as they suck out completely the young shoots so that they dry out. If we have oneyear-old stems of pears and plums which, during the first year, have clothed themselves all over and in a regular manner with shoots, beginning fifteen centimeters above the ground, we cut these back to three buds. The stem itself is taken back one-third its length, and is then and ever thereafter cut to a spur or stub.

"THE SECOND YEAR. - At the winter pruning of the second year, the side shoots of seed fruits are reduced to four to six buds and those of the stone fruits to three to four buds. With the seed fruits, we try to eall forth weak shoots from all buds by means of eross-cuts above them. In the case of stone fruits, this must never be done, as by this means the outflow of sap and the so-called bleeding would be induced. The stem, when strong and over thirty centimeters long, is cut back to one-half its length, or to about six to eight buds. Weak and short shoots up to twenty centimeters remain uncut. The summer pruning or pinching back is practiced on all trees. As soon as the strongest shoots have developed six buds, they are pinched back to four buds, and this treatment is gradually given to the others as they develop. If the shoots should again grow out, the new growth is pinched back to two buds, and this treatment is continued all summer, so that every new shoot is reduced to two buds. This repeated pinching has for its object the thickening of the buds at the base of the shoot and to change them to fruit-buds. The bearing wood in the seed fruits ean bear fruit for years, and it is therefore only necessary to induce the gradual change of the woody shoots into bearing wood.

"The tree in July of its second year is shown in Fig. 246. $Z$ is the stub to be removed in July at the point $S$. At $a$ 
are points at which side shoots are pinched back. Fig. 247 shows the winter pruning on the two-year-old tree. $S$, points at which all side shoots are to be eut. 1, 2, 3, buds which are to receive cross-cuts. St, the bud destined to lengthen the stem; it must be above the point of last year's eut, as at $O$; $S t$, up to $i$, the new stub; $i$, point at which the shoot is cut.

"In the stone fruits, the wood which has borne dies off, and it is necessary to have new bearing wood each year. We must, therefore, prune in such a manner that continually new bearing wood for the next year is formed. Therefore, on every fruiting branch of a peach there should be two leaf-buds at its base as a reserve. On the branches of the peach are found buds of varying appearance,-thick roundish, and thin pointed. The former are flower-buds and the latter leaf-buds. It happens at times that a flowerbud stands alone, generally on thin bearing branches, and again that a leaf-bud stands alone, as on strong shoots and young stems. We may also find a flower-bud and a leafbud or two flower-buds united, and finally a pointed leafbud between two round flower-buds. Our peach trees are therefore cut for the first time in the early spring, when even the beginner can distinguish flower and leaf-buds. On many strong branches nothing but leaf-buds are found, on single, thin fruit branches again only flower-buds. The latter, we may as well mention here, are the worst, as they must die from lack of leaf-buds. The best fruit branches are studded with triple and double buds, and have at their base some simple leaf-buds. The majority of fruit branches have only simple and double buds and at the point a leaf-bud. Excellent fruit-bearers are the very short cluster spurs but a few centimeters long. These have at their tip a whole bouquet of flower-buds and a leaf-bud in the center, and these are not pruned. Our task is, then, to keep the shortest possible branches, and allow those to bear fruit which have leaf-buds above their flowers, in order to 
lead away the superfluous sap not necessary for the fruit. At the same time, these branches must have at their base several leaf-buds to which we may cut back and cause the production of bearing wood for the next year. Long and thin branches, with but single or double flower-buds and a leaf-bud at the point, can bear fruit, but leave behind only bare places in the fall when they die. It is, finally, to be observed, in cutting-back, that this should not be done to a single flower-bud, as otherwise the shoot dies off to the next leaf-bud. Those shoots on which the dead flowers fall off can be cut back immediately after flowering to the two leaf-buds at the base. An observance of these directions will make it an easy matter to prune peaches in the spring. The pyramidal form which is to be given must, however, always be kept in mind in determining the position of the branches to be saved.

"THE THIRD AND FOLLOWING YEARs. - In the winter pruning of the third and following years, the shoots of the year before, on all fruits, are cut-back to three to four buds, and here it is that the pyramidal form must be looked after. All trees clothe themselves with weak bearing wood at the base of last year's stem, and the pruning of the stem growth must be done accordingly. If it were cut too long, many of the buds would not grow, and bare places would result. Too heavy pruning would cause the formation of strong, woody shoots at the lower part of the tree. With our seed fruit and stone fruit pyramids in pots, the branches must not stand too thick or shade each other. At all times light and air must reach the stem in order to benefit the fruits. The removal of single large stems in later years will make this possible. It may also be mentioned here that the dry wood forming in the tree in later life should be removed. In the third, as in all following years, the summer pinching-back is executed the same as in the first year, and in the stone fruits, particularly in peaches, provide for the fruiting wood in the coming year. Thus 


\section{2}

we build out our pyramid in the pot, and by means of the regular use of the stub to tie to, the lengthening shoot is given a pleasing, erect form. The wood shoot will moderate with increasing fruitfulness, so that in later years it will not be necessary to eut it much, and pinching in the summer will be sufficient."

The growing of cherry trees in pots, by $\mathrm{Mr}$. Rivers, one of the best English growers, is thus described:*

"The method of growing cherries in Rivers' orchardhouses is given below in detail, with plans of a house. Most of the trees are grafted on cherry stock, except the Duke cherries and Early Rivers and Governor Wood, which are grafted on Mahaleb stock. They are never lifted or replanted before potting.

"Early in autumn one and two-year-old trees are taken up, their roots shortened so that they can be put into the pots without breaking, and planted in eight or twelve-inch pots. This potting must be done carefully, and the trees must be set so deep that the big roots near the surface will be covered with an inch of soil. Cover the bottom of the pots with a good, thick layer of drainage. The soil used in potting is a light, sandy loam, enriched with one-third of well-decayed fertilizer. It is important to firm the soil well around and among the roots. Fill it in by degrees, ' in small quantities, and beat it down firmly all through the pot, taking care not to injuve the roots. After potting, the trees are set in a sheltered place outdoors, the pots being covered with leaves. If the soil is moist enough when the trees are potted, they will not need watering.

"When spring comes the tree must be thinned out and the pots plunged one-third of their depth in the earth.

*A. K. Anderson in "American Garden," xiii., 594. 
The trees remain here all the summer, are watered earefully every morning when the weather is bright and dry, and syringed with pure water if the greenfly is troublesome. In July, when the trees are well rooted, a top-dressing of stable-manure and kiln-dust in equal parts is given the trees. A few days before the top-dressing is used it is spread out in thin layers somewhere outdoors, and soaked several times with liquid manure. It is applied to the soil in the pots, in layers two inches thick near the rims, but thinner near the stems of the trees. This top-dressing greatly improves and strengthens the trees for the eoming year.

"After growing in pots one summer, trees are fit to be sold the following autumn or spring. From Rivers' nursery three or four hundred potted cherry trees are sold yearly, the number increasing constantly. Old cherry trees that have been cultivated in pots for years are kept during winter in one of the orchard-houses. When spring comes and their buds begin to start, the pots are plunged up to the rim in the ground in the cherry-house.

"The pyramidal form is best and most used for potted cherry trees. Pruning is not often necessary the first year after potting, for the strength of the tree goes to form short fruit-branches; but after the trees are well rooted, strong shoots are sent out in summer. Summer pruning consists mainly in pinching back these strong shoots to six or seven leaves each. If after this first stopping they grow out again, they are again pinched-back. On the leading branches, side-shoots that are not needed to fill empty spaces or make new leaders, are stopped at the third leaf. The sour cherries, which form young buds better on the side-shoots, might be pruned less. Much winter pruning is not needed for trees that have been well stopped in summer. Winter pruning must be done as soon as leaf and bloom-buds can be distinguished. It is done upon the same principle as outdoor pruning, but as the room in orchard- 
houses is limited, all growth must soon be pruned into fruitbranches.

"After the cherries are all gathered, the trees are plunged outside in a sunny, sheltered place, and left there until repotting time in October or November. Trees that have been potted but one year seldom need larger pots at this time, so two or three inches of the top soil in their pots is taken out and replaced with fresh. Larger pots are given, in after years, when these young trees become root-bound and require them. Cherry trees ought to be repotted every other year."

Various forms of training pot-grown gooseberries, as grown by James Veitch \& Sons, Chelsea, England, are shown in Figs. 248, 249, 250 .*

\section{OTHER SPECIAL MODES OF TRAINING}

Plants are often trained so as to allow them to be bent to the ground in the fall, and covered for winter protection. $\dagger$ J. T. Macomber describes the training of peach trees for this purpose, and I insert a part of the account as an example of this kind of training. The tree "should be planted where it is wanted to grow, and all branches must be cut off, leaving the central shoot, upon which allow only one bud to grow. The tree should be visited every week or two, and all branches that

\footnotetext{
*These cuts are used by courtesy of "The Gardeners' Chronicle," where they appeared in the issue of July 31, 1897.

tSee "Principles of Fruit Growing", Chap. I.

f"American Garden," xi. 231.
} 


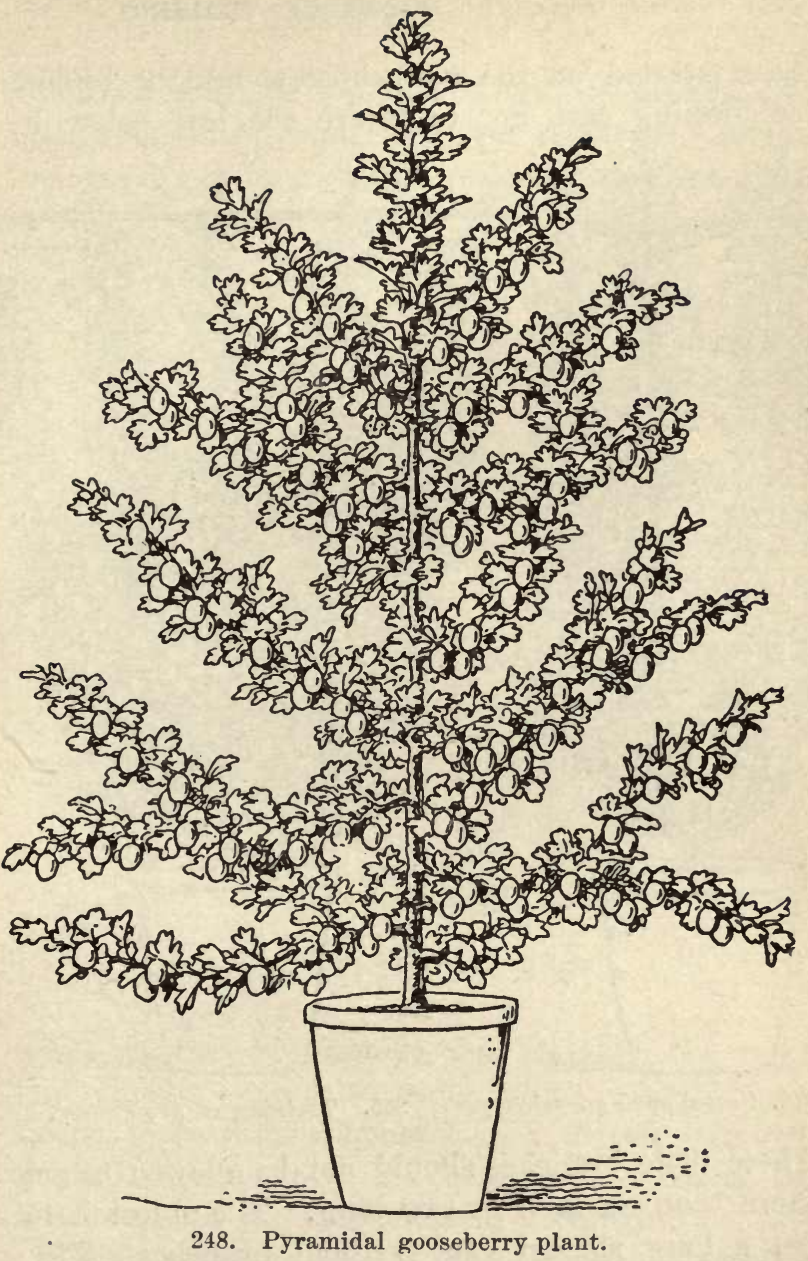


386 SOME SPECIFIC MODES OF TRAINING

have started on the new shoot should be broken off, taking care not to injure the leaf below it.
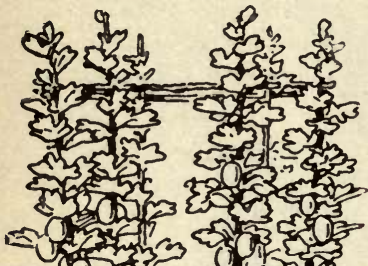

cit?
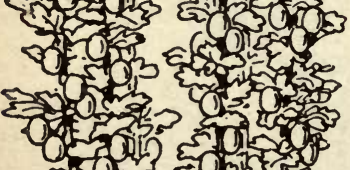

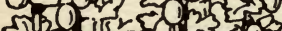
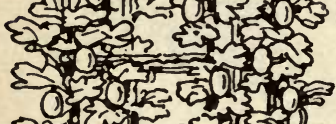

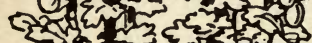
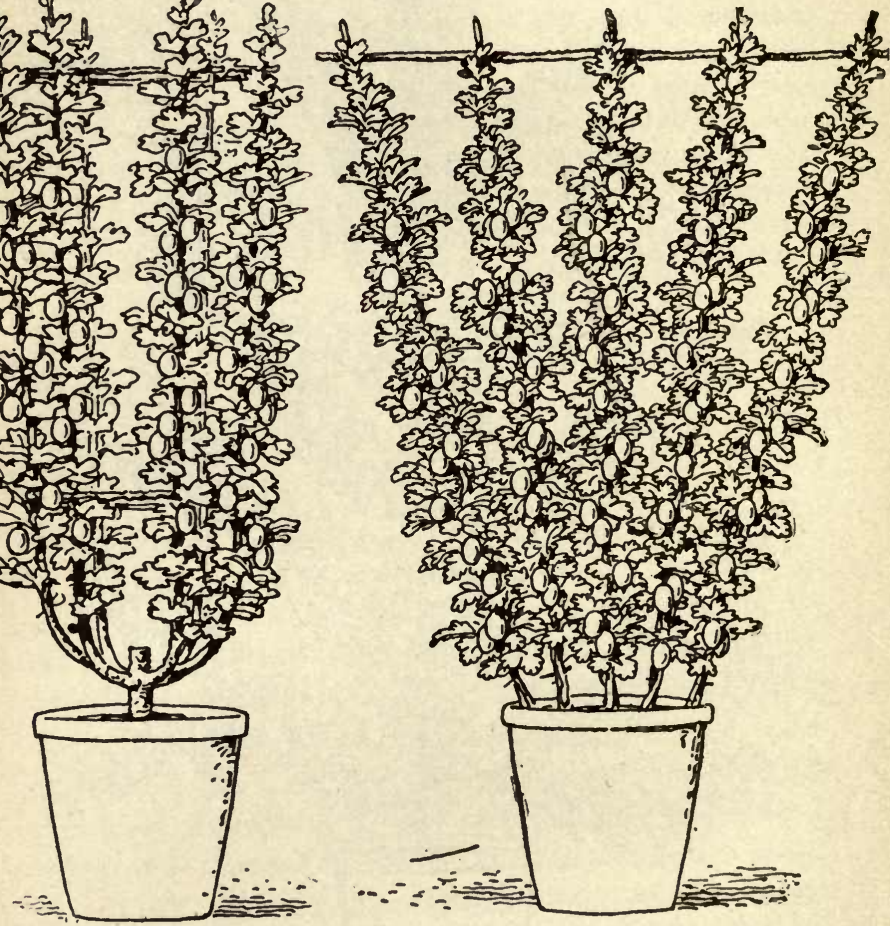

249. Cup-shaped gooseberry. 250. Training of gooseberry.

These little branches should not be allowed to get more than an inch or two long. The object is to get a long, slender cane without branches. Fig. 251 shows a tree in training; $a a$ are the little 
branches near the top that should be broken off. All those below them have been removed. About

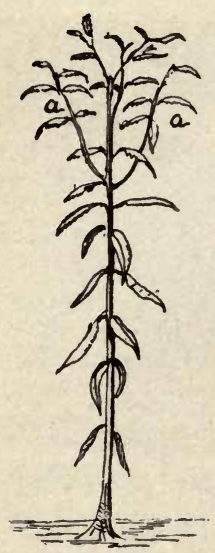
four or five weeks before frost may be expected, stop breaking off the branches, so as to allow the wood to ripen enough to stand the winter. On the approach of freezing weather, place a round block of

251. Diagram to illustrate training of peach.

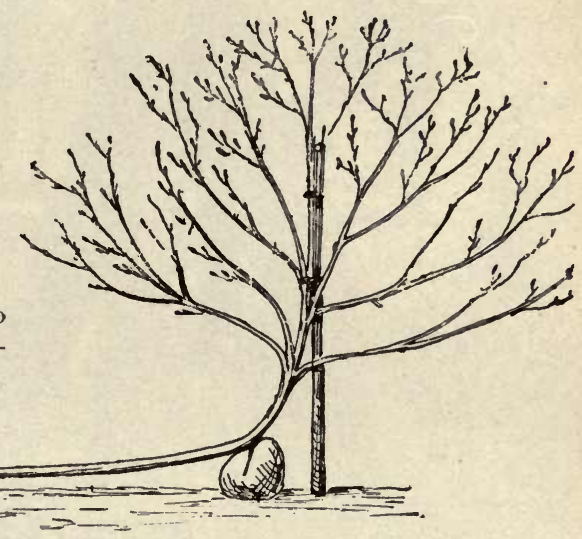

252. The tree at bearing age.

wood on the ground at the root of the tree, and slowly bend the cane down over it and fasten there with a hooked stick driven into the ground. Then cover the cane with a couple of boards nailed together to form a trough.

"When frost is out of the ground in spring, remove the covering and straighten up the tree. 


\section{SOME SPECIFIC MODES OF TRAINING}

After it has begun to grow, cut or rub off all the branches and allow but one bud to grow, and treat

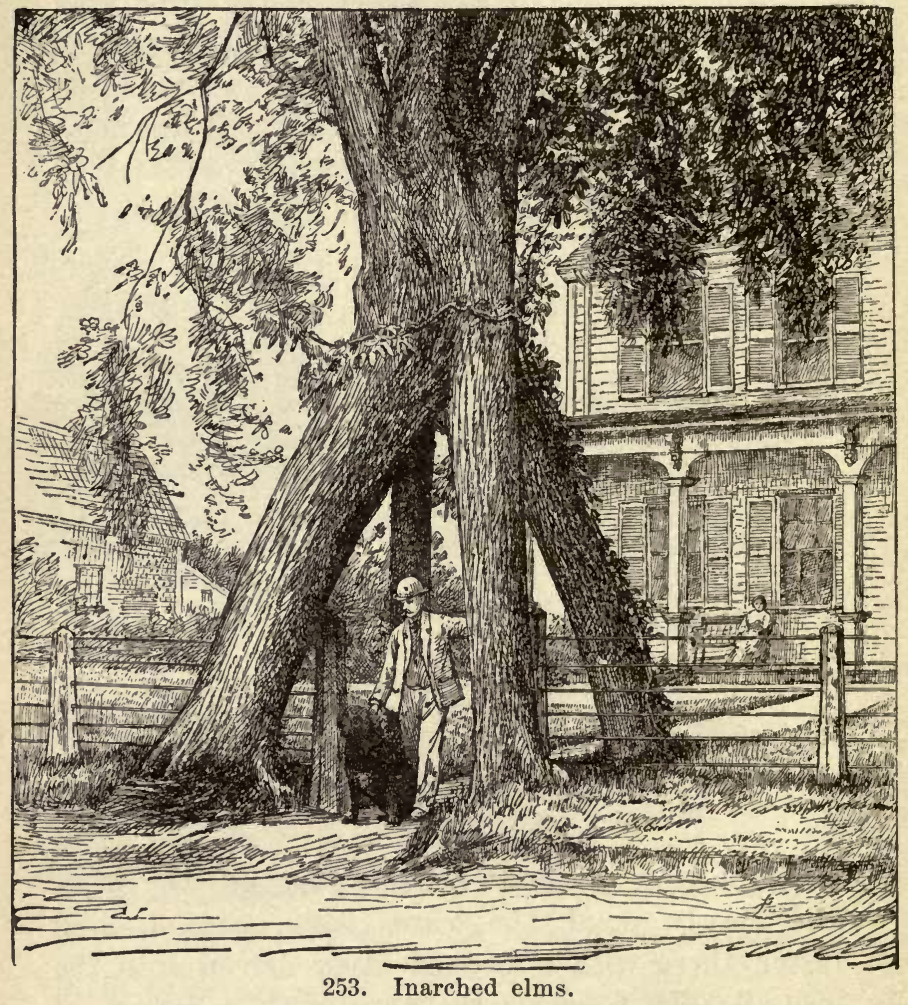

the tree just as you did the previous season. At the end of the third season you will probably have a cane long enough for your purpose. Now the 
tree should not be lifted in the spring, but is kept in a horizontal position and allowed to grow at the end and form a head, which should be trained fan-shaped and parallel with the horizontal trunk (Fig. 252).

"There should be a soft pad of straw or eloth between the tree trunk and the block. On the approach of freezing weather, loosen the tree from the supporting stake, and after having placed some evergreen boughs on boards on the ground to keep the twigs off the earth, bend the head of the tree down sidewise to the ground, weight it, if necessary, and then cover the whole head with boards." The trunk will be flexible enough to allow the head to be laid down every winter. Protect the trunk from sun-scald.

Trees and branches may be made to grow to: gether in various fantastic ways if they are securely bound to each other. The union takes place more rapidly if the bark is removed from the conjoined surface and the exposed parts of the wounds covered with wax. This is a species of inarching. However, simply binding together young branches will cause them to unite, if the parts are in very intimate contact and if they cannot move upon each other when shaken by wind. Fig. 253 shows an arch made by binding four elms together. 


\section{Chapter VII}

\section{AMERICAN GRAPE TRAINING - GENERAL SKETCH}

Pruning and training the grape are perplexed questions, even to those who have spent a lifetime in grape-growing. The perplexity arises from several diverse sources, as the early effort to transplant European methods, the fact that many systems present almost equally good results for particular purposes and varieties, and the failure to comprehend the fundamental principles of the operations.

It is sufficient condemnation of European methods, when applied in eastern America, to say that the American grapes are distinct species from the European grapes, and that, consequently, they are different in habit. This fact does not appear to have been apprehended clearly by the early American grape-growers, even after the native varieties had begun to gain prominence. American viticulture, aside from that upon the Pacific slope, which is concerned with the European grape, is an industry of very recent development. It was little more than a century ago that the first American variety gained favor, and so late as 1823 that 
the first definite attempt was made in Adlum's "Memoir on the Cultivation of the Vine in America," to record the merits of native grapes for purposes of cultivation.* Even Adlum's book was largely given to a discussion of European varieties and practices. In 1846 "Thomas' Fruit Culturist" mentioned only six "American hardy varieties," and all of these, excepting the Catawba, are practically not in cultivation at the present time. The Concord appeared in 1853. American grape training is, therefore, a very recent development, and we are only now outgrowing the influence of the practices early imported from Europe. The first decided epoch in the evolution of our grape training was the appearance of Fuller's "Grape Culturist," in 1864 ; for while the system which he depicted, and which yet often bears his name, was but a modification of pictures of grape pruning European methods, and

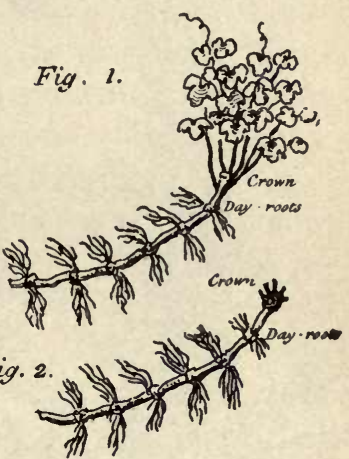
254. The first American and training. had been outlined by earlier American writers, it was at that time placed clearly and cogently before

*Persons who are interested in the historical development of American grape-growing, may consult the author's "Sketch of the Evolntion of our Native Fruits." 

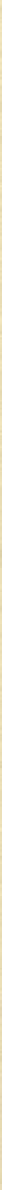

to $50^{\circ}$. $40 \quad 50$ 6.0 Frect:

scate

25.5. The first American pictures of grape pruning and training. 1806. 
the public, and became an accepted practice. The fundamental principles of pruning are alike for both European and American grapes, but the details of pruning and training must be greatly modified for different species. We must understand at the outset that American species of grapes demand an American system of treatment.

The earliest American pictures of grape training of which I know are those in S. W. Johnson's "Rural Economy," published at New Brunswick, New Jersey, in 1806. These pictures are here reproduced full size (Figs. 254, 255). The successive figures illustrate the events in the pruning. Fig. 1 shows the growth of the first year and Fig. 2 the first pruning. Fig. 3, the second year's growth, is pruned to the condition shown in Fig. 4. Fig. 6 shows the training, the bearing eanes being supported on the main stake and the growing or renewal canes on intermediate stakes. Figs. 7-12 show the system of renewal. To one familiar with grape training, these various pictures suggest European patterns.

John Adlum, of the District of Columbia, appears to have been the first person to systematically undertake the cultivation and amelioration of the native grapes. His method of training, as described in 1823, is as follows: One shoot is allowed to grow the first year, and this is cut back to two buds the first fall. The second year two shoots are allowed to grow, and they are tied 
to "two stakes fixed down to the side of each plant, about five or six feet high;" in the fall each cane is cut back to three or four buds. In the third spring, these two short canes are spread apart "so as to make an angle of about forty-five degrees with the stem," and are tied to stakes;

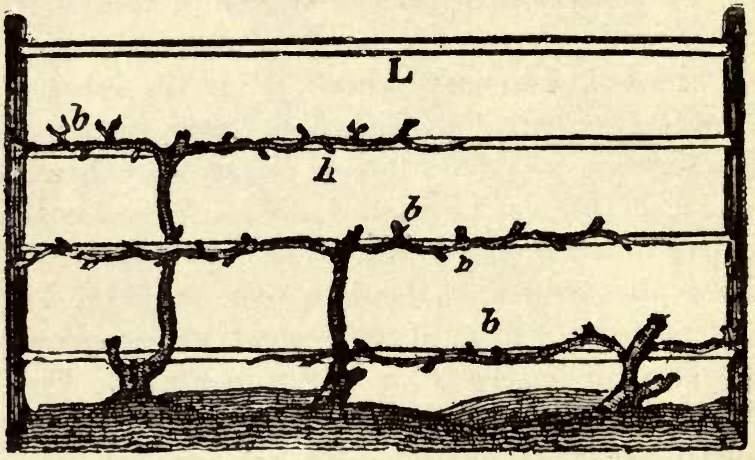

256. Dufour's trellis training. 1826.

this season about two shoots are allowed to grow from each branch, making four in all, and in the fall the outside ones are cut back to three or four buds, and the inner ones to two. These outside shoots are to bear the fruit the fourth year, and the inside ones give rise to renewal canes. These two outer canes or branches are secured to two stakes set about sixteen inches upon either side of the vine, and the shoots are tied up to the stake as they grow. The renewal shoots from the inside stubs are tied to a third stake set near 
the root of the vine. The outside branches are to be cut away entirely at the end of the fourth year. This is an ingenious renewal post system, and it is easy to see how the Horizontal Arm and High Renewal systems may have sprung from it.

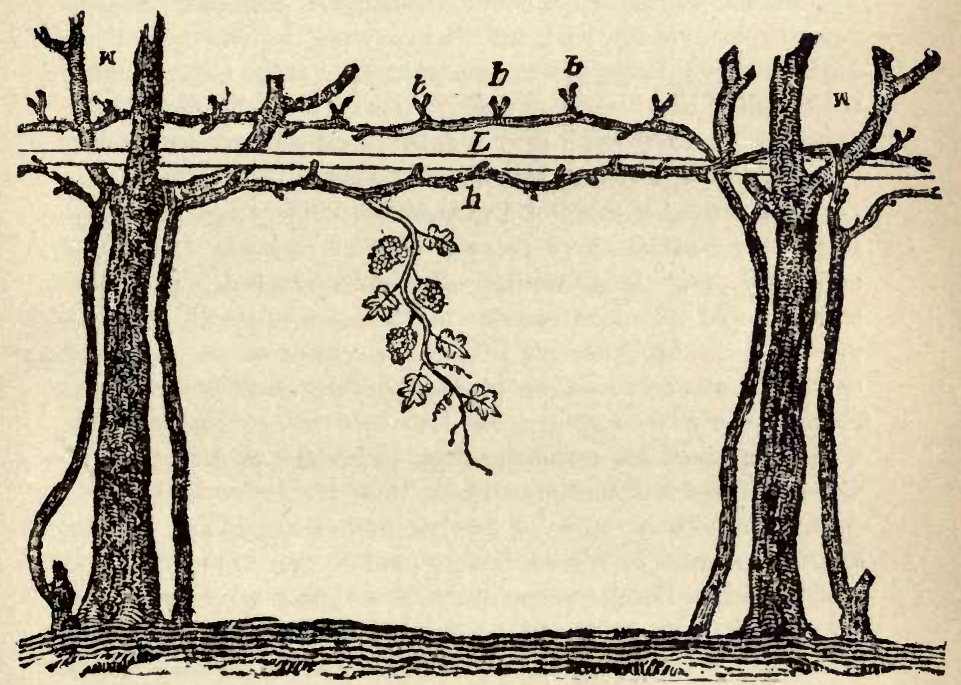

257. Dufour's sketch of training on mulberry trees, suggested by European practice. 1826.

The next important account appears to be that of John James Dufour, who wrote the "American Vine-Dresser's Guide" in 1826. Dufour published the second pictures of grape-training, two of which are here reproduced (Figs. 256, 257). A part of Dufour's sketch will interest us: 
"Now for bowers and espaliers or hedgerows: Any way a vine is trained on the lattice work as to furnish regularly the wall for an espalier, and top of a bower, answers the purpose. But as the sap of plants, and of grape vines particularly, always tends to run upwards, it will happen that a vine which is to give branches at different heights, the uppermost of all will shoot overgrown branches of the lowest part, which will be always weak; therefore, if a high wall or a large bower in a garden is to be covered with an espalier of vines, the wall or bower must be divided in sections, that one vine may furnish wood enough to fill one story in that section; say from fifteen to thirty feet long, according to the force of the ground. The height of one story being about three feet; a wall of eighteen feet high and fifty feet long would offer two sections, and five stories, also it would require ten vines to furnish it; one per story in each section; then five vines, or as many as there are stories must be planted before each section, not close to the wall or bower, but four or five feet from it; and when the vines are strong enough to be laid as directed for vines planted by mulberry trees, they are to be laid down in the same way, nine or twelve inches deep, and raised against the wall or bower, and pruned to three eyes: Vines planted immediately where they are to grow would perhaps do as well; but I have done myself and seen it done the other way. It is supposed that a vine which is to nourish more branches and more fruit than one in a vineyard, will be stronger if it runs some space into the ground, it will surely shoot more roots from the stock; but I think any plant will get roots in proportion to the branches it has to nourish: also, I do not think that it is absolutely necessary to plant them first at a distance from a wall or a bower, but it is surely better to do it against a tree, on account of the roots of the tree, which keeps the ground very dry within their reach; it is best, however, to do it always when it can be done most conveniently. After the vines 
have acquired the proper strength, they are to be trained along the laths, so that one vine should furnish one story only, or that all its branches should shoot on a horizontal line, and nowhere else. (See Fig. 256.) The vine in the left edge of the section being brought up twelve or fifteen inches perpendicular to the lowest lath, there it must be bent square to the right, and tied to the lath as far as the other edge of the section. If that do not give too great a load to the vine, every foot along the lath, a bud must be left to grow, and the vine is full loaded with twelve or fifteen growing buds, so that a lath twenty-five feet long will require two or three years to fill it, without overloading the plant. The next vine being brought up perpendicular, three feet higher to the second lath, and there bent and tied along the lath about as the first one; there may be also twelve or fifteen buds to grow, one being left at each foot; all the buds in that part of the vines which are perpendicular, must be rubbed off except one or two just under the elbow where the lath in that section has to be filled up with a next year's shoot, when the vine of one story has reached the boundary of the section, there it must be stopped. The next vine, or the third, must go up first to the third lath, and so on until the middle of the section, where, after having brought the vine up to its lath, it must be then bent to the left, having there more room. To have a perfect espalier or bower, it requires much nursing until the wall or bower is completely filled, then you will have a horn every foot along each lath except the top one, which must be left naked, that you may tie to it the sprouts of the story under it. This horn must be made anew every year, by the pruning, as directed for the festoons between the mulberry trees, and what grows from them must be suckered and tied to the lath above, and may be pinched a couple of feet higher up. What grows on the top or roof of a bower, may be left to grow at liberty after it has been pruned. An espalier of vines thus trained cover a wall or a 
bower most beautifully, and bears abundance of grapes, which come to fine perfection and make a noble appearance; every exposure I expect would answer in this country; the southwest is the exposure that I saw grapes come first to maturity. There is in Swisserland such an espalier in full perfection, thirty feet high, on the side of a large barn, planted there by myself thirty five years since."

The sketch in Fig. 256 "shows a piece of an espalier or" hedgerow. Letter $\mathrm{L}$ the laths; $\mathrm{b}$ the horns to be renewed yearly; $h$ the horizontal branches. At the lower lath as it appears immediately after the training of it. Along the next lath above, shows the horns made the subsequent prunings." Fig. 257 "represents two mulberry trees and vines trained from tree to tree-letter $h$ the main horizontal branches-L the lath $-\mathrm{m}$ the trees-b the horns to be renewed every year, and what will grow from them will often hang as shown by the branch with leaves and fruit on."

The great diversity of opinion which exists among the best grape-growers concerning the advantages of different systems of training is proof that many systems have merit, and that no one system is better than others for all purposes. The grower must recognize the fact that the most important factor in determining the merits of any system of training is the habit of the vine-as its vigor, rate of growth, normal size, relative size and abundance of leaves, and season and character of fruit. Nearly every variety differs from others in some particular habit, and it therefore requires different treatment in some important detail. Varieties may thrive_equally well upon the same 
general system of training, but require minor modifications; so it comes that no hard and fast lines can be laid down, either for any system or any variety. One system differs from another in some one main principle or idea, but the modifications of all may meet and blend. If two men practice the Kniffin system, therefore, this fact does not indicate that they prune and train their vines exactly alike. It is impossible to formulate rules for grape-training; it is, therefore, important that we understand thoroughly the philosophy of pruning and training, both in general and in the different systems which are now most popular.

These Chapters (VII. and VIII.) on grape training are a revision of my "American Grape Training," published by the Rural Publishing Company in 1893. The motive of the book was thus set forth in the preface: "This little book has grown out of an attempt to teach the principles and methods of grape training to college students. I have found such teaching to be exceedingly difficult and unsatisfactory. It is impossible to firmly impress the lessons by mere lectures. The student must apprehend the principles slowly and by his own effort. He must have time to thoroughly assimilate them before he attempts to apply them. I therefore cast about for books which I could put before my class, but I at once found that there are very few succinct accounts of the sub- 
ject of grape pruning and training, and that none of our books portray the methods which are most largely practised in the large grape regions of the east. My only recourse, therefore, was to put my own notes into shape for print, and this $I$ have now done. And inasmuch as all grape-growers are students, I hope that the simple account will find a use beyond the class-room.

"This lack of adequate accounts of grape training at first astonished me, but is not strange after all. It must be remembered that the cultivation of the native grape is of very recent origin. There are many men who can remember its beginning in a commercial way. It seldom occurs to the younger generation, which is familiar with the great vineyards in many states, that the Concord is yet scarcely forty years old, and that all grapegrowing in eastern America is yet in an experimental stage. Progress has been so rapid in recent years that the new methods outstrip the books. The old horizontal arm spur system, which is still the chief method in the books, has evolved itself into a high renewal training, which is widely used, but which has not found its way into the manuals. The Kniffin type has outgrown its long period of incubation, and is now taking an assured place in vineyard management. So two great types, opposed in method, are now contending for supremacy, and they will probably form the basis of all future developments. This 
evolution of American grape training is one of the most unique and signal developments of our modern horticulture, and its very recent departure from the early doubts and trials is a fresh illustration of the youth and virility of all horticultural pursuits in North America.

"This development of our grape-training should form the subject of a historical inquiry. I have not attempted such in this little hand-book. I have omitted all reference to the many early methods, which were in most cases transportations or modifications of European practices, for their value is now chiefly historical, and their insertion here would only confuse the reader. I have attempted nothing more than a plain account of the methods now in use; in fact, I am aware that I have not accomplished even this much, for there are various methods which I have not mentioned. But these omitted forms are mostly of local use or adaptation, and they are usually only modifications of the main types here explained. It is impossible to describe all the variations in grape training in a book of pocket size; neither is it necessary. Nearly every grower who has given grape raising careful attention has introduced into his own vineyard some modifications which he thinks are of special value to him. There are various curious and instructive old books to which the reader can go if he desires to know the history and evolution of grape training in America. He 
will find that we have now passed through the long and costly experiment with European systems; and we have also outgrown the gross or long-wood styles, and now prune close, with the expectation of obtaining superior and definite results."*

\section{PRUNING THE GRAPE}

Pruning and training are terms which are often confounded when speaking of the grape, but they represent distinct operations. Pruning refers to such removal of branches as shall insure better and larger fruit on the remaining portions. Training refers to the disposition of the different parts of the vine. It is true that different methods of training demand different styles of pruning, but the modification in pruning is only such as shall adapt it to the external

*In the original edition, all the manuscript was read by three persons -by George C. Snow, Penn Yan, N. Y.; William D. Barns, Middle Hope, N. Y., and L. C. Corbett, my assistant in the Cornell Experiment Station at that time, but now professor of horticulture in West Virginia. Mr. Snow is a grower in the lake region of Western New York, and employs the High Renewal system; Mr. Barns is a grower in the Hudson River Valley, and practices the Kniffin system; while Mr. Corbett has been a student of all the systems, and has practiced two or three of them in commercial plantations. In this revision, I have been greatly aided by John W. Spencer, Westfield, N. Y., one of the representative grapegrowers of the famous Chautauqua district. To these persons is to be attributed very much of any value which the book may possess.

The reader will find a good account of grape training by the late E. G. Lodeman, in Year-Book of the Department of Agriculture for 1896. For southern conditions he should consult Starnes' "Grape Culture," Bull. 28, Ga. Exp. Sta. 
shape and size of the vine, and does not in any way affect the principle upon which it rests. Pruning is a necessity, and, in essence, there is but one method; training is largely a conven-

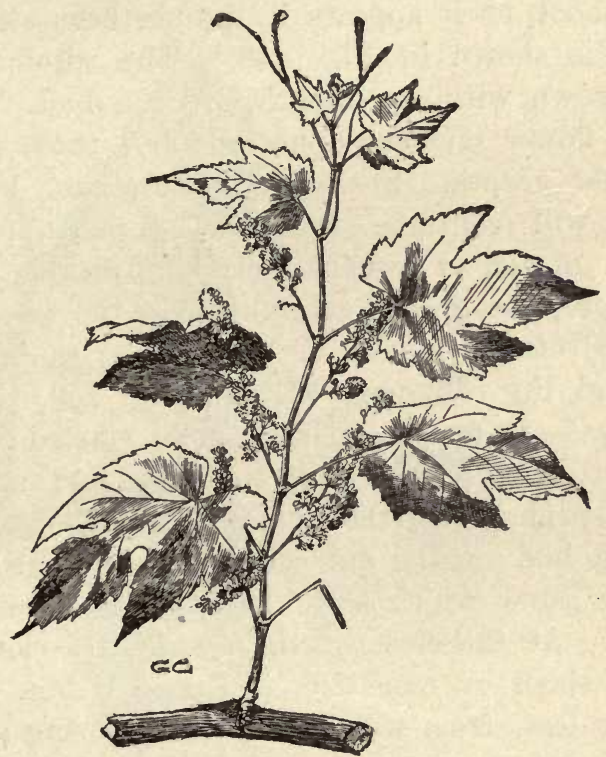

258. Grape shoo.

ience, and there are as many modes as there are fancies among grape-growers.

All intelligent pruning of the grape rests upon the fact that the fruit is borne in a few clusters near the base of the growing shoots of the season, and which spring from wood of last year's growth. 
It should be said here that a growing, leafy branch of the grape vine is called a shoot; a ripened shoot is called a cane; a branch or trunk two or more years old is called an arm.

A shoot, as it appears in the northern states in June, is shown in Fig. 258. The whole shoot has grown within a month, from a bud. As it grew, flower clusters appeared, and these are to bear the grapes. Flowering is now past, but the shoot will continue to grow, perhaps, to the length of ten or twenty feet. At picking time, therefore, the grapes all hang near the lower end or base of the shoots or new eanes, as in Fig. 259 and Fig. 52, page 65. In Fig. 259, the old cane was cut at $A$. Then a shoot started from a bud at $\mathrm{B}$ and grew beyond $\mathrm{BB}$, and another shoot sprung from the uppermost bud.

Each bud on the old cane, therefore, produces a new _cane which may bear fruit as well as leaves. At the close of the season, this long ripened shoot or cane has produced a bud every foot or less, from which new fruit-bearing shoots are to spring next year. But if all these buds were allowed to remain, the vine would be overtaxed with fruit the coming year, and the crop would be a failure. The cane is, therefore, cut off until it bears only as many buds as experience has taught us the vine should carry. The cane may be cut back to five or ten buds, and perhaps some of these buds will be removed, or 
"rubbed off," next spring if the young growth seems to be too thick, or if the plant is weak. Each shoot will bear, on an average, two or three clusters. Some shoots will bear no clus-

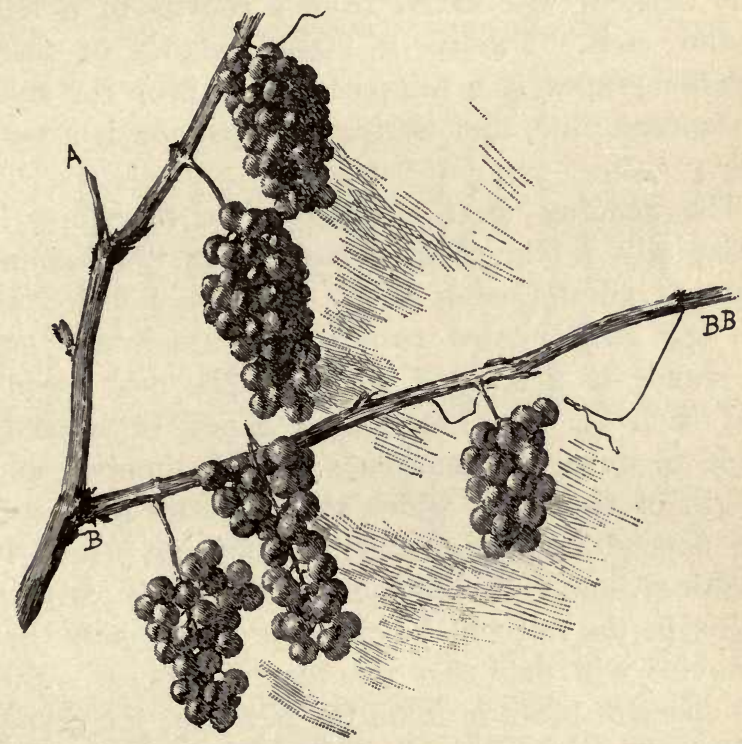

259. The bearing wood.

ters. From one to six of the old canes, each bearing from five to ten buds, are left each spring. The number of clusters which a vine can carry well depends upon the variety, the age and size of the vine, the style of the training, and the soil and cultivation. Experience is the 
only guide. A strong vine of Concord, which is a prolific variety, trained in any of the ordinary systems and set nine or ten feet apart each way, will usually carry from thirty to sixty clusters. The clusters will weigh from a fourth to a half pound each. Twelve or fifteen pounds of marketable grapes is a fair or average crop for such a Concord vine, and twenty-five pounds is a very heavy crop.

The pruning of the grape vine, therefore, is essentially a thinning process. In the winter pruning all the canes of the last season's growth are cut away except two to six, which are left to make the fruit and wood of the next year ; and each of these remaining canes is headedback to three to ten buds. The number and length of the canes which are left after the pruning depend upon the style of training which is practiced. A vine which may completely cover a trellis in the fall will be cut back so severely that a novice will fear that the plant is ruimed. But the operator bears in mind the fact that the grape, unlike the apple, pear and peach, does not bear distinct fruit-buds in the fall, but buds which produce both fruit and wood the following season.

Let us now suppose, therefore, that we have pruned our vine in the fall of 1891 to two canes, each bearing ten buds (Fig. 260). We will call these canes $A$ and $B$ respectively. In 1892, therefore, twenty shoots grew from them, and each of 
these shoots or new canes branches, or produces laterals. We will call these new canes of 1892 A1, A2, A3, B1, B2, and so on. Each of the new canes bears at the base about two clusters of grapes, giving a total yield of about forty clusters. These clusters stand opposite the leaves, as

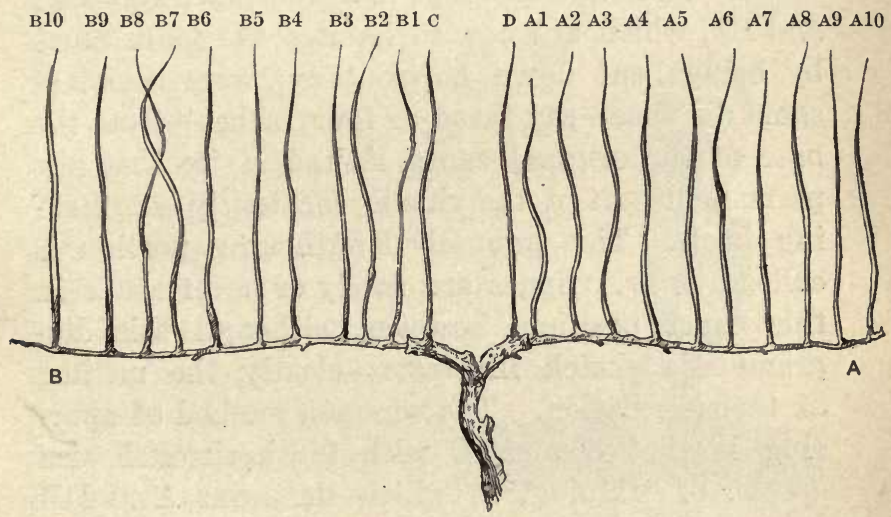

260. Diagram to illustrate pruning.

seen in Fig. 258. In the axil of each leaf a bud is formed which will produce a cane, and perhaps fruit, in 1893. If each of these new canes, A1, A2, etc., produces ten buds-which is a moderate number-the vine would go into the winter of 1892-3 with two hundred buds for the next year's growth and crop; but these buds should be reduced to about twenty, as they were in the fall of 1891. That is, every year we go back again to the same number of buds, and the top of the vine 
gets no larger from year to year. We must, therefore, cut back again to two canes. We cut back each of these original canes, $\mathrm{A}$ and $\mathrm{B}$, to one new cane. That is, we leave only $A 1$ and $\mathrm{B} 1$, eutting off $\mathrm{A} 2, \mathrm{~A} 3$, etc., and $\mathrm{B} 2, \mathrm{~B} 3$, etc. This brings the vine back to very nearly its condition in the fall of 1891 ; but the new canes, A1 and $\mathrm{B} 1$, which are now to become the main canes by being bent down horizontally, were borne at some distance-say three or four inches-from the base of the original canes, $A$ and $B$, so that the permanent part of the vine is constantly lengthening itself. This annually lengthening portion is called a spur. Spurs are rarely or never made in this exact position, however, although this diagrammatic sketch illustrates clearly the method of their formation. The common method of spurring is that connected with the horizontal arm system of training, in which the arms $A$ and $B$ are allowed to become permanent, and the upright canes, $\mathrm{A} 1, \mathrm{~A} 2, \mathrm{~B} 1, \mathrm{~B} 2, \mathrm{~B} 3$, etc., are cut back to within two or three buds of these arms each year. The cane A1, for instance, is cut back in the fall of 1892 to two or three buds, and in 1893 two or three canes will grow from this stub. In the fall of 1893 only one cane is left after the pruning, and this one is cut back to two or three buds; and so on.

Thus the spur grows higher every year, although every effort is made to keep it short, both by re- 
ducing the number of buds to one or two and by endeavoring to bring out a cane lower down on the spur every few years. Fig. 261 shows a short spur of two years' standing. The horizontal portion shows the permanent arm. The first upright part is the remains of the first-year cane, and the upper part is the second-year cane after it is cut back in the fall. In this instance, the cane is cut back to one fruiting-bud, $b$, the small buds, $a$, being rubbed out. There are serious objections to spurs in any position. They become hard and comparatively lifeless after a time; it is often difficult to replace them by healthy, fresh wood; and the bearing portion of the vine is constantly receding from the main trunk.

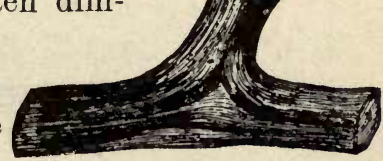

261. Spur.

The bearing wood should spring from near the central parts of the vine, or be kept "near the head," as the grape-growers say. In order to do this, it is customary to allow two canes to grow out each year back of the canes A1 and B1 (Fig. 260), or from the head of the vine; these canes may be designated $\mathrm{C}$ and $\mathrm{D}$.

These canes, C and D, are grown during 1892when they may bear fruit like other canes-for the sole purpose of forming the basis of the bear- 
ing top in 1893, while all the old top, $\mathrm{A}$ and $\mathrm{B}$, with the secondary canes, A1, A2, B1, B2, B3, etc., is cut entirely away.

Here, then, are two distinct methods of forming the bearing top for the succeeding year: either from spurs, which are the remains of the previous top; or from renewals, which are taken each year

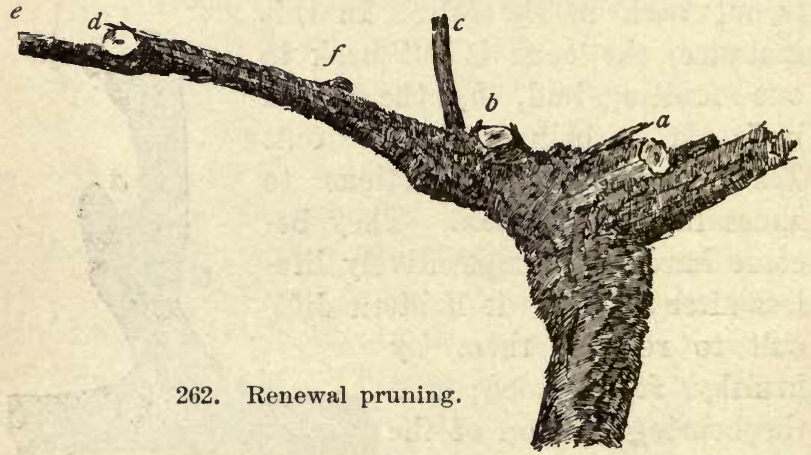

from the old wood near the head of the vine, or even from the ground. Renewals from the ground are now little used, however, for they seldom give a sufficient crop unless they are headed-in the first fall and are allowed to bear the second year. It should be borne in mind that the spur and renewal methods refer entirely to pruning, not to training, for either one can be used in any system of training. Spur pruning, however, is growing in disfavor among commercial grape-growers, and renewal is more or less used in all systems of training. 
Renewal pruning is illustrated in Fig. 262. This engraving shows the head of a vine seven years old, and on which two canes are allowed to remain after each annual pruning. The part extending from $b$ to $f$ and $d$ is the base of the bearing cane of 1892. In the winter of 1892-3, this cane is cut off at $d$, and the new cane, $e$, is left to make the bearing wood of 1893. Another cane sprung from $f$, but it was too weak to leave for fruiting. It was, therefore, eut away. The old stub, $b, f$, $d$, will be cut away a year hence, in the winter of 1893-4. In the meantime, a renewal cane will have grown from the stub $c$, which is left for that purpose, and the old cane, $b d$, will be cut off just beyond it, between $c$ and $f$. In this way, the bearing wood is kept close to the head of the vine. The wound $a$ shows where an old stub was cut away this winter, 1892-3, while $b$ shows where one was cut off the previous winter. A scar upon the back of the head, which does not show in the illustration, marks the spot where a stub was cut away two years ago, in the winter of 1890-1. This method of pruning can be kept up almost indefinitely, and if care is exercised in keeping the stubs short, the head will not enlarge out of proportion to the growth of the stock or trunk.

PRuning young vines.-The time required after planting to get the vine onto the wires or trellis varies with the strength of the vine when 
set, the variety, the soil and cultivation, and the system of training; but, as a rule, the training begins the second or third year, previous to which time the vine is pruned, not trained. Two-yearold vines are most popular for planting, although in the strong varieties, as Concord and Niagara, well-grown yearling vines are probably as good, if not better. The strong-growing kinds are commonly set from eight to ten feet apart in the row, and the rows eight or nine feet apart. Delawares and other small vines may be set closer, although eight feet is preferable. When set, the vine is cut back to two or three buds. During the first year, the young canes are usually allowed to lie upon the ground at will, as seen in Fig. 263. In the fall or winter, all the canes but one are cut off, and this one is cut back to two or three buds. The vine is, therefore, no larger at the expiration of a year's growth than it was when planted; but in the meantime the plant has become thoroughly established in the soil, and the second year's growth should be strong enough to form the basis for the permanent trunk or arm. If, however, the second year's growth is weak, it may be cut back as before, and the third season's growth used for the trunk. On the other hand, the growth of the first year is sometimes carried onto the wires to form the permanent trunk and arms, but it is only with extra strong vines in good soil that this practice is admissible. From 
this point, the treatment of the vine is discussed under Training (Chapter VIII.).

WHEN TO PRUNE. - Grape vines may be pruned at any time during the winter. It is the practice

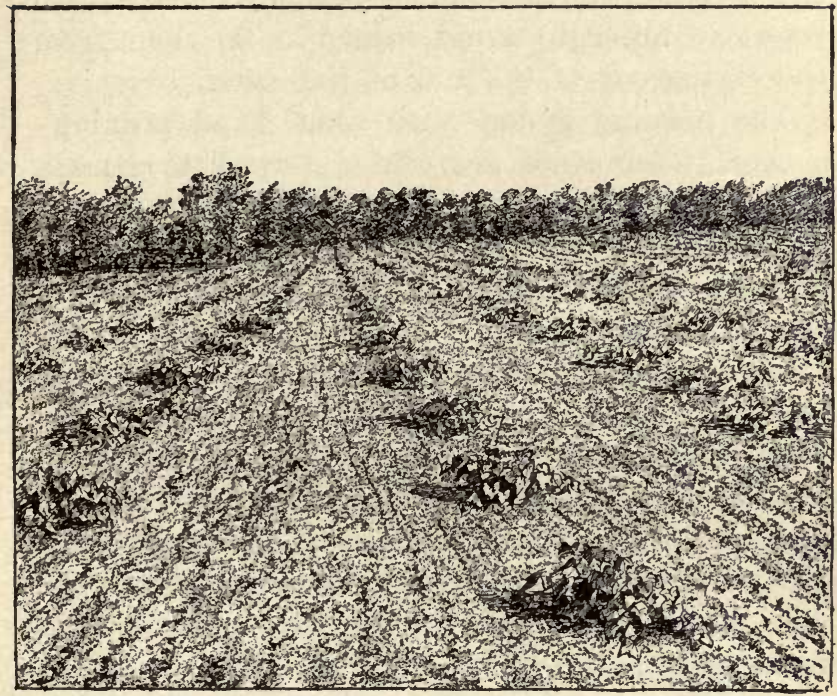

263. A newly-planted vineyard.

among most grape-growers in the North to prune as time permits from November to late in February, or even early in March. The sap flows very freely from cuts made in spring and early summer, causing the phenomenon known as "bleeding," or in Europe as "weeping," and in order to prevent this loss, pruning is stopped six 
weeks or more before the time at which the buds usually swell. It is yet a moot point if this bleeding injures the vine, but it is a safe practice to prune early. The vine is eut off an inch or two beyond the last bud which it is desired to leave, in order to avoid injury to the bud from the drying-out of the end of the cane.

The pruning is done with small hand pruningshears. The canes are often allowed to remain tied to the wires until the pruning is accomplished, although it is the practice with most growers who use the Kniffin system to cut the strings before pruning. The removal of the severed canes is known as "stripping." In large vineyards, the pruner sometimes leaves the stripping to boys or other cheap labor. The stripping may be done at any time after the pruning is performed, until spring. It must be done before the growth starts on the remaining parts of the vine, however, to avoid injury to the young buds when tearing the vines off the trellis.

SUMMER PRUNING. - There is much discussion as to the advisability of summer pruning. It is essential to the understanding of the question that the grower bear in mind that this summer pruning is of two kinds-the removal or "breakingout" of the superfluous shoots, and heading-in or "stopping" the main canes to keep them within limits. The superfluous shoots are such as spring from small, weak buds, or those which break from 
the old arms or trunk of the vine. Shoots which start from the very base of the old cane are usually weak, and should be removed. Buds in this position are shown at $a a$, in Fig. 261. The secondary or axillary branches, which often start from the base of the season's shoots, should be removed or broken out. These superfluous shoots are pulled off from time to time as they appear, or the buds may be rubbed off before the shoots begin to grow.

The heading-in of the main canes, while desirable for the purpose of keeping the vine within bounds, is apt to cause a growth of laterals which choke up the vine, and which do not mature, and in those styles of training in which very little wood is allowed to grow, the practice may prevent the development of a sufficient amount of leaf surface to properly sustain the vine. Vines are often weakened by summer pruning. These dangers can be overcome by careful attention, however, especially by heading-in very lightly, and by doing it as late in the season as possible, when new lateral growth does not start readily. The necessity of much heading-in has been largely obviated in late years by the adoption of high and drooping systems of training, and by setting the vines far apart. The strong varieties, like Concord, Brighton and Niagara, should be set ten feet apart in the row, especially if grown upon the Kniffin system. Catawba, being a very up- 
right grower, and especially well adapted to upright training, may be set eight feet apart, and Delawares are often set as close as six or eight feet. It is doubtful, however, if any variety should be set less than eight feet apart for trellis culture. In Virginia and southward, where the growth is large because of the long seasons, vines are often set more than ten feet apart. In the South, the rows should run north and south, that the fruit may be shaded from midday sun. The only summer heading-in now generally recommended is the clipping of the tips when they fall over and begin to touch the ground. This clipping is often done with a sickle or sharp corncutter.

\section{MAKING THE TRELLIS}

The fall or winter following the planting of the vineyard, the trellis is begun if the upright systems are used (see Chapter VIII.); but this operation is usually delayed a year longer in the Kniffin systems, and stakes are commonly used, or at least recommended, during the second season. In the South the trellis is made the first year. The style of trellis will depend upon the style of training, but the main features are the same for all.

Strong posts of some durable timber, as cedar, locust or oak, are placed at such distance apart that two vines can be set between each two. If the vines are set nine feet apart, the posts may be 
eighteen or twenty feet apart, and a vine will then stand four or five feet from each post. If the posts in the row are eighteen feet apart and the rows eight feet apart, about three hundred and thirty posts will be required to the acre. Except in very hard and stony lands, the posts are driven

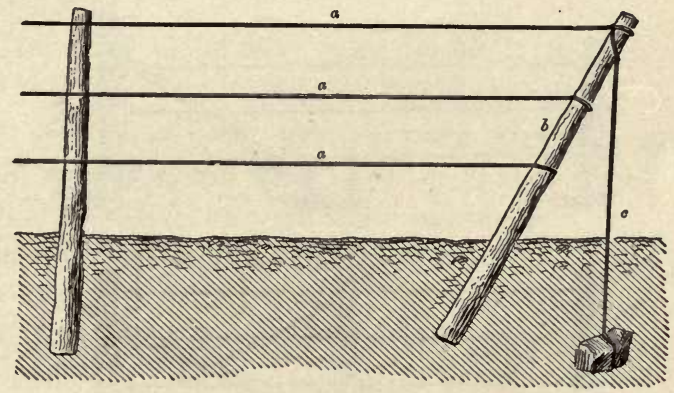

264. A poor way of bracing the post.

with a heavy maul, although many people prefer to set the end posts in holes, thinking that they endure the strain better. In all loose soils, however, posts can be made as firm by driving as by setting with a spade. All posts should be as firm as possible, in order to hold up the heavy loads of vines and fruit. In setting posts on hillsides, it is a common practice to lean them slightly uphill, for there is always a tendency for the posts to tilt down the slope. For the Kniffin systems, especially for the strong-growing grapes, the posts must stand six or six and one-half feet high when 
set, but a foot less will usually be sufficient for the upright and horizontal systems. The posts should stand higher at first than is necessary for the support of the wires, for they will need to be driven down occasionally as they become loose. The end posts of each row should be well braced,
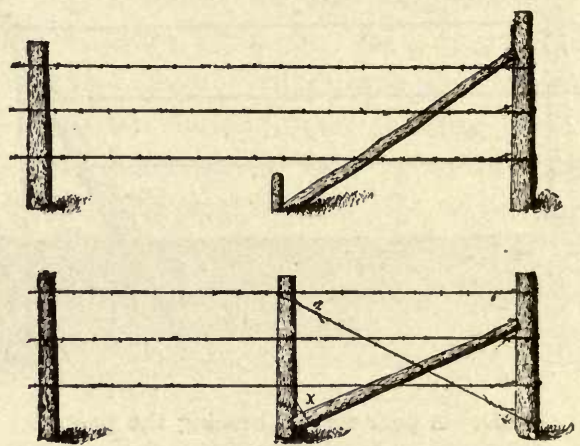

265. Bracing the end post.

as shown in Figs. 289, 290. A style of brace which is sometimes recommended, is to anchor the post to a stone, as in Fig. 264, but this is impracticable. Fig. 265 illustrates the bracing of fence posts, of which the Prairie Farmer says: "The usual way of bracing, shown in the upper figure, is faulty, the brace being too high up on the post and standing too vertical. It should rest nearly against the center of strain on the post and more nearly in a horizontal position, as shown in the lower figure. A wire connecting the top of the 
second post with the bottom of the end post prevents the brace from pushing it over."

It is only a question of time when iron posts will come into general use. Second-hand steampipe could no doubt be used. Iron posts are not only more durable, but they do not harbor insects and fungi.

The wire ordinarily used is No. 12 , except for the top wire in the Kniffin training, which is usually No. 10, as the greater part of the weight is then upon the top wire. No. 9 is sometimes used, but it is often heavier than necessary. No. 14 is occasionally used for the middle and upper rows in the upright systems, but it is not strong enough. The following figures show the sizes and weights of these and similar iron and steel wires:

$\begin{array}{ccrcc}\text { No. Diameter in inches. } & \text { Weight of } 100 \text { feet. } & \text { Feet in } 2,000 \text { pounds. } \\ 9 & .148 & 5.80 \text { pounds. } & 34,483 \\ 10 & .135 & 4.83 & \text { " } & 41,408 \\ 11 & .120 & 3.82 & \text { " } & 52,356 \\ 12 & .105 & 2.92 & \text {." } & 68,493 \\ 13 & .092 & 2.24 & \text { " } & 89,286 \\ 14 & .080 & 1.69 & \text {. } & 118,343 \\ 15 & .072 & 1.37 & \ldots & 145,985 \\ 16 & .063 & 1.05 & & 190,476\end{array}$

The plain annealed iron wire costs about three cents per pound, and the galvanized-which is less used for vineyards-three and one-half cents. Of No. 12 wire, about one hundred and sixty pounds is required per acre for a single run on rows eight feet apart, and about five hundred 
pounds for three runs. The cost of No. 12 wire per acre, for three runs, therefore, is about fifteen dollars.

The wire is secured to the intermediate posts by staples driven in firmly, so that the wire will not pull through readily of its own weight, but still loosely enough to allow of the tightening of the wires. In other words, the head of the staple should not quite touch the wire. Grape staples are of three lengths, about an inch, inch and aquarter, and an inch and a-half respectively. The shortest length is little used. The medium length is used for hard-wood posts and the longest for soft posts, like chestnut and cedar. These staples cost five cents per pound, usually, and a pound of the medium length contains from ninety to one hundred of the No. 10 wire size. An acre, for three wires, will therefore require, for this size, about nine or ten pounds of staples. In windy regions, the wires should be placed on the windward side of the posts, and on hillsides it should be on the up-hill side.

There are several devices on the market for stretching the wires on a trellis, such as the "come-alongs" used by linemen and fence builders. The one commonly used in the Chautauqua district of New York is shown in Fig. 266. The hook is secured to the post, and the wire is held in the clamp or jaws at the opposite end. The operator pulls the rope, and when the wire is 


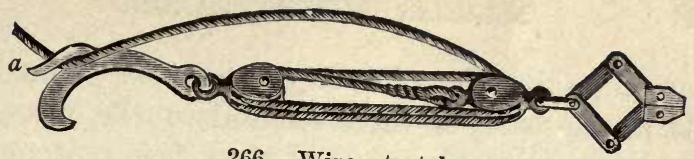

266. Wire stretcher.

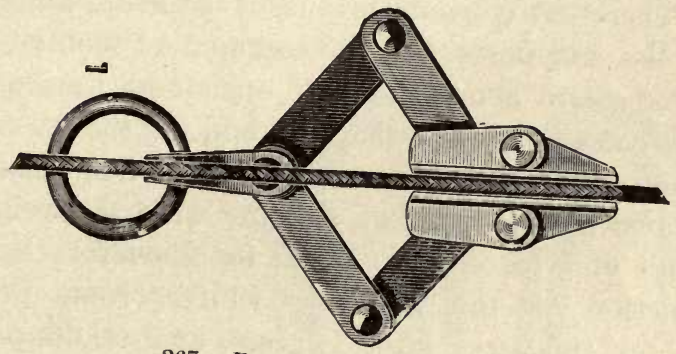

267. Parallel wire stretcher.

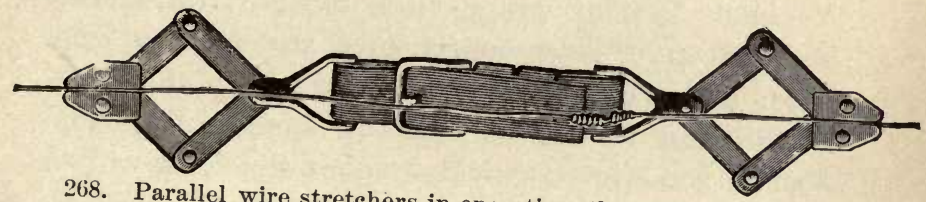

268. Parallel wire stretchers in operation, the slack being pulled up by the strap.

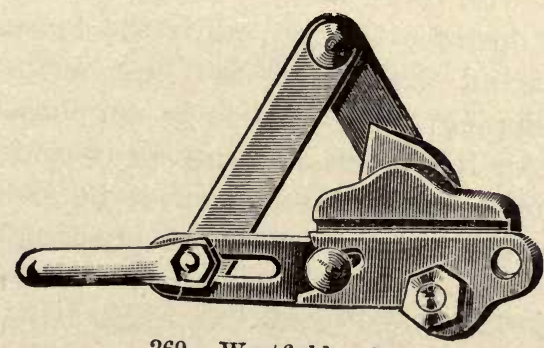

269. Westfield grip. 
taut, slips the rope in the eatch at $a$. The loose end of the wire is then secured to the post, and the machine is removed. Other forms of "comealongs" are shown in Figs. 267, 268, 269.*

There are various means of securing the wires to the end posts, but the commonest method is to wind them about the post once and secure them with a staple, or twist the end of the wire back upon itself, forming a loop. The wires should be drawn taut to prevent sagging with the weight of fruit and leaves. In order to allow for the contraction of the wires in winter, some growers loosen the wires after harvest, and others provide some device which will relieve the strain. The Yeomans patent grape-vine trellis is a simple and effective lever-contrivance attached to each wire, and which is operated to loosen the wires in fall and to tighten them in spring. The end post is sometimes provided upon the back with a square-headed pin which works tightly in an inch and a-half auger hole, and about which the end of the wire is wound. A square-headed iron wrench operates the pin, while the tension of the wire around the side of the post keeps the pin from slipping. This device is not durable, however. An ingenious man can easily contrive some device for relieving the tension, if he should think it necessary. As a matter of practice, however,

\footnotetext{
*Manufactured by Eureka Tempered Copper Works, North East, Penna.
} 
the wires soon stretch and sag enough with the burden of fruit and vines to take up the winter contraction, and most growers do not release the wires in fall. It will be found necessary, in fact, to tighten the wires and to straighten up the posts from year to year, as they become loose. It is always a profitable labor to tamp the ground firmly about all the posts every spring. The wires should always be kept tight during the growing season, to prevent the whipping of the vines by the wind. This is especially important in

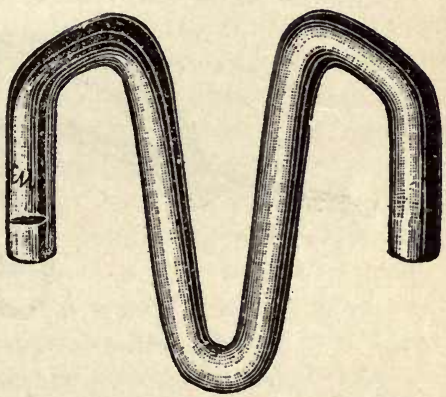

270. Device for taking up the slack.

white grapes, which are discolored by the rubbing of leaves and twigs. Unless the vines are very strong, it will be necessary to put up only one wire the first winter.

A German knack for taking up the slack is shown in Figs. 270 and 271. The device is made from heavy wire, and the trellis wire is caught up and wound about it, as seen in Fig. 271. A notch filed in either end of the device prevents it from slipping.

Trellises are often made of slats, as shown in Fig. 256, but these are always less durable than 
the wire trellises and more expensive to keep in repair; and in the older portions of the country, where timber is dear, they are also more expensive at the outset. They catch the wind, and, not being held together by continuous strands, are likely to blow down in sections. Fuller partic-

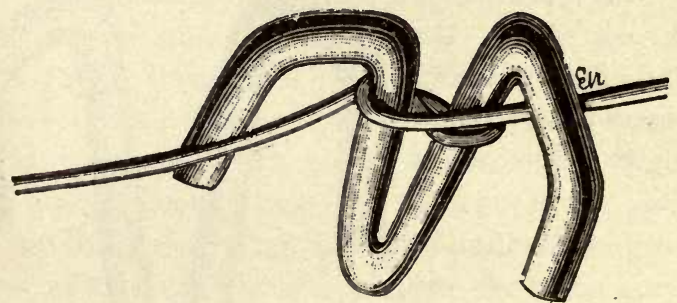

271. The slack gathered up.

ulars concerning the styles of trellis are given in the discussions of the different systems of training.

Spencer gives the following supplementary advice for the trellis and general lay-out of the vineyard:

"The vineyardists of the Chautauqua grape belt have developed a mode of pruning and training of grapes which has many features peculiar to that district. The trellis is made of two wires, of No. 9 or No. 10 gauge, and chestnut posts. The posts are from six feet to eight feet in length, and cost one cent per lineal foot at the railroad station. In later years, since experience has shown how important air and sunshine are in ripening the fruit, eight-foot posts are most commonly used. Grape posts should be somewhat 
heavier than those commonly used for wire fence-from a third to a half larger-and the heaviest should be sorted out for the end posts, for these bear the strain of the wire. An experienced farmer need not be told that they should be sharpened with a true lead-pencil taper, excepting the crooked ones, which should be so beveled as to counteract the crook in driving.

"The usual distance apart for the posts in the row of grapes is one post to every three vines, or, in other words, twenty-seven feet, and for ease in stretching the wire, they should be in as straight a line as possible. The posts are driven, but a hole should first be made by an unusually large crowbar with a bulb near the lower end. After the posts are stuck into the holes, they are most conveniently driven by the operator standing in a wagon which is hauled through the row by a horse. A fair weight of maul is twelve pounds, and it requires a good man to swing one of that size all day. Iron mauls are commonly used because they are the cheapest, but one with an iron shell filled with wood "brooms" or frays the top of the post less than the iron maul. Eighteen inches is a fair depth to drive the posts on most soils. If the proprietor delegates the driving to another man, he had better direct that twenty and twenty-two inches be the proper depth, for to the man swinging the maul the post seems deeper than it really is.

"A vineyard should have a break or an alley at right angles to the rows as often as every fifty grape vines, for the purpose of dumping grape brush and shortening the trip when hauling fauit. If the vineyard is in fair thrift, longer rows will give so much brush as to be inconvenient in hauling out.

"The end posts should not only be the largest of the lot, but should also be well braced. The most common mode is the "hypotenuse brace," consisting of a stiff rail or a fourby-four scantling twelve feet long, with one end notched into the post about midway between the two wires, and the 
other end resting on the ground against a two-foot peg of about the same size as the end post.

"The wires (two wires in the Chautauqua trellis) should be strung on the windward side of the post; that is, on the side from which the prevailing winds come. This is very important when the wind is blowing at thirty to forty miles an hour, and the vines have sails of many square feet of foliage, and perhaps three and four tons of fruit per acre. The staples should be of the same gauge of wire as that used in barbed wire fences, but about one-half inch longer, unless the grape posts should be of hard wood like locust, then fence staples will be long enough. The bottom trellis wire is usually placed from twenty-eight to thirty-two inches from the ground. Owing to the arm system of pruning in the Chautauqua grape belt, the height of the lower trellis wire is permanent. The upper trellis wire is, in many instances, raised as the vineyard comes to maturity. The first year of fruiting, it may not be more than twenty-four inches above the lower wire, and year by year be raised to thirty and thirty-two inches. It is not advisable to go more than thirty-six inches apart without putting in a middle or third wire. Each spring many of the posts will sag, and the upper wire will be slack, and many of the braces will be out of place. All of these faults should be corrected just before tying up the canes."

\section{$T Y I N G$}

Probably the best material for tying the canes and shoots to the trellis is raffia. This is a bastlike material which comes in skeins, and which can be bought of seedsmen and nurserymen for about twenty cents a pound. A pound will suffice to tie a quarter of an acre of upright training throughout the season. Raffia is obtained from the strip- 
pings of an oriental palm (Raphia Ruffia). Wooltwine is also still largely used for tying, but it is not so cheap and handy as raffia, and it usually has to be cut when the trellis is stripped at the winter pruning, while the raffia breaks with a quick pull of the vine. Some complain that the raffia is not strong enough to hold the vine during the season, but it can easily be doubled. Osier willows are much used for tying up the old canes in the spring, and also for summer tying, especially in the nursery regions where the slender trimmings of the cultivated osier willows are easily procured. Wild willows are often used if they can be obtained easily. These willows are tied up in a small bundle, which is held upon the back above the hips by a cord passed about the body. The butts project under the right hand, if the person is right-handed, and the strands are pulled out as needed. The butt is first used, the tie being made with a twist and tuck, the strand is then cut off with a knife, and the twig is employed in like manner until it is used up. When wool-twine is used, the ball is often held in front of the workman by a cord which is tied about it and then passed about the waist. The ball is unwound from the inside, and it will hold its shape until the end becomes so short that it will easily drag upon the ground. Some workmen carry the ball in a bag, after the manner of carrying seed-corn. Raffia is not so easily carried in the field as the wool-twine 
or the willow, and this fact interferes with its popularity. Green rye straw, eut directly from the field, is much used for tying the shoots in summer. Small wire, about two-thirds the size of broom-wire, is used oceasionally for tying up the canes in spring, but it must be used with care or it will injure the vine. Corn-husks are also employed for this purpose when they can be secured. Bass-bark is sometimes used for tying, but in most of the grape regions it is difficult to secure, and it has no advantage over raffia.

It is very important that the old canes be tied up early in spring, for the buds are easily broken after they begin to swell. These canes are tied rather firmly to the wires to hold them steady; but the growing shoots, which are tied during the summer, are fastened more loosely, to allow of the necessary increase in diameter.

Further advice on tying is given by Spencer:

"Tying is done by women, boys and girls and cheap men. The tying materials are wire, wool-twine, raffia, willow and earpet-rags. By turning to Fig. 278 , it will be seen how the canes are arrayed on the two trellises after the Chautauqua method. The horizontal arms, at the lower wire, are more or less permanent, and they are loosely confined to the wire, always by string or willow. The vertical canes, which are fastened to the top trellis, are now universally tied with annealed wire of No. 18 gauge, and cut in lengths of four inches. The economy in using the wire is the despatch in tying, and the fact that the work ean be done on cool days when light gloves are necessary. The 


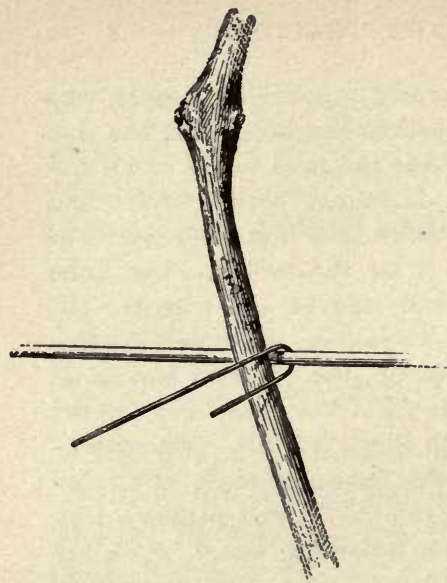

272. Tying with wire. The first movement.

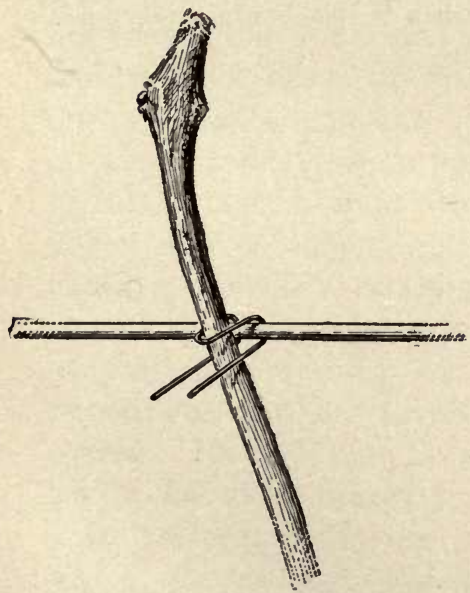

274. The third movement.

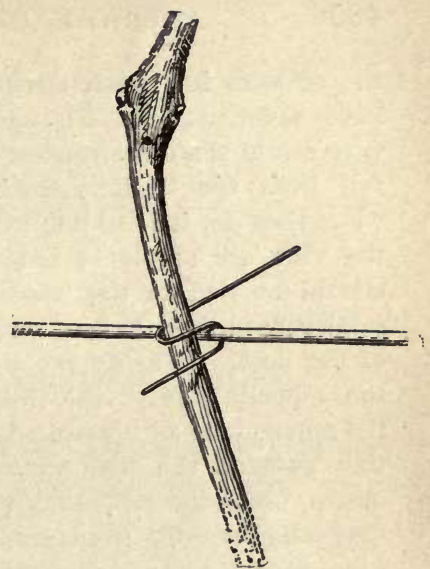

273. The second movement.

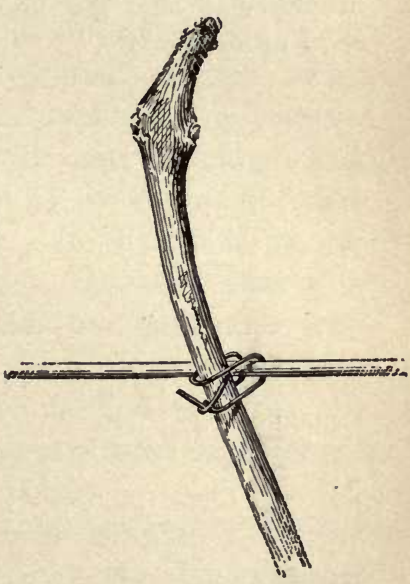

275. The tie complete. 
use of wire has been strenuously opposed by people who have never used it. The objection has been that the fine wire would chafe the cane so that the cane would break and fall from the trellis. Such instances oceur rarely, and when they do, it is so late in the season that the tendrils of the vine are ample to hold it to the trellis. The cane should be tied to the windward side of the wire for the same reason that the wire was stapled on the windward side of the post. In using the wire tie, the operator stands on the opposite side of the trellis from the cane, and follows the movements as illustrated in Figs. 272-275. This operation puts on the wire with the fewest number of movements, binds the cane snug to the trellis, and makes a loop that falls from the trellis on the following season, when the cane is torn away. The tying wire should be thoroughly annealed, so that it ean be easily bent and give no springy reaction after being worked. This wire is also useful in tying thorny shrubs to a trellis when a mittened hand is necessary to hold the branches in place while the other hand makes the tie." 


\section{Chapter VIII}

\section{AMERICAN GRAPE TRAINING, CON - CLUDED-THE VARIOUS MODES}

The grape is trained for the purpose of keeping the vine in convenient shape and to allow each cluster to receive its full share of space and light. A well trained vine is easily cultivated and sprayed, and the grapes are readily harvested, and it is only upon such vines that the best and fairest fruit is uniformly produced. Some kind of training is essential, for a vine will not often bear good fruit when it lies upon the ground. Grape training is described by one vineyardist as a process of hanging the vine up for air and sunshine, and he thinks that different ways of accomplishing that object may be equally good. He likens it to the hanging-out of a washing. He says that his mother and his wife each has her particular way of putting a washing on the line, and each is punctilious that her favorite method shall be observed. He says that he speaks from experience, for he has been bossed by both.

In essence, there are three general types or styles of training, which may be denominated the upright, drooping, and horizontal, these terms 
designating the direction of the bearing shoots.* The upright systems carry two or more canes or arms along a low horizontal wire, or sometimes obliquely across a trellis from below upwards, and the shoots are tied up, as they grow, to the wires above. The horizontal systems carry up a perpendicular cane or arm, or sometimes two or more, from which the shoots are carried out horizontally, and are tied to perpendicular wires or posts. The drooping systems, represented in the Kniffin and post-training, carry the canes or arms up on a high horizontal wire or trellis, and allow the shoots to hang without tying. To one or another of these types all the systems of American grape training can be referred.

There is no system of training which is best for all purposes and all varieties. The strong-growing varieties more readily adapt themselves to the high, drooping systems than the weaker varieties, although the Delaware is often trained on a comparatively low Kniffin with good effect. The high or drooping systems are of comparatively recent origin, and their particular advantages are the saving of labor in summer tying, cheapness of the trellis, and the facility with which the ground can be cultivated without endangering the branches of the vine. The upright training distributes the bearing wood more evenly upon the vine, and is

\footnotetext{
* Classification first made in the original edition of "American Grape Training."
} 
thought, therefore, to insure more uniform fruit; it keeps the top near the root, which is sometimes thought to be an advantage, and it is better suited to the stature of the small-growing varieties. There is, perhaps, a greater temptation to neglect the vines in the drooping systems than in the others, because the shoots need no tying, and do not, therefore, demand frequent attention, whereas in the upright systems the shoots soon become broken or displaced if not watched. For very large areas, or circumstances in which the best of care cannot be given the vineyard, the Kniffin or drooping systems are perhaps always to be recommended. Yet the Kniffin profits as much from diligence and skill as the other systems; but it will give better results than the others under partial neglect. The strong varieties, especially those making long and drooping eanes, are well adapted to the Kniffin styles; but the smaller sorts, and those stronger kinds which, like Catawba, make an upright and stocky growth, are usually trained on the upright systems. But the merits of both systems are so various and even so little understood, that it is impossible to recommend either one unqualifiedly. The advantages in either case are often little more than matters of personal opinion. It should be said, however, that the Kniffin or drooping systems are gaining in favor rapidly, and are evidently destined to - overthrow much of the older upright training. 
This fact does not indicate, however, that the upright system is to be entirely superseded, but rather that it must be confined to those varieties and conditions for which it is best adapted. The two systems will undoubtedly supplement each other. The horizontal systems are occasionally used for choice varieties, but they are little known.

To Mr. Spencer, who has observed many modes of training, the subject appeals as follows: "The fundamental idea of grape pruning is to find the proper balance between the energy which the vine has and the labor that it is expected to perform. What we treat as training is nothing more or less than spreading the vines to light and air, and there are many ways of doing it. Many of them are good, and some better for some varieties of grapes and for certain locations. As a rule, the difference in results of different methods of training is not worth the contention that it has provoked. The great point is to determine what the plant is capable of doing, and then to cut and train the top to correspond. Select any system of training which you fancy or with which your help is the most familiar, anc then leave your wood in the form most convenient for that system."

Spencer gives the following notes on general methods of grape pruning in the Chautauqua vineyards : 
"A large part of the pruning is done in the winter months - some beginning in the fall soon after the crop is harvested. Two grades of labor can be employed in this operation-the skilled and the unskilled. The man of skill, or the expert, goes ahead and blocks out. He stands in front of a vine of far more tangled brush than that seen in Fig. 282, and, at a glance, tells by a judgment ripened by much observation, just how many buds are required to ballast and not over-ballast the vine for another year. As the expert stands before the vine making the estimate, he might be likened to a man weighing a ham with steelyards, pushing the weight backward and forward, noteh by notch, finding the point of balance. The expert, with his pruning shears, makes a dive here and a lunge there, a clip at the bottom and a snip at the top, and with a few more seemingly wild passes, all wood is severed from the bearing vine, but the number of buds desired to give fruit another year are left. The unskilled help, who receives possibly a dollar a day less than the expert, follows the expert, eutting the tendrils and other parts of the vine that are attached to anything but the trellis. The next process is 'stripping' the brush, and it is one involving brute force, ragged clothes and leather mittens. If the laborer does not put on a ragged suit, he will be apt to have one before he is done with his job. There is a little knack even in doing this work to the best advantage. The dismembered vines still hang to the upper trellis and often eling with considerable tenacity, and a particular jerk or yank, more easily demonstrated than described, is most effectual to land the brush on the ground between the rows.

"The next operation is to haul the brush out to the end of the row. Many tools have been devised for this purpose, some of them involving considerable expense. It is now the universal practice to use a simple pole-one a little larger than would be used to bind a load of logs, and not so large as required in binding a load of hay. It may be a 
sapling about four inches at the butt and two and one-half inches at the top, and ten to twelve feet long. The small end is to be held in the right hand, and the butt end to be pushed along the ground. A horse is hitched to this pole by a rope drawn through an inch hole about four feet from the butt or ground end. When starting at the end of the row, it seems that the straight pole would not gather any brush at all. It is a question of catching the first wad, and all the rest of the brush will eling to it. At the end of the row, the brush is hauled to a convenient pile, where it is to be burned, and is dumped by letting the end of the pole held in the hand revolve over towards the horse. If the pole hits the horse, the operator will see that there is not enough stretch of rope between the pole and whiffletree, and more must be provided."

The cost of pruning an acre of grapes is reported as follows:*

Blocking out . . . . . . $\$ 1.00$

Cutting curls . . . . . . . . 1.50

Stripping, removing brush, tapping

posts, stretching wire . . . 1.50

Labor of tying . . . . . . 1.50

Cost of ties . . . . . . . . . . . . 55

$\$ 575$

\section{THE UPRIGHT SYSTEMS}

The upright systems are the oldest and best known of the styles of American grape training. They consist, essentially, in carrying out two horizontal canes, or sometimes arms, upon a low wire,

*John W. Spencer, Proc. W. New York Hort. Soc., 1896, p. 44. 
and training the shoots from them vertically. These shoots are tied to the upper wires as they grow. This type was first clearly and forcibly described in detail by A. S. Fuller, in his "Grape Culturist," in 1864, and it became known as the Fuller system, although it was practiced many years previous to this time.

HORIZONTAL ARM SPUR SYSTEM.-There are two types, or styles, of this upright system. The older type and the one described in the books, is known as the Horizontal Arm Spur training. In this method, the two horizontal branches are permanent, or, in other words, they are true arms. The canes are cut back each fall to upright spurs on these arms, as explained on page 409 (Fig. 261). Two shoots are often allowed to grow from each of these spurs, as shown in Fig. 276. These spurs become overgrown and weak after a few years, and they are renewed from new shoots which spring from near their base or from the arm itself. Sometimes the whole arm is renewed from the head of the vine, or even from the ground.

The number of these upright canes and their distance apart upon these permanent arms depend upon the variety, the strength of the vine and soil, and the fancy of the grower. From twelve to twenty inches apart upon the arm is the common distance. If a vine is strong enough to earry five canes and the vines are eight feet apart, then the canes are distributed at intervals of about 
twenty inches. Some very strong vines of vigorous varieties will carry eight canes upon the two

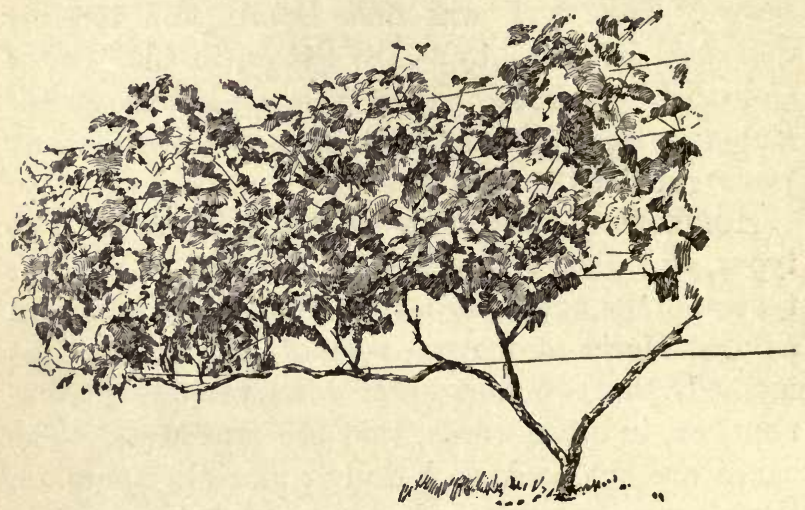

276. Horizontal arm spur training.

arms together, and in this case the canes stand about a foot apart. In the fall or winter, the cane is cut away and the strongest new cane which springs from its base is left for the bearing wood of the following year. This new cane is itself headed-in to the height of the trellis; that is, if the uppermost and lowermost wires are thirty-four inches apart-as they are in the Brocton vineyards of Western New York, where a modification of this system is largely used-this new cane is shortened-in to about thirty-six inches long. On this length of eane there will be about seven good buds in the common varieties.

A modification of this horizontal arm system is 
shown in Fig. 278. It is used in the vineyards of Chautauqua county, New York. The arms in this case are very short, and canes are taken out only at two or three places. The picture shows a vine in which two or three canes are taken from

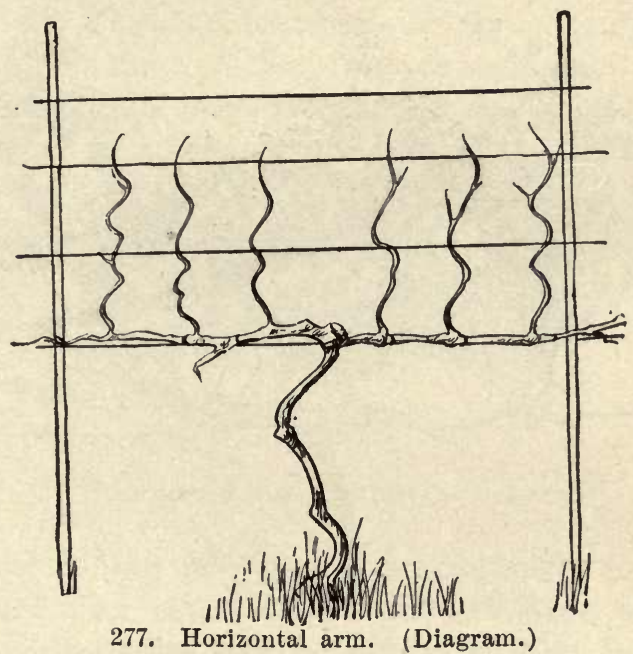

the end of each arm, making five canes for the bearing top of the vine. These canes are cut back to spurs in the fall, as explained in the above paragraph. Sometimes one or two other canes are taken out of these arms nearer the main trunk. One is taken out in Fig. 278. The advantages urged for this style of training are the stronger growth which is insured by so few canes, and the 
small amount of old or permanent wood which is left to each vine.

The true horizontal arm training is less popular than it was twenty years ago. It has serious faults, especially in the persistence of the old

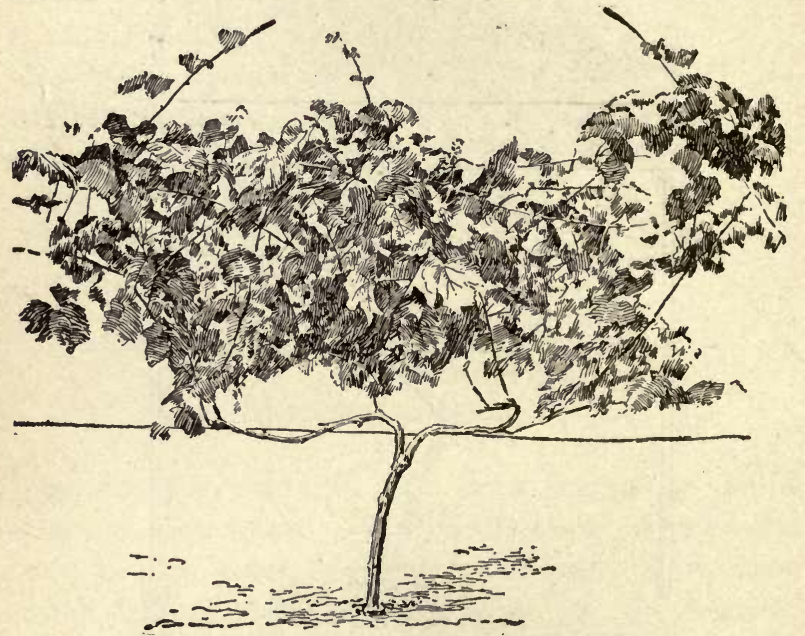

278. Chautauqua or Brocton training.

spurs, and probably will eventually give place to other systems. Aside from the spur-pruning, the system is much like the following, which is a modification to allow of renewal, and to which the reader is referred for further details. This modification, which may be called the High Renewal,* and which is one of the most serviceable

*Term first used in the original edition of "American Grape Training," 1893. 
of any of the styles of training, although it has never been fully described, we shall now consider.

THE HIGH RENEWAL. - This is an upright training which is now very extensively employed in the lake regions of New York and elsewhere. It starts the head or branches of the vine from eighteen to thirty inches from the ground. The ideal height for most varieties is probably about

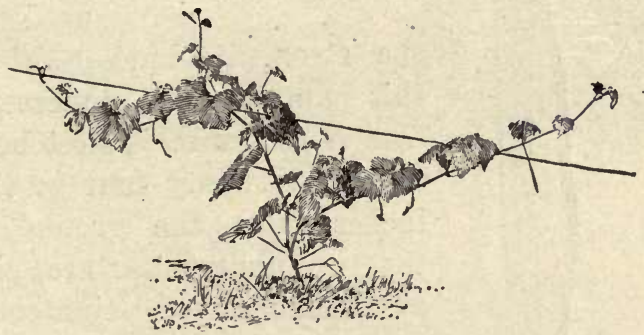

279. The second season of upright training.

two feet to the first wire, although thirty inches is better than eighteen. If the vines are lower than two feet, they are liable to be injured by the plow or cultivator, the earth is dashed against the clusters by heavy rains, and if the shoots become loose they strike the ground and the grapes are soon soiled. A single trunk or arm is carried up to the required height, or if good branches happen to form lower down, two main canes are carried from this point up to the required distance to meet the lower wire, so that the trunk becomes Yshaped, as seen in Figs. 279, 281, 285. In fact, 
vineyardists usually prefer to have this head or crotch a few inches below the lowest wire, to facilitate the spreading and placing of the canes. The trellis for the upright systems nearly always comprises three wires, although only two are sometimes used for the smaller-growing varieties, and very rarely

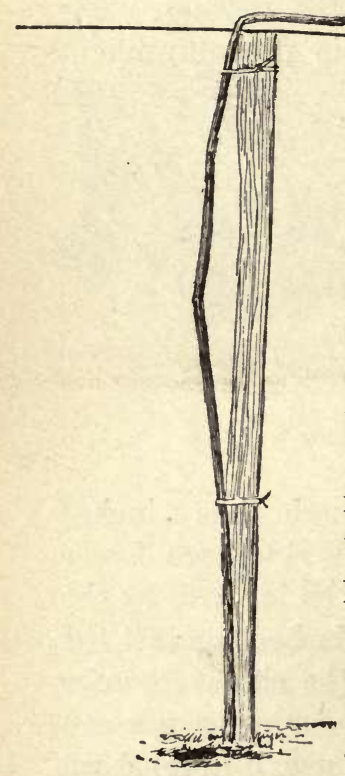

four are used for

the strongest kinds, although this number is unnecessary. The lowest wire is stretched at eighteen, twenty-four or thirty inches from the ground, and the two upper ones are placed at distances of eighteen or twenty inches apart.

The second season after planting should see the vine tied to the first wire. Fig. 279 is a photograph taken in July, 1892, of a Concord vine which was set in the spring of 1891. In the fall of 1891, the vine was cut back to three or four buds, 280. Making the T-head. and in the spring of 1892 , two of these buds were allowed to make canes. These two canes are now tied to the wire, which was stretched in the spring of 1892. In this case, the branches start near the 
surface of the ground. Sometimes only a single strong shoot grows, and in order to secure the two branches it is broken over where it passes the wire, and is usually tied to a stake to afford support. Fig. 280 shows this operation. A bud will develop at the bend or break, from which

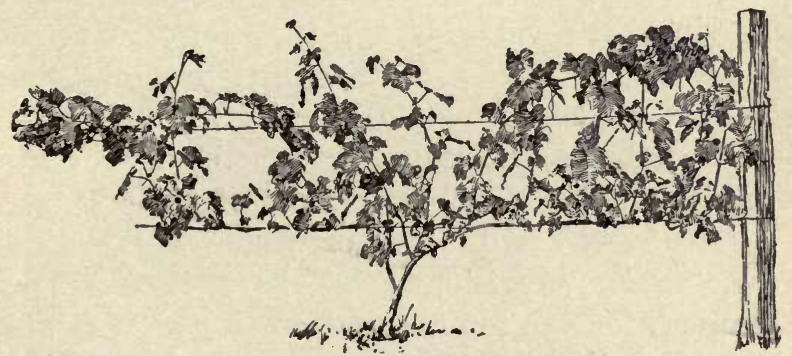

281. The third season of high renewal. Concord.

a cane can be trained in the opposite direction from the original portion, and the $\mathrm{T}$-head is secured.

The close of the second season after planting, therefore, will usually find the vine with two good canes extending in opposite directions, and tied to the wire. The pruning at that time will consist in cutting off the ends of these canes back to firm and strong wood, which will leave them bearing from five to eight buds. The third season, shoots will grow upright from these buds and will be tied to the second wire, which has now been supplied. Late in the third season the vine should have much the appearance of that shown 


\section{AMERICAN GRAPE TRAINING, CONCLUDED}

in Fig. 281. The third wire is usually added to the trellis at the close of the second season, at the same time that the second wire is put on; but occasionally this is delayed until the close of the third season. Some of the upright shoots may bear a few grapes this third season, but unless the vines are very strong, the flower clusters should be removed; and a three-year-old vine should never be allowed to bear heavily. It must be remembered, however, that both these horizontal canes, with all their mass of herbage, are to be cut away in the fall or winter of the third year. Some provision must have been made, therefore, for the top for the fourth year. It will be recalled that in discussing the renewal pruning (page 411, Fig. 262), it was found that two or more shoots are allowed to grow each year to form the basis of the top the following year. In Fig. 281 three or four such shoots ean be seen springing from the $\mathrm{Y}$-shaped portion in the center of the vine. These shoots or canes are to be bent down to the lowest wire next spring, and the bearing shoots will arise from them. This process will be seen at a glance from Figs. 282, 283 and 284. The first shows a full-grown old vine, trained on three wires. Fig. 283 shows the same vine when pruned. Two long canes, with six or eight buds each, are left to form the top of the following year. The two stubs from which the renewal canes are to grow for the second year's 


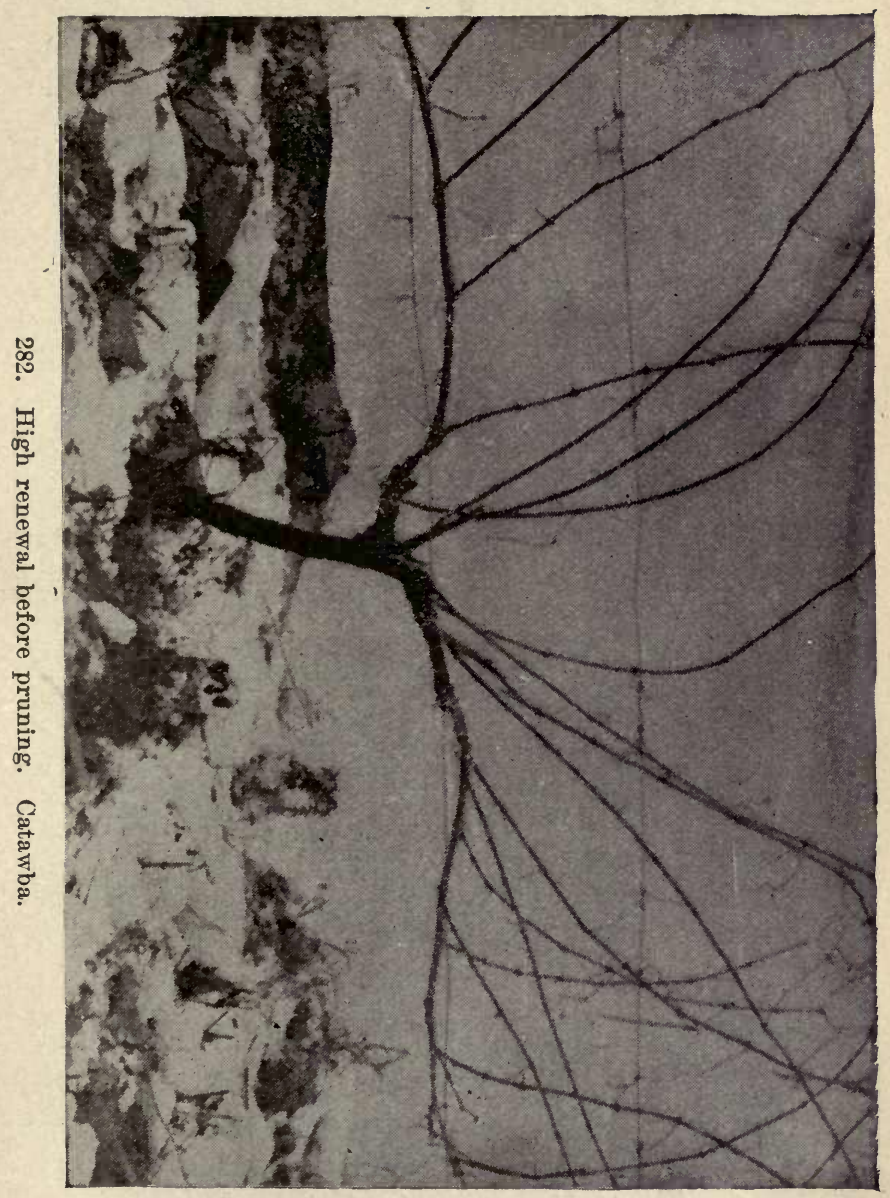


446 AMERICAN GRAPE TRAINING, CONCLUDED

top, are seen in the center. In the fall of the next year, therefore, these two outside canes will be cut away to the base of these renewal stubs; and the renewal canes, in the meantime, will have

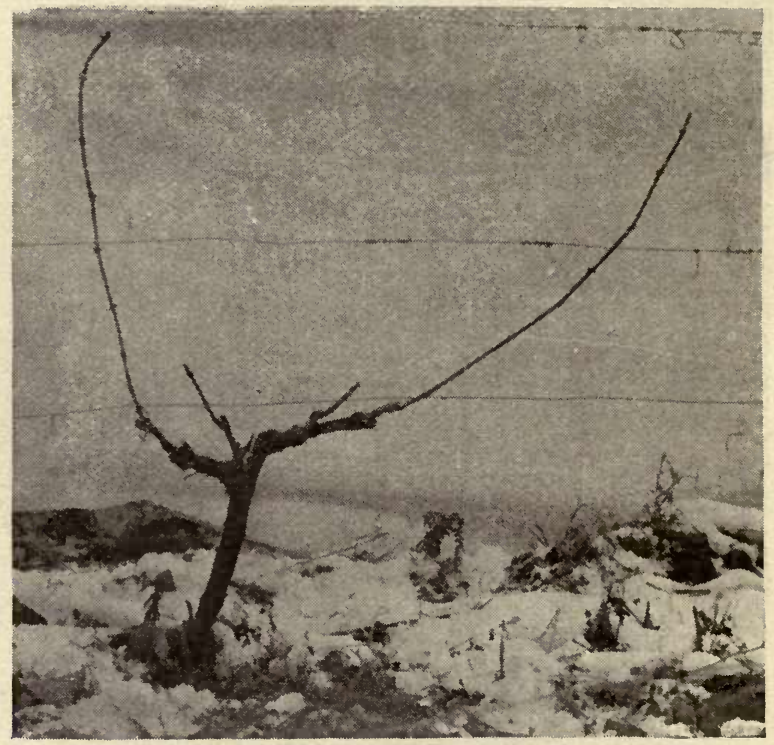

283. High renewal, pruned.

made a year's growth. These renewal stubs in this picture are really spurs, as will be seen; that is, they contain two ages of wood. It is the purpose, however, to remove these stubs or spurs every two or three years at most, and to bring new canes directly from the old wood or head. 


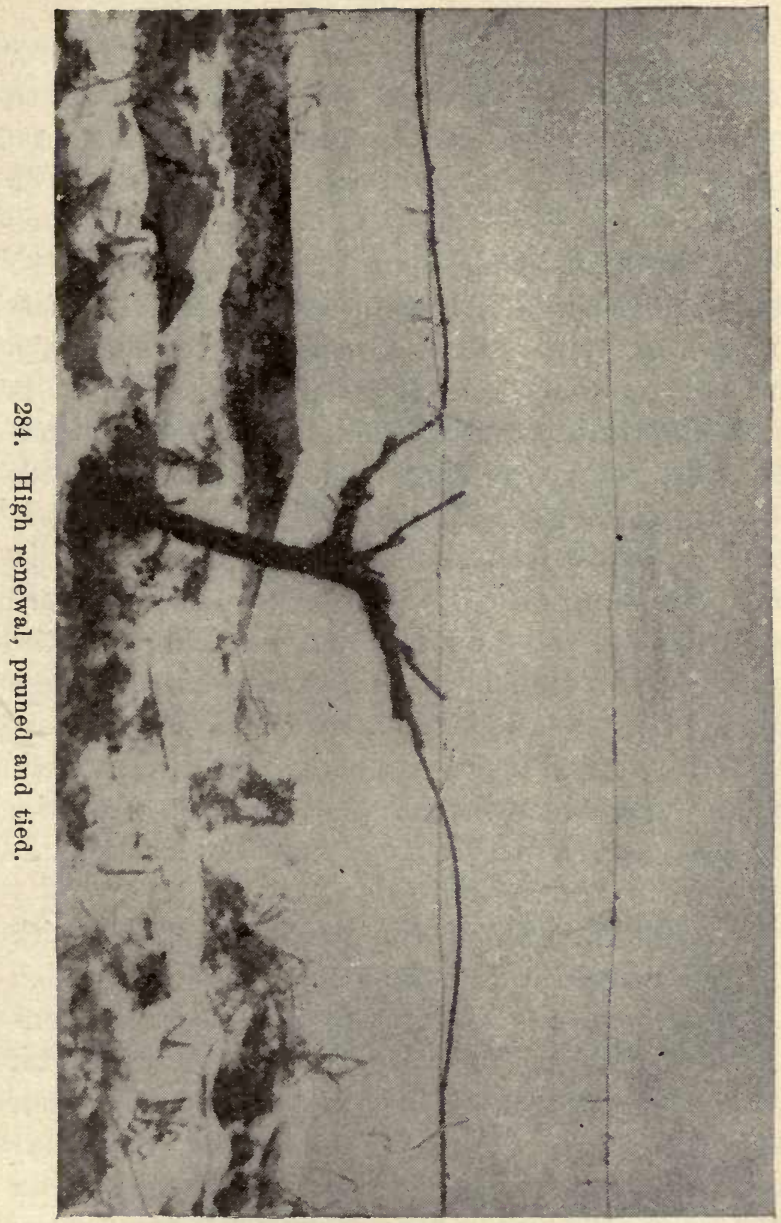


If possible, the renewal cane is brought from a new place on the old wood every year, in order to avoid a spur. Such was the case in the vine shown in Fig. 262, page 410. Fig. 284 shows the vine tied down to the lowest wire. Two ties have been made upon each cane. Fig. 285 shows a vine in which four eanes have been left to form the top for the following year. The stubs for the renewals ean be seen in the $Y$. It is customary to leave more than two canes, occasionally, in strong-growing varieties like Concord. Sometimes four, and occasionally six are left. If four canes are left, two may be tied together in each direction on the bottom wire. If six are used, the two extra ones should be tied along the second wire, parallel with the lowest ones. These extra canes are sometimes tied obliquely across the trellis, but this practice should be discouraged, for the usual tendency of the vine is to make its greatest growth at the top, and the lower buds may fail to bear.

The ideal length of the two canes varies with different varieties and the distance apart at which the vines are set. Very strong kinds, like Concord and Niagara, can carry ten or twelve buds on each cane, especially if the vines are set more than eight feet apart. Fig. 286 shows half of a Concord vine in which about ten buds were left on each cane. These strong sorts can often carry forty or fifty buds to the vine to advantage, but 
when this number is left the canes should be four, as explained in the last paragraph. In Delaware and other weak-growing varieties, twenty or twenty-five buds to the vine should be the maximum and only two canes should be left. In shortjointed varieties, the canes are usually cut to the desired length-four to six feet-even if too great a number of buds is left, but the shoots which spring from these extra buds are broken out soon after they start. A Delaware vine which has made an unusually short or weak growth will require fewer buds to be left for next year's top than a neighboring vine of the same variety which has made a strong growth. The Catawba, which is a short but very stiff grower, is usually cut back to six or eight buds, as seen in Figs. 282, 283, 284. Fig. 287 is a good Catawba vine four years set.

The grower soon learns to adjust the pruning to the character of the vine, without effort. He has in his mind a certain ideal crop of grapes, perhaps about so many bunches, and he leaves enough buds to produce this amount, allowing, perhaps, ten per cent of the buds for accidents and barren shoots. He knows, too, that the canes should always be cut back to firm, well-ripened wood. It should be said that mere size of cane does not indicate its value as a fruit-bearing branch. Hard, smooth wood of medium size usually gives better results than the very large and softer canes 
which are sometimes produced on soils rich in nitrogenous manures. This large and overgrown wood is known as a "bull cane." A cane does not attain its full growth the first year, but will increase in diameter during the second season. The tying, therefore, should be sufficiently loose

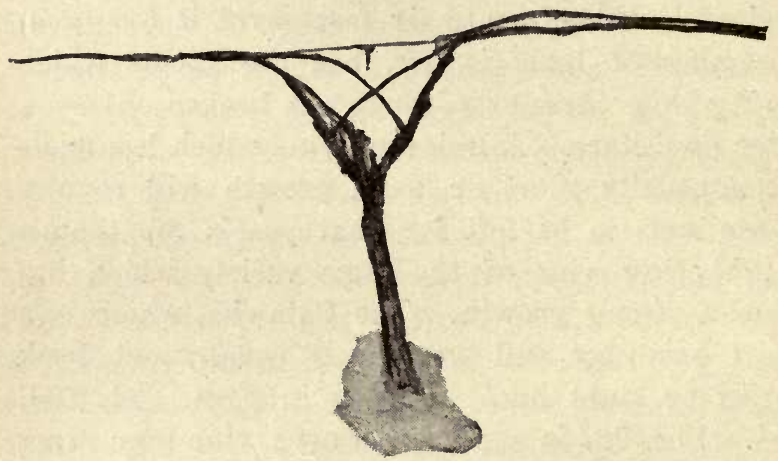

285. High renewal with four canes.

or elastic to allow of growth, although it should be firm enough to hold the cane constantly in place. The cane should not be hung from the wire, but tied close to it, provision being made for the swelling of the wood to twice its diameter.

The shoots are tied to the second wire soon after they pass it, or have attained firmness enough to allow of tying, and the same shoots are tied again to the top wire. All the shoots do not grow with equal rapidity, and the vineyard must be gone over more than twice if the shoots are kept prop- 
erly tied. Perhaps four times over the vineyard will be all that is necessary for careful summer tying. Many vineyardists tie only once or twice, but this neglect should be discouraged. This tying is mostly done with green rye straw or raffia. A piece of straw about ten inches long is used for each tie, it usually being wrapped but once about the shoot. The knot is made with a twist

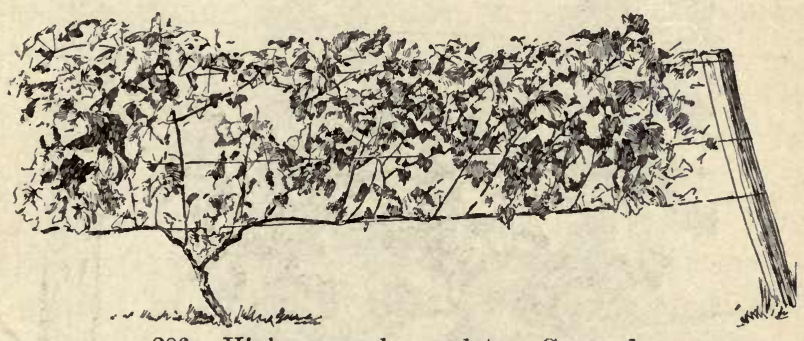

286. High renewal complete. Concord.

and tuck. If raffia is used, a common stringknot is made. When the shoots reach the top of the trellis, they are usually allowed to take care of themselves. The Catawba shoots stand nearly erect above the top wire, and ordinarily need no attention. The long-growing varieties will be likely to drag the shoots on the ground before the close of the season. If these tips interfere with the cultivation, they may be clipped off with a sickle or corn-cutter, although this practice should be delayed as long as possible to prevent the growth of laterals (see page 415 ). It is prob- 
ably better to avoid eutting entirely. Some growers wind or tie the longest shoots on the top wire, as seen in Fig. 289. It is probably best, as a rule, to allow the shoots to hang over naturally, and to clip them only when they seriously interfere with the work of the hoe and cultivator. The

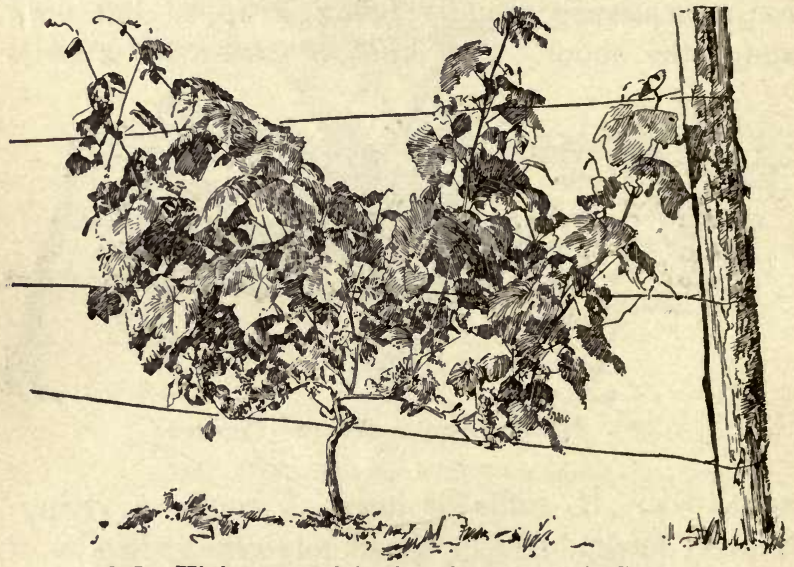

287. High renewal in fourth year, with Catawba.

treatment for slat trellises is essentially the same as on wire trellises, except that longer strings must be used in tying.

It is apparent that nearly or quite all the fruit in the High Renewal is borne between the first and second wires, at the bottom of the trellis. If the lower wire is twenty-four or thirty inches high, this fruit will hang at the most convenient height for picking. The fruit trays are set upon 
the ground, and both hands are free. The fruit is also protected from the hot suns and from frost; and if the shoots are properly tied, the clusters are not shaken roughly by the wind. It is, of course, desirable that all the clusters should be fully exposed to light and air, and all superfluous shoots should, therefore, be pulled off, as already explained (page 415). In rare cases it may also be necessary, for this purpose, to prune the canes which droop over from the top of the trellis.

After a few years, the old top or head of the vine becomes more or less weak, and it should be renewed from the root. The thrifty vineyardist anticipates this circumstance, and now and then allows a strong shoot which may spring from the ground to remain. This shoot is treated very much like a young vine, and the head is formed during the second year (page 408). If it should make a strong growth during the first year, and develop stout laterals, it may be cut back only to the lowest wire the first fall ; but in other cases, it should be cut back to two or three buds, from one of which a strong and permanent shoot is taken the second year. When this new top comes into bearing, the old trunk is cut off at the surface of the ground, or below, if possible. A top will retain its vigor for six or eight years under ordinary treatment, and sometimes much longer. These tops are renewed from time to time as oceasion permits or demands, and any vineyard 
which has been bearing a number of years will nearly always have a few vines in process of renewal. The reader should not receive the impression, however, that the life or vitality of a vine is necessarily limited. Vines often continue to bear for twenty years or more without "renewal; but the head after a time comes to be large and rough

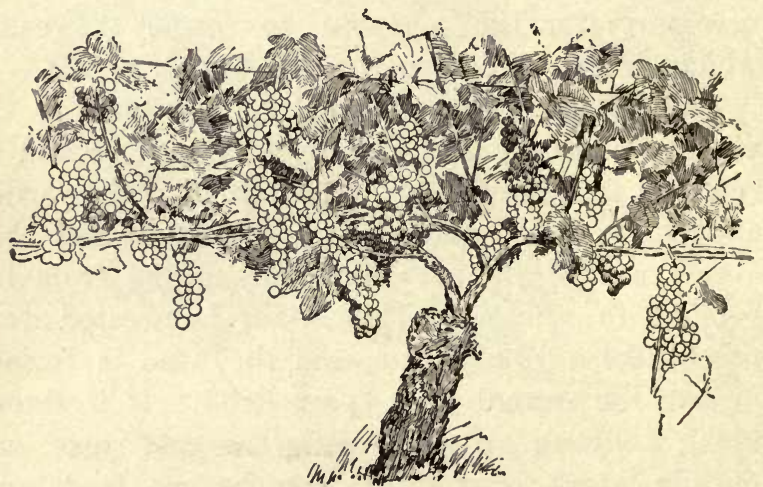

288. A Concord vine thirty years old.

and crooked, and often weakened by scars, and better results are likely to be obtained if a new, clean vine takes its place. Fig. 288 shows the great stump of a Concord vine thirty years old, and which is still in thrifty bearing condition.

The High Renewal is extensively used in the lake region of Western New York for all varieties. It is particularly well adapted to Delaware, Catawba, and other weak or short varieties. 
When systematically pursued, it gives fruit of the highest excellence. This High Renewal training, like all the low upright systems, allows the

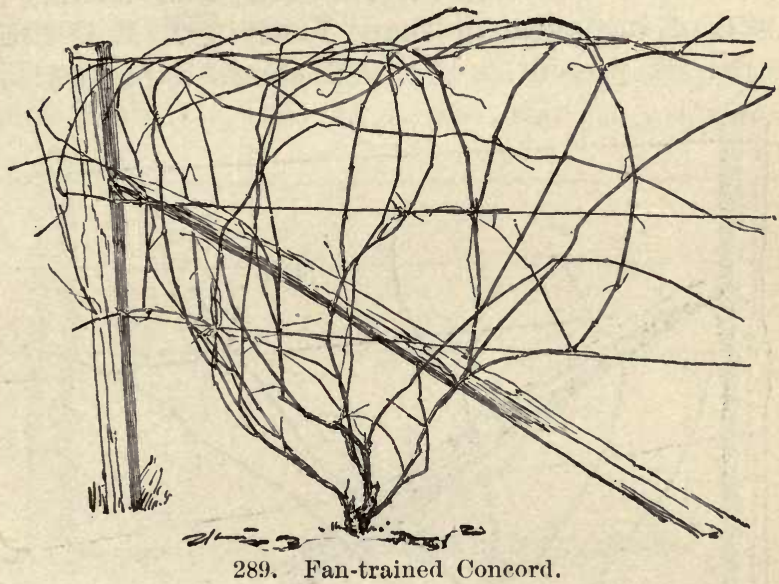

vines to be laid down easily in winter, which is an important consideration in many parts of Canada and in the colder Northern states. It is often called, but erroneously, the horizontal arm system.

Fan-Training.- A system much used a few years ago, and still sometimes seen, is one which renews back nearly to the ground each year, and carries the fruiting canes up in a fan-shaped manner. This system has the advantages of dispensing with much of the old wood, or trunk, and 
facilitating laying down the vine in winter in cold climates. On the other hand, it has the disadvantages of bearing the fruit too low-unless the lower clusters are removed-and making a vine of inconvenient shape for tying. It is little used at present. Fig. 289 shows a fan-trained

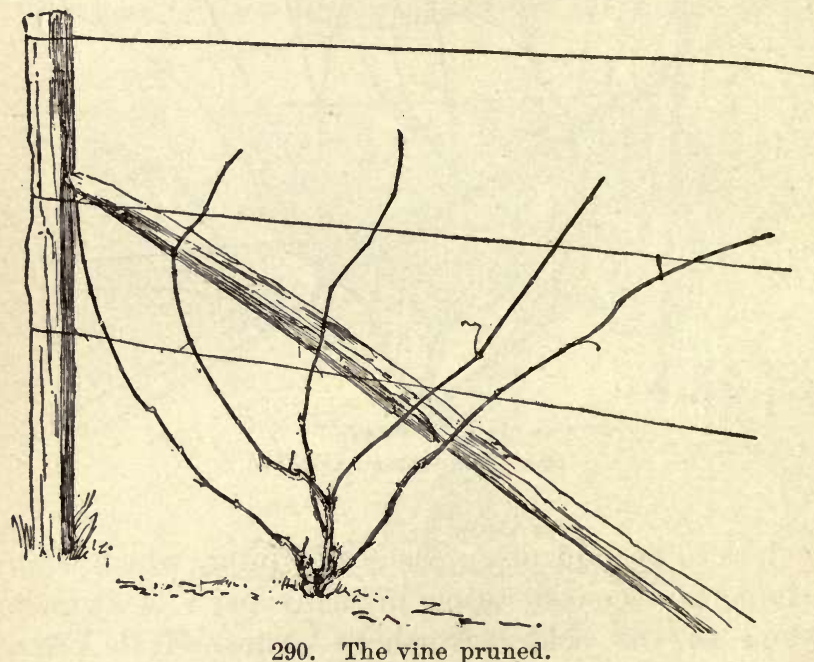

vine before pruning. Fig. 290 is the same vine pruned, although it is by no means an ideal plant. This vine has not been properly renewed, but bears long, crooked spurs, from which the canes arise. One of these spurs is seen to extend beyond the lower wire. The spurs should be kept very short, and they should be entirely removed every two 
or three years, as explained in the above discussion of the High Renewal training.

The shoots are allowed to take their natural course, being tied to any wire near which they chance to grow, finally lopping over the top wire. Sometimes the canes are bent down and tied horizontally to the wires, and this is probably

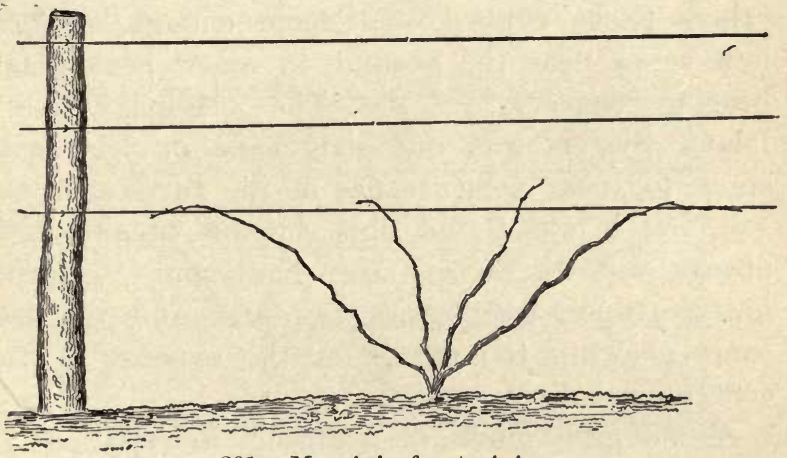

291. Marvin's fan-training.

the better practice. Two canes may be tied in each direction on the lower wire, or the two inner canes may be tied down to the second wire. In either case, the vine is essentially like the High Renewal, except that the trunk is shorter.

Another form of fan-training, which is a modification of the Kelly's Island System, is shown in Fig. 291, and is thus described:* "The engraving represents a sample vine ten years old pruned.

*D. S. Marvin, Pop. Gard. iii. 140. 
It will be observed that the right-hand cane is two-thirds of it old wood, to be all cut away at the next pruning. The old canes that bore a heavy crop of fruit have been pruned away, all but the stumps of the right-hand cane. Three or more buds at the end of the cane, as the vine may be strong or weak, are to be left to bear fruit, the others to be rubbed off, except enough to form new canes near the ground, to renew next year's bearing eanes. * * * The original Kelly's Island System was one long cane or arm, with spurs for next year's canes at the surface of the soil, but it was found objectionable because it is always difficult to get the fruit-spurs to grow uniform upon long canes, the first and the last canes growing too strong at the expense of the center canes."

A mongrel mode of training is reported in Fig. 292. The diagram is described* as "a wellnanaged six-year-old vine; heavier parts show old wood ; light parts, this year's wood." It is seen to be a combination of High Renewal (renewal cane at A), horizontal arm and fantraining.

\section{THE DROOPING SYSTEMS}

In 1845 William T. Cornell planted a vineyard in the Hudson River Valley. A neighbor,

*By "a well-known horticulturist" in Pop. Gard. iii. 278. 
William Kniffin, was a stone mason with a few acres of land to which he devoted his attention during the leisure seasons of his trade. Cornell induced Kniffin to plant a few grapes. He planted the Isabella, and succeeding beyond his expectations, the plantation was increased into a respectable vineyard, and Kniffin came to be regarded as a local authority upon grape culture.

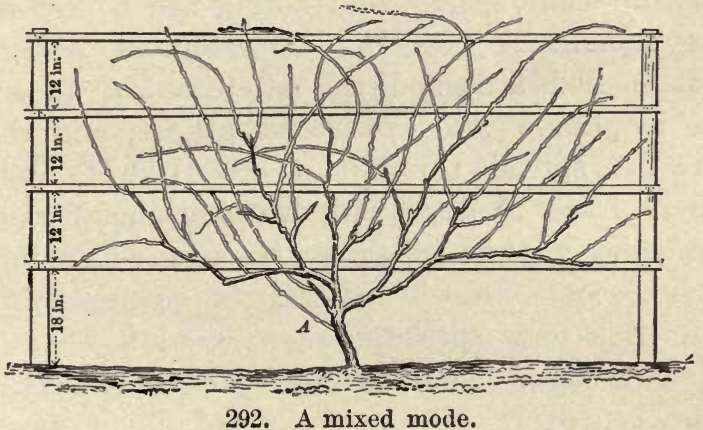

Those were the pioneer days in commercial grape growing in North America, and there were no undisputed maxims of cultivation and training. If any system of close training and pruning was employed, it was probably the old horizontal arm spur system, or something like it. One day a large limb broke from an apple-tree and fell on a grape-vine, tearing off some of the canes and crushing the vine into a singular shape. The vine was thought to be ruined, but it was left 
until the fruit could be gathered. But as the fruit matured, its large size and handsome appearance attracted attention. It was the best fruit in the vineyard! Mr. Kniffin was an observant man, and he inquired into the cause of the excellent fruit. He noticed that the vine had been pruned, and that the best canes stood out horizontally. From this suggestion he developed the four-cane system of training which now bears his name. A year or two later, in 1854, the system had attracted the attention of those of his neighbors who cultivated grapes, and thereafter it spread throughout the Hudson Valley, where it is to-day, with various modifications, the chief method of grape training. Its merits have become known beyond its original valley, and it is now spreading more rapidly than any other system. The ground upon which the old Isabellas grew is now occupied by Concords, which are as vigorous and productive as those grown upon newer soils. William Kniffin died at his home in Clintondale, Ulster county, New York, June 13, 1876, at fifty-seven years of age.

The TRUE OR FOUR-CANE KNIFFIN SYSTEM.The true Kniffin system, very nearly as practiced by its originator, is shown in Fig. 293. A single stem or trunk is carried directly to the top wire, and two canes are taken out from side spurs at each wire. Mr. Kniffin believed in short canes, and cut them back to about six buds on both 


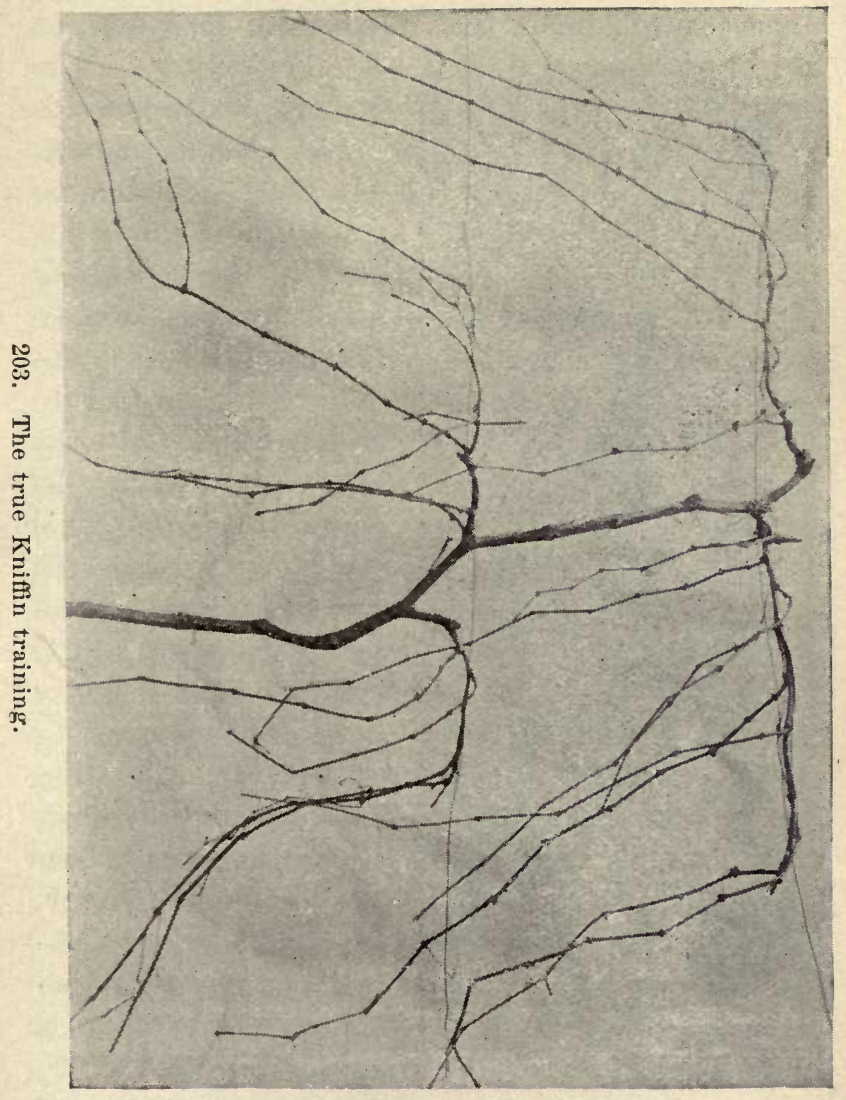




\section{AMERICAN GRAPE TRAINING, CONCLUDED}

wires. But most growers now prefer to leave the upper canes longer than the lower ones, as seen

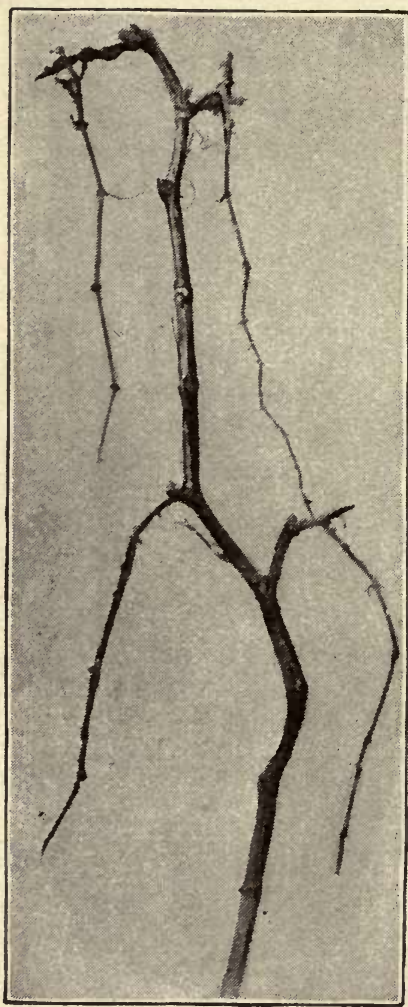

294. No, 293 when pruned. in illustration. The bearing shoots are allowed to hang at will, so that no summer tying is necessary; this is the distinguishing mark of the various Kniffin systems. The main trunk is tied to each wire, and the canes are tied to the wires in spring. This system possesses the great advantage, therefore, of requiring little labor during the busy days of the growing season; and the vines are easily cultivated, and if the rows are nine or ten feet apart, currants or other bushfruits can be grown between. The system is especially adapted to the strong varieties of grapes, particularly to those which are most drooping. For further comparisons of the merits of 
different systems of training, the reader should consult pages 432 to 434 .

The pruning of the Kniffin vine consists in cutting off all the wood except a single cane from each spur. Fig. 294 illustrates the process. This is the same vine which is shown with the full amount of wood on in Fig. 293. The drooping shoots shown in that illustration bore the grapes of 1892 ; and now, in the winter of 1892-3, they are all to be cut away, with the horizontal old canes from which they grew, except only the four canes which hang nearest the main trunk. Fig. 294 shows the vine after it had been pruned. It is not obligatory that the canes which are left after the pruning should be those nearest the trunk, for it may happen that these may be weak; but, other things being equal, these canes are preferable because their selection keeps the old spurs short. The careful grower will take pains to remove the weak shoots which start from this point, in order that a strong cane may be obtained. It is desirable that these side spurs be removed entirely every three or four years, a new cane being brought out again from the main body or trunk. There is little expectation, however, that there shall be such a complete renewal pruning as that practiced in the High Renewal, which we discussed in the preceding pages.

It will be seen that the drooping canes in Fig. 294 are shorter than they were originally, as 


\section{AMERICAN GRAPE TRAINING, CONCLUDED}

shown in Fig. 293. They have been eut back. The length at which these eanes shall be left is a moot point. Much depends on the variety, the distance between the wires, the strength of the soil, and other factors. Nearly all growers now agree that the upper canes should be longer than the lower ones, although equal eanes are still used in some places. In strong varieties, like Worden, each of the upper canes may bear ten buds and each of the lower ones five. This gives thirty buds to the vine. Some growers prefer to leave twelve buds above, and only four below.

These four pruned canes are generally allowed to hang during winter, but are tied onto the wires before the buds swell in spring. They are stretched out horizontally and secured to the wire by one or two ties on each cane The shoots which spring from these horizontal canes stand upright or oblique at first, but they soon fall over with the weight of foliage and fruit. If they touch the ground, the ends may be clipped with a sickle, corn-cutter or scythe, although this is not always done, and is not necessary unless the canes interfere with cultivation. There is no summer pinching or pruning, although the superfluous shoots should be broken out, as in other systems. It is imperative, for best results, that the shoots do not grow out horizontally on the wires. They should be torn off the wires once 
or twice during the summer, so that they will hang free.

Only two wires are used in the true Kniffin trellis. The end posts are usually set in holes, rather than driven, to render them solid, and they should always be well braced. The intermediate posts are driven, and they usually stand between every alternate vine, or twenty feet apart if the vines are ten feet apart-which is a common distance for the most vigorous varieties. For the strong-growing varieties, the top wire is placed from five and one-half to six feet above the ground. Five feet nine inches is a popular height. The posts will heave sufficiently to bring the height to six feet, although it is best to "tap" the posts every spring with a maul in order to drive them back and make them firm. The lower wire is usually placed at three and one-half feet. Delawares, if trained Kniffin, should not stand above five feet four inches, or at most five feet six inches. Strong vines on good soil are often put onto the trellis the second year, although it is a commoner practice, perhaps, to stake them the second season, as already explained (page 412), and put them on the wires the third season. The year following the tying on the trellis, the vine should bear a partial crop. The vine is usually carried directly to the top wire the first season of training, although it is the practice of some growers, especially outside the Hudson Valley, to stop 
the trunk at the lower wire the first year of permanent training, and to carry it to the top wire the following year.

Yields from good Kniffin vines will average fully as high and perhaps higher than from other species of training. W. D. Barns, of Orange county, New York, has had an annual average of twenty-six pounds of Concords to the vine for nine years, 1,550 vines being considered in the calculation. While the Delaware is not so well suited to the Kniffin system as stronger varieties, it can nevertheless be trained in this manner with success, as the following average yields obtained by Mr. Barns from 200 vines set in 1881 will show:

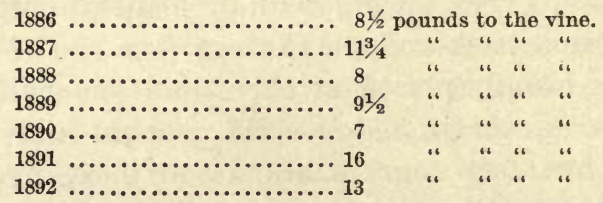

Modifications of THE FOUR-CANE KNIFFIN.Various modifications of this original four-cane Kniffin are in use. The Kniffin idea is often carelessly applied to a rack trellis. In such cases, several canes were allowed to grow where only two should have been left. Fig. 295 is a common but poor style of Kniffin used in some of the large new vineyards of western New York. It differs from the type in the training of the 
young wood. These shoots, instead of being allowed to hang at will, are carried out horizontally and either tied to the wire or twisted around it. The advantage urged for this modification is the little injury done by wind, but, as a matter of practice, it affords less protection than the true drooping Kniffin, for in the latter the shoots

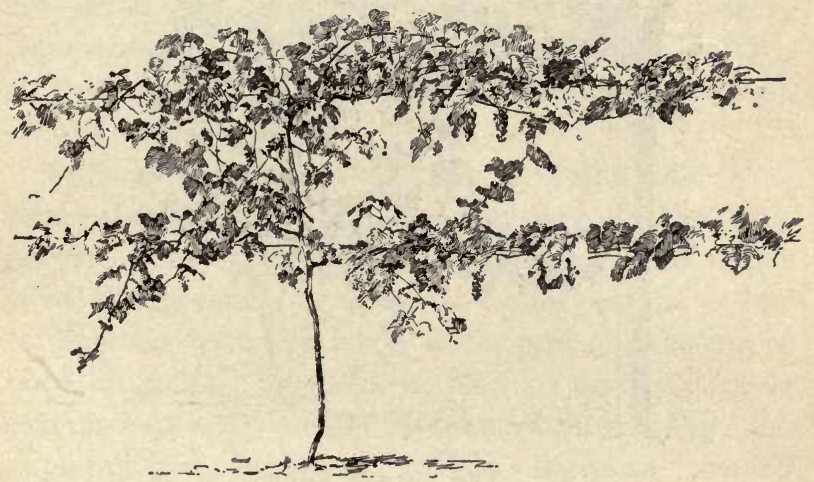

295. A common but poor type of Kniffin.

from the upper cane soon cling to the lower wire, and the shoots from both tiers of canes protect each other below the lower wire. There are three serious disadvantages to this holding up of the shoots, -it makes unnecessary labor, the canes are likely to make wood or "bull canes" (see page 450) at the expense of fruit, and the fruit is bunched together on the vines. The true and successful Kniffin does not allow 
the growing shoots to run out on the wires in this way (see page 464).

Another common modification of the four-cane Kniffin is that shown in Fig. 296, in which a crotch or $\mathrm{Y}$ is made in the trunk. This crotch is used in the belief that the necessary sap sup-

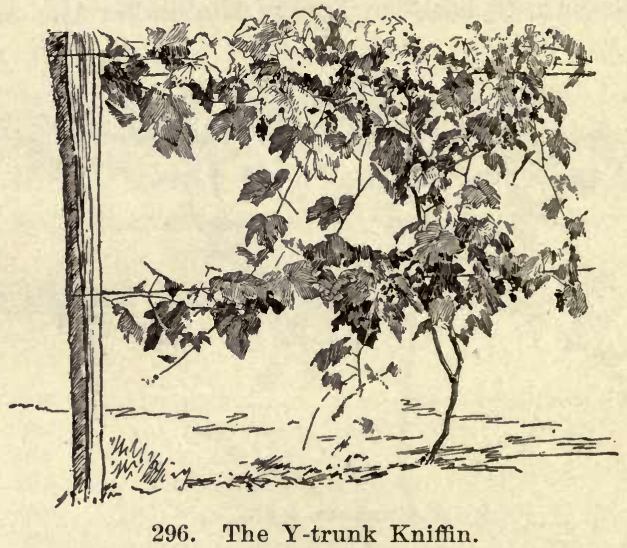

ply is thereby more readily deflected into the lower arms than by the system of side spurring on a straight or continuous trunk. This is probably a fallacy, and may have arisen from the attempt to grow as heavy canes on the lower wires as on the upper one. Nevertheless, this modification is in common use in western New York and elsewhere.

This Y-trunk Kniffin, as understood in western New York, is explained in its various stages in 
Figs. 297 to $303, *$ the cross-marks indicating where cuts are to be made.

If it is desired to leave an equal number of buds on both wires, the Double Kniffin will probably be found most satisfactory. Two distinct trunks are brought from the root, each supplying a single wire only (Fig. 304). The trunks are often tied together to hold them in place. This system, under the name of Improved Kniffin, is just coming into notice in restricted portions of the Hudson Valley.

ThE TWO-CANE KNIFFIN, OR UMBRELLA SYSTEM.-Inasmuch as the greater part of the fruit in the Four-Cane Kniffin is borne on the upper wire, the question arises if it would not be better to dispense with the lower canes and cut the upper ones longer. This is now done to a considerable extent, especially in the Hudson Valley. Fig. 305 explains the operation. This shows a pruned vine. The trunk is tied to the lower wire to steady it, and two canes, each bearing from nine to fifteen buds, are left on the upper wire. These canes are tied to the upper wire, and they are then bent down, hoop-like, to the lower wire, where the ends are tied. In some instances, the lower wire is dispensed with, but this is not advisable. This wire holds the vine in place against the winds, and prevents the too violent whipping of the hanging shoots. During the growing sea-

*H. P. Van Dusen, in Pop. Gard. iii. 69. 


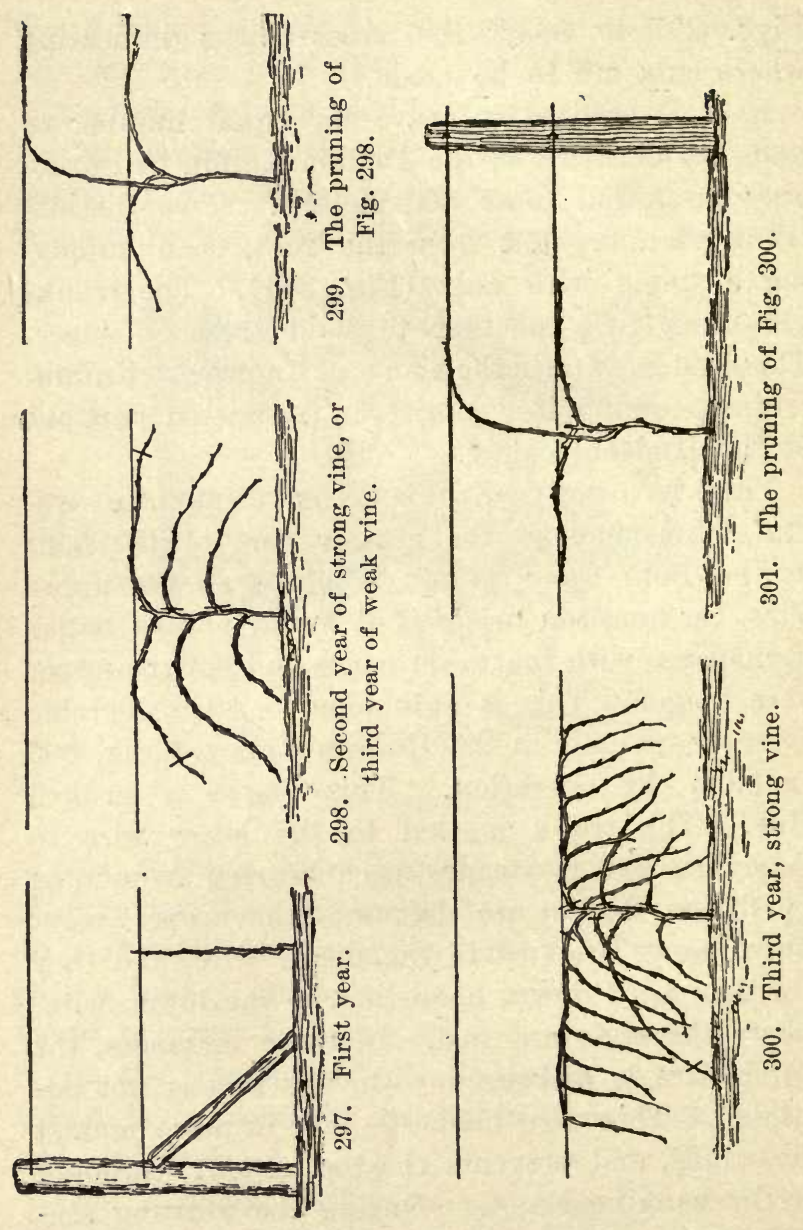



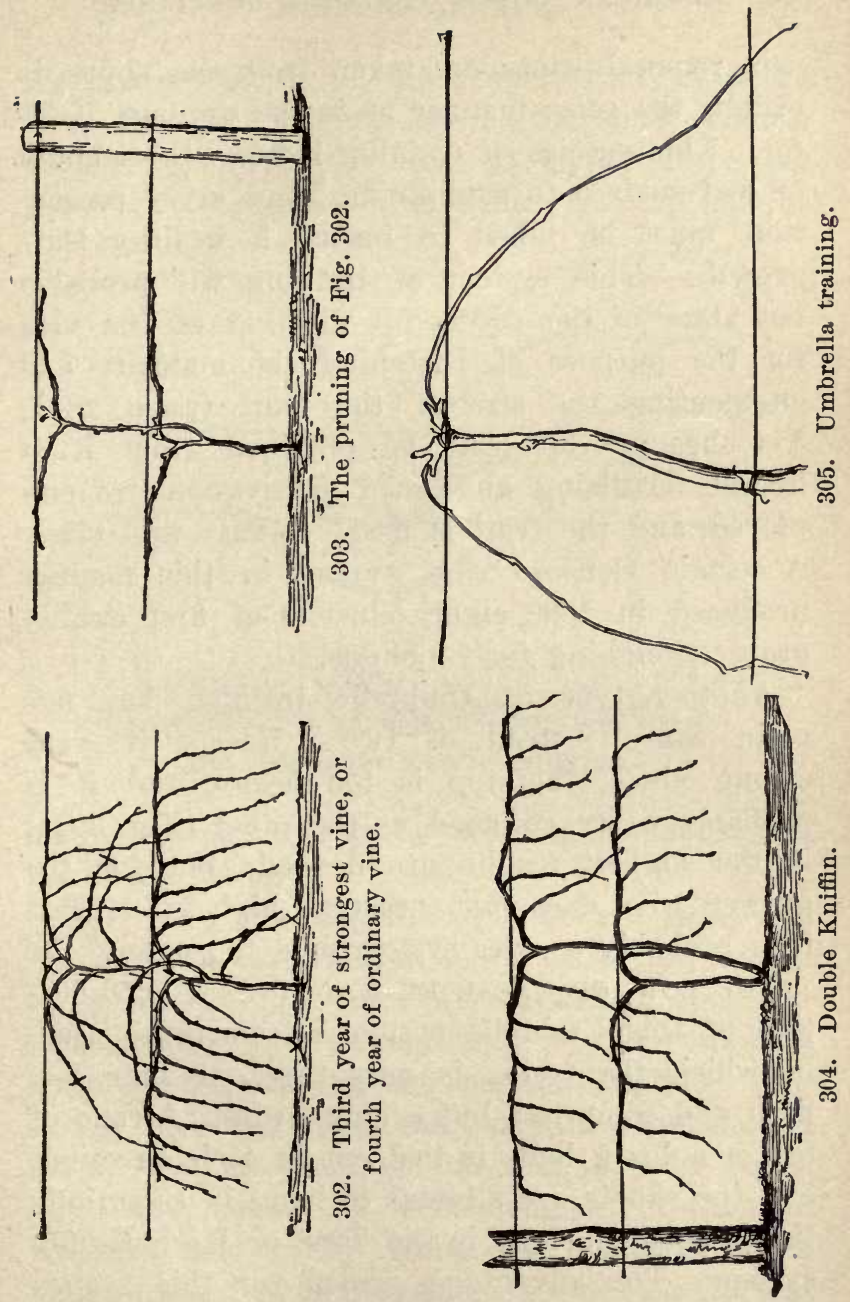
son, renewal canes are taken from the spurs in exactly the same manner as in the ordinary Kniffin. This species of training reduces the amount of leaf-surface to a minimum, and every precaution must be taken to insure a healthy leafgrowth. This system of training will probably not allow of the successful girdling of the vine for the purpose of hastening the maturity and augmenting the size of the fruit (page 284). Yet heavy crops can be obtained from it, if liberal fertilizing and good cultivation are employed, and the fruit is nearly always first-class. A certain Concord vine trained in this manner produced in 1892 eighty clusters of first quality grapes, weighing forty pounds.

Another type of Umbrella training has five main canes instead of two. Except in very strong vines, this top is too heavy, and it is probably never so good as the other (Fig. 305), if the highest results are desired; but for the grower who does not practice high cultivation it is probably a safer system than the other.

THE LOW, OR ONE-WIRE KNIFFIN.-A modification of this Umbrella system is sometimes used, in which the trellis is only three or four feet high and comprises but a single wire. A cane of ten or a dozen buds is tied out in each direction, and the shoots are allowed to hang in essentially the same manner as in the True or High Kniffin system. The advantages urged for this system 
are the protection of the grapes from wind, the large size of the fruit due to the small amount of bearing wood, the ease of laying down the vines, the readiness with which the top can be

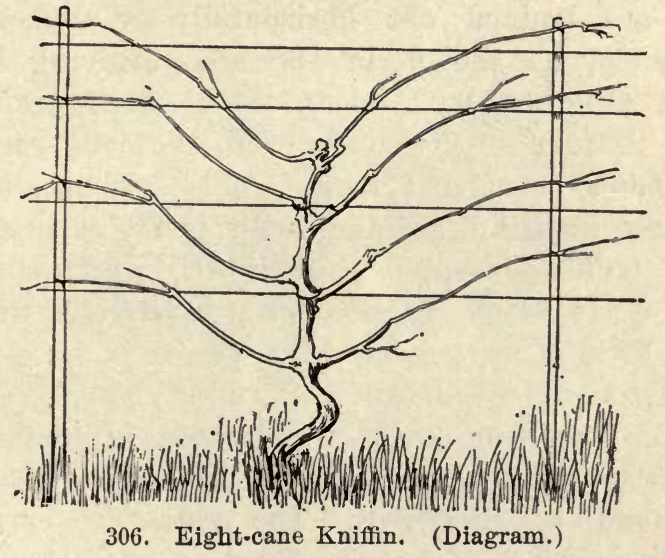

renewed from the root as occasion demands, and the cheapness of the trellis.

The SIX-CANE KNIFFin.-There are many old vineyards in eastern New York which are trained on a six-cane or three-wire system. The general pruning and management of these vines do not differ from that of the common Kniffin. Very strong varieties, which can carry an abundance of wood, may be profitable on this style of training, but it cannot be recommended. A Concord vineyard over thirty years old, comprising 295 vines, trained in this fashion, is still thrifty and 


\section{AMERICAN GRAPE TRAINING, CONCLUDED}

productive. Twice it has produced crops of six tons.

Eight-Cane KNIFfin. - Eight and even ten canes are sometimes left on a single trunk, and are trained out horizontally or somewhat obliquely, as shown in the accompanying diagram (Fig. 306). Unless these canes are cut back to four or five buds each, the vine carries too much wood and fruit. This system allows of close planting, but the trellis is too expensive. The trunk is soon overgrown with spurs, and it is likely to become prematurely weak. This style is very rarely used.

CAYWOOD, OVERHEAD, OR ARBOR KNIFFIN.-A curious modification of the Kniffin is employed somewhat on the Hudson, particularly by Sands Haviland, at Marlboro'. The vines are carried up on a kind of overhead arbor, as shown -in Figs. 307, 308. The trellis is six feet above the ground, and is composed of three horizontal wires lying in the same plane. The central wire runs from post to post, and one upon either side is attached to the end of a three-foot crossbar, as represented in Fig. 307. The rows are nine feet apart, and the vines and posts twelve feet apart in the row. Contiguous rows are braced by a connecting-pole, as in Fig. 308. The trunk of the vine ends in a T-shaped head. From this $\mathrm{T}$-head, five canes are carried out from spurs. It was formerly the practice to 
carry out six canes, one in each direction upon each wire, but this was found to supply too much wood. Now two canes are carried in one direc-

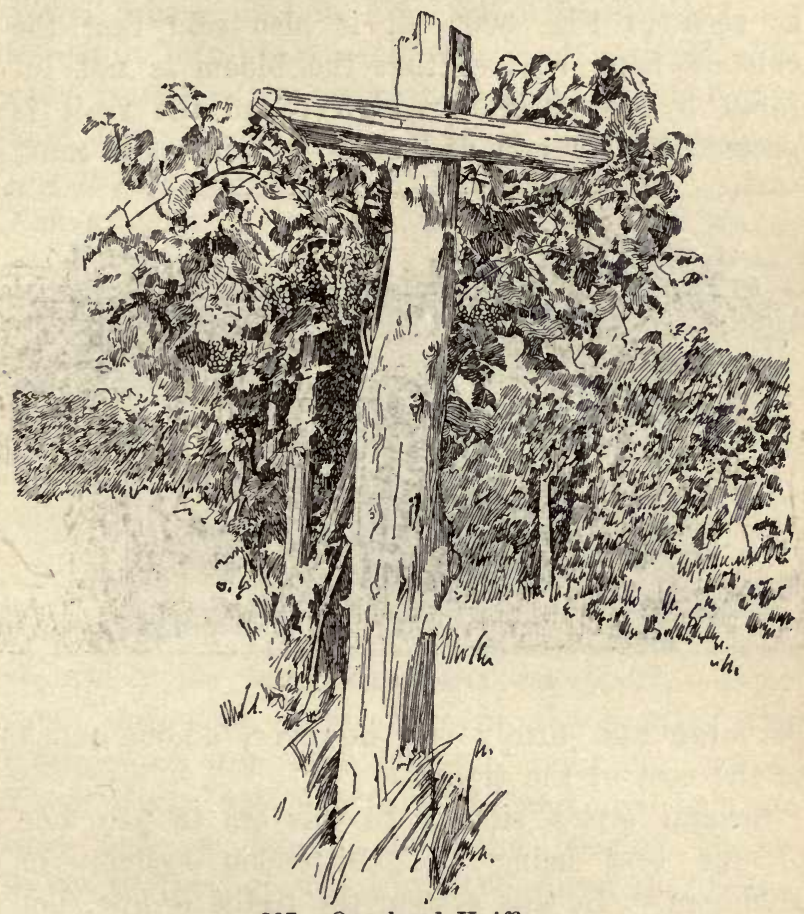

307. Overhead Kniffin.

tion and three in the other; and the positions of these sets are alternated each year, if possible. The canes which are left after the winter pruning are tied along the wires in spring, as in the 
Kniffin, and the shoots hang over the wires. The chief advantage of this training is that it allows of the growing of bush-fruits between the rows, as seen in Fig. 308. It is also said that the clusters hang so free that the bloom is not injured by the twigs or leaves, and the fruit is protected from sun and frost. Every post must

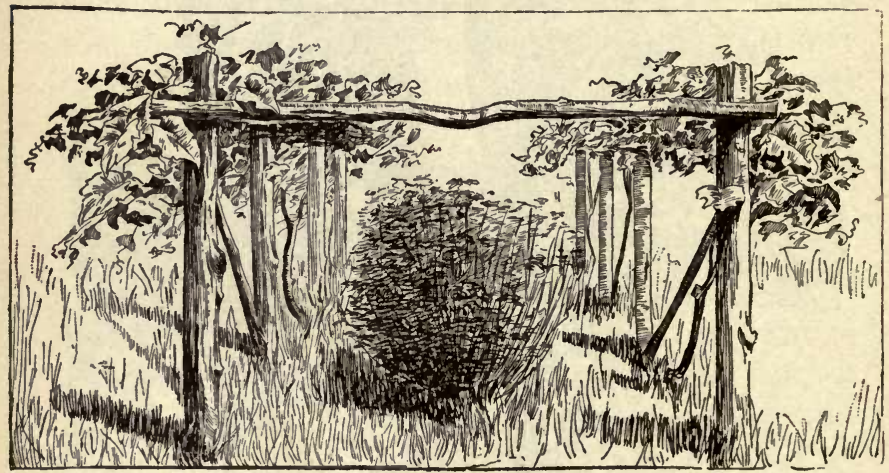

308. Overhead Kniffin.

be large and firmly set, however, adding much to the cost of the trellis.

Several styles similar to this are in use, one of the best being the Crittenden system, of Michigan. In this system the trellis is low, not exceeding four or five feet, and the vines cover a flat-topped platform two or three feet wide. By midsummer the drooping shoots have reached the ground, making a continuous drapery of foliage, as seen in Fig. 309. 
The CROSS-wIRe SYSTEM.-Another high Kniffin training, and which is also confined to the vicinity of Marlboro', New York, is the CrossWire, represented in Fig. 310. Small posts are set eight feet apart each way, and a single wire runs from the top of post to post-six and onehalf feet from the ground-in each direction, forming a check-row system of overhead wires. The grape-vine is set at the foot of the stake,

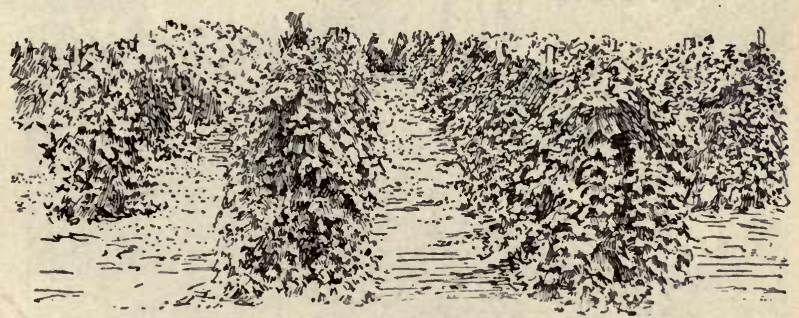

309. Crittenden training in the original vineyard.

St. Joseph, Mich.

to which the trunk is tied for support. Four canes are taken from spurs on the head of the trunk, one for each of the radiating wires. These canes are cut to three and one-half or four feet in length, and the bearing shoots droop as they grow. Fig. 310 shows this training as it appears some time after the leaves start in spring. Later in the season the whole vineyard becomes a great arbor, and a person standing at a distance sees an almost impenetrable mass of herbage. This system appears to 
have little merit, and will always remain local in application. It possesses the advantage of economy in construction of the trellis, for very slender posts are used, even at the ends of the rows. The end posts are either braced by a pole, or anchored by a wire taken from the top

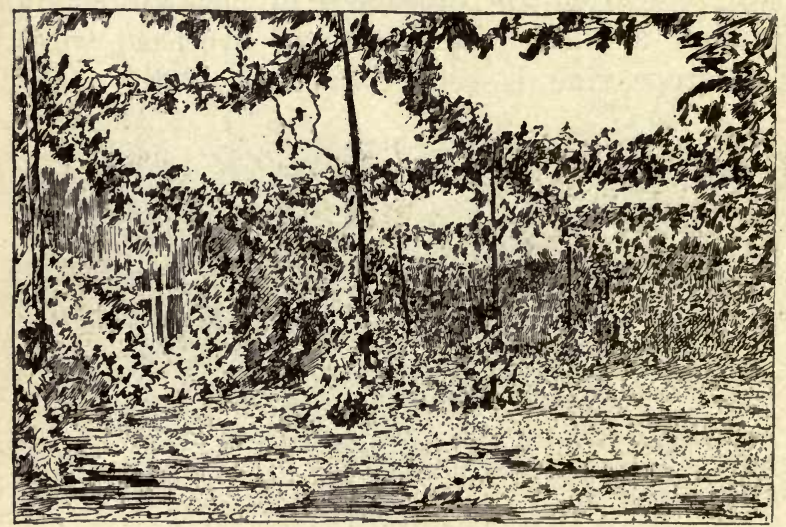

310. Cross.wire training.

and secured to a stake or stone eight or ten feet beyond, outside the vineyard.

Renewal KNIFFin. - It is an easy matter to adapt the Kniffin principle of free hanging shoots to a true renewal method of pruning. There are a few modifications in use in which the wood is annually renewed to near the ground. The trellises comprise either two or three wires, and are made in the same manner as for the 
upright systems, as the High Renewal. At the annual pruning only one cane is left. This comprises twelve or fifteen buds, and is tied up diagonally across the trellis, the point or end of the cane usually being bent downward somewhat, in order to check the strong growth from the

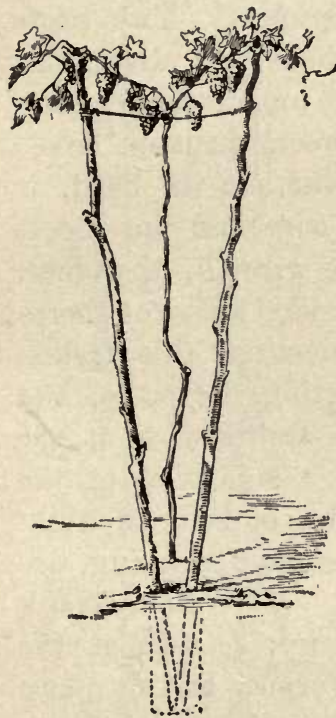

311. Munson training. End view. uppermost parts. The shoots hang from this eane, and they may be pinched back when they reach the ground. In the meantime, a strong shoot is taken out from the opposite side of the headwhich usually stands a foot or less from the ground-to make the bearing wood of the next year; and this new cane will be tied in an opposite direction on the trellis from the present bearing cane, and the next renewal shoot will be taken from the other side of the heaid, or the side from which the present bearing wood sprung; so that the bearing top of the vine is alternated in either direction upon the trellis. This system, and similar ones, allows of laying down the vines easily in winter, and insures excellent fruit because the amount of bear- 
ing wood is small; but the crop produced is not large enough to satisfy the demands of most grape growers.

The Munson system.-An unique system of training, upon the Kniffin principle, has been devised by T. V. Munson, of Denison, Texas, a well-known authority upon grapes.* Two posts are set in the same hole, their tops diverging. A wire is stretched along the top of these posts, and a third one is hung between them on crosswires. The trunk of the vine, or its head, is secured to this middle lower wire and the shoots lop over the side wires. The growth, therefore, makes a V-shaped or trough-like mass of herbage. Fig. 311 is an end view of this trellis, showing the short wire connecting the posts, and which also holds the middle trellis-wire at the point of the V. Fig. 312 is a side view of the trellis. The bearing canes, two or four in number, which are left after the annual pruning, are tied along this middle wire. The main trunk forks just under the middle wire, as seen at the left in Fig. 312. A head is formed at this place not unlike that which characterizes the High Renewal, for this system also employs renewal pruning. The trellis stands six feet high. The shoots stand upright at first, but soon fall down and are supported by the side wires. The fol-

\footnotetext{
*Mr. Munson described and illustrated this mode of training in "American Garden," xiii. 333 (1892).
} 


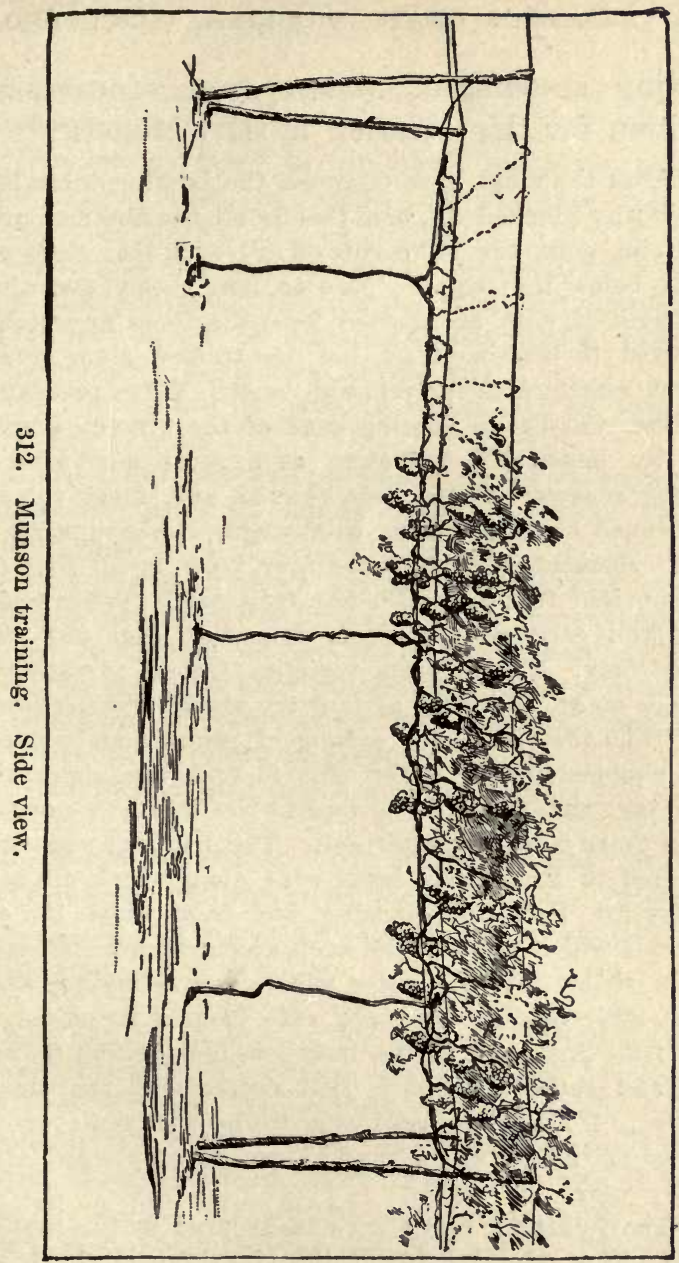




\section{AMERICAN GRAPE TRAINING, CONCLUDED}

lowing account of this system of training is written for this occasion by Mr. Munson:*

"After the vines have flowered, the bearing laterals have their tips pinched off, and that is all the summer pruning the vine gets, except to rub off all eyes that start on the body below the croteh. Two to four shoots, according to strength of vine, are started from the forks or crotch, and allowed to bear no fruit, but are trained along over the lower central wire for renewal canes. When pruning time arrives, the entire bearing eane of the present year, with all its laterals, is cut away at a point near where the young renewal shoots have started, and these shoots are shortened back, according to strength of vine; some, such as Herbemont, being able at four years to fill four shoots six or eight feet long with fine fruit, while Delaware could not well earry over three or four feet each way of one shoot only. The different varieties are set at various distances apart, according as they are strong or weak growers.

"Thus the trellis and system of pruning are reduced to the simplest form. A few euts to each vine cover all the pruning, and a few ties complete the task. A novice can soon learn to do the work well. The trunk or main stem is secured to the middle lower wire, along which all bearing canes are tied after pruning, and from which the young laterals which produce the crop are to spring. These laterals strike the two outer wires, soon elinging to them with their tendrils, and are safe from destruction, while the fruit is thrown in the best possible position for spraying and gathering, and is still shaded with the canopy of leaves. I have now used this trellis five years upon ten acres of mixed vines, and I am more pleased with it every year.

"The following advantages are secured by this system:

"1. The natural habit of the vine is maintained, which

*American Grape Training, 80. 
is a canopy to shade the roots and body of vine and the fruit, without smothering.

"2. New wood, formed by sap which has never passed through bearing wood, is secured for the next crop-a very important matter.

"3. Simplicity and convenience of trellis, allowing free passage in any direction through the vineyard; circulation of air without danger of breaking tender shoots ; ease of pruning, spraying, cultivating, harvesting.

"4. Perfect control in pruning of amount of erop to suit eapacity of vine.

" 5 . Long canes for bearing, which agrees exactly with the nature of nearly all our American species far better than short spurs.

"6. Ease of laying down in winter. The vine being pruned and not tied, standing away from posts, ean be bent down to one side between the rows, and earth thrown upon it, and ean be quickly raised and tied in position.

"7. Cheapness of construction and ease of removing trellis material and using it again.

"8. Durability of both trellis and vineyard."

The Munson system of training has found many friends. Waugh writes of it as follows from experience at the Oklahoma Experiment Station:*

"It may be well to explain, for those not intimate with this form of trellis, the construction used and advocated by Mr. T. V. Munson. According to this method, the posts are made six feet high. At the top runs a cross-piece two feet long, at each end of which is fastened one of the wires of the trellis. Mr. Munson originally used two posts set in a V-shape, with the tops two feet apart. The result

*Garden and Forest, May 8, 1895, 185. 


\section{AMERICAN GRAPE TRAINING, CONCLUDED}

is the same either way. Eight inches lower than the two side wires there is a third wire fastened to the posts. This brings the three wires into a very broad $\mathrm{V}$ shape. There are no other wires on the trellis.

"The system of pruning, which forms a necessary part of the scheme, provides that one or two stems be brought up to the lower or middle wire, and that from these stems canes shall be run each way along this wire. From these canes the bearing shoots come at right angles, and naturally fall out over the top wires. Renewals are most easily made by spurring at the point on the lower wire where the canes are given off from the main stem, though it is often a very easy matter to renew quite from the ground.

"This system has been in use at the Oklahoma Experiment Station from the first, though that is not very long, and has given abundant satisfaction in most particulars. At the first glance, those who are familiar with our severe winds, but not with the working of this trellis, are much inclined to fear great damage from the whipping of the shoots, but, as a matter of fact, this serious difficulty is nearly overeome by the Munson trellis. It is one of the most vexing problems in the ordinary horizontal-arm training, but the increased height of the trellis does not increase the trouble. On the other hand, the peculiar position occupied by the growing wood gives it almost complete immunity. The green shoot is supported in two places near its base, while most of its length hangs free. Though it may swing in the wind, there is nothing against which it may strike, and so the damage is avoided.

"Mr. Munson sets forth his ideas of the advantages of this system in Professor Bailey's 'American Grape Training,' page 81. However, in our experience here, his summary is unsatisfactory. Some of the advantages which he claims do not seem to be peculiar to this system of training. Others are of slight importance. Those which are important ought to be more emphasized. In our experience 
the chief advantages of the system are (1) that it greatly reduces the damage from the wind; (2) that it reduces damage by heat reflection from the soil; (3) that it saves summer tying. The first of these advantages has already been explained. Regarding the second, it should be said that in this country, wherever bunches of fruit hang near the ground they are usually more or less dried out by the excessive rellection of heat from the soil during hot summer days. The loss amounts to a great deal. A conservative estimate placed this loss at from ten to sixty per cent through this country last season, and in some exceptional cases the crop was quite destroyed. With the fruit hanging five or six feet from the ground, and overshadowed by a canopy of foliage at least two feet wide, this evil is evidently much mitigated. The young shoots do not need to be tied at all, but are left to swing freely from the support which is given at their bases. In most other systems summer tying is a considerable and expensive item. Some summer pruning usually has to be done, but this is much facilitated and probably reduced in absolute quantity by the Munson training.

"Certain weak-growing varieties, like the well-known Delaware, do not find this trellis adapted to their needs. Many other circumstances may decide against its use; but it is being widely adopted through this country, and there are many favorable reports from it in other states."

Modified Munson.- " This system, which might better be termed the 'Alternate-Renewal' Munson, presents two advantages which the True Munson does not possess, and to my mind is preferable. It permits the bearing wood to be alternated from one side of the vine to the other, and is cheaper by one wire. 


\section{AMERICAN GRAPE TRAINING, CONCLUDED}

"No middle wire is used, and a slat is tacked across the $\mathrm{V}$ in place of the slack wire. A fork is formed below the wire in $\mathrm{Y}$-shape. From this fork a cane is trained to the right on one wire, and to the left on the other wire. A shoot on each cane, taken from a point near the wire, is trained in the opposite direction from, but on the same wire with, the cane, with which to renew the next season, when the bearing wood will be pruned to a spur, which in its turn will form a renewal shoot, and so on, alternately, the bearing canes extending always in opposite directions and on different wires, and alternating each year. The position of the vine the next season will simply be shifted or reversed.

"Sometimes instead of six feet, the trellis is made only four feet high. This height appears to have done just as well as the other at the Georgia Station. Here, the V supports have been made of one-by-three slats. When the sharpened ends are dipped in coal tar, or even white lead, driven in the ground so that they will cross each other just above the surface and tacked with two tenpenny nails, a firm, durable and sightly support is the result."*

MISCELLANEOUS SYSTEMS

Horizontal TRAINING.-There are very few types of horizontal-shoot training now in use.

*Hugh N. Starnes, Bull. 28, Ga. Exp. Sta. 270. 
One of the best may be described. Two wires run from post to post, as in the ordinary trellis, one about two and one-half feet above the ground and the other five and one-half feet high. The posts are set at the ordinary distance of sixteen or eighteen feet apart. The vines are set six or eight feet apart, if Delawares or other weak growers. A strong stake is driven in the ground just behind each vine, standing as high as the top of the trellis. The permanent trunk or head of the vine stands about a foot high. The vine is renewed back to the top of this trunk every year. One cane is left at each pruning, which, when tied up to the stake, is as high as the trellis. From this perpendicular eane, the bearing shoots are carried out horizontally. About six of these shoots are allowed to grow upon either side of the cane. As the shoots grow, they are tied to perpendicular slats which are fastened on the wires. These slats do not touch the ground. Two slats are provided upon either side, making four to a vine. They stand a foot or fifteen inches apart. The clusters hang free from the horizontal shoots. If the shoots grow too long, they are pinched in when they have passed the second slat. While these shoots are covering the trellis, another shoot is taken out from the head or trunk of the vine, and without being allowed to fruit, is tied up along the central stake. This shoot is to form the top 


\section{AMERICAN GRAPE TRAINING, CONCLUDED}

next year, for all the present vine is to be entirely cut away at the winter's pruning. So the vine starts every spring with but a single cane.

Excellent results are obtained from the slendergrowing varieties by this method of training, but it is too expensive in trellis and in the labor of tying to make it generally practicable. Delaware, however, thrives remarkably well when trained in this fashion.

Post TRAINING.-There are various methods of training to posts, all of which possess two advantages - the saving of the expense of trellis and allowing of cultivation both ways. But they also have grave disadvantages, especially in the thickness of the head of foliage, which harbors rot and mildew and prevents successful spraying, and hinders the fruit from coloring and ripening well. These faults are so serious that post training is now little used for the American grapes. The saving in cost of trellis is not great, for more posts are required to the acre than in the trellis systems, and they do not endure long when standing alone with the whole weight of the vines thrown upon them.

There are various methods of pruning for the stake training, but nearly all of them agree in pruning to side spurs on a permanent upright arm which stands the full height of the vine. There may be one or two sets of these spurs. We might suppose the Kniffin vine, shown in 
Fig. 294, to be tied to a post instead of stretched on a trellis ; in that event, the four canes would hang at will, or they might be wrapped about the post, the shoots hanging out unsupported in all directions. The post systems are essentially Kniffin in principle, for the shoots hang free. In low styles of post training, the permanent head of the vine may be only three or four feet high. This head will have a ring of spurs on it, and at the annual pruning three to five canes are left with from six to ten buds each.

The main trunk is usually tied permanently to the post. The canes left after pruning are variously disposed. Sometimes they are bent upwards and tied to the post above the head of the vine, but they are oftenest either wound loosely about the post, or are allowed to hang loose. Two trunks are frequently used to each post, both coming from the ground from a common root. These are wound about the post in opposite directions, one outside the other, and if the outside one is secured at the top by a small nail driven through it, or by a cord, no other tying will be necessary. Sometimes two or three posts are set at distances of one foot or more apart, and the vines are wrapped about them, but this only augments the size and depth of the mass of foliage. Now and then one sees a careful post training, in which but little wood is left and vigorous breaking out of shoots practiced, 
which gives excellent results; but on the whole, post training cannot be recommended. The European post and stake systems, or modifications of them, are yet occasionally recommended for American vines, but under general conditions, especially in commercial grape growing, they rarely succeed long. One of the latest recommendations of any of these types is that of the single pole system of the Upper Rhine Valley, by A. F. Hofer, of Iowa, in a little treatise published in 1878.

ARBors.-Arbors and bowers are usually formed with little reference to pruning and training. The first object is to secure shade and seclusion, and these are conditions which may seriously interfere with the production of fine grapes. As a rule, too much wood must be allowed to grow, and the soil about arbors is rarely ever cultivated. Still, fair results in fruit can be obtained if the operator makes a diligent use of the pruning shears. It is usually best to carry one main or permanent trunk up to the top or center of the arbor. Along this trunk at intervals of two feet or less, spurs may be left to which the wood is renewed each year. If the vines stand six feet apart about the arbor-which is a satisfactory distance-one cane three feet long may be left on each spur when the pruning is done. The shoots which spring from these canes will soon cover up the intermediate spaces. At the close of the season, this entire cane, with 
its laterals, is cut away at the spur, and another three-foot cane-which grew during the seasonis left in its place. This pruning is essentially that of the Kniffin vine in Fig. 294. Imagine this vine, with as many joints or tiers as necessary, laid upon the arbor. The canes are tied out horizontally to the slats instead of being tied on wires. This same system-running up a long trunk and cutting-in to side spurs-will apply eqnally well to tall walls and fences which it is desired to cover. Undoubtedly a better plan, so far as yield and quality of fruit is concerned, is to renew back nearly to the root, bringing up a strong new cane, or perhaps two or three every year, and cutting the old ones off; but as the vines are desired for shade, one does not care to wait until midsummer for the vines to reach and cover the top of the arbor.

REModeling OLD vines.-Old and neglected tops can rarely be remodeled to advantage. If the vine is still vigorous, it will probably pay to grow an entirely new top by taking out a cane from the root. If the old top is cut back severely for a year or two, this new cane will make a vigorous growth, and it can be treated essentially like a new or young vine. If it is very strong and ripens up well, it can be left long enough the first fall to make the permanent trunk; but if it is rather weak and soft, it should be cut back in the fall or winter to two or three buds, from one of 
which the permanent trunk is to be grown the second season. Thereafter, the instructions which are given in the preceding pages for the various systems will apply to the new vine. The old trunk should be cut away as soon as the new one is permanently tied to the wires,-that is, at the close of either the first or second season of the new trunk. Care must be exercised to rub off all sprouts which spring from the old root or stump. If this stump can be cut back into the ground and covered with earth, better results may be expected. Old vines treated in this manner often make good plants, but if the vines are weak and the soil is poor, the trouble will scarcely pay for itself.

These old vines can be remodeled easily by means of grafting. Cut off the trunk five or six inches below the surface of the ground, leaving an inch or two of straight wood above the roots. Into this stub insert two cions exactly as for cleftgrafting the apple. Cions of two or three buds, of firm wood the size of a lead pencil, should be inserted. The top bud should stand above the ground. The cleft will need no tying or wax, although it is well to place a bit of waxed cloth or other material over the wound to keep the soil out of it. Fill the earth tightly about it. Great care must be taken in any pruning which is done this first year, or the cions may be loosened. If the young shoots are tied to a stake there will be less danger from wind and careless workmen. In the 
vine shown in the illustration (Fig. 313), no pruning or rubbing out was done, but the vine would have been in better shape for training if only one or two shoots had been allowed to grow.

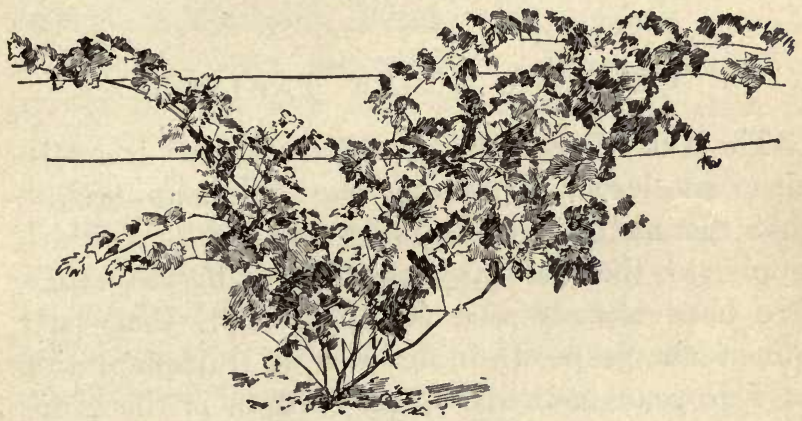

313. A good yearling graft.

If it is desired, however, to keep the old top, it will be best to cut back the annual growth heavily at the winter pruning. The amount of wood which shall be left must be determined by the vigor of the plant and the variety, but three or four canes of six to ten buds each may be left at suitable places. During the next season a strong shoot from the base of each cane may be allowed to grow, which shall form the wood of the following season, while all the present cane is cut away at the end of the year, so that the bearing-wood is renewed each year, as in the regular systems of training. Much skill and experience are often required to properly rejuvenate an old vine; and in very many cases the vine is not worth the trouble. 


\section{Chapter IX}

\section{VINIFERA GRAPE TRAINING}

The Old World grape, Vitis vinifera, is a distinct species or type from the American grapes, and the methods of training and pruning which apply to the one may not apply to the other. We have already seen (Chapter VII.) that early American grape training was a transplantation of European methods. The Vinifera is the grape which is grown in the Pacific region for wine and raisins, and it is the grape of glass-houses.

\section{CALIFORNIA PRACTICE*}

(F. T. BIOLETTI)

The literature relating to the pruning and training of the vine is already very voluminous, but there seems to be no one work which treats

*This account is founded on "Vine Pruning," by F. T. Bioletti, Bull. 119, Cal. Exp. Sta., Dec., 1897, the bulletin being used for this purpose by permission. Unless otherwise stated, the chapter is a verbatim tran. scription of Bioletti's essay. Not all of the bulletin, however, is here reproduced. Some of the illustrations have been redrawn, and others have been reduced in size. The bulletin was reprinted in the "California Fruit-Grower," Jan. 15 to Feb. 5, 1898.

Persons who are interested in the pruning and training of the wine or raisin grape in America should also consult Wickson's "California Fruits" and Eisen's "Raisin Industry." 
the subject in a thorough and convenient way for California vine-growers. Publications in English refer generally to methods suited to the Eastern states or to hot-house cultivation, while foreign publications, besides being more or less inaccessible, treat the subject so widely that the grower is at a loss what to choose from such a mass of material. It is the purpose of this bulletin, therefore, to present a brief summary of what in foreign methods seems useful and applicable to California conditions, together with the results of experiments on the University of California vine plots, and of observations made in numerous vineyards in various regions of the state.

Almost every vine-growing district has its peculiar systems of training, ranging from the non-training usual in parts of Italy, where the vine spreads almost at will over trees planted for the purpose, to the acme of mutilation practiced in many localities where the vine is reduced to a mere stump barely rising above the surface of the ground. These various systems will not be discussed here, but only those which experience has shown to be most adapted to California conditions.

No account, however detailed, of any system can replace the intelligence of the cultivator. For this reason the general principles of plant physiology which underlie all proper pruning 
and training are discussed in connection with the several systems described. This should aid the grower in choosing that system most suited to the conditions of his vineyard, and to modify it to suit special conditions and seasons. All the operations of pruning, tying, staking, etc., to which a cultivated vine owes its form, are conveniently considered together.

A description of a typical vine giving the names of the principal parts will make clear the accounts of methods to be given later. Fig. 314 represents a vine of no particular order of pruning, showing the various parts. The main body of the vine $(t)$ is called the trunk or stem; the principal division $(b)$ branches; the smaller divisions (a) arms, and the ultimate ramifications (c) shoots when green, and canes when mature. A shoot growing out of the vine above ground on any part older than one year $(w s)$ is called a watersprout. Shoots coming from any part of the vine below ground $(s)$ are called suckers. When a cane is cut-back to $1,2,3$, or 4 r eyes, it is called a $\operatorname{spur}(r)$. When a shoot or cane of one season sends out a secondary shoot the same season, the latter ( $l$ ) is called a lateral.

The Fig. 315 represents an arm of a vine as it appears in winter after the leaves have fallen. The canes $\left(\mathrm{w}^{1}\right)$ are the matured shoots of the previous spring. $w^{2}, w^{3}, w^{4}$ represents two, three and four-year-old wood respectively. Near the 
base of each cane is a basal bud or eye $\left(\mathrm{B}^{\circ}\right)$. In counting the number of eyes on a spur, the basal eye is not included. A cane cut at $\mathbf{K}^{1}$, for instance, leaves a spur of one eye, at $\mathrm{K}^{2}$ a spur of two eyes, and so on. When more than four eyes are left, the piece is generally called a fruiting cane (Fig. 314, $f$ ). The canes $\left(\mathrm{c}, \mathrm{c}^{1}\right)$ coming from

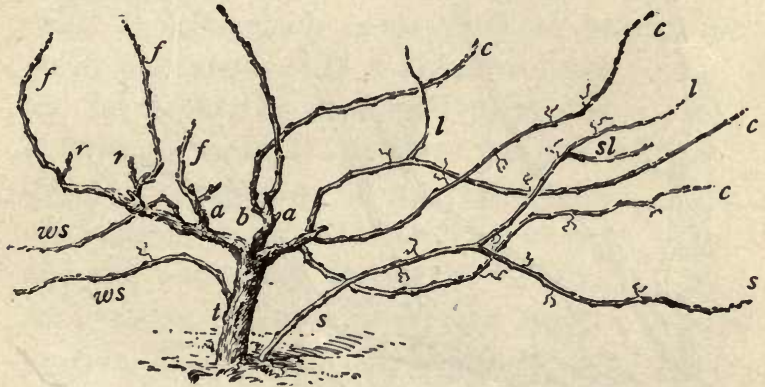

314. Diagram to illustrate terminology.

two-year-old wood $\left(w^{2}\right)$ possess fruit buds; that is, they are eapable of producing fruit-bearing shoots. Watersprouts (ws) and suckers (s) do not ordinarily produce fruit-bearing shoots. Below the basal bud each cane has one or more dormant buds (b, Fig. 316), which do not grow unless the number of eyes left by pruning or frost is insufficient to relieve the excess of sap pressure. These buds produce sterile shoots. Each eye on a cane has at its base two dormant buds. One of these sometimes grows out the year it is 
formed, making a lateral (l, Figs. 314, 315). These laterals may send out secondary laterals (sl, Fig. 314). It is on the laterals and secondary laterals that the so-called second and third crops are borne.

Proper method of MAKING CUTS. - It is by no means a matter of indifference just where the cut

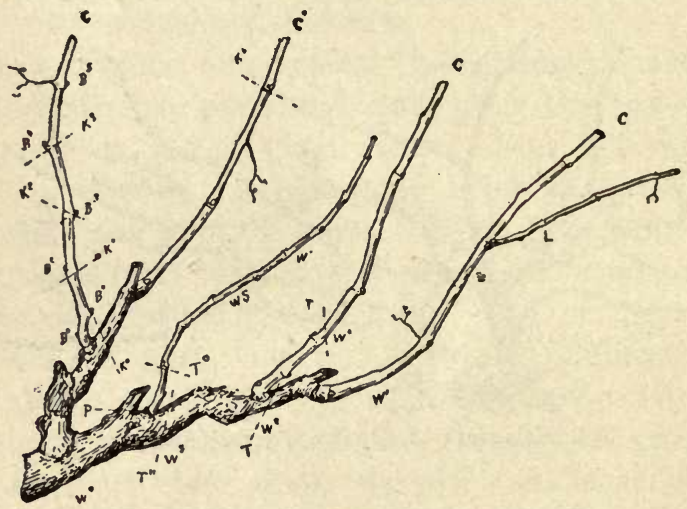

315. Illustrating the parts of the vine.

is made in removing a cane or arm. This will be made clearer by referring to Fig. 316. The upper part of the spur is represented as split in two longitudinally, in order to show the internal structure of the cane. It will be noted that at each bud there is a slight swelling of the cane. This is called a node, and the space between an internode. The internodes are filled with soft. pith, but at each node there is a growth of hard. 
wood extending through the cane. Now, if the cane be cut off at $\mathrm{C}^{1}$, in the middle of an internode, the pith will shrink away and leave a little hollow in which the rain collects. This is an excellent breeding place for fungi and bacteria, which cause rotting of the pith and frequently kill the bud. If, on the contrary, the cane be cut at $\mathrm{c}^{2}$, through a node, a protecting cover of hard wood is left which is an effectual barrier against decay organisms. If a spur projects too far from the vine, and it is desirable to make it as short as possible in order not to interfere with cultivation, it should be cut at $\mathrm{c}$, and the cut made as nearly vertical as possible. This allows the water to run off, and leaves less pith to foster the growth of the fungi. At the base of the cane there is a slight enlargement ( $\mathrm{E})$. In removing a cane completely, the cut should be made just above this enlargement. This is the most favorable place for healing, as it makes the smallest

possible wound, and does not leave make the cuts. a projecting stump of dead wood to

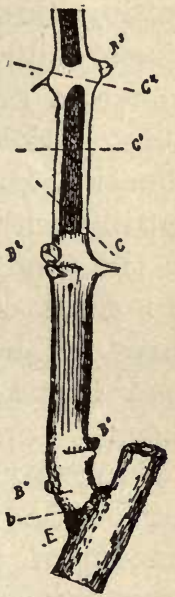
prevent the healing tissues from closing over the wound. In removing a piece of older wood, as at $\mathrm{K}^{\circ}$ and $\mathrm{T}^{1}$, Fig. 315 , it is advisable not to eut too close for fear of injuring the spur by the dry- 
ing out of the wood. The projecting pieces of dead wood left in this way should be carefully removed the next year, in order to allow the wound to heal over. The large cuts which are thus occasionally necessary are most easily performed by means of a well-made and wellsharpened pair of two-hand pruning shears. These shears are often to be preferred to the ordinary one-hand shears, because they render the cutting through the nodes easier, and do away almost entirely with the necessity of a saw. Of course, a careless workman may split and injure vines seriously by using long-handled shears clumsily, but the bending of arms to facilitate cutting with the one-hand shears, often results in the same evil. The one-hand shears, however, are more convenient when many long fruiting canes are left, as the necessary trimming off of tendrils and laterals is more easily performed with them.

ShorT AND LONG PRUNING.-The winter-pruning of the vine consists in cutting off a certain amount of the mature wood of the immediately preceding season's growth (canes), and occasionally of the older wood. The main problem of winter-pruning, then, resolves itself into determining how much and what wood shall be left. In all kinds of pruning most of the canes are removed entirely.

In short-pruning the remainder are cut back 
to spurs of one, two or three eyes. The number of spurs is regulated by the vigor and age of the vine. This mode of pruning can be used only for varieties in which the eyes near the base of the cane are fruitful. For all other cases long or half-long pruning is necessary.

In half-long pruning, certain canes are left with from four to six eyes, according to the length of the internodes. These canes or fruit-spurs will bear more fruit than short spurs for three reasons: 1 , because there will be more fruitbearing shoots; 2 , because the upper eyes are more fruitful than the lower; and 3 , because a larger number of eyes being supplied with sap from the same arm, each shoot will be less vigorous and therefore more fruitful. Owing, however, to the tendency of the vine to expend the principal part of its vigor on the shoots farthest removed from the base of the canes, the lower eyes on the long spurs will generally produce very feeble shoots. In order, then, to obtain spurs of sufficient vigor for the next year's crop, it would be necessary to choose them near the ends of the long spurs of the previous year, if no others were left. This would result in a rapid and inconvenient elongation of the arms. In order to avoid this it is necessary to leave a spur of one or two eyes below each long-fruiting spur, that is to say, near the trunk. These short wood spurs having only one or two eyes, 
will produce vigorous canes for the following year, and the spurs which have borne fruit may be removed altogether, thus preventing an undue elongation of the arms. In half-long pruning, however, it is very hard to retain the proper equilibrium between vigor and fruitfulness. If a little too much wood is left the shoots from the wood spurs will not develop sufficiently, and the next year we have to choose between leaving small under-sized spurs near the trunk and spurs of proper size too far removed from the trunk. In long-pruning this difficulty, as will be seen, is to a great extent avoided.

In long-pruning, the fruit spurs of half-long pruning are replaced by long fruit canes. These are left two or three feet long, or longer. The danger here that the vine will expend all its energies on the terminal buds of these long canes and leave the eyes of the wood spurs undeveloped is still greater than in half-long pruning. This difficulty is overcome by bending or twisting the fruit canes in some manner. This bending causes a certain amount of injury to the tissues of the canes, which tends to check the flow of sap towards their ends. The sap pressure thus increases in the lower buds and forces them out into strong shoots to be used for spurs for the next pruning. The bending has the further effect of diminishing the vigor of the shoots on the fruit canes, and thus increasing their fruitfulness. 
This principle of increase of fruitfulness by mechanical injury is very useful if properly understood and applied. It is a well-known fact that vines attacked by phylloxera or root-rot will for one year bear an exceptionally large crop on account of the diminution of vigor caused by the injury to their roots. A vine also which has been mutilated by the removal of several large arms will often produce heavily the following year. In all these cases, however, the transient gain is more than counter-balanced by the permanent injury and loss. The proper applications of the principle is to injure tissues only of those parts of the plant which it is intended to remove the next year (fruit canes), and thus increase fruitfulness without doing any permanent. injury to the plant.

PRUNing of Young vines.-When a rooted vine is first planted, it should be cut back to two eyes. If the growth is not very good the first season, all the canes but one should be removed at the first pruning, and that one left with two or three eyes, according to its strength. The next year, or the same year in the case of strong growing vines in rich soil, the strongest cane should be left about twelve inches long and tied up to the stake. The next year two spurs may be left, of two or three eyes each. These spurs will determine the position of the head or place from which the arms of the vine spring. It is 
important, therefore, that they should be chosen at the right height from the ground. From ten to twenty inches is about the right height; the lowest for dry hillsides, where there is no danger of frosts; the highest for rich bottom lands, where the vine will naturally grow large. Vines grown without stakes will have to be headed lower than this in order to make them support themselves. In the following few years the number of spurs should be increased gradually, care being taken to shape the vine properly and to maintain an equal balance of the arms.

In general, young vines are more vigorous than old, and tend more to send out shoots from basal and dormant buds. They should, therefore, be given more and longer spurs in proportion than older vines. They also tend to bud out very early in the spring, and are thus liable to be frost-bitten. For this reason they are generally pruned late (March) in frosty locations. This protects them in two ways. In the first place, in unpruned vines the buds near the ends of the canes start first and relieve the sap pressure, and though these are caught by the frost, the buds near the base, not having started, are saved. In the second place, the pruning being done when the sap is flowing, there is a loss of sap from the cut ends of the spurs, which further relieves the sap pressure and retards the starting 
of the lower eyes. This method of preventing the injury of spring frosts by very late pruning has been tried with bearing vines, but is very in. jurious. Older vines, being less vigorous are unable to withstand the heavy drain caused by the profuse bleeding which ensues; and though no apparent damage may be done the first year, if the treatment is continued they may be completely ruined in three or four years.

\section{Systems of Pruning}

The systems of pruning adapted to vineyards in California may be divided into six types, according to the form given to the main body of the vine and the length of the spurs and fruiting canes.

A. Vine pruned to a head, with short arms.

I. With spurs of two or three eyes only (short-pruning).

II. With wood spurs of one or two eyes and fruit spurs of four to six eyes (halflong pruning).

III. With wood spurs of one or two eyes and long fruit canes (long-pruning).

B. Vine with a long horizontal branch or continuation of the trunk.

IV. With spurs of two or three eyes only (short-pruning). 
V. With wood spurs of one or two eyes and fruit spurs of four to six eyes (halflong-pruning).

VI. With wood spurs of one or two eyes and long fruit canes (long-pruning).

These types are applicable to different varieties of vines, according-(1) To the natural stature of the vine-that is to say, whether it is a large or small grower and tends to make a large, extended trunk or a limited one. (2) To the position of the fruit-buds. In some varieties all the buds of the canes are capable of producing fruitful shoots, while in others the one, two or three buds nearest the base produce only sterile shoots. (3) To the size of the individual bunches. It is necessary in order to obtain a full crop from a variety with small bunches, to leave a larger number of eyes than is necessary in the case of varieties with large bunches.

What type or modification of a type shall be adopted in a particular instance, depends both on the variety of vine and on the nature of the vineyard. A vine growing on a dry hillside must not be pruned the same as another vine of the same variety growing on rich bottom land. In general, vines on rich soil, where they tend to grow large and develop abundant vegetation, should be given plenty of room and allowed to spread themselves, and should be given plenty of fruiting-buds in order to control their too strong inclination to "go 
to wood." Vines on poor soil, on the contrary, should be planted closer together and pruned shorter, or with fewer fruiting-buds, in order to maintain their vigor.

Type I.-This is the ordinary short-pruning practiced in ninety per cent of the vineyards of California, and is the simplest and least expensive manner of pruning the vine. It is, however, suited only to vines of small growth, which pro-

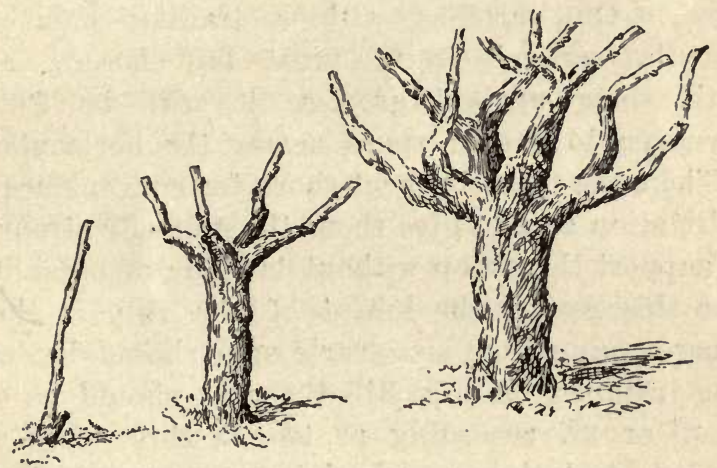

317. Epochs in the common short-pruning system.

duce fruitful shoots from the lowest buds, and of which the bunches are large enough to admit of a full crop from the small number of buds which are left by this method. The chief objection to this method for heavily-bearing vines is that the bunches are massed together in a way that favors rotting of the grapes and exposes the different bunches unequally to light and heat. 
The Fig. 317 represents the simplest form of this style of pruning. The vine should be given as nearly as possible the form of a goblet, slightly flattened in the direction of the rows. It is important that the vine be kept regular and with equally balanced arms. This is the chief difficulty of the method, and calls for the exercise of some judgment. From the first, the required form of the vine should be kept in view. On varieties with a trailing habit of growth, vertical spurs must be chosen, and with some upright growers it will be found necessary to choose spurs nearer the horizontal.

The arms must be kept short for convenience of cultivation and to give them the requisite strength to support their crop without bending or breaking. For this reason the lowest of the two or three canes coming from last year's spur should be left. For instance, on Fig. 315 the cane should be cut at $\mathrm{K}^{2}$ or $\mathrm{K}^{3}$, according as two or three eyes are needed, and the rest of the arm removed at $\mathrm{K}^{\circ}$. As even with the greatest care some arms will become too long or project in wrong directions, it is necessary to renew them by means of canes from the old wood or watersprouts. For instance, if the other arm represented on Fig. 315 were too long, it should be removed and replaced by another developed from the cane (ws). As the cane comes from three-year-old wood it cannot be depended on to produce grapes. For this reason 
it is best the first year to prune the arm at $\mathrm{T}$, leaving a spur for fruit, and cut the watersprout at $\mathrm{T}^{\circ}$, leaving a wood spur of one eye. The next year the cane coming from the first eye of ws can be left for a fruit-spur, and the arm removed at $\mathbf{T}^{1}$. The cutting-back of an elongated arm should not be deferred too long, as the removal of old arms leaves large wounds, which weaken the vine and render it liable to attacks of fungi.

In order to maintain the equilibrium of the arms, it is often necessary to prune back the more vigorous arms severely in order to throw the strength of the vine into the weaker arms. If the vine appears too vigorous, that is, if it appears to be "going to wood" at the expense of the crop, two spurs may be left on some or all of the arms. In this case the upper spur should be cut above the third eye ( $\left.\mathrm{K}^{4}, \mathrm{Fig} .315\right)$, and the lower above the first or second $\left(\mathrm{K}^{1}\right.$ or $\left.\mathrm{K}^{2}\right)$. This will cause the bulk of the fruit to be borne on the upper spur, and the most vigorous shoots to be developed on the lower, which provides the wood for the following year. This is an approach to the next (half-long) method of pruning.

[Professor Wickson sends me Fig. 318 as "a clear, satisfactory and characteristic view of the illimitable valley raisin extensions" of California. -L. H. B.]

TyPE II.-Vines which require more wood than can well be given by ordinary short pruning, or 


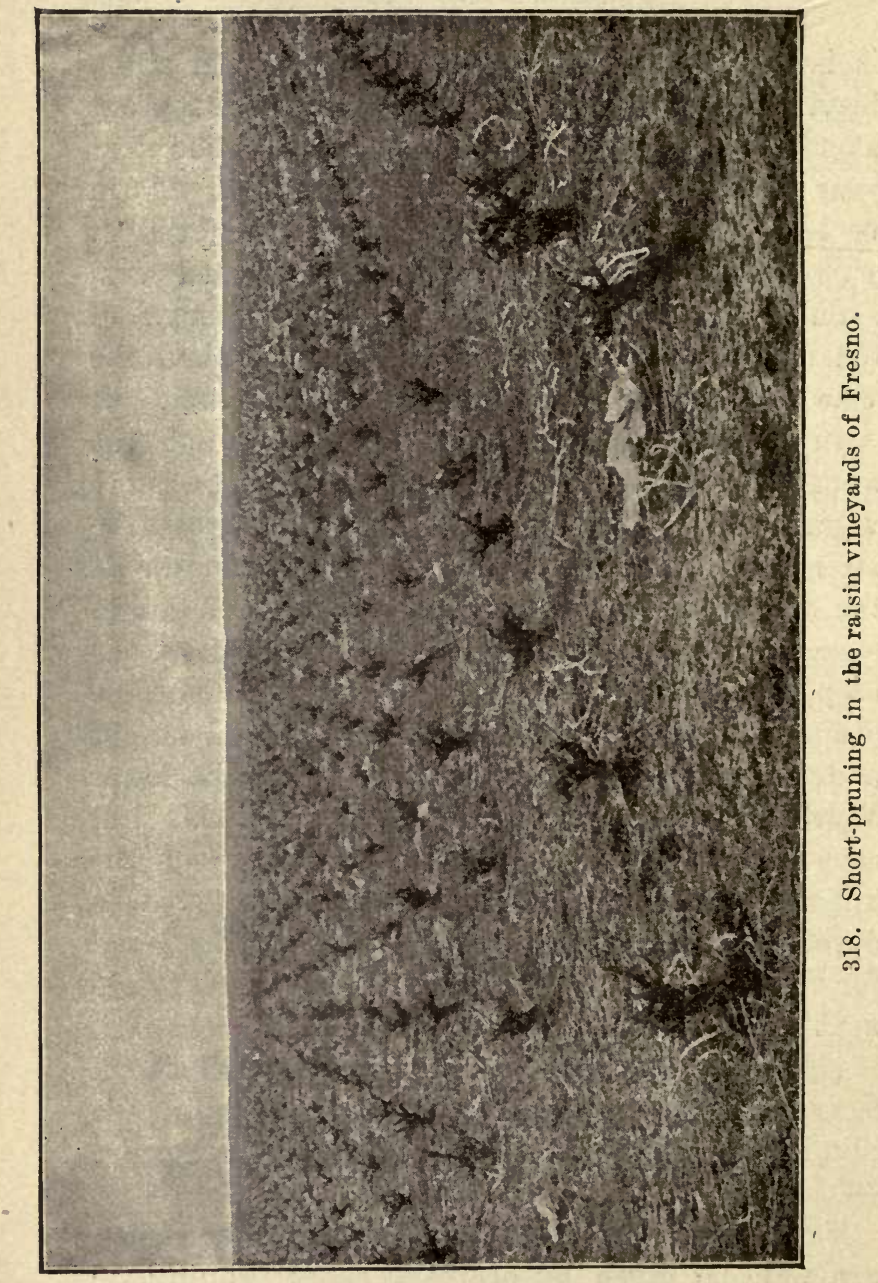


of which the lower eyes are not sufficiently productive, may in some cases be pruned in the manner illustrated by Fig. 319. For some varieties it is necessary to leave spurs of only three eyes, as at $s$; for others, short canes of four or five eyes must be left, as at $c c$. These shorter spurs can be left without support, but the longer ones require some arrangement to prevent their

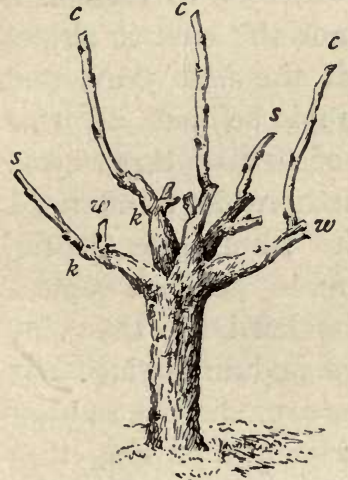

319. Another type of short-pruning.

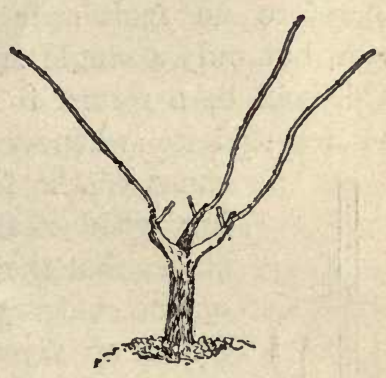

320. Still longer pruning.

bending over with the weight of fruit and destroying the shape of the vine. In some cases simply tying the ends of the canes together will support them fairly well, but it is better to attach them to a stake, and bend them at the base a little when possible, in order to retard the flow of sap to the ends. It is very necessary to leave strong spurs of one eye (not counting the 
basal eye) in order to provide wood for the following year. At the pruning following the one represented in the cut, the fruiting part of the arms will be removed at $k k$, and a new fruiting spur or cane made of the cane which comes from the eye on the wood spurs $w$. The basal bud on $w$ will in all probability have produced a cane which ean be cut back to one eye to furnish a new rood-spur. If this is not the case it shows that too much wood was left the first year, and therefore no fruit-cane should be left on this arm, but only a single spur of two or three eyes. This will be a return to short pruning, and must be resorted to whenever the small size of the

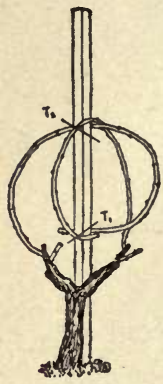

321. Tying the canes. canes or the failure to produce replacing wood near the head of the vine shows that the vigor is diminishing. If, on the contrary, the arm shows an abundance of vigorous canes, proving that the vine has not overborne, a fruit-cane may be left from one of the shoots coming from the lower buds of the fruit-cane $c$, and a new wood-spur of two eyes left on the shoot coming from the wood-spur of the previous year $(w)$. In this case, the removal of the arm at $k$ is deferred one year, and the extra vigor of the vine is made use of to produce an extra crop.

TrPe III.-This style is an extension of the 
principles used in Type II, as will be understood by referring to Fig. 320. The fruiting canes are left still longer, and in some cases almost the full length of the cane. As each cane will thus produce a large amount of fruit, fewer arms are necessary than in the preceding method. It is especially necessary to leave good, strong spurs of one or two eyes to produce wood for the following year. There are various methods of disposing of the long fruiting canes, the worst of which is to tie them straight up to the stake, as was recommended for the half-long canes. In the latter case, owing to their shortness, a certain amount of bending of the canes is possible with this method of tying. With long canes, on the contrary, it usually allows of no bending, and as a result there ensues a vigorous growth of shoots at the ends of the fruiting eanes, and little or no growth in the parts where it is necessary to look for wood the following year. Often, indeed, each long cane will produce only three shoots, and these from the three terminal eyes, all the other eyes of the cane remaining dormant. The object of long pruning is thus doubly defeated, 1st, because no more shoots are produced than by short pruning; and 2nd, because the shoots which should produce fruit are rendered especially vigorous by their terminal and vertical position, and therefore less fruitful. Each year all this vigorous growth of 
wood at the ends of the canes must be cut away in order to keep the vine within practical bounds, and the fruit-canes renewed from the less vigorous cane below. These canes are less vigorous because the main strength of the vine has been expended on the upper canes, which are most favorably placed for vegetative vigor. - Vines treated in this way may be gradually exhausted, though producing only a moderate

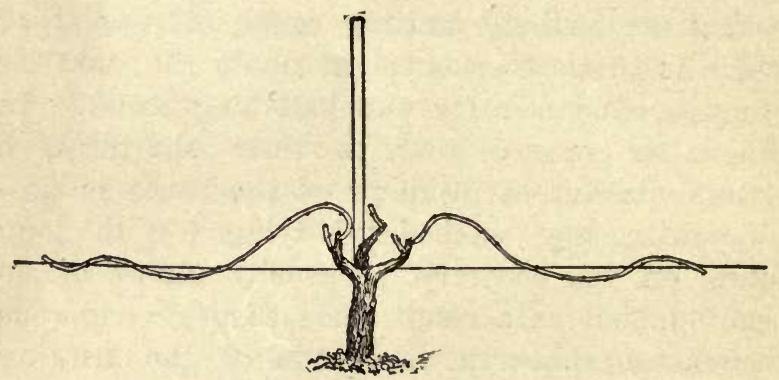

322. Another method of tying the canes.

or small crop of fruit, by being forced to produce an abundant crop of wood.

One of the simplest ways of tying the fruiting canes is illustrated by Fig. 321. The canes are bent into a circle, the ends tied to the stake near the head of the vine, and the middle of the circle attached higher up. The tying should be done so that the cane receives a severe bend near the base-that is, about the region of the second and third eyes. This can usually be accomplished 
by tying the end of the cane first, and then pressing down on the middle of the bow until the desired bend is attained. If two fruiting canes are left, they should be made to cross each other at right angles in order to distribute the fruit as equally as possible. As a rule, more than two canes should not be tied up in this way, as it makes too dense a shade, and masses the fruit too much.

The Fig. 322 shows another method of tying the long canes. A horizontal wire is stretched along the row at about fifteen to twenty inches above the ground. To this the fruiting canes should be attached, using the same precaution of bending the canes near the bases. The upper part of the canes is not bent in this case as in the last, but the necessary diminution of vigor and increase of fruitfulness is brought about by the horizontal position. Two canes may be attached to the wire on each side, The stake is best used to support the shoots destined for the wood for the following year. This makes it possible, where topping is practiced, to cut off the ends of the shoots from the fruiting canes, and to leave the rest their full length. Another, or even two other wires, may be used above the first for more canes, but this is seldom profitable, and considerably increases the cost, both of installation and of pruning.

This style of pruning is especially favorable to 
varieties of small growth, which bear small bunches, and principally on the upper eyes, and to varieties of larger growth in hilly or poor soils. One of its main objections is that. it renders some varieties more liable to sumburn.

It will be noticed that the long-pruned vines are represented in the figures as having much fewer arms than the short-pruned. This is necessary and important. In order to maintain a well-balanced vine, and keep it under control, there should be only about as many arms as long eanes, or at most one or two more.

[The views in Figs. 323, 324 show the longpruning or "pruning to a high stake." They are supplied by Professor Wickson.-L. H. B.]

TyPES IV., V. AND VI.-The three styles of pruning so far described have been fairly thoronghly tested in California, and each has been found applicable to certain varieties and conditions. There are some varieties, however, which do not give good results with any of these systems. This is the case with many valuable table grapes, especially when grown in rich valley soil, where they should do best. For these cases some modification of the French cordon system is to be recommended. Little trial of this method has been made as yet, but what has been done is very promising. The tendency of many grapes to coulure is overcome, and rich soils are made to produce crops in proportion to their richness. The method consists 


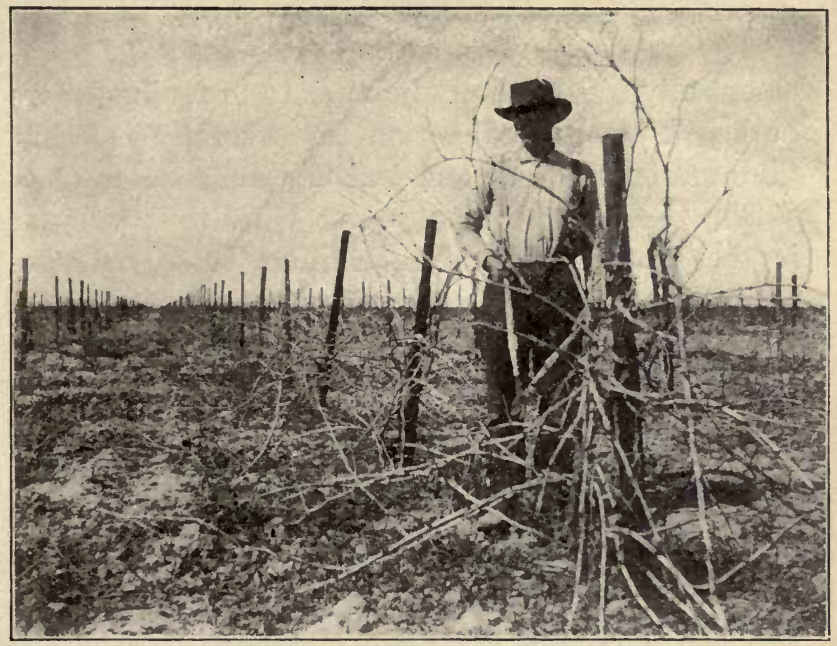

323. Long-pruning, before the vines are trimmed.

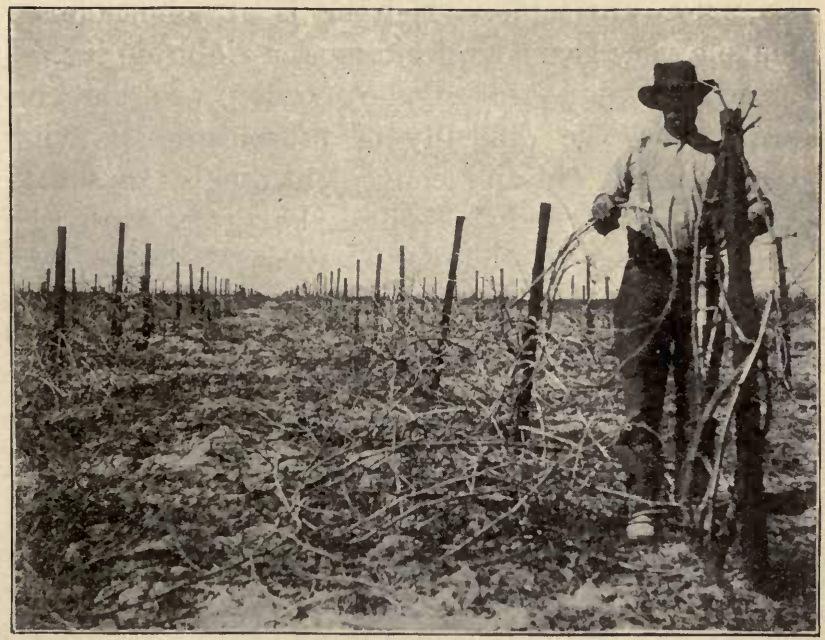

324. Long-pruning, after the vines are trimmed. 
essentially in allowing the vine to grow in a more or less horizontal direction for several feet, thus giving a larger body and fruiting surface.

The treatment of the young vines the first year is the same as for head-pruning, as already described. As soon as the young vine produces a good, strong shoot it is tied up to the wire and to the stake which is placed between the vines in the rows. Each vine should finally reach its neighbor, but it requires two or three years for this if the vines are six or seven feet apart in the rows. It is possible, by cutting the vine back nearly to the ground for the first year or two, to obtain a cane which will stretch the whole distance between the vines at the first tying up; but this is not necessary nor advisable. Neither is it advisable to make a very sharp angle (almost a right angle), as is usually done in regular cordon pruning, on account of the difficulty of preventing the vine from sending out an inconvenient number of shoots at the bend. The vine might be grown with two branches, one stretching in either direction, but this has been found inconvenient on account of the difficulty of preserving an equal balance of the branches. The direction in which the vine is trained should be that of the prevailing high winds, as this will minimize the chances of shoots being blown off. When the cordon or body of the vine is well-formed, it may be pruned with all the modifications of short, half-long and long-pruning 
already described in head-pruning, and the same precautions are necessary to preserve the balance and symmetry of the vine and to maintain it at the highest degree of fruitfulness without unduly exhausting it.

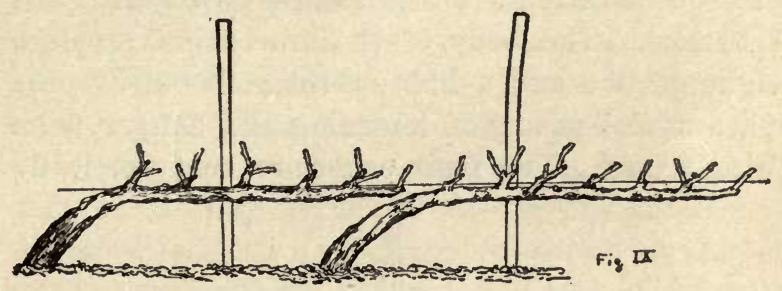

325. Training short-pruned cordons.

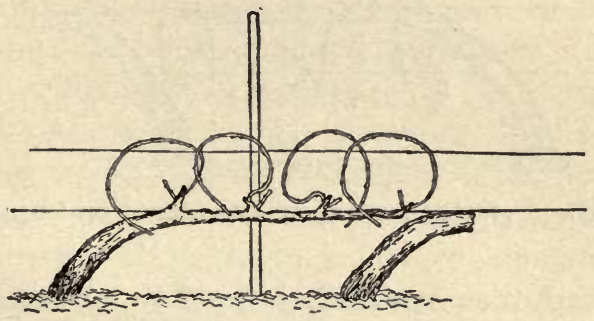

326. Training of long-pruned cordons.

The Figs. 325 and 326 will sufficiently illustrate the way of shaping and tying short and longpruned vines. For some table grapes, extension of the method shown in Fig. 325 in the direction of half-long pruning is useful. On a heavy soil the short spurs do not provide sufficient outlet for 
the vigor of the vine, while long-pruning would unduly increase the number of bunches on a single eane, and so reduce their size, which would deteriorate from their value as table grapes.

The Fig. 327 represents a style of pruning used with suceess in some of the richest low-lying soils of France. The body of the vine raised up to a height of two and a-half or three feet above the soil, a useful means of lessening the danger from spring frosts. The fruit-canes are bent vertically

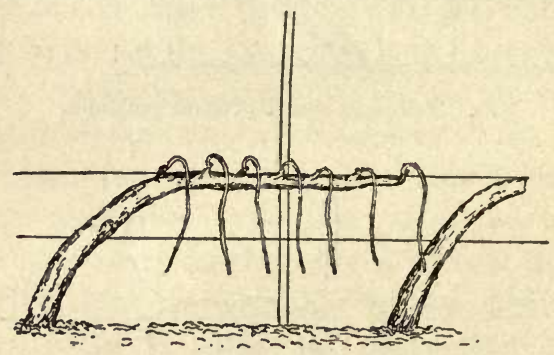

327. Drooping training of long-pruned cordons.

downward, thus restricting the flow of sap sufficiently to foree out the lower buds of the fruitcanes into strong shoots, which ean be used for fruit canes of the following year. This does away, to some extent, with the necessity of leaving wood-spurs, and much simplifies the pruning. Arms, of course, are formed in time, and very gradually elongate, so that it is necessary to remove one occasionally and replace it by a 
water-sprout, as already explained under shortpruning.

\section{Summer Pruning}

Some form of summer or green pruning is practised in most California vineyards, if in the term we include all the operations to which the green shoots are subjected. There seems, however, to be little system used, and very little understanding of its true nature and object. In general, it may be said that green pruning of the vine is least needed, and is often harmful in warm, dry locations and seasons, and of most use under cool and damp conditions.

The principal kinds of green pruning are: 1, Pinching; 2, Suckering and Sprouting; 3, Topping; 4, Removal of Leaves.

Pinching consists in removing the extreme growing tip of a young shoot. It is necessary to remove only about half an inch to accomplish the purpose of preventing further elongation of the shoot, as all growth in length takes place at the extreme tip. The immediate result of pinching is to concentrate the sap in the leaves and blossoms of the shoots, and finally to force out the dormant buds in the axils of the leaves. It has been found useful in some cases to combat coulure or dropping with heavy-growing varieties, such as the Clairette Blanche. It is also of use in preventing unsupported shoots from be- 
coming too long while still tender, and being broken off by the wind. It can, of course, be used only on fruiting shoots, and not on shoots intended for wood for the following year.

Suckering is the removal of shoots that have their origin below or near the surface of the ground. The shoots should be removed as thoroughly as possible, the enlargement at the base being cut off in order to destroy the dormant basal buds. An abundant growth of suckers indicates either careless suckering of former years (which has allowed a mass of buds below the ground, a kind of subterranean arm, to develop), or too limited an outlet for the sap. The latter may be due to frost or other injuries to the upper. part of the vine, but is commonly caused by too close pruning.

Sprouting is the removal of sterile shoots or "watersprouts" from the upper part of the vine. Under nearly all circumstances this is an unnecessary and often a harmful operation, especially in warm, dry locations. An exception may perhaps be made under some conditions of varieties like the Muscat of Alexandria, which has a strong tendency to produce "watersprouts" which, growing through the bunches, injure them for table and drying purposes.

WATERSPROUTS are produced from dormant buds in the old wood, and as these buds require a higher sap pressure to cause them to start than do the 
fruitful buds, the occurrence of many watersprouts indicates that too limited a number of fruitful buds has been left upon the vine to utilize all the sap pumped up by the roots. To remove these watersprouts, therefore, while they are young is simply to shut off an outlet for the superabundant sap, and thus to injure the vine by interfering with the water equilibrium, or to cause it to force out new watersprouts in other places. Any vigorous vine will produce a certain number of watersprouts, but they should not be looked upon as utterly useless and harmful, because they produce no grapes. On the contrary, if not too numerous, they are of positive advantage to the vine, being so much increase to the feeding surface of green leaves. Watersprouts should be removed completely during the winter pruning, and the production of too many the next year prevented by a more liberal allowance of bearing wood.

Topping, or cutting off the ends of shoots, is done by a means of a sickle or long knife. At least two or three leaves should be left beyond the last bunch of grapes. The time at which the topping is done is very important. When the object is simply to prevent the breaking of the heavy, succulent canes of some varieties by the wind, or to facilitate cultivation, it must, of course, be done early, and is well replaced by early pinching. These objects are, however, bet- 
ter attained by appropriate methods of planting and training. Early topping is inadvisable because it induces a vigorous growth of laterals, which make too dense a shade, and it may even force the main eyes to sprout, and thus injure the wood for the next year. The legitimate function of topping is to direct the flow of food material in the vine first into the fruit, and second into the buds for the growth of the following year. If the topping is done while the vine is in active growth, this object is not attained; one growing tip is simply replaced by several. In this way, in rich, moist soils vines are often, by repeated toppings, kept in a continual state of production of new shoots, and as these new shoots consume more food than they produce, the crop suffers. Not only does the crop of the current year suffer, but still more the crop of the following year, for the vine devotes its energy to producing new shoots in the autumn instead of storing up reserve food-material for the next spring growth. If, on the other hand, the topping is done after all leaf growth is over for the season, the only effect is to deprive the vine of so much food-absorbing surface.

The topping, then, should be so timed that, while a further lengthening of the main shoot is prevented, no excessive sprouting of new laterals is produced. The exact time differs for locality, season and variety, and must be left 
to the experience and judgment of the individual grower.

REMOVAL OF LEAVES. - In order to allow the sun to penetrate to and aid the ripening of late grapes, it is often advisable late in the season to lessen the leafy shade of the vine. This should be done by removing the leaves from the center of the vines, and not by cutting away the canes. In this way only those leaves are removed which are injurious, and as much leaf surface as possible is left to perform the autumn duty of laying up food-material for the spring. The removal of leaves should not be excessive, and if considerable, should be gradual, otherwise there is danger of sunburn. It is best, first, to remove the leaves from below the fruit. This allows free circulation of the air and penetration of the sun's rays, which warm the soil and are reflected upon the fruit. This is generally sufficient, and in any case only the leaves in the center of the vine, and especially those which are beginning to turn yellow, should be removed.

\section{Classification of the Varieties}

In the list of varieties which follows, an attempt has been made to indicate the mode of pruning which is likely, in the light of our present knowledge, to give the best results for each variety. It should be understood, however, that 
it is to some extent tentative and provisional. Many of the varieties have proved successful in certain soils and locations when pruned in the way indicated, but others have never, so far as we know, been tested in the way proposed. As these latter, however, have proved more or less unsuccessful under the common methods of treatment, the method proposed is the one which seems most suitable to their habit and general characters. It seems probable that the tendency to coulure of some varieties, such as the Muscat, Malbeck, Merlot, Clairette, etc., can be combatted to a great extent by appropriate methods of pruning and training. Unevenness of ripening and liability to sunburn of Tokay, Zinfandel, etc., can doubtless be controlled by the same means.

Very few varieties succeed under strictly shortpruning, that is, cutting back to one and two eyes, so that for most of the varieties in the first eategory, the modification of short-pruning which gives fruit-spurs of three or four eyes and wood-spurs of one eye is recommended.

Type I.-Charbono, Cinsaut, Mataro, Carignane, Grenache, Petit and Alicante Bouschet, Aramon, Mourastel, Verdal, Ugni-blane, Folleblanche, Burger, Zinfandel, Grüner Velteliner, Peverella, Zierfahndler (?), Rother Steinschiller (on poor soils), Slankamenka, Green Hungarian (on poor soils), Blue Portuguese (on poor soils), 
Tinta Amarella, Moscatello fino, Pedro Ximenes, Palomino, Beba (?), Peruno, Mantuo, Mourisco Branco, Malmsey, Mourisco Preto, Feher Szagos, Muscat of Alexandria, Barbarossa.

TrPe II.-St. Macaire, Beclan (longer or shorter, according to richness of soil), Teinturier male, Mondeuse, Marsanne, Chasselas, Muscatel, Grosse Blaue, Sauvignon Blanc, Sauvignon Vert, Nebbiolo, Fresa, Aleatico.

TYPE III.-Cabernet Sauvignon and Cabernet Frane (on poor soils and hillsides), Verdot, Tannat, Gamai Teinturier, Gros Mansenc, Pinots, Meunier, Gamais, Pinot Blanc, Pinot Chardonay, Rulander, Affenthaler, Johannisberger, Franken Riesling (on hillsides), Kleinberger, Traminer, Walschriesling, Rothgipfler, Lagrain (? perhaps short), Marzemino, Blue Portuguese (on rich soils), Barbera, Moretto, Refosco, Tinta de Madeira, Tinta Cao, Verdelho, Boal, Sultanina, Sultana.*

TyPe IV.-Green Hungarian, Rother Steinschiller (on rich soils), Neiretta, Mission, West's Prolific, Robin Noir.

Type V.-St. Macaire and Mondeuse (on rich bottom soils), Tinta Valdepeñas, Marsanne, Clairette Blanche, Semillon, Sauvignon Blanc (on rich soils), Muscadelle du Bordelais, Ver-

*In the original, Sultanina and Sultana are in the list of shortpruned varieties, but I am informed by the California Experiment Station that they should be placed with the long-pruned varieties. 


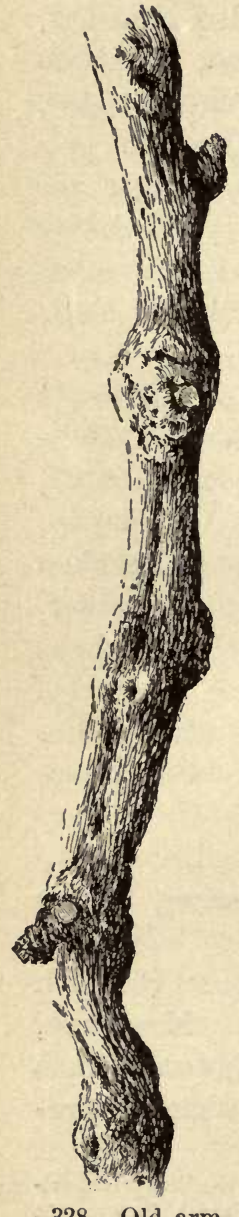

328. Old arm 328. Old arm with short spurs.

naccia Bianca, Furmint Bakator, Tadone, Gros Colman, Black Moroceo (?), Cornichon (?), Emperor, Tokay (?), Almeria, Pizzutello, California Black Malvoisie.

Trpe VI.-Malbec, Petite Sirah and Serine, Cabernet Sauvignon and Cabernet Franc (on rich bottom soils), Merlot, Gros Mansene (? on rich bottom soils), Chauché Noir, Bastardo, Trousseau, Ploussard, Etraie de l'Adhui, Chauché Gris, Franken Riesling (on rich soils).

\section{GLASS-HOUSE PRACTICE}

There are many systems of training vines in graperies. In fact, nearly every gardener has a mode or a method of his own, which he insists is better than all others; and this is proof that many systems are equally good. In general, the vine is trained to one arm, which extends from the ground to the top of the house. From the sides of this arm, spurs are taken out; and these spurs are cut back each year to one or two buds. Fig. 328 shows a part of an arm after prun- 
ing, with the very short spurs. Some growers prefer to have longer spurs, as in Fig. 329. It

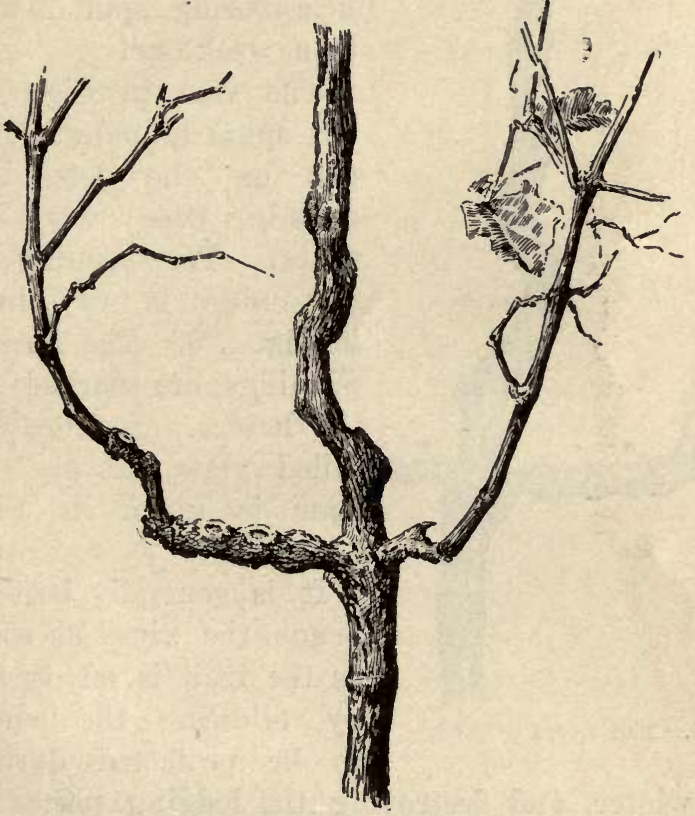

329. Long-spur pruning.

is generally desired to have an alternation of fruitbearing on these spurs. This is done by pinching the flower clusters from some of the shoots, or by cutting to a strong or fruit-bearing bud on one spur, and to a weak or barren bud at $\mathrm{HH}$ 
the very base of the other. The weak bud gives only a shoot; but the next year it is cut

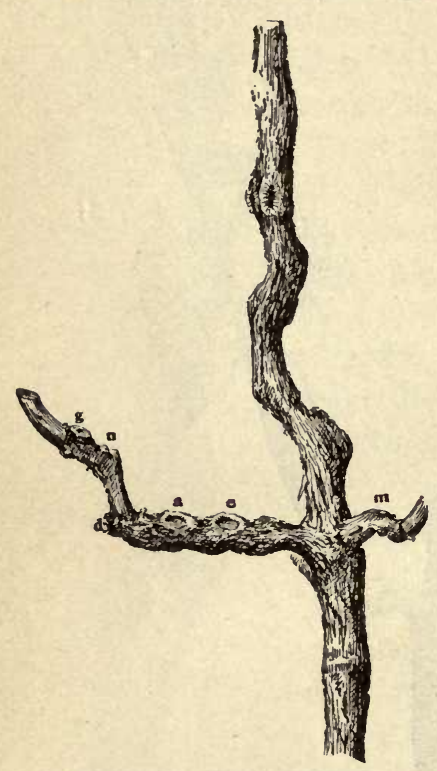

330. The spurs pruned. to a strong bud and the neighboring spur is cut to a weak one.

The vine in Fig. 329 has spurs in pairs. The one on the left has already been cut six times. The pruning of this vine is explained in Fig. 330. The former prunings are marked by the letters. A more detailed view of an old spur is given in Fig. 331.

It is generally best to prune the vines as soon as the fruit is off, thereby allowing the vines to be protected during the winter, and destroying the lodging places of insects and fungi.

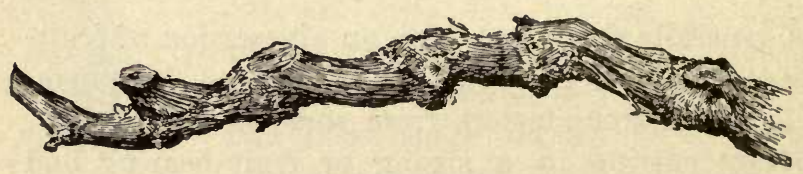

331. An old spur. 


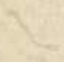





\section{INDEX}

PAGE

Adlum, quoted............391, 393

Almond, fruit-bearing........ 74

Althæa .................338, 340

Anderson, A. K., quoted........ 382

Apple, fruit-buds........22, 30, 69

- leaf-bud.................27, 69

- flowers ................... 55

- pruning and references .....309

- root-pruning..............248

Apples, dwarf...............278

- experiments on.............103

Apricot, fruit-bearing.......50, 74

- pruning and references......310

Arbor Kniffin..............474

Arbors, of grapes ............490

Arches........................ 351

Arm, defined................404

Ash logs................. 86

Azalea ..................... 340

Bacteria in wounds ........... 92

Balmer, quoted........187, 215, 308

Barberry .....................340

Bark-bound................ 78

Bark, expansion of............ 76

Barns, William D............402

- - - grape training..........466

- - quoted ...............296

Bast, for tying..............428

Beach, quoted ............328, 331

Bearing year................176

Bellair, G. A., quoted ............363

Bending....................167

Bioletti, F. T., quoted.........494

Blackberry, fruit-bearing ....64, 75

- pruning...................323

Bleeding................103, 413
PAGE

Bois, D., quoted................355

Bolting trees................. 125

Bordeaux Mixture for wounds..109,

119,121

Borers, injury by............122

Brambles, fruit-bearing.......63 63

Bréhaut, quoted................364

Bridge-grafting ..............120

Brunk, T. L., quoted ......236, 240

Buchatt, on ringing..........285

Bud, cutting near............221

Budd, Professor, quoted........145

Budded trees................263

Burning prunings.............308

Burroughs, on ringing........296

Bushes, pruning..........195, 335

Butternut, fruit-bearing....... 72

California.........200, 215, 308, 310

- vine pruning..............494

Callus ..................... 83

- on roots .................233

Cambium ................. 82

Candelabrum ................358

Cane, defined...............404

Card, on pruning...............185

- quoted ...................113

Caywood system.............474

Chautauqua training......434, 439

Cheal, J., quoted..............349

Checking growth..............162

Chemical analyses...........178

Cherry, black .............. 9

- fruit-spur.............46, 74

- pruning and references.......313

- split ....................122

- struggle for existence in....7, 11 
PAGR

Cherry, wild................ 7

Chestnut, fruit-bearing......72, 75

Chisels for pruning........115, 302

Clematis ....................340

Climate and pruning...185, 187, 199

Coal-tar for wounds............111

Coates, quoted................115

Come-alongs................420

Conifers, pruning.............140

Copings for fruits.............. 350

Co-terminal fruit-bearing....59, 74

Corbett, quoted...........233, 402

Cordon..............342, 343, 357

Cornell, W. T. ..............458

Cornell, root-pruning at .......240

Crab, flowering ...............340

- pruning.................... 15

Crittenden system ............476

Cross-wire system............477

Crotehes .....................125

Currant, fruit-bearing ....56, 66, 74

- pruning...............327, 340

Cutting-back..............95, 157,

$174,180,195,205$

Dendroscope..................303

Des Cars, quoted.......100, 111, 302

Devitalizing by pruning........ 4

Devol, W. S., quoted...........306

Dewberry, fruit-bearing......64, 75

- pruning ...................323

Dextrine ....................179

Downing, A. J., quoted .........151

Dressings..........84, 89, 109, 190

Drooping grape training.......458

Du Breuil, quoted .........343, 368

Dufour, quoted.................395

Duggar, B. M., quoted ......... 90

Dwarfing.....................227

Dwarfs, management of .......269

Eisen, book by...............494

Elder..........................340

Elm, growth of bark.......... 76

Elms, inarched................388

Espalier..............342, 343, 357
PAGE

Evergreens, pruning........140, 150

Exochorda ........................ 340

Fan training................ 455

Farlow, W. F., quoted ..........129

Fences, for fruits ...............351

Filbert, fruit-bearing.......72, 74

Fisher, on ringing ...........286

Florida freezes.................147

Form of top .................193

Forsythia .................... 340

Freezing, splitting by...........122

Frozen trees, repairing.........141

- wood .......................107

Fruit-bud ............21, 27, 68

Fruit-spur ..............30 et seq.

Fuller, grape training..........391

Fungi of wounds............. 92

Garden and Forest, quoted......337

Gardeners' 'Chronicle, quoted...384

Gaucher, quoted ..............284

Girardin's grafts................345

Girdles, repairing............120

Girdling ..............17, 116, 119,

$162,163,167,281$

Glass-house grape training......528

Gnawed trees ..................122

Goblet training...............368

Goessmann, on ringing ........285

Goff, E. S., quoted..............144

Gooseberries, training..........384

Gooseberry, fruit-bearing ....56, 74

- pruning ...................327

Grafted trees................263

Grafting vines...............492

- wounds...................120

Grape, fruit-bearing.........63, 75

- ringing ...................284

- training ...................390

- young plant............210, 411

Grapes, frozen...............149

Graperies ....................528

Green, Professor, quoted........145

Habit of fruit-bearing..........163

Hale, J. H., quoted........262, 316 
PAGE

Hardy, J. A., quoted...........361

Harris, J. S., quoted...........145

Hartwig, quoted ..............364

Haviland, Sands.............474

Hazel, fruit-bearing........72, 74

Heading-in ............96, 157, $174,180,195,205$

Healing of wounds .........76, 189

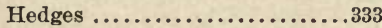

Hemlock knots............. 79

Henderson, quoted .............167

Hewett, B. W., quoted..........146

Hickory, fruit-bearing....61, 72, 75

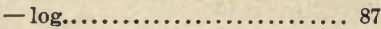

High renewal ...............441

Hirschinger, C., quoted.........146

Hofer, A. F. ...............490

Horizontal arm...............437

- training .................486

Hudson, R., girdling...........293

Husks, for tying.............428

Hydrangea .............338, 340

Inarching ...............120, 388

Indian Riv. Advocate, quoted ..147

Iowa..$\ldots \ldots \ldots \ldots \ldots \ldots \ldots \ldots \ldots \ldots$

Iron, sulfate of..........344, 347

Johnson, S. W., quoted.........393

Juneberry, fruit-bearing....... 56

Kalmia ....................340

Kellogg, G. J., quoted ..........146

Kerria ......................340

Kieffer pear, treatment of ......159

Knife......................298

- ringing ..................295

Kniffin, William..............459

Kniffin training ..........432, 460

Knisely, quoted..............178

Knot-holes.................. 81

Knots .................... 79

Koopmann, K., quoted ........169

Label wires..................116

Leader .....................150

Lichen on trees...............111

Lilac, pruning...........336, 340
PAGE

Lilac shoot ................ 1

Lindley, quoted...............284

Lodeman, on grape training....402

- quoted ...................278

Loquat, fruit-bearing........ 75

Lord, O. M., quoted ...........145

Macomber, J. T., quoted........384

Magnolia ...................340

Maple, fruit-bearing......... 59

$-\log \ldots \ldots \ldots \ldots \ldots \ldots \ldots \ldots . . . . . .68$

- tapping .................. 85

Marvin, D. S., quoted .........457

Mask, pruning..............307

Medlar, fruit-bearing........ 75

Meehan's Monthly, quoted ....140

Mending trees...............116

Minnesota ..................145

Mock orange ............336, 340

Moss on trees ...............111

Mulberry, fruit-bearing ...... 75

Munson training ............480

Myticuttah shears ...........304

Nectrias .................... 94

Neff, J. B., quoted............. 310

Notching ...............167, 169

Oak knots................. 79

Obstructions to $\operatorname{sap} . . . \ldots . .161,167$

Olive, fruit-bearing.......... 75

Opoix, quoted ...............170

Orange, fruit-bearing.......... 75

- pruning ....................314

Oranges, frozen...............147

Ornamental plants ...........335

Overbearing ...................165

Overhead grape training .......474

Paint for wounds ......109, 113, 190

Peach, fruit-bearing.........50, 74

- pruning and references ......315

- root-pruning ...............245

- twig of.................. 95

Peaches, laying down...........384

Pear, fruit-spur ...........40, 74

- pruning and references ......319

- root-pruning ..........230, 245 


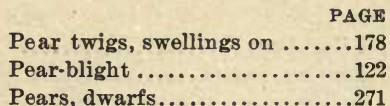

Pentosans ....................179

Persimmon, fruit-bearing ......75

Philips, A. J., quoted..........146

Physiology of pruning........ 13

Pine, girdled ................117

Plains, pruning on the $.144,185,199$

Plashing.....................334

Plugging cavities ............. 124

Plum, fruit-spur .........46, 74

- headed-in ..................195

- pruning and references ......320

- root-pruning ..............247

Polyporus sulphureus ......... 94

Pome-fruits.................189

Poplars, fruit-bearing ........ 71

Positions of fruit-buds........ 74

Post training..............488

Pots, trees in ................374

Powell, quoted ..............313

Prairie Farmer, quoted........418

Price, R. H., quoted ..........236

Principles of pruning .........133

Prunus serotina, wound on.... 94

Punk-fungus.............. 94

Pyramids ...............342, 356

Quince, fruit-bearing........60, 55

- pruning and references ......322

Raffia .....................426

Raspberry, fruit-bearing ....64, 75

- pruning ...................323

Reasons for pruning...........135

Reducing sugar..............179

Reid, E. W., quoted ...........306

Rejuvenating trees ...........139

Renewal, defined............410

Rhododendron...............340

Ringing .............. 17, 281

Rivers, on pot trees............382

- on pyramids ...............358

- on root-pruning ..........230

Robbers ...........................

Rot-pruning .0.0.0.0.0.138,

Rose, flower-bearing..........67 67

Roses, pruning.........137, 336, 340

Rural New-Yorker, quoted...121, 307

Sargent, C. S., quoted .........100

Saws .......................300

Seaffold limbs ...............204

Schizophyllum commune...... 94

Seraping trees ................121

Season for pruning ............181

Shade trees, pruning ...........333

Shaping the top .............222

Shears .................298, 301

Shellac for wounds ............109

Shoot, defined ...............404

Shredding .................167

Shrubs, pruning..........195, 335

Snow, Geo. C.................402

Snowball .....................340

Sorauer, quoted ..........154, 182

Spencer, John W...402, 424, 428, 434

Spirea, pruning ..........336, 340

Splitting of trunks ............122

Spur.................... 30 et seq.

- defined ...................410

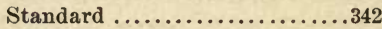

Starch in twigs ..............179

Starnes, H. N., quoted ....402, 486

Stone-fruits ................189

Straw, for tying ..............428

Strawberry, trimming.........304

Street trees, injuries to........129

Stringfellow system ..........236

Stripping vines.............414

Stub-root pruning ............236

Subsequent treatment.........250

Suckers.....................155

Sugar, reducing .............179

Sulfate of iron...........344, 347

Summer pruning..........140, 181

Sun-scald ...............122, 185

Tallow for wounds............. 109

Tamarisk ..............338, 340

Tap-hole ................. 85 
Tap-root ....................151

Tar for wounds ............... 109

Thinning the fruit.............174

Thomas, quoted ...............391

Thomson, quoted.............365

Tools ......................297

Top, form of.................193

Top-worked trees.............263

Training, specific modes........341

Transplanting, root-pruning at..232

Trellis, for grapes ...........416

Trunk, expansion of......... 76

Twisting.......................

Tying grapes ................426

Umbrella training............469

Upright grape training ........436

Van Dusen, H. P., quoted ......469

Vase ........................356

Veitch, quoted.................384

Viburnum .................... 340

Vines, grafting ................492

Vineyard, layout of............424

Vinifera grape training.........494

Vitis vinifera.................494

Walker, E., quoted.........137, 336

Walls for fruits................348

Walnut, fruit-bearing .......72, 75

- Japanese ...................103

Warneken, quoted.............376

Washington ............187, 216

Waters' pruner .................301

Watersprouts................155

Waugh, quoted .............483

Wax for wounds.............. 109

- recipe for ..................119

Weeping of vines .............413

Weigela......................340

When to prune........102, 181, 189

Whitford, Leroy, quoted........121

Why we prune...............135

Wickson, quoted .....200, 315, 494,

509,516

Williams, H. S., quoted .......147

Willow, Kilmarnock...........269

Willows, for tying............427

- fruit-bearing .............. 71

Winter-injured trees............141

Winter-killed buds ........... 73

Wire, for tying .............428

- for vineyards .............419

Wire-stretchers ..............420

Wisconsin ..............144, 146

Wool twine, for tying..........427

Wound, how to make........99, 114

- nature of................. 82

Yeomans, on pruning .....221, 272

Young trees, trimming ........205

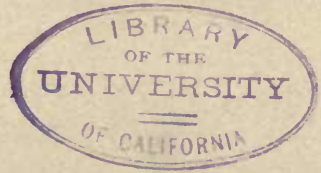





\section{The FRuxal Sriente Sexies.}

Edited by Professor L. H. BaILey.

OOKS which state the underlying principles of agriculture in such language that they may be read at the home fireside, in the office, at the club or grange, or used as text-books. Each is substantially bound in blue eloth. These books combine the results of the very latest and best science with the best skill of practical farm work and management. Each one is written by a specialist who has attained reputation for long-continued and conscientious work. Each volume is readable, simple, clear-cut, practical, up to date, and thoroughly scientific and reliable. The detailed information given in these volumes is of the most valuable character to every cultivator of the soil. Five volumes are now ready:

\section{THE SOIL:}

Its Nature, Relations, and Fundamental Prineiples of Management. By F. H. KIng, Professor of Agricultural Physies in the University of Wisconsin. 303 pages, 45 illustrations.

75 ets.

It comprises an introduction, which discusses the making of soils by natural agencies ; and chapters follow on the nature, functions, origin and wasting of soils ; texture, composition, and kinds of soils ; nitrogen of the soil ; capillarity, solution, diffusion, and osmosis ; soil water ; conservation of soil moisture ; distribution of roots in the soil; soil temperature; relation of air to the soil; farm drainage ; irrigation; physical effect of tillage and fertilizers. It has received the warmest approbation of teachers and farmers is all parts of the country.

"I consider it a most desirable addition to our agricultural literature, and a distinct advance over previous treatises on the same subject, not only for popular use, but also for students and specialists, who will find many new and useful suggestions therein."

E. W. HILGARD,

Director of Agricultural Experiment Station, Berkeley, Cal.

\section{THE FERTILITY OF THE LAND :}

A Summary Sketeh of the Relationship of Farm-Practice to the Maintaining and Increasing of the Productivity of the Soil. By I. P. RoBerts, Director of the College of Agriculture, Cornell University. 440 pages; fully illustrated. 


\section{The Fuxal Srience Sexies.}

Edited by Professor L. H. Balley.

\section{THE SPRAYING OF PLANTS:}

A Suceinet Account of the

History, Princlples and Practice of the Application of Liquids and Powders to Plants for the Purpose of Destroying Insects and Fungi. By E. G. Lodeman, late Instructor in Horticulture in the Cornell University. 399 pages, 92 illustrations.

$\$ 1.00$

The only complete manual of the spraying of plants, and the standard work upon the subject. The first part is a complete history of the rise of spraying, both in this country and abroad. There are also full illustrated accounts of pumps and nozzles, complete recipes of formulas, and the like. The second part, comprising 135 pages, is an alphabetical illustrated account of the various insects and fungi, with methods of treating them. The book as a whole is not only a complete monograph upon the subject, but a most valuable manual of practice.

"I have looked it carefully over with a great deal of interest, and feel that it is a very timely book, and one that can be safely recommended to all horticulturists and fruit-growers as the best."

PRES. H. H. GOODELL, Massachusetts Agricultural College, Amherst, Mass.

\section{THE PRINCIPLES OF FRUIT - GROWING:}

By Professor L. H. Bailey. 520 pages, 114 illustrations. $\$ 1.25$

This book is designed to treat all those underlying matters of fruit-growing which are common to most or all of the various fruits. The author in preparing a monograph upon the Apple, concluded that it would serve the purpose of his readers better if all the essentials of fruit-growing were placed in a separate and initial volume. He has, therefore, delayed the preparation of the Apple book for the present.

"The Principles of Fruit-Growing" is a unique book, and brings the very best science of the day to join hands with the best practice. It includes illustrations of every important operation, and may be taken as a consensus of the opinions and methods of the most successful growers. The contents are as follows: Introductory Discussion, comprising an inventory and classification of fruits, the fruit zones, the outlook for fruit-growing; the Location and Its Climate, with a full discussion of frosts; the Tilling of Fruit Lands; the Fertilizing of Fruit Lands; the Planting of Orchards; Secondary Care of Orchards; Diseases, Insects and Spraying; Picking and Packing and Storing Fruits, Shipping, etc : and a bibliography of American writings on the subject. 


\section{The Fuxal Srience Sexixs.}

Edited by Professor L. H. BAILey.

\section{MILK AND ITS PRODUCTS:}

A Treatise upon the Nature and Qualities of Dairy Milk, and the Manufacture of Butter and Cheese. By HENRY H. Wing, Assistant Professor of Dairy Husbandry in the Cornell University. 280 pages, 33 illustrations.

$\$ 1.00$

This is the only book which adequately covers the whole field of dairying. Its range is indicated by the table of contents : Secretion of Milk; Composition of Milk; Testing of Milk ; Ferments and Fermentations of Milk, and their Control; Market Milk ; Separation of Cream : Ripening of Cream ; Churning; Finishing and Marketing Butter; Milk for Cheese-Making; Cheddar CheeseMaking ; Varieties of Cheese ; By-Products of the Dairy ; Butter and Cheese Factories; Statistics and Economics of the Dairy Industry ; Appendix, comprising useful rules and tests, metric system, dairy laws, and references to dairy literature.

** So long as the demand warrants, new volumes will be added to the Rural ScImnce Library. Definite arrangements have now been completed for the following:

PHYSIOLOGY OF PLANTS. By J. C. Arthur, Purdue Univ. PRINCIPLES OF BREEDING OF ANIMALS. By W. $\mathrm{H}$. BREWER, of Yale University.

BUSH FRUITS. By F. W. CARD, of University of Nebraska.

PLANT PATHOLOGY. By B. T. GALLOWAY and associates, of United States Department of Agriculture.

SEEDS AND SEED-GROWING. By G. H. Hicks, of United States Department of Agriculture.

LEGUMINOUS PLANTS AND NITROGEN-GATHERING. By E. W. Hilgard, of University of California.

FEEDING OF ANIMALS. By W. H. JoRDAN, of New York State Experiment Station.

IRRIGATION AND DRAINAGE. By F. H. KING, of the University of Wisconsin.

FERTILIZERS. By E. B. Voorhees, of N. J. Exp. Station. RURAL WEALTH AND WELFARE. By GEorge $T$. FAIRCHILD, Ex-President of the Agricultural College of Kansas.

FARM POULTRY. By George C. WATson, of Pennsylvania State College. 


\section{The Gaxder-Craft Sexies.}

Edited by Professor L. H. Bailey.

COMPRISING practical hand-books explaining the methods practiced by the horticulturist. They are tastily bound in green flexible cloth. Four volumes are now ready, all written by Professor BaIley, of Cornell University.

\section{PLANT - BREEDING:}

\section{Being Five Lectures upon} the Amelioration of Domes-

tic Plants. 293 pages, 20 illustrations.

$\$ 1.00$

This is the only book devoted to this subject. It comprises five chapters or lectures: The Fact and Phylosophy of Variation; The Philosophy of the Crossing of Plants ; How Domestic Varieties Originate; Borrowed Opinions, being translations from the writings of Verlot, Carrière, and Focke; Pollination, or How to Cross Plants. Chapter III. contains the list of fifteen rules for plantbreeding which DeVarigny, the eminent French writer, has called "the quindecalogue of the horticulturist," and of which he says, "Solomon-if he had devoted himself to hor'iculture-could not have judged more soundly than Mr. Bailey." It is the purpose of the book to tell how varieties of cultivated plants come about, and how man may originate them.

"I have read the work on 'Plant-Breeding,' by Professor L. H. Bailey, with keen interest, and find it just what I expected from such a source; viz., a most satisfactory treatise on a sulject of most pressing horticultural importance. Professor Bailey combines a breadth of view with knowledge of detail, and produces written work most delightful to the scholar, and at the same time fit to command the respect and correct the practice of the craftsman. I honor Professor Bailey as a leader in the advancement of horticulture."

E. J. Wrickson,

Agricultural Experiment Station, Berkeley, Cal.

\section{THE HORTICULTURIST'S RULE - BOOK :}

A compendium of useful information for fruit-growers, truck-gardeners, florists, and others. Fourth edition. 312 pages.

75 ets.

This is the standard work of reference for horticulturists, and is now so well known that a detailed description is no longer necessary. The fact that the index contains 2,000 entries shows the great range of its contents. It is heaping full of information upon such matters as recipes for insecticides and fungicides, descriptions (with remedies) of insects and diseases, weeds, lawns, grafting-waxes, seed and planting-tables, tables of yields, rules for greenhouse heating and management, with figures, methods of storing produce, tariff and postal rates, rules of societies for naming and exhibiting specimens, score-cards and scales of points, analyses of fertilizing substances, lists of currant horticultural books and journals, with prices and publishers, etc. 


\section{The Gaxden-Citat Sexixs.}

Edited by Professor L. H. BaIley.

\section{THE NURSERY - BOOK:}

A Complete Guide to the Multiplication of Plants.

Third edition, thoroughly revised and extended. 365 pages, 152 illustrations.

$\$ 1.00$

This manual, which has been one of the most popular of recent horticultural books, was first published in 1891. In this third edition, all the features of the first two editions have been preserved, and the work has been extended to include many new subjects, such as'seed-testing, mutual influence of stock and cion, the question of the devitalizing effects of graftage, the management and fertilizing of nursery lands, the grading of trees, storing of trees, trimming trees in the nursery, the healing of wounds, dwarfing trees, root-grafted vs. budded trees, and a full glossary. Very many new and original illustrations have been added. The book comprises full practical directions for seed-sowing, the making of all kinds of layers, stools, cuttings, propagation by bulbs and tubers, and very complete accounts of all the leading kinds of budding, grafting and inarching. Aside from this, The Nursery List is an alphabetical catalogue of about 1,500 plants,- of fruit, kitchen-garden, ornamental and greenhouse species,-with directions for their multiplication. The book is the most complete treatise of its kind in the language, and is the standard reference book of nurserymen.

"This book should be in the home of not only every horticulturist, but of every family, irrespective of occupation, who love flowers or ornamental plants, for it treats of the propagation of these as well as of food-plants."-Michigan Fruit-Grower.

\section{THE FORCING-B00K: A Manual of the Cultiva-} tion of Vegetables in Glass

Houses. 266 pages, 88 illustrations. $\$ 1.00$

A handbook of instructions upon the forcing of vegetables for market, which is the completest work of the kind yet published in this country. It is based on careful experimentation at the Cornell University Station, and a long familiarity with the forcing business. It contains full estimates of the cost of heating forcinghouses and of the labor necessary to run them, with illustrated chapters on the construction of forcing-houses, and their management. Very complete directions are given for the watering, ventilating, shading, and piping of houses; for the control of insects and fungous diseases, the making of forcing-house soils, etc. Then follow detailed instructions as to how to force lettuce, cauliflower, radish, asparagus, rhubarb, pea, salad plants and mints, root-crops, pepino, cucumber, muskmelon, bean, pepper, egg-plant, and others. The final chapter is a collection of summaries of the leading points in the management of each croup, so arranged that the busy man can turn to any one of them instantly. The book should be had by every person who has a greenhouse. 


\section{The Gaxden-Cixaft Sexies.}

Edited by Profissor L. H. Banley.

THE FORCING-B0OK-Continued.

"The discussion of the various forms of houses, with their structural details, is very complete, althongh concise, and for the space it takes it gives more valuable information than can be found elsewhere in the same compass. All such practical questions as would be treated under the head of soil, fertilizers, irrigation, shading, pollination, etc., have received careful study, and the beginner can feel safe in following them to the letter."-Garden and Forest.

"It would have saved us dollars and dollars if we could have had it a few years ago."

C. J. Pennock, Kennett Square, Pa.

\section{GARDEN-MAKING: Suggestions for the Utilizing of Home Grounds. By L. H.} BAILeY, aided by L. R. TAFT, F. A. WAUGH, and ERNest WALKER. 417 pages, 256 illustrations.

$\$ 1.00$

Here is a book literally "for the million" who in broad America have some love for growing things. "Every family can have a garden. If there is not a foot of land, there are porches or windows. Wherever there is sunlight, plants may be made to grow; and one plant in a tin-can may be a more helpful and inspiring garden to some mind than a whole acre of lawn and flowers may be to another." Thus Professor Bailey introduces his subject, and the book which follows is one to instruct, inspire, edify and educate the reader, if he can raise his eyes from city cobble-stones! It tells of ornamental gardening of any range, with lists of trees and shrubs most suitable for various effects; treats of fruits and of vegetables for home use, and gives the word of instruction so often wanted, but hitherto unattainable in any one simple and compact book. No modern American work covers this important field. The illustrations are copious and beautiful.

GaRDEN-MAKING includes General Advice; the Plan of the Place (The Picture in the Landscape, How to make the improvements, etc.); Planting the Ornamental Grounds ; The Fruit Plantation; The Vegetable Garden; Seasonal Reminders (Calendars for North and for the South).

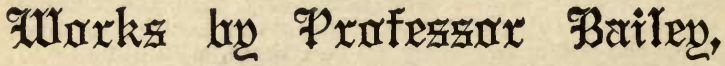

Not included in either of the foregoing series.

THE SURVIVAL OF THE UNLIKE: A Collee-

Evolution Essays Suggested by the Study of Domestic Plants. Second edition.

$\$ 2.00$

This is an illustrated volume of 515 pages by Professor Bailey. containing an immense amount of fact, experiment and philosophy 


\section{Wllaxks tw Pxufessax Failey.}

\section{THE SURVIVAL OF THE UNLIKE-Continued.}

respecting the evolution of plants, and particularly of their modification under cultivation. It is the most thorough discussion of the running-out of varieties, acclimatization, and the like. It is, in fact, the only book which can be called a philosophy of horticulture. It conprises thirty essays, as follows: The Survival of the Unlike; Neo-Lamarckism and Neo-Darwinism; The Plant Individual in the Light of Evolution, or The Philosophy of BudVariation, and its Bearing upon Weismannism; Experimental Evolution amongst Plants; Van Mons and Knight, and the Production of Varieties; Some Bearings of the Evolution-Teaching upon Plant-Cultivation; Why Have our Enemies Increased? Coxey's Army and the Russian Thistle, or a Sketch of the Philosophy of Weediness; Recent Progress in American Horticulture; On the Supposed Correlations of Quality in Fruits; The Natural History of Synonyms; Reflective Impressions of the Nursery Business; The Relation of Seed-Bearing to Cultivation; Variation after Birth; A Pomological Alliance; Sketch of the Relationship between American and Eastern Asian Fruits; Horticultural Geography; Some Emphatic Problems of Climate and Plants, Comprising "Speculative Notes upon Phenology (the Physiological Constant, and the Climatal Modification of Phenological Phenomena)" and "Some Interrelations of Climatology and Horticulture"; Are American Fruits Best Adapted to American Conditions? ; Acclimatization: Does it Occur?; On the Longevity of Apple Trees; Sex in Fruits; Are Novelties Worth their Cost?; Why do Promising Varieties Fail ?; Reflections upon the Longevity of Varieties, comprising "Do Varieties Run Out?" "Are the Varieties of Orehard Fruits Running Out?" "Studies in the Longevity of the Varieties of Tomatoes"; Whence Came the Cultivated Strawberry?; The Battle of the Plums; The Evolution of American Grapes; The Progress of the Carnation, comprising "Types and Tendencies in the Carnation," "John Thorpe's Ideal Carnation," and "Border Carnations"; Evolution of the Petunia; The Amelio. ration of the Garden Tomato, comprising "The Origin of the Tomato from a Morphological Standpoint," "History of the Trophy Tomato," "The Probable Course of Evolution of the Tomato," and "Direction of Contemporaneous Improvement of the Tomato"; Glossary.

"Whatever Professor Bailey writes is interesting reading. He has the rare gift of an entertaining style, and what he writes people want to read. All his previous books have been widely read, and this will prove no exception to the well-established rule. The secret of this popularity, if there be any secret about it, is that when he writes he has something new to say,-something based upon experiences and observations. These are by no means all his own, for he has the ability to see with the eyes of other people, as well as with his own. $\mathrm{He}$ is thus able to bring into his pages a rich mass of new matter, which gives them aditional interest and value."

Professor C. E. Bessey,

University of Nebraska, in "Science."

\section{THE MACMILLAN COMPANY}




\section{Announcement of Important Horticultural Books.}

In addition to the volumes extending the Rural Science Series, as given on a previous page, the following important works are in preparation:

\section{THE EVOLUTION OF OUR NATIVE FRUITS. A com-} panion volume to "The Survival of the Unlike," and written on the same original lines, by Professor L. H. BaILEY. It will be copiously illustrated, and is now on the press.

\section{A TEXT BOOK OF AGRICULTURE FOR SCHOOL USE.}

Designed to supply a practical and efficient statement of the Elements of Agricultural Science. By Professor L. H. BAILEY.

\section{ENCYCLOPEDIA OF AMERICAN HORTICULTURE. TO}

be published in three large illustrated volumes, dated 1900. This work will be the first comprehensive and adequate presentation of American horticulture in its widest sense, and under the editorial supervision of Professor Bailey will contain signed articles by eminent specialists on various topics, arranged alphabetically. The illustrations may be expected to excel in beauty and accuracy any found in horticultural literature to-day; they are being now prepared by artists of ability, upon a consistent plan. The typography and binding will be likewise of high grade, befitting a work of international importance.

Inquiry is solicited concerning terms of publication, etc., of this work. Address

\section{THE MACMILLAN COMPANY 66 Fifth Ave.





THIS BOOK IS DUE ON THE ILAST DATE

\section{STAMPED BELOW}

AN INITIAL FINE OF 25 CENTS WILL BE ASSESSED FOR FAILURE TO RETURN THIS BOOK ON THE DATE DUE. THE PENALTY THIS BOOK ON THE TO CENTS ON THE FOURTH
WILL INCREASE TO 50 ON THE SEVENTH DAY
DAY AND TO \$1.00 ON OVERDUE.

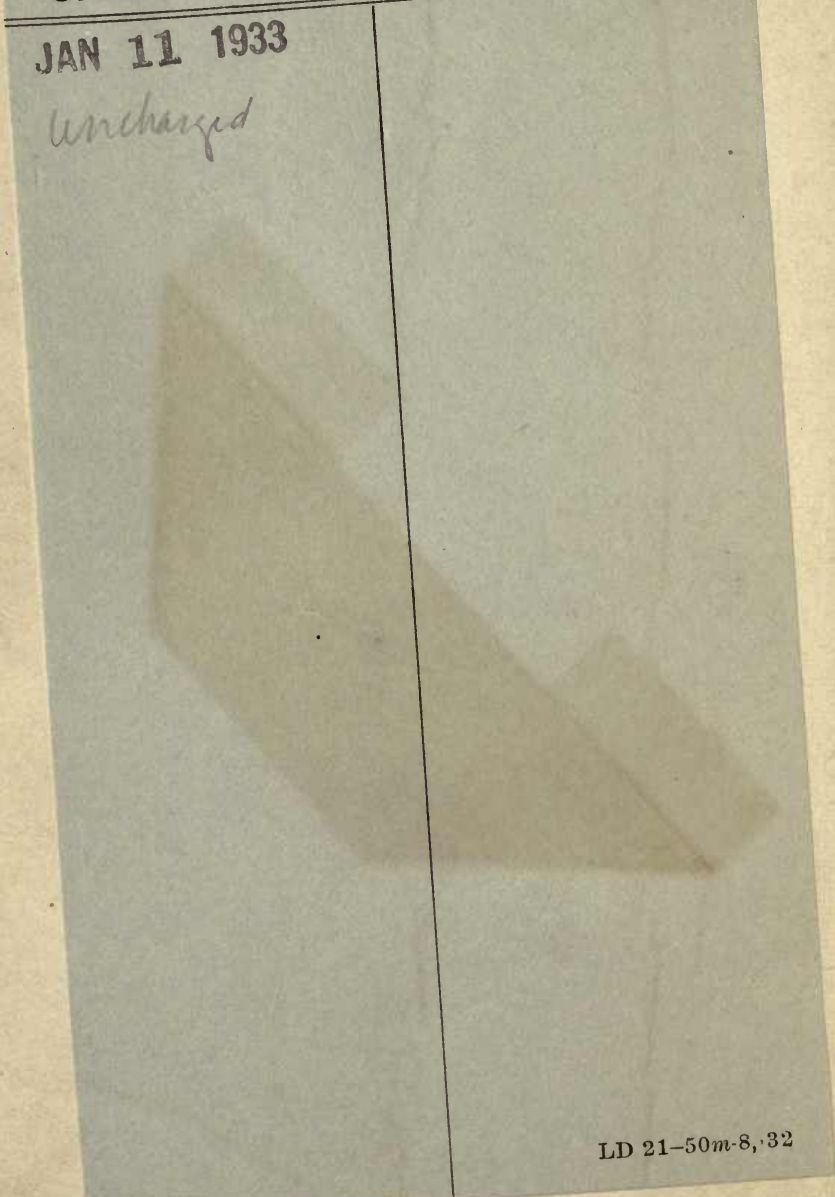




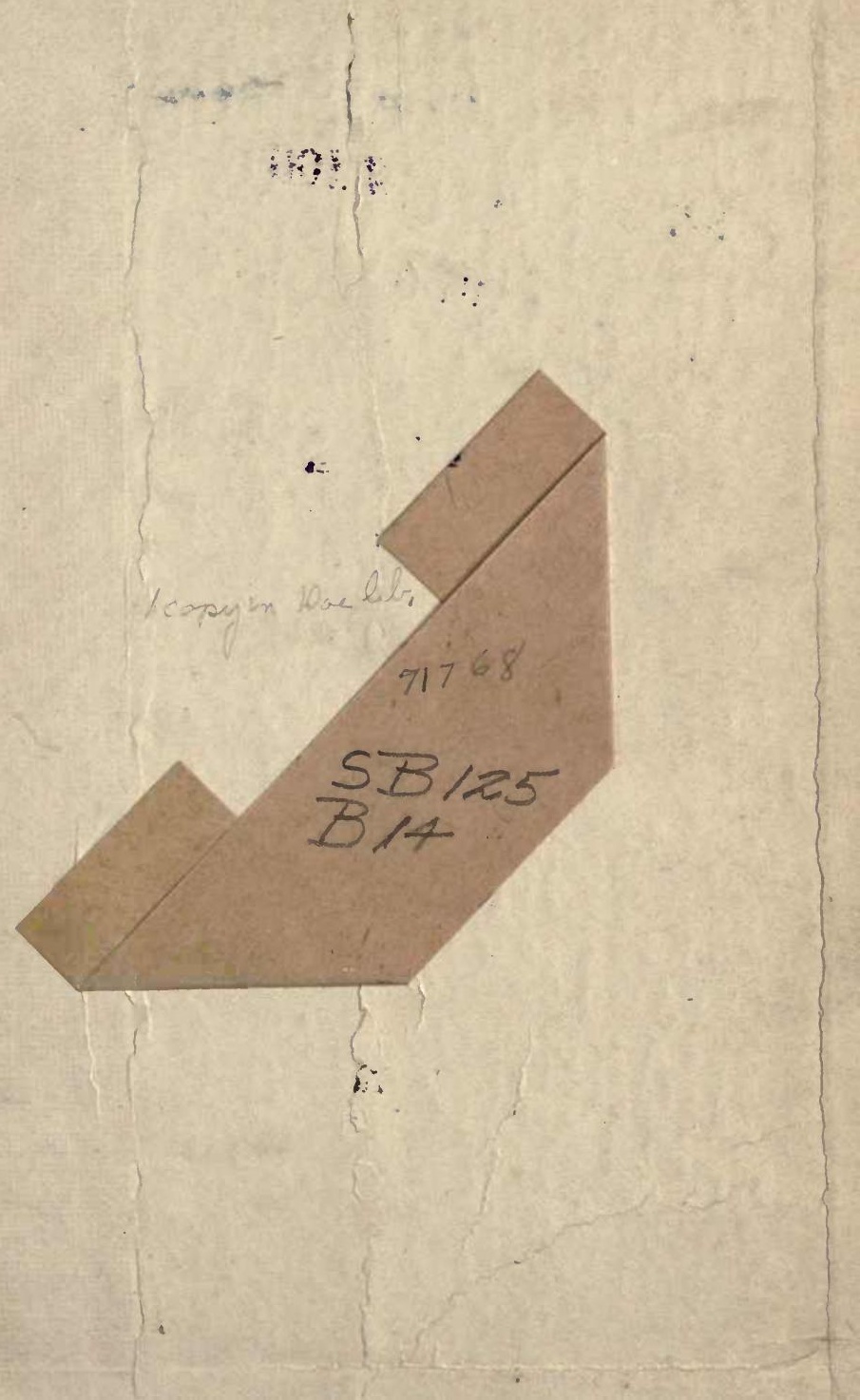


